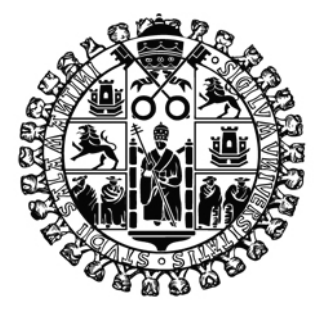

Universidad de Salamanca

Facultad de Ciencias Sociales

Departamento de Sociología y Comunicación

\title{
La belleza de las arrugas. Un estudio sobre la vejez en el Nordeste de Brasil.
}

Autora: Lígia Maria Bandeira Guerra 


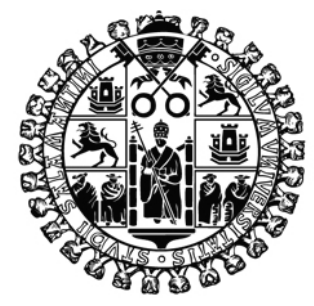

Universidad de Salamanca

Facultad de Ciencias Sociales

Departamento de Sociología y Comunicación

\section{La belleza de las arrugas. Un estudio sobre la vejez en el Nordeste de Brasil}

Trabajo de Tesis de Doctorado presentado para la obtención del título de Doctor en Sociología en el

Programa Estructura Social y Desigualdad.

Autora: Lígia Maria Bandeira Guerra

Director: Dr. Fernando Gil Villa 


\section{Esta tesis es dedicada:}

A las dos mujeres más maravillosas de mi vida: Maria Estela Guerra (68 años) y Rosa Guerra (91 años), mi madre y mi abuela, que a lo largo de sus vidas, siempre me han acompañado con dedicación e incentivo a construir la mía, a pesar de las limitaciones financiera y de formación educacional. 


\section{Agradecimientos}

Al Dr. Fernando Gil Villa, amigo y director de tesis, por la infinita paciencia, orientación exigente, inestimable auxilio en la elaboración de este trabajo y además, por permitirme avanzar en mi formación científica;

A los maestros de la Universidad del Estado de Río Grande del Norte - UERN/Brasil, en especial al Prof. José Walter da Fonseca y Dr. Aécio Cândido, por la beca que nos fue concedida;

A mis familiares más cercanos, madre, hermanos, abuela, tías y sobrinos, cuyos apoyos e incentivos fueron indispensables e inconmensurables durante los cuatro años de estudios;

A las personas de la comunidad mossoroense, sobre todo a los que participaron en la Encuesta y por lo tanto fueron los protagonistas del primer estudio sociológico de la tercera edad de Mossoró/RN;

A los maestros, Vera Núbia Bezerra, Mademerson Leandro da Costa, Wilson Bezerra de Moura de la Universidad Estadual del Estado del Río Grande del Norte (UERN), a los alumnos de los cursos de Pedagogía, Historia y Servicio Social y a los amigos que contribuyeron con la realización de la encuesta;

A los amigos que hice en Salamanca, latinoamericanos, africanos, europeos y asiáticos, por la amistad motivadora que en la convivencia más directa compartieron conmigo las dudas, angustias y alegrías.

A todos los que me han ayudado y alentado en mi estudio directa o indirectamente y que estuvieron a mi lado para la realización de este trabajo. 


\section{Lista de Siglas}

\begin{tabular}{|c|c|}
\hline ABIFARMA & Asociación Brasileña de Industria Farmacéutica \\
\hline $\mathrm{ACIM}$ & Asociación Comercial e Industrial de Mossoró \\
\hline ABRAMGE & Asociación Brasileña de Medicina de Grupo \\
\hline ANAPS & Asociación Nacional de los Servidores de la Seguridad Social \\
\hline ANSS & Agencia Nacional de Salud Suplementar \\
\hline BNDES & Banco Nacional de Desarrollo Económico y Social \\
\hline CNBB & Conferencia Nacional de los Obispos de Brasil \\
\hline CEPAL & Comisión Económica para la América Latina y Caribe \\
\hline ANG & Asociación Nacional de Gerontología \\
\hline AVD & Actividad de Vida Diaria \\
\hline AIVD & Actividad Instrumental de Vida Diaria \\
\hline CAGED & Catastro General de Empleados y Desempleados de Brasil \\
\hline $\mathrm{CBO}$ & Consejo Brasileño de Oftalmología \\
\hline CAERN & Compañía de Aguas y Sumideros de Río Grande del Norte \\
\hline CEPAL & Comisión Económica para América Latina y Caribe \\
\hline CIRES & Centro de Investigaciones sobre la Realidad Social \\
\hline CPMF & $\begin{array}{l}\text { Contribución Provisoria sobre la Movimentación } \\
\text { Financiera }\end{array}$ \\
\hline COSERN & Compañía Energética de Río Grande del Norte \\
\hline COBAP & Confederación Brasileña de Aposentados y Pensionistas \\
\hline DIEESE & $\begin{array}{l}\text { Departamento Intersindical de Estadística y Estudios } \\
\text { Socioeconómicos }\end{array}$ \\
\hline ESEB & Estudio Electoral Brasileño \\
\hline FIERN & Federación de las Industrias del Estado de Río Grande del Norte \\
\hline FIOCRUZ & Fundación Oswaldo Cruz \\
\hline FGV & Fundación Getúlio Vargas \\
\hline IBGE & Instituto Brasileño de Geografía y Estadística \\
\hline IDEMA & $\begin{array}{l}\text { Instituto de Desarrollo Económico y Medio Ambiente } \\
\text { del Estado de Río Grande del Norte }\end{array}$ \\
\hline IDH & Índice de Desarrollo Humano \\
\hline INAF & Indicador Nacional de Analfabetismo Funcional \\
\hline INCA & Instituto Nacional del Cáncer \\
\hline INCRA & Instituto Nacional de Colonización y Reforma Agraria \\
\hline INEP & $\begin{array}{l}\text { Instituto Nacional de Estudios y Pesquisas Educacionales } \\
\text { Anísio Teixeira }\end{array}$ \\
\hline $5 S$ & Instituto Nacional de Seguridad Social \\
\hline
\end{tabular}




\begin{tabular}{|c|c|}
\hline INSERSO & Instituto Nacional de Servicios Sociales \\
\hline IPEA & Instituto de Pesquisa Económica Aplicada \\
\hline LOAS & Ley Orgánica de Asistencia Social \\
\hline MS & Ministerio de Salud \\
\hline MEIOS & Movimiento Estatal de Integración Social \\
\hline MET & Ministerio de Trabajo y Empleo \\
\hline MEC & Ministerio de Educación y Cultua \\
\hline NEPTI & Núcleo de Estudio y Pesquisa de la Tercera Edad \\
\hline OIT & Organización Internacional del Trabajo \\
\hline OMS & Organización Mundial de Salud \\
\hline ONU & Organización de las Naciones Unidas \\
\hline ONG & Organización No Gubernamental \\
\hline PACS & Programa de Agentes Comunitarios de Salud \\
\hline PAISM & Programa de Asistencia Integral de Salud de la Mujer \\
\hline PAl & Programa de Jubilación Incentivada \\
\hline PEA & Población Económicamente Activa \\
\hline PDDI & Plan Director de Desarrollo Integrado \\
\hline PDV & Programa de Dimisión Voluntaria \\
\hline PMM & Ayuntamiento Municipal de Mossoró \\
\hline PNAD & Pesquisa Nacional por Muestra de Domicilios \\
\hline PNUD & Programa de Naciones Unidas para el Desarrollo \\
\hline PNI & Política Nacional del Anciano \\
\hline PSF & Programa Salud de la Familia \\
\hline POF & Pesquisa de Previsiones Familiares \\
\hline PDDI & Plano Director de Desarrollo Integrado \\
\hline RGPS & Régimen General de Previsión Social \\
\hline RPPS & Régimen Propio de Previsión Social \\
\hline SBGG & Sociedad Brasileña de Gerontología y Geriatría \\
\hline SEADE & Sistema Estatal de Análisis de Datos \\
\hline SESAP & Secretaría de Salud Pública \\
\hline SIDA & Síndrome de Inmuno Deficiencia Adquirida \\
\hline SM & Salario Mínimo \\
\hline SIS & Síntesis de los Indicadores Sociales \\
\hline SUS & Sistema Único de Salud \\
\hline SVS & Secretaría de Vigilancia Sanitaria \\
\hline TSE & Tribunal Superior Electoral \\
\hline UNICAT & Unidad central de Agentes Terapéuticos \\
\hline UERN & Universidad del Estado de Río Grande del Norte \\
\hline
\end{tabular}




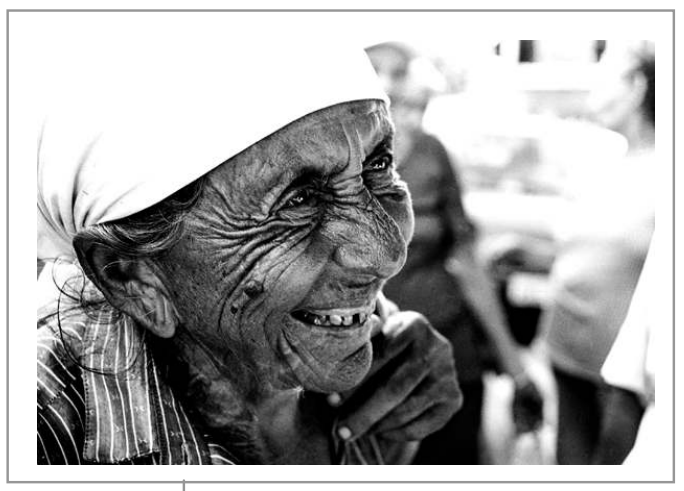

Envejecer es todavía el único medio que se ha encontrado para vivir mucho.

Charles Augustin Saint-Beuve (1804-1969), Escritor y crítico francés. 


\section{Resumen}

El objetivo de este estudio es contribuir al debate actual sobre la temática del envejecimiento y su consecuencia natural, la vejez, analizando la evolución demográfica y socioeconómica de una población del Nordeste de Brasil, caracterizada por el declive de la fecundidad y del aumento de la expectativa de vida. Dado que la mayoría de los estudios apuntan una gran falta de información de toda la sociedad sobre la vejez y las necesidades reales de los senescentes, nuestro propósito fue generar datos sobre el grupo de personas con 60 años o más de edad, que corresponde al 7,8\% del total de la población de Mossoró y así contribuir para el perfil de la población mayor brasileña. El trabajo de campo fue llevado a cabo entre Junio de 2004 a Junio de 2005, a través de una encuesta con 83 preguntas, planteadas en 10 bloques temáticos (aspectos demográficos, profesión y recursos financieros, familia, la subjetividad de la vejez, el peso del tiempo, vivienda, salud y asistencia sanitaria, habilidades funcionales, servicios y prestaciones sociales, la vejez ante el cambio social y la muerte. La muestra fue recogida con 500 mayores, hombres y mujeres de igual número, que supone $3 \%$ de la población investigada. Los análisis estadísticos de la encuesta, pionero en el Estado del Río Grande del Norte (Región Nordeste de Brasil), exponen que las necesidades específicas de las personas de edad requieren una planificación de políticas públicas ajustadas y sólidas. Seguridad y protección social, asistencia sanitaria, solidaridad intergeneracional y apoyo a las familias.

Los datos empíricos sirvieron de base para profundizar, más allá del diagnóstico lógico de las necesidades de una población concreta, en los debates de política social y, sobre todo, en la comprensión del fenómeno del envejecimiento en las sociedades globales con niveles de desarrollo diferentes. 


\section{Abstract}

The goal of this study is to contribute to the present debate on the theme of aging and its natural consequences. Analyzing the demographic and socioeconomic ageing process of a population of the Northeast of Brazil characterized for the declivity of the fecundity and the increase of the life expectancy. The remarkable Demographic Transition in Brazil is taking place

in a fast and intense way, from the Sixties, due to the. As the studies show, a great lack of information of the society on the old age and the real needs of old people. Therefore, our intention is to generate data on the group of people with 60 years and more (7.8\% of the total population of Mossoró), and thus to contribute to the profile of the Brazilian elder population. This study was carried out between June 2004 and June 2005, through a survey with 83 questions, organized in 10 thematic blocks (demographic aspects, financial profession and resources, family, the subjectivity of the old age, the weight of the time, the house, health and medical assistance, functional abilities, social services and benefits, ageing and the social evolution and the death. The sample was gathered with 500 old men and women of equal number (3\% of the investigated population). The statistical analyses of the survey, pioneer in the State of the Grande River of the North (Northeastern Region of Brazil), point out that old people require strong and scheduled public policies, security and social protection, medical assistance, intergenerational solidarity and support to the families.

The having analyzed all these aspects, we have come to the conclusion that the logical diagnostic of the necessity of a concrete population in the debates of the social politic $y$ in the comprehension of the ageing at the global societies with different development. 
$\begin{array}{ll}\text { Introducción } & 18\end{array}$

$\begin{array}{ll}\text { Trayectoria de la investigación } & 18\end{array}$

Objeto y objetivos 28

Método, base documental y muestra $\quad 30$

Instrumento adoptado 30

Análisis y estadísticas $\quad 32$

Estructura del trabajo 33

\section{Parte I}

\section{Marco Teórico y Conceptos Fundamentales}

\section{Capítulo 1.}

Teorías sociológicas sobre la vejez

Introducción

1. Primera Generación (1949-1969)

1.1. Teoría de la actividad

1.2. Teoría del retraimiento o desvinculación

1.3. Teoría de la subcultura

2. Segunda Generación (1972-1984)

2.1. Teoría de la continuidad

2.2. Teoría de la ruptura social

2.3. Teoría del medio social

2.4. Teoría de la estratificación por edad

2.5. Teoría de la modernidad

2.6. Teoría marxista o economía política de la vejez

3. Tercera Generación (1970-1992)

3.1. Teoría de la reconstrucción social

3.2. Teoría perspectiva del curso de vida

3.3. Teorías feministas del envejecimiento

3.4. Teoría social crítica 


\section{Capítulo 2.}

Conceptos básicos y denominación de vejez y envejecimiento

Introducción

1. Gerontología y geriatría

2. Dimensiones del envejecimiento

2.1. Perspectiva demográfica

2.2. Perspectiva cronológica

2.3. Perspectiva biológica

2.4. Perspectiva psicológica

2.5. Perspectiva social

3. Distintos vocablos para referirse la vejez

6. Tipos de envejecimiento

6.1. Envejecimiento normativo o primario

6.2. Envejecimiento patológico o secundario

6.3. Envejecimiento terciario o terminal

6.4. Envejecimiento con éxito

\section{Capítulo 3.}

Introducción a los aspectos demográficos de la vejez

Introducción

1. El envejecimiento como efecto de la transición demográfica

2. La mortalidad: factores biológicos y sociales

3. Algunas causas y consecuencias del envejecimiento demográfico

4. El debate en torno al envejecimiento en las organizaciones internacionales: Naciones Unidas, Unión Europea, Latinoamérica y Caribe 


\section{Capítulo 4.}

Cuestiones básicas del envejecimiento demográfico en Brasil en la perspectiva mundial y de América Latina

Introducción

1. La participación del anciano en la población brasileña 124

1.1. Mortalidad y fecundidad

1.2. Mayor esperanza de vida

1.3. Población senescente

1.4. La feminización de la vejez

2. Indicadores económicos: el sistema de pensión y condición económica de los adultos mayores brasileños

2.1. Participación de los mayores en la sociedad

3. El estado de salud de los adultos mayores brasileños

4. Acerca de las políticas públicas para los adultos mayores en Brasil

4.1 Constitución Federal

4.2 Ley Orgánica de la Asistencia Social

4.3 Política Nacional del Mayor

4.4 Estatuto del Mayor

\section{Capítulo 5.}

El envejecimiento demográfico de Mossoró en el contexto del estado de Río Grande del Norte. Algunos indicadores básicos Introducción

1. Aspectos demográficos y sociales

1.1. Localización y población

1.2. Economía

1.3. Indicadores de mortalidad y fecundidad

1.4. Educación, longevidad y renta 


\section{Parte II}

Perfil sociológico de la vejez en Mossoró

Presentación y discusión de los resultados de la investigación

\section{Capítulo 1}

\section{La vejez en Mossoró}

Introducción

1. Estructura socio demográfica de las personas de 60 años en adelante

1.1. Estructura de la población anciana en Mossoró según el sexo, edad, escolarización y renta

1.2. Personas de 60 años en adelante residentes en Mosssoró por barrio según sexo y grupos de edad

\section{Capítulo 2}

\section{Aspectos demográficos}

1. Sexo y edad

2. Estado civil

3. Nivel educativo

4. Estructura familiar

5. Lugar de nacimiento

6. Situación laboral actual

7. Resumen

\section{Capítulo 3}

Profesión y recursos financieros

1. Fuente de renta que cobra actualmente

2. Ingresos mensuales

3. Grado de satisfacción de los mayores con su situación económica

4. Trabajos anteriores a la jubilación

5. Área de trabajo actual

6. Causas del desempleo

7. Preferencias en el ámbito laboral

8. Resumen 


\section{Capítulo 4}

\section{Entre la familia y la residencia}

1. Hijos vivos

2. Relación con las personas con quienes vive el mayor

3. Formas de convivencia - familia, vecindario y amigos

4. Forma de vida preferida por los mayores

5. Bajo qué circunstancia estarían los mayores dispuestos a vivir en una Residencia para mayores

6. Mayores que opinan que hace falta una Residencia en Mossoró

7. Sugerencia para la construcción de una Residencia

8. Resumen

\section{Capítulo 5}

\section{La ancianidad como categoría subjetiva}

1. Lo que hace a una persona ser mayor

2. Mejor expresión para referirse a una persona mayor

3. Percepción del trato

4. Opinión del mayor sobre cuándo debe llegar la jubilación

5. Responsabilidad del pago de la jubilación según el mayor

6. Resumen

\section{Capítulo 6}

El peso del tiempo: trabajo, obligaciones del hogar, tiempo libre y ocio

1. Ocupación del tiempo libre

2. Qué escuchan en la radio

3. Preferencia hacia los programas televisivos

4. Actividad física que practica

5. Frecuencia con la que sale de vacaciones

6. Motivo por el cual nunca sale de vacaciones

7. La valoración del sexo

8. Capacidad para administrar los ingresos

9. Dónde suele comer habitualmente

10. Comidas que suele hacer al día

11. Grado de satisfacción con la comida

12. Resumen 


\section{Capítulo 7}

\section{Vivienda}

1. La vivienda del mayor

2. Régimen de tenencia de la vivienda

3. Coste de la vivienda alquilada

4. Dispone o no de habitación propia

5. Grado de satisfacción con la vivienda

6. Problemas en el contexto de la vivienda

7. Equipamientos y servicios de los que disponen en su domicilio

8. Prestaciones y servicios existentes cerca de su vivienda

9. Situaciones que dificultan sus desplazamientos

10. Medio de transporte que suele usar

11. Resumen

\section{Capítulo 8}

\section{Salud y asistencia sanitaria}

1. Percepción del estado de salud durante el último año

2. Enfermedades declaradas actualmente

3. Capacidad auditiva

4. Uso de prótesis auditivas

5. Vacunas administradas al año

6. Frecuencia con la que ha estado hospitalizado

7. Motivos del ingreso hospitalario

8. Realización de chequeos generales

9. Motivo por el que nunca se ha hecho un chequeo general

\section{Capítulo 9}

\section{Cuidados de la salud}

1. Frecuencia de consultas al médico

2. Medios por los que adquiere medicamentos

3. Revisiones oftalmológicas que le hicieron en el último año

4. Mujeres que visitan al Ginecólogo

5. Hombres que visitan al Urólogo

6. Cobertura Sanitaria que tiene actualmente

7. Cómo debe recibir asistencia médica el anciano

8. Consumo de tabaco

9. Consumo de bebidas alcohólicas 
10. Hábito y frecuencia de consumo de bebidas alcohólicas

11. Resumen

\section{Capítulo 10}

\section{Habilidades funcionales}

1. Actividades que suelen realizar mediante ayuda

2. Grado de dificultad para realizar las AVDs y la AIVDs

3. Quién desearía que le prestara ayuda para realizar las AVDs y AIVDs

4. Motivos por los que no recibe ayuda para realizar las AVDs y AIVDs

5. Capacidad para utilizar los cajeros automáticos

6. Resumen

\section{Capítulo 11}

\section{Servicios y prestaciones sociales para personas mayores}

1. Servicios y prestaciones sociales conocidos o de los que se ha oído hablar destinados a las personas mayores

2. Mayores que han utilizado o se han beneficiado de alguna de las prestaciones o servicios

3. Cuáles son las prestaciones o servicios utilizados

4. Grado de conocimiento sobre las leyes que benefician a los mayores

5. Resumen

\section{Capítulo12}

\section{La vejez ante el cambio social}

1. Aborto, pena de muerte, divorcio, pago de impuestos fiscales, relación sexual antes de la boda, relación sexual entre personas del mismo sexo y legalización de las drogas

2. Ejercicio del voto en las elecciones

3. Motivos aducidos por el mayor para no votar

4. Resumen

\section{Capítulo 13}

\section{La vejez ante la muerte}

1. Sentido de la vida

2. Satisfacción con la vida

3. Auto definición religiosa

4. Frecuencia del pensamiento sobre la muerte

5. Con quién suele hablar de la muerte

4. Resumen 
Conclusiones

Referencias Bibliográficas

Índice de gráficos

512

Índice de tablas

514

Índice de figuras

515

Índice de fotos

Anexos

Cuestionario

Distribuciones Marginales 


\section{Introducción}

Todos los seres humanos sentimos un ansia de no morir, un hambre de inmortalidad, un anhelo de eternidad.

Miguel de Unamuno y Jugo (1864-1936), Escritor, poeta y filósofo español.

\section{Trayectoria de la investigación}

Se puede decir que la reflexión sobre el proceso del envejecimiento y su consecuencia natural, la vejez, es un tema tan antiguo como la idea de la inmortalidad. En cierta ocasión dijo Unamuno que "todos los seres humanos sentimos un ansia de no morir, un hambre de inmortalidad, un anhelo de eternidad"'. La convicción íntima del inicio de la vejez, de su trayecto "inevitable", es punto de partida para vastos cuestionamientos sobre nuestro porvenir. Conseguir la tan ansiada inmortalidad y buscar las razones del deterioro de la vida humana, ha generado confusión en la mente de profesionales e investigadores a lo largo de los tiempos. El carácter ambivalente y complejo de la vejez genera un sinnúmero de soportes teóricos para todos los gustos. Los efectos asociados a ese proceso son diversos, sin embargo, ganan expresión y legitimidad, sobre todo, los de orden económico y social. Por eso, la atención dispensada a este tema moviliza individuos en diversas culturas y épocas y se acentúa en las sociedades occidentales técnicamente avanzadas, dado el hecho de que los ancianos corresponden a una porción de la población adulta cada vez más numerosa.

En Brasil, no es novedad el hecho de que la población está pasando por un acelerado proceso de envejecimiento. A pesar de ocupar el $5^{\circ}$ lugar en la lista de las naciones más pobladas del planeta y llegar al final de 2006 con 186.770.562 millones de habitantes, según datos del Instituto Brasileño de al enfoque positivo. Revista de Educación, no 323, p. 162. 
Geografía y Estadística (IBGE), el crecimiento demográfico brasileño se está desacelerando en las últimas cinco décadas. En 1950, la tasa de crecimiento demográfico era del $3 \%$ al año; en 2007 , fue del $1,37 \%$. Mundialmente hablando, de acuerdo con datos de la Organización de las Naciones Unidas (ONU), en el 2050 la Tierra tendrá alrededor de 9 mil millones de habitantes, creciendo a un ritmo anual del $0,33 \%$, bastante inferior al actual del 1,17\%. Según los expertos, los principales factores de esa desaceleración son la reducción del número de hijos por mujer y el aumento de la mortalidad en los países más afectados por el SIDA, como los del África Subsahariana. En el caso de Brasil, eso ocurre porque la tasa de fecundidad está descendiendo año tras año. En la década de los sesenta, ese índice anual era de 6,3 hijos por mujer. En 2006, según datos del IBGE (PNAD/2006), la tasa de fecundidad fue de 2 nacimientos por mujer, indicando una caída hasta el nivel de reposición de la población. Algunas estimaciones indican que si se mantuviera el actual modelo reproductivo (una media de dos hijos por mujer), de aquí a 50 años la población debería dejar de crecer.

La tendencia en el escenario de la población del país es, por lo tanto, al envejecimiento. La población de los mayores de 60 años es la que más crece, a causa de la caída de la fecundidad total y de la mayor expectativa de vida. En el año 1940, el grupo de personas con hasta 14 años de edad representaba casi la mitad de los brasileños, en el año 2000 corresponde a menos de un tercio de la población total. Según la Síntesis de los Indicadores Sociales, publicada en 2007, Brasil está entre los diez países del mundo con mayor porcentaje de población con edad superior a los 60 años. Hay 19 millones de personas de 60 años o más y superan los 13 millones en el grupo de 65 años o más, correspondiendo al $10,2 \%$ y 7,1\% del total de la población, respectivamente. Su participación se duplicó ampliamente en los últimos 50 años; pasó del $4 \%$ en 1940 al $9 \%$ en el año 2000. Por cada 100 mujeres con más de 65 años hay 78,6 hombres. ${ }^{2}$ Además, en Brasil, entre los adultos mayores, el segmento que más crece es justamente el de los más viejos: en el grupo

\footnotetext{
2 De acuerdo con el ranking de las Naciones Unidas (2006), Brasil ocupa el 92 ${ }^{\circ}$ lugar en esperanza media de Vida al nacer y el $85^{\circ}$ con relación a la mortalidad infantil. En 2000, el país estaba en el $89^{\circ}$ puesto. De los 195 países que componen la clasificación, Japón es el número uno en expectativa de vida con 82,6 años.
} 
con 75 años o más, el crecimiento fue del $49,3 \%$ entre 1991 y el 2000 . A efectos de comparación, el número de individuos de 60 a 64 años creció el 26,5\% en el mismo período. El estudio apunta la existencia de 2,4 millones de brasileños octogenarios en 2006, que representan el 1,3\% de la población. En 1995, dichos mayores suponían el 0,9\%. Los estados con mayor número de personas, en proporción relativa, en esta franja de edad son Río de Janeiro con el 14,1\%, Río Grande del Sur con el 12,4\%, Minas Gerais con el 10,9\%, Paraíba con el 10,8\% y São Paulo con el 10,7\%. También merece la pena considerar que el índice de envejecimiento de población del país (calculado como la proporción entre las personas con 65 años o más y los menores de 15) que era de 0,11 en la década de 1980, se elevó hasta el 0,25 en 2000. Esos números demuestran que hay 25 mayores por cada 100 jóvenes. En el 2050, serán 102 por cada 100 jóvenes. Eso deja claro que aún a pesar de ser considerado joven, Brasil va envejeciendo. Proyecciones recientes indican que ese segmento podrá ser responsable de casi el 15\% de la población brasileña en el año 2020 (Camarano, 1997), gracias a la alta fecundidad observada en los años 50 y 60 y a la caída de la mortalidad, que benefició a todos los grupos poblacionales.

Pero, esto no es un fenómeno aislado. En todo el mundo, tanto en términos absolutos como relativos, hay un notable incremento de los sujetos con más de sesenta años. La tasa de crecimiento de la población mayor de 60 años es del $1,9 \%$ al año, bastante mayor que el crecimiento del $1,17 \%$ de la población en general. Esa transformación demográfica que el mundo está experimentando es algo sin precedentes. Hasta el 2050, el número de personas de más de 60 años aumentará de los 606 millones actuales a casi 2.000 millones, y se prevé que el porcentaje de personas de 60 años o más se duplique, pasando de un $10 \%$ a un $21 \%$. Ese incremento será mayor y más rápido en los países en desarrollo, donde se prevé que la población de edad se multiplique por cuatro en los próximos 50 años $^{3}$. De acuerdo con el Informe de las Naciones Unidas en Asia y América Latina, el colectivo de personas de 60 años o más aumentará del $8 \%$ al 15\% entre 1998 y 2025, mientras que en

\footnotetext{
Informe de la Segunda Asamblea Mundial sobre el Envejecimiento, Madrid, 8 a 12 de Abril de 2002 (publicación de las Naciones Unidas, Nueva York, Número de Venta: S.02.IV.4), resolución 1, anexo 1 , art. 2.
} 
África se prevé que esa proporción aumente sólo del 5\% al 6\% durante el mismo período, y que después se duplique hacia el año 2050. En Europa y América del Norte, entre 1998 y 2025 la proporción de población clasificada como personas de edad aumentará del $20 \%$ al $28 \%$ y del $16 \%$ al $26 \%$, respectivamente.

En cada rincón, la humanidad experimentará una evolución gris. Sin embargo, de momento, a pesar de que el envejecimiento es una tendencia global, al menos se destacan dos hechos en su estructura demográfica y su tendencia para el futuro: primero, en las naciones avanzadas, las personas viven más que en los países en desarrollo, en particular en los menos desarrollados, donde se registra una alta incidencia de la pobreza, aguda inequidad social ${ }^{4}$ y desigualdad de ingresos ${ }^{5}$. Japón y Suecia, por ejemplo, tienen la mayor expectativa de vida, que sobrepasa los 80 años, mientras, que en Suazilandia, en África, las personas viven menos de 40 años (PNUD: 2006). Segundo, el ritmo del envejecimiento en las regiones menos desarrolladas es más rápido de lo que fue históricamente en los países avanzados. Francia necesitó poco más de un siglo para que la proporción de adultos mayores pasase del $8 \%$ al $15 \%$, mientras que China vivirá esta brutal transformación en un período de apenas veinte años, entre el 2010 y el 2030. Esto significa que los países avanzados, a partir de la Revolución Industrial, se enriquecieron y luego comenzaron a envejecer. El envejecimiento fue, por lo tanto, consecuencia de la mejora de la calidad de vida.

En América Latina y el Caribe, según Guzmán (2002) la proporción de población de 60 años o más aumentará del 8\% en el año 2000 al 14.1\% en el 2025 y al $22.6 \%$ en el 2050. De acuerdo con las tendencias actuales, la proporción femenina de senescentes es más alta que la masculina, particularmente en el área urbana. Para Guzmán (2002), en el documento de la CEPAL, tres situaciones caracterizan a los países en el proceso de envejecimiento demográfico en América Latina y el Caribe. En el primer grupo el proceso está más avanzado como en Uruguay, Argentina, Cuba y Chile y en

\footnotetext{
CEPAL (2000): Panorama social de América Latina 1999-2000. Santiago, Chile.

Morley, Samuel (2000): La distribución del ingreso en América Latina y el Caribe. Santiago, Chile CEPAL/FCE.
} 
países del Caribe (Trinidad y Tobago y Barbados), donde más de un 10\% de la población es mayor de 60 años. En el otro extremo se ubican países que se encuentran menos avanzados en su transición demográfica (Guatemala, Bolivia, Paraguay, Honduras, Haití, entre otros), donde un porcentaje inferior al 6,5\% de la población sobrepasa los 60 años. $Y$ en la tercera situación de países en situación intermedia, que experimentarán los aumentos de su población con edad superior a 60 años en las próximas décadas se encuentran Brasil, México, Colombia, Costa Rica y Panamá (Guzmán, 2002:10).

En Mossoró, segunda ciudad más desarrollada del estado de Río Grande del Norte/RN, situada en la región Nordeste de Brasil, donde se llevó a cabo la investigación, el aumento continuo de la población de adultos mayores es patente, no escapa a la tendencia. En el último Censo de Población (IBGE: 2000), el total era de 213.000 habitantes y los adultos mayores 16.510 , lo que representaba el $7,6 \%$ del total de la población, una cifra en progresión. Se ha llegado a ello tras un proceso de envejecimiento iniciado al final de la primera mitad del siglo XX causado por un proceso de alta fertilidad, combinado con un descenso de la mortalidad. Actualmente, el número de mayores alcanza los 18.103 (mayo/2008), lo que corresponde al 7,8\% del total de la población.

Así que en nuestra ciudad el aumento de la visibilidad de la vejez y de los senescentes puede comprobarse por los datos demográficos divulgados por los medios de comunicación. Poco a poco este tema de tanta transcendencia atrae la atención de nuestra sociedad y los longevos van entrando en la agenda política de la ciudad. En el ámbito de la intervención hacia los mayores, la instalación del Consejo Municipal del Mayor (Octubre de 2007), el Programa Mayor Ciudadano del Ayuntamiento Municipal de Mossoró y las acciones del Movimiento de Integración y Orientación Social (Meios) del Gobierno del Estado del Río Grande del Norte componen las parcas acciones en beneficio de los mayores mossoroenses. Actualmente, la vejez y su consiguiente problemática están presentes, tímidamente, también en 
discusiones de diferentes áreas del conocimiento ${ }^{6}$. La difusión de la información científica y profesional deja mucho que desear. De esa forma, es comprensible que este trabajo revele nuestra pretensión de participar en esas discusiones. Creemos poder contribuir al progreso del saber, y al mismo tiempo, ofrecer bases para afrontar el reto de las innumerables cuestiones sociales que afectan directa e indirectamente al colectivo de los mayores de 60 años, un número cada vez más significativo en las sociedades contemporáneas.

De modo particular, nuestro interés por este campo de estudio se debe a dos hechos importantes: primero, en el año que comencé el doctorado de Estructura Social y Desigualdad se llevó a cabo la II Asamblea Mundial Sobre el Envejecimiento (2002), encuentro auspiciado por la Organización de las Naciones Unidas (ONU) en Madrid. Un tema actual que se extendía por supuesto a los países en desarrollo. España, como país anfitrión, se mostraba orgullosa de organizar el evento por primera vez desde la anterior cumbre sobre la vejez, veinte años atrás, en Viena. Y yo, a mi vez, por estar tan cerca del centro de las discusiones estratégicas a nivel mundial, para afrontar los problemas con garantías a la revolución silenciosa que seguramente iba a marcar el siglo XXI. Me henchí de ilusiones. Estaban presentes autoridades, líderes, profesionales procedentes de 160 países y cerca de 5.000 participantes, con el compromiso de hacer un examen global de los avances logrados y adoptar un plan de acción a favor de los adultos mayores. Una época importante que marcó la historia de España, la mía y la de mi pueblo, consecuentemente.

Segundo, me llamaba la atención la cantidad de personas mayores de 60 años en las calles salmantinas; en toda mi vida nunca había visto tantos senescentes presentes en un escenario urbano. Lo comparé con mi ciudad. Estaba acostumbrada a ver en Mossoró niños yendo a la escuela y/o en las

\footnotetext{
6 Durante la investigación realizada en la Biblioteca de la Universidad del Estado del Rio Grande Norte - UERN, sobre la temática de la vejez, fueron encontradas monografías de grado en las siguientes facultades: Servicio Social entre los años 1980 a 2000 (33), Enfermería entre los años 2000 y 2002 (05). En los cursos de posgrado en nivel de especialización encontramos en Políticas Públicas entre 1999 y 2000 (02), en Pluralidad Cultural en 2002 (01) y en Gerontología Social en 2005 (02). No hemos encontrado ningún registro de Disertación de Maestría o Tesis Doctorales en el área del envejecimiento y/o de la vejez.
} 
calles, adolescentes estudiando o empezando a trabajar, madres jóvenes embarazadas, adultos en todos los ambientes y personas de edad en algunos sitios, pero en menor proporción, que en tierras charras. En Salamanca, las cafeterías, tiendas, plazas, jardines y conciertos parecían y, todavía los son, sus ambientes predilectos. Se dejan ver, participando en las diferentes áreas de la vida social, son valorados. La imagen en aquel momento parecía adelantarme en el tiempo. Vivir en una sociedad para todas las edades ${ }^{7}$ podía ser una "realidad". Allí brotó en mí el profundo deseo de que un día eso fuera posible en Mossoró y en todo Brasil.

Sobre el primer punto, destaco que he acompañado los debates de las futuras líneas de actuación sobren las personas mayores desde el punto de vista humano y social, a través de la televisión, de los periódicos y de los posicionamientos de algunas autoridades de España, por ejemplo, del discurso inaugural de Kofi Annan, Secretario General de la ONU. El secretario resaltó el hecho de que los ancianos no son un grupo compacto, sino una categoría diversa con necesidades muy distintas los unos de los otros. En su discurso Su Alteza Real la Infanta Doña Cristina como Embajadora de Buena Voluntad de las Naciones Unidas para la II Asamblea Mundial del Envejecimiento, hizo una invitación juntos vamos a construir una imagen positiva del envejecer, que no debe significar únicamente una prolongación de la vida, sino conseguir que la etapa de la vejez sea saludable, autónoma, activa y de plena integración en la sociedad y en su intervención el Presidente del Gobierno del Reino de España, Sr. José María Aznar dijo, independientemente de su valoración, el envejecimiento es ya, para muchos de nosotros, "un hecho", un fenómeno nuevo e inapelable que exige cambios profundos y respuestas decididas por parte de todas las estructuras e instituciones de la sociedad. Además, a raíz de las intervenciones de los Jefes de Estado y Gobierno, ministros, embajadores y miembros de las delegaciones de varios países participantes en aquél evento, se agudizó mi curiosidad por saber cómo estaba siendo

El concepto de una sociedad para todas las edades, formulado como tema del Año Internacional de las Personas de Edad, que se celebró en 1999, tenía cuatro dimensiones: el desarrollo individual durante toda la vida; las relaciones multigeneracionales; la relación mutua entre el envejecimiento de la población y el desarrollo; y la situación de las personas de edad. El Año Internacional contribuyó a promover la conciencia de esos problemas, así como la investigación y la acción en materia de políticas, en todo el mundo. 
planteada esta temática en Brasil y, sobre todo, si era verdad que estábamos en la lista de los que estaban envejeciendo rápidamente.

Me puse a investigar, específicamente, en las páginas oficiales de organismos públicos brasileños y mis dudas se confirmaron un par de semanas más tarde. La mayor esperanza de vida era una realidad en todo el país, pero con diferencias regionales. Una sorpresa: Brasil, tendría que hacer frente a una importante limitación de recursos e intentar resolver los retos simultáneos del desarrollo y del envejecimiento de la población. Tenía por delante los desafíos de la Seguridad Social, del sistema sanitario y de la lucha contra la pobreza entre los adultos mayores, un problema primordial, para poder proporcionar un buen nivel de bienestar a la sociedad. Mi interés creció más aún por el tema. Me empeñé en buscar datos de producción científica. Para comprobar mi desconfianza, el área del envejecimiento y de la vejez estaba siendo más desarrollada en las regiones Sur, Sudeste y Centro-Oeste del país ${ }^{8}$. Las regiones menos desarrolladas, Norte y Nordeste, carecían fundamentalmente de investigaciones en este ámbito, como también sufrían de otras necesidades. A partir de ese momento se abría un abanico de posibilidades para explorar esa área del conocimiento, sobre todo, bajo un enfoque inédito en el ámbito de la sociología.

El segundo punto que justifica mi interés por el tema de la vejez se debe al hecho de que el aumento del envejecimiento de la población en Mossoró es una realidad en el presente siglo. La inversión de la pirámide de edad plantea fuertes exigencias a la política y a la sociedad. De ese modo, generar un diálogo social sobre el envejecimiento y su repercusión en la familia, la sociedad y el Estado a través del presente trabajo de investigación sería un paso en el compromiso de trabajar a favor de una sociedad para todas las edades. Convencida y motivada por esa idea, me puse a buscar encuestas,

\footnotetext{
$8 \quad$ Según Lucila L. Goldstein (1999), en 1997, la investigadora Anita Liberallesso Neri realizó un análisis de 36 relatos de investigación de tesis y trabajos de Máster defendidos en Programas de posgrado en Psicología entre los años 1975 y 1996, en las Universidades de São Paulo, Universidade Estadual de Campinas y Pontificias Universidades Católicas de São Paulo y de Campinas. En este trabajo la investigadora localizó 60 trabajos sobre la vejez, en otras áreas del conocimiento como: enfermería, salud pública, fonoaudiología, sociología, antropología, periodismo, comunicaciones y marketing.
} 
muestras sobre el envejecimiento y la vejez realizadas en España para dibujar un modelo adecuado a la realidad de Mossoró.

La elaboración del cuestionario fue inspirado en algunos modelos de diferentes investigaciones: Informe Sobre la Tercera Edad - Estudio sociológico sobre la ancianidad en Cataluña (Rogeli Duocastella, Barcelona, 1976); Los ancianos en Salamanca, hoy 1983 - Departamento de Ética y Sociología de la Universidad de Salamanca; Los mayores en la Comunidad de Madrid - Estudio sobre las necesidades y recursos para la tercera edad de J. D. Nicolás (1996); Situación socioeconómica, opinión y actitudes de los ancianos leoneses, Tesis Doctoral de J. B. González de la Universidad Complutense de Madrid (1988) y La problemática de los viejos (investigación), Tesis Doctoral de Enrique-Alfonso Giraldes y García, Universidad Complutense de Madrid, 1993. Además, la estructura y organización del cuestionario contó con la contribución del Prof. Dr. Modesto Escobar, experto en Estadística, del Departamento de Sociología y Educación y catedrático del Doctorado de "Estructura Social y Desigualdad".

Esa eficiente técnica posibilitó que las preguntas pudieran ser contestadas por un segmento poblacional menos instruido y/o analfabeto. Nuestra mayor ventaja fue la de conseguir analizar los datos cuantitativa y cualitativamente.

Estructurada con 83 preguntas directas concebidas de forma simple y de fácil comprensión - que resultaron en 212 variables - el trabajo de campo fue realizado entre junio de 2004 y junio de 2005, y movilizó la participación de aproximadamente cien alumnos universitarios de las Facultades de Educación, Filosofía y Ciencias Sociales de la Universidad del Estado del Río Grande del Norte (UERN). Orientamos a los estudiantes en su debido curso, con el imprescindible apoyo de los profesores y del jefe de departamento. En estos años, fui a Brasil dos veces para supervisar todo el sondeo. El cuestionario tenía 17 folios y cada alumno se responsabilizaba de al menos 5 formularios. Como cada entrevista duraba cerca de 2 horas, se sobrentiende que cada estudiante dedicó cerca de 10 horas a esta actividad. En total, se necesitaron unas 1.000 horas para la realización de todos los cuestionarios. 
Al regreso a Mossoró, entre los años 2006 y 2008, nuestra investigación había adquirido cierta relevancia. Algunas charlas informales sobre nuestro trabajo fueron el detonante para despertar el interés de periodistas de la localidad y de algunos profesionales del Ayuntamiento de Mossoró que trabajan en el ámbito de la vejez. Tuvimos ocasión de conceder entrevistas y participar en la I Conferencia Municipal de los Derechos de la Persona Mayor en Mossoró. Nuestra contribución en los debates de la I Conferencia, donde proponíamos y perfeccionábamos las políticas públicas de protección y defensa de la persona mayor, nos dio la oportunidad de participar en la II Conferencia Estatal de los Derechos de la Persona Mayor en la capital, Natal. La Conferencia Municipal elaboró cuarenta propuestas, que fueron discutidas en la Conferencia Estatal. Las reflexiones generadas en ambas conferencias son de la mayor importancia para las deliberaciones de la II Conferencia Nacional de los Derechos de la Persona Mayor, realizada en Brasilia en 2008.

En lo que se refiere al título de la tesis, nos inspiramos en el diseñador español Adolfo Domínguez que, en 1979 lanzó la campaña publicitaria "La arruga es bella" para vender el lino. Treinta años después, esa declaración aun genera controversia y resulta incómoda para muchos de nosotros. La búsqueda obsesiva de un rostro sin arrugas y un cuerpo perfecto nunca estuvo tan de moda. Los recursos de la cirugía plástica para la preservación artificial del cuerpo se desarrollan frenéticamente y se traducen en el sueño de consumo de hombres y mujeres de todas las edades, muchas veces, debido a la dificultad de aceptar el avance de la edad.

Pero, los años pasan por más que disfracemos sus efectos. ¿Por qué no aceptarlos? ¿Por qué nos resistimos en no percibir belleza incluso cuando se nos presentan las temidas imperfecciones? Los retoques pueden eliminar las arrugas, pero no la edad. Así pues, es preciso destacar que los valores inherentes a la belleza de la sabiduría, de la experiencia, del discernimiento, de la prudencia que sólo el tiempo es capaz de generar sobrepasan la mera apariencia. Una imagen positiva del envejecimiento es un aspecto esencial para ahuyentar los estereotipos negativos y engañosos del envejecimiento. Realzar los puntos fuertes, las calidades humanas, las aportaciones, el valor y 
la inventiva de hombres y mujeres de edad es descubrir verdaderamente la belleza de las arrugas de nuestros protagonistas. Cuando el envejecimiento se acepta como un éxito, el recurso a las competencias, experiencias y recursos humanos de los grupos de más edad se asume con naturalidad como una ventaja para el crecimiento de sociedades humanas maduras, plenamente integradas (Artículo 6 del Informe de la II Asamblea Mundial sobre el Envejecimiento, Madrid: 2002).

\section{Objeto y objetivos de este estudio}

Este crecimiento continuo, desde el punto de vista económico y social, apunta a la necesidad de crear las condiciones que favorezcan la llegada de las personas de más de 60 años al siglo XXI. Fortalecer la capacidad de los países para abordar de manera efectiva el envejecimiento de su población, atender a las preocupaciones y necesidades especiales de las personas de edad y fomentar una respuesta internacional adecuada a los problemas del envejecimiento poniendo en práctica medidas para el establecimiento del nuevo orden económico internacional y el aumento de las actividades internacionales de cooperación técnica, en particular entre los propios países en desarrollo. Estas son las metas del Plan de Acción Internacional de Viena sobre el Envejecimiento (1982) y de la II Asamblea Mundial sobre el Envejecimiento, realizada en Madrid (2002). Para promover el desarrollo de una sociedad para todas las edades, Fernández-Ballesteros (2004) proclama que el envejecimiento de la población exige intervención social en múltiples áreas: sanitaria, educativa, legislativa, laboral, de tiempo libre y ocio, etc., lo cual, a su vez, requiere la creación y el reciclaje de medios humanos y técnicos para hacer frente a tales necesidades de atención $e$ intervención (Prólogo 2004:25). Aunque hay diferencias importantes entre países y dentro de estos en el proceso de envejecimiento, existe un consenso en cuanto a la posibilidad de afrontar los problemas, tanto de la capacidad del Estado para generar y aplicar políticas públicas como de los patrones de organización familiar y otros tipos de apoyo comunitario. 
Considerando parte de las necesidades de atención de la población con edad superior a los 60 años, de modo particular en Mossoró y, atendiendo a los principios y las recomendaciones contenidas en el Plan de Acción Internacional sobre el Envejecimiento, que las Asambleas de las Naciones Unidas hicieron suyas en 1982 (Viena) y 2002 (Madrid), además de los compromisos contemplados en la Declaración del Milenio ${ }^{9}$, a través de las Metas de Desarrollo del Milenio ${ }^{10}$ que promuevan el establecimiento de una sociedad para todas las edades y los Principios de las Naciones Unidas ${ }^{11}$ en favor de las personas de edad, que orientan sobre las cuestiones de la independencia, la participación, los cuidados, la autorrealización y la dignidad el objetivo de este trabajo es:

a) Generar conocimiento en relación a la actual situación biopsicosocial, económica y cultural de las personas de 60 años o más residentes en Mossoró. Analizar de modo interdisciplinar la problemática humana, socioeconómica, cultural, profesional y familiar que plantea esa población como constituyente de un grupo social, partiendo de los actuales estudios demográficos, en la prospectiva del último censo de IBGE (2000) y de la encuesta "El Perfil Sociológico de la Vejez en Mossoró", Parte II de nuestra investigación.

b) Investigar sobre el proceso demográfico de envejecimiento de la población de Mossoró de modo a contribuir a una intervención social en esa temática, observando las políticas públicas existentes en el estado y las políticas que tratan esa cuestión en los países más desarrollados.

c) Analizar el debate sobre el envejecimiento y la vejez, considerando que la transición demográfica en Brasil es rápida e intensa. Eso se verifica en el estado de Río Grande del Norte (región Nordeste), donde

\footnotetext{
9 En esta Declaración se establecieron los fundamentos de una agenda de desarrollo basada en valores que enriquecen profundamente las relaciones internacionales para el siglo XXI: la libertad, la igualdad, la solidaridad, la tolerancia, el respecto de la naturaleza y la responsabilidad común. Véase la resolución 55/2 aprobada por la Asamblea General en su quincuagésimo quinto período de sesiones, Declaración del Milenio.

$10 \quad$ Las Metas de Desarrollo del Milenio son un conjunto de ocho objetivos de mejora del nivel de vida, a ser alcanzados mundialmente hasta 2015, por medio de medidas adoptadas en cada país. Fueron definidas en septiembre de 2000, cuando líderes de 189 países, incluido Brasil, decidieron reunir acuerdos relativos a los avances sociales en un único documento.

11 Resolución 48/91 de la Asamblea General, anexo.
} 
se ubica la ciudad de Mossoró, que ocupa la novena posición, entre las

27 Unidades de la Federación Brasileña, con el colectivo más viejo de la nación.

Además, se busca ofrecer un instrumento práctico para ayudar a los encargados de la formulación de políticas públicas y los agentes implicados en tareas de gestión de servicios y equipamientos para este grupo social.

Método y base documental Muestra

Con el fin de superar los datos insuficientes del padrón municipal de Mossoró sobre la población mayor de 60 años y ampliar los datos a nivel nacional, para la realización de este trabajo se ha utilizado la encuesta "Perfil Sociológico de la Vejez en Mossoró/RN - Brasil". La muestra estuvo constituida por 500 adultos, hombres y mujeres, mayores de 60 años de un total de 16.510 personas (Censo, IBGE: 2000), lo que corresponde al 3\% de la población anciana de la ciudad.

Los criterios de selección fueron:

a) Tener una edad igual o superior a 60 años;

b) Vivir en el medio urbano de Mossoró (zonas periféricas, centrales o intermedias);

c) Poseer lucidez suficiente para contestar a las preguntas;

d) Que no vivan en una residencia;

e) Pertenecer a distintas clases sociales.

\section{Instrumento adoptado}

Constituida como uno de los procedimientos más usados en la investigación de campo y de gran importancia sociológica, la entrevista fue la técnica elegida para la recogida de datos. La encuesta consta de 10 bloques, a saber: 
I) Aspectos generales: sexo, edad, estado civil, lugar de nacimiento, máximo nivel educativo alcanzado, estructura familiar, situación laboral actual y opinión sobre temas actuales (7 ítems);

II) Opinión sobre la vejez: lo que hace a una persona ser mayor, percepción del trato social y mejor expresión para referirse a una persona mayor (3 ítems);

III) Estructura familiar: si vive con sus familiares, relación con las personas con quienes vive el mayor, formas de convivencia familia, vecindario y amigos, hijos vivos y bajo qué circunstancia estarían los mayores dispuestos a vivir en una Residencia para mayores (5 ítems);

IV) Vivienda: tipo de vivienda, régimen de tenencia, coste de la vivienda alquilada, problemas en relación con la vivienda, satisfacción con la vivienda, condiciones de comodidad, equipamientos, prestaciones y servicios que han declarado percibir, si cuenta con ayuda en las actividades diarias, forma de vida preferida por los mayores, mayores que opinan que hace falta una Residencia en Mossoró y opinión de dónde debe ser construida (12 ítems);

V) Estructura de la ciudad y medio ambiente: sobre la infraestructura urbana y medio de transporte que suele utilizar (2 items);

VI) Aspectos alimenticios: dónde suele comer habitualmente, cuántas comidas hace al día y grado de satisfacción con la alimentación ( 3 ítems);

VII) Situación sanitaria y médica: percepción del estado de salud durante el último año, dificultad de realizar AVD y AIVD, preferencia en el tipo de ayuda, frecuencia de consultas al médico, medios por los que adquiere medicamentos, como es la audición, uso de prótesis auditiva, visitas al oftalmólogo, ginecólogo y 
urólogo, motivos y frecuencias de los ingresos hospitalarios, si cuenta con seguro médico, cómo debe recibir asistencia médica el anciano, realización de chequeo general, enfermedades declaradas, consumo de tabaco y bebidas alcohólicas, servicios destinados a los mayores conocidos y utilizados y vacunas suministradas (25 ítems);

VIII) Tiempo libre y ocio: ocupación del tiempo libre, preferencias en la radio y televisión, actividad física que practica, frecuencia con la que sale de vacaciones y motivos por los cuáles no disfruta de vacaciones (6 ítems);

IX) La vejez ante el cambio social y la muerte: concepto de la vida, satisfacción ante la vida, valoración del sexo, elecciones, frecuencia con la que acude a las elecciones, conocimiento de las leyes para mayores, sobre religión, frecuencia con la que piensa en la muerte y con quién habla de ello (9 ítems);

X) Aspectos económicos: causas del desempleo, fuentes de ingresos, satisfacción con los ingresos económicos, capacidad para administrar los ingresos, capacidad para manejar los cajeros automáticos, de cuánto dinero disponen al mes, área de trabajo actual y por qué trabajan, trabajos anteriores a la jubilación, preferencias en el ámbito laboral, cuándo debe llegar la jubilación y responsabilidad del pago por jubilación (11 ítems).

\section{Análisis y estadísticas}

Para el almacenamiento de datos utilizamos el programa Statistica, versión 5.0. La codificación del sondeo fue encargada al profesor Maderson Leandro da Costa, estadístico de la Facultad de Ciencias Naturales (UERN - Mossoró/RN Brasil) que almacenó los datos en el transcurso de tres meses. Sin embargo, todos los gráficos, tablas con los cruces de datos deseados y lectura de los resultados estuvieron a cargo de la investigadora del presente estudio. Eso nos proporcionó un verdadero panorama sociológico de la ancianidad mossoroense, en otras palabras, un minucioso y valioso trabajo. 
En cuanto a la base teórica, el texto busca en los pensamientos filosóficos griegos de Platón y Aristóteles además de en las ideas romanas de Cicerón y Séneca, las primeras concepciones antagónicas y contradictorias de la vejez. Sin embargo, gran parte de los fundamentos teóricos sobre el envejecimiento, la vejez y el viejo se encuentran en autores de distintas generaciones como Havighurst y Albrecht (1953), Neugarten y Tobin (1968), Rose y Peterson (1965), Cumming y Henry (1961), Kuypers y Bengston (1973), Cowgill y Holmes (1972), Atchley (1989), Mishara y Riedel (1986), Burgess y Parrot (1997), Adorno, Habermas y Schultz (1998). Para la investigación sobre el proceso de envejecimiento, más específicamente en las dimensiones cronológica, biológica, psicológica y social, las ideas provienen las ideas de varios autores, con énfasis en las obras de Neugarten (1975), Havighurst (1969), Kalish (1983), Moragas (1991), Bazo (1992), Shock (1973), McTavish (1971), Palmore (1970), Beauvoir (1980), Lehr (1980), Neri (2001), Bühler (1968), Riley (1976), Casals (1982), Fernández Ballesteros (2004). Además, la sustentación del trabajo se amplía con las fuentes primarias, como los informes y anales de organismos públicos, de orden nacional e internacional, como la Organización de las Naciones Unidas (ONU), la Comisión Económica para América Latina (CEPAL), el Programa de Naciones Unidas para el Desarrollo (PNUD), el Instituto Brasileño de Geografía y Estadística (IBGE), el Instituto de Pesquisa Económica Aplicada (IPEA), el Departamento Intersindical de Estadística e Estudios SocioEconómicos (DIEESE), la Pesquisa Nacional por Muestra de Domicilios (PNAD), en su mayoría disponibles en Internet. En una perspectiva menor estos datos se completan con las encuestas de organismos públicos del Gobierno del Estado; por ejemplo, del Instituto de Desarrollo Económico y Medio Ambiente (IDEMA), de la Secretaría de Estado de Salud Pública (SESP), de la Secretaría de Educación, Cultura y Deportes (SECD) y del Instituto Brasileño del Medio Ambiente (IBAMA) y otros documentos del Ayuntamiento de Mossoró/RN.

\section{Estructura del trabajo}

El trabajo de investigación cuenta con tres partes: en la primera se han agrupado el marco teórico y los conceptos básicos del envejecimiento, fundamentales para la contextualización y la delimitación del trabajo; la 
segunda la conforman los análisis de la primera encuesta: Perfil Sociológico de la Vejez en Mossoró/RN - Brasil, analíticamente comentados. El chequeo social de la ancianidad mossoroense se elevó a 500 entrevistas, lo que equivale al 3\% de la población total de personas de 60 años o más y que juzgamos satisfactoriamente amplio. Por último, la tercera parte versa sobre las conclusiones, donde se responden a las indagaciones que orientaron la investigación y confirman las hipótesis suscitadas.

Parte I - Comienza con algunas cuestiones relacionadas con los conceptos en torno al envejecimiento demográfico en la que de modo particular, en el Capítulo I, destacamos las teorías psicosociales sobre la vejez, clasificadas en tres generaciones. En el Capítulo II introducimos los conceptos básicos y la aproximación conceptual a la vejez y el envejecimiento. En el Capítulo III puntualizamos los aspectos demográficos de la vejez. El Capítulo IV versa sobre las cuestiones básicas del envejecimiento demográfico en Brasil en la perspectiva mundial y de América Latina y en el Capítulo $V$ tratamos sobre algunos indicadores básicos del envejecimiento demográfico de Mossoró en el contexto del estado de Río Grande del Norte.

Parte II - Trata de exponer los análisis de los datos de la muestra "Encuesta del Perfil Sociológico de la Vejez en Mossoró/RN - Brasil”, distribuidos en 13 capítulos. Observaremos, además de los datos generales que incluyen quiénes son los ancianos mossoroenses, por edad, sexo, estado civil, nivel de estudio, profesión y origen de nacimiento, los temas de que los cuales opinan los encuestados sobre la vejez, la situación familiar, la vivienda, la estructura de la ciudad y el medio ambiente, los aspectos alimenticios, la situación sanitaria y médica, el tiempo libre y el ocio, sobre la vida, la muerte, la política, la religión y el sexo y por último sobre los aspectos económicos.

Conclusiones - La última parte del trabajo versa sobre las respuestas que les han dado hasta hoy la sociedad brasileña o mossoroense a estos protagonistas. ¿Han sido suficientemente favorables y satisfactorias? Además de una propuesta de programa social a favor de la ancianidad. 
Marco Teórico y Conceptos Fundamentales
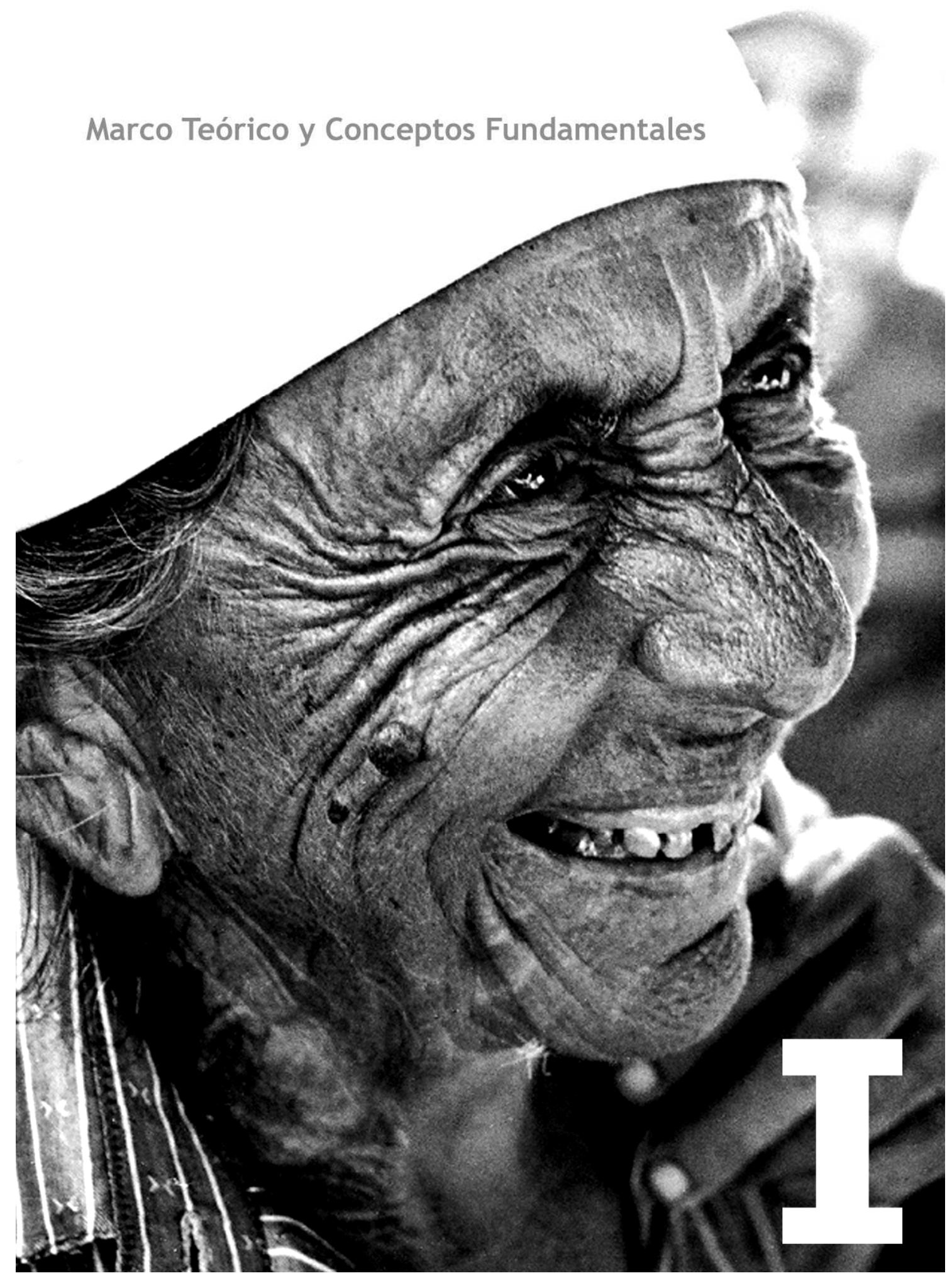


\section{1. \\ Teorías sociológicas sobre la vejez}

Saber envejecer es la obra maestra de la vida, y una de las cosas más difíciles en el arte dificilísimo de la vida.

Henri Frédéric Amiel (1821-1881), Filósofo, poeta y crítico suizo.

Durante el pasado siglo se expusieron un sinnúmero de teorías - desde la biología, la psicología o la sociología - con objeto de explicar el envejecimiento y la vejez. Sin embargo, cada día se aportan más evidencias de que esos procesos son multifactoriales $\mathrm{y}$, por ese motivo no pueden ser explicados por un modelo exclusivo. Tal y como señala Fernández-Ballesteros (2004) “ninguna de estas teorías - por separado - será capaz de explicar adecuadamente el envejecimiento, ya que, los cambios que el tiempo conlleva en el organismo humano son de todo tipo (bioquímicos, celulares, sistémicos, intelectuales, afectivos, familiares, laborales, etc.), y las razones para dichos cambios son múltiples; Por tanto, ninguna teoría biológica, psicológica o social, en exclusiva, permitirá dar cuenta del producto interactivo y tal vez sinérgico de tales cambios complejos" (FernándezBallesteros, 2004:43).

En el ámbito de las ciencias sociales y - desde la perspectiva sociológica - los diferentes marcos conceptuales en que ha intentado explicarse el envejecimiento comenzaron a ser sistematizados en la década de 1960 12, clasificándose principalmente conforme a sus orígenes intelectuales y niveles de análisis. En la variedad de los modelos teóricos presentados, algunos son especulativos, otros más consistentes. Pero, en general, para Siqueira (2002) las clasificaciones teóricas susodichas, arbitrarias y objeto de críticas, contribuyen a la comprensión de la elaboración teórica como un

12 Ver por ejemplo Hendricks y Achenbaun (1999). 
proceso dinámico y en permanente construcción ${ }^{13}$. Además las podemos elegir de acuerdo con nuestras necesidades y preferencias.

Entre las diversas maneras de exponer u organizar los fundamentos teóricos, Bergston, Burgess y Parrot (1997) presentan una clasificación de las teorías teniendo como criterio tres generaciones. La primera generación comprende las teorías elaboradas entre 1949 y 1969; la segunda generación alberga teorías formuladas entre 1970 y 1985 y la tercera generación agrupa teorías que critican y sistematizan las proposiciones de las anteriores.

En este primer capítulo resumiremos las tres generaciones. Estos marcos teóricos presentan diferencias a veces muy pequeñas así como numerosas superposiciones, a medida que nos acercamos a teorías más recientes. En el campo de las teorías psicosociales de la primera generación se encuentran las teorías adaptativas, relacionadas con la capacidad de interacción del individuo con su medio social. Se puede afirmar que, hasta el final de la década de los años 60, dos grandes teorías dominan los enfoques en el seno del campo de la gerontología social: la teoría de la actividad y la teoría de la desvinculación. Otra teoría que adquiere relevancia en esta época es la de la subcultura. La agrupación teórica de la segunda generación tiene sus orígenes intelectuales en el interaccionismo simbólico, el funcionalismo estructural, el desarrollo en psicología y el marxismo. Corresponden a este grupo las teorías estructurales cuyo campo de análisis son los componentes estructurales (impacto de la organización social sobre el envejecimiento) y su influencia en las diferentes cohortes de las personas que envejecen. Ganan terreno, entre otras, las Teorías de la continuidad, de la ruptura de la competencia, del medio social, de la estratificación por edades y la político-económica. En la última generación del conocimiento sistematizado sobre los aspectos sociológicos del envejecimiento intervienen las teorías del construccionismo social, del medio social, de la perspectiva del ciclo de vida, las teorías feministas y de la crítica en gerontología. En este bloque se reconcilian los puntos de vista más individuales con los estructurales y fundan lo que se ha

13 Siqueira, M. E. C. de (2002): Teorias Sociológicas do Envelhecimento, em FREITAS, PY, NERI, CANÇADO, GORZONIi y ROCHA (eds.): Tratado de Geriatria e Gerontologia. Rio de Janeiro: Guanabara Koogan, pp. 47-71. 
llamado la "economía moral"; aquí se asocian los aportes de las teorías del desarrollo y ciclo de vida con los aportes de las teorías relacionadas con el rol del Estado y las políticas de la vejez.

\section{Primera Generación (1949-1969)}

\subsection{Teoría de la actividad}

Los supuestos básicos de la Teoría de la Actividad del envejecimiento - una de las más antiguas - parten del principio de que el envejecimiento normal implica el mantenimiento de las actividades, hábitos o situación productiva, incluso contractual, habituales de la persona tanto tiempo como sea posible. La hipótesis principal de esta teoría afirma que sólo el individuo activo puede sentirse feliz y satisfecho. De visión optimista, la más antigua de las teorías psicosociales, planteada por Robert W. Havighurst y R. Albrecht (1953) sitúa la actividad como benéfica y necesaria para sentirse satisfecho con la vida durante la vejez. Lo más importante era estar socialmente involucrado, independientemente del tipo de roles sociales que desempeñaran. Para los teóricos adeptos a esta corriente el declive de actividades físicas y mentales, generalmente asociado a la vejez, es un hecho determinante de enfermedades psicológicas y del retraimiento social de la persona mayor.

Algo similar sugieren Havighurst, Neugarten y Tobin (1968) cuando mencionan que "La persona de edad que envejece en forma óptima es aquella que permanece activa y que logra resistir la reducción progresiva de su mundo social. Mantiene las actividades de la edad madura mientras le es posible, y después halla sustitutos para las actividades que se ve forzado a abandonar: sustitutos del trabajo cuando se ve forzado a retirarse; sustitutos de los amigos y de los seres amados cuando los pierde por causa de la muerte." ${ }^{14} \mathrm{La}$ teoría de la actividad promueve en el individuo que envejece, la reconstrucción de su propia imagen que ha sido deteriorada por las mismas pérdidas. Con la vejez, según los autores, las necesidades psicológicas y sociales continúan siendo las mismas de antes. En ese contexto, envejecer en buenas condiciones presupone que la persona permanezca activa y se resista a

14 Havighurst, R. J., Neugarten, B. Y Tobin, S. S. (1968): “Disengagement and pattterns o aging, en B. Neugarten (comp.) Middle age and aging. Chicago, University of Chicago Press, p. 161. 
la desvinculación social. El interés de mantener los mismos niveles de actividades de los estadios anteriores de la vida adulta o bien encontrar nuevos roles que supongan una aceptación real contribuye de forma importante al envejecimiento saludable ${ }^{15}$. En la interpretación de Lehr (1980), “esta teoría sostiene que sólo es feliz y se siente satisfecha la persona que es activa, que produce algún rendimiento y que es “útil” a otras personas. Al contrario se muestra desgraciada y descontenta” ${ }^{16}$. Para Erikson (1985) esto significa que los sujetos deben mantener una función generativa: por un lado producir y crear, y, por otro, relacionarse con los demás y sentirse responsables por ellos. A partir de esta hipótesis cuanto mayor es el mantenimiento de los ancianos en actividades, mejor será la adaptación a la pérdida de sus obligaciones laborales anteriores, y así, mejor será la salud física y mental, el auto concepto de uno mismo y la aceptación social. El foco de la teoría es la sustitución de los papeles por medio de actividades desarrolladas en contextos permitidos a los ancianos, como por ejemplo el ocio, la educación informal y el trabajo voluntario. En esa fase de la vida, Mendizábal señala que "la carencia de actividad supone apatía, pesimismo, desgracia, y la edad no debe ser considerada negativamente, ya que es mucha la experiencia que el anciano ha ido acumulando y que las generaciones mayores pueden transmitir a los más jóvenes” (1997:293). Por tener un fuerte ámbito cultural, esta teoría influyó enormemente en la formación de grupos informales y organizados de los Golden Age Clubs y otros similares que, en general, se proponen el fomento de los contactos sociales en particular. El movimiento de los ancianos norteamericanos en los años 60 , que se difundió en muchos países, fue advertido por Rose y Peterson, en el libro Older people and their social world, 1965 (Los viejos y su mundo social) por favorecer la formación de una "subcultura", como es la "subcultura de la juventud"17. Alegan que tal subcultura distancia a los viejos de los demás grupos, ya que al

15 Sobre las diferentes definiciones de envejecimiento bien sucedido, ver Rowe y Kahn (1998), Featherman, Smith y Peterson (1991) y Baltes y Baltes (1991).

16 Lehr, Úrsula (1980): Psicología de la Senectud. Barcelona: Herder, p. 245.

17 Gil Villa, Fernando (2004): La delincuencia y su circunstancia - Sociología del crimen y la desviación. Valencia: Tirant lo Blanch, p. 62ss y Gil Villa, F. (2007): La juventud a la deriva. Barcelona: Ariel. 
pertenecer a un determinado conjunto de personas de la misma edad sólo se relacionan con los de su propio grupo.

Entre las principales limitaciones apuntadas con relación a esta teoría destacamos la no consideración de la heterogeneidad y la diversidad de las experiencias de la vejez; Al enfocar la relación entre actividad y satisfacción, realzando principalmente las relaciones entre condiciones socioeconómicas, estilo de vida, salud y bienestar y considerar que el "buen envejecimiento" significa estar activo, encontrar papeles sociales sustitutos sin tocar nunca el tema de la muerte (Siqueira, 2002; Fernández-Ballesteros, 2004).

Sin embargo, a pesar de las limitaciones, es necesario señalar que la teoría de la actividad fue válida para un gran número de investigadores y que aún hoy día proporciona fundamentos a diversas intervenciones e investigaciones sobre el "envejecimiento exitoso" o el "envejecimiento sin traumas" (Havighurst, 1969) por estimular la actividad en la vejez. La proposición básica de la teoría puede ser considerada como una perspectiva "anti envejecimiento". Junto con la teoría del retraimiento, de la cual es un contrapunto, la teoría de la actividad es una de las más influyentes en la Gerontología Social.

\subsection{Teoría del retraimiento o desvinculación}

Formulada por Elain Cumming y William E. Henry a principios de los años sesenta en su obra Growing Old (1961), fue una de las primeras tentativas de explicar el proceso de envejecimiento y los cambios en las relaciones entre individuo y sociedad, utilizando proposiciones del paradigma sociológico del funcionalismo estructural en el análisis de la condición del adulto mayor y de sus reacciones psicológicas y sociales frente a la vejez. En contraposición a la Teoría de la Actividad, esta teoría ve en la reducción de las actividades, en la separación o distanciamiento entre el individuo y su entorno la llave del envejecimiento exitoso. Propone que el envejecimiento es un proceso de retraimiento progresivo universal, inevitable e intrínseco, casi biológico, mutuamente consentido por los ancianos y por la sociedad, por tanto, funcional para ambas partes involucradas. Al mismo tiempo que el individuo se va apartando de la sociedad, ésta, en su conjunto, tiende a separarse del 
individuo. Este proceso de recíproca separación en los últimos años de la vida, se ha definido con el término inglés disengagement. Así la sociedad puede llegar a aceptar como normal la desvinculación y las instituciones lo facilitan, dado que éstas disponen de normas sociales para esa finalidad. El carácter universal es sustentado por la idea de que todo sistema social necesita promover la desvinculación de sus mayores para mantener el equilibrio de la sociedad. En otras palabras, los autores afirman que la mutua desconexión es beneficiosa tanto para la sociedad, que de esta manera facilita la incorporación de otras generaciones a la maquinaria social, como para la persona, que se ve liberada de una serie de compromisos y obligaciones sociales implícitas adscritas a su anterior rol más activo. En ese sentido, la función principal del proceso de separación es preparar tanto a la persona anciana como a la sociedad para la separación final que es la muerte.

Como un proceso natural y espontáneo, la tesis del disengagement refuerza la idea de que la disminución de las interacciones sociales es inherente al proceso de envejecimiento y por lo tanto, requisito funcional para su estabilidad. Para sus formuladores la desvinculación sería no sólo una forma normal de envejecer sino también la más adecuada. De esta manera, los autores se contraponen por completo a la tesis de la teoría de la actividad y ponen en duda que "ejercer una función", o "ser útil", contribuya a la satisfacción del anciano.

Cummings y Henry $(1961)^{18}$, intentando explicar y teorizar sociológicamente el envejecimiento, tras estudiar a personas entre 50 y 90 años, independientes y autónomos, detectaron de modo sistemático en "El estudio de Kansas City de la vida adulta", dos tipos de desvinculación: la desvinculación social, que se refiere a la reducción del número y la duración de las interacciones sociales, y la desvinculación psicológica, referida a un descenso en el desarrollo emocional a medida que las personas envejecen (Kalish, 1983). Así, los autores, sugieren que las personas de edad necesitan retirarse hacia su propio interior para mantener su equilibrio psicológico.

18 Cummings, L.L. y HENRY, W.E. (1961): Growing old: The process of disengagement. New York: Basic Books. 
Pero, independientemente de la plausibilidad de la teoría de la desvinculación, y de la adhesión entusiasta que recibiera a sus comienzos, muchas son las autoridades que la rechazan como interpretación general de la senectud $^{19}$. Así, no siempre ha existido acuerdo sobre la cuestión de saber si el retraimiento es frecuente y si es o no beneficioso para el individuo implicado (Mishara y Riedel, 1986). Se argumenta que la separación no ocurre en todos los individuos; no siempre existe acuerdo sobre si el retraimiento es frecuente o si es beneficioso, tanto para la sociedad como para el individuo. Algunos, incluso, creen que es el individuo quien inicia por sí mismo el proceso de desvinculación y otros sostienen que es la sociedad quien gradualmente obliga a los individuos a retirarse de una vida activa.

En general, ha tenido y tiene importantes repercusiones en el establecimiento de políticas públicas y en la forma de contemplar la vejez. Así mismo, estimuló la proposición de la teoría de la actividad.

\subsection{Teoría de la subcultura}

Formulada por A. Rose y W. Peterson (1965/68), esta teoría está basada en el funcionalismo estructural, pero también en una rama del interaccionismo simbólico, dado que enfatiza que las normas y expectativas de comportamiento se establecen a partir de interacciones sociales y preconiza que los viejos, de hecho, forman un grupo aparte. En opinión de los autores los viejos forman una subcultura, con un estilo propio de vida que se superpone a las diferencias de ocupación, sexo, religión e identidad étnica. Reflejada en la realidad de los Estados Unidos, la tesis pregona que este estrato social puede desarrollar una subcultura, aunque no todos los mayores formen parte de ella. Una subcultura se desarrolla cuando cualquier grupo de la sociedad comparte gustos, una concepción de la vida y unos intereses comunes sobre la base del criterio de la edad. En el caso de la subcultura anciana, según la teoría, las creencias e intereses comunes a ese grupo social surgen a causa de la exclusión social, de la restricción de oportunidades de

19 Ver críticas a las teorías de actividad y desvinculación en Maddox, 1969. 
interacción con otros grupos de diferentes edades y por la existencia de políticas segregacionistas.

Algo similar sugiere G. F. Streib (1968), cuando considera a los viejos como grupo diferenciado, del mismo modo que los negros y los indios, como consecuencia de su discriminación basada en ciertas características biológicas. En el caso de la población anciana, según Rose (1962/1965), la Teoría de la Subcultura favorece la interacción de las personas de edad con otras que como ellas están envejeciendo, objetivando por un lado la conciencia de grupo y por otro pudiendo incentivar la segregación social. Para la autora, la existencia de los centros de convivencia y las residencias para mayores constituyen un ejemplo muy claro de políticas segregacionistas. Forzados, por así decirlo, a formar una minoría, crece la posibilidad de interacción entre ellos $y$, en consecuencia, se crean valores y prácticas propias del grupo. Para Strieb (1965), es la sociedad la que obliga a las personas mayores a formar parte de una minoría, alejándolas de la vida activa habitual. Grupos activistas, como los Panteras Grises (Grey Panters) y la Asociación Americana de Jubilados (AARP - American Association for Retired Person), son ejemplos de la subcultura del envejecimiento en los Estados Unidos. Actualmente, proliferan clubes y asociaciones de adultos mayores cuya organización y funcionamiento, a pesar de ser heterogéneos y atractivos, están motivados por la segregación social que padecen.

Sin embargo, no todos los componentes que distinguen a los mayores pueden ser atribuidos a una subcultura, ya que pueden ser condicionados por cambios biológicos, expectativas sociales y diferencias generacionales típicas del envejecimiento, que contribuyen a segregar al mayor aún más que otras categorías de edad. Por un lado, la existencia de esa subcultura puede favorecer el aumento del concepto negativo sobre el mayor. Por otro, puede estimular la toma de conciencia de ese grupo en defensa de sus derechos. De hecho, una subcultura se desarrolla cuando miembros particulares de una sociedad interaccionan entre sí más que con otros grupos de esa sociedad y cuando un grupo que tiene intereses o experiencias comunes es excluido de interacciones con otros grupos. 
La teoría de la subcultura es importante para el entendimiento de las relaciones entre los mayores y la sociedad y en la corrección de una imagen pasiva del envejecimiento, prevista por el abordaje funcionalista. Sin embargo, falla al enfatizar apenas el nivel micro social reconociendo poco la fuerza de los componentes estructurales sobre el comportamiento social.

\section{Segunda Generación (1970-1985)}

\subsection{Teoría de la continuidad (A Continuit Theory)}

La Teoría de la Continuidad (Atchley, 1971) es un intento de superar las críticas recibidas por las teorías anteriores. Esta teoría del desarrollo se basa en la premisa de que las personas en las diferentes etapas de sus vidas van desarrollando actitudes, valores, hábitos y comportamientos que conservan en cierta manera en la senectud. Se asume, por tanto, que las habilidades y patrones adaptativos que una persona ha ido forjando durante su vida, van a persistir en el tiempo, estando presentes también en este último tramo. A diferencia de la teoría de la actividad y desvinculación, propone que no hay ruptura radical ni transición brusca entre la edad adulta y la tercera edad, sino que se trata tan sólo de cambios menores u ocasionales que surgen de las dificultades de la adaptación a la vejez. A medida que aumenta la edad existe una tendencia a mantener una continuidad y estabilidad de estilo de vida y preferencias personales entre estas dos etapas ${ }^{20}$.

Para esta teoría del desarrollo humano, el individuo lleva a cabo una serie de elecciones adaptativas a lo largo de la adultez y senectud que suponen una continuación de los esquemas anteriores sostenidos de manera más o menos estable a lo largo de su ciclo vital. Sostiene la teoría de Atchley (1971), que la edad avanzada no implica un cambio drástico en los patrones de vida de las personas, así que los hábitos, gustos y estilos personales adquiridos y elaborados durante la vida, persisten y se mantienen, si es posible, en la vejez. La teoría de la Continuidad plantea que "la adaptación social a la vejez, a la jubilación y a los acontecimientos del mismo género está determinada principalmente por el pasado" (Mishara y Riedel, 1984:68). Por

20 Le François, R. (1997): Sociologie Du Vieillissement, en Arcand M., Hébert R. Précis Pratique de Gériatrie, Québec: Edisem, Inc., pp. 47-57. 
lo tanto, se asume, que los valores y roles pasados, van a persistir en el tiempo, estando presentes también en este último tramo de la vida.

Con enfoque constructivista, la Teoría de la Continuidad, subraya que las personas desarrollan sus propias concepciones tanto acerca de sí mismos como de su estilo de vida (Atcheley, 1993). Las personas definirán a partir de su propia historia los patrones de comportamiento que supongan una continuidad de su trayectoria vital. Sin embargo, no quiere decir que no haya cambios, dado que la personalidad sigue evolucionando durante toda la vida, aunque exista un predominio de hábitos de vida del pasado.

Para finalizar, esta orientación refleja que durante el proceso de envejecimiento no se puede afirmar, con carácter general, que se produce una desvinculación social del sujeto, ni que un aumento de su actividad o participación llevará aparejado un incremento en su nivel de bienestar subjetivo en la misma medida. Lo que establece es que el nivel de actividad que una persona va a manifestar en este proceso estará en función de su trayectoria vital y del patrón de actividades que haya presentado durante las etapas anteriores. La continuidad representa, de esta manera, un modo de afrontar los cambios físicos, mentales y sociales que acompañan al proceso de envejecimiento. ${ }^{21}$

A pesar de que la Teoría de la Continuidad sirva para explicar la complejidad del proceso de adaptación al envejecimiento en las sociedades contemporáneas y permita que los adultos mayores se adapten más adecuadamente a sus pérdidas, uno de los puntos resaltados por los críticos sobre este modelo es que las personas son programadas para envejecer de determinada manera, sin otras perspectivas. Es decir, los trazos de personalidad y los estilos de vida son definitivos en la determinación de las experiencias del desarrollo a lo largo de la vida y condicionan principalmente a los individuos y sus relaciones con los otros, no cuestionando si los factores estructurales pueden constreñir, prevenir o reforzar dicha continuidad.

21 Martín, M. A. G. (2002): La actividad y el ocio como fuente de bienestar durante el envejecimiento, Revista Digital, Buenos Aires, Año 8, n 47. http://www.efdeportes.com. 


\subsection{Teoría de la Ruptura Social}

Otro punto de vista que intenta explicar el envejecimiento humano surge en la década de 1970. Formulada a principios de los 70 por Kuypers y Bengston (1973), esta teoría considera el envejecimiento como una forma de distanciamiento social y como un proceso de pérdida progresiva de funciones de papeles sociales. Analiza las consecuencias negativas que pueden acarrear las crisis que afligen con frecuencia a las personas en edades avanzadas. Para los autores, esas crisis pueden ser desencadenadas por la pérdida de la salud, pérdida del cónyuge, pérdida de los papeles sociales $\mathrm{y}$, por otras pérdidas que desafían la competencia social del mayor y pueden llevar a una espiral de resultados negativos. Se argumenta que esas pérdidas, sumadas a los estereotipos negativos asociados a la vejez, pueden desencadenar en el anciano un auto concepto de vulnerabilidad y con eso llegan a ser tildados, por profesionales o parientes, como dependientes en relación al ambiente social. Con eso, otras competencias y habilidades se atrofian, aumentando aún más la fragilidad del mayor, tanto en la perspectiva social como en la psicológica. Para los teóricos de esa corriente, ese cuadro puede ser invertido con una "terapia de reconstrucción social", que proporciona un ambiente propicio, favorece la expresión de fuerza personal y fortalece la sensación de competencia.

\subsection{Teoría del medio social}

El máximo exponente de esta teoría fue Gubrium Jaber F. (1973). Gubrium centra su interés en cómo las personas construyen cotidianamente su propia versión de realidad ante el envejecimiento y la vejez. Así, el autor plantea que el comportamiento social del individuo en la etapa de la vejez está condicionado por tres factores importantes: la salud, los condicionamientos económicos y los apoyos sociales imperantes en su medio ambiente. En otras palabras, el comportamiento a lo largo del período de la tercera edad va a depender de ciertas condiciones biológicas y sociales. El contexto - el medio ambiente en que se encuentra la persona de edad avanzada - incluye no solamente el contexto social con sus normas, costumbres, etc., sino también 
los bienes de orden material y las posibilidades que se ofrecen al anciano. Sobre el nivel de actividad de una persona de edad avanzada influyen tres factores importantes: salud, dinero y apoyos sociales.

\subsection{Teoría de la estratificación por edad}

Actualmente, la Teoría de la Estratificación Social, propuesta inicialmente por Matilde Riley, Johnson y Foner (1972), es considerada una de las más influyentes teorías en la investigación social del envejecimiento. Sus pilares teóricos se basan en el estructuralismo funcional $y$ en los supuestos psicológicos del desarrollo. La teoría examina los movimientos de distintos grupos en el transcurso del tiempo. Según esta teoría, las personas forman parte de un determinado colectivo, por ejemplo, el de los viejos o de los niños donde se manifiestan los comportamientos, desempeñan los papeles y ocupan los lugares que les corresponden en la estructura social. Es decir, la infancia, adolescencia, vida adulta y vejez son fases construidas socialmente, por medio de normas y sanciones que determinan las exigencias y las oportunidades de cada grupo de edad en el orden social y que albergan diferencias históricas y geográficas. Sus defensores abogan que las personas de la misma franja poseen algunas características biológicas comunes y desempeñan más o menos los mismos papeles sociales en la misma época de sus vidas. Señalan que aquéllas nacidas en la misma generación comparten también los eventos de un mismo período histórico. Por eso, el modelo teórico subraya que la gente experimenta el envejecimiento según el momento histórico que vive. Así pues, cada conjunto de todos los vivientes coetáneos es único por sus propias características. Asume que la sociedad se compone de generaciones sucesivas de individuos que van envejeciendo de manera distinta y que, continuamente, fuerzan a sus predecesores a abandonar determinados roles. Las proposiciones defendidas por esa perspectiva son: a) el estudio del movimiento de los grupos de edad para identificar sus diferencias y similitudes; b) el estudio de la sincronía entre los cambios estructurales e individuales en el tiempo; c) el estudio de la interdependencia entre los grupos de edades y las estructuras sociales. (Siqueira: 2002). 
Esta teoría presenta avances en relación a otras teorías en gerontología social en los siguientes aspectos: a) Aproxima los conceptos de Sociología, como estratificación social y demografía para un estudio del envejecimiento; b) Demuestra que existen grandes variaciones entre personas mayores y por eso enfatiza la importancia del análisis de los hechos históricos y sociales para ese grupo; c) Permite distinguir los cambios evolutivos que se ven afectados por factores genético-biológicos o por factores socio-culturales.

Sin embargo, sus principales limitaciones son: a) Ignorar que las estructuras pueden ser controladas por elites sociales, políticas o económicas; b) A pesar de utilizar el concepto "cohorte" para explicar el proceso de envejecimiento, el mismo concepto no tiene en cuenta la dimensión subjetiva de la edad; c) El énfasis en las diferencias entre cohortes no toma en consideración factores como la clase social, la renta, la ocupación, la raza, el género y el espacio geográfico. En 1999 la Teoría de la Estratificación por Edad es presentada como un nuevo paradigma, Ilamado "envejecimiento social". El papel de envejecimiento social, propuesto por Riley, Jonson y Foner, enfatiza que las transformaciones presentes en la vida de las personas influyen y son influidas por cambios ocurridos en las estructuras sociales y en las instituciones.

\subsection{Teoría de la modernidad}

El enfoque de la teoría de la modernidad, expuesta por Cowgill y Holmes (1972), plantea como "normal" que en la vejez se produzcan pérdidas en el ámbito social, como resultado de los procesos de modernización. Con base en el estructuralismo funcional parte del siguiente hecho: describe la relación entre la modernización y los cambios en los papeles sociales y en el estatus de los adultos mayores. Es decir, desde un contexto más socioeconómico, esta teoría ha justificado tal desvinculación a partir de la pérdida de estatus de los ancianos, como consecuencia de su dependencia social y económica, favorecida por una cultura basada en el trabajo y en el culto a la juventud ${ }^{22}$.

22 Cowgill, D. O. Holmes, L. D. (1972): Aging and Modernization, Nueva York: Appleton Century Crofts. 
Para Cowgill y Holmes (1972), la edad es una categoría para un estatus social que indica la variabilidad del prestigio a lo largo del tiempo.

Según esta óptica, la proposición principal es que el estatus de las personas de edad está directamente vinculado al grado de industrialización de la sociedad, de modo particular, en cada contexto histórico y cultural. De acuerdo con Mishara y Riedel (1986) "el valor de las personas de edad se encuentra consecuentemente disminuido y aumenta en proporción el de los jóvenes. La necesidad de renovar sus conocimientos a fin de realizar determinadas funciones coloca a las personas de edad en una posición de inferioridad dentro del mercado de trabajo y debilita su posición económica" (1986:72). Esta nueva relación muestra la merma paulatina del estatus anterior del anciano en las sociedades preindustriales, donde se le reconocía por su experiencia y sabiduría. La reducción del estatus significa, de manera considerable, la disminución de los papeles de liderazgo, del poder y de la influencia, además del retraimiento de los mayores de la vida en la comunidad en la que habitan. La teoría postula que son cuatro los factores que contribuyen directamente a la desvalorización de la condición de los adultos mayores entre sus ciudadanos en una sociedad en proceso de modernización: 1) La tecnología científica aplicada a la producción económica, que destaca la descalificación de los viejos en el ámbito laboral. Esto es debido a las nuevas exigencias que exigen mayor competitividad y mejor formación en las tecnologías de vanguardia. De esta forma, dentro de un contexto evolutivo, las personas mayores se vuelven obsoletas y eso genera las luchas intergeneracionales por empleos, a la vez que acelera el tiempo para la jubilación, con consecuencias de mayor pobreza. 2) La urbanización, que maximiza la distancia entre las generaciones. La segregación entre el trabajo y la vida doméstica así como el distanciamiento geográfico entre jóvenes emigrantes urbanos y sus familias, debilita los lazos familiares y las relaciones intergeneracionales, lo que contribuye a la reducción del estatus social del mayor. 3) La educación formal dirigida - como los jóvenes representan el progreso, se genera una situación en la cual ellos pasan a estar más capacitados que los más viejos. Así pues, se invierten los papeles sociales 
lo que provoca el declive del estatus de los mayores debido a la capacitación y preferencia de recursos educacionales para los jóvenes. 4) El desarrollo de la tecnología sanitaria - Las medidas de salud preventiva, la mejora en los niveles de nutrición y las nuevas tecnologías curativas (que modificaron la estructura demográfica y provocaron la disminución de la tasa de mortalidad infantil), el aumento de la perspectiva de vida y el número de personas ancianas, ha propiciado una competición intergeneracional por el empleo, y en consecuencia fuerza a los mayores a abandonar el mercado de trabajo, con reducción de renta, prestigio y estatus ${ }^{23}$.

En resumen, las principales críticas a esta teoría son que: destaca que los mayores ya gozaron de un alto estatus en las sociedades preindustriales. Sin embargo, no hay como comprobar esa tesis, pues estudios muestran que en algunas sociedades los mayores sufrían segregación y pérdida de estatus. También, se cree que en la modernización de una sociedad hay estados que pueden provocar impactos positivos y negativos sobre el estatus de los mayores. Otra crítica es que el proceso de modernización afecta a los distintos grupos de edades de forma diferente. En conjunto, la Teoría de Modernización no es completamente válida, dado que existe aún la necesidad de integración de variables como género, etnicidad, clase social, localización geográfica y período histórico para una mejor comprensión del proceso de envejecimiento. Frente a este escenario, hay muy pocos estudios transculturales que avalen esta teoría (Siquiera, 2002 y FernándezBallesteros, 2004).

\subsection{Teoría marxista o economía política de la vejez}

La teoría político-económica refleja las contribuciones de autores como Walker (1981), Meredith Minkler (1984) y Carol Estes (1991). Dicha teoría examina el papel de las políticas sociales, las instituciones y los intereses de grupo en moldear los patrones del envejecimiento. Es decir, defienden que el examen de las políticas públicas, las tendencias económicas y los factores

23 Siqueira, M. E. C.: op. cit., 50ss. 
socio-estructurales, permite la comprensión de las variaciones en el tratamiento y en el estatus de la persona de edad. Sus proposiciones incluyen los conceptos de constreñimiento estructural, de control de recursos sociales, de marginación y de clase social, pudiendo ser explicadas: a) la interacción de fuerzas económicas y políticas influencian el estatus de los mayores y determinan como les serán atribuidos los recursos sociales; b) las restricciones económicas y políticas que moldean la experiencia del envejecimiento dan lugar a una pérdida de poder, autonomía e influencia de los mayores; c) las experiencias de vida son influenciadas no solo por la edad, sino también por factores como la clase, el género, la raza o la etnia; d) factores estructurales, tanto institucionalizados como los reforzados por la economía y por las políticas públicas, restringen oportunidades, elecciones y experiencias en los últimos estadios de la vida. Sin embargo, los principales aspectos criticados en ese modelo son que la teoría no considera ambientes particulares y retrata a los mayores como pasivos, mediante el determinismo de las estructuras sociales.

\section{Tercera Generación (1970-1992)}

\subsection{Teoría de la reconstrucción social}

La teoría de la reconstrucción social se apoya en el interaccionismo simbólico (Mead, 1934), en la fenomenología (Berger y Luckmann, 1966) y en la etnometodología (Garfinkel, 1967) y se propone reconsiderar las ideas y los esquemas mentales, es decir, la concepción predominante que se tiene en Occidente sobre la vejez, como una etapa de decadencia, sustituyéndola por una visión más constructiva y de respeto a la dignidad humana. Los principales conceptos planteados por esta teoría incluyen las cuestiones del significado social, sus realidades y relaciones sociales del envejecimiento, las actitudes ante la edad y el envejecimiento, los eventos de la vida y su temporalidad (Siquiera, 2002). Bajo estas perspectivas la teoría propone: a) enfatizar la explicación y comprensión sobre las formas en que los procesos individuales de envejecimiento se ven influenciados por definiciones sociales y por la estructura social; b) estudiar los aspectos situacionales, constitutivos y emergentes del envejecimiento, examinando cómo sus significados sociales y 
los relacionados al auto concepto emergen de la negociación y el discurso; c) Estudiar cómo las realidades sociales del envejecimiento cambian con el tiempo, reflejando las diferentes situaciones de la vida y los papeles sociales que brotan de la madurez.

Además de estas propuestas, Gubrium y Holstein (1999) afirman que las principales tendencias en el área son: a) construccionistas, con tendencias románticas, que focalizan la manera en la cual sentimientos y valores se interponen en la construcción social del envejecimiento; b) etnometodologistas en los que a través de la observación participativa documentan los métodos usados por adultos mayores de varias condiciones sociales para establecer un orden en la vida cotidiana; c) análisis de historias personales, buscando comprender cómo el proceso de narrar la historia de la propia vida contribuye a la construcción de las experiencias; d) contribuciones feministas, también focalizando las perspectivas étnicas que acompañan la construcción social e influencian la realidad del proceso de envejecimiento.

Las tendencias de estas diversas perspectivas continúan prioritariamente focalizadas en cómo las categorías y estructuras de vida de las personas son agrupadas, manejadas, sustentadas y cómo moldean el proceso del envejecimiento.

Las principales contribuciones de esta teoría para el análisis del envejecimiento son: a) la observación de cómo los individuos participan en la creación y manutención de significados para sus vidas. Ese proceso de interacción es considerado dialéctico, dado que el comportamiento individual produce una realidad que, a su vez, influye en la vida de los individuos; b) la teoría es adecuada al escenario multidisciplinar de la gerontología, posibilitando investigaciones y estudios de una amplia gama de cuestiones; c) la teoría ha influenciado otras perspectivas actuales en el área del envejecimiento, especialmente las teorías feministas y críticas.

Las críticas a esta teoría pueden ser resumidas al mencionar que en el nivel individual no se da la debida consideración a factores macro estructurales, tales como cohorte, contexto histórico y estratificación por edad. 


\subsection{Teoría perspectiva del curso de vida}

Según la bibliografía encontrada, el modelo del curso de vida gana fuerza en los años setenta en los campos de la sociología y la psicología, incorporando contribuciones de diversos expertos en el área del envejecimiento. Conforme a esta perspectiva teórica, los estudios e investigaciones se clasifican en los niveles macro y micro social, teniendo las siguientes proposiciones fundamentales a) el envejecimiento es enfocado desde el nacimiento hacia la muerte; b) el envejecimiento es considerado como un proceso social, psicológico y biológico, c) los factores históricos forjan las experiencias del envejecimiento (Dannefer e Uhlenberg, 1999).

Las contribuciones de esta teoría pueden ser descritas como: a) la incorporación a un único modelo analítico de los efectos históricos y de la estructura social, ligados a los significados sociales del envejecimiento; b) la utilización de principios y métodos multidisciplinares, resaltando puntos comunes y complementarios entre ellos, en el estudio del curso de vida y c) la adopción de una visión dinámica que focaliza este estudio en su totalidad.

Las críticas respecto a esa teoría pueden ser resumidas del siguiente modo: a) es una teoría o paradigma de difícil caracterización; b) encuentra dificultades para incorporar las variables identificadas en un único análisis y c) los datos recogidos no son capaces de probar los efectos de variables como la edad, período y cohorte sobre el comportamiento de los individuos y grupos a lo largo del tiempo.

En resumen, la edad no es el único criterio utilizado por la sociedad para organizar el curso de la vida, ya que la clase social, etnia, educación, profesión, se entrecruzan para determinar la posición de individuos y grupos en una sociedad.

\subsection{Teorías feministas del envejecimiento}

Según la opinión de Bengston, Burgess y Parrot (1997) las Teorías feministas son bastante difusas y por eso no es posible clasificarlas en el área del 
envejecimiento como una tradición teórica única. Emergidas en la década de los setenta, se diferencian de las demás teorías sociales del envejecimiento, según sus autores, al relacionar género y envejecimiento y al incorporar a esa relación la cuestión de la diversidad.

En el núcleo de las teorías feministas las conexiones entre individuo y estructura social así como las relaciones de poder involucradas en el proceso de senescencia asumen una posición importante. En ese sentido, en la perspectiva feminista, se analizan los aspectos macro y micro sociales del proceso senil. En el nivel micro social destaca la red social, los cuidadores y las familias de mayores, los significados sociales y las identidades en el proceso de envejecimiento. Por otro lado, el nivel macro social estudia la estratificación por género y la estructura de poder de las instituciones sociales. Adicionalmente, las corrientes y modelos teóricos del envejecimiento feminista llamaron la atención sobre los prejuicios de género dentro de las ciencias sociales.

Para este modelo teórico las principales proposiciones destacadas son: a) el género debería ser el principal enfoque en las tentativas de comprensión del envejecimiento y del individuo viejo; b) el género se erige en un principio organizador para la vida social, durante todo el curso de vida y c) las principales corrientes y modelos teóricos del envejecimiento fallan por no incluir las relaciones de género y las experiencias de las mujeres en el contexto del envejecimiento (Siqueira, 2002).

Con base en sus conceptos, el modelo feminista presenta algunas limitaciones, ya que al poner el énfasis en la feminización del envejecimiento, ignora la faceta masculina del proceso. Sin embargo, se muestra fuerte cuando focaliza las necesidades de la mayoría de la población anciana femenina; enfatiza la importancia de explorar otras fuentes de diferencias en el envejecimiento, como la etnicidad y la clase social; provee modelos en los niveles micro y macro social, ligando las cuestiones individuales, y estructurales, criticando las principales teorías feministas que 
ignoran las cuestiones de edad y desafiando además los prejuicios de género de los principales modelos teóricos sociales del envejecimiento.

Según Quadagno y Reid (1999), las teorías feministas muestran cómo las mujeres pueden sufrir desventajas en la vejez, debido a que los programas de bienestar social están basados en el modelo masculino de participación en la fuerza de trabajo formal, desconsiderando el trabajo doméstico e informal de las mujeres.

\subsection{Teoría social crítica}

La Teoría Social Crítica subraya dos dimensiones: la estructural y la humanista, y utiliza los conceptos de poder, de acción social y de significados sociales, como sustento para la investigación gerontológica. Influenciada por la tradición teórica europea, representada por pensadores de la Escuela de Frankfurt como Adorno, Horkheimer, Habermas, Husserl y Schultz, por el abordaje político-económico de Marx y por el post-estructuralismo de Foucault, esas proposiciones, en la síntesis de Siqueira (2002), destacan los siguientes aspectos: a) la subjetividad y la dimensión interpretativa del envejecimiento; b) la praxis, entendida como propuesta de políticas públicas para la población anciana; c) la praxis, entre académicos y profesionales para la producción de conocimientos que destaquen el envejecimiento como proceso emancipatorio; d) la necesidad crítica del conocimiento ya existente, la cultura y la economía vigente para la creación de modelos positivos de envejecimiento que resalten la fuerza y la diversidad del proceso ${ }^{24}$.

Ante la configuración de este cuadro, y en el propio ámbito del modelo crítico, se considera que la gerontología social fundamentada en la corriente positivista produjo un modelo de envejecimiento que considera como problema social aspectos que se desvían de los patrones considerados normativos.

$24 \quad$ Siqueira, M. E. C. de.: op. cit., 55. 
Por otra parte, la proposición de abordaje humanístico, propone que los propios mayores definan las cuestiones más significativas del envejecimiento dignas de ser abordadas en investigaciones (Torsnstam, 1992, apud Siqueira, 2002:55).

Continuando con la síntesis de Siqueira (2002), las principales dificultades en la aplicación de esta teoría se deben al alto grado de abstracción y la dificultad de uso de los investigadores en la perspectiva positivista. A pesar de esas limitaciones, los puntos fuertes están en la apertura de un espacio importante para la discusión de las principales corrientes teóricas en el campo del envejecimiento y la propuesta para que la gerontología establezca proposiciones en la perspectiva humanista para profundizar y enriquecer el debate sobre las cuestiones asociadas al envejecimiento (Siqueira, op. cit., 56)

A partir del abanico de las teorías subrayadas, como la teoría políticoeconómica del envejecimiento, las teorías feministas y del construccionismo social, se reflejan las proposiciones de la Teoría Crítica.

Como conclusión, el principal objetivo de este capítulo es presentar un breve apunte histórico sobre las teorías biológica, psicológica y social más importantes que tratan de explicar la vejez y el envejecimiento humano. Todo indica que se requieren muchos más esfuerzos de colaboración entre biólogos, psicólogos y sociólogos para construir una teoría integrada del envejecimiento y la vejez. 


\title{
Conceptos básicos y denominación de vejez y envejecimiento
}

\author{
Todos deseamos llegar a viejos, \\ y todos negamos que hayamos llegado. \\ Francisco de Quevedo (1580-1645), \\ Noble, político y escritor español.
}

\section{En el presente capítulo apuntamos un conjunto de términos básicos} sobre la vejez y el envejecimiento más frecuentemente utilizados en los campos de la geriatría y la gerontología. Las bases históricas, conceptuales y metodológicas de las disciplinas que tratan del envejecimiento orientan la primera parte de este segundo capítulo. A continuación, hacemos una revisión de las dimensiones del envejecimiento, especialmente en sus aspectos demográfico, cronológico, psicológico y social así como las terminologías específicas para referirse a los adultos mayores. Por último, tratamos de las categorías de la autonomía e independencia consideradas imprescindibles en esa franja de edad, y caracterizaremos los estados de senectud y senilidad además de los tipos de envejecimiento entendido en su forma más amplia.

\section{Gerontología y Geriatría}

Los pensamientos filosóficos sobre la vejez de Platón (427-347 a. C.) y Aristóteles (384-322 a. C.) en la sociedad griega, Marco Tulio Cicerón (106-43 a. C.) y Séneca (4-65 d. C.) en el mundo romano, encontrados en diversos textos, son considerados precursores de la gerontología. Siglos después, las investigaciones de Francis Bacon (1561-1626), Quetelet (1796-1874), Darwin (1801-1882), Francis Gaton (1832-1911), Stanley Hall (1844-1924) e Ivan Pavlov (1894-1936) pueden "ser consideradas paradigmáticas en una inicial investigación científica sobre la vejez y el envejecimiento y por tanto, son antecedentes de la gerontología" (Fernández-Ballesteros, 2004:33). 
En el caso de Platón, el filósofo hace incondicional defensa del anciano y reclama para él poder social; resalta la idea de que se envejece como se ha vivido y da importancia a cómo habría que prepararse para la vejez en la fase de la juventud. Concretamente, en La República ideal con la que él sueña, el personaje Céfalo en conversación con Sócrates enfatiza "a medida que van debilitándose los placeres físicos, van creciendo mis necesidades y goces con las cosas del espíritu ${ }^{25}$. Platón no tenía en cuenta el derrumbamiento físico del individuo, ya que el cuerpo no era más que una apariencia y lo importante era el alma. Abogaba por la gerontocracia ${ }^{26}$, pues en la vejez reunía el varón más conocimientos y se acercaba a la verdad" (Casals, 1982:12).

Minois (1987) capta muy bien su filosofía idealista: "El hombre de bien, educado en una vida virtuosa, disfrutará feliz de los últimos días; su vejez será la culminación de su vida" (Minois, 1987:87). Platón era, por tanto, un antecedente de la visión positiva de la vejez. En su República ideal, lo esencial de la argumentación consiste en vincular la felicidad de la vejez a la virtud.

Aristóteles, en cambio, adopta una postura totalmente distinta. No oculta su crítica a la ancianidad, en la medida en que "refleja al mismo tiempo la situación objetiva y los prejuicios de su época de civilización, que son claramente desfavorables para los ancianos”"27. Creía que los viejos debían, preferentemente, ser apartados del poder.

En su Ética a Nicómaco, Aristóteles hace a la vejez responsable de cuantos males encarnan los humanos. También reproduce la identificación entre vejez y enfermedad. "Para él la vejez podía ser una bella edad, siempre que no hubiera invalidez" (Casals, 1982:12).

En Aristóteles se presenta lo que podríamos considerar las etapas de la vida del hombre: la primera, la infancia; la segunda, la juventud; la tercera la más prolongada - la edad adulta y la cuarta, la senectud, en la que se llega a una

\footnotetext{
25 Platón: La República, I, 328.

26 Gobierno de viejos. Cf. Ferreira Aurélio Buarque de Holanda (2004): Miniaurélio da língua portuguesa, $6^{a}$ edição revisada e atualizada, Curitiba: Positivo, p. 434.

27 Minois, Georges (1987): Historia de la vejez de la Antigüedad al Renacimiento, (Traducción: Celia María Sánchez). Madrid: Nerea, p. 91.
} 
ineluctable decadencia y a la ruina. En este sentido, considera a la vejez como una "enfermedad incurable" ("senectus insanabilis morbis").

Centrándonos en lo que tratan Platón y Aristóteles, vemos que estas dos visiones antagonistas y contradictorias de la vejez, van a verse representadas a lo largo de toda la historia en el pensamiento humano occidental. Así por ejemplo Cicerón en su obra De Senectute ${ }^{28}$ amplía las ideas positivas de Platón sobre el tema ${ }^{29}$ y Séneca sigue la línea de pensamiento aristotélico sobre la vejez y sus deterioros.

La importancia del estudio de la vejez gana su espectacular relieve con el extraordinario crecimiento numérico de viejos en todo el mundo, especialmente en el siglo XX. A partir de la década de 1930, después de que la médica inglesa Marjory Warren (1897-1960) empezara a promover acciones de revisión geriátrica con pacientes del West Middlesex County Hospital en Londres, comienzan a surgir numerosos trabajos en todas las áreas que en nuestra época componen la ciencia del envejecimiento.

Sin embargo, históricamente, fue en 1903, a principios del siglo XX, cuando el ruso Michel Elie Metchnikoff (1845-1916) sociólogo y biólogo, sucesor de Pasteur, defendió la idea de la creación de una nueva especialidad de investigación sobre los más viejos, utilizando por primera vez el término gerontología. Así señala: “... pienso que es extremamente probable que el estudio científico de la vejez (edad mayor) y de la muerte - dos ramas de la ciencia que pudieran ser llamadas, respectivamente, gerontología y tanatología - nos aportará numerosas modificaciones en el curso del último período de la vida" ${ }^{30}$. Así, la Gerontología, etimológicamente, procede de los términos griego geron, gerontos/es "hombre viejo", o los más notables del pueblo griego, y logos, logia o tratado del "estudio de". Por ello, la

\footnotetext{
28 Cícero M. T. (2006): A velhice Saudável - O sonho de Cipião, Coleção Grandes Obras do Pensamento Universal, nº 63, Texto Integral, Tradução: Luíz Feracine, São Paulo: Editora Escala.

$29 \quad$ León Rappoport, subraya que Cicerón pudo reproducir una de las versiones más positivas que jamás se han escrito sobre el tema mediante el recurso de ignorar las dolencias físicas que se asocian con la edad avanzada y de apelar constantemente a las diferencias individuales. Ver la obra La personalidad desde los 26 años hasta la ancianidad - El adulto y el viejo, Paidós, Psicología Evolutiva, Barcelona, $1^{\mathrm{a}}$ reimpresión en España, 1986, p.56.

30 Metchikoff, M. E. (1903): The nature of Man, Putman, Nueva York, pp. 297-298, citado por Fernández-Ballesteros R. (2004): Gerontología Social. Madrid: Psicología-Pirámide, p. 34.
} 
gerontología se define como "ciencia que trata de la vejez", y los fenómenos que la caracterizan, en virtud de las modificaciones que ocurren en el último tramo de la vida humana. Así, el objeto de estudio de la Gerontología es tanto el proceso de envejecimiento como el estado llamado la vejez (Schoots, 1996). El científico Metchnikoff, previó que la gerontología tendría creciente importancia en el transcurso del siglo XX, en virtud del aumento de la longevidad de los individuos y las poblaciones, provocadas por los avances científicos y tecnológicos biomédicos, educativos y sociales.

Así, tenemos, actualmente, la gerontología como una rama de la ciencia que se propone estudiar el proceso de envejecimiento en sus aspectos biopsicosociales y los múltiples problemas que puedan involucrar al ser humano ${ }^{31}$. Por abordar los aspectos físicos, culturales, psicológicos y económicos relacionados con el envejecimiento, a su vez, una de las principales características de la gerontología es la multi e interdisciplinariedad. Para Maddox (1987), Gerontología es el campo multi e interdisciplinario que visa la descripción y la explicación de las transformaciones típicas del proceso de envejecimiento y de sus determinantes genético-biológicos, psicológicos y socioculturales. Se interesa también por el estudio de las características de la persona mayor de edad, así como de las varias experiencias de la vejez y envejecimiento que tienen lugar en diferentes contextos socioculturales e históricos. En ese sentido, la gerontología es un amplio campo disciplinar y profesional que abarca numerosos temas, intereses y cuestiones relacionados con los mayores, la vejez y el envejecimiento. La justificación para tal hecho la encontramos en Fernández-Ballesteros (2004) que lo ilustra muy bien: "la gerontología arranca y se nutre esencialmente de las ciencias biológicas, psicológicas y de las ciencias sociales" (2004:35). La gerontología enfoca al anciano en su conjunto, es decir, el aspecto médico, social, urbanístico, habitacional, legal y todo aquello que redunde en su auténtico provecho y bienestar. Así, para la autora conviene destacar que, aunque la gerontología cuente con distintas

$31 \quad$ Beauvoir, Simone de (1983): A velhice. Rio de Janeiro: Nova Fronteira. 
especialidades, en ninguna de ellas se debe abdicar de los conocimientos multidisciplinares que exige. En este sentido, Rodrigues y Rauth (2002), citan que para muchos, "la Gerontología no es una disciplina unificada, sino un conjunto de disciplinas científicas que intervienen en el mismo campo, que necesitan emprender esfuerzos interdisciplinares, los cuales excedan los límites de sus propios paradigmas y teorías, para crear concepciones diferenciadas sobre el viejo y los fenómenos de la vejez y del envejecimiento" (2002:106).

Como el envejecimiento no siempre viene acompañado de manifestaciones patológicas, aunque sean muy frecuentes las dolencias en esa franja de edad, para Papaléo Netto (2002) los problemas de discriminación económica y social a que está sometida la mayoría de las personas mayores adquieren particular importancia en la gerontología social.

Para Costa Santos $(2003)^{32}$, la justificación de la existencia de la Gerontología está relacionada con cuestiones sociales expresivas, tales como el aumento de la expectativa de vida, que acarrea problemas demográficos; la creciente demanda de los servicios de salud para mayores y los problemas epidemiológicos; la alta incidencia y elevados gastos de las Dolencias Crónicas No Transmisibles (DCNT); la cuestión de las desigualdades sociales, originadas por el modelo económico y las relaciones sociales entre los seres humanos y las clases sociales; el ejercicio pleno de ciudadanía y otras cuestiones de largo alcance, no deja dudas sobre el carácter interventivo de la Gerontología.

Por tanto, cabe a la Gerontología no apuntar la vejez como un problema social, sino concebir esa fase de la vida y sus posibilidades como resultantes de acciones multidimensionales.

Años después, al final de la primera década del siglo XX, en 1909, con un artículo escrito para el New York Medical Journal, Ignatz Leo Nascher (18631844), médico vienés radicado en Estados Unidos, introdujo el término Geriatría, como parte de la Medicina que trata de enfermedades que pueden

32 Costa Santos, S. S. (2003): O ensino da Enfermagem gerontogeriátrica no Brasil de 1991 a 2000 à luz da complexidade de Edgar Morin. Tesis doctoral en Enfermería de la UFSC, Santa Catarina. 
padecer los adultos mayores y es, "al igual que la Pediatría, una verdadera medicina general y no una especialidad, pues abarca toda la patología si bien referida a una determinada edad"33. Así, la Geriatría nace como especialidad médica, cuyo objeto epistémico son las enfermedades que ocurren en la vejez. En otras palabras, las condiciones biológicas del organismo humano modificadas en gran parte por el "reloj biológico" determinan el campo de estudio de la Geriatría. Este estudioso, considerado padre de la Geriatría, fundó la Sociedad de Geriatría en Nueva York en 1912 y publicó el libro Geriatrics: the Diseases of Old Age and Their Treatment, Including Physiological Old Age, Home and Institutional Care, and Medico-legal Relations en 1914, estableciendo las bases de abordaje clínico de los mayores. Hoy, el campo de la Geriatría comprende la prevención y el tratamiento de las dolencias del envejecimiento. Es una especialidad de la Medicina, pero también de la Odontología, la Enfermería y la Fisioterapia, donde se desarrolla a medida que aumenta la población de adultos más viejos y portadores de dolencias crónicas y típicas de la vejez, en virtud del aumento de la longevidad de esos segmentos de población.

Así pues, podemos decir que la Gerontología y la Geriatría son ciencias hermanas que se hallan aunadas por fuertes lazos de interdependencia, al servicio de la salud del ser humano en las edades finales de su existencia. En suma, para la Organización Mundial de Salud (OMS) la Geriatría es una rama de la Medicina que estudia la sintomatología clínica, tratamiento y readaptación en todos los procesos patológicos donde las alteraciones debidas a la edad contribuyen de una manera decisiva, y la Gerontología estudia los aspectos relacionados con el envejecimiento de la población y sus manifestaciones sociológicas, biológicas, psicológicas, ambientales y especialmente sanitarias.

Francis Bacon destacó en la primera mitad del siglo XVII, aportando una gran contribución a la Gerontología y Geriatría, al afirmar que uno prolongaba la vejez con una dieta adecuada, actividades físicas, ciertas hierbas, masajes y duchas especiales. Quetelet, matemático y astrónomo, investigó cuestiones

33 Granjel, Luis S. (1991): Historia de la vejez - Gerontología Gerocultura Geriatría. Salamanca: Universidad de Salamanca, p. 25. 
tales como tasas de nacimiento de la población, tendencias de mortalidad por edad, diferencias de franjas de edad en estatura, peso y fuerza y cambios en la inteligencia fruto del envejecimiento. Darwin, con los principios de su teoría de la evolución de las especies, influenció decisivamente las investigaciones en el área de la biología y la psicología del desarrollo. Galton describió las transformaciones que el organismo sufre en la edad avanzada y las correlacionó con las transformaciones en el campo de la psicomotricidad, de la percepción y de los procesos mentales superiores. Stanley Hall, con la obra Senescence: the Last Half of Life - 1917 (Senectud: la última mitad de la vida), al estudiar la vejez como "segunda edad de la vida" uno de los descubrimientos empíricos del psicólogo norteamericano, quiso resaltar que las diferencias individuales en la vejez son significativamente mayores que las que aparecen en otras edades de la vida.

\section{Dimensiones del envejecimiento}

Las relaciones de los hombres con la temática de la vejez y el envejecimiento han sido estudiadas y comprendidas en los campos afectivo, racional, económico y político, así como analizada filosófica, biológica, psicológica, sociológica $\mathrm{o}$ antropológicamente, $\mathrm{o}$ en todos los campos científicos simultáneamente. Pero, todavía el proceso de envejecimiento continúa siendo objeto de discusión. Así pues, la afirmación de Simone de Beauvoir de que "ninguna de estas investigaciones nos permitirá definir la vejez" ${ }^{34}$, continúa de actualidad a partir del momento en que consideremos que cada enfoque científico aporta, a su modo, la amplitud y complejidad que el tema presenta. Es importante considerar que el modo con que los problemas de la vejez son definidos y tratados y la forma de sanarlos varían conforme las distintas sociedades y culturas, así como el enfoque epistemológico sobre el mismo. Con propiedad, Moragas ${ }^{35}$ señala que la vejez es un concepto elástico que se define según los tiempos y las circunstancias, y su diversidad genera

\footnotetext{
$34 \quad$ Beauvoir, Simone de: op. cit., 17.

35 Moragas Moragas, R. (1991): Gerontología Social - Envejecimiento y calidad de vida. Barcelona: Herder.
} 
numerosas definiciones, de modo que, encontramos distintos abordajes científicos sobre el tema.

Otro punto importante que se debe tener en consideración al analizar la temática es reconocer las dos caras que el envejecimiento humano presenta en los diversos campos de estudios: las ganancias y las pérdidas. En ese apartado se abordan algunas dimensiones del envejecimiento. Para ello en este capítulo, se hace especial hincapié en la perspectiva demográfica, cronológica, biológica, psicológica y social del envejecimiento, consideradas, salvo mejor juicio, como las más usadas en Gerontología.

\subsection{Perspectiva demográfica}

Desde el surgimiento de la especie humana, cerca de 200 mil años atrás, hasta el año 1800, la población mundial alcanzó 1 billón de personas. El segundo billón fue alcanzado en 1925 y el tercero alrededor de 1960. Desde entonces, la población se duplicó en menos de 40 años. Esa explosión demográfica sucedió principalmente en los países de Asia, África y América Latina, que, entre las décadas de 1950 y 1970, presentaron tasas de crecimiento en torno al 2,5\%36. En ese escenario, los datos estadísticos (PNUD: 2000) también indican que entre los humanos los adultos mayores adquieren relevancia. La proporción de personas mayores sobre el total de la población alcanza actualmente niveles superiores a cualquier otra época histórica. Como se ha dicho anteriormente, existen más de 600 millones de personas que cuentan con más de 60 años; y según las previsiones, para el 2.050 sumarán 2.000 millones. Se estima que para el 2.030 el $71 \%$ de esta población vivirá en los países en vías de desarrollo, y del $12 \%$ al $16 \%$ vivirán en los países ricos. Ese proceso es fruto, principalmente, de disminuciones importantes de los coeficientes de mortalidad y de las tasas de fecundidad y natalidad. La caída de la mortalidad en todas las franjas de edad llevó, inicialmente, al aumento de la expectativa de vida al nacer y, a continuación, a la expectativa de vida a los 60 años. Esto, seguido por la caída de la fecundidad y la natalidad, ha

36 Almanaque Abril - A enciclopédia da atualidade Brasil 2003, São Paulo: abril, 2002, p.58. 
ocasionado el aumento de la proporción de adultos mayores. Esa situación, conocida como Transición Demográfica (TD), fue acompañada por cambios de morbi-mortalidad, con mayor incidencia y predominio de dolencias $y$ condiciones crónicas y disminución de las dolencias infecciosas, un proceso denominado Transición Epidemiológica (TE). Si el número de nacimientos disminuye, como ocurrió en el pasado siglo, y el de los fallecimientos, como ocurrió en los últimos lustros, la proporción de viejos aumenta. Con menos nacimientos de niños y personas viviendo durante más tiempo, la proporción de ancianos en el conjunto de la población no sólo aumenta, sino que la media de edad de la población se ve igualmente acrecentada.

Aunque la demografía del envejecimiento no está repartida de igual modo en todos los países y continentes, ese panorama preocupa en general a la sociedad actual, principalmente por la problemática social y económica que pueda generar. Así, los que se mueven en la línea de análisis de la perspectiva demográfica del envejecimiento de la población, llaman la atención de la intervención pública en sistemas de servicios claves que forman parte o incluyen el entorno de los problemas de la vejez y el envejecimiento, tales como seguridad social, salud, educación, vivienda, empleo y servicios sociales personales. En el seísmo demográfico, Paul Wallace habla de que esa “implosión demográfica" genera graves consecuencias socioeconómicas ${ }^{37}$. Es decir, predomina la preocupación con gastos sanitarios, utilización de servicios de salud y sus consecuentes costes. Este tipo de información puede mejorar la política de desarrollo y los programas de planificación. A ella se incorpora con fuerza el concepto de "ciudadanía plena", noción que se estima debe permitir una redefinición sociocultural de los senescentes.

\subsection{Perspectiva cronológica}

La dimensión cronológica de la vejez es medida puramente en términos de años. Para Kalish (1983) no hay una única respuesta correcta a la pregunta 
“¿Cuándo se es viejo?”, pues son usadas muchas aproximaciones, siendo cada cual justificable y abierta a la crítica. Pero, en esta perspectiva, el enfoque de la vejez corresponde al paso del tiempo. Según Lehr ${ }^{38}$, la vejez, se sostiene en la perspectiva cronológica, donde el criterio de las normas de edad equipara el envejecimiento con el número de años transcurridos desde el nacimiento.

En ese sentido, la edad cronológica viene generalmente acompañada de un fenómeno de identificación con los estadios tradicionalmente reconocidos, subrayados por Aristóteles en el mundo griego, como constituyentes de la juventud, la edad madura y la vejez. Los primeros estudios sobre el envejecimiento mostraron que las personas tienen conciencia de ser primero jóvenes, después adultos, de envejecer, de convertirse en individuos de edad y finalmente en viejos. ${ }^{39}$ Considerando lo que sostienen los investigadores sobre esas etapas de vida, la Organización Mundial de Salud (OMS), admite cuatro períodos en la metamorfosis humana: infancia (entre los 0 y los 9 años); adolescencia (entre los 10 y los 19); adultez (de los 20 a los 69), y ancianidad (cuando se rebasan los 70 años).

Para Neugarten ${ }^{40}$ la clasificación de vejez con base en la edad cronológica obedece a dos categorías bien definidas: los jóvenes-viejos (de los 55 a los 75 años) y la de viejos-viejos (a partir de los 75 años). Sin embargo, Riley ${ }^{41}$ da otra versión a esa clasificación y considera los jóvenes-viejos aquellos entre los 65 y 74 años, los viejos-viejos a los individuos entre 75 y 85 años, y los viejos más viejos a las personas mayores de 85 años. No obstante, para la OMS la edad en que se empieza a envejecer obedece a la siguiente clasificación: entre los 60 y 74 años las considera personas de edad; a las de 75 a 90, viejas o ancianas, y a las de más de 90, muy viejas. A pesar de esa tendencia, en la

\footnotetext{
38 Lehr, Úrsula: op., cit., 121-123.

39 Burgess, Cavan y Havinghurst, (1948): citado por Anita Liberalesso Neri (2001): Palavraschave em Gerontologia. Campinas: Alínea.

$40 \quad$ Neugarten, (1975): The future and the young old. The Gerontologist, 15, 49, en FernándezBallesteros, R. (dir.): Gerontología Socia., Madrid: Pirámide, 2004.

41 Riley, M. W. Froward (1988): en Fernández-Ballesteros, R. (Dir.), Gerontología Social. Madrid: Pirámide, 2004.
} 
visión de otros investigadores ${ }^{42}$, acerca de cuándo a una persona se la puede considerar vieja, la identificación con el grupo de jóvenes, de los adultos, de las personas de edad madura o de los viejos no depende exclusivamente de la edad del sujeto sino también de su estado de salud, de su raza, así como de su manera de comprender los términos empleados para designar los estados de la vida (Mishara y Riedel, 1986). Para ello, a finales del siglo XX, no son los años los únicos condicionamientos que la definen. Resume, Moragas (1991), que "a la edad cronológica, dato importante pero no determinante, se suman otras condiciones personales y ambientales que determinan el estado global de una persona" (1991:22).

Una información más abundante y detallada sobre esta cuestión aclara que la definición de la vejez a través de la edad cronológica tiene una explicación política. Las bases legales y económicas para esa definición son consideradas arbitrarias y poco racionales. Según las convenciones sociodemográficas actuales se utiliza, como línea divisoria, la frontera de la jubilación, la edad de sesenta años en los países en desarrollo, y de más de sesenta y cinco, en los países desarrollados. Así, la iniciación propiamente dicha de la vejez ${ }^{43}$, según Lehr ${ }^{44}$ es el fenómeno típico de la industrialización, de una sociedad basada en el rendimiento. Es el cambio de una sociedad agraria a una urbanoindustrial lo que ha posibilitado que los trabajadores se jubilen y no sigan trabajando mientras son capaces de hacerlo. Para Moragas (1991) "lo que fue política social progresiva de protección a la vejez se ha vuelto hoy en contra de los trabajadores, reconociéndose que los topes cronológicos al derecho al trabajo infringen derechos esenciales de la persona, y que los sesenta y cinco años constituye una edad en la que se puede desempeñar perfectamente un trabajo" (1991:30). Por tanto, las edades de 60 ó 65 años marcan el comienzo de la vejez, porque coinciden frecuentemente con el momento de la jubilación. En esta perspectiva, el ingreso en la vejez se halla establecido jurídicamente. Eso se atribuye, sobre todo, a la tesis de que los signos de

$42 \quad$ Busse, Jeffers y Obrist, (1957): Jeffers, Eidorfer y Busse (1962): citado por Anita Liberalesso Neri em Palavras-chave em Gerontologia. Alínea, Campinas, 2001.

43 Cf. Havighurst, Munnichs, Neugarten, Thomae, (1969): Lehr y Dreher, (1968): Lehr, (1969):

44 Lehr, Úrsula: op. cit., 222. 
declive del funcionamiento físico comienzan a aparecer con mayor frecuencia en esa franja de edad (Zinberg y Kaufman, 1987).

Sin embargo, para muchos autores, considerar que el individuo entra en la ancianidad a la edad cronológica de sesenta o sesenta y cinco años genera controversia, dado que el envejecimiento tiene un ritmo distinto para cada individuo, y la intimidad de los individuos difiere según los órganos y tejidos. Hay un envejecimiento general o corporal, y otro parcial u orgánico. Las razones varían; en ciertas personas, la transición se efectúa gradualmente mientras que en otras es rápida y traumática. Así, podemos encontrar personas de edades avanzadas visiblemente íntegras, tanto psíquica como físicamente, como individuos de menos edad presentando evidentes deterioros. Las diferencias individuales no solo dependen en gran parte del "reloj biológico", sino también de sus relaciones con los factores económicos, sociales y culturales, así como de los hábitos de higiene del sujeto (Mishara y Riedel, 1986).

A este respecto, Moragas (1991) también da su contribución: "la edad constituye una variable, objetiva y esencial pero no determinante de la condición del sujeto, ya que por sí sola nos dice muy poco, vista la diversidad existente entre los individuos. La variable edad debe ir acompañada, de una valoración integral del individuo, de otras variables originarias como sexo, raza, origen familiar, estatus social, familia de orientación (o de matrimonio), etc. De esta forma se sustituye una valoración subjetiva y parcial por una visión integral de la persona" (1991:25). Es igualmente importante mencionar lo que Teresa Bazo (1992) subraya: "la definición de la vejez en función de la edad cronológica resulta un criterio insatisfactorio. Existen diversas formas de envejecer, diversas 'carreras'”45. El concepto de vejez es relativo al tiempo, la época, el contexto y la cultura en la que uno vive y se desarrolla.

\subsection{Perspectiva biológica}

45 Bazo, María T. (1992): La nueva sociología de la vejez: de la teoría a los métodos. Revista Española de Investigaciones Sociológicas, $\mathrm{n}^{\circ} 60$, p. 78. 
A pesar de la edad cronológica, definir al viejo en muchas situaciones, como se ha dicho, no es la única alternativa. Otros criterios que pueden definir el envejecimiento son los cambios físicos y biológicos. El estudio del plano biológico de ese proceso viene siendo más investigado desde la perspectiva de la salud, en detrimento de los enfoques que estudian otros aspectos. ${ }^{46}$ Durante mucho tiempo la senescencia fue considerada exclusividad de la Medicina, por eso la vasta investigación científica de los procesos del envejecimiento está mejor desarrollada en comparación con otras áreas del conocimiento.

Los que analizan el envejecimiento desde una óptica biológica del cuerpo, trabajan en la perspectiva médica, en razón de los cambios físicos y biológicos "por los que el organismo del hombre de edad presenta ciertas singularidades" ${ }^{47}$. A menudo, el envejecimiento biológico tradicionalmente ha sido definido como un proceso progresivo de deterioro y de destrucción del organismo humano, como el de otros animales, con el paso del tiempo. Para Amâncio (1975), eso significa excesiva vulnerabilidad y reducida viabilidad frente a las fuerzas normales de la mortalidad.

Los trabajos de Shock y colaboradores ${ }^{48}$, comprueban que al cesar el período de crecimiento y una vez alcanzada la fase de madurez reproductiva, se comprueba una decadencia gradual de las diferentes funciones y mecanismos de adaptación y homeostasis. Ese declive es un fenómeno natural que obedece a instrucciones genéticas, propias de cada especie, pero no se puede excluir la participación de factores intrínsecos, metabólicos o ecológicos, en la velocidad de deterioro del organismo. El envejecimiento biológico existe pero no tiene que ser necesariamente asociado a una limitación, enfermedad o achaques. En ese plano, hay quien afirma que la vejez comienza a una edad muy temprana. Así, biológicamente, el envejecimiento se inicia en el momento en que se nace, y no exclusivamente a partir de los 60 o 65 años.

\footnotetext{
$46 \quad$ Lahud Loureiro, M. A. (2000): A velhice, o tempo e a morte. Brasília: UnB, Brasília, p. 18.

$47 \quad$ Beauvoir, Simone de. op. cit., 15.

48 Shock, N. W. (1973): Teorías biológicas y fisiológicas del envejecimiento. Res. del Congreso Latinoamericano de Gerontología y Geriatría. Buenos Aires.
} 
Los estudios documentados de Birren, Butler, Sokoloff y Yarrow (1971) también sostienen que los mecanismos físicos declinan muy pronto al comienzo de la edad madura. Para Chateaubriand, citado por Simone de Beauvoir, "La vejez es un naufragio"49. Chateaubriand, supuestamente se refiere a las pérdidas desagradables, al naufragio físico-biológico, citado por los autores, en el que se sumergen gradualmente los individuos después de la madurez.

Concretamente, la tesis de McTavish ${ }^{50}$ sitúa la vejez en la perspectiva biológica, bajo la concepción de envejecimiento equivalente a la involución y senilidad $^{51}$. Esta equiparación con la senilidad contribuye a concebir la vejez como un conjunto de cambios naturales que, desde el momento del nacimiento y hasta la muerte afectan a todos los seres vivos. Esas modificaciones pueden caracterizarse en forma de lesiones, enfermedades, disfunciones o disminución de capacidades físicas y mentales. A ejemplo de ese perfil, con profunda amargura, a juicio de Miguel Ángel Buonarroti, también citado por Beauvoir (1983), describe la disminución de sus capacidades sin dejar escapar el disgusto ante la vejez: "Estoy roto, agotado, dislocado por mis largos trabajos, y la hostería a donde me encamino para vivir y comer en común es la muerte... En un saco de piel lleno de huesos y de nervios retengo una avispa que zumba y en un canal tengo tres piedras de pez. Mi cara parece un espantajo. Soy como esos trapos tendidos los días de sequía en los campos y que bastan para espantar los cuervos. En una de mis orejas corre una araña, en otra un grillo canta toda la noche" ${ }^{25}$.

No es menos cierto también decir que este tipo de envejecimiento no se debe exclusivamente a factores endógenos, es decir, que se origina en virtud de causas internas, genéticas o debido a cambios moleculares o celulares, sino también a factores exógenos o medioambientales, como la clase social a la

\footnotetext{
$49 \quad$ Beauvoir, Simone de: op. cit., 357.

50 McTavish, D. G. (1971): Perceptions of old people: A review of research methodologies and findings. The Gerontologist, 11, pp. 90-101.

51 Degeneración progresiva de las facultades físicas y psíquicas debida a una alteración de los tejidos. Diccionario de la Real Academia Española.

52 Beauvoir, Simone de: op. cit., 358.
} 
que uno pertenece, al estilo de vida, los recursos económicos o el nivel educativo.

Desde la óptica médica, la ancianidad es vista como una patología específica. De modo gradual, constante y lento, el ritmo de deterioro es algo irreversible - al menos de momento - en los seres humanos y varía entre los individuos. La vejez es la única cosa que viene sin que hagamos esfuerzo. Ese proceso empieza muy pronto en relación con la duración cronológica de la vida, y se manifiesta en el organismo cuando declina sus posibilidades de subsistir, escribe Simone de Beauvoir. En esta perspectiva, es importante añadir "que la mayoría de los seres humanos sienten disminuir poco a poco sus fuerzas entre los 30 y los 35 años, pero no dan importancia al hecho en tanto que no se vean afectadas sus actividades cotidianas" (Mishara y Riedel, 1986:24).

Dada la información que tenemos sobre el envejecimiento biológico creemos que en todas las sociedades y culturas el hombre ha tenido conciencia de las alteraciones y ha experimentado las ambiguas señales que el cuerpo manifiesta. En general, un conjunto de síntomas y señales decurrentes del proceso de envejecimiento permite el diagnóstico biológico, disminución de la energía, de la capacidad receptiva de los sentidos, sequedad y arrugas en la piel, caída y encanecimiento del cabello, endurecimiento de determinados tejidos, pérdida general de flexibilidad. Este diagnóstico, todavía, no es sinónimo de dolencia, dado que la vejez, con sus características biológicas específicas, es un momento de la vida como los otros, que puede o no tener dolencias asociadas con la edad.

En verdad, el transcurso del envejecimiento es un proceso dinámico y progresivo en el que hay modificaciones tanto morfológicas como funcionales y bioquímicas que determinan la progresiva pérdida de capacidad de adaptación al medio ambiente, ocasionado una mayor incidencia de procesos patológicos. De otro modo, el envejecimiento del cuerpo se rige por factores genéticos, pero se ve afectado, evidentemente por influencias psicológicas y sociales. Así, es tan frecuente la realidad del anciano sano y con energías físicas, como la de personas más jóvenes que pueden tener problemas relacionados a la vejez, ya que todos somos vulnerables en todas las edades. 
En general, se cree que el límite biológico que puede vivir un ser humano, alrededor de ciento veinte años, está programado por sus genes ${ }^{53}$. La predilección de los estudios médicos biológicos es contundente, aún hoy día la búsqueda incesante para definir el fenómeno de la vejez arranca de fundamentos biológicos ${ }^{54}$.

Como señala Beauvoir en la obra La Vejez, "la vejez no es un hecho estadístico, es la prolongación y conclusión de un proceso" (1983:17). Para la autora, la vejez como destino biológico es una realidad transhistórica. Ese destino se vive de manera diferente según el entorno social. En suma, la vejez es consecuencia de un proceso biológico pero es también una construcción cultural (Beauvoir, 1983).

\subsection{Perspectiva psicológica}

Como hemos visto los parámetros para diagnosticar la vejez, desde la perspectiva biológica, son todavía bastante populares. Su planteamiento básico es que el organismo individual experimenta primero el crecimiento y el desarrollo seguido de la involución y declive. En el plano psicológico las variables, a pesar de no parecer sencillas, sin duda alguna, son importantes, puesto que una persona es mayor si se siente mayor. Para Amâncio (1975), "Los parámetros son muy imprecisos y variables y, más que cualquier análisis científico, parecen predominar las prenociones, las ideologías y los factores económicos históricamente determinados" (Amâncio, 1975:6). Así, para el diagnóstico psicológico de la vejez en este apartado, tomaremos como principio la descripción básica enfocada por la psicóloga brasileña Anita Liberalesso Neri.

Neri (2001) sitúa el concepto de edad psicológica en dos sentidos: "Uno es análogo al significado de edad biológica, y se refiere a la relación que hay entre la edad cronológica y la capacidad, tales como percepción, aprendizaje y memoria, las cuales prenuncian el potencial de funcionamiento futuro del individuo" (2001:65). Esa perspectiva tiende a analizar y explicar los

53 Para una exposición detallada sobre el tema, revísese Vetón y Parson (1899); Franz Kallman (1950) y Andrew P. Wickens (1998), citados por Fernández-Ballesteros (2004).

$54 \quad$ Para estas cuestiones cf. Curtis 1966, 1968; Bischoff, 1969; Palmore, 1970. 
intrincados mecanismos de la conducta individual de la persona frente al deterioro psíquico de la vejez, teniendo en consideración las diferencias de unos individuos respecto de otros. Para la autora, ese uso de concepto está muy próximo al de senescencia o envejecimiento normal. Comúnmente, se dice que alguien se está haciendo viejo psicológicamente cuando sus facultades cognitivas comienzan a fallar, presentando problemas de memoria, atención, orientación y concentración. La autora aún menciona que el segundo uso del concepto de edad psicológica, tiene relación con la idea subjetiva de edad. "Esta depende de cómo cada persona evalúa la presencia o la ausencia de marcadores biológicos, sociales y psicológicos de envejecimiento en comparación con otras personas de su edad" (2001:65). Como Claude Olievenstein (2001) escribió: “la vejez no es solamente una cuestión de edad, es también, y antes de todo, una cuestión de estado de espíritu. Con la misma edad, uno es un viejo friolero, cerrado sobre sí mismo, estrechamente fiel a sus hábitos reducidos al mínimo; el otro, al contrario, es más que un conquistador, como si quisiera devorar el tiempo, ser más fuerte que él, construyendo cada día una inmortalidad"55. Así, en el mismo individuo el proceso de envejecimiento es diferente en los distintos procesos psíquicos y cognitivos de personalidad, existiendo formas individuales de envejecimiento. En ese sentido, personas de mediana edad o en la vejez inicial tienden a indicar una edad psicológica menor que su edad cronológica, en parte para salvaguardar la imagen social y la autoestima tal vez, por dificultades de auto aceptación. En rigor, el hombre psicológicamente viejo no necesita de edad mientras tenga características psicológicas generalizables empíricamente, o sea que, la sensación de la senescencia no guarda una relación directa con el número de años vividos. La observación elemental permite reconocer que hay jóvenes viejos y viejos jóvenes. Muchos creen que esa etapa de la vida es un estado de espíritu, en el sentido de que no depende de la edad cronológica y de otros marcadores de la vejez.

En general la vejez desde el punto de vista psicológico, persigue el objetivo de conservar la salud psíquica y mental, actuando con prácticas 
psicoterapéuticas sobre los componentes cognitivos y afectivos de la personalidad. Así, según $\operatorname{García}^{56}$, hay que poner en marcha todos los programas de prevención de enfermedades y de hábitos sanos de vida para conseguir envejecer con éxito y dignidad, porque ese proceso es irreversible.

Se considera; por tanto, que el envejecimiento es un fenómeno particular en cada persona. Así, Lehr ${ }^{57}$, observa que la combinación de la herencia genética, el estado de salud, el estatus socioeconómico, las influencias sociales de la educación y de la ocupación ejercida, las diferencias por cohorte y la personalidad son, sobre todo, individuales y, por tanto, definidoras de la vejez.

\subsection{Perspectiva social}

Con lo dicho hasta el momento, se aprecia que el tema de la vejez puede ser abordado desde distintas perspectivas, siendo un concepto muy relativo. En la perspectiva demográfica, el envejecimiento está relacionado con la proporción de personas mayores sobre el total de la población; bajo el criterio biológico, está ligado al desarrollo somático gradual de cada individuo; en el plano psicológico se refiere a la sensación subjetiva de sentirse viejo y, finalmente, en la perspectiva social, la edad se refiere a las costumbres y funciones de los individuos en relación con sus grupos respectivos o la sociedad a la que pertenezcan. Cómo el diagnóstico de la vejez no es exclusivamente un hecho cronológico, la Organización Mundial de la Salud, acepta el plano biológico, psicológico y social como los principales parámetros de la vejez. Sin embargo, cómo situación social designa a esas personas, la Organización de las Naciones Unidas (ONU, 1985) marca el inicio de la vejez para aquellas personas con 65 años de edad en los países desarrollados y 60 años de edad para los países en desarrollo.

Desde el punto de vista sociológico, Bühler y colaboradores han subrayado que la descripción de la vejez está delimitada por factores cronológicos sociales,

56 García, María José, N. (1999): El tabú de la vejez en Yubero, Latorre, Larrañaga y Montañés (eds.) Envejecimiento, sociedad y salud. Cuenca: Humanidades, p. 179.

57 Lehr, Úrsula (1991): Aging in Europa New Directions in psychology, European Journal of Gerontology, 1, pp. 43-52. 
iniciada a partir de los 65 años y definida por la edad social de jubilación, ${ }^{58}$ en razón de la desvinculación de la obligación productiva laboral, pudiendo variar de cultura, región y grupos de profesión ${ }^{59}$. Hay una cierta concordancia implícita entre los diversos autores en torno al problema de la vejez. Casals (1982), por su parte, subraya que, "la vejez es un hecho social y no únicamente un hecho biológico. Son viejos aquellos a los que la sociedad llama así, tengan cuarenta, cincuenta o sesenta y cinco años, y esta etiqueta es más clara que nunca" (1982:126). En este sentido, la vejez actual es sobre todo una invención del modo de producción capitalista que ha inventado la jubilación y con ella la división de los adultos en dos grupos distintos, los productivos y los no productivos. Así, socialmente, la vejez variará de acuerdo con el momento histórico y cultural.

La jubilación, instancia que inscribe socialmente la ancianidad como factor medidor de la vejez, continúa Casals (1982), "es el hecho de interrumpir bruscamente la actividad laboral o profesional desarrollada durante la vida o una parte importante de la vida por causa de la edad. La edad social, arbitrariamente prefijada por la ley, es el elemento definitorio de la vejez que sobrepone los aspectos físicos y psíquicos del trabajador"60. Por razones obvias, según el autor, la jubilación se inventó para la clase trabajadora industrial, para la fuerza de trabajo manual, en la que la fuerza y la agilidad físicas son fundamentales. La normativa social de la jubilación no existe, por lo tanto, para los profesionales liberales, para los literatos, o para los políticos. Desde un punto de vista sociológico, en esta misma línea de pensamiento, es interesante lo que subraya Barenys (1993): "la persona es anciana cuando ha finalizado su rol de trabajador-productor-activo que le inscribe en el proceso productivo referido; básicamente a la mayoría de los que hoy son hombres ancianos. Y si ha finalizado su papel de reproductoracuidadora e imprescindible pilar de la vida familiar si es hoy una mujer anciana. La instancia que inscribe socialmente a la ancianidad es la

\footnotetext{
58 Bühler, Ch.; Brind, A. Y Horner, A. (1968): Old age as a phase of human life. Human development, 11, pp. 53-61.

59 Riley, M. (1976): Age strata in social systems, en R.H. Bistock y E. Shanas (eds.), Handbook of aging and the social sciences. New York: Van Nostrand.

60 Casals, I. (1982): Sociología de la ancianidad en España. Madrid: Mezquita, p. 51.
} 
jubilación, en la cual se adhiere la mujer a la jubilación del marido, aun cuando ella no hubiese trabajado fuera del hogar"61. Se reconoce, por tanto, que esta definición meramente cronológica es arbitraria, visto que el envejecimiento individual no se produce concomitantemente con la edad cronológica.

En la sociedad actual, la práctica obligatoria del "retiro" se convierte en las sociedades avanzadas, inevitablemente, en una pena de muerte social ${ }^{62}$. El hecho de "apartar" al individuo del mundo laboral a partir de una edad, en la cual muchas veces se encuentran con plenas fuerzas vitales, se convierte en una desgracia. Según Fericgla (1992), "A partir de una edad arbitrariamente prefijada, la legislación ordena que los individuos no sigan trabajando, es decir, se margina forzosamente a las personas del mundo del trabajo y, consecuentemente, de todo lo que implica, además de la obligación laboral: relaciones y prestigio social, posibilidad de ascenso y de mejora de la propia auto estima, referente importante de la identidad social, beneficios económicos superiores a los que se reciben como jubilado y de otras derivaciones de la colocación laboral"63. Los aspectos psicosociales, económicos y providenciales intrínsecos a este proceso son experimentados, a menudo, por los jubilados con resistencia, por ser un proceso brusco y muchas veces sin la debida preparación para quien va a jubilarse.

En relación, precisamente, con esta discusión tan actual sobre el ritual de entrada en la vejez social, simbolizada por los años, reviste singular importancia la afirmación de Domínguez Rodríguez (1989), según la cual "se establece convencionalmente por atención a criterios socioeconómicos, de rendimiento de consumo, por cuanto la sociedad actual suele privilegiar los valores de actividad y rendimiento de la población juvenil y adulta

$61 \quad$ Pía Barenys, María (1993): El significado sociológico de la vejez y de las residencias de los ancianos en Pedro Sánchez Vera, Sociedad y población anciana. Murcia: Universidad de Murcia, p. 57.

62 Guillemard, A.M: La retraite, una mort sociale: Sociologie des conduites en situation de retraite. Paris, Mouton.

63 Fericgla, J. M. (1992): Envejecer una antropología de la ancianidad. Barcelona: Antropos, p. 72. 
provocando la marginación económica y social del hombre jubilado"64. Es la dinámica de la sociedad capitalista, pero para minimizar los traumas de la jubilación es necesario dar a conocer en la práctica los cuidados necesarios para convivir con la edad y todas sus consecuencias. Además, como señala Riley (1976), la sociedad ya no puede mantenerse mucho más tiempo con tantas personas capacitadas sin ningún papel social que interpretar.

Así pues, la convicción sociológica de la vejez se ocupa de la situación del anciano desde el fin de la vida laboral activa, con independencia de factores biológicos o psicológicos, pero según los análisis de Barenys (1993) no vuelve a situar al anciano socialmente, es decir, no se ha elaborado en las sociedades industriales un rol coherente del individuo anciano, por más que las teorías de procedencia psico-sociológica lo hayan intentado. De todas maneras y en relación con lo expuesto, indica Rodríguez (1994) que "es necesario que la sociedad envejecida plantee el nuevo significado de la jubilación y defina socialmente los nuevos papeles sociales del jubilado para dar sentido a esta etapa de la vida" ${ }^{65}$.

En razón de nuestro estudio nos apropiaremos del punto de vista sociológico.

\section{Distintos vocablos para referirse a la vejez}

A la luz de lo expuesto en las líneas precedentes, vemos que son muchos los indicadores, a veces un poco conflictivos, capaces de identificar o mesurar las dimensiones del envejecimiento. Los diversos indicadores provocan la formulación de una gran variedad de definiciones para un mismo aspecto del fenómeno. Pero, en general, lo que no genera controversias es que el envejecimiento puede definirse como un proceso universal, individual, natural y gradual de cambios y transformaciones a consecuencia del paso del tiempo. Como un fenómeno inexorable, inmutable y "democrático" en los seres humanos, el envejecimiento, biológicamente hablando, se tradujo en la

64 Domínguez, R. S. (1989): La vejez: historia y actualidad, Estudios pedagógicos $\mathrm{n}^{\mathbf{0}} 29$, Salamanca: Universidad de Salamanca, Acta salmanticense, p. 88.

65 Rodríguez, Josep, A. (1994): Envejecimiento y familia. Madrid: C.I.S., (137): pp. 5-6. 
disminución de plasticidad comportamental, en el aumento de vulnerabilidad, en la acumulación de pérdidas evolutivas y en el aumento de probabilidad de muerte. Siendo el ritmo, la duración y el efecto de ese proceso diferente para cada individuo y grupos de edad, dependientes de eventos de naturaleza genético-biológica, socio-histórica y psicológica (Mishara y Riedel, 1986; Neri, 2001). Así el envejecimiento no es un acontecimiento misterioso que ocurre por casualidad. Al contrario, entre tantas intervenciones que influyen en este proceso, se trata, según los científicos ${ }^{66}$, del fallo del sistema inmunológico (Eisdorfer, 1971), del envejecimiento de las células (Hayflick, 1976), de las alteraciones del sistema endocrino (Finch y Hayflick, 1977) y desencadenantes genéticos (Selye, 1974; Comfort, 1972). Pues bien, si históricamente el envejecimiento es un proceso biológico, psicológico y social, que se inscribe en el tiempo del nacimiento y concluye inevitablemente con la muerte, la vejez se refiere a una fase de la vida, incluso la más larga y a la vez la más desconocida de la vida, como bien dijo Antonio Cabezas (1989), que pasan los seres humanos, y que coincide con la última fase del ciclo vital.

No obstante, la cosa no es tan simple como parece. La denominación "vejez" no es una realidad bien definida, de término impreciso, la variación de conceptos complica la cuestión. De hecho, existe una cierta ambigüedad en cuanto a la estimación del inicio de la vejez, en la medida en que los informantes condicionan ese evento, como ya se ha dicho, de factores de salud, sexo, jubilación y nivel económico. ${ }^{67}$ Dichos indicadores pueden acelerar o retardar la evolución biofisiológica e introducir a los individuos en la vejez en edades muy diferentes. No somos iguales ante la entrada en la vejez; cada persona tiene una forma peculiar de envejecer. "Y lo somos aún menos en la elección de los instrumentos que permiten contener, retardar, usar las señales o los estigmas, las imposibilidades, las limitaciones que el hecho de envejecer nos impone" (Olievenstein, 2001:14). La frontera que inscribe la vejez es tan compleja como lo son los distintos vocablos para

\footnotetext{
66 Que participaran del Congreso de la Asociación Americana para el Avance de la Ciencia, celebrado en 1974.

$67 \quad$ Véase algunas investigaciones que se preocupan en preguntar a sus sujetos cuando empieza la vejez. Tuckman y Lorge, 1953; Blau, 1956; Zola, 1962; Shanas, 1962; Peters, 1971; Harris y col., 1975; Kogan, 1979 y Neri y Wagner, 1985.
} 
denominarla. La palabra viejo tiene un campo semántico bastante amplio, que puede generar ciertas confusiones. En la literatura especializada, para referirse a este público, desde el punto de vista de las ciencias sociales, encontramos un abanico de expresiones valorativas, pero también cargadas de perjurios y eufemismos. En casi todas las publicaciones aparecen conceptos como tercera edad, población de edad avanzada, cuarta edad (para referirse generalmente a mayores de 75 años), ancianos, viejos, edad de oro, mayores, nonagenarios, gente grande, seniors, senectos, jubilados, octogenarios, etc. De una forma u otra, estas denominaciones han introducido confusiones y no se ha evitado el trato social despreciativo y discriminatorio.

Para la connotación semántica del término "viejo" el más propagado y popular en la sociedad actual, según los diccionarios de la lengua española y portuguesa, respectivamente, significa, (Del lat. vulg. veclus), la persona de edad (Adj.); comúnmente puede entenderse que es vieja la que cumplió 70 años; antiguo o del tiempo pasado; deslucido, estropeado por el uso ${ }^{68}$. Para Aurélio Buarque de Holanda ${ }^{69}$, diccionario de portugués, viejo es: persona muy anciana; de época remota; algo antiguo; que tiene mucho tiempo de existencia; gastado por el uso; anticuado; obsoleto. Convertida en sinónimo de fragilidad e inutilidad, la vejez es temida y mayoritariamente rechazada en las sociedades actuales. "Despreciada, devaluada, considerada por unos como un mal incurable anunciador de la muerte, es negado por otros, que no quieren reconocer sus transformaciones físicas" (Minois, 1987:14). Nadie quiere ser viejo. Una típica representación de la vejez, creada a partir de estas tipologías, la encontramos también en La Vejez de Beauvoir cuando Julliette Drouet, acometida por un cáncer y desesperanzada por el amor de Hugo, sólo siente la vejez como decadencia: "Es inútil que me apoye en mi amor, siento que todo se hurta y se desmorona en mí: la vida, la memoria, la fuerza, el coraje, el diablo del cuerpo"70. 0 lo mismo que ha subrayado Zélia

\footnotetext{
68 Diccionario de la lengua española - Real Academia Española, vigésimo segunda edición, Rodesa, Madrid, 2001, p. 2299.

69 Ferreira Aurélio Buarque de H. (2004): Miniaurélio da língua portuguesa, $6^{a}$ edição revisada e atualizada. Curitiba: Positivo, p. 810.

$70 \quad$ Beauvoir, Simone de: op. cit., 377.
} 
Gattai $^{71}$. “\{...\} quien dice que la vejez es una maravilla está mintiendo. No es ninguna maravilla, precisamos tener más restricciones. Es otro ritmo...,"72. En esta etapa, para la gran mayoría, todo les parece pasar al plano de la imposibilidad.

Es por tanto una evidencia que, en las circunstancias actuales, la situación de los viejos, en las sociedades capitalistas modernas, mayoritariamente sigue siendo vivida y contemplada negativamente. Denominaciones peyorativas como: improductivos, inútiles, antiguos, frágiles, incapaces, débiles, seniles, entre tantas otras, son frecuentes y resultan rechazadas socialmente. De este modo, según $\mathrm{Bazo}^{73}$ se considera el volumen y proporción de las personas mayores como un problema social. Es decir, en términos económicos, la sobrecarga en el sistema hace que las personas menores de 65 años que todavía están activas tengan que soportar una gran sobrecarga para alimentar las pensiones, retiros y subsidios de la vejez. La base de esta percepción constituye el principal problema de la vejez (Laslett, 1991). Pero, no olvidemos que los que aportaron obligatoriamente la remuneración de su trabajo a lo largo de toda su vida laboral no constituyen sobrecarga para la Seguridad Social, más allá de ser la justa restitución de su contribución. Las pensiones fueron un logro social, paralelo a las conquistas de la jornada de ocho horas, el descanso semanal y las vacaciones anuales; conquistas que se hicieron realidad por las luchas de los trabajadores y no por bondad del capital.

Al contrario, según el creador de la "psicología arquetípica" posjunguiana, James Hillman, la palabra old (viejo en inglés), es muy antigua, y su raíz significa "nutrir". Él afirma que "una cosa 'antigua' - que tiene mucho tiempo de existencia, está internamente nutrida, crecida, madurada". La palabra inglesa que la precede es eald, que revela confianza, vulnerabilidad, valor. Así que también se puede decir que el término viejo alberga su positividad.

\footnotetext{
71 Escritora brasileña de 91 años, viuda del escritor baiano Jorge Amado, fallecida en 17 de Mayo de 2008.

$72 \quad$ Cf. http://www.folhaonline.com.br, agosto/2002.

73 Bazo, María T. (1993): La vejez como problema social, en Pedro Sánchez Vera (ed.) Sociedad y población anciana. Murcia: Universidad de Murcia, pp. 181-188.
} 
De hecho, la vejez no es solamente decadencia; puede verse también como crecimiento. Comúnmente se dice que el carácter peyorativo de la palabra viejo tiene su origen en la modernidad.

Así que no han faltado quienes valoren positivamente la edad que viven. Es oportuno señalar que Platón (427-347 a. C.) en La República no ahorra elogios a la vejez. Según el filósofo, esta época de la vida conduce a una mejor armonía. Es el momento en el que se alcanza la prudencia, la discreción, la sagacidad y la capacidad de juicio. El filósofo ruso Tolstoi, ${ }^{74}$ perdiendo su aliento, expresaba que el progreso moral de la humanidad se debe a los ancianos. Los ancianos se vuelven mejores y más sabios. 0 como escribe Joubert: aquellos que tienen una larga vejez están como purificados del cuerpo. Con Juan Pablo II, concluimos: "Los ancianos ayudan a contemplar los acontecimientos terrenos con más sabiduría, porque las vicisitudes los convirtieron en más expertos y maduros" ${ }^{\prime 75}$. Nadie llega a la vejez sin hacer el camino de las etapas anteriores, la niñez, la adolescencia y la adultez; como una determinación de la naturaleza pueden ofrecer oportunidades de aprendizaje, madurez, encantos y personalización. Aceptar las propias limitaciones, superar la pérdida de las fuerzas adecuadamente parece ser el secreto de llegar a la vejez de modo tranquilo y equilibrado. Pues, "a todos nos afecta el proceso de envejecimiento porque en ningún momento podemos dejar de estar inmersos en él”76. Llenar de sentido la propia vejez es valorar la propia existencia.

Mientras no tengamos un lenguaje común para referirnos a los que llegan al final obligado de todo lo viviente, los conceptos ayudan a comprender esa fase vital. Arbelo Curbelo y Hernández Rodríguez (1981), por su parte, hacen una diferencia entre los términos viejo y anciano. El primero, en lo que la Medicina denomina senectud, es el individuo que llega a su fase final en condiciones que se resumen en una disminución de la capacidad física y un incremento de la vulnerabilidad a la enfermedad. El segundo, es la persona

\footnotetext{
$74 \quad$ Beauvoir, Simone de: op. cit., 377.

75 Cf. João Paulo II, Carta aos Anciãos, Paulinas, São Paulo, 1999, p. 10.

76 Kalish, Richard, A. (1982): La vejez perspectiva sobre el desarrollo humano, traducción de Juan Manuel Cosano. Madrid: ediciones pirámide, p. 2.
} 
que alcanza la cuarta edad dotada de salud, llena de experiencia, consejera y venerable. Sobre este tema existen también muchos estereotipos científicos.

Para Bandera $^{77}$, la terminología más conveniente para referirse a esa categoría es el término "personas mayores" y descarta totalmente el vocablo "viejos", por tener un carácter directamente peyorativo de desgaste e inutilidad. Además, a los propios individuos de edad no les gusta ser llamados así. Sin embargo, esa denominación parece confusa. ¿Qué es un mayor? Siempre hemos entendido que una persona mayor es una persona adulta, o al menos una persona que ha sobrepasado la mayoría de edad legal. A partir de este punto de vista, ¿cómo de mayor es una persona? Ya Víctor Alba ${ }^{78}$ piensa al contrario: en la investigación social insiste en la idea de llamar "viejos" a los viejos por dos razones: "porque no hay nada vergonzoso en ser viejo y porque es bueno que quienes no lo son se vayan acostumbrando a la idea de llegar a serlo si antes no se convierten en cadáveres”.

En cualquier caso, ese no es el problema de fondo, pues la "edad" se ve afectada por valores sociales y la "no vejez" lleva emparejada un valor intrínseco. Los autores Yubero y Larrañaga ${ }^{79}$ consideran adecuado el término “anciano", pues se podría justificar, "al tratarse del cuarto período o edad de la existencia humana después de la infancia (entre los 0 y los 9 años), la adolescencia (entre los 10 y los 19 años) y la adultez (de los 20 a los 69 años), coincidiendo con lo que admite la OMS; o el término "tercera edad", oficialmente introducido en Francia (la "troisième âge"), y que ha tenido una buena aceptación - pues no se ha asumido como peyorativo - pero de difícil explicación, ya que no se habla de primera edad o de segunda edad". Más allá de eso, también creen Vázquez ${ }^{80}$ y Pinillos $^{81}$ que el término "tercera edad" asume connotaciones negativas, considerando la posible similitud en cuanto al

77 Bandera, J. (1993): Interacción y elaboración de la identidad en la Tercera Edad, en, Pedro Sánchez Vera (ed.), Sociedad y población anciana. Murcia: Universidad de Murcia, p. 103.

$78 \quad$ Víctor, Alba (1992): Historia Social de la vejez. Barcelona: Laertes, $1^{\text {a }}$ edición, (nota del autor).

79 Yubero, Santiago y Larrañaga, Elisa: La Imagen del Anciano en Yubero, Latorre, Larrañaga y Montañés (eds.), op. cit., 60.

80 Vázquez, E. R. (1993): La Ancianidad, un producto social, en: Sánchez Vera, Pedro (ed.), Sociedad y Población Anciana. Murcia: Universidad de Murcia, p. 112.

81 Pinillos, J. L. y otros. (1994): Una aproximación pluridisciplinar al entorno de la vejez. Madrid: Fundación Caja Madrid. 
concepto numérico marginal "tercer o tercero", en tanto en cuanto la tercera edad sea valorada como una edad de tercera, con otro término que se acuñó, aproximadamente al mismo tiempo, como es el de Tercer Mundo, que lleva a fijar la marginación tanto al grupo social al que el término hace referencia como a los países subdesarrollados. En efecto, para ellos el término "tercera edad" no es posiblemente el más afortunado para describir la realidad de estos destinatarios.

Otra cuestión es que, habitualmente, se recurre a los conceptos viejo y anciano como sinónimos. Cabe decir que, según el punto de vista de la demografía sanitaria, los dos términos son diferentes. Harbelo y Hernández ${ }^{82}$ esclarecen que la ancianidad es el cuarto periodo de la existencia humana y puede situarse entre los 60 y 70 años. Así, la ancianidad coincidiría con el fin de la etapa productiva, o la jubilación decretada oficialmente en las diferentes culturas. Sin embargo, la vejez es un estado patológico de la ancianidad, que implica enfrentarse con las abrumadoras fuerzas biológicas y psicológicas que disminuyen las capacidades funcionales y que conlleva la discapacidad y la pérdida de independencia. Como puede verse, las distintas conceptualizaciones que nos permiten clasificar la vejez son exhaustivas.

Por todo ello, en mi exposición hablaré fundamentalmente de personas con 60 años o más, teniendo el mayor cuidado en no dejarme llevar por eufemismos.

\section{Senescencia (senectud) y senilidad}

Entre los múltiples aspectos del envejecimiento surgen dos condiciones relevantes en el área de la investigación gerontológica: la senectud y la senilidad. El primer término no es más que un período del ciclo vital de la persona humana, con aspectos positivos y negativos como cualquier otra etapa de la vida. Así es "normal" llegar a la senectud al cumplir, según Rodríguez Carrajo "el proceso que se va alargando a lo largo del tiempo y que nos sobreviene sin apenas darnos cuenta" (Rodríguez Carrajo 1999:77). La

82 Arbelo, A. y Hernández, G. (1981): Demografía sanitaria de la ancianidad. Madrid: Karpos, p. 9. 
senectud, se refiere al último estadio del ciclo vital de una persona acompañado de los efectos naturales o fisiológicos del proceso de envejecimiento. Clasificado como envejecimiento saludable, resulta de la suma de las alteraciones orgánicas, funcionales y psicológicas propias del envejecimiento primario. La senectud es relativa, y actualmente sabemos que no corresponde de forma automática con la edad. En este sentido, la senectud no se refiere a las patologías asociadas al envejecimiento (senilidad) sino únicamente al envejecimiento considerado normal o primario. Otro término que se usa para las alteraciones fisiológicas asociadas al envejecimiento normal o primario es Eugeria.

El segundo término, senilidad, contrario al primero, se refiere a las alteraciones producidas por las afecciones patológicas que frecuentemente acometen a individuos en edades avanzadas. Definido como envejecimiento secundario o patológico, al pie de la letra, literalmente significa, "la degeneración progresiva de las facultades físicas y psíquicas debida a una alteración de los tejidos" ${ }^{\prime 3}$. Con la prolongación de la vida del ser humano y de su envejecimiento se espera la visita senil y su consecuencia, la muerte. Este término no se refiere, por tanto, a las alteraciones fisiológicas consideradas normales del envejecimiento (senescencia). También se usa la palabra Patogeria, para designar las alteraciones provocadas por enfermedades en los adultos mayores.

\section{Autonomía e independencia}

Los múltiples aspectos del proceso de envejecimiento y de la vejez justifican también la importancia de dos conceptos bastante conocidos y particularmente útiles en ese contexto: la autonomía y la independencia. Se admite que para gozar de una buena vejez los dos estados son imprescindibles. En Stuart Mill (1909) encontramos una de las bases teóricas utilizadas para el principio de la autonomía. En la obra On Liberty ${ }^{84}$ Mill

83 Michaelis (1996): Pequeno dicionário espanhol/português, português/espanhol /Helena B. C. Pereira, Rena Signer. São Paulo: Companhia Melhoramentos, p. 278.

$84 \quad$ Mill, John S. (1909): On Liberty, Boston: Collier, p. 5. 
señala que sobre uno mismo, sobre su cuerpo y su mente, el individuo es soberano. Así que, "tener la capacidad de decisión, de comando y la condición de realizar algo con sus propios medios” (Papaléo Netto, 2004:11), puede estar en el plan ideal de los que se encaminan a la senectud.

De fácil comprensión, los significados se encuentran en la literatura gerontológica, siendo la "autonomía" la noción y el ejercicio del propio gobierno, la capacidad de tomar decisiones, de establecer y seguir las propias reglas $^{85}$. Pero, según el contexto, las dificultades para realizar tal concepto son, naturalmente innumerables. La autonomía puede tener significados diferentes para el individuo que vive en una gran ciudad de un país desarrollado, o para aquel que vive en una zona rural de un país subdesarrollado. Para el primero, la autonomía puede ser medida a través de su capacidad de cuidar de sí mismo (higiene personal, preparación de las comidas). Para el segundo, ese concepto puede significar algo más complejo, por ejemplo, capacidad de realizar trabajo físico en el campo. Para Collopy (1988, apud Kane, 1991), el concepto incluye además libertad individual, privacidad, libre elección, autogobierno, autorregulación e independencia moral.

Por lo que se refiere al concepto de “independencia”, el aspecto principal es la capacidad funcional, que en su expresión máxima significa poder sobrevivir sin ayuda, o sea, realizar actividades básicas de la vida diaria o de auto cuidado y actividades instrumentales cotidianas (Baltes, 1996). En la vejez, la manutención de la independencia está íntimamente ligada a la calidad de vida. De este modo, una forma práctica de cuantificar la calidad de vida de una persona es a través del grado de independencia con que ella misma desempeña las tareas del día a día - capacidad de hacer las propias compras, manutención básica de la casa - que la vuelven independiente dentro de su contexto socioeconómico cultural (Kalache y Gray, 1985, apud Kalache, 1987). Para Neri (2001), “la independencia no es condición necesaria para la autonomía, aunque sea una condición frecuentemente presente en personas capaces de decidir por sí mismas” (2001:10). La autora argumenta que la

85 Evans J.G. (1984): Prevention of age-associated loss of autonomy: epidemiological approaches. J. Chron Dis, 37(5), pp. 353-361. 
dificultad para el desempeño de las actividades instrumentales de la vida diaria de ningún modo implica un impedimento para el funcionamiento psicosocial del individuo. Así, la expresión autonomía para un mayor, según Evans (1984), es más útil que la de independencia, como un objetivo global, dado que puede ser restaurada por completo, aun cuando el individuo continúa siendo dependiente. Pachoal (1996) ejemplifica esto: una señora con fractura de fémur, que quedó postrada en silla de ruedas, podrá ejercer su autonomía, a pesar de no ser totalmente independiente.

En resumen, envejecer manteniendo todas las funciones es una aspiración natural de todo individuo que envejece. Si en una sociedad los individuos alcanzan edades cada vez más avanzadas manteniendo buenas condiciones de salud y autonomía, no existen mayores problemas para la sociedad en cuestión. Sin embargo, para postergar su deterioro se necesita invertir en la mejoría de la calidad de vida, dado que mantener la autonomía y la independencia es una tarea compleja que exige, sobre todo, políticas públicas.

\section{Tipos de envejecimiento}

Los múltiples aspectos del proceso de envejecimiento y de la vejez justifican también la importancia de dos conceptos bastante conocidos y particularmente útiles en ese contexto: la autonomía y la independencia. Se admite que para gozar de una buena vejez los dos estados son imprescindibles. En Stuart Mill (1909) encontramos una de las bases teóricas utilizadas para el principio de la autonomía. En la obra On Liberty ${ }^{86}$ Mill señala que sobre uno mismo, sobre su cuerpo y su mente, el individuo es soberano. Así que, tener la capacidad de decisión, de comando y la condición de realizar algo con sus propios medios (Papaléo Netto, 2004:11), puede estar en el plan ideal de los que se encaminan a la senectud.

De fácil comprensión, los significados se encuentran en la literatura gerontológica, siendo la "autonomía" la noción y el ejercicio del propio gobierno, la capacidad de tomar decisiones, de establecer y seguir las propias 
reglas ${ }^{87}$. Pero, según el contexto, las dificultades para realizar tal concepto son, naturalmente innumerables. La autonomía puede tener significados diferentes para el individuo que vive en una gran ciudad de un país desarrollado, o para aquel que vive en una zona rural de un país subdesarrollado. Para el primero, la autonomía puede ser medida a través de su capacidad de cuidar de sí mismo (higiene personal, preparación de las comidas). Para el segundo, ese concepto puede significar algo más complejo, por ejemplo, capacidad de realizar trabajo físico en el campo. Para Collopy (1988, apud Kane, 1991), el concepto incluye además libertad individual, privacidad, libre elección, autogobierno, autorregulación e independencia moral.

Por lo que se refiere al concepto de "independencia", el aspecto principal es la capacidad funcional, que en su expresión máxima significa poder sobrevivir sin ayuda, o sea, realizar actividades básicas de la vida diaria o de auto cuidado y actividades instrumentales cotidianas (Baltes, 1996). En la vejez, la manutención de la independencia está íntimamente ligada a la calidad de vida. De este modo, una forma práctica de cuantificar la calidad de vida de una persona es a través del grado de independencia con que ella misma desempeña las tareas del día a día - capacidad de hacer las propias compras, manutención básica de la casa - que la vuelven independiente dentro de su contexto socioeconómico cultural (Kalache y Gray, 1985, apud Kalache, 1987). Para Neri (2001), "la independencia no es condición necesaria para la autonomía, aunque sea una condición frecuentemente presente en personas capaces de decidir por sí mismas" (2001:10). La autora argumenta que la dificultad para el desempeño de las actividades instrumentales de la vida diaria de ningún modo implica un impedimento para el funcionamiento psicosocial del individuo. Así, la expresión autonomía para un mayor, según Evans (1984), es más útil que la de independencia, como un objetivo global, dado que puede ser restaurada por completo, aun cuando el individuo continúa siendo dependiente. Pachoal (1996) ejemplifica esto: una señora con

87 Evans J.G. (1984): Prevention of age-associated loss of autonomy: epidemiological approaches. J. Chron Dis, 37(5): 353-361. 
fractura de fémur, que quedó postrada en silla de ruedas, podrá ejercer su autonomía, a pesar de no ser totalmente independiente.

En resumen, envejecer manteniendo todas las funciones es una aspiración natural de todo individuo que envejece. Si en una sociedad los individuos alcanzan edades cada vez más avanzadas manteniendo buenas condiciones de salud y autonomía, no existen mayores problemas para la sociedad en cuestión. Sin embargo, para postergar su deterioro se necesita invertir en la mejoría de la calidad de vida, dado que mantener la autonomía y la independencia es una tarea compleja que exige, sobre todo, políticas públicas.

\subsection{Envejecimiento normativo o primario}

Comúnmente se entiende por envejecimiento primario o envejecimiento fisiológico, aquel causado por la acumulación de los años, que es universal, es decir, está presente en todas las personas, está genéticamente determinado o pre-programado y es progresivo, Por tanto, es un fenómeno que sucede a todos los seres vivos después de la madurez sexual que evoluciona sin patologías inhabilitantes y carente de enfermedades agudas. Kastenbaum ${ }^{88}$, sostiene que el envejecimiento normal constituye una etapa vital, como la niñez, la adolescencia y la madurez con unas enfermedades características propias y también oportunidades, pero que no tiene necesariamente que asociarse con enfermedad o molestias. Así pues debemos entenderlo como los cambios inherentes al proceso de envejecimiento. Para Moragas (1991) "las causas de una vejez saludable orgánica (normal), deben buscarse en factores genéticos, originales y hereditarios de cada persona y en factores del medio ambiente material y psicosocial" (1991:55).

Se plantea que un concepto relacionado con el envejecimiento primario es la calidad de vida. Así, dada la circunstancia histórica, geográfica, cultural y social que viva cada persona, factores como la educación, la alimentación, el medio ambiente y el estilo de vida forman parte de ese proceso. En ese sentido, resulta posible entender que las transformaciones que no aumentan 
directamente nuestra vulnerabilidad hacia la muerte son denominadas envejecimiento primario o normal. Para Birren y Schoots (1996), como hemos dicho en el epígrafe anterior, el envejecimiento normal, también referido como senescencia, engloba un declive gradual y acumulativo en las funciones del organismo, que se altera con la edad en todos los seres humanos. Aún desde la perspectiva biológica, Busse y Blazer $(1996)^{89}$ comparten que el envejecimiento primario es intrínseco al organismo mismo, y se caracteriza por los cambios inherentes al proceso del envejecimiento. Consiste en un deterioro en los procesos fisiológicos que evolucionan sin patologías inhabilitantes como consecuencia de la edad. La vejez primaria corresponde a una vejez con una mínima interrupción de las funciones usuales. El encanecimiento, la atrofia de la piel, la flacidez muscular y el déficit sensorial son, por tanto, sólo algunos indiciadores de este tipo de envejecimiento (Birren, Schaie, Schroots, 1996 apud Neri, 2001:32). En la actualidad, Yates (1996) denomina envejecimiento al conjunto de cambios debidos a la edad mientras que senescencia se refiere a la pérdida progresiva de estabilidad de los sistemas biológicos.

Baltes y Baltes (1990), desde una perspectiva biológico-funcional, describen tres patrones de envejecimiento: el normal o usual, caracterizado por la inexistencia de patología biológica o mental: el óptimo o competente y saludable que asocia un buen funcionamiento cognitivo y una adecuada capacidad física a una baja probabilidad de existencia de enfermedad y/o discapacidad.

\subsection{Envejecimiento patológico o secundario}

Contrariamente al envejecimiento normal, el envejecimiento patológico conlleva alteraciones ocasionadas por enfermedades, frecuentemente crónicas, debido a la edad, que no se confunden con los cambios normales de ese proceso. Para Busse (1969) este tipo de envejecimiento hace referencia a los cambios causados por la enfermedad que - por la relación entre edad y salud - son reversibles o que, en sí mismas, no están causadas por la edad,

89 Busse, E.W; Blazer, D.G. (1996): Textbook of Geriatric Psychiatry, Washington: American Psychiatric Press. 
sino por los cambios de ésta. En la vejez, la probabilidad de enfermar y originar consecuencias negativas en el organismo es mucho mayor que en otras etapas de la vida. El envejecimiento secundario se refiere a la aparición de discapacidades producidas por eventos biológicos, pero también se relaciona con eventos socios-estructurales, ecológicos y psicológicos, que pueden contribuir a su empeoramiento más rápido o a su mitigación (Neri: 2004). Por tanto, el envejecimiento secundario se refiere a la degeneración progresiva que ocurre de acuerdo con la interacción de las causas genéticas y ambientales. Forman parte del envejecimiento patológico, la esclerosis múltiple, las enfermedades cardiovasculares, las enfermedades cerebrovasculares y ciertos tipos de cáncer, que, acostumbran a aparecer entre la tercera y cuarta década de vida, en virtud, en parte, de la programación genética, de los factores ambientales y del estilo de vida.

En líneas generales, para Baltes y Baltes (1990) el envejecimiento patológico está determinado por la etiología médica y los síndromes de las enfermedades.

\subsection{Envejecimiento terciario o terminal}

Siguiendo con la secuencia, una vez señalados los dos primeros tipos de envejecimiento, normal y patológico se pasa a describir el terciario o terminal. Identificado como el inevitable deterioro progresivo al que nadie escapa, este tipo de envejecimiento está relacionado con un gran aumento en las pérdidas físicas y cognitivas en un período de tiempo relativamente corto. Es conocido, según los estudiosos Birren, Schaie y Schroots, (1996) como el punto final de las enfermedades terminales, en cualquier edad. Para Neri (1999), "el tipo del envejecimiento terciario se refiere a un patrón de decadencia terminal y está caracterizado por un gran aumento de pérdidas físicas y cognitivas en un período relativamente pequeño al cabo del cual sobreviene la muerte, o debido a las enfermedades que dependen de la edad, de la interacción entre los procesos primario, secundario y terciario. No se sabe con exactitud si ese es un patrón universal, pero el fenómeno de acumulación de pérdidas es reconocido como el punto final de enfermedades 
terminales que ocurren en cualquier edad, sin embargo, se presenta con mayor probabilidad en la vejez avanzada"90.

\subsection{Envejecimiento con éxito}

Por último ha de procederse al análisis del envejecimiento activo. Éste fue impulsado a partir de los principios de las Naciones Unidas en favor de las personas de edad ${ }^{91}$ y de la Organización Mundial de Salud (OMS) que lo define como el proceso de optimización de las oportunidades para obtener bienestar físico, social y mental durante toda la vida, con el fin de extender la esperanza de vida saludable, la productividad y la buena calidad de vida a la vejez. Específicamente, en las propuestas resultantes de la II Asamblea Mundial sobre el Envejecimiento (Madrid: 2002), bajo las directrices que orientan las políticas públicas relativas a población envejecida para el siglo $X X I$, la estrategia internacional se centra en viabilizar la inclusión de este colectivo social en la sociedad. Construido en torno al concepto de envejecimiento productivo ${ }^{92}$, el Plan de Acción Internacional prevé que las personas, a medida que envejecen, deben disfrutar de una vida plena, con salud, seguridad y participación activa en la vida económica, social, cultural y política de sus comunidades y en el desarrollo de sus sociedades. ${ }^{93}$ La idea aspira a fomentar políticas que mantengan activas a las personas durante el mayor tiempo posible. Con ello, se entiende que se pueden modificar ciertos estereotipos negativos con que se diseñaron los primeros estudios gerontológicos y que un nuevo optimismo se extiende en el campo de los senescentes.

En resumen, los parámetros que definen la vejez exitosa o saludable (successfull aging), en las ideas de los científicos Rowe y Kahn (1998) incluyen tres componentes principales: baja probabilidad de padecer enfermedades 0

\footnotetext{
90 Neri, A. L. (1999): Envejecimiento competente en el trabajo, en Simposio Internacional Envejecimiento Competente, Retiro y Seguridad, Caja Colombiana de Subsidios Familiar COLSUBSIDIO, Santafé de Bogotá, p. 11.

91 Resolución 46/91 de la Asamblea General.

$92 \quad$ Ver Rowe y Kahn (1998); Featherman, Smith y Peterson (1991); Baltes y Baltes (1991).

93 Informe de la II Asamblea Mundial Sobre el Envejecimiento, Madrid, 8 a 12 de abril de 2002. (Publicación de las Naciones Unidas, número de venta: S.02.IV.4), cap. I, artículos 5 y 6.
} 
invalidez, elevada capacidad funcional física y cognitiva y mantenimiento de una vida activa en la sociedad ${ }^{94}$. De modo semejante, en la propuesta de Neri (2004), se puede envejecer bien, mediante la ausencia de enfermedades físicas y mentales crónicas y de discapacidades funcionales que comprometan el funcionamiento en niveles esperados para las personas adultas en una determinada sociedad: la ausencia de factores de riesgo, tales como la hipertensión, el tabaquismo y la obesidad, el mantenimiento del funcionamiento físico y mental y el compromiso activo con la vida. Para la autora, la vejez exitosa va más allá de este potencial e incluye autonomía, independencia e implicación activa con la vida personal, con la familia, con el ocio y con la vida social. Eso se revela en la productividad y en la conservación de los papeles sociales adultos. Envejecer con éxito tiene que ver con la capacidad para responder con elasticidad a los retos que surgen tanto del cuerpo y la mente como del entorno.

El concepto del "envejecimiento exitoso" adoptado por el Plan de Acción Internacional (2002), según Fuente (2002) ${ }^{95}$, elabora un nuevo discurso sobre la vejez, basado en el concepto de envejecimiento activo que rompe con el tradicional estereotipo sobre la senescencia. Antaño vinculada con la imagen de peso social y económica, o como una carga para la familia y la sociedad, pasa, en esa nueva perspectiva a ser vista exactamente en dirección opuesta: "las personas de edad deben tener la oportunidad de trabajar hasta que quieran y sean capaces de hacerlo, en el desempeño de trabajos satisfactorios y productivos, y seguir teniendo acceso a la educación y a los programas de capacitación"96.

Con los datos que contamos hasta aquí, parece que gozar de buena salud, implicarse en el trabajo y en la vida social podría ayudar a alcanzar un envejecimiento con éxito. Sin embargo, ha de observarse que el número de personas capaces de alcanzar completamente ese patrón es muy pequeño,

\footnotetext{
$94 \quad$ Rowe, J. W. y Kahn, R. L. (1998): Successful Aging, New York: Pantheon Books.

95 Fuente, Isolda B. da (2002): Diretrizes Internacionais para o Envelhecimento e suas conseqüências no Conceito de Velhice, trabajo presentado en el XII Encuentro de Asociación Brasileña de Estudios Poblacionales, realizado en Ouro Preto, Minas Gerais, Brasil.

96 Informe de la II Asamblea Mundial Sobre el Envejecimiento, op., cit., cap. I, artículo12.
} 
principalmente en los países en desarrollo, porque, genética aparte, el estilo de vida y las condiciones socioeconómicas y culturales pueden imponer restricciones para alcanzar tal resultado. En palabras de FernándezBallesteros (1998), "envejecer con éxito no es una cuestión de azar. Las organizaciones de personas mayores, los responsables de las políticas públicas de los mayores, así como las instituciones formativas han de comprometerse en la tarea de lograr un envejecimiento competente"97.

A lo largo de éste capítulo se han presentado las semejanzas y diferencias entre la gerontología y la geriatría. La primera, es un campo multi e interdisciplinar donde la investigación gira, especialmente, sobre el eje formado por la biología, la psicología y las ciencias sociales. La segunda, visa la prevención y los cuidados de las dolencias típicas del envejecimiento. Es una especificidad, sobre todo, de la medicina que se desarrolla a medida que aumenta la población de adultos mayores. En seguida vemos que existen distintos abordajes científicos para presentar el envejecimiento. La perspectiva cronológica, biológica, psicológica y social descrita nos da apenas una idea de su complejidad. Más adelante, percibimos que son muchos los vocablos que clasifican a las personas que alcanzan edades cada vez más avanzadas. Estos no siempre son los más adecuados o mejor aceptados por las personas mayores. Otros conceptos de suma importancia en las sociedades que envejecen son la senescencia, la senilidad, la autonomía y la independencia. Estos términos, que son de máximo interés para la población anciana, necesitan un abordaje teórico y práctico responsable por parte de las políticas sociales y por los servicios sociosanitarios. Por último, como no se tiene una explicación ni simple ni única respecto a la vejez, buscamos en los análisis de Baltes y Baltes, Garfein y Herzog, Birren y Schroots, las definiciones más aceptadas de los estados del envejecimiento. La importancia de distinguir el primario del patológico o terminal puede promocionar y marcar la diferencia en la calidad de vida en la vejez.

97 Fernández-Ballesteros, R. (1998): La vejez con éxito o la vejez competente: un reto para todos, en Ponencias de las IV Jornadas de la AMG; Envejecimiento y Prevención. Barcelona: AMG, p. 7. 


\title{
Introducción a los aspectos demográficos de la vejez
}

\author{
Estamos en medio de una revolución silenciosa. \\ Es una revolución que excede lo demográfico y tiene repercusiones \\ económicas, sociales, culturales, psicológicas y espirituales.
}

Kofi Annan, Ex secretario General de las Naciones Unidas.

\section{El siglo XXI empieza con una especial atención al fenómeno inevitable ${ }^{98}$}

e irreversible" bautizado como "envejecimiento demográfico o poblacional" ${ }^{100}$. Las diferentes regiones del mundo se encuentran en diferentes etapas de ese proceso. La proporción de senescentes en los países desarrollados (21\%) es en estos momentos mucho mayor que la de los países en desarrollo (8\%). En el pasado siglo se produjo la revolución de la longevidad. Europa es la región donde el envejecimiento se ha manifestado más intensamente. De acuerdo con la ONU (2007), alrededor del $37 \%$ de los europeos tendrá más de 60 años en 2050, frente al 21\% verificado actualmente. En los países en desarrollo, la proporción de personas de 60 años o más aumentará de un $8 \%$ en 2005 a cerca de un $20 \%$ en 2050 . Ahora bien, aunque esas poblaciones de más edad se encuentren en los países desarrollados y en países con economías en transición, la mayoría de los senescentes del mundo vive en los países en desarrollo (el 63\% en 2005) y las tendencias actuales prevén que, para el 2050, prácticamente el $80 \%$ de la población mundial mayor de 60 años vivirá en lo que ahora son países en desarrollo. Otro aspecto a destacar del envejecimiento de la población es que, a nivel mundial, el grupo de edad que registra el crecimiento más rápido

\footnotetext{
$98 \quad$ Hayflick y Moorhead, 1961.

$99 \quad$ En la magnífica Historia de la vejez - de la Antigüedad al Renacimiento de Georges Minois, el principal mérito de Hipócrates, fue definir la vejez como un fenómeno puramente natural, físico e irreversible (1987:104) (subrayado nuestro).

$100 \quad$ Pérez Díaz (1998): define el envejecimiento demográfico como un cambio en la estructura de edades o, en otras palabras, en el mayor o menor peso de unas edades respecto a otras en el conjunto de las poblaciones. Generalmente se traduce en un aumento del porcentaje de personas de edad avanzada, aunque resulta más correcto utilizar el aumento del promedio de edad como indicador. Traducido en términos gráficos, significa que la pirámide de población va perdiendo anchura por su base mientras la gana por la cúspide.
} 
es el de mayores de 80 años. Aunque este grupo de edad representa en estos momentos menos del $1,5 \%$ de la población total del mundo, se prevé que se cuadriplique en los próximos cuatro decenios.

Desde una perspectiva general, la vejez es inevitable e irreversible, porque es un proceso natural sin retroceso. "El elixir de la juventud que ha sido la más loca esperanza del hombre occidental"101 de momento no ha sido descubierto. Los cosméticos, los fármacos que prometen milagros y las cirugías plásticas, en el fondo sólo maquillan algunos de los efectos del envejecimiento, pero no erradican los temidos y devastadores efectos de la edad. Para camuflar la edad hombres y mujeres se entregan a los más variados tratamientos estéticos de forma indiscriminada.

En este escenario nos detenemos, según escribió Gil Calvo (2003), en la paradójica ambigüedad que se produce en torno al envejecimiento. Para el sociólogo “la vejez es tanto encarecida como al mismo tiempo escarnecida, en la medida en que por un lado se la protege materialmente - a través de un ingente gasto público en salud, pensiones y servicios sociales - mientras por otra parte se la humilla moralmente - pues se la descalifica con el estigma que la identifica como una carga familiar y social”102. En palabras del ex secretario general de la ONU, Kofi Annan, el envejecimiento es una “revolución silenciosa”, porque va más allá de un aspecto demográfico. En este sentido, aunque el envejecimiento de la población sea inevitable, sus consecuencias dependerán de las medidas que se adopten para hacer frente a todos los retos que plantea. Así pues, en el capítulo III se examina los discutidos aspectos demográficos de la vejez y la conquistada prolongación de la vida que, a nivel mundial, pasó de los 47 años en 1950-1955 a los 65 años en 2000-2005, y está previsto que llegue a los 75 años en 2045-2050. Pondremos especial atención en algunos factores que pueden modificar el perfil de una pirámide de población. Además, introduciremos algunos puntos debatidos en torno al envejecimiento en las organizaciones internacionales de Naciones Unidas, Unión Europea, Latinoamérica y el Caribe.

\footnotetext{
$101 \quad$ Minois, Georges: op. cit., 395.

102 Gil Calvo, Enrique (2003): El Poder Gris - Una nueva forma de entender la vejez, Barcelona: Mondadori, p.70.
} 


\section{El envejecimiento como efecto de la transición demográfica}

Actualmente la población mundial de personas mayores de 60 años aumenta a una velocidad sin precedentes. El proceso se presenta hoy como una tendencia global, a pesar de que su intensidad pueda mostrar enormes diferencias de un lugar a otro y entre los diversos estratos de sus poblaciones. El aumento de la esperanza de vida y la reducción de la fecundidad son los factores clave que impulsan la "Transición Demográfica" (TD). A nivel mundial, en el período comprendido entre 1950-1955 y 2000-2005, la fecundidad total se redujo de 5,0 a 2,6 hijos por mujer y está previsto que continúe descendiendo hasta llegar a 2,0 hijos por mujer en 2045-2050. En varias partes del mundo, y no solo en los países desarrollados, sino también en muchos países en desarrollo, la cifra de fecundidad a lo largo de la vida no llega a los 2 hijos por mujer y, por tanto, está por debajo del nivel necesario para la sustitución de la población a largo plazo.

Debemos reconocer que, por un lado, el envejecimiento de la población está ligado a las transformaciones económicas y sociales ocurridas en Europa a partir de la Revolución Industrial en el siglo XVIII, donde se produjeron cambios importantes en el comportamiento demográfico, caracterizados por descensos de la mortalidad en una primera etapa y posteriormente en la fecundidad (Chackiel, 1999). Para este autor, la transición demográfica se entendería como el cambio de un régimen demográfico de equilibrio, constituido por altos niveles de mortalidad y fecundidad, a una nueva fase de equilibrio con baja mortalidad y fecundidad. Por países, a título individual, el de más edad es Japón con un 26,3 por ciento de la población con 60 años 0 más en el año 2005. Muchos países de Europa, por ejemplo, también presentan porcentajes bastante elevados, en la misma época: Italia (un $25,6 \%$ ), Alemania (un 25,1\%), Suecia (un 23,4\%) y Grecia (un 23,0\%).

Como resume Chackiel (1999), este proceso que en Europa ha llevado entre 150 y 200 años, en los países en desarrollo se da de forma más acelerada. Haciendo un análisis de lo ocurrido en las últimas 50 décadas en algunos países desarrollados del hemisferio norte, nos damos cuenta de que Francia necesitó cerca de 115 años para envejecer, Reino Unido 95 años y Suecia 85 
años, mientras que en países asiáticos, como Tailandia y China, donde la población está envejeciendo a pasos agigantados, en sólo dos décadas se ha conseguido una revolucionaria reducción de la fecundidad.

En países de América Latina y el Caribe, la tasa de personas mayores de 60 años aumenta rápido y este proceso se presenta antes de que se produzca un aumento considerable de la riqueza. Es decir, los primeros tuvieron tiempo de adaptarse al envejecimiento ya que fue gradual, más lento del que está ocurriendo actualmente en América Latina. Según reiteran los demógrafos reunidos en Tours (2005), esta será una de las transformaciones sociales más importantes del siglo XXI. En el año 2000, el 62 por ciento de las personas con 60 años o más vivía en las regiones menos desarrolladas. Para el año 2050, este porcentaje aumentará hasta el 80 por ciento. Por regiones, la mayoría de este grupo de población a escala mundial vive en Asia, siendo las cifras más elevadas las de Asia Oriental y China.

Por otro lado, el aumento substancial del número de personas mayores de 60 años en los países menos desarrollados observado a partir de 1960 es fruto del alto número de nacimientos durante las primeras décadas del siglo $\mathrm{XX}$, asociado a un progresivo descenso en las tasas de mortalidad. Así, la proporción de los de 60 años o más en América Latina y el Caribe aumentará desde el $8 \%$ en el año 2000 al $14.1 \%$ en 2025 y al $22.6 \%$ en 2050 (CELADE, 1999). Para Guzmán (2002), el envejecimiento demográfico está más avanzado en Uruguay, Argentina, Cuba y Chile y en países del Caribe (Trinidad y Tobago y Barbados), donde más del $10 \%$ de la población es mayor de 60 años. En el otro extremo se ubican países que se encuentran menos adelantados en su transición demográfica (Guatemala, Bolivia, Paraguay, Honduras, Haití, entre otros), donde un porcentaje inferior al $6.5 \%$ de la población sobrepasa los 60 años. Sin embargo, hay un grupo de países en situación intermedia - con una transición demográfica bastante avanzada que experimentarán los mayores aumentos de sus mayores de 60 años en las próximas décadas. Entre estos se encuentran Brasil, México, Colombia, Costa Rica y Panamá. Chesnais (1990), por ejemplo, destaca que cuando la fecundidad es muy baja y la reducción de la mortalidad se da con fuerza en 
las edades superiores, el proceso de envejecimiento se hace más notorio y acelerado. En estos casos se puede hablar de poblaciones envejecidas, en las que el porcentaje de personas de 60 años o más es cercano al 20 por ciento. Uruguay es el país más próximo a esta situación, con un 17 por ciento.

Como se puede percibir, la proporción de ancianos creció de forma continua y se prevé que la tendencia prosiga en este siglo. Ante esta situación, Kalache escribió: “El proceso es por tanto, dinámico; para que una población envejezca es necesario, que primero nazcan muchos niños; segundo, que los mismos sobrevivan hasta edades avanzadas y que, simultáneamente, el número de nacimientos disminuya. De esta forma la presencia de jóvenes en la población disminuye, y la proporción de aquellos que sobrevivirán hasta edades más avanzadas pasa a aumentar” (Kalache op cit., 1987:204/5).

En todo el mundo, en 1950 la proporción de personas de edad era del 8\%; en el 2000, del 10\%; y en el horizonte del 2050 se prevé que llegará al $21 \%{ }^{103}$. Según Naciones Unidas (2002), el número de personas de más de 60 años, que era de alrededor de 606 millones en el año 2000, llegará a casi 2.000 millones en el 2050. Así mismo, como ya se ha dicho, esto sucederá cuando por primera vez en la historia de la humanidad el porcentaje correspondiente a los niños se reducirá en un tercio y pasará del 30 al 21\%. La notable transición demográfica que se está produciendo indica que el grupo de personas de edad que crece más rápidamente es el de los más ancianos, es decir, los que tienen 80 años o más. En el año 2000, su número llegaba a los 70 millones, y se estima que en los próximos 50 años esa cifra aumentará más de cinco veces $^{104}$. Otra novedad no muy apreciada por muchos investigadores es que desde la década de los 50, la mayoría de los adultos mayores vive en países del Tercer Mundo, al contrario de lo que habitualmente se piensa al asociar la vejez a los países más desarrollados de Europa o de América del Norte ${ }^{105}$.

\footnotetext{
103 Fuente: World Population Prospects: The 2002 revision.

104 Informe World Population Ageing: 1950-2050 y Informe de la Segunda Asamblea Mundial sobre el Envejecimiento, 8 a 12 de abril de 2002 (publicación de Naciones Unidas, número de venta: S.02.IV.4), cap. I, Anexo II.

$105 \quad$ Kalache, A. et al. O envelhecimento da população mundial - Um desafio novo. Rev. Saúde pública, São Paulo, 21:2000-10, 1987, p. 2000.
} 
Sin duda, estas transformaciones implican una planificación innovadora y unas reformas considerables en las políticas de los países desarrollados y los países en transición, al mismo tiempo que repercuten en sus capacidades para cumplir con los Objetivos de Desarrollo del Milenio ${ }^{106}$, especialmente en aquellos componentes relacionados con la reducción de la pobreza y la desigualdad.

Destacamos que el ritmo de este fenómeno no es el mismo en todo el planeta. A pesar de ser una tendencia global, mantiene rasgos de heterogeneidad entre y dentro de los países. Es decir, el envejecimiento de la población no es un proceso homogéneo a escala internacional ni nacional: ciertos países y sectores sociales todavía están en una etapa incipiente de la transición, mientras que en otros el proceso ha avanzado mucho más. Aún así, todos muestran claros indicios de la tendencia descrita y las diferencias de los cambios demográficos responden a las grandes transformaciones económicas, sociales y culturales que han tenido lugar en las diversas regiones. Como ya se ha dicho, en Europa el envejecimiento fue gradual y requirió muchos años para producirse. En cambio, en los países de América Latina y el Caribe se produjo con más rapidez, históricamente hablando, que en los países desarrollados y se da en un contexto, según un estudio de la CEPAL (2002), de "una alta incidencia de la pobreza, una persistente y aguda inequidad social, una baja cobertura de la seguridad social y una probable tendencia hacia el deterioro de las redes de apoyo familiar"107. Morley (2000), por su parte, destaca la enorme desigualdad de ingresos que caracteriza a la mayoría de los países de la región, que tiene la peor distribución de ingresos del mundo y, más aún, esa situación no ha mejorado ni hay indicios de que vaya a hacerlo a corto plazo.

\footnotetext{
106 En el año 2000, líderes de 189 naciones se movilizaron para reunir varios acuerdos internacionales relativos al desarrollo social en un mismo documento. Del esfuerzo conjunto nació la Declaración del Milenio, un compendio de compromisos producidos por la ONU y adoptado por todos los países signatarios. En conjunto, son ocho las metas que deben ser cumplidas por las naciones, estableciendo como fecha límite el año 2025: 1. Erradicar la pobreza extrema y el hambre, 2. Lograr la enseñanza primaria universal, 3. Promover la igualdad entre los géneros y la autonomía de la mujer, 4. Reducir la mortalidad infantil, 5. Mejorar la salud materna, 6. Combatir el SIDA, el paludismo y otras enfermedades, 7. Garantizar la sustentabilidad del medio ambiente y 8. Fomentar una asociación mundial para el desarrollo.

107 Guzmán, M. J. (2002): Envejecimiento y desarrollo en América Latina y el Caribe, CEPAL/ECLARC, Santiago de Chile: Serie población y desarrollo (28), p. 5.
} 
Otra diferencia significativa del envejecimiento demográfico está en la esperanza de vida de los países. En las naciones desarrolladas las personas viven más que en los países en desarrollo. Mientras en Japón, Suiza y España la mayor expectativa de vida sobrepasa los 80 años, en 27 países de África la expectativa de vida no va más allá de los 50 años. En Botsuana, Lesoto, Suazilandia y Zimbabwe, bajo el fuerte impacto de la devastadora pandemia del SIDA, las personas viven menos de 40 años. ${ }^{108}$ Esas diferencias están asociadas al aumento del nivel de vida de las poblaciones, resultado de la urbanización adecuada de las ciudades, la mejora nutricional, las prácticas de higiene personal, las mejores condiciones sanitarias en general $y$, principalmente, unas condiciones ambientales de trabajo y habitación adecuadas, desarrollados de modo distinto en los países ricos y en los países pobres. El porcentaje más alto de ancianos vive en Asia: 54\%, seguido por Europa con el $24 \%$. En la mayoría de ellos al menos una de cada cinco personas tiene 60 años de edad o más. Se estima que para el año 2050 alrededor de uno de cada tres sean adultos mayores en esos países, mientras que en muchas de las regiones menos desarrolladas los adultos representarán a más de uno de cada cuatro habitantes. Situación desafiante para el Plan de Acción Internacional sobre el Envejecimiento (2002) que tiene por objetivo garantizar, a través de los gobiernos, que todas las personas del planeta puedan envejecer con seguridad y dignidad, fortaleciendo sus derechos como ciudadanos.

Si el encanecimiento se hará sentir más rápido especialmente en los países de economías ricas, se prevé que la población de edad se cuadruplicará en los próximos 50 años. Frente a ese escenario, el mundo industrializado está obligado a brindar apoyo a los países menos favorecidos, que deben afrontar ese proceso antes de haber alcanzado su desarrollo. Además, es indispensable que la política sobre el envejecimiento mundial, sobre todo en los países menos adelantados y con economías en transición, incorpore elementos adecuados y sostenibles, de modo que las personas de edad participen del proceso de desarrollo y compartan también los beneficios que reporte.

108 Fuente: División de Población de la ONU (2007). 
Siendo el ritmo de crecimiento de la población de ancianos mucho más intenso en las sociedades en vías de desarrollo, cabe resaltar que éstas tendrán menos tiempo para adaptarse a las consecuencias del envejecimiento de la población. Para Kalache y colaboradores (1987), el envejecimiento de la población en los países avanzados, difiere de los más pobres, dado que los mecanismos que llevan a tal envejecimiento no son los mismos en todas partes. El envejecimiento de población en los países menos adelantados se registra en condiciones que reflejan un nivel de avance socioeconómico inferior al de los países ricos y con implicaciones drásticamente más desfavorables. Siguiendo con Kalache y colaboradores (1987), el aumento actual de la expectativa de vida consecuencia de la reducción de la mortalidad verificada en la mayoría de los países subdesarrollados, es un fenómeno que se puede considerar "artificial", ya que está ocurriendo en función de la disponibilidad de medios inexistentes hasta el presente. A diferencia de lo que se observó en Europa, los cambios demográficos no se producen como fruto de la conquista social, sino, como consecuencia de un proceso masivo de urbanización, sin alteraciones marcadas en la distribución de la renta y en la estructura del poder social.

Otro dato que marca esa diferencia demográfica es que, en la actualidad, en los países de economías ricas, la inmensa mayoría de personas de edad vive en zonas urbanas, mientras que la mayoría de personas de edad de los países pobres viven en zonas rurales. También existe una diferencia marcada en la expectativa de vida en el momento de nacimiento dependiendo del sexo. Según datos de la ONU, las mujeres viven más que los hombres en la mayoría de los países y en 22 naciones desarrolladas ellas rebasan, de media, los 80 años de edad. Kalache y colaboradores (1987) subrayan que la expectativa de vida de la mujer supera a la de los hombres sobre todo en los países ricos una diferencia de 7,5 años en 1980 y cada vez más a medida que la edad aumenta. En los países menos desarrollados, esa diferencia es inferior a 2,2 años para el conjunto de algunos países. $Y$ en los países de América Latina y el Caribe esta situación ocupa una posición intermedia entre las observadas en los países industrializados y en los demás países del Tercer Mundo. 
Actualmente, la edad media en el mundo es de 26 años. Yemen es el país con la población más joven, con una edad media de 15 años. Mientras que Japón es el que tiene la población más vieja, con una edad media de 41 años. Hacia el año 2050, se prevé que la edad media aumentará en 10 años, es decir a 36 años, y que en ese momento el país con la población más joven será Níger, con una edad media de 20 años, mientras que el país con la población más vieja será España, con una edad media de 55 años (ONU:2005).

Nótese que los cambios demográficos clasificados como uno de los mayores logros de la humanidad, que comenzaron en los siglos XIX y XX, y que continuarán durante el siglo XXI, están transformando el mundo. Lo que en el pasado era exclusividad de una pequeña parcela de población pasó a ser realidad para un número creciente de personas en todos los continentes. Por consiguiente, será necesario hacer frente a nuevos desafíos para ofrecer un marco adaptado a las personas de todas las edades, ya se trate de hombres o de mujeres. En ese sentido, tomo como actual el pensamiento de Casals: ${ }^{109}$ "la ancianidad se ha convertido en los últimos cien años en un problema social importante”. Y, por lo demás, las premoniciones de Paul Wallace, "el envejecimiento global establecerá los parámetros sociales y económicos del futuro próximo"110.

Para ajustarse de manera más adecuada a un mundo que envejece tan rápidamente, delegados de 160 países han jurado recientemente en la Segunda Asamblea sobre Envejecimiento, celebrada en Madrid en 2002, defender la salud y los derechos de la "generación gris", haciendo hincapié en el Plan Internacional de Viena (1982) bajo los principios de las Naciones Unidas, a favor de las personas de edad. En dichos principios se proporciona la orientación en las esferas de la independencia, la participación, los cuidados, la autorrealización y la dignidad ${ }^{111}$ para el siglo XXI y, se promueve el desarrollo de una sociedad para todas las edades, sobre todo en los países pobres, donde el aumento será más rápido. Esa transformación demográfica planteará a todas nuestras sociedades el reto de aumentar las oportunidades

\footnotetext{
$109 \quad$ Casals, Ignasi (1982), op., cit., 1.

$110 \quad$ Wallace, Paul (2000), op., cit., 46.

111 Resolución 46/91 de la Asamblea General- Principios de las Naciones Unidas a favor de las personas de edad, 16 de diciembre de 1991.
} 
de las personas, en particular las oportunidades de las personas de edad para aprovechar al máximo sus capacidades de participación en todos los aspectos de la vida. Para ello de nada servirán los buenos propósitos si los países participantes no se comprometen a generar políticas reales que permitan afrontar el reto del envejecimiento en los próximos años.

\section{La mortalidad: factores biológicos y sociales}

Como se ha subrayado, desde 1950, la expectativa de vida en el mundo ha aumentado en más de 20 años. La expectativa de vida es el número medio de años que se espera que una persona viva en el momento de su nacimiento. Para explicar ese triunfo la reducción de la mortalidad es uno de esos logros. Así pues, existen diversas tesis relativas a las causas que dieron origen al descenso de la mortalidad. Para algunos especialistas, el descenso se debió al avance tecnológico en la agricultura que permitió la mejora en la nutrición y la resistencia a enfermedades infecciosas, independientemente de la intervención médica y de las mejoras en la higiene. Para otros, fue esencialmente, gracias a "los avances científicos y tecnológicos concernientes al control del medio ambiente y a los cuidados de la salud. Hoy se muere menos de dolencias infecciosas, principalmente en la infancia"112. Pero también se argumenta que las malas condiciones de trabajo y el bajo poder adquisitivo afectan de modo particular a la vida de una persona.

A pesar de los factores biológicos de la mortalidad, las variables más clásicas que caracterizan el envejecimiento, se hallan en el campo de la biología molecular y de la ingeniería genética. Las teorías de la pre-programación genética de la vejez subrayan que las células humanas sólo se reproducen hasta cierta edad, después de la cual ya no pueden separarse (Hayflick, 1974). Una parte de esta hipótesis sostiene que algunas células están genéticamente pre-programadas para tener un carácter maligno para el cuerpo después de algún tiempo, con lo cual la biología del organismo se vuelve "autodestructiva" (Pereira-Smith op., cit., 1988).

112 Ramos, L.R., op. cit., 73. Conf. En, Schofield R., D. Reher, A. Bideau (Eds.) (1991), The Decline of Mortality in Europe, Oxford. 
Una aproximación simple, pero práctica, a esta cuestión se apoya en la idea de Aristóteles (384-322). Como hemos visto en el capítulo II, el filósofo presenta la vida del hombre en cuatro etapas: la infancia (la primera), la juventud (la segunda), la edad adulta (la tercera y más larga) y la senectud (la cuarta, el deterioro y la muerte). Investigaciones más recientes, sin embargo, siguiendo el pensamiento aristotélico, Meireles (1999), sostiene que, en general, la vida de un organismo multicelular acostumbra a estar dividida en tres etapas: la etapa del crecimiento y desarrollo, la etapa reproductiva y la senescencia o envejecimiento. Durante la primera fase, argumenta Meireles, tiene lugar el desarrollo y crecimiento de los órganos especializados; el organismo crece y adquiere habilidades funcionales que lo hacen apto para reproducirse. La siguiente fase está caracterizada por la capacidad de reproducción del individuo, que garantiza la supervivencia, continuación y evolución de la propia especie. La tercera y última fase, la senescencia, está caracterizada por la disminución de la capacidad funcional del organismo. Ese declive se vuelve perceptible al final de la fase reproductiva, a pesar de que las pérdidas funcionales del organismo comienzan a producirse mucho antes. Así, concluye el autor, el desarrollo, la reproducción y el envejecimiento son etapas naturales de la vida de cada especie, que ocurren de forma secuencial e interdependiente: el inicio de la senescencia es dependiente de la fase reproductiva que, a su vez, es dependiente del desarrollo. Dicho esto, García (2004) resume que: "el envejecimiento humano es el resultado del paso del tiempo, del desgaste mecánico de los órganos y estructuras corporales y de los procesos programados del propio organismo" (2004:105).

Un segundo planteamiento que conviene resaltar es aquel donde las condiciones individuales y sociales influyen en el estado de salud de los longevos. Por ejemplo, la falta de una nutrición adecuada, y el acceso a servicios de atención sanitaria de calidad son factores determinantes de carácter social que exacerban las vulnerabilidades biológicas. En general, las personas de edad sufren un incremento de los problemas de salud y presentan mayores tasas de mortalidad que el resto de la población en total, sin embargo, no quiere decir que más edad y senectud signifiquen la misma cosa. 
Factores como el estatus socioeconómico, los hábitos alimenticios o poco saludables (tabaquismo y consumo de alcohol), son importantes en esa fase de la vida. Esto hace suponer que la experiencia de envejecer no es un fenómeno que todos experimenten del mismo modo. Dada su complejidad, que afecta a todos los seres vivos, el envejecimiento es un proceso sobre todo individual. Para Bazo (1992), "un error que suele cometerse es considerar a las personas ancianas como grupo homogéneo"113. Factores como la herencia genética, la influencia social de la educación y la ocupación ejercida, las diferencias por cohorte y la personalidad tienen una gran influencia frente al envejecimiento ${ }^{114}$.

Igualmente debe entenderse que dentro de las ciencias de la salud, las diferencias biológicas entre los hombres y las mujeres tienen más influencia que las diferencias sociales como tal $\mathrm{y}$, por ello, la mortalidad tiene características particulares en cada individuo. Sin embargo, en muchas circunstancias las desventajas sociales también son los factores determinantes primordiales de los resultados de la salud desigual entre los sexos.

\section{Algunas causas y consecuencias del envejecimiento demográfico}

En base a lo anterior, en nuestra época, las sociedades van notando cada vez más la metamorfosis en la estructura de edad de sus poblaciones. El aumento espectacular de la población mayor de 60 años es fruto de una cantidad de variables, en las que influyen múltiples indicadores (intrínsecos e extrínsecos) siendo todos ellos necesarios para analizar y comprender el envejecimiento y, en consecuencia, la vejez en su realidad global.

El aumento del peso relativo de las personas por encima de determinada edad, considerada como determinante de la vejez (Carvalho y García: 2002) pasa a ser un campo exploratorio para un gran número de disciplinas, principalmente en las últimas décadas del siglo XX, gracias al pionerismo de Elie Metchnikoff y lgnatz Nascher, que establecieron los fundamentos de la gerontología y de la geriatría en 1903 y 1909, respectivamente.

113 Bazo, María Teresa (1992), op., cit., 78.
$114 \quad$ Lehr, Ursula (1991), op., cit., 43-52. 
Efectivamente, es sintomático el aumento de conocimientos generados en torno al crecimiento del número de personas de edad avanzada. Sin embargo, para Papaléo Netto, todo parece indicar que todavía hay un largo camino por recorrer para dilucidar los puntos obscuros tales como la dinámica y naturaleza del fenómeno del envejecimiento (2002:02). La evidencia de que el hombre, en todas las sociedades a lo largo de la historia, se ha planteado algunas cuestiones en torno al envejecimiento parece todavía no responder en su totalidad a las inquietudes que ello provoca. El campo del envejecimiento tiene múltiples significados. La evolución de los puntos de vista es tan diversa como lo son los efectos que él promueve en los campos demográficos, sociales, económicos y culturales a los cuales llega.

A pesar de que los factores responsables del envejecimiento son discutidos, hay unanimidad, por lo menos desde la perspectiva demográfica, en cuanto a que la dinámica de este fenómeno se debe a dos factores esenciales: "el descenso de la natalidad" y "el descenso de la mortalidad" en todas las edades, que se traduce en mayores esperanzas de vida (Warrem Thompson, 1929). En conjunto, los descensos de natalidad y mortalidad llevan a un menor ingreso de jóvenes en las poblaciones, que pasan a vivir periodos más largos. Este proceso gradual es conocido como "Transición Demográfica".

Por lo general, tras la aceleración de la Revolución Tecnológica e Industrial, en los primeros lustros del siglo pasado, varios factores fueron preponderantes. Entre estos, además de los avances de la medicina tecnológica para el control de la mortalidad, Thomas McKewn ${ }^{115}$ destaca dos en particular: la mejora de la oferta alimenticia y la mejora de las condiciones sanitarias, que consiguió erradicar las enfermedades infecciosas provocadas por las fosas sépticas de aguas fecales. Adicionalmente, la utilización de antibióticos contribuyó significativamente a la disminución de la mortalidad y al aumento del promedio de la esperanza de vida. Por otro lado, también el uso de los métodos anticonceptivos contribuyó a la reducción de la fecundidad ${ }^{116}$. Además, el trabajo de la mujer fuera del hogar no siempre ha

\footnotetext{
115 McKeown, Thomas (1978): El crecimiento moderno de la población, Barcelona: Antoni Bosch, Barcelona.

$116 \quad$ Schofield, Reher y Bideau, 1991.
} 
sido compatible con la maternidad; la ausencia de protección de la familia y de la natalidad, así como la escasez de viviendas de tamaño adecuado y a precios accesibles, principalmente en los países desarrollados, ocupan también un lugar relevante para este escenario demográfico. Como no podía ser menos, los actuales índices de natalidad y mortalidad de casi todos los países industrializados son bajos con respecto a los que se registraban en el pasado $^{117}$.

Este cuadro del envejecimiento demográfico, causado por el aumento del número de personas mayores y la reducción progresiva del número de jóvenes, planteará a todas nuestras sociedades el reto de aumentar las oportunidades de las personas, en particular de aquellas de mayor edad para aprovechar al máximo sus capacidades de participación en todos los aspectos de la vida ${ }^{118}$. Pero no deja de ser menos cierto subrayar que también surge un problema importante en materia de recursos. Para afrontar los desafíos de una población que envejece se necesitará una planificación innovadora y reformas considerables en las políticas de los países desarrollados y los países en transición. Tampoco podemos menospreciar que, en general, las consecuencias del envejecimiento demográfico suelen analizarse desde perspectivas apocalípticas, sobre todo cuando la economía juega un papel importante en los análisis.

Según Gil Calvo (2003), "el peor alarmismo que se deriva del temor al fantasma del envejecimiento es atribuir al conjunto de las personas mayores el estatus de clase pasiva, en tanto que pesada carga familiar y estatal" (2003:97). Así, pues conviene subrayar que el envejecimiento demográfico plantea importantes retos para los gobiernos, las familias y las mismas personas mayores. Existe consenso en que, para garantizar la seguridad económica, es preciso incrementar la cobertura de los sistemas de seguridad social de la fuerza de trabajo actual, frenando las tendencias a su estancamiento o a su franco descenso observado en los últimos años en varios países y ampliando la cobertura de las personas que hoy son adultos mayores,

117 Giddens, Anthony (2002): Sociología, cuarta edición, Madrid: Alianza Editorial, versión castellana de Jesús Cuellar Menezo,

118 Informe de la Segunda Asamblea Mundial sobre el Envejecimiento, 2002, op., cit., Art. 2. 
incluida la opción a pensiones no contributivas o asistenciales. Los sistemas de jubilaciones de los países en desarrollo necesitan evolucionar, como evolucionaron en los países ricos, para garantizar condiciones de vida más favorables que las actuales para los mayores del mañana.

En términos de atención sanitaria, existe el desafío de incrementar la demanda de bienes y servicios sanitarios, residencias geriátricas, centros de día, ayudas a domicilio y tele-asistencia, tan necesarios para los adultos mayores. Aunque la vejez es una etapa natural de la vida y no una patología en sí misma, resulta incuestionable que con el paso del tiempo, los individuos sufren pérdidas sensoriales y presentan con mayor frecuencia padecimientos somáticos y psíquicos crónicos, que requieren tratamientos médicos prolongados (Durán, A. y E. Chávez, 1998). En ese escenario, se advierte que los sistemas de salud serán cada vez más costosos de mantener, por el incremento en el aumento de las dolencias crónicas (principalmente las cardiovasculares, diabetes y cáncer) y las incapacidades propias de la vejez, al mismo tiempo que tendrán que lidiar con dolencias infecciosas. Además, es fundamental incorporar el nuevo paradigma de salud en la vejez, centrado en la necesidad de mantener al máximo la funcionalidad, postergando la discapacidad, dando relevancia a las acciones de prevención y promoción de la salud no sólo en la vejez, sino también en todas las otras etapas del ciclo vital.

El rápido envejecimiento de los países en vías de desarrollo va acompañado de espectaculares cambios en las estructuras y en los roles familiares. En esa esfera y en correspondencia con algunas sociedades tradicionales, se procura que los ancianos se mantengan el mayor tiempo posible en su propia vivienda y en el seno de su núcleo familiar; pero debido al aumento del número de adultos mayores que no tienen hijos, o que viven muy alejados de ellos, va creciendo la cantidad de ancianos institucionalizados. Para la mujer, el envejecimiento da lugar a que frecuentemente viva los últimos años de su vida, en ocasiones durante una década o más, en el estado conyugal de viudedad, debido al conocido fenómeno de la sobre mortalidad masculina. Es 
la mujer la que habitualmente se hace cargo de la atención a los ancianos en el núcleo familiar, lo cual la sobrecarga en el desempeño de sus demás labores domésticas, en especial cuando no existe una adecuada distribución de tareas entre los miembros del grupo familiar (Chávez, E., 1998). Además, padecen más carencias en múltiples aspectos: menos ingresos, más discapacidad, más soledad, menos acceso a la educación y a la cultura.

No cabe duda de que los responsables políticos y las personas que llevan a cabo iniciativas sociales pueden adoptar políticas y programas "favorables a los mayores", a fin de proveer recursos adecuados de apoyo a las familias, de manera que ese soporte sea un suplemento y no el reemplazo de los servicios públicos. De este modo podrán seguir participando la mayor parte de tiempo posible en la sociedad y tendrán unos servicios accesibles, apropiados y ajustados a sus necesidades.

4. El debate en torno al envejecimiento en las organizaciones internacionales: Naciones Unidas, Unión Europea, Latinoamérica y Caribe

Como ya se ha dicho, en las sociedades actuales hay dos hechos que despiertan la atención en torno al tema del envejecimiento. El primero es la prolongación de la vida de los individuos, que como tal, es ineluctable; las personas viven de promedio más años que antes. En segundo lugar hay un importante crecimiento en el número de personas de edades avanzadas, lo que corresponde al envejecimiento de las poblaciones, que generalmente se expresa en un aumento de la proporción de personas mayores en el total de la población. Los indicadores de tal envejecimiento muestran importantes discrepancias entre ellos. En los países desarrollados la inmensa mayoría de las personas de edad vive en zonas urbanas y la mayoría de las personas de edad de los países menos desarrollados vive en zonas rurales. El proceso no sólo varió de intensidad a lo largo de la historia, sino que ha sido significativamente diferente para las poblaciones masculina y femenina, más avanzado para esta última. Asimismo, dicho aumento es más pronunciado en las edades más avanzadas. Es innegable también que casi todas las regiones 
del planeta van experimentando esa victoria, que después de conquistada se ve cercada de posibilidades y desafíos. El envejecimiento ha pasado a ser el centro de debates pluridisciplinarios, como problema, tanto demográfico como “económico y de organización social"119. Las proyecciones del $25^{\circ}$ Congreso Internacional de Población (Tours: 2005), diseñan para las próximas décadas, el rostro de una población mundial de crecimiento bastante lento, cuya esperanza de vida se verá aumentada, y un planeta en el cual las desigualdades entre el Norte y el Sur continuarán siendo bastante pronunciadas. La importante repercusión del envejecimiento poblacional en los campos sociales, económicos, culturales, políticos y éticos especialmente en los países del hemisferio sur (en vías de desarrollo) aumentó los debates internacionales. Esto sucede sobre todo cuando no existen condiciones para su ajuste social y el acceso a los recursos monetarios y no monetarios (ingresos, bienes y servicios) no son suficientes para que los mayores vivan su vejez sanos y activos.

Esta transición demográfica presenta grandes desafíos para la vida de las personas, que va más allá de la simple adición de años, ya que adquieren dimensiones muy complejas y multifacéticas. Este aumento en la longevidad, si bien es aplaudido por la sociedad en su conjunto y por sus miembros individuales, plantea a nuestros responsables políticos algunas cuestiones preocupantes relativas a la calidad de vida y al envejecimiento saludable, a la edad y la integración social, a la situación de las mujeres de más edad y al fomento del apoyo y la seguridad colectiva durante toda la vida. Así pues, la cuestión de las personas de edad resulta de gran interés para las organizaciones internacionales, especialmente debido a sus implicaciones en políticas y planes de acción vinculados al tema. De este modo, las Naciones Unidas llevan estudiando la cuestión de las personas de edad desde 1948, cuando la Asamblea General aprobó la resolución 213 (III) relativa al proyecto de declaración de los derechos de la vejez. Desde entonces el tema fue abordado de forma directa e indirecta por las Asambleas y por los organismos interesados en las cuestiones sociales. En 1949, la resolución 128 (III) de las

119 Loriaux. M. (1995): El envejecimiento de la sociedad europea. El capital humano europeo en el umbral del siglo XXI. Colección seguridad social. Madrid: Ministerio de Trabajo y Seguridad Social, p. 657. 
Naciones Unidas, daba cuenta de aspectos tales como seguridad económica, vivienda, salud, atención en instituciones, empleo, bienestar y entretenimiento. En 1969, a través de la resolución 2599 (XXIV), se da prioridad a temas relacionados con personas de edad, enfatizando la urgencia de establecer criterios para abordar, en términos de políticas y programas, los problemas y las necesidades de las personas senescentes como parte de la planificación económica y social general de cada país, afirmando que no deben, por tanto, tratarse de forma separada. Sin embargo, en 1977 se abordó el problema de forma directa, al hacer énfasis en que era necesario organizar un encuentro mundial sobre las personas de edad y en 1978, a través de la resolución $33 / 53$, se decidió convocar dicha asamblea en 1982, ante la evidencia del envejecimiento progresivo, tanto individual como poblacional.

De esta forma, el Plan de Acción Internacional sobre el Envejecimiento aprobado por la Asamblea General en 1982, tras ser adoptado por la Primera Asamblea Mundial sobre el Envejecimiento, celebrada también en Viena en 1982, fue el primer documento internacional sobre el envejecimiento. Dicho documento guiaría el pensamiento político y científico de un gran número de países que acudieron a la Asamblea para alcanzar el mayor bienestar posible de la población adulta mayor. Los objetivos del Plan eran los de garantizar la seguridad económica y social de los individuos mayores, además de identificar las oportunidades para su integración al proceso de desarrollo de los países. Tuvo como marco de referencia la Conferencia de los Derechos Humanos realizada en Teherán en 1968. Dicho Plan de Acción fomentó la investigación científica, especialmente en los países desarrollados, a través de la creación de centros de investigación gerontológica y una serie de iniciativas que iban desde lo legislativo e institucional hasta lo educativo y cultural. El Plan de Acción Internacional sobre el Envejecimiento comprende 66 recomendaciones estructuradas en siete áreas formuladas para abordar las cuestiones relacionadas con las personas de edad: Salud y nutrición, protección de los consumidores de edad, vivienda y medio ambiente, familia, asistencia social, seguridad de ingresos y empleo y educación. Además, se considera a las 
personas de edad como un grupo de población heterogéneo y activo con aptitudes diversas y necesidades especiales en algunos casos.

De hecho, el Plan de Viena fue un logro notable de amplio alcance, dado que sus recomendaciones se ajustaban fundamentalmente a las necesidades y circunstancias del mundo desarrollado, donde se evidenciaban los signos más visibles de los cambios demográficos en esa época. Sin embargo, las implicaciones del envejecimiento permanecen prácticamente invisibles en la política internacional. Cerca de las dos terceras partes de la población mundial de personas mayores viven en países en desarrollo, pero a diferencia de los Estados de la Cooperación y Desarrollo Económicos (ECDE), los países en desarrollo están envejeciendo antes de alcanzar la prosperidad. Montes de Oca (2003) argumenta que: “en los países menos desarrollados escasamente se puso en acción dicho compromiso internacional, en parte porque en la década de 1980 se experimentaban severas crisis económicas. En ese momento, el tema principal en la discusión sobre la población y desarrollo era el descenso de la fecundidad y sólo algunos académicos habían pronosticado el inicio del envejecimiento demográfico como un efecto de la caída de la mortalidad y posteriormente de la natalidad. Además, existía un gran desconocimiento sobre el envejecimiento regional y la situación de los adultos mayores en contextos específicos de menor desarrollo" ${ }^{120}$. Aunque los debates muestran que los progresos alcanzados desde la celebración de la Primera Asamblea Mundial sobre el Envejecimiento son desiguales y varían de un país a otro en función de la disparidad de los recursos disponibles, de las prioridades y de factores de otras índoles, se alcanzaron progresos en varios campos: desarrollo de la infraestructura nacional relacionada con el envejecimiento, mejora de los servicios de salud y vivienda, mayor seguridad de ingresos para las personas de edad y aumento de su participación en la sociedad. Así mismo cabe destacar que en esa época era notoria la ausencia de un discurso sobre el envejecimiento desde una perspectiva interdisciplinaria que integrara la dimensión demográfica, médica, psicológica, sociológica y antropológica, por recordar sólo algunas en general.

$120 \quad$ Oca, Vera Montes de (2003): El envejecimiento en el debate mundial: reflexión académica y política, Papeles de Población, enero-marzo, número 35 Universidad Autónoma del Estado de México, Toluca, México, pp. 74-104, p. 81. 
A la vista de lo anterior, el Plan de 1982 constituyó una base sólida para establecer y tener en cuenta los avances realizados durante los veinte años transcurridos desde su aprobación. Entretanto, la Secretaría de Naciones Unidas ha identificado, más de una decena de nuevos aspectos/áreas adicionales no abordadas adecuadamente en el Plan de Acción de 1982. Por ejemplo:

Derechos Humanos de las personas de edad

$\checkmark$ Violencia contra las personas de edad (malos tratos, conflictos bélicos, etc.)

$\checkmark$ Envejecimiento y cuestiones de género, incluyendo a las mujeres de edad

$\checkmark$ Globalización

$\checkmark$ Estrategias para dirigir la "gran corriente" del envejecimiento incorporándola a los programas internacionales ya existentes

$\checkmark$ Estrategias para aliviar la pobreza en todas las edades

$\checkmark$ Empleo y lugar de trabajo

$\checkmark$ Problemas de salud pública (Ej. influencia de las enfermedades crónicas no transmisibles en las personas de edad; o impacto del SIDA sobre la estructura de la población)

$\checkmark$ Prestación de cuidados formales/informales

$\checkmark$ Tecnología

$\checkmark$ Envejecimiento activo

$\checkmark$ Migración

$\checkmark$ Desarrollo durante el curso de la vida, incluida la etapa de transición intermedia

$\checkmark$ Investigación sobre el envejecimiento, incluyendo nuevos datos y requisitos estadísticos

$\checkmark$ Las personas de edad como recurso de la sociedad: criterios orientadores, imagen, estereotipos y función de los medios de información

$\checkmark$ Función del sector privado

$\checkmark$ Planificación urbana y rural, incluyendo diseño ambiental y arquitectónico

$\checkmark$ Financiación de iniciativas de autoayuda. Utilización de microcréditos.

Este elenco es resultado, según Montes de Oca (2003) de que la mayoría de los países asistentes no consideraba relevante esta transformación demográfica, ni tampoco aludía a las repercusiones sobre el desarrollo nacional. Ello se 
debe a que en ese momento, no se debatía sobre los efectos económicos y políticos del envejecimiento y se mostraba una escasa reflexión sobre el vínculo entre los procesos macro demográficos y económicos de estos países.

Casi una década después de la adopción del Plan de Acción, la Asamblea General aprobó, en 1991, los Principios de las Naciones Unidas en favor de las Personas de Edad. Los 18 principios confieren un especial reconocimiento a la condición de personas de edad y están agrupados en cinco ámbitos principales: independencia, participación, cuidados, autorrealización y dignidad.

La promoción de la independencia requiere políticas públicas que garanticen la autonomía física y financiera, es decir, el acceso a los derechos básicos de todo ser humano: alimentación, agua, vivienda, vestimenta, salud, trabajo y educación, mediante ingresos, apoyo de sus familias y de la comunidad y su propia autosuficiencia.

En cuanto a la participación, las personas de edad deberán permanecer integradas en la sociedad, participar activamente en la formulación y la aplicación de las políticas que afecten directamente a su bienestar y poder compartir sus conocimientos y habilidades con las generaciones más jóvenes.

Hablar de los cuidados significa que las personas de edad disfruten de todos los derechos humanos y libertades fundamentales a través de la atención familiar e institucional.

La autorrealización corresponde a la posibilidad de que las personas de edad dispongan de oportunidades para desarrollar plenamente su potencial por medio del acceso a los recursos educativos, culturales, espirituales y recreativos de la sociedad.

Por último, la dignidad requiere que se asegure a las personas de edad la posibilidad de vivir con dignidad y seguridad y verse libres de toda forma de explotación y de malos tratos físicos o mentales. 
Resumiendo, los Principios tienen como objetivo lograr que dichas personas puedan lograr su independencia, la participación en su sociedad, los cuidados adecuados a sus necesidades, su autorrealización y el respeto por su dignidad $^{121}$.

En 1992, décimo aniversario de la aprobación del Plan de Acción, la Asamblea General de la ONU celebró una conferencia internacional sobre el envejecimiento en la cual se establecía la orientación general para seguir aplicando el Plan de Acción. Tratando el envejecimiento como un proceso intergeneracional y complementando las críticas recibidas, la ONU propuso en 1999 el Año Internacional para las Personas de Edad (International Year of Older Persons) con el tema central "Una sociedad para todas las edades" (Towards a society for all ages).

Precisamente, en ese mismo año, la Asamblea General solicitó a la Secretaría de las Naciones Unidas que recogiera información de los Estados Miembros y otras partes interesadas para averiguar si era deseable y viable que en 2002 se convocara una Segunda Asamblea Mundial sobre el Envejecimiento. Esta segunda asamblea se dedicó a evaluar el trabajo de la Primera Asamblea Mundial, realizado en las dos últimas décadas y a actualizar el Plan de Acción Internacional, con el fin de que los gobiernos de países en desarrollo, a escala mundial, asumieran compromisos que permitieran iniciar, continuar o fortalecer las iniciativas gubernamentales y no gubernamentales dedicadas a mejorar el bienestar de las personas mayores, y fortalecer sus derechos como ciudadanos. La información recopilada a partir de una amplia muestra representativa indicó que se trataba, en efecto, de una propuesta oportuna.

En ese contexto, dos décadas más tarde, después de la realización de la I Asamblea en 1982, en virtud de la rapidez con que este fenómeno llega a los países en desarrollo y la velocidad de los efectos entre la población en general, la cuestión del envejecimiento se ha situado en el centro del debate público y en forma muy particular dentro de las fronteras del mundo en desarrollo. Refrendado por todos los países miembros de las Naciones Unidas

121 Naciones Unidas. Principios de las Naciones Unidas a favor de las personas de edad (DPI/1261/Rev. 1-98-18897 - Septiembre 1998/7. 
el Plan de Acción Internacional de Madrid sobre el Envejecimiento define tres principios básicos: a) cómo insertar el envejecimiento poblacional en la agenda del desarrollo; b) la importancia singular y global de la salud; y c) cómo desarrollar políticas de medio ambiente (tanto físico como social) que atiendan las necesidades de individuos y sociedades que envejecen.

El primer principio considera que el envejecimiento de la población no es un proceso que, necesariamente, diezme los recursos de la sociedad. Al contrario, ello puede significar una acumulación de capital humano, social y económico. En términos de políticas, se puede pensar en la adecuación de las instituciones para que el crecimiento de la población de mayor edad sea un elemento propulsor de bienestar de la sociedad. En ese caso, son importantes políticas de trabajo, integración social y seguridad. Para cumplir el segundo principio son necesarias políticas que promuevan mejoras en la salud desde la infancia y que se prolonguen a lo largo de la vida. Son necesarios, también, programas de capacitación de profesionales en las áreas de geriatría, gerontología y de servicios sociales. Por último, asegurar un entorno propicio y favorable al envejecimiento implica promover políticas dirigidas a la familia y a la comunidad que aseguren un envejecimiento seguro y promuevan la solidaridad intergeneracional. Por tanto, es necesaria que las políticas sean concebidas con base en la colaboración entre el Estado y la sociedad civil, de forma a construir un mayor acceso al entorno físico, a los servicios y recursos, incluida la protección ambiental. En ese sentido, los mayores pueden contribuir al bienestar de la sociedad y al mismo tiempo beneficiarse de los derechos de ciudadanos, de recibir atención, ser independientes, participar y ser tratados con dignidad (ONU; 2001). El nuevo plan es un documento amplio que contiene 35 objetivos y 239 recomendaciones de adopción de medidas dirigidas a los gobiernos nacionales, pero reforzando la necesidad de pactarlas con miembros de la sociedad civil y el sector privado para su ejecución en el inicio del siglo XXI.

La Organización Mundial de Salud (OMS), como agencia especializada de la ONU, desempeñó un papel particularmente importante en las formulaciones específicas del Plan de Acción. En la Asamblea de Madrid, la entidad lanzó el 
documento Envejecimiento activo: un marco para elaboración de políticas, que complementa y amplia el Plan Internacional. En este documento, la OMS recomienda que las instituciones sanitarias tomen en consideración en el área del envejecimiento los determinantes de salud a lo largo de todo el curso de vida, así como los determinantes sociales, económicos, comportamentales, personales, culturales, además del ambiente físico y el acceso a los servicios, con particular énfasis en las cuestiones de género y las desigualdades sociales.

Paralelamente a la Segunda Asamblea realizada en Madrid en el 2002 se llevaron a cabo mesas redondas, talleres, jornadas y presentaciones con el fin de crear un espacio interactivo de debate entre gobiernos y sociedad civil. En dichas actividades, se podían encontrar tanto discusiones de expertos en el envejecimiento como análisis sobre el compromiso de la Iglesia, la iniciativa privada y las organizaciones no gubernamentales de la sociedad civil respecto a la población mayor. Además, la Segunda Asamblea se complementó con dos reuniones científicas: el Foro de Valencia (1-4 de abril) y el Foro Mundial de las ONG (5-9 de abril). Los temas y las discusiones, como describe Montes de Oca (2003), "buscaron orientar el pensamiento de los especialistas a nivel mundial, tomaron como punto de discusión el envejecimiento y la pobreza, el envejecimiento y las políticas de salud, la influencia de la vida productiva en el mismo, el papel del sector público y privado, las perspectivas gerontológicas y geriátricas, los derechos de los adultos mayores, la discriminación de género, el envejecimiento rural, las relaciones intergeneracionales, la vivienda, la familia, la comunidad y las redes sociales, entre otros" (2003:85). Partiendo de estos pensamientos, el envejecimiento traspasa la esfera del primer mundo y en algunos países en vías de desarrollo se comienza a sistematizar la discusión tomando en cuenta el contexto demográfico, la situación económica y las condiciones específicas, políticas y sociales de cada región. De esta manera, se convierte en un asunto de gran importancia en el siglo XXI.

Dentro de los actos paralelos a la celebración de la Asamblea de Madrid, en el Foro "Diálogos 2020", el futuro del envejecimiento, en los análisis de Mary Ann Tsao, de la ONG HelpAge International, marcó el centro de los debates. 
Con una postura ideológica diferente, Tsao subrayó que los que viven más viven más pobres en los países en desarrollo y señaló que es imposible erradicar la pobreza en el mundo sin la erradicación de la pobreza de los mayores. Y por ahora las medidas tomadas no responden a la gravedad del problema. Sin duda, la pobreza material tiene impactos profundos y de largo alcance sobre las personas mayores. La capacidad de las personas para satisfacer sus necesidades básicas se ve cada vez más comprometida por la edad. Muchas personas mayores carecen de los recursos más fundamentales comida, agua y techo - y son inmensamente pobres según las diferentes definiciones de pobreza ${ }^{122}$. Además, en gran parte de los países en desarrollo se cuenta con políticas sociales insuficientes, se carece de sistemas de seguridad social o los existentes tienen una cobertura mínima para la población con 60 años o más. Por esa razón el envejecimiento seguro y la lucha contra la pobreza entre los adultos mayores se convierten en una preocupación central.

Vale la pena destacar, que la Asamblea General de las Naciones Unidas, en su resolución 47/5 del 16 de octubre de 1992, al designar el año de 1999 como el Año Internacional de las Personas de Edad destacó definitivamente que el envejecimiento ya no era sólo un problema del primer mundo. Con este concepto se abarcaban cuatro dimensiones importantes: Primero, promover el desarrollo individual durante toda la vida, especialmente en una fase temprana del curso de la vida (infancia y adolescencia). Eso significa que las influencias e interacciones que experimentan las personas a lo largo de su vida pueden afectar positiva o negativamente a sus capacidades en años posteriores. Las políticas y programas ajustados a la edad que promueven el aprendizaje de por vida, las formas de vida saludable y la flexibilidad en el lugar de trabajo durante las etapas de transición, como por ejemplo, de la juventud a la mediana edad, y de la mediana edad a los años posteriores, pueden influenciar las elecciones con efectos acumulativos. Segundo, impulsar las relaciones multigeneracionales, o sea las personas de edad tienen a su favor la experiencia y el conocimiento de la historia de su

122 Ver Informe Estado mundial de las personas mayores 2002 - HelpAge International Acción global sobre envejecimiento, Londres, N1 9ZN, Reino Unido, p. 4. 
generación, mientras que los jóvenes miran hacia el futuro, tarea no menos importante para poder distinguir los objetivos que marcarán su propia existencia. Las diversas habilidades y expectativas de todas las edades pueden aunarse, encontrando vías mutuamente beneficiosas que pueden ser abordadas desde múltiples direcciones, incluyendo la educación permanente, la planificación comunitaria para personas de todas las edades, el desarrollo social y económico, así como los esfuerzos socialmente activos para terminar con la pobreza, la exclusión, las violaciones de derechos humanos y la guerra. Tercero, relacionar el envejecimiento de la población con las iniciativas al desarrollo, lo que constituye una compleja interacción de los patrones generales del mercado laboral y financiero, pensiones del Estado, servicios, sistemas de apoyo tradicionales y transferencias intergeneracionales, determinados por factores adicionales como el cambio tecnológico y las transformaciones culturales.

Por último, en cuarto lugar, continuar el estudio y las propuestas para mejorar la situación de las personas de edad. En esta última área se examina la vida cotidiana de las personas de edad y cómo se las arreglan y salen adelante en relación con la seguridad de ingresos, la asistencia sanitaria multisectorial, la vivienda, la prestación de servicios sociales, y su participación, integración y potencial de desarrollo dentro de la sociedad.

Precisamente, "la propuesta del Año Internacional de las Personas de Edad superó una visión transversal del tema y llevó a pensar en el envejecimiento en términos longitudinales de cohorte y generación"123. El concepto ha ido adquiriendo mayor aceptación y apoyo en todo el mundo y fue adoptado por la Asamblea General como contexto para la revisión del Plan Internacional y la elaboración de una estrategia a largo plazo sobre el envejecimiento.

Después de la Segunda Asamblea Mundial sobre el Envejecimiento, en 2002, se celebraron reuniones, seminarios y congresos en las diversas regiones del mundo. Por un lado, precisamente en Europa y Norteamérica se llevaron a cabo algunas reuniones sobre el envejecimiento, entre las cuales podemos

$123 \quad$ Oca, Vera Montes de (2003), op.cit., 82-83. 
destacar el congreso PPA Meeting, la $4^{\text {a }}$ Conferencia Internacional sobre la Investigación en Seguridad Social (ISSA). Por otro lado, en América Latina el Centro Latinoamericano y Caribeño de Demografía (CELADE) está desarrollando un conjunto de actividades que buscan ayudar a los países en el diseño, ejecución y puesta en práctica del Plan de Acción Internacional de Madrid sobre el Envejecimiento. En materia específica de debates, las reuniones de expertos sobre redes de apoyo social en Santiago de Chile en 2002 y salud, envejecimiento y seguridad económica en Ciudad de Panamá en 2003, respectivamente fueron fundamentales para ampliar las discusiones. Otros marcos significativos en favor de los adultos mayores en la región fueron: 1) la Conferencia Regional Intergubernamental sobre el Envejecimiento (Santiago de Chile 2003), que se planteó metas, objetivos y recomendaciones para la acción, dirigidas a las personas mayores de 60 años en cada una de las tres áreas prioritarias (política, económica y social) acordadas en Madrid; 2) la Reunión de Gobiernos y Expertos sobre el Envejecimiento de los países de América del Sur (Argentina 2005), que examinó los avances logrados en estos países en las principales áreas establecidas en la II Asamblea Mundial sobre Envejecimiento; 3) la Reunión del Comité Especial sobre Población y Desarrollo del Período de Sesiones de la CEPAL (Uruguay 2006), que se encargó de evaluar el Plan de Acción de Madrid en la Región. En Brasil, la realización de las conferencias sobre el Pacto de Gestión Para un Envejecimiento Digno y Saludable lanzado en 2008 por la Presidencia de la República, pretende discutir y construir colectivamente propuestas de políticas públicas para las personas de edad.

Como puede observarse, las estrategias prácticas para alcanzar los objetivos mundiales sobre el envejecimiento de las poblaciones están siendo discutidas por organismos y órganos competentes de las Naciones Unidas, en particular, entre gobiernos, organismos especializados, organizaciones no gubernamentales y el sector privado. Aunque se progresa en esta cuestión, también se puede pensar que aún queda mucho por hacer. Las directrices básicas para las políticas públicas dirigidas al bienestar de la población mayor de 60 años trazados en el Nuevo Plan de Acción Mundial, son de carácter altamente genérico. Esto significa que cualquier tentativa de implementación 
del referido Plan en la esfera nacional pasa, necesariamente, por un proceso de adaptación a la realidad y necesidades locales. De este modo, los debates no sólo amplían los conocimientos acerca del fenómeno, sino que también contribuyen con valiosos subsidios para la tan necesaria implementación del Plan de Madrid en cada una de las regiones. 


\title{
Cuestiones básicas del envejecimiento demográfico en Brasil en la perspectiva mundial y de América Latina
}

\author{
Considerado en su totalidad, el problema \\ del envejecimiento no es un problema en absoluto. \\ Es sólo la manera pesimista de \\ considerar un gran triunfo de la civilización... \\ Frank Notestein, (1945) \\ Demógrafo inglés.
}

LoS nacimientos y las defunciones son los principales agentes discutidos en la dinámica de una población y delimitan su campo de acción. Como ya se ha explicado en el capítulo anterior, el panorama demográfico mundial está cambiando y con todo fundamento afirman que lo hará aún más aceleradamente en los próximos años en los países en desarrollo. Desde el punto de vista socio-demográfico, el siglo XXI estará marcado por el envejecimiento a gran escala, dado que la proporción y el número absoluto de individuos de edad igual o superior a los 60 años se incrementarán sensiblemente en este siglo. Tal fenómeno es al mismo tiempo signo y resultado del desarrollo socioeconómico tanto en sentido cuantitativo como cualitativo experimentado inicialmente en los países desarrollados y que se extiende actualmente a casi todos los países, aunque existan enormes diferencias entre ellos y entre los diversos estratos de sus poblaciones.

Como ya ha quedado claro, en los países industrializados, la Transición Demográfica fue paulatina, gradual y perceptible desde el inicio del siglo XX. La transición de una etapa de mortalidad y fecundidad altas a otra de valores más bajos tiene precedentes históricos en lo sucedido en Europa a partir de la Revolución Industrial, sumada a los avances de la investigación médica y al control de las enfermedades, así como a la seguridad de los medios de planificación familiar. De modo más rápido el fenómeno ha sido notable en la segunda mitad del siglo XX en muchos países en desarrollo, entre los cuales están los de América Latina. El descenso de la mortalidad que empezó la 
Transición Demográfica en estos países fue determinado más por la iniciativa médico-sanitaria del Estado que por transformaciones estructurales que pudieran traducirse en una mejora de la calidad de vida de la población. En otras palabras, la ampliación de la cobertura de los sistemas de protección social y la mejora de las condiciones de habitación, alimentación, trabajo y saneamiento básico no fueron realizadas en los países de América Latina como sucedió en los países industrializados ${ }^{124}$. En las primeras décadas del siglo XX, en los países latinoamericanos, tal transición se dio a través de políticas urbanas de salud pública como vacunación, higiene y otras campañas sanitarias y a partir de la década de los años cuarenta por la ampliación y desarrollo tecnológico de la atención médica en la red pública ${ }^{125}$.

Ante este panorama, ya se ha subrayado, el envejecimiento de las poblaciones, que generalmente se expresa en un aumento en la proporción de personas mayores, es un hecho universal, natural, inevitable e irreversible, pero maleable, y su comportamiento presenta diferencias muy importantes entre países, regiones, clases sociales y grupos culturales. Esto pone en evidencia la importancia del análisis no sólo de su patrón general, sino también del comportamiento de grupos particulares y las principales causas de defunción.

En el presente capítulo se examinan las principales cuestiones del envejecimiento demográfico en Brasil en la perspectiva mundial y de América Latina. Para ello trataremos en primer lugar, de la participación relativa del anciano en la población brasileña, la expectativa de vida, la población senescente y la feminización de la vejez. En segundo lugar, expondremos los indicadores económicos como el sistema de pensiones y la posición económica de las personas con 60 ó más años. En tercer lugar, contextualizaremos el estado de salud de la población anciana brasileña y finalmente explicaremos las normativas y las políticas públicas desarrolladas para este segmento de la población.

\footnotetext{
$124 \quad$ Kalache, A.; Veras, R. P.; Ramos, L. R. (1987): O envelhecimento da população mundial: um desafio novo. Rev. Saúde Pública, 21:200-10.

Oliveira, L. A. P. \& Felix, C. (1995): A dinâmica demográfica recente: níveis, tendências e diferenciais. Em Fundação IBGE. Indicadores sociais: uma análise da década de 1980. Rio de Janeiro, pp. 25-41.
} 


\section{La participación del anciano en la población brasileña}

\subsection{Mortalidad y fecundidad}

Podemos observar, casi en el mundo entero, que en las últimas generaciones el proceso de "Transición Demográfica", caracterizado por la disminución significativa de los coeficientes de mortalidad y de las tasas de fecundidad y natalidad, está ocasionando el aumento de la proporción de individuos mayores de 60 años. Por un lado, en sí mismo, ese proceso no es negativo, dado que indica una mejora de la calidad de vida, progresos en el control de la mortalidad perinatal e infantil, mejora de la alimentación, de la atención sanitaria básica, del control de muchas enfermedades infecciosas, de la asistencia a los recién nacidos y bebés y del aumento de la longevidad. Por otro lado, aún en muchas situaciones las personas mayores siguen siendo un grupo olvidado, más que nada invisible para aquellos que promueven el desarrollo económico, la atención sanitaria y la educación ${ }^{126}$. Aunque las altas tasas de nacimiento que experimentaron muchos países están disminuyendo, las personas jóvenes siguen siendo el tema central de la atención de los planificadores.

Síntoma de la vida urbana desde 1950, las tasas de fecundidad ${ }^{127}$ disminuyeron en casi todos los continentes. La media en el mundo en 2005, era de 2,6 hijos por mujer ${ }^{128}$. En términos generales la tasa de fecundidad es inferior al umbral de sustitución mundial, que es de 2,1, en los países de América del Norte: Canadá $(1,48)$; en América Central y la mayoría de las islas del Caribe: Cuba $(1,62)$, Barbados $(1,50)$; en Asia: Tailandia $(1,89)$, China $(1,72)$, Japón $(1,35)$ y Corea del Sur $(1,19)$; en Oceanía: Australia $(1,75)$, Nueva Zelanda $(1,96)$ y en casi la totalidad de los países de Europa como Alemania $(1,33)$, Bélgica $(1,66)$, España $(1,33)$, Grecia $(1,25)$ y Portugal $(1,47)$. Sin embargo las cinco menores tasas de fecundidad en el mundo en

\footnotetext{
126 El informe sobre el Envejecimiento y el Desarrollo: Un resumen. Pobreza, Independencia y las Personas Mayores en el Mundo. HelpAge International. Acción global sobre envejecimiento, 2002.

127 Estimación anual de los hijos nacidos vivos que cada mujer tendría durante el período reproductivo (Del 15 a 49 años). Sólo entran en esa cuenta los bebés nacidos vivos. El indicador refleja las tendencias de crecimiento o de la caída de la población del país.

$128 \quad$ Para que una población permanezca estable es preciso que las mujeres tengan de media 2,1 hijos, pues dos niños de la pareja sustituyen a los padres, y la fracción 0,1 compensa los niños que mueren antes de llegar a la edad reproductiva. 2,1 es por lo tanto considerada la tasa de reposición poblacional.
} 
2005 según el Fondo de Población de las Naciones Unidas (FNUAP) son: Ucrania $(1,13)$, Taiwán $(1,18)$, República Checa $(1,19)$, San Marino $(1,20)$ y Eslovenia $(1,21)$.

Aunque el crecimiento demográfico ${ }^{129}$ de los países ricos sea lento, un $0,27 \%$ al año y el de las naciones en desarrollo sea cinco veces más rápido, un 1,38\%, las disparidades se deben sobre todo a las tasas de fecundidad. Los países desarrollados mantienen esas tasas por debajo del nivel de reposición desde hace más de 30 años. La tasa en Italia es de 1,35; en España de 1,33; en la República Checa de 1,19 y en algunos de los países del este Europeo, como Georgia alcanza el 1,41. Así, en 19 naciones europeas la población está disminuyendo. ${ }^{130}$ Para revertir ese cuadro, por ejemplo, en 2005 Francia cuya tasa de natalidad es de 1,86, pasó a ofrecer 750 euros al mes durante un año, a las familias que tuvieran un tercer hijo. Otros países pagan para que las parejas tengan hijos. El gobierno de Italia paga 1.500 dólares por hijo, Japón 3.000, España 3.500, Australia 4.000 y Rusia 9.000, respectivamente. En Alemania el gobierno paga un auxilio-maternidad de dos tercios del salario por año y en Suecia el valor pagado es de 150 dólares hasta que el niño cumple 16 años (ONU/Instituto de Política Familiar).

Desde la década de los setenta, gran parte de esas naciones han ido reduciendo la tasa de fecundidad. La ONU estima que disminuya a menos de 2,1 niños por mujer a mediados del presente siglo. Se sabe que se sitúa en este punto el nivel mínimo indispensable para la renovación de las generaciones en los países que cuentan con las mejores condiciones sanitarias. Sin embargo, algunos de los países más pobres, concentrados principalmente en África, aún viven con altos índices de natalidad y mortalidad.

Según el brasileño Alexandre Kalache (1987), coordinador del Programa de Envejecimiento y Curso de Vida de la OMS, en Ginebra (Suiza) desde 1994, América Latina es el continente donde más rápido envejecen las personas. El

\footnotetext{
129 Aumento medio anual del número de individuos de un país, expresado en porcentaje. Resulta de la diferencia entre nacimientos y las muertes (crecimiento vegetativo) más la diferencia entre inmigrantes y emigrantes (crecimiento migratorio).

${ }_{130}$ Fuente: Divisão da população da ONU y El Instituto Demográfico de Estúdios Demográficos (INED).
} 
autor destaca que desde la década de los cincuenta, la mayoría de las personas mayores de 60 años vive en países del Tercer Mundo, hecho aún no apreciado por muchos que continúan asociando la vejez a los países más desarrollados de Europa o de América del Norte. Según el documento Panorama Social de América Latina (CEPAL: 2005), estos países han experimentado profundas transformaciones demográficas, cuyas expresiones distintivas son la disminución del crecimiento de la población (del 2,7\% anual en el período 1950-1955 al $1,5 \%$ en la actualidad) y el creciente envejecimiento de las estructuras de edades. Detrás de esa evolución, sobresale la acelerada caída de la fecundidad, especialmente desde mediados de la década de los sesenta, que fue precedida por la reducción sostenida de la mortalidad desde finales de la primera mitad del siglo XX. La esperanza de vida al nacer hoy, en promedio para ambos sexos, es de 72 años, en el quinquenio 2000-2005. Esto significa que es 8 años más alta que la del conjunto de las regiones en desarrollo y la segunda más alta entre las grandes regiones del mundo. En este sentido, ya se han observado los aumentos en la expectativa de vida masculina y femenina en países como Argentina $(71,3 / 78,8)$, Brasil $(67,7 / 75,3)$, Chile $(75,4 / 81,4)$, Colombia $(70,1 / 76,0)$, Ecuador $(71,9 / 77,9)$, Uruguay $(72,3 / 79,6)$ y Venezuela $(70,6 / 76,5)$. Las más drásticas reducciones en la tasa de natalidad las encontramos sobre todo en Argentina y Brasil, donde el índice de fecundidad (hijos por mujer) es de 2,27 y en Chile de $1,95^{131}$. Se considera el quinquenio 1960-1965, período en que la mayoría de los países inicia su fase transicional, y el período 2000-2005, en el cual se puede apreciar un significativo cambio ocurrido en la natalidad. Para la CEPAL, los factores determinantes en esta caída del número de nacimientos por cohorte de mujeres en edad fértil, se produce, sobre todo, por el incremento de la escolaridad de las mujeres, la mayor participación económica femenina y el deseo de tener menos hijos como medio de conseguir mejores condiciones de vida, especialmente, para las que viven en las ciudades. En la zona rural, en las regiones donde aún domina la economía de subsistencia, un gran número de hijos puede significar más mano de obra y mayor capacidad de producción. En las ciudades, en cambio, la renta dividida

$131 \quad$ Almanaque Abril, 2007, pp. 374-377. 
entre un número más pequeño de personas aumenta la posibilidad de que haya recursos para invertir en educación, salud y ocio, por ejemplo.

Aunque incipiente, si se compara el envejecimiento de la población de América Latina con el de los países desarrollados, la Comisión Económica para América Latina y el Caribe reconoce la trascendencia de este fenómeno para el desarrollo económico equitativo y la formulación y ejecución de políticas sociales en la región ${ }^{132}$. Por ende, desde hace un tiempo, ha estado desarrollando una serie de actividades de seguimiento de los acuerdos emanados del Plan de Acción Internacional sobre el Envejecimiento aprobado en la Segunda Asamblea Mundial sobre el Envejecimiento celebrada en Madrid en 2002.

Dicho esto, lo que realmente nos interesa aquí y ahora es contextualizar a Brasil en ese proceso de envejecimiento. Para ello, desde el siglo XIX hasta mediados de la década de los cuarenta el país tropical se caracterizó por el predominio de elevadas tasas de natalidad y mortalidad. La gran mayoría de las personas no llegaba a la vejez, dado que moría antes de los 50 años a causa principalmente de dolencias infecciosas y parasitarias (Almanaque Abril: 2003). A partir de ese período, con la incorporación de políticas de salud pública y el avance de la medicina, particularmente de los antibióticos recién descubiertos en la época e importados en la posguerra, el país experimentó una primera fase en su transición demográfica, caracterizada por el inicio de la caída de las tasas de mortalidad. Sin embargo, se observó también la permanencia de altas tasas de natalidad, ocasionando elevados índices de crecimiento poblacional: el $2,39 \%$, en los años cuarenta y el 3,04\% en la década de los cincuenta. Las tasas de natalidad, a su vez, sólo inician su trayectoria de descenso a mediados de la década de los sesenta, período en el que se inicia la paulatina difusión de métodos contraceptivos orales en Brasil. Flávio Chaimowicz ${ }^{133}$, señala las diferencias regionales que existen sobre esta cuestión. Para el autor la reducción de la fecundidad que se observa en Brasil en esta época, está lejos de representar la conquista de derechos sociales,

\footnotetext{
132 Comisión Económica para América Latina y el Caribe (CEPAL). Panorama Social de América Latina, serie LCG2259-P, Santiago de Chile, 2005.

133 Chaimowicz, Flavio (1997): A saúde dos idosos brasileiros às vésperas do século XXI: problemas, projeções e alternativas, São Paulo: Revista de Saúde Pública, v. 31, nº 2.
} 
como por ejemplo, el acceso al sistema de salud para la adecuada planificación familiar. Se caracteriza, principalmente en las regiones más pobres, por la falta de información de las mujeres y la dificultad para obtener métodos contraceptivos reversibles. Chaimowicz recuerda que en 1986, entre las mujeres de 15 a 54 años usuarias de métodos contraceptivos, el 81,9\% de las residentes de Río Grande del Sur utilizaba métodos no definitivos (65,5\% contraceptivos orales), mientras que en los Estados del Maranhão y Goiás, respectivamente, el 75,9 y el 71,9\% de las mujeres ya se había sometido a la salpingoclasias (ligadura de trompas). En el Nordeste, la proporción de esterilizadas entre las mujeres casadas en edad reproductiva se elevó un 50\% en cinco años (del $24,6 \%$ en 1986 al $37,6 \%$ en 1991). La irreversibilidad del proceso de envejecimiento poblacional en Brasil se refuerza por esta tendencia; en 1986, el 16\% del total de las brasileñas entre 25 y 29 años y más de un cuarto de aquellas entre 30 y 34 años de edad habían sido esterilizadas. Además, la reducción del número de hijos se impone como respuesta de las familias brasileñas al proceso de urbanización de la sociedad - en 1995, el $79,0 \%$ de la población residía en áreas urbanas - y a la crisis económica, factores que, en conjunto, agravan las condiciones de vida de las familias numerosas (Oliveira op. cit., 1995).

Como consecuencia, en el decenio 1960-1970 se observa una discreta disminución de las tasas de crecimiento poblacional $(2,89 \%)$, fenómeno que se confirma a lo largo de los diez años siguientes, cuando se constata una tasa de crecimiento del $2,48 \%$. En la década de los setenta, tanto la mortalidad como la fecundidad se encontraban en franco proceso de descenso de sus niveles generales. Pero, en los años ochenta, la aceleración del ritmo de disminución de la tasa de natalidad, debido a la propagación de la esterilización femenina en el país, contribuyó a la continuidad de la caída de las tasas de crecimiento (un $1,93 \%$ entre 1980 y 1991 y un $1,64 \%$ entre 1991 y 2000) ${ }^{134}$.

Dicho con otras palabras, después de que la población brasileña se multiplicara casi por diez entre $1900(17.438 .434)$ y $2000(169.799 .170)$, el

134 Oliveira, Juarez de C., Albuquerque, Fernando R. P. de C. y Lins, Ivan Braga (2004): Projeção da população do Brasil por sexo e idade para o período 1980-2050 - Revisão 2004 Metodologia e Resultados Estimativos anuais e mensais da população do Brasil e das Unidades da Federação: 1980 2020, IBGE, p. 53. 
Capitulo 4. Cuestiones básicas del envejecimiento demográfico en Brasil en la

crecimiento demográfico se ha ido desacelerando desde el inicio de la década de los sesenta. Actualmente, el índice de crecimiento es de un 1,33\% al año (2007). Caerá al 0,24\% en 2050 y, finalmente, llegará a cero en 2062, cuando la población brasileña comenzará a disminuir. Eso ocurre porque la tasa de fecundidad está cayendo año tras año. En los años sesenta ese índice era de 6,3 hijos por mujer y hoy día es de 2,25 hijos por mujer - tasa próxima a la de los países desarrollados (IBGE: 2007). La proyección para 2023 es de 2,01. Según el Fondo de Población de las Naciones Unidas (FNUAP) en 2005 Brasil ocupaba el $101^{\circ}$ puesto en tasa de fecundidad entre 192 países.

Las Pesquisas Nacionales por Muestra en Domicilios de la década de los setenta pasaron a revelar que el fenómeno se extendía paulatinamente a las demás regiones del país, tanto a las áreas urbanas como rurales, y a todas las clases sociales ${ }^{135}$. La tasa de fecundidad total cayó de 5,8 a 2,3 hijos por mujer entre 1970 y 1990, reducción ésta superior al 50\% ${ }^{136}$ (Ver gráfico abajo).

135 Carvalho, J. A. M. (1993): Crescimento populacional e estrutura demográfica no Brasil. Belo Horizonte, CEDEPLAR/UFMG. Presentado en el Seminario "Crescimento Populacional e Estrutura Demográfica", Rio de Janeiro.

136 Oliveira, L. A P. \& Felix, C. (1995): Novas tendências demográficas: breves notas a partir dos resultados do censo demográfico de 1991. Em Fundação IBGE. Indicadores sociais: uma análise da década de 1980. Rio de Janeiro, pp. 45-60. 


\section{GRÁFICO 1}

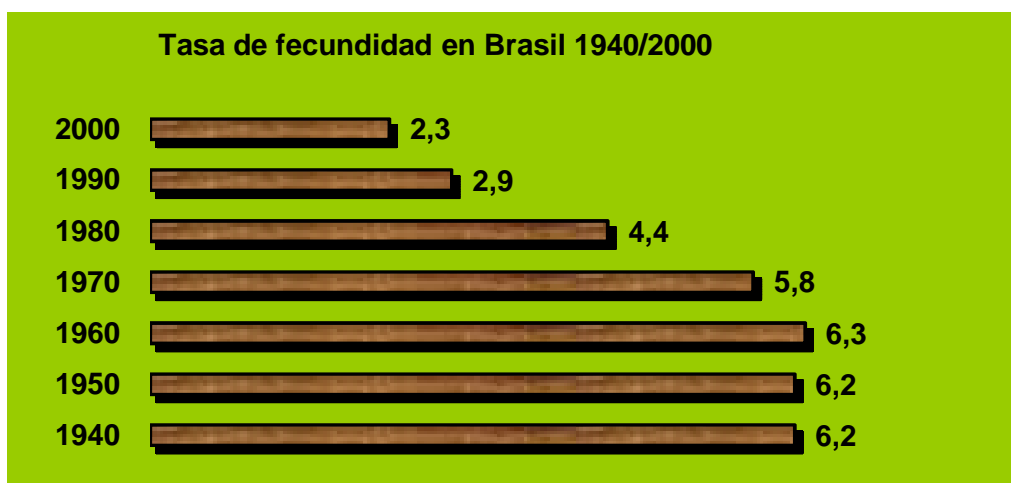

FUENTE: Censo demográfico 2000, fecundidad y mortalidad infantil Resultados preliminares de la muestra, 2002.

Como consecuencia, el peso relativo de los jóvenes cayó del $41,9 \%$ al $34,7 \%$ en el mismo período y la proporción de adultos mayores creció del 3,1\% al 4,8\%. Berquó y Cavenaghi ${ }^{137}$, señalan que la reducción de los niveles de fecundidad, entre 1991 y 2000, no fue uniforme en los distintos segmentos sociodemográficos de la población. Fueron apuntadas diferencias importantes, revelando una caída más acentuada en aquellos grupos donde la fecundidad era más elevada en 1991, es decir, entre las mujeres más pobres, menos escolarizadas, negras, domiciliadas en las áreas rurales, y en las regiones Norte y Nordeste. En ese sentido, la reducción del número medio de hijos es acentuada entre las mujeres de las clases media y alta de los centros urbanos del Sur y Sudeste, es gradual en las demás clases sociales y regiones del país. En la franja de edad de 30 a 44 años, el 70\% de las brasileñas usan algún método para tener hijos. Los más utilizados son la esterilización quirúrgica y la píldora anticonceptiva. En Brasil también se recurre a la práctica del aborto, aunque sea ilegal en la gran mayoría de los casos - es practicado clandestinamente por médicos, legos e incluso por las propias mujeres, con eventuales daños graves para su salud. Actualmente (2008), entre las regiones brasileñas, el Norte tiene el mayor índice de fecundidad (2,3 hijos por mujer) y el Sur, el menor (1,7 hijos por mujer).

En el mundo, al final del siglo XX, la tasa de fecundidad era de 2,9 hijos por mujer. Hoy día es de 2,6 hijos por mujer. En los países más desarrollados esta

137 Berquó, E. y Cavenaghi, S. (2004): Fecundidade em declínio: Breve nota sobre a redução de filhos por mulher no Brasil, PNAD, p.11. 
tasa era de 1,5 y en los países menos desarrollados, de alrededor de 3,2. Compare la fecundidad en Brasil con la fecundidad en otros países de América del Sur en el gráfico de abajo.

\section{GRÁFICO 2}

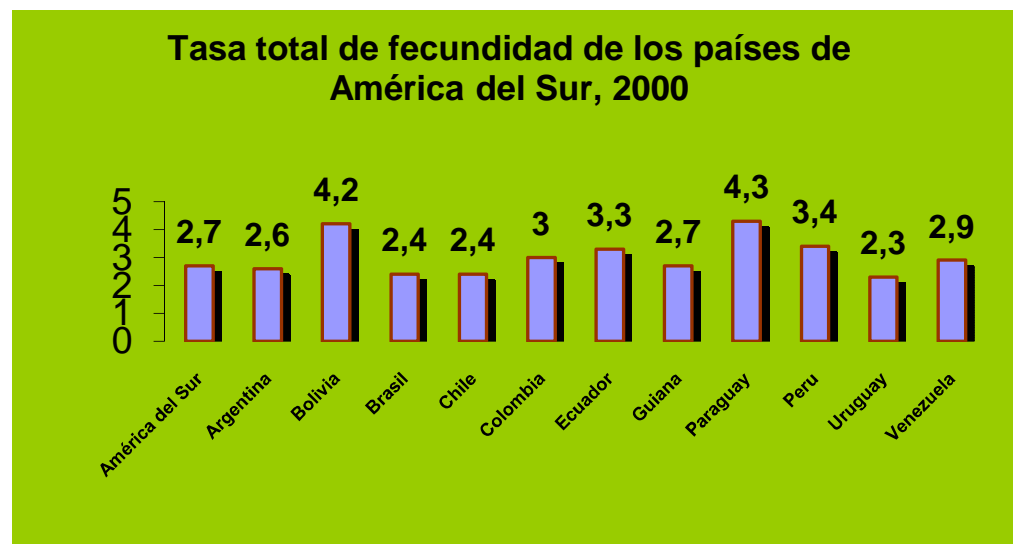

FUENTE: CEPAL (2000).

Otra variable que contribuye a esta Transición Demográfica es el descenso de las tasas de mortalidad infantil ${ }^{138}$. En todo el mundo hubo una reducción, pero aún es un problema humanitario preocupante en las regiones más pobres; los índices todavía son elevados y considerados inaceptables, ya que muchas muertes podrían ser evitadas. Entre las principales causas están la falta de asistencia y orientación a las embarazadas y parturientas, la deficiencia en la asistencia hospitalaria a los recién nacidos, la ausencia de un saneamiento básico - lo que favorece la contaminación de los alimentos y el agua y causa diversas molestias a los niños pequeños - y la desnutrición que afecta a las poblaciones pobres. Según el Fondo de las Naciones Unidas para la Infancia (UNICEF/2005) la tasa de mortalidad infantil en el mundo es de 51 niños de hasta 1 año por cada mil nacidos vivos. En los países ricos, la mortalidad infantil es de apenas 6 niños por cada mil nacidos, mientras en el grupo de las naciones pobres llega a 75 por mil. El escenario más dramático es el del África Subsahariana: de cada mil niños nacidos, 96 mueren antes de completar 1 año. En Brasil, la mortalidad infantil ha disminuido considerablemente en los últimos 30 años, a pesar de que aún ostenta índices altos para los patrones

\footnotetext{
138 Número de niños que mueren en el primer año de vida, entre mil nacidos vivos. Este indicador refleja las condiciones de salud del país. La mortalidad infantil tiene también un peso importante en el cálculo de la expectativa de vida de la población.
} 
internacionales. Desde 1980, los indicadores relacionados con ese problema han caído en más de un $60 \%$, hasta llegar a 24 muertes por mil niños con menos de 1 año de edad, según la Tabla de Vida de 2007. Su reducción puede ser atribuida a la disminución de las muertes causadas por dolencias infecciosas en los niños menores de 1 año, adquiridas principalmente por falta de saneamiento básico y desnutrición. De acuerdo con el Ministerio de la Salud (MS), entre 1990 y 2002, la caída fue del 42,1\% en las muertes de los niños de hasta 1 año de edad, estando el índice actualmente en menos de 24 muertes por cada mil nacidos vivos (IBGE: 2007), cifra que supera la meta establecida por la Organización Mundial de la Salud (OMS) de disminuir en un tercio la incidencia de muerte infantil en el país ${ }^{139}$. Dicho retroceso, según los expertos, es el resultado de la descentralización de la política de salud pública, sobre todo, en lo que respecta al estado de salud de la madre, las condiciones del parto y a los cuidados del recién nacido en las cuatro primeras semanas de vida. Las regiones Nordeste y Sudeste, fueron las que presentaron las mayores reducciones - $42,13 \%$ y $33,34 \%$ respectivamente. En el Norte $(35,86 \%)$, Centro Oeste $(32,67 \%)$ y Sur $(32,75 \%)$ las caídas fueron menores. Aunque estos resultados demuestren la persistencia de las desigualdades sociales en términos de desarrollo social, esta diferencia ha ido disminuyendo a lo largo de los años. Sin embargo, a pesar del avance, en general, los números son relativamente altos cuando se comparan con países desarrollados.

Cuando nos referimos a la perspectiva mundial, según el cuadro de la población mundial de las Naciones Unidas, América Latina posee la tercera mayor tasa de mortalidad infantil (23), después de Asia (49) y África (90). Esas tasas sobresalen aún más cuando se comparan con las de Europa (9) y con las de América del Norte (6). Las menores tasas de mortalidad infantil por mil niños nacidos vivos entre 2000-2005, de acuerdo con el Programa de las Naciones Unidas para el Desarrollo, la encontramos en Singapur y Japón $(3,0)$, Islandia $(3,2)$, Suecia $(3,3)$, Noruega $(3,5)$ y Corea del Sur $(3,7)$. En estas naciones, los determinantes de la mortalidad infantil que aún persisten no

139 La Organización Mundial de Salud (OMS) considera aceptable índices inferiores a 20 muertes por mil nacidos vivos. 
dependen de políticas de infraestructura social, como es el caso de Brasil, donde un $24 \%$ de las muertes de menores de un año siguen asociadas principalmente a la falta de saneamiento básico y asistencia médica adecuada. En países como Japón y Suecia, por ejemplo, los determinantes de la mortalidad en el primer año de vida, según los datos, están asociados a algunas causas neonatales para las cuales la medicina y ciencias afines no obtuvieron éxito en los aspectos preventivos y curativos, pues son enfermedades cuyo control depende de una extraordinaria inversión en investigación en el área de la biotecnología y la ingeniería genética. Por otro lado, las mayores tasas de mortalidad infantil se encuentran en Sierra Leona $(162,4)$, Nigeria $(149,0)$, Afganistán $(145,4)$, Liberia $(136,9)$ y Angola $(134,4)$. En la clasificación mundial Brasil ocupa la $96^{\text {a }}$ posición en mortalidad infantil, con una situación peor que la de nuestros vecinos más pobres como Surinam, Ecuador y Venezuela y la $11^{\mathrm{a}}$ posición en América Latina, respectivamente entre 2000-2005 (PNUD/ONU).

Dada su gran extensión territorial y heterogeneidad, la mortalidad en Brasil varía significativamente entre las regiones. Las desigualdades sociales y económicas crean una realidad de contrastes entre lo urbano y lo rural y entre las pequeñas y las grandes ciudades. Camarano y Beltrão ${ }^{140}$, argumentan que después de registrar una caída importante de la mortalidad en la década de los cuarenta, como respuesta a las mejoras del saneamiento básico, al programa de los fármacos (antibióticos, sulfas, etc.), al descubrimiento del DDT, al control más eficaz de las dolencias infecciosas y a la ampliación de los servicios de asistencia médica, entre otros factores, las tasas de mortalidad disminuyeron gradualmente en todas las regiones y grupos sociales, pero de forma más acentuada en las regiones más desarrolladas y entre los grupos sociales más acomodados.

En este sentido, si bien la mortalidad infantil ha experimentado un descenso evidente, las regiones Norte y Nordeste continúan presentando los peores índices. De esta forma, en 2005, los mejores puestos son ocupados por la región Sur, donde mueren 16,7 niños por cada mil nacidos vivos y las personas 
viven una media de 74,2 años y la región Sudeste, donde mueren 18,3 niños por mil nacidos vivos y las personas alcanzan los 73,5 años. En el otro extremo, en situación menos favorable, están la región Norte con un índice de 25,8 muertes por mil y la región Nordeste, donde ese número es de 36,9 muertes por cada mil niños nacidos vivos y la esperanza de vida media es de 71 y 69 años, respectivamente. Opinan los especialistas que las disparidades regionales están íntimamente asociadas a la calidad de vida de las ciudades y al nivel de estudios de las madres. En familias de la región Sur por ejemplo, en las cuales las madres tienen ocho años o más de estudio, la tasa de mortalidad es de apenas 13,9 por mil. La combinación de estos elementos lleva a situaciones extremas, dependiendo del Estado. Los Estados de Alagoas y Maranhão poseen las peores tasas de óbito infantil. En Alagoas de cada 1.000 niños nacidos vivos en 2006, 51,9 no alcanzaron su primer año de vida. En Maranhão, fueron registradas 40,7 muertes en un grupo de mil niños en el mismo año. Río Grande del Sur, donde la red de alcantarillado alcanza al $80,7 \%$ de las residencias, tiene la menor tasa de óbito infantil: 13,9 por mil. Río Grande del Norte, estado objeto de nuestra investigación, ostenta la quinta mayor tasa de mortalidad infantil entre las 27 unidades de la federación brasileña, 36,1 por mil nacidos vivos en 2006. Estos indicadores están más allá de los compromisos firmados en la Declaración de la Cumbre del Milenio de las Naciones Unidas, realizada en Nueva York, en septiembre de 2000.

Lo cierto es que la caída de la mortalidad infantil en Brasil es el resultado de la implementación de programas orientados básicamente al ámbito de la salud pública. El éxito parcial de este proceso es el resultado primero del advenimiento de los antibióticos para combatir las enfermedades infectocontagiosas en la década de los 40 , que benefició en particular a las poblaciones infantil y femenina en edad fértil. Seguido de las campañas de vacunación en masa, de la atención prenatal, del incentivo a la leche materna, del trabajo a domicilio realizado por los agentes comunitarios de salud, unido a la mejora de las condiciones de saneamiento básico y al aumento de la escolaridad femenina. Todos esos factores fueron decisivos para el cambio del cuadro epidemiológico en Brasil. Una de las entidades que 
más influyó en esa reducción fue la Pastoral del niño, órgano de la Confederación Nacional de los Obispos de Brasil (CNBB). Presente en todos los Estados brasileños, la entidad asiste a niños con menos de 6 años. Sus voluntarios enseñan acciones básicas de salud, nutrición y educación a madres y familiares. En 2004, el gobierno crea el Comité Nacional de Prevención del Óbito Infantil y Fetal.

Para alcanzar el cuarto compromiso, entre los ocho Objetivos de Desarrollo del Milenio, Brasil deberá reducir en dos tercios (66,6\%) entre1990 y 2015 el número de muertes de niños con hasta cinco años de edad. En 2006, entre los países de América Latina, Brasil con 24,9 muertes por mil nacidos vivos está por detrás de Cuba (5), Chile (7), Costa Rica (10), Uruguay (12), Trinidad y Tobago (13), Jamaica (14), Argentina (14), Venezuela (16), México (18), Panamá (19), Ecuador (22), Colombia (23) y El Salvador (23). En el mismo grupo de países, presentaban una tasa de mortalidad infantil por en cima de la brasileña Nicaragua (27), Belice (29), Honduras (29), Perú (30), República Dominicana (31), Paraguay (35), Guatemala (33), Guyana (45), Bolivia (48) Y Haití (58). Se sabe que la meta de los ODM es de 16,5 muertes para cada mil niños nacidos vivos.

\subsection{Mayor esperanza de vida}

En términos globales, desde 1950 la expectativa de vida ${ }^{141}$ en el mundo aumentó en más de 20 años. A pesar de los contrastes, estamos sencillamente ante un proceso que no cesa de crecer; longevidad como norma para la mayoría de los humanos. En las naciones desarrolladas, las personas viven más que en los países en desarrollo y en los países pobres. Mientras Japón, Hong Kong, Islandia, Suiza y Australia tienen las cinco expectativas más altas del mundo tanto en hombres como en mujeres, en Suazilandia, Botsuana, Lesoto, Zimbabue y Zambia en África se constatan las cinco más bajas. Según la Organización Mundial de la Salud, la expectativa de vida de la población

\footnotetext{
141 Estimación del tiempo que se espera que una persona viva en el momento de su nacimiento. La expectativa de vida de la humanidad presenta una curva ascendente, que tiene como factores principales los avances tecnológicos de los últimos años y el mayor acceso a servicios de salud, de educación y al saneamiento básico. El reflejo de esos cambios es el aumento del número de adultos mayores.
} 
mundial, que actualmente es de 66 años, pasará a ser de 73 años en 2025. Hoy la población de 120 países tiene una esperanza de vida media de más de 60 años y en 2025, según la OMS, en 26 países la esperanza de vida será de 80 años $^{142}$. Por otro lado, los indicadores de la ONU muestran que las mujeres viven más que los hombres en la mayoría de los países y en 22 naciones desarrolladas ellas superan, de media, los 80 años de edad. El proceso de envejecimiento es, así, diferente según el grupo social y el sexo a que pertenecemos.

En efecto, esta expectativa de vida más larga de la población se verifica en Brasil. En general, la esperanza de vida al nacer experimentó un aumento de cerca de 30 años entre 1940 y 1970, como resultado, principalmente, de la caída de la mortalidad infantil (Camarano, Beltrão y Neupert 1988).Tal esperanza viene experimentado, a lo largo de las décadas, incrementos paulatinos. En 2006, la media nacional alcanzó los 72,4 años, de acuerdo con la encuesta Tabla de Vida, divulgada por el Instituto Brasileño de Geografía y Estadística. El resultado mostró un incremento de dos meses y doce días en relación a la expectativa de 2004 y de 9,4 años desde 1980. Conforme al diseño demográfico de referencia de la Estadística del Siglo XX (IBGE: 2000), especialmente de los Anuarios Estadísticos Brasileños, se acelera el promedio de vida de una persona. Los datos indican que en 1900 la expectativa de vida de un brasileño al nacer era de 33,7 años y en la década de los cuarenta de 39 años; en los años cincuenta, el índice aumentó hasta 43,2 años y en la década de los sesenta a 55,9 años. De 1960 a 1980, esa expectativa se amplió hasta los 63,4 años, es decir, se sumaron veinte años en tres décadas, según informa el Anuario Estadístico de Brasil de 1982 (IBGE). De 1980 hasta 2000, el aumento se sitúa en alrededor de cinco años, momento en que cada brasileño, al nacer, tiene una esperanza de vida de 68,5 años, por encima de la media mundial que era de 66 años. Las proyecciones para el período de 2000 a 2025 nos permiten suponer que la expectativa media de vida del brasileño estará próxima a los 74 años, para ambos sexos (Kalache, 1987). Como se puede percibir, Zimerman (2005) subraya que "no es posible ignorar más la necesidad de prestar atención a la vejez en el ámbito institucional,

142 Zimerman, Guite I. (2005): Velhice - Aspectos Biopsicossociales, Porto Alegre: Artmed. 
político, económico o de salud. En función del cambio del perfil demográfico mundial, es necesaria toda una reestructuración social, política y económica. Los viejos tienen necesidades propias, características y peculiaridades que deben ser atendidas. Ese cambio demográfico acarrea cambios también en el estilo de vida de las personas, la necesidad de crear nuevos espacios, nuevos productos y servicios y, obviamente, exige la reformulación de conceptos y de posturas" (2005:15).

Los estudios del IBGE también compararon la esperanza de vida al nacer en las distintas regiones brasileñas entre 2000 y 2005 y descubrieron que los mayores incrementos se produjeron en las regiones Norte y Nordeste. Aunque ocupen los últimos lugares en el ranking de esperanza de vida al nacer, los estados de Alagoas, Maranhão y Pernambuco experimentaron los mayores aumentos. En los dos primeros estados, se ganaron 2,1 años de vida. En Pernambuco, la expectativa aumentó dos años entre 2000-2005.

Siguiendo estas constataciones, los datos también revelan desigualdades y contrastes regionales en el país en cuanto a la expectativa de vida. Mientras el Nordeste ostenta la peor media, 69,4 años en 2006, la región Sur exhibe la más alta expectativa de vida representada por 74,4 años. Los Estados de esta región también registraron los más pequeños aumentos en la esperanza de vida al nacer: Rio Grande del Sur $(1,4)$ y Santa Catarina $(1,3)$. Una diferencia de 8,9 años separa al campeón de expectativa de vida del país, el Distrito Federal, con 75,1 años, de Alagoas, último de la lista con 66,4 años. El contraste, sin embargo, está disminuyendo. En 2000, la diferencia era de 9,8 años. Cada persona y cada generación experimenta la vejez de un forma diferente $y$ eso está relacionado con innumerables aspectos biológicos y ambientales. De ese modo, las diferencias regionales en el país surgen porque mientras algunas regiones cuentan con buena estructura de asistencia a la salud, otras ni siquiera poseen aún saneamiento básico. Los resultados son meramente reflejo de la desigualdad socioeconómica que existe entre los estados. Así, no es una novedad que un brasileño nacido en el Distrito Federal (Centro-Oeste) tenga una esperanza de vida al nacer superior a otro nacido en Alagoas (Nordeste). 
Aunque el país haya avanzado entre los años 2000 y 2005, aún es necesaria una mejora considerable para alcanzar a nuestros vecinos latinoamericanos. Como ejemplo de países que ostentan expectativas de vida mejores que Brasil podemos mencionar a Argentina (74), Chile (76), México y Uruguay (75). El escenario mundial también nos muestra que, cuando se compara con países como Japón, la expectativa de vida del brasileño aún es baja. En este país, la esperanza de vida es superior a 82,2 años. Según los últimos datos del IBGE, Brasil sólo alcanzará el umbral de los 80 años de expectativa de vida hacia el año 2040. De acuerdo con el informe de la ONU para 195 países o áreas, Brasil ocupaba la $92^{\mathrm{a}}$ posición en el ranking de expectativa de vida, con 72,4 años en 2006. Próximos a Brasil están Colombia $(72,6)$ y Paraguay $(71,2)$.

Conviene señalar que la expectativa de vida al nacer aumentó mucho en todo el mundo de manera variada gracias, sobre todo, a los adelantos de la ciencia. Por un lado, la esperanza de vida se ha incrementado enormemente en los países más avanzados mientras que en los que se encuentran en vías de desarrollo esta realidad necesitará de algunos años para establecerse. Más años vividos, especialmente en Brasil, según Paschoal (2002), "pueden representar años de sufrimiento para los individuos y sus familias; años marcados por enfermedades con secuelas, declive funcional, aumento de la dependencia debido a la pérdida de la autonomía, aislamiento social y depresión" (2002:79). El desafío que se propone a los individuos y a las sociedades es conseguir una sobrevida mayor y de mejor calidad, para que los años vividos en edades avanzadas estén llenos de significado. Así, no sólo basta con incrementar los años de vida. Es necesario que éstos sean vividos dignamente, como puso de manifiesto la Organización Mundial de la Salud al afirmar que lo importante no es dar años a la vida sino añadir vida a los años.

\subsection{Población senescente}

Se entiende estadísticamente por población senescente el aumento de la proporción de personas mayores con respecto a otros grupos de edad. El ritmo de envejecimiento de la población depende del estado de transición demográfica hacia tasas más bajas de fecundidad y mortalidad. A medida que el ritmo de la transición se acelera, aumenta rápidamente la proporción de 
mayores (Rodríguez Carrajo, 1999). Actualmente, ya se ha dicho, el número de personas de más de 60 años en el mundo es de 606 millones y se prevé que para el 2050 sea de cerca de 2.000 millones. De esta manera, según Andrews $^{143}$, una de cada diez personas tiene 60 o más años de edad. Para el 2050, se estima que la relación será de una por cada cinco en todo el mundo y de una por cada tres en los países desarrollados. Aún según estimaciones de Andrews (2000), el número de personas con 100 años de edad o más aumentará 15 veces, pasando de 145.000 a 2.200 millones en 2050. En realidad, el mundo verá una "oleada" de aumento de los mayores de 60 años, cuyo incremento evidencia que el presente siglo estará dominado por los senescentes.

Este proceso, como ya se expuso más arriba, que en Europa ha llevado entre 150 y 200 años, ocurrirá en los países en vías de desarrollo de forma mucho más rápida. Las proyecciones de las Naciones Unidas indican que el aumento de la proporción de la población de más de 60 años, en muchos países, se manifestará en los próximos decenios y especialmente en el primer cuarto del siglo XXI. Para ilustrar lo perceptible de este fenómeno demográfico en América Latina y Caribe, basta recordar que en esta región, en el último medio siglo, la esperanza de vida al nacer aumentó aproximadamente 20 años, de 50 a 70 años durante la primera mitad del siglo pasado y la tasa global de fecundidad disminuyó a menos de la mitad, de alrededor de 6 hijos por mujer a menos de $3^{144}$. En el mismo período, el porcentaje de personas de 60 años o más ascendió de un $6 \%$ a un 8\%. En 1950, según el Centro Latinoamericano y Caribeño de Demografía (CELADE/CEPAL/Naciones Unidas) había en la región aproximadamente 10 millones de personas de 60 o más años; al terminar el siglo la cifra era de un poco más de 41 millones de personas de este grupo etario, que se incrementará en menos de 25 años a más del doble, unos 98 millones y al llegar el 2050 se verá casi duplicado con más 184 millones. Se calcula que más de 115.000 personas cumplen 60 años

\footnotetext{
143 Andrews, Garry A. (2000): Los desafíos del proceso de envejecimiento en las sociedades de hoy y del futuro, en el Encuentro Latinoamericano y Caribe sobre las personas de edad, 1999, Santiago. Anaïs. Santiago: CELADE, pp. 247-256 (Seminarios y Conferencias - CEPAL 2).

144 Chackiel, Juan (2000): El envejecimiento de la población latinoamericana: ¿hacia una relación de dependencia favorable?, Centro Latinoamericano y Caribeño de Demografía (CELADE) - División de Población, Serie 4 población y desarrollo, Santiago de Chile.
} 
mensualmente y se incorporan al grupo de los llamados adultos mayores. Se afirma que la región del Caribe es hoy la región en desarrollo más vieja del mundo. Esto implica que para adaptarse a ese proceso tendrá menos tiempo que el que tuvo el mundo desarrollado. Siguiendo las tendencias actuales, se prevé que, para 2050, prácticamente el $80 \%$ de la población mundial de 60 años vivirá en lo que son ahora países en desarrollo. No obstante, esta evolución en América Latina y el Caribe no es homogénea ni a escala internacional ni nacional, pero todos los indicios apuntan a esta tendencia que se inició en períodos diferentes y dentro de configuraciones nacionales distintas. Como ya fue mencionado, este panorama, responde a las grandes transformaciones económicas y sociales que han tenido lugar en América Latina y que se reflejan en la dinámica demográfica, sobre todo en la mortalidad y fecundidad.

Según los indicadores de la Investigación Nacional por Muestra en Domicilio (PNAD/IBGE) en Brasil, a lo largo de las últimas décadas, la proporción de niños y jóvenes con edad de hasta 14 años se redujo intensamente, llegando a suponer en 2005 el 27\% del total de la población. Esa proporción que hasta la década de los 70 era del $42,1 \%$, descendió al $38,2 \%$ en 1980 y al $34,7 \%$, en 1990. La razón principal de esa disminución es que, con los progresos de la medicina y las mejoras en las estructuras sociales acentuadas en la segunda mitad del siglo XX, las personas viven más tiempo, lo que contribuye al aumento de adultos en la población total, en relación al número de jóvenes. De este modo, la proporción de adultos mayores, era del 6,1\% en 1980 y pasó al 7,3\%, en 1990. Actualmente (2007), la población brasileña con edad igual o superior a 60 años es de 19.077 millones, lo que corresponde al 10,2\% de la población. La distribución porcentual, por grupo de edad es la siguiente: de 60 a 64 años (3,1\%), de 65 a 69 años (2,5\%), de 70 a 74 años (1,9\%), de 75 a 79 años $(1,3 \%)$ y con más de 80 años $(1,3 \%)$. Ese grupo, que crece cada año, aumentó en más de cinco millones de personas, en el período comprendido entre 1995 y 2005. Además pasó del 4\%, en 1940, al 8,6\%, en el año 2000 (PNAD/IBGE, 2006). Según Camarano (1997) ese segmento corresponderá casi al 15\% de la población brasileña en el año 2025. Aún de acuerdo con los datos de la PNAD, en el 2000 la población de 60 años de edad o más era de 
14.536.029, frente a 10.722 .705 en 1991. También la proporción de población con más de 80 años ha aumentado, alterando la composición de edad dentro del propio grupo, lo que significa que la población considerada de edad avanzada también está envejeciendo. Representa el segmento poblacional que más crece según la Investigación Nacional por Muestra en Domicilios (PNAD) aunque sea un contingente pequeño; en 2005 había 2,4 millones de brasileños octogenarios, que representaban el $1,3 \%$ de la población total. Pero, según las pesquisas de IBGE, en 2050 ese contingente podrá ser de 13,7 millones. En cuanto a la distribución por sexo, el 54,9\% estaba representado por hombres y el 55,1\% por mujeres. En 1996 había 16 adultos mayores por cada 100 niños. Este índice representa una tendencia ascendente ya que en 1991, su porcentaje era de 13,9 y en 1980 de 10,49. Por eso, cabe sostener, que la pirámide de edad brasileña se encuentra en transición; la reducción del número de nacimientos, el declive de la mortalidad infantil y la disminución de muertes de adultos son los principales indicadores esa realidad. El estrechamiento ocurrido en la base de la pirámide apunta a la reducción del grupo de personas de 0 a 14 años de edad. En 1940, el grupo de niños y adolescentes representaba casi la mitad de los brasileños (42,6\%); en 2000 corresponde a menos de un tercio $(29,6 \%)^{145}$. Entre 1992 y 2002, hubo un descenso del 2,6\% en el número de personas en esa franja de edad. En 1940, el promedio de vida de los brasileños era de 45 años; en 2000 ese índice sube a 71,9 años y en 2006 pasa a 72,4 años. Se observa también que la concentración de personas en las edades más avanzadas ha ido aumentado con el paso del tiempo. La proporción de personas de más de 70 años en 1980 era igual al 38\%; en 1991 pasa a un 40\%; y en 1996 correspondió aproximadamente a un 45\% (PNAD: 2000). Con el envejecimiento de los brasileños, asociado al número de nacimientos, la proporción entre niños y adultos mayores tiende a igualarse. Las proyecciones indican que en 2050, por primera vez en la Historia de la Humanidad, el grupo de personas con edad entre 0 y 14 años y los ciudadanos con más de 60 años serán iguales y representarán el $18 \%$ de la población.

145 Fuentes: IBGE, Censo Demográfico 1940/2020, Proyecto UNFPA/Brasil (BRA/98/POB) y Sistema Integrado de Proyecciones y Estimativas Poblacionales y Indicadores Socio demográficos. 
En 2007, por primera vez el IBGE divulgó resultados sobre personas con cien años o más. El país cuenta con 11.044 personas que nacieron entre el final del siglo XIX y el inicio del siglo XX. De estos, 7.950 son mujeres el $70 \%$, más del doble que de hombres, que suman 3.472. Bahía es el estado con mayor número de centenarios, existen 1.877 personas en esa franja de edad. El segundo estado con mayor número de personas que alcanzaron el siglo de vida es Minas Gerais con 1.420. Maranhão viene a continuación con 767 centenarios. Y uno de los menores estados de la federación, Roraima tiene, por el contrario a penas 15 personas con 100 años o más.

Por eso, la pirámide de la edad brasileña, que antes tenía una base ancha y una cumbre estrecha, ahora presenta un diseño más proporcionado (ver gráfico abajo). Según Carvalho y García (2002), el nivel de fecundidad en el año 2000 está ya muy próximo al de reposición, es decir, el suficiente para mantener una población del mismo tamaño. Para los autores, la fecundidad de la población se encuentra por debajo del nivel de reposición y el nivel medio del país continuará cayendo, pues hay evidentes indicadores de rápido declive en el Nordeste y en los grupos más pobres de la población. Como consecuencia, creen los demógrafos, la población brasileña entra en un sustentado proceso de desestabilización de su estructura de edad, con el estrechamiento continuado de la base de la pirámide y, consecuentemente, el envejecimiento de la población. 


\section{GRÁFICO 3}

\section{Pirámide de la población brasileña}

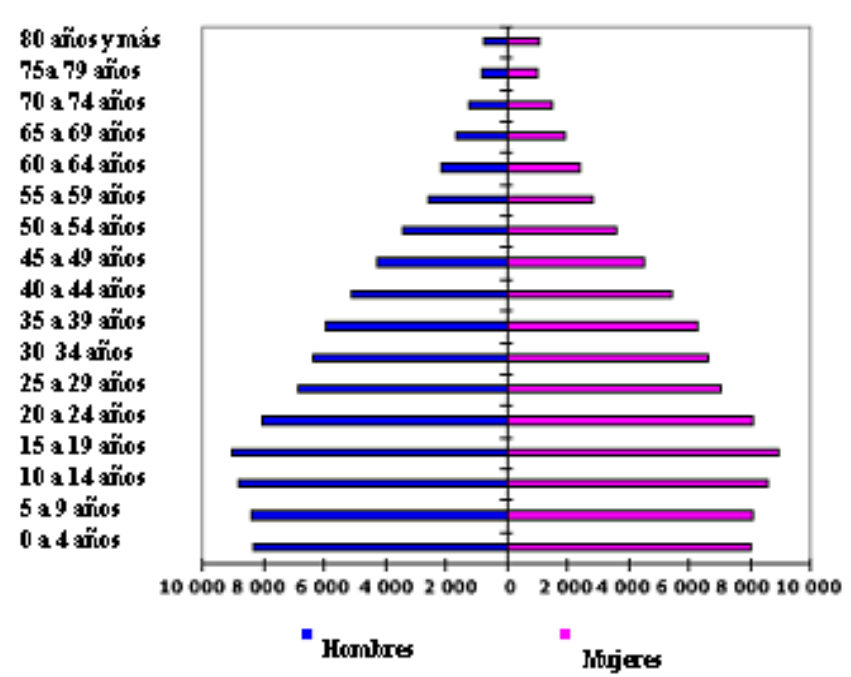

Fuente: IBGE, Censo Demográfico 2000.

Esta inversión de la pirámide de edades plantea un sinfín de cuestiones sanitarias, sociales, económicas, políticas, familiares, entre otras, que tienen como sustrato las cuestiones éticas. Entre las de cuño social, podemos observar la convivencia de 3 ó 4 generaciones en cada familia poseyendo una o más personas con edad madura o avanzada, y la existencia de más mujeres, ya que su longevidad es mayor. Otro factor importante es que a medida que la población envejece aumenta la demanda de instituciones de larga permanencia para los adultos mayores. En el ámbito médico, el aumento de los adultos mayores (sobre los 60 años) significa un crecimiento de la demanda de servicios de salud, más gastos en medicamentos y mayor ocupación de los hospitales por mayor período de tiempo, ya que normalmente esas personas tardan más en recuperarse, además de padecer trastornos mentales y dolencias típicas de esa edad que pueden provocar demencia. En cuanto a la repercusión económica, se da principalmente por la gran cantidad de personas con ninguna o casi ninguna condición de auto sustento, debido a los gastos en salud y a la reducción del número de individuos económicamente activos.

Por último, hay que mencionar que el envejecimiento en Brasil es un fenómeno predominantemente urbano y relativamente reciente. Semejante a 
lo que ocurre en algunos países latinoamericanos, tal hecho es el resultado sobre todo del intenso movimiento migratorio iniciado en la década de los 60, motivado por la industrialización desencadenada por las políticas desarrollistas del siglo pasado, especialmente en la segunda mitad. Actualmente en los países en desarrollo, hay más personas de edad en las zonas rurales que en las zonas urbanas. Las proyecciones demográficas indican que para el año 2025 el $82 \%$ de la población de los países desarrollados vivirá en zonas urbanas, mientras que menos de la mitad de la población de los países en desarrollo vivirá en esas zonas (Naciones Unidas, 2002). En Brasil, sin embargo, se verifica una excepción, dado que la mayor parte del colectivo con más de 60 años vive en la zona urbana lo que representaba el $77 \%$ de la población total en 1991 , frente al $81 \%$ en 2000 . Por lo que todo indica, si persiste la tendencia del envejecimiento como fenómeno urbano, las proyecciones para la primera década del presente siglo apuntan a que el $83 \%$ de los las personas mayores de 60 años estará viviendo en las ciudades. Por lo que se refiere a la distribución de adultos mayores por región, cabe destacar que en 2006, el Sudeste y Sur presentaban los mayores porcentajes de personas con más de 60 años: el 11,3 y el 10,9\%, respectivamente. En tercer lugar, aparece el Nordeste, con un 9,6\%, donde la caída de la fecundidad y el tradicional flujo de salida de los jóvenes hacia las regiones más desarrolladas del Sur del país contribuyen al envejecimiento poblacional. En cuarto y quinto lugar están las regiones Centro-Oeste y Norte que registraron el $8,2 \%$ y el $6,5 \%$, respectivamente. Hay que tener en cuenta que esas diferencias están relacionadas con la espectacular desigualdad en la distribución de la renta y de los servicios entre las cinco regiones del país. Las más urbanizadas, como las Sur y Sudeste, aún ofrecen las mejores posibilidades de empleo, disponibilidad de servicios públicos y las mejores condiciones de alimentación, vivienda y asistencia médica y social. Como la inversión en educación y salud no ha recibido la debida atención desde hace décadas, tiende a perpetuar las desigualdades en Brasil. Se supone así que, en los grandes centros urbanos del Sudeste y Sur y en las capas más altas de renta, las oportunidades para enfrentar la vejez con salud y confort son infinitamente mayores que en las menos desarrolladas del Norte, Nordeste y Centro-Oeste brasileño. 
Tal es la rapidez con que se procesan los cambios demográficos que Brasil, probablemente, pasará entre 1960 y 2025 de la $16^{\mathrm{a}}$ a la $6^{\mathrm{a}}$ posición mundial en términos de número absoluto de individuos con más de 60 años de edad (Kalache et al, 1987). Una transformación demográfica nacional de este tipo tiene profundas consecuencias para cada uno de los aspectos de la vida individual, comunitaria, nacional e internacional. Esto, a su vez, da lugar a que se implementen y crezcan demandas en las facetas sociales, económicas, políticas, culturales y psicológicas.

\subsection{La feminización de la vejez}

Después del "boom" de los estudios sobre el envejecimiento poblacional, un dato que suscita el interés de los investigadores en las sociedades occidentales, es el de la "feminización de la vejez". Dada la menor tasa de mortalidad femenina, las mujeres predominan entre los individuos mayores de 60 años. Según Ramos (2002), gran parte de los estudios longitudinales sobre la vejez nos llevan a entender que, más allá de la edad, el sexo del individuo parece ser determinante a la hora de considerar el riesgo de muerte, con los hombres presentando un riesgo mayor que las mujeres. Todas las demás variables como raza, clase social, situación marital, cuidado de la salud, entre otras, son dependientes de una compleja interacción entre el individuo y el medio ambiente, lo cual, a su vez, varían de una cultura a otra y de una época a otra. Las estadísticas reflejan que en la última etapa de la vida ellas viven cerca de 9 años más que los hombres y que su mayor longevidad está comprobada en todas las sociedades desarrolladas o no.

En vista de que ellas viven más que los hombres, las mujeres constituyen la mayoría de los ancianos en casi todos los países. Además, el porcentaje de mujeres aumenta apreciablemente con la edad. En todo el mundo, según el Estudio Económico y Social Mundial (2007), las mujeres representan el 55\% de la población mayor de 60 años y superan en número a los hombres en unos 70 millones. Entre los mayores de 80 años de edad, las mujeres prácticamente duplican el número de hombres y representan el $65 \%$ de la población de este grupo de edad. 
De ese modo, el envejecimiento manifiesta su discrepancia en cuanto al género. Las diferencias de mortalidad por sexo, que favorecen a las mujeres desde los primeros años de vida, dan lugar a que la proporción de mujeres sea superior a la de hombres en todos los grupos de edad después de la infancia. El grupo de los viejos más viejos, los que tienen 80 años de edad o más, crece más rápidamente entre las mujeres. Así, no hace mucho que las sociedades actuales perciben el predominio femenino en el total de la población mayor de 60 años. Este fenómeno es visible en Brasil, en América Latina y en todo el mundo. Según Coleman y colaboradores (1993), históricamente, las mujeres viven más que los hombres y superan al sexo opuesto cada vez más a medida que la edad aumenta (McDaniel, 1986; Denton y cols., 1987).

Hombres y mujeres viven y envejecen de forma diferente. Las hipótesis explicativas para el hecho de que los hombres mueran más temprano varían desde las biológicas entre los sexos, tales como la mayor inmunidad de las mujeres ante las dolencias infecciosas o la mayor protección hormonal femenina frente a las dolencias cardiovasculares, pasando por explicaciones que envuelven diferencias sociales y estilos de vida asociados a factores endógenos como accidentes de trabajo y de tráfico, homicidios, consumo de alcohol y tabaco, uso de drogas, dietas inadecuadas, sedentarismo, comportamiento y ocupaciones de riesgo y la migración. En este sentido, resulta pertinente argumentar que los factores biológicos tienen, en este caso, menos importancia que la multitud de factores sociales que hacen que la población masculina se auto-someta a riesgos "innecesarios" con una mayor intensidad que la femenina (Goldani, 1999). Por tanto, asumimos como presupuesto teórico que el sexo de los individuos es construido socialmente de modo diferenciado entre clases, grupos culturales y étnicos y, como tal, precisa ser explorado para la mejor comprensión de los fenómenos. Frente a estas explicaciones, el fenómeno de la feminización de la vejez apunta a que en la actualidad, hay 328 millones de mujeres mayores de 60 años en el mundo, frente a 265 millones de hombres en la misma edad. 
Aunque la longevidad femenina, en comparación con la de los hombres sea superior, no siempre es vista como un premio. Considerada como ventaja e indicador de mejor calidad de vida, su mayor longevidad acaba siendo, también, uno de sus problemas. En general, en la literatura gerontológica, Arber y Gini (1991), Bazo (1993), Nery (2001) destacan que la calidad de vida de la mujer, hablando en términos estrictamente saludables, sobre todo en edades avanzadas, es más deficiente que la del sexo opuesto; ellas suelen estar más enfermas, tienen más posibilidades de vivir en instituciones asilares o solas por la viudez y de depender material y físicamente de la familia. Mayoritariamente, están más sujetas a deficiencias físicas y mentales, tienen menos oportunidades de obtener dinero, porque están menos instruidas y reciben menos sueldo que los hombres por el mismo trabajo. Como consecuencia, sus pensiones son más bajas y sobre el Estado recae una mayor responsabilidad. Además, muchas de ellas no poseen seguro de salud y se convierten en cuidadoras impagadas, responsables de sus esposos y de sus padres ancianos. Cuando las mujeres de edad avanzada están incapacitadas se constituyen en un grave problema para la familia. La menor mortalidad femenina, tiene por tanto, la contrapartida de una vida menos valorada social y económicamente que la masculina. En suma, desde el punto de vista médico-social, ser mujer significa riesgo físico y social porque las mujeres son más frágiles, más pobres y están más enfermas y más aisladas que los hombres. Todo eso las pone en una situación puramente desventajosa.

Goldani (1999), recuerda que ambos, hombres y mujeres, sufren pérdidas con la edad y enfrentan prejuicios y estereotipos. La diferencia es que los recursos con que cuentan para enfrentarse a la vejez son distintos. Las mujeres encaran, en esta fase de la vida, todas las desventajas acumuladas a lo largo de una vida de discriminación y desigualdades estructurales. Es oportuno traer a colación que las mujeres han tenido tradicionalmente menos oportunidades para estudiar, trabajar y ganar dinero. Cuando trabajan como mano de obra remunerada, su participación será, probablemente, más breve e irregular, pues pueden interrumpir su carrera para desempeñar sus deberes familiares o para prestar asistencia a un miembro mayor de la familia. En gran parte de las sociedades, se sigue confiando el cuidado de los mayores a las 
mujeres, lo que restringe las posibilidades de éstas de percibir cualquier remuneración. Tales imágenes de género, según Goldani (1999), fueron reforzadas por el Estado por medio de una legislación restrictiva y de políticas públicas, así como por el mercado, a través de un modelo de división sexual del trabajo. Esta situación es aún más preocupante en los países en desarrollo que no cuentan con los mínimos sistemas formales de seguridad y asistencia social, especialmente porque se calcula que para el año 2030 residirá en ellos el $75 \%$ de la población de personas de edad del mundo. En este sentido, se puede entender que la feminización de la vejez suponga una fuerte demanda de políticas de salud y protección social y una candente cuestión social, pues se trata de retribuir las contribuciones que las mujeres ofrecieron y ofrecen a la sociedad, representadas por la maternidad, el cuidado de los hijos, de la casa y el conyugue, cuidado del que son responsables hasta la vejez, cuando se tornan cuidadoras también de otros mayores y de los hijos y nietos de mujeres jóvenes que tienen que salir de casa para trabajar.

Sin embargo, algunas de estas situaciones poco a poco avanzan y se seguirán transformando a lo largo de la historia. El papel femenino ha cambiado sin que el masculino se haya alterado. Cada vez más, las mujeres modifican sus cursos de vida y asumen otro perfil; trabajan, progresivamente asumen el papel de jefes de familia y de proveedoras del hogar, tienen actividades extra domésticas, participan en organizaciones y movimientos de mujeres, realizan cursos especiales, viajan (Camarano, 2004). Tampoco falta quien argumenta, incluso de manera optimista, que la viudez significa autonomía y libertad para las mujeres de hoy con edad igual o superior a 60 años (Debert, 1999; Peixoto, 1997).

La dimensión femenina del envejecimiento y la situación de las mujeres de edad en el mundo fueron temas de discusión en la Segunda Asamblea Mundial sobre Envejecimiento realizada en Madrid (2002). Además, constituye la tercera Meta del Milenio a ser cumplida por las naciones hasta 2015 promover la igualdad de género y la autonomía de las mujeres. En ese sentido, la mayor supervivencia femenina y su mayor longevidad apuntan, claramente, a la necesidad mundial de políticas sociales que faciliten la vida social, cultural, 
política y económica de ese colectivo. Los gobiernos y las sociedades necesitan nuevas respuestas ante el carácter cambiante de los procesos de envejecimiento, y estas sociedades deben reconocer especialmente las necesidades de las mujeres de edad. "Reconocer los efectos diferenciales del envejecimiento en las mujeres y los hombres es esencial para lograr la plena igualdad entre hombres y mujeres y para formular medidas eficaces y eficientes para hacer frente al problema. Por consiguiente, es decisivo lograr la integración de una perspectiva de género en todas las políticas, programas y leyes" ${ }^{146}$.

La notable feminización del envejecimiento también se observa en Brasil. El número de mujeres de edad, si se compara con el de hombres de 60 o más años, ya constituye un contingente expresivamente superior desde hace mucho. En el total de la población de edad se acentúa el desequilibrio por sexo. De media, ellas suelen vivir cerca de ocho años más que los hombres. Las diferencias de expectativa de vida entre sexos muestran lo siguiente: en 1991, las mujeres suponían un 54\% de la población de mayores; en 2000, pasaron al 55,1\% y en 2005 ellas representan el 57\% frente al $43 \%$ de los hombres. En el Censo de 2000, para cada 100 mujeres mayores había 81,6 hombres mayores. Entre los de edad superior a 80 años, esa proporción sube hasta el $60,1 \%$. Números que constatan una feminización del envejecimiento (OPAS, 2002). Actualmente, el predominio de mujeres se aprecia en todas las regiones del país. Ellas son mayoría en los centros urbanos pero se encuentran en minoría en las zonas rurales: son el $47,6 \%$, frente al $52,4 \%$ de hombres (PNAD/IBGE: 2005).

Según los registros, el predominio femenino se inició en la década de los cuarenta. Antes de eso, había más hombres que mujeres, principalmente a causa del mayor número de inmigrantes masculinos. En 1872, año del primer censo realizado en Brasil, las mujeres totalizaban el 48,5\% de la población. En 1940, la parcela femenina subió hasta el 50,01\% y no paró de crecer. Elza Berquó (1999), por su parte, destaca que “desde 1950 las mujeres han tenido

\footnotetext{
146 Informe de la II Asamblea Mundial sobre el Envejecimiento, Madrid, 8 a 12 de Abril de 2002 (publicaciones de las Naciones Unidas, número de venta: S.02.IV.4, ISBN 92-1-330176-6), Introducción, párrafo 8.
} 
mayor esperanza de vida al nacer y esta diferencia está alrededor de los siete años y medio. En 1980, mientras la esperanza de vida para los hombres era de 59 años, a las mujeres les correspondía 65 años, es decir, la posibilidad de vivir 6 años más que los hombres. En 1991, esa diferencia creció hasta los 7 años. Las proyecciones para 2010 y 2020 mantienen una diferencia de alrededor de 6 años" (1999:23). La demógrafa brasileña aún menciona que la esperanza de vida de las mujeres prácticamente se duplicó entre 1910 y 1990 - pasando de 34,6 a 69,1 años. Pero, también, la expectativa de vida masculina creció 28,9 años en el mismo período, pasando de 33,4 años en 1910 a 62,3 años en 1990. La tendencia de aumento se mantuvo hasta el fin del siglo XX: en 2000, la expectativa de vida para ambos sexos era de 68,6 años (64,8 para hombres y 72,6 para las mujeres). En este universo, la dimensión de los problemas que las mujeres enfrentan en la vejez es mayor si tenemos en cuenta el fenómeno de la feminización de la vejez. Por región, según el IBGE 2006, la Sudeste es la que posee más mujeres con 60 años o más $(57,2 \%)$, seguida de la Región Sur $(55,9 \%)$, Nordeste $(55,2 \%)$, Centro Oeste $(52,5 \%)$ y Norte $(51,5 \%)$.

A pesar del aumento en la expectativa de vida para ambos sexos, los expertos suponen que ese indicador podría tener un crecimiento más expresivo si no fuera por el gran número de muertes prematuras de jóvenes por violencia. Según las estadísticas, el ritmo de crecimiento más lento de la esperanza de vida masculina, comparativamente a la femenina, encuentra explicación en el aumento gradual del índice de mortalidad masculina en edades comprendidas entre los 15 y los 30 años. Ese índice de mortalidad es debido a causas externas, es decir, a motivos violentos como homicidios y accidentes de tráfico verificados, sobre todo, desde la década de 1980. Esta no es una realidad exclusiva de Brasil. Se observa que en todos los continentes las situaciones se asemejan en esta cuestión.

Para la economista Ana Amélia Camarano del Instituto de Pesquisa Económica Aplicada (IPEA: 1999), en 1980 a los 60 años, los hombres podrían esperar vivir 14,2 años más y las mujeres, 17,6 años más; en 1991, esas tasas alcanzaron 15,3 para los hombres y 18,1 para las mujeres. En 2000, fueron de 16 años 
para los hombres y de 19,5 para las mujeres. En esa fecha la esperanza de vida del brasileño a los 60 años era de 17,8 años; a los 65, de 14,3; a los 70, de 11,1 ; a los 75 , de 8,4 , y a los 80 , de 6,1 años. En este sentido, los datos indican que hay diferencias significativas entre hombres y mujeres. Actualmente la expectativa de vida masculina, como ya se ha adelantado, es de media, 68,2 años, casi ocho años menos que la femenina, de 75,8. De acuerdo con los datos del IBGE, en las regiones metropolitanas de Porto Alegre, Belo Horizonte, São Paulo, Rio de Janeiro y Recife, el número de personas de edades avanzadas en más del doble del número de hombres mayores del mismo grupo, indicando una concentración femenina en los grandes centros urbanos.

No obstante, se debe resaltar que el acentuado desequilibrio entre hombres y mujeres de edad no es una especificidad brasileña. En efecto, las razones del sexo, indicadas en el gráfico de abajo, señalan que en todos los continentes la esperanza de vida para las mujeres es mayor que para los hombres. El siguiente gráfico ilustra la esperanza de vida por sexo en los seis continentes en el año 2001. Las mayores tasas están en América del Norte y Europa.

\section{GRÁFICO 4}

Esperança de vida por sexo e continentes, 2001

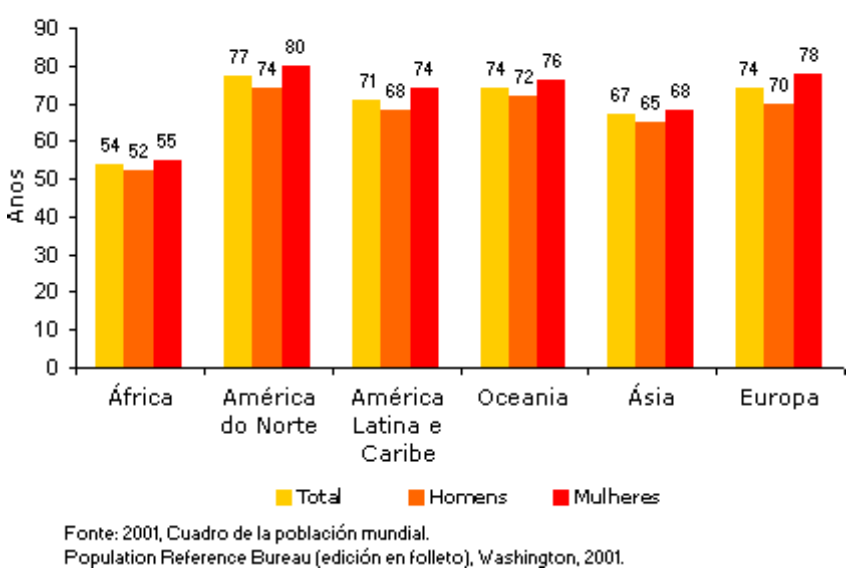

A escala mundial, debemos reconocer que el hecho de estar viviendo más años no es un problema en sí, sino un logro. Podemos suponer, sin embargo, que el crecimiento de la población mayor de 60 años, sobre todo en los países en desarrollo, exige una preparación adecuada para asistir a ese colectivo, principalmente en lo que se refiere a la proporción de mujeres en relación a 
los hombres. Esto, naturalmente, demanda ciertos cambios de actitudes. Por un lado, esa preparación envuelve desde los aspectos ambientales y el suministro de recursos materiales y humanos, hasta la definición e implementación de acciones de salud especifica. Por otro lado, es necesario que la sociedad entienda que el envejecimiento de su población es una cuestión que se extrapola a la esfera familiar y, por tanto, a la responsabilidad individual, alcanzando el ámbito público, las organizaciones no gubernamentales y los diferentes segmentos sociales.

\section{Indicadores económicos: el sistema de Seguridad Social y condición económica de los adultos mayores brasileños}

Desde el punto de vista económico, la seguridad financiera es una de las más grandes preocupaciones de los ancianos. Por relacionarse directamente con la calidad de vida, los ingresos suelen asumir un papel importante. Sin ellos la gente mayor puede estar condenada a pasar el último tramo de su vida con dificultades y alcanzar la temida pobreza (Waker, 1991, apud Bazo, 1998). La disminución de las posibilidades económicas y el deterioro de la salud, a menudo, incrementan la vulnerabilidad ante la pobreza a medida que las personas envejecen. No obstante, esas condiciones varían mucho en los distintos contextos y entre diferentes grupos de personas mayores. En las economías desarrolladas, las pensiones son la principal fuente de ingresos y protección en la vejez, mientras que en los países en desarrollo son pocos los que tienen acceso a una pensión y, por tanto, existe la necesidad de recurrir a otras fuentes de ingresos. De hecho, a escala mundial, según Dirk JaspersFaijer (CEPAL), actualmente el $80 \%$ de la población no tiene cobertura de asistencia social y se prevé que, si no hay un cambio en las políticas, cerca de 1.200 millones de adultos mayores tendrán que hacer frente a la inseguridad de la renta hasta 2050. En otras palabras, eso quiere decir que, sólo en los países en desarrollo, unos 342 millones de personas mayores no disfrutan hoy en día de una garantía suficiente de ingresos. A ese respecto, con la finalidad de esbozar la situación financiera de los adultos mayores, vamos a subrayar el sistema de pensiones adoptado en Brasil para este colectivo, la posición 
económica que ellos ocupan en el seno de la familia y su consecuente participación en la sociedad.

Como en los demás países de América Latina, la Seguridad Social brasileña, “instituida por la Ley Eloy Chaves en 1923 (Decreto 4.682) pasa fundamentalmente por el principio bismarkiano de cotización para el acceso a la protección social. Con la promulgación de la referida ley, que no se dirigía a los trabajadores en general, tampoco al concepto de ciudadanía, fue instituido un fondo especial de jubilaciones y pensiones, la Caja de Aposentadurías y Pensiones (CAP), destinada en primer lugar a los ferroviarios $\mathrm{y}$, posteriormente, a los marineros y portuarios" ${ }^{147}$.

Sin embargo, debido a la alta incidencia de las relaciones informales de trabajo asalariado y de la elevada pobreza, sea estructural o resultante de la inestabilidad económica y social de las tres últimas décadas, el sistema intenta universalizar su cobertura en el medio urbano y rural, alcanzando a aquellos que nunca cotizaron para adquirir el beneficio. Actualmente, conocida como una de las mayores seguridades sociales públicas del mundo, el conjunto de derechos es amplio para los asegurados y sus familias; podemos mencionar como ejemplo las jubilaciones por tiempo de contribución, por edad, especial y por invalidez, el auxilio por enfermedad, accidente, funeral y reclusión, el abono anual, los salarios-maternidad y familia; la pensión por viudedad.

En 85 años la Seguridad Social ha sufrido muchas alteraciones. Al final de los años 80, la Constitución Ciudadana de 1988 implanta un nuevo concepto en Brasil, el de Seguridad Social. En vez de un modelo bismarkiano, se trataba ahora de introducir en el sistema de protección social brasileño, conscientemente, conceptos universalistas "beveridgianos", o sea, inspirados en el modelo propuesto por Lord Willian Beveridge para la pos-guerra inglesa. La propuesta de Beveridge preveía que, además de un eje contributivo de Seguridad Social, el Estado también proveyese de beneficios básicos mínimos, financiados por medio de tributos, para evitar la pobreza de aquellos grupos

147 Borges, M. C. M. (2003): O Idoso e as Políticas Públicas e Sociais no Brasil, em, Von Simson, O. R. M., Neri, A. L. y Cachioni, M. (org.) As múltiplas faces da velhice no Brasil. Capinas São Paulo: Editora Elínea, p. 92. 
sociales que poseyeran baja capacidad contributiva individual. Semejante al modelo adoptado por la mayoría de los países desarrollados, el sistema de Seguridad Social pasa a comprender un conjunto integrado de acciones de los poderes públicos y de la sociedad, destinados a asegurar los derechos ciudadanos. En su capítulo de Orden Social, la Constitución estableció que la seguridad está compuesta por tres segmentos básicos: Seguridad Social, Salud y Asistencia Social. Los siguientes principios pasaron a guiar el poder público: universalidad de la cobertura y de la atención - todos los ciudadanos tienen acceso a la protección social; uniformidad y equivalencia de los beneficios y servicios a las poblaciones rurales; y selección y distribución en la prestación de beneficios y servicios - por los cuales las necesidades individuales determinan que deben ser concedidos $^{148}$. Aún según la Constitución de 1988 el sistema de seguridad social está dividido en dos vertientes: una obligatoria y otra facultativa. La primera, fue fundada en la modalidad de repartición simple, responsable de la previsión básica del régimen general de trabajadores de la iniciativa privada y del régimen propio de los servidores públicos. La segunda es necesariamente capitalizada con base en la constitución de reservas, accesible a los empleados de empresas y a los servidores públicos en general y a los asociados, o miembros de personas jurídicas de carácter profesional, clasista o sectorial. Con base en esta orientación constitucional, en Brasil existen dos regímenes de seguridad distintos: el Régimen General de Seguridad Social (RGSS), los Regímenes Propios de Seguridad Social (RPSS), además de la Seguridad Complementaria $(\mathrm{SC})$.

En los últimos años, la necesidad del severo ajuste fiscal puso el tema de los sistemas de pensiones en evidencia. Con el objetivo de buscar el equilibrio inmediato entre ingresos y gastos, todo el sistema pasó por una amplia reforma; la primera fue en 1998 (Enmienda Constitucional-20), la segunda en 1999 (Ley $n^{\circ}$ 9.876) y la última en 2003 (Enmienda Constitucional-41). Tal enmienda trae consigo grandes alteraciones del marco jurídico general, necesitando, para su implementación, de reglamentación por medio de leyes

148 Ministério da Previdência Social - MPS: Panorama da previdência social brasileira. Assessoria de Comunicação Social - ACS, Brasilia, 2004, p. 10. 
complementares y ordinarias, bien como resoluciones de los Consejos de Gestión de cada régimen.

La estructura del sistema de Seguridad Social presenta dos conceptos. El primero, el RGSS, cubre a los empleadores, trabajadores asalariados urbanos, domésticos, autónomos y trabajadores rurales. Es la Seguridad Social de los trabajadores de la iniciativa privada y de los funcionarios públicos con contratos de trabajo firmados. Formulado por el Ministerio de Seguridad Social y administrado por el Instituto Nacional de Seguridad Social (INSS) se caracteriza por los siguientes beneficios: jubilaciones (por tiempo de contribución, edad o invalidez) y pensiones por viudedad.

La jubilación por edad es, por definición, un beneficio para atender especialmente a los mayores. Concedida a los hombres con 65 años y a las mujeres con 60 años en el área urbana, y a los hombres con 60 años y mujeres con 55 años en el área rural ${ }^{149}$. El tiempo mínimo de cotización es de 15 años. Por otro lado, hombres y mujeres pueden jubilarse por tiempo de cotización. Los hombres necesitan contribuir durante 35 años, y las mujeres durante 30. El valor corresponde al $100 \%$ del salario. Este régimen protege a la mayor parte de los trabajadores del país.

Respecto a la jubilación por invalidez, cubre al individuo contribuyente, que, estando o no en disfrute del auxilio por enfermedad, es considerado incapaz de rehabilitarse para el trabajo. Esta pensión, a su vez, presenta una modalidad que sólo es concedida a los dependientes del asegurado por motivo de fallecimiento. Tienen derecho a ese beneficio el marido, la mujer o compañero(a), hijo no emancipado y menor de 21 años, hijo incapacitado para el trabajo de cualquier edad, padre o madre y hermano menor de 21 años o discapacitado de cualquier edad. No hay requisitos para la pensión por viudedad, basta que se compruebe la calidad del asegurado. Los mayores absorbieron, de media, el $46 \%$ de los beneficios de este tipo de pagos entre 1995 y 2003 (Camarano, 2005). Desde 1993 la mayoría de las pensiones han

149 Ese límite fue establecido por las Normas Mínimas de la Seguridad Social de la Organización Internacional del Trabajo (OIT) (convención 102) en 1952. 
sido pagadas a las mujeres. Esa proporción se mantiene estable en torno al 60\% (Beltrão, Camarano y Melo (2004).

El segundo concepto del sistema RPPS, de carácter contributivo, gestionado por el Instituto de Previsión del Estado (IPE), es el régimen asegurado a los funcionarios públicos titulares de cargos efectivos de la Unión, de los Estados, del Distrito Federal y de los municipios, incluidas sus autarquías y fundaciones. La jubilación es obligatoria a los 70 años para hombres y mujeres, y las jubilaciones por tiempo de cotización a los 35 años para hombres y a los 30 años para las mujeres. Su administración es pública. En este régimen, el funcionario recibe su jubilación directamente del Estado. Siendo así, el jubilado continúa como servidor público, alterando apenas su condición de activo a inactivo. Queda entendido hasta aquí que tenemos, en el ámbito federal, servidores públicos que disponen de una Seguridad Social determinada por el Régimen Jurídico Único, y que hay 27 tipos de protección para los servidores públicos estatales, ya que cada estado tiene la suya propia. El cuadro general de Seguridad Social pude ser resumido así: hay una para la actividad privada, que es absolutamente uniforme en todo el territorio nacional, y otra que se ocupa de la actividad pública, que, además de no ser uniforme, está descentralizada en su ejecución.

Por último, la Seguridad Complementaria brasileña que es voluntaria y de administración privada, presenta dos pilares: las entidades cerradas y las abiertas. Las primeras, llamadas de fondo de pensión, son organizaciones sin ánimo de lucro, bajo la forma de fundaciones de derecho privado o de sociedades. Las entidades abiertas, a su vez, están organizadas bajo la forma de sociedades anónimas y actúan en el mercado de seguridad complementaria con ánimo de lucro. Esta modalidad ofrece a la población planes de jubilación de diferentes tipos que pueden ser individuales o colectivos. En suma, este sistema posee arreglos variados y constituye un complemento eficaz para mantener el patrón de vida del trabajador cuando éste ya no tenga condiciones para ejercer su actividad profesional.

Si analizamos el universo de contribuyentes y beneficiarios del sistema, según un estudio del IPEA (2007), observamos que sólo un $56,4 \%$ de los trabajadores 
brasileños contribuyen a la Seguridad Social. En todo el país ese número alcanza el 67,1\%. El número es de aproximadamente 25 millones de personas que contribuyen al INSS, incluyendo a jubilados y pensionistas. De estos, un $69,53 \%$ son asegurados residentes en el área urbana y un 30,47\% residentes en la zona rural. Sin embargo, cerca del $36 \%$ de la población que trabaja, con edad entre 16 y 59 años, está fuera del régimen de protección social y más de la mitad de los trabajadores que actualmente tiene plaza en el mercado, más del $40 \%$, no contribuye al sistema, según datos del Ministerio de Seguridad Social de junio de 2007. Estos 28,8 millones de brasileños tienen, en su mayoría, entre 30 y 40 años. Reciben de uno a dos salarios mínimos y trabajan en el sector servicios, en el comercio o en el trabajo doméstico. Como no contribuyen, necesitarán algún tipo de asistencia en el futuro, cuando pierdan la capacidad laboral. Ese será un problema social que enfrentará el país y por el cual la actual reforma puntúa ${ }^{150}$. Según el secretario de Políticas de Seguridad Social, Helmut Schwarzer, en muchos casos, los trabajadores no contribuyen por no poder pagar el valor de la contribución, dado que, alrededor de 12 millones tienen una renta inferior a un salario mínimo. Sobre esta cuestión, de acuerdo con el estudio Determinantes da Sustentabilidade e do Custo Previdenciario: Aspectos Conceituais e Comparações Internacionais (2006), elaborado por el economista Marcelo Caetano, del Instituto de Pesquisa Económica Aplicada (IPEA), el valor de la cuota brasileña es el segundo mayor del mundo: la carga tributaria de la Seguridad Social brasileña es del $31 \%$, siendo el $11 \%$ pagado por los trabajadores y el $20 \%$ por los empleadores. En Chile la carga es de un 10\%, en México del 6,2\% y en los Estados Unidos del $12,4 \%$. Sólo nos supera Italia, que cobra el $32,7 \%$ de la hoja salarial. La media mundial oscila entre el 15 y el $20 \%$.

A pesar de todo eso, el total de beneficios pagados por la Seguridad Social es gigantesco y en julio de 2007 estuvo representado por 24,8 millones, lo que supera la suma de las poblaciones de países europeos como Finlandia (5,3

$150 \quad$ A pesar de ser aún bajo, es importante recordar que el porcentaje de trabajadores que contribuyen a la Seguridad Social ha ido creciendo a lo largo de los años. De acuerdo con los datos del PNAD, son tres años consecutivos de crecimiento, pasando del 45\% en 2002 al 47,8\% en el año 2005, una subida del 6,2\%. El índice llegó a oscilar en torno al $42 \%$ a principios de los años noventa. El número absoluto de contribuyentes pasó de 35,5 millones en 2002 a R \$ 40,8 millones en 2005, un aumento del $15 \%$. 
millones), Dinamarca (5,4 millones) y Suecia $(9,1$ millones) o de países latinoamericanos como Chile (16,5 millones) y Paraguay (6,3 millones) en el mismo año. De acuerdo con el estudio del Instituto de Pesquisa Económica Aplicada (IPEA) de 2007 , Brasil es el $14^{\circ}$ país que más gasta en protección social, en una lista que incluye a 113 países del mundo. Los gastos corresponden al $11,7 \%$ de PIB brasileño. El país que encabeza la lista, Italia, gasta un $17,6 \%$ del PIB nacional. De ese modo, la Seguridad Social hoy garantiza la supervivencia, de forma directa o indirecta, de 75,74 millones de brasileños, o sea más de un 40\% de la población y de 14,6 millones (el 76,6\%) de brasileños de más de 60 años. Cuando se considera a los mayores de 65 años o más, ese porcentaje se eleva hasta el $84,6 \%$. Según el IBGE, para cada beneficiario de la Seguridad Social, de media, hay 2,5 personas beneficiadas indirectamente. Como uno de los mayores programas de renta mínima del mundo, paga beneficios de un salario mínimo por mes a 7,9 millones de brasileños que nunca cotizaron al sistema. Por ello, el RGSS es uno de los mecanismos más efectivos de protección social de Brasil. De acuerdo con el Dosier de la Seguridad (2004), los datos son auto-explicativos. En 1999, el 34\% de los brasileños vivía por debajo de la línea de la pobreza, con menos de U\$ 2 al día. De no ser por la seguridad social, este porcentaje habría sido del $45,3 \%$, o sea, la protección social fue responsable de una reducción del $11,3 \%$ del nivel de pobreza, lo que significa que 18,1 millones de personas dejaron de ser pobres. El grado de pobreza entre las personas de edad es substancialmente inferior al de población más joven. En caso de que no existieran las transferencias de pensiones, este estado se triplicaría entre los mayores. En esta óptica uno de los principales impactos sociales del RGSS es la reducción de la pobreza en el país. De acuerdo con el Estudio Económico y Social Mundial (2007), el sistema de pensión para la vejez cubre al $77 \%$ de los adultos mayores en Brasil, al $78 \%$ en Uruguay, al $56 \%$ en Argentina y al $55 \%$ en Chile. Entre los países con cobertura insuficiente están Haití con el 1\%; Bolivia con el $11 \%$; Paraguay con el $12 \%$ y México con el $20 \%$.

Considerada como la mayor áncora social del país, la Asociación Nacional de los Servidores de la Seguridad Social (ANAPS), informa que en más del $90 \%$ de los municipios el pago de beneficios sociales supera su recaudación; en el 
$57,3 \%$ de ellos el pago de las pensiones supera los repases, proporcionales al número de habitantes, del Fondo de Participación de los Municipios; representa el $20,3 \%$ de la renta monetaria de las familias de las localidades con más de 5 mil habitantes; en el Nordeste, representa también el 22,8\% de renta monetaria de las familias de las ciudades con población entre 20 y 50 mil habitantes. En este sentido, los recursos de los sistemas de pensiones son fundamentales para la mejora de las condiciones de vida, en la medida en que reducen la pobreza. Además de mover la economía y el comercio de municipios pequeños y medios, también contribuye a disminuir el éxodo rural y el proceso de chabolización en las grandes ciudades.

\subsection{Participación de los mayores en la sociedad}

Aunque el sistema de jubilaciones y pensiones sea un mecanismo de protección social, en Brasil una de las características de la población que envejece es la pobreza. En Brasil, jubilarse y vivir de los beneficios de la jubilación significa generalmente ingresar en el umbral de la pobreza. La gran mayoría de las jubilaciones no dan a los jubilados la posibilidad de disfrutar de una vida digna. Aún así, jubilaciones y pensiones constituyen la principal fuente de recursos de este colectivo. De acuerdo con Alexandre Kalache, coordinador del Programa de Envejecimiento y Curso de Vida de la Organización Mundial de la Salud (OMS), el mayor brasileño puede estar situado dentro de tres categorías en función de sus condiciones económicas. La primera categoría es la de los privilegiados, o sea, las personas que tuvieron privilegios durante toda su vida y que llegan a la vejez con una buena pensión, con buenos cuidados y acceso a lo mejor, incluyendo los servicios de salud. A este grupo pertenece una minoría. La segunda categoría está constituida por un grupo substancial que, de alguna forma, tiene sus necesidades atendidas, aunque con dificultades. Es el grupo de la clase media baja, que cuenta con alguna forma de pensión, de recursos o de ahorros reunidos durante toda la vida, o con algún familiar que le proporciona ayuda. La tercera categoría de adultos mayores brasileños es la más importante porque es la de los que nunca recibieron privilegios. Son los pobres que se encuentran en todas las regiones del país. Es una población que nunca cotizó 
a la Seguridad Social y que termina en la vejez sin una pensión, con una asistencia sanitaria muy pobre, con servicios inadecuados para sus problemas y enfermedades crónicas. Esto hace que la vejez sea un premio vacío, o sea, llegan a la vejez en unas condiciones de vida muy bajas. En general, el grado de pobreza entre las personas mayores varía dependiendo del nivel educativo, el género y la organización de vida. Una mejor educación reduce la probabilidad de que uno se encuentre en la pobreza en la vejez. Peixoto (2004), traduce este escenario afirmando que son los factores socioeconómicos y culturales (sexo, estudios, trayectoria profesional, condiciones de salud y valor de la jubilación) los que determinan la situación de cada individuo de edad.

No obstante, todo lo indicado hasta el momento nos revela, a efectos prácticos, que poco a poco este cuadro está cambiando. Bajo la denominación del mayor programa social y de distribución de renta de América Latina, la cobertura de la protección social (jubilaciones, pensiones y asistencia social) está aliviando la pobreza en Brasil, como subrayamos anteriormente. La pobreza en la vejez, según el Estudio Económico y Social Mundial (2007), tiende a ser elevada en países que carecen de un sistema estructurado y amplio de pensiones; la introducción de pensiones en esta fase de la vida o de transferencias en efectivo ha sido un instrumento poderoso para reducir la pobreza en la vejez tanto en países en desarrollo como en países desarrollados. En Brasil, conforme el estudio del PNAD 2005, la cobertura de la Seguridad Social y de otros sistemas de prestaciones asistenciales de vejez de carácter no contributivo para las personas a partir de 60 años, pasó del $81,5 \%$ en 2002 al 82,0\% en 2005 en todo el país. La seguridad económica para los mayores latinoamericanos, en cambio, es deficiente, desigual y poco equitativa, según José Miguel Guzmán de la CEPAL. Para Guzmán más de un tercio de las personas de 65 años o más no dispone de ingresos ni de pensiones o jubilaciones ni tampoco de un trabajo remunerado. Dos de cada cinco personas mayores disponen de ingresos provenientes de la protección social en el área urbana y, en las zonas rurales, apenas una de cada cinco. Estar entre el $82 \%$ de los mayores con algún tipo de cobertura social no necesariamente significa buena calidad de vida. Dos tercios de los beneficios 
equivalen a un salario mínimo (hoy, $\mathrm{R} \$ 415,00$ en algunos estados), dinero muchas veces insuficiente para la supervivencia de un jubilado. Además, en Brasil $^{151}$, casi la mitad (el 49\%) de los que tienen más de 60 años no tienen renta o reciben hasta un salario mínimo mensual. En el Nordeste, la situación es aún peor. Dos de cada tres habitantes con esa edad (el 66\%) no tiene recursos o recibe sólo un salario mínimo al mes.

En nuestro país, el porcentaje de protección de la Seguridad Social (régimen urbano y rural) crece más en el Nordeste, según la citada investigación. Piauí y Paraíba, con el $90,0 \%$ y el 88,2\%, respectivamente son los Estados con mayor índice de cobertura de mayores, especialmente por la fuerte difusión de la seguridad rural en los estados nordestinos. En Río Grande del Sur, la cobertura llegó al $88,0 \%$, en Santa Catarina al $87,8 \%$, en Minas Gerais al $84,4 \%$ y en Paraná al $81,5 \%$. Esa realidad contribuye a que el número de personas por debajo del umbral de pobreza no alcance índices alarmantes. Según el Ministerio Social, en 2003, sin considerar el pago de beneficios, el 48,6\% de la población brasileña estaba por debajo de la línea de la pobreza. Considerando las transferencias de beneficios, el porcentaje caía hasta el 37,2\% en el mismo año. En 2005, los índices eran del $42,5 \%$ sin considerar los beneficios y del $30,9 \%$ teniendo en cuenta el pago de pensiones y otros beneficios asistenciales. En otras palabras: en función de recibir pensiones y beneficios asistenciales, 21,0 millones de personas, entre los beneficiarios y sus familiares, superaron en 2005 la línea de renta familiar de 1/2 salario mínimo por persona, usada como referencia para el análisis.

Según Helmut Schwarzer, el impacto de los sistemas de pensiones sobre la pobreza varía de acuerdo con la realidad regional. Los datos sobre la cobertura de la protección social parten del estudio Evolução da Proteção Social e Impactos sobre a Pobreza, elaborado por el Ministerio de Seguridad Social (2006), que muestra la capacidad que las pensiones y los beneficios asistenciales tienen de apartar a las personas de la miseria. En todo el país, el $30,9 \%$ de la población vive con una renta domiciliar per cápita inferior a medio salario mínimo. En caso de no existir esa renta, el porcentaje subiría

$151 \quad$ Investigación Nacional Mayores en Brasil - Vivencias, desafíos y expectativas en la tercera edad, realizada por la Fundación Perseu Abramo en 2006. 
hasta el $42,5 \%$. Por estados, Santa Catarina $(87,8 \%)$, con el mayor índice de cobertura de trabajadores activos incluso en la Seguridad Social, es también el que tiene el menor índice de pobreza del país: el 10,6\%. Los estados de Río Grande del Sur $(73,1 \%)$, Distrito Federal $(70,1 \%)$, São Paulo $(68,7 \%)$, Paraná $(67,5 \%)$, Minas Gerais $(66,6 \%)$, Espírito Santo $(66,1 \%)$, Rondônia $(65,9 \%)$, Río de Janeiro $(65,3 \%)$ y Mato Grosso $(63,9 \%)$ ostentan porcentajes intermedios entre Santa Catarina y la media de Brasil (63,5\%). Para los investigadores del IBGE, una de las causas que explican el mayor número de jubilados en la zona rural está en el hecho de que los beneficios del sistema prácticamente se hayan universalizado en la década de los 90 , garantizando jubilaciones en el medio rural a aquellos mayores muy pobres que nunca habían cotizado al sistema de protección social. Queda claro que el sistema, ocupa un papel importante en la distribución de la renta, aunque ofrezca beneficios de valor reducido.

Por ello, parece oportuno subrayar que la importancia de los mayores para el país no se resume a su creciente participación en el total de la población. Ellos son responsables por una parte importante de la renta familiar, parcela esta que ha crecido a lo largo del tiempo. Una parte considerable de los mayores es Cabeza de Familia en la actualidad y en esas familias la renta media es superior a aquellas encabezadas por adultos no ancianos. Simões (2004) destaca que en las familias donde los mayores son la fuente principal de renta, se encuentra un número cada vez mayor de mujeres ocupando ese papel de "proveedor", también se verifica una parcela expresiva de hijos viviendo junto a padres y abuelos. Por ende, el número de mayores con 60 años o más que se considera cabeza de familia en Brasil llega al $71 \%$, porcentaje que alcanza el $74 \%$ en la región nordestina, de acuerdo con los datos de la Pesquisa Nacional Mayores en Brasil (2006). Esa contribución, presenta diferencias por sexo: el $88 \%$ de los que se consideran jefes de familia son hombres y el $58 \%$ son mujeres. Entre los hombres, la participación en esta condición cae con la edad: del $90 \%$ de los de 60 a los 69 años, al $77 \%$ con 80 años o más. Entre las mujeres, la tasa crece con la edad: del $52 \%$ de los 60 a los 69 años al $72 \%$ entre las que pasaron de los 80 años. Además del sustento familiar, poco a poco, los mayores son responsables de generar empleos, 
especialmente en la creciente industria del turismo y en la industria y el comercio de productos médicos y farmacéuticos.

La investigación muestra además que la gran mayoría de la población mayor tiene alguna fuente de renta propia, tanto los hombres $(97 \%)$, como las mujeres (87\%). Este índice, en el Nordeste, queda tres puntos porcentuales por encima del nacional. De estos, el $88 \%$ contribuye a la renta familiar, siendo la mayoría hombres (un 95\% frente a un $83 \%$ de mujeres). Entre los mayores brasileños con alguna fuente de renta, el $80 \%$ dependen de la Seguridad Social: el $28 \%$ son jubilados por edad, el $26 \%$ por tiempo de servicio, el $10 \%$ por invalidez y el $16 \%$ reciben pensión. Las fuentes de renta predominantes, entre los hombres mayores, son la jubilación por tiempo de servicio (39\%) o por edad (28\%); entre las mujeres mayores la jubilación por edad (28\%) y pensión por viudedad (26\%). De los hombres mayores, el $79 \%$ están jubilados, entre los cuales el 18\% aún trabajan. Entre las mujeres mayores el $13 \%$ están en la PEA. En este contexto, se comprende que tener un mayor en la familia ayuda a elevar la renta media mensual de la vivienda. Para los Indicadores Sociales Municipales en 2000 (IBGE), tres de cada diez mayores prácticamente sustentaba a toda su familia.

Es importante señalar que la degradación de las condiciones de vida de los mayores obliga a hombres y mujeres a permanecer trabajando hasta edades avanzadas. Sobre la cuestión, Peixoto sentencia “la jubilación no significa el fin de una actividad profesional y el inicio del uso del tiempo libre. Al contrario, es una forma de reconversión, pues en Brasil, la jubilación no representa una ruptura definitiva con la vida activa, una vez que el beneficio recibido no es suficiente para que uno sobreviva" (2004:60). En ese sentido, factores como la edad precoz de jubilación ${ }^{152}$ y el aumento de la longevidad asociados principalmente a pensiones de jubilación muy bajas, que no permiten a los jubilados disfrutar del tiempo de reposo, y de un sistema de Seguridad Social precario, incapaz de atender convenientemente a la población concerniente, colaboran para que los mayores vuelvan al mercado

152 La mayor parte de los brasileños comienza a trabajar aún muy joven: el 16,6\% de los niños entre 10 y 14 años y el 44,6\% de los adolescentes entre 15 y 17 años trabajan (IBGE, 2000). De ese modo, no es por casualidad que el $75 \%$ de los hombres se jubilen con poco más de 50 años, tasa que aumenta hasta el $83 \%$ entre las mujeres (Beltrão y Oliveira, 1999). 
de trabajo (Peixoto, 2004). Por un lado, según datos del IBGE en 2005 el 30,2\% de los adultos mayores estaban ocupados en el mercado de trabajo, lo que corresponde a alrededor de 6 millones de personas. La proporción era mayor en el grupo de 60 a 64 años de edad, el 46,7\%, con destaque para la región Nordeste, con el $53,1 \%$. Hay más hombres mayores trabajando que mujeres, un $43 \%$ frente a casi un $20 \%$. Entre los mayores del sexo masculino con edad superior a 70 años, casi el $28 \%$ estaban ocupados. En el Sur, ese porcentaje era del 36,4\%. Estos números marcan una diferencia en la economía del país. Los mayores realmente contribuyen a la renta mensual de sus familias. El retorno o la permanencia en actividades remuneradas, no obstante, se dan sobre todo en condiciones menos favorables y más precarias en las clases populares, bajo la economía informal, es decir, en actividades mal remuneradas y con jornadas de trabajo extensas. Peixoto (2004) apunta que los hombres trabajan, en general, como operarios autónomos, desempeñando funciones de carpinteros, pintores de pared, conductores de camión, fontaneros, traperos y chatarreros recogiendo periódicos, latas y cuantos objetos puedan ser reciclados o revendidos, etc. Las mujeres ejercen principalmente actividades domésticas remuneradas como costureras, lavanderas, manicuras o hacen pasteles y dulces para venderlos; las que trabajan fuera de casa acostumbran a limpiar en domicilios particulares o a vender productos de belleza o lencería. Por otro lado, los datos de la Encuesta Idosos no Brasil - Vivências, dasafios e expectativas na $3^{a}$ Idade de 2006 revelan que el 22\% de los mayores forma parte de la Población Económicamente Activa - PEA, siendo el $11 \%$ jubilados. Sólo el $5 \%$ está en el mercado formal y el $15 \%$ en la economía informal, actuando principalmente de modo temporal, haciendo "chapuzas" (12\%). Fuera de la PEA, el 21\% de las mayores se declaran amas de casa.

El fenómeno social que está trasladando a los ancianos brasileños de la posición de dependientes a la de proveedores refleja también, conforme la Síntesis de los Indicadores Sociales de 2006, un contexto desfavorable: el deterioro económico de otros grupos de edad a causa del desempleo, en especial entre los más jóvenes, la caída de la renta media y de las oscilaciones de la economía en las últimas décadas. A eso se puede agregar el 
aumento de las tasas de embarazo en la adolescencia, el mayor número de divorcios y separaciones en todas las franjas de edad y el mayor tiempo que los hijos adultos pasan como dependientes de sus padres. Esto sucede principalmente en la clase media, durante el periodo de graduación, postgrado o durante un período de desempleo. $Y$ todavía hay que mencionar a los que vuelven a mantener a los hijos cuando éstos están desempleados, por motivo de viudez o de separación después de matrimonios duraderos. Ese nuevo papel del mayor en la familia puede ser observado bajo múltiples puntos de vista. Si por un lado esa situación propicia la solidaridad familiar y un intercambio enriquecedor entre las generaciones, haciendo que el mayor gane importancia y se sienta útil y participante, por otro sugiere problemas y dificultades financieras. En otras palabras, eso quiere decir que sobra menos dinero para los medicamentos, para el ocio, la alimentación y otros gastos. Además, muchos de los mayores vuelven a trabajar y pierden un tiempo precioso que podrían estar dedicando a los estudios y a la realización de sueños que no pudieron llevar a cabo mientras la prioridad de sus vidas era el sustento y la crianza de los hijos.

\section{El estado de salud de los adultos mayores brasileños}

Aunque el hecho vivir más conlleva mayores probabilidades de padecer dolencias crónico-degenerativas no transmisibles e incapacitadoras, como las cardiovasculares, entre ellas la hipertensión y la diabetes mellitus, cáncer, osteoporosis, las pulmonares obstructivas, mal de Alzheimer, entre muchas otras e ingresar en hospitales con mayor frecuencia en relación a otras edades, envejecer por sí sólo no debe ser necesariamente sinónimo de enfermar. Estas dolencias alcanzan a personas de todas las edades. Pero, para muchos y desde los pensadores más remotos, la vejez es una enfermedad. Tal como dijo Antífonas La vejez es, por así decir, el santuario de los males: todos encuentran refugio en ella.

En general, las personas mayores no están condenadas a enfermar sólo por tener más edad; hay personas de edad avanzada bien dispuestas, en buenas condiciones de salud y con gran capacidad funcional, así como también hay gente joven con muchos problemas de salud. La imagen estereotipada de los 
adultos mayores asociada a la fragilidad, pérdidas progresivas, incapacidad, impotencia, decrepitud y a la dependencia, según Motta (2000), aún presente en la vida cotidiana, poco a poco va cambiando. Principalmente en los países más desarrollados las personas llegan a una edad más avanzada en mejor estado de salud, gracias a los avances de la medicina y a las mejoras sociales conseguidas $^{153}$. Tal visión estereotipada, es el resultado de la dificultad de distinguir entre envejecimiento normal y patológico, senescencia y senilidad. Para Paschoal y Berzins (2008), está situación lleva a la negación de la vejez o a la negligencia de sus necesidades, voluntades y deseos. Las personas de edad tienden a ignorar síntomas como la tristeza, el dolor o el cansancio, o esos mismos síntomas son ignorados por los profesionales de la salud. Para los autores, muchos profesionales intentan explicar las quejas de los mayores como una parte del proceso natural del envejecimiento, lo que lleva a omisión o negligencia, impidiendo el tratamiento, rehabilitación, adaptación, mejoría y cura. La falta de atención a los síntomas retarda o impide conductas y tratamientos, lo que puede tener consecuencias negativas para la vida y su calidad.

No obstante, existe un consenso acerca de que los problemas de salud son más frecuentes con la edad y que la gente mayor representa un grupo de riesgo (Kalache, 1987; Kinsella, 1994; Caballero, 1992). Sigue siendo verdad que la tercera edad es una época de la vida en que la persona es particularmente vulnerable, víctima de la fragilidad humana. Es muy frecuente que la aparición de enfermedades crónicas reduzca al anciano a la invalidez y recuerde, inevitablemente, el momento del final de la vida ${ }^{154}$. Los adultos mayores están potencialmente bajo riesgo, no sólo porque envejecen, sino en virtud de que el proceso de envejecimiento los vuelve más vulnerables a la incapacidad, en gran medida, derivada de las condiciones adversas del medio físico, social y económico. En realidad con el avance de la edad aumenta la posibilidad de que se produzcan dolencias y prejuicios que afecten a la funcionalidad física, psíquica y social. Vivir más puede dar lugar a una

\footnotetext{
153 Sobre este tema ver Palmora, 1976; H. Cox, 1984; J. A. Brody, 1982; B. Neugarten, $1988 ;$ V. W. Marshall, 1982.

$154 \quad$ Ver Carta de Juan Pablo II a la Asamblea mundial sobre el envejecimiento (Vaticano, 3 de abril de 2002).
} 
sobrevida marcada por incapacidades y dependencia. Por tanto, es preciso distinguir entre lo que es dolencia y lo que es propio de la vejez, con sus transformaciones naturales. De este modo, la vejez no debe ser tratada sólo con soluciones médicas. Son necesarias intervenciones sociales, económicas y ambientales en ese proceso.

Siendo la salud ${ }^{155}$ un bien inapreciable de las personas, una de las preocupaciones de los adultos mayores es envejecer gozando de buena salud. Ellos quieren entrar en la etapa de la ancianidad con un grado de salud suficiente para disfrutar de esos años de vida. En Brasil, esto se podría garantizar de modo eficiente con la ejecución, en la práctica, de los derechos sociales de los mayores, previstos en las leyes y estatutos que vamos a subrayar en el próximo apartado. Envejecer de forma saludable y con calidad de vida siempre fue un sueño natural de cualquier persona o sociedad. "Deseamos envejecer bien, sin dolor o con el mínimo de sufrimiento. Usualmente, miramos con admiración a aquellos que atraviesan los años revelando bienestar, realización personal, vivacidad y vigor preservados” ${ }^{\text {156. }}$. En ese sentido, el desafío que se propone a los individuos y a las sociedades es conseguir una sobrevida cada vez mayor, con una calidad de vida mejor, para que los años vividos en edad avanzada estén llenos de significado. Particularizando este tema, Peláez (2005), enfatiza que "ésta tendrá que superar el simple conocimiento científico del desarrollo y bienestar infantiles para poder erigir los cimientos de una buena calidad de vida y de una buena capacidad funcional en la vejez" (2005:299).

Todavía, es importante notar que aunque los indudables avances en la mejora de la salud sean una realidad, no pueden ocultar que en numerosos lugares del mundo las personas mayores no gozan de buena salud y tampoco tienen acceso a la atención sanitaria. Muchas de ellas se encuentran discriminadas en su derecho básico de protección a la salud y no pueden disfrutar de los

\footnotetext{
155 La Organización Mundial de la Salud define la salud como un estado de completo bienestar físico, mental y social, y no meramente como la ausencia de enfermedades o padecimientos. (Informe de la Segunda Asamblea Mundial sobre el Envejecimiento, 8-12 de abril de 2020 - Recomendaciones para adopción de medidas $\left.\mathrm{n}^{\circ} 59\right)$.

156 Brigeiro, Mauro (2005): Envejecimiento exitoso y tercera edad: Problemas y retos para la promoción de la salud Invest. educ. enferm, mar./sep. 2005, vol.23, no.1, pp.102-109. ISSN 0120-5307.
} 
avances científicos. Ante la marginación del anciano en la sociedad actual, la vulnerabilidad de esa categoría de personas se acentúa de manera importante en el caso de las mujeres, dado que ellas viven más que los hombres. En su mayoría el deterioro de la salud es intenso. Como subraya Litvak (1990), los problemas sociales, económicos y de salud de los adultos mayores, son en gran parte, los de las mujeres de edad avanzada, dada su mayor esperanza de vida.

En este universo, aún cuando la evidencia en algunos países avanzados parece indicar que el envejecimiento se está convirtiendo en un período de vida donde las condiciones de salud están mejorando, son pocas las evidencias de que esto sea así en los países en desarrollo y en aquellos menos desarrollados. A pesar de que la salud es reconocida como un derecho social, necesario para garantizar una existencia digna a las personas, en gran parte de los países de América Latina, mucha gente no cuenta con servicios médicos asequibles, apropiados y ajustados a sus necesidades. Además de eso, las personas mayores son privadas de los cuidados de salud y socio sanitarios que garantizan la autonomía personal y la calidad de vida. Esta es una situación que se suma a otras múltiples circunstancias graves como las dificultades económicas, la ausencia de servicios sociales, la exclusión de la cultura y la educación, el trato inadecuado, la escasa participación en la vida social y política. En ese sentido, los problemas de salud de las personas mayores se agudizan como consecuencia de las condiciones en las que vive buena parte de ellas

En Brasil, Carboni y Reppetto (2007), argumentan que "la población mayor brasileña no sólo está viviendo más, sino también mejor, dado que los individuos que consiguen vivir hasta edades más avanzadas son seleccionados por sus mejores condiciones de salud y su mejor calidad de vida"157. Según las autoras, la inversión en la medicina moderna a lo largo de los últimos 60 años, propició una mejora en la calidad de vida de las personas y consecuentemente, el aumento de expectativa de la vida. Otros factores que han contribuido exponencialmente a la prolongación de la vida en Brasil

157 Carboni, R. M. y Reppetto, M. A. (2007): Uma reflexão sobre a assistência à saúde do idoso no Brasil, Revista Eletrônica de Enfermagem (serie online) 2007 jan-abr; 9(1): 251-260, p. 255. 
incluyen las medidas de saneamiento, el proceso de universalización de la seguridad social, el mayor acceso a los servicios de salud, entre otros cambios sociales.

Sin embargo, características socioeconómicas como el bajo nivel de renta y de educación ${ }^{158}$, así como el desarrollo de actividades remuneradas en edades avanzadas, representan algunos de los indicadores que suponen precariedad de las condiciones y de la calidad de vida para la gran mayoría de los ancianos en Brasil, en especial en la zona rural. Con relación al aspecto educativo, está comprobado que las personas más instruidas tienden a adoptar hábitos de vida más saludables y a buscar más servicios médicos, especialmente los cuidados preventivos, una vez que al poseer más informaciones sobre las dolencias y los posibles tratamientos o diagnósticos, tienden a valorar de forma diferente el cuidado de la salud.

Para reforzar las ideas planteadas, Rodriguez y Rauth (2002), resaltan que, a pesar de la heterogeneidad de la vejez, hay una característica recurrente en las sociedades que es la de que las personas mayores son más pobres que los adultos más jóvenes de la misma población. Lo mismo ocurre en nuestro país, donde, al lado de un Brasil industrializado, desarrollado y más o menos rico, hay un Brasil extremamente pobre, donde los viejos son numerosos, con bajas pensiones y jubilaciones o con un beneficio de prestación continuada. Las mujeres mayores son más pobres que los hombres.

En ese sentido, una vida más larga no significa en su totalidad vivir mejor en Brasil. La más reciente encuesta que traza el perfil de las condiciones de salud de los mayores en Brasil $^{159}$, revela que el $81 \%$ de los ancianos padece alguna enfermedad, cerca del $26 \%$ de las mujeres mayores de 60 años nunca

\footnotetext{
158 De acuerdo con la Pesquisa Nacional Mayores en Brasil - Vivencias, desafíos y expectativas en la tercera edad (2006), el 89\% no pasó de la enseñanza fundamental, el 18\% no recibió ninguna educación formal y apenas el $3 \%$ llegó al $3^{\circ}$ grado de escolaridad.

La Pesquisa Mayores en Brasil - Vivencias, desafíos y expectativas en la $3^{\text {a }}$ edad por medio de su Núcleo de Opinión Pública, junto con el SESC Nacional y SESC São Paulo, en abril de 2006, escuchó a 3.759 brasileños y brasileñas. Distribuidos en 204 ciudades de las cinco macro regiones del país, mayores (2.136) y no mayores (1.623) respondieron a un cuestionario de 155 preguntas sobre sus percepciones acerca de la vejez.
} 
se realizó pruebas ginecológicas como el Papanicolaou y sólo el $22 \%$ se las realizan una vez al año. El de útero es el tercer tipo cáncer que más afecta a las brasileñas. El primero es el cáncer de mama y el segundo el de piel (no melanoma). De acuerdo con los datos del Instituto Nacional del Cáncer (INCA), actualmente el cáncer de mama y de útero mata a más de 7 mil mujeres al año; en el mundo son más de 230 mil muertes anualmente. Su incidencia es mayor en las regiones norte y nordeste del país. Es una dolencia muy común en países pobres o en desarrollo. En cuanto a los hombres, el índice de los que nunca se realizaron pruebas de próstata alcanza el $42 \%$; sólo el $6 \%$ se las hicieron en los últimos 6 meses y el 16\% en el último año. Una gran parte de los mayores equivalente al $86 \%$ nunca se hizo la prueba del SIDA. Según las estadísticas epidemiológicas, el cáncer de próstata ocupa, en los países occidentales, el tercer lugar en frecuencia y mortalidad entre las enfermedades malignas que afectan a los varones. Los datos aún apuntan que el $31 \%$ de los hombres y el $22 \%$ de las mujeres mayores nunca se sometieron a un examen cardiológico. El $59 \%$ de los hombres y $56 \%$ de las mujeres nunca se realizaron un examen de audición; el 51\% afirma no haber recibido nunca la visita de los agentes de salud y el $88 \%$ la de los médicos del programa Salud de la Familia. Entre el $48 \%$ que ya fue visitado por los agentes de salud el $24 \%$, que corresponde a la mitad, recibe visitas regulares. Las visitas regulares de médicos del Programa sólo alcanzan al $3 \%$ de los mayores. Mientras los servicios públicos de salud son utilizados por el $68 \%$ de los mayores, otro $24 \%$ posee convenio médico o plan particular de salud. El 11\% acostumbra a pagar a médicos u hospitales privados y el $7 \%$ afirma recurrir a la medicina casera. El 5\% cuenta con los agentes comunitarios de salud. Como puede observarse, el mayor brasileño de hoy no cuenta, y a lo largo de la vida no contó, con un sistema de atención dirigido a la consecución de un envejecimiento exitoso. Como consecuencia, hay un contingente poblacional que necesita y no tiene acceso a los bienes y servicios capaces de garantizar la calidad de vida en ese período de la existencia. Frente a esta situación, el documento Carta de Fortaleza - Envelhecimento com saúde e dignidade, um direito do cidadão (2005) reconoce que, a pesar de los esfuerzos del Sistema Único de Salud ${ }^{160}$, 
aún existe una falta de respeto a los principios de acceso universal e igualitario a las acciones y servicios para la promoción y recuperación de la salud de los mayores brasileños previstos en el artículo 196 de la Constitución Federal de 1988.

Teniendo en cuenta lo indicado del proceso de envejecimiento acelerado y de la transición epidemiológica, Brasil tiene un desafío crucial por delante que es el de crear condiciones económicas y sociales que permitan una buena calidad de vida a todos los mayores, especialmente a los más pobres y vulnerables. La actualización, en 2006, de la Política Nacional de Salud a la Persona Mayor (Portaría $n^{\circ} 2528$, de 19 de octubre) y del Pacto por la Salud con el Pacto por la Vida (Portaría n $399 / G M$, de 2 de febrero) colocaron a la población mayor en el centro de las prioridades del SUS. Sin embargo, las políticas de asistencia existentes no son suficientes. Es necesario que haya políticas universales de acceso a servicios básicos de salud por medio de la atención primaria y un fortalecimiento de estas acciones, a través de los centros de salud que prestan asistencia a comunidad local. Además, según Veras y Caldas (2004), el aumento de la proporción de mayores en la población implica, en términos de utilización de servicios de salud, un mayor número de problemas de larga duración que, frecuentemente, exigen intervenciones costosas y el uso de tecnología para un cuidado adecuado. Todos deseamos envejecer con buena salud para seguir participando de la vida social. Por eso, la situación exige la planificación de acciones de corto, medio y largo plazos para la promoción de un envejecimiento saludable. Los grandes ejes de la agenda, para este país que envejece rápidamente, deben implicar a todos los sectores de la sociedad sean gubernamentales, no gubernamentales, voluntarios 0 privados. SUS realiza de modo gratuito, muchos procedimientos, entre los cuales citamos los trasplantes, diálisis en general, cirugías complejas como las cardíacas, prótesis y ortopedias sofisticadas, procedimientos de alta complejidad, medicamentos de alto costo, tratamientos de SIDA, tratamiento del Alzheimer, de dolencias crónicas, vacunación contra el virus de la gripe, ingresos y asistencia domiciliar. (Paschoal y Berzins, 2008). 
Frente a este contexto la Carta de Fortaleza recomienda sobre todo un cambio de paradigmas;

1. El prejuicio contra el envejecimiento se traduce en la resistencia a incluir a la población mayor en las acciones de salud y da lugar a la inacción por parte de los gestores. Es necesario superar ese problema y reconocer a la vejez como una fase natural y deseable de la vida y que, por lo tanto, toda inversión que se haga a favor del envejecimiento revertirá en conquistas para la sociedad como un todo.

2. El mayor brasileño ha sido injustamente acusado de provocar la falencia del sistema de seguridad social y de generar dificultades al sistema de salud. Será necesario un amplio trabajo de concienciación de toda la sociedad y de valoración del mayor, incluso entre los gestores.

3. Para minimizar el impacto del envejecimiento poblacional es necesario crear mecanismos de desarrollo y de inclusión social de todas las franjas de edad que sostienen las políticas de seguridad social.

4. La capacidad funcional es un indicador de salud del mayor y debe ser la base de los modelos asistenciales. Estos modelos deben ser diferentes en función del grado de dependencia y la capacidad funcional. La pérdida de ésta y de la autonomía pueden ser prevenidas con el control de dolencias crónicas a través de acciones de rehabilitación en todos los niveles de atención a la salud del mayor.

5. De esta forma, el envejecimiento debe ser incluido en la agenda de acciones intersectoriales, contemplando todos los aspectos que visen reducir la vulnerabilidad del mayor y promover la capacitación de la red asistencial para el cuidado de los que poseen 60 años de edad o más. 


\section{Acerca de las políticas públicas para los adultos mayores en Brasil}

Como todo fenómeno social, la vejez de las personas y el envejecimiento poblacional suponen determinantes y consecuencias frente a las cuales las sociedades deben asumir la disposición de actuar con eficiencia y eficacia. Una de las capacidades de respuestas se refiere al tema del diseño de políticas y prácticas sociales que deben constituirse no sólo en perspectiva de una acción pública, sino también en acciones privadas y voluntarias en concreto. En este sentido, como apuntan Veras y Caldas (2004), "la revolución demográfica fórmula para los expertos, hombres públicos y colectividades uno de los mayores desafíos sociales de la historia humana y una intensa demanda de estudios y análisis para una mejor definición de las políticas públicas ${ }^{161}$ de prevención de salud en el envejecimiento" ${ }^{\text {162 }}$.

En Brasil, el aumento sin precedentes de la visibilidad social de los adultos mayores de 60 años, tanto por el factor numérico como por el crecimiento de instituciones sociales que pasaron a atender a ese segmento y a trabajar en defensa de los derechos de las personas de edad, fue uno de los factores que instigaron la movilización de órganos gubernamentales y no gubernamentales para atender las nuevas demandas surgidas principalmente en el ámbito de la salud, de la asistencia y de la seguridad social (Rodríguez y Rauth, 2002:106). En opinión de Kalache (1996), el brasileño está viviendo más y eso es un triunfo, pero para disfrutar de la vejez, es preciso disponer de políticas adecuadas que puedan garantizar un mínimo de condiciones de calidad de vida para los que llegan hasta ella. Según Paim (2004), la infraestructura para responder a las demandas de la población mayor de 60 años en términos de instalaciones y programas está muy lejos de lo deseable. Sin embargo, antes de discurrir sobre las políticas sociales, conviene dejar bien claro que en

\footnotetext{
161 Las políticas públicas deben garantizar los derechos fundamentales (vivienda, renta, alimentación), y desarrollar acciones orientadas a las necesidades específicas de la población de adultos mayores, como la atención integral institucional, centros de referencia especializados de asistencia social, centros de convivencia, asistencia especializada a la salud, centros diurnos, asistencia domiciliar, programas de medicamentos, universidad de la tercera edad, institución de larga permanencia, viviendas provisionales para los mayores en situación de violencia, entre otros.

162 Veras, R. P.y Caldas, C. P. (2004): Promovendo a saúde e a cidadania do idoso: o movimento das universidades da terceira idade. Temas Libres. Ciencia \& Saúde Coletiva, 9(2):423-432, p. 424.
} 
Brasil hay 3 edades distintas para definir a una persona mayor. La primera aparece recogida en la Constitución Federal de 1988 que, para asegurar el derecho a la gratuidad en los transportes colectivos urbanos, determina que el adulto mayor es aquel que tiene más de 65 años (CF, artigo 230, ๆ $2^{\circ}$ ). La segunda, la Ley Orgánica $n^{\circ}$. 8.742/93, que organiza la asistencia social, subraya que el mayor, para el fin de recibir el beneficio de un salario mínimo mensual, es aquél que tiene una edad igual o superior a 70 años (LOAS, artigo 20) ${ }^{163}$. El Código Penal, Decreto-Ley $n^{\circ}$. 2.848 de 1940, también define como "mayor" a los que alcanzan la edad de 70 años. Finalmente, la Ley $\mathrm{n}^{\circ}$. 8.842/94 que traza la Política Nacional del Mayor, considera anciano, para todos los efectos de esta ley, a la persona mayor de 60 años de edad (PNI, artigo $2^{\circ}$ ), conforme es indicado por la Organización Mundial de Salud (OMS).

La preocupación por las políticas y prácticas sociales de atención a los adultos mayores tiene su origen en el esfuerzo de segmentos específicos del Gobierno y de la gran movilización de la sociedad civil en busca del cumplimiento de las normativas internacionales, especialmente de las Asambleas Mundiales sobre el Envejecimiento celebradas en Viena en 1982, en Madrid en 2002 y nacionales, en Brasil en 1994 con la publicación de la Ley $\mathrm{n}^{\circ}$. 8.842/94. Es pertinente destacar que hasta la década de los setenta, el trabajo realizado en Brasil con adultos mayores era de carácter caritativo, paliativo y fragmentado, desarrollado especialmente por órdenes religiosas o entidades filantrópicas. El Servicio Social del Comercio (SESC), fundado en 1946, es una excepción ya que desde su fundación viene desarrollando un trabajo de atención a las personas mayores. Actualmente el Centro de Referencia del Envejecimiento (CRE), proyecto desarrollado por el SESC en Río Grande del Sur, utiliza el ambiente virtual para informar y actualizar a la sociedad sobre un proceso de envejecimiento digno y activo. Según los datos del Informe Nacional Brasileño sobre el Envejecimiento de la Población Brasileña de 2002, el SESC ya asistió en todo el territorio nacional a una clientela de aproximadamente 70.000 adultos mayores.

163 Después de pasados 24 y 48 meses del inicio de la concesión de este beneficio, la edad fue reducida a 67 y 65 años para hombres y mujeres, respectivamente (LOAS, Artigo 38). 
En este apartado, citaremos las principales leyes y entidades que diseñan las políticas públicas para los senescentes brasileños, así como la participación de la sociedad civil en la ejecución de las mismas.

\subsection{Constitución Federal}

La Constitución Federal de 1988 fue escrita al finalizar el gobierno militar (1984). Después de dos décadas de dictadura, la sociedad brasileña estaba ávida de una estructura constitucional que preservase los derechos fundamentales de los brasileños. Promulgada el 5 de octubre por el ex presidente José Sarney, la carta magna garantiza los derechos sociales, colectivos e individuales. La Constitución Federal propone políticas sociales universales, no contractualitas, lo que significa que el ciudadano no precisa pagar por ellas. "Esas políticas deben ser generadas de forma solidaria, sistémica y obligatoria, por medio de una recaudación justa de impuestos”164. Distinta de las constituciones anteriores, la octava carta brasileña incluye la vejez como elemento de atenciones obligatorias, como registra el Artículo 230. La definición estipula que "la familia, la sociedad y el Estado (gobierno) tienen el deber de amparar a los adultos mayores, asegurando su participación en la comunidad, defendiendo su dignidad y bienestar y garantizándoles el derecho a la vida". Más adelante la carta magna especifica aún más los cuidados dirigidos a los ancianos. El Art. 229 subraya que "los hijos mayores tienen el deber de ayudar y amparar a los padres en la vejez, pobreza o enfermedad".

La CF/88 pone en pie de igualdad la responsabilidad de los tres segmentos: Gobierno, sociedad y familia a la hora de actuar en favor de los mayores. Las acciones deben ser una actitud de vida que implique a todos, individual y colectivamente, creando así, condiciones para asimilar mejor esa etapa de la vida. Compete a cada uno de nosotros brasileños el desafío de cuidar de los mayores, en medio de una sociedad de modelo económico neoliberal, que sobrevalora el lucro, la productividad, el consumo y la eficiencia. En este

164 Borges, M. C. M. (2003), op., cit., 84. 
modelo, el colectivo es considerado frecuentemente como inútil, una carga para la sociedad, algo improductivo.

\subsection{Ley Orgánica de la Asistencia Social (LOAS)}

La Ley Orgánica de Asistencia Social (LOAS), $\mathrm{n}^{\circ}$ 8.742, de 1993, vino a reglamentar el Beneficio de Protección Continuada (BPC) previsto en los principios fijados por la Constitución Federal de 1988 (Art. 203, V). El Artículo $1^{\circ}$ de la LOAS afirma que "la asistencia social, derecho del ciudadano y deber del Estado, es una Política de Seguridad Social no contributiva, que prevé los mínimos sociales, y es realizada a través de un conjunto integrado de acciones de la iniciativa pública y de la sociedad, para garantizar la atención de las necesidades básicas". Esto significa que la asistencia social está pautada por la universalidad de la cobertura de atención y protección de los brasileños, siendo un deber del Estado y un derecho para quien la necesite, independientemente de su contribución. Implantado tres años después, en enero de 1996 en el Gobierno de Fernando Henrique Cardoso, el Beneficio de Protección Continuada (BPC) de la Ley Orgánica de Asistencia Social (LOAS) establece que los derechos sean garantizados a través de servicios, programas y proyectos implementados en los municipios, proponiendo, para ello, la creación de Consejos Municipales de Asistencia Social - CMAS. Los CMAS tienen poderes deliberativos sobre la Política Municipal de Asistencia Social realizada en nombre de las organizaciones gubernamentales y no gubernamentales. El BPC es pagado por el Ministerio de Desarrollo Social y Combate al Hambre. Ese Ministerio administra el Fondo Nacional de la Asistencia Social (FNAS) e integra la política nacional de asistencia social para los adultos mayores y portadores de deficiencia.

La Seguridad Social paga, mensualmente, alrededor de 3 millones de beneficios asistenciales en todo Brasil, con un valor equivalente a 1,1 billones $^{165}$. El beneficio asistencial al mayor y al discapacitado, concedido y pagado por el INSS, es destinado a personas sin condiciones financieras de

\footnotetext{
165 Beneficios: Casi tres millones de personas reciben beneficios asistenciales. Mayores y portadores de deficiencia tienen derecho. Noticia de 08/06/2007. Página web http://www.previdenciasocial.gov.br/AgPREV visitada en 21/06/2007.
} 
contribuir a la seguridad social. Tienen derecho al amparo asistencial los mayores a partir de 65 años de edad, que no ejerzan actividad remunerada, así como los portadores de deficiencia, incapacitados para el trabajo y la vida independiente. Tal beneficio es equivalente a 1 (uno) salario mínimo, hoy R\$ 415,00 . En caso de muerte, el valor no podrá ser transferido a otro miembro de la familia.

Para tener derecho al BPC, el solicitante debe demostrar una renta familiar inferior a un $1 / 4$ del salario mínimo por persona, lo que equivale hoy en día a $\mathrm{R} \$ 103,75$. Para saber el valor de la renta familiar es necesario sumar la renta de todas las personas que viven en la misma vivienda. Después, se divide el valor resultante por el número de personas de la residencia. En el caso de los mayores, además de la renta y de la edad, es necesario demostrar que la persona no recibe otro beneficio social (como por ej. jubilación, pensión por viudedad o auxilio por enfermedad). Sin embargo, hay que observar, que si hay otra persona en la misma casa recibiendo el BPC, ese valor no es usado para calcular la renta familiar.

De acuerdo con la LOAS (Art. 21), los beneficios son revisados cada dos años. Comprobarlos no significa excluir a los beneficiarios sino garantizar sus derechos y propiciar las condiciones necesarias de inclusión para ellos y su grupo familiar en programas y proyectos sociales del municipio, en la medida que la evaluación social permite un diagnóstico de sus necesidades. Un cambio positivo de la situación económica del mayor o de su familia puede generar la paralización de la concesión del beneficio.

Para muchas familias brasileñas las pensiones no contributivas representan una experiencia social de gran importancia, caracterizándose por ser la única fuente de sustentación familiar. Los municipios también son beneficiados en la medida que el montante del recurso financiero, procedente de las ayudas, es invertido en el comercio local, generando ganancias en la recaudación municipal. Recibir beneficios de la seguridad social mejora la calidad de vida de los miembros del domicilio permitiendo, según Delgado y Cardoso Jr., (2000), la adquisición de electrodomésticos. Con ese dinero también es 
posible mejorar las residencias de los mayores, una vez que se pueden adquirir materiales de construcción (Schwarzer, 2000). Las consecuencias positivas subrayadas evitaron y continúan evitando que se produzcan en mayor cantidad migraciones hacia las grandes ciudades, que hinchan las periferias metropolitanas.

Rocha (2000) destaca que la percepción de las ayudas sociales redefinió el papel social de los mayores en las familias y comunidades rurales brasileñas. El cambio en los papeles es particularmente evidente en el caso de las mujeres, que ahora poseen una fuente de renta propia. También es importante enfatizar que, en vez de erosionar los lazos familiares, la solidaridad en las familias normalmente se ve fortalecida con el sistema de jubilaciones y pensiones no contributivas.

La Ley Orgánica de Asistencia Social fue un importante paso dado para mejorar la distribución de la renta y dar condiciones de supervivencia a brasileños que eran enteramente marginalizados, excluidos y carentes. De acuerdo con los resultados alcanzados por el PNAD (2000) el impacto del Beneficio de Prestación Continuada año tras año reduce significativamente la pobreza en Brasil. Desde 2003, el Estatuto del Mayor ha reducido de 67 a 65 años la edad mínima para que los mayores realicen la solicitud. En este sentido hubo un aumento de la cobertura del BPC, al que accedió un mayor número de ancianos brasileños.

\subsection{Política Nacional do Idoso (= Mayor) (PNI)}

Para reforzar lo que está garantizado en la Constitución Federal de 1988, fue aprobada la Ley $n^{\circ} 8.842$ de 4 de enero de 1994, de Política Nacional del Mayor destinada a establecer los principios básicos que deben orientar las iniciativas de la Unión Federal, Estados y Municipios en favor del adulto mayor, así como para coordinar la actuación de las diversas esferas de poder en la ejecución de programas y proyectos en ese área. Considerada moderna, define los derechos sociales, asegura autonomía, integración y participación efectiva del anciano en la sociedad, en ejercicio de su propio derecho de ciudadanía (art. $1^{\circ}$ ). Esos derechos básicos deben ser concretizados a partir de 
políticas sociales en el área de la salud, promoción y asistencia social, educación, trabajo y seguridad social, habitación y urbanismo, justicia y cultura, deporte y ocio. Sus directrices priorizan la atención a domicilio; el estímulo a la capacitación de los médicos en el área de Gerontología y Geriatría; la descentralización político administrativa y la divulgación de estudios e investigaciones sobre aspectos relacionados con la tercera edad y el envejecimiento.

Elaborada y reivindicada por la sociedad, teniendo como ancla la Asociación Nacional de Gerontología (ANG), la entidad promovió innumerables discusiones y consultas en algunos estados brasileños, en las cuales participaron ancianos, jubilados, profesores y estudiantes universitarios, gerontólogos y geriatras, varias entidades representativas de ese sector, voluntarios e interesados. Al Presidente de la República le entregaron, después de ser debatido tanto en el área gubernamental como en la no gubernamental, el documento "Recomendaciones sobre Políticas Sociales, para los ancianos en los años 90". La estrategia posibilitó la aprobación de la referida Ley y en consecuencia del Decreto n. 1.948 de 3 de julio de 1996 que la reglamenta. La Política creó las condiciones necesarias para promover la longevidad con calidad de vida, poniendo en práctica acciones destinadas tanto a los que están envejeciendo como a aquellos que van a envejecer. Su implantación estimuló la articulación e integración de los ministerios para la elaboración, en 1997, de un Plan de Acción Gubernamental para Integración de la Política Nacional del Anciano, el cual recibió influencia y subsidios del gobierno de España por intermedio de un convenio de cooperación técnica y financiera con el INSERSO - Instituto Nacional de Servicio Social. Para hacer cumplir lo que establece la Ley actúan en conjunto los Ministerios de Previsión y Asistencia Social, de Educación, Justicia, Cultura, Trabajo y Empleo, de Salud, Deporte y Turismo, Planificación, Presupuestos y Gestión, todo bajo la coordinación de la Secretaria de Asistencia Social.

Para la implementación de la política nacional, la ley atribuye al Poder Público competencias muy claras en las más diversas áreas. Señalamos las tres principales; 
a) En la promoción y asistencia social, se prevén acciones en el sentido de atender las necesidades básicas del adulto mayor, estimulando la creación de centros de convivencia, centros de cuidados nocturnos, residencias, oficinas de trabajo, atención a domicilio, además de la capacitación de recursos humanos para tales fines (Art. 10, I);

b) En el ámbito de la salud, el adulto mayor debe disfrutar de toda la asistencia preventiva, protegida y de recuperación a través del Sistema Único de Salud; debe ser incluida la Geriatría como especialidad clínica, para efecto de concursos públicos federales, estatales y municipales (Art. 10,II);

c) En el área de la educación se prevé la adaptación del currículo de las escuelas con contenidos dirigidos al proceso de envejecimiento, de forma que se eliminen todos los prejuicios; la inserción de la Gerontología y Geriatría como asignaturas curriculares en los cursos superiores; la creación de programas de enseñanza destinados a las personas mayores de 60 años; apoyo a la creación de universidades abiertas para la tercera edad.

Aunque la ley prevea la garantía de los derechos sociales de modo amplio para la población mayor no podemos dejar de mencionar que hay una distancia muy acentuada entre teoría y práctica cuando se trata de la aplicación de los dispositivos de la ley. Falta mucho para que las políticas públicas de protección social dirigidas a ese colectivo sean plenamente respetadas y tomadas en serio en Brasil. En la práctica, muchos programas aún no se extendieron a todo el país y en este sentido, diversas regiones donde la demanda por tales servicios es relevante sufren la ausencia de estas políticas. En general, el contingente de los envejecidos no dispone de mecanismos o medios suficientes que garanticen la exigibilidad y el cumplimiento definidos en la ley. Por regla general, la sociedad civil trata con discriminación, negligencia, y sin respeto a la población senescente. A título de ejemplo, recordamos la ausencia de sectores de atención geriátrica y gerontológica en los hospitales; irregularidades en la distribución de medicamentos gratuitos para el tratamiento de dolencias crónicas; número irrisorio de servicios 
sociales como centros de convivencia, centros de cuidados diurnos, residencias y cuidadores de mayores. Observamos, entonces, que sólo desde el punto de vista legal la gente mayor está protegida en Brasil ya que la realidad es otra. Como dijo Fernandes (2003) en el artículo Envejecimiento y Ciudadanía, la política nacional del mayor debe ser entendida de forma eficiente, para una aplicación racional.

\subsection{Estatuto del Mayor}

El proceso de envejecimiento por el cual viene atravesando la población brasileña, demanda una mirada atenta a las peculiaridades de ese segmento de edad por parte del poder público, de la familia y de la sociedad, dado que el mismo exige estrategias, acciones y servicios que respondan a las necesidades de atención, protección y defensa de los derechos de las personas mayores. Para ello, emergió en la sociedad civil organizada la demanda de un Estatuto que garantizase derechos y estipulase deberes para mejorar la vida de las personas mayores de 60 años que viven en el país. Así, el Diputado Federal Paulo Paim (PT/RS), actualmente Senador de la República (2008), creó el Proyecto de Ley 3.531/97 que, seis años después de intensos debates, fue sancionado como Estatuto del Mayor, Ley n ${ }^{\circ} 10.741$ de 2003 . El proyecto se basa en la idea de la necesidad de aglutinar las legislaciones sobre ancianos del país, exigiendo un nuevo direccionamiento de prioridades de las líneas de acción de las políticas públicas. El avance de la legislación social brasileña garantiza que el país dé cada día más pasos en dirección a la justicia social.

Con el objetivo de garantizar unas condiciones mínimas de trato digno para este colectivo, la Política Nacional del Mayor cuida esencialmente de la actuación del poder público en la promoción de las políticas sociales básicas de asistencia a los mayores, mientras que el Estatuto del Mayor consolida los derechos ya garantizados por la Constitución Federal de 1988, sobre todo intentando protegerlos de una situación de riesgo social. Son las nuevas exigencias de la sociedad brasileña para la asistencia a la población senescente. 
El texto definitivo del Estatuto, una de las raras iniciativas que recibieron el consenso de todos los segmentos de la sociedad, define medidas de protección para las personas con edad igual o superior a 60 años. Fue sancionado por el Presidente Luis Inácio Lula da Silva, el $1^{\circ}$ de octubre de 2003, fecha que coincide con el Día Internacional del Mayor, para beneficio de más de 15 millones de ancianos en el país. En vigor desde el primero de enero de 2004, Lula da Silva dijo que, a partir del Estatuto, envejecer en Brasil será más que sobrevivir, resistir y mirar la puerta esperando una visita que no llega. A partir de este día, la dignidad del anciano pasa a ser un compromiso civilizador del pueblo brasileño, afirmó el Presidente.

Los 118 artículos constituyen un amplio abanico de garantías legales para los que pasaron de los 60 años y un día serán ancianos. La ley determina para este colectivo más acceso a la vivienda, la salud y el transporte, protección jurídica, educación, cultura, deporte y ocio entre otros beneficios. Entre las principales conquistas se destacan:

a) En los programas habitacionales públicos o subsidiados con recursos del gobierno el adulto mayor goza de prioridad en la adquisición del inmueble para vivienda propia, con la reserva del $3 \%$ (tres por ciento) de las unidades ofrecidas y la disminución de las barreras arquitectónicas (Art. 38)

b) En la promoción y la asistencia social asegura el beneficio mensual de un salario mínimo ( $R \$ 415,00 \pm 166 €)$ a los brasileños con más de 65 años considerados incapaces de proveer a su subsistencia y cuyas familias no demuestren una renta para tal fin (Art. 34).

Hasta 1988 el beneficio era concedido solamente a las personas con 67 años según lo estipulado por la LOAS. Este beneficio social es pagado por el INSS (Instituto Nacional do Seguro Social) para mayores carentes que nunca hayan contribuido a la seguridad social. Es considerado carente todo adulto mayor cuya renta familiar per cápita no supere un cuarto del salario mínimo, actualmente ( $R \$ 103,75 \pm 41,50 €)$. 
c) En el ámbito laboral, la admisión del mayor en cualquier trabajo o empleo, no puede estar condicionada a su edad y eso vale para las oposiciones, exceptuando los casos en que la naturaleza del puesto lo exija (Art.27).

d) En el área de la salud, veda la discriminación de los mayores de 65 años en los planes de salud mediante el cobro de precios diferentes en razón de la edad. Incumbe al Poder Público distribuir gratuitamente al colectivo medicamentos, especialmente los de uso continuado, así como prótesis y otros recursos relativos al tratamiento, habilitación o rehabilitación (Art. 15).

e) Asegura a los mayores de 65 años la gratuidad de los transportes colectivos públicos urbanos municipales e interprovinciales. En el primer caso se reservan el 10\% (diez por ciento) de los asientos para los mayores que acrediten su condición mediante un documento personal que demuestre su edad. (Art. 39). En el segundo caso se reservan dos plazas gratuitas por vehículo para el colectivo con renta igual o inferior a dos salarios mínimos y un descuento del 50\% (cincuenta por ciento), como mínimo, en el valor del billete, para los mayores que excedan las plazas gratuitas (Art. 40). Aún sobre el transporte colectivo urbano, la gratuidad concedida al viajero entre 60 y 65 años, quedará sometida al criterio de la legislación local (Art. 39).

f) El estatuto define crímenes y prevé puniciones. La mayor pena es la reclusión de 4 a 12 años, por malos tratos con resultado de muerte (Art. 99). Detención de 6 meses a 1 año para personas que dejen de prestar asistencia al adulto mayor sin causa justa (Art. 97), que discriminen o dificulten su acceso a operaciones bancarias y a los medios de transporte por motivo de la edad (Art. 96) y detención de 6 meses a 3 años para la persona que abandone a un mayor en hospitales, casas de salud o de larga permanencia (Art. 98). Además, garantiza prioridad a las personas con edad igual o superior a 60 años en la tramitación de los procesos y procedimientos de la Administración Pública, empresas prestadoras de servicios públicos e instituciones 
financieras, atención preferencial en la Defensoría Pública de la Unión, del Estado y del Distrito Federal relacionada con los Servicios de Asistencia Jurídica (Art. 71).

g) En el área de la cultura, la Ley asegura un descuento del 50\% en las actividades culturales, de ocio y deportivas, así como el acceso preferencial a los respectivos locales (Art. 23).

Así, el Estatuto del Mayor es un excelente dispositivo legal que presenta puntos muy positivos según el análisis de la ONU, aunque esta organización cree que todavía queda mucho por hacer. La ley no tiene aplicabilidad en su conjunto y muchos de los artículos encuentran resistencia por parte de ciertos sectores de la sociedad. De acuerdo con Alexandre Kalache, el estatuto es un documento reciente, pero en los últimos diez años, el trato al adulto mayor ha experimentado avances en Brasil, porque se ha observado más preocupación y hay un debate vivo. Hace diez años los problemas de ese contingente no repercutían en los medios de comunicación y no había una preocupación por parte de los políticos. Para Paulo Paim, autor del Estatuto, la ley es una pieza revolucionaria que tiene como papel fundamental promover la ciudadanía y el respecto a los más viejos. Una ley que vino para establecerse y que depende únicamente de nosotros, ciudadanos brasileños. Conociendo y reclamando su cumplimiento estaremos colaborando a la construcción de un país más solidario, más humano y con mejores condiciones de vida. Cada brasileño, sea joven o viejo, es responsable de la aplicación de esa ley.

Además de la esfera de acción gubernamental, la sociedad civil brasileña ha desempeñado un papel fundamental en la reivindicación de los derechos sociales, en la construcción y puesta en práctica de las políticas públicas dirigidas a la población senescente. Se trata, en la gran mayoría de los casos, de ONGs de alcance local, integradas por miembros de la propia comunidad. En el plan Nacional cabría destacar, entre otras organizaciones existentes, la Sociedad Brasileña de Geriatría y Gerontología (SBGG), entidad científica afiliada a la Asociación Médica Brasileña (AMB) con presencia en 17 estados brasileños. En conjunto con sus secciones regionales, promueve un intenso 
programa de formación de recursos humanos. A través de cursos, simposios, congresos y jornadas, buscan esclarecer, enseñar y difundir los conocimientos del área de la Geriatría y Gerontología. Con características semejantes, la Asociación Nacional de Gerontología (ANG), es una entidad de naturaleza técnico-científica vinculada a acciones relativas a los adultos mayores que tiene por finalidad contribuir al desarrollo de una mayor conciencia gerontológica en favor de mejorar las condiciones de vida de la población senescente.

Otra institución destacada que organiza y representa aproximadamente a veinte millones de brasileños jubilados es la Confederação Brasileira de Aposentados e Pensionistas (COBAP). Su objetivo es defender los intereses de este sector y reivindicar el cumplimiento de sus derechos. Para ello, promueve acciones con sus federaciones y demás entidades afiliadas para tratar de asuntos de interés del movimiento y definir estrategias de acción.

Además de lo señalado, otra acción eficaz y oportuna desarrollada en pro de los mayores es la que realiza la Pastoral de la Tercera Edad de la Conferencia Nacional de los Obispos de Brasil (CNBB). En el programa, los mayores son orientados sobre la importancia de las actividades físicas, la ingestión de líquidos, la prevención de caídas y la vacunación contra la neumonía y la gripe. La atención a domicilio es la metodología utilizada; a través de una visita residencial mensual realizada por los líderes comunitarios, se evalúa la situación de los mayores. Desde luego, podemos afirmar, que uno de los motivos del éxito del Programa Tercera Edad en la Pastoral es su ágil sistema de informaciones, capaz de emitir informes mensuales y circunstanciales sobre la situación de la salud y desarrollo de algunas actividades de la vida diaria de más de veinte mil mayores supervisados en todo el país. Con la intención de dar continuidad a ese trabajo y de estimular el surgimiento de una cultura de envejecimiento saludable en el seno de las familias, la CNBB definió para la Campaña de la Fraternidad de 2003, el tema "Fraternidad y las personas mayores - Vida, Dignidad y Esperanza".

Entre las diversas acciones del Gobierno Federal a favor de las personas con 60 años o más, corresponde a la Secretaría Especial de Derechos Humanos 
(SEDH) la atención a las situaciones de violencia y de malos tratos practicados contra este colectivo. En ese sentido, la Subsecretaría de Derechos Humanos de la Presidencia de la República de Brasil lanza el Plan de Acción Nacional para la Erradicación de la Violencia Contra la Persona Mayor en 2005. El plan se constituye en un instrumento que refuerza los objetivos de implementar la Política de Promoción y Defensa de los Derechos entre el segmento de la población de mayores de 60 años, dentro de un enfoque de respeto, tolerancia y convivencia intergeneracional. Se busca, así, instituir y hacer efectivos, en todos los niveles, mecanismos e instrumentos institucionales que permitan el entendimiento, el conocimiento y el cumplimento de la política de garantía de los derechos. Tiene como objetivo promover acciones que lleven al cumplimento del Estatuto del Mayor (Ley $n^{\circ} 10.741$, de $1^{\circ}$ de octubre de 2003), que se ocupen de la erradicación de la exclusión social y de todas las formas de violencia contra ese grupo social. Según el Plan, la violencia contra los mayores en Brasil es un fenómeno de notificación muy reciente, con fecha posterior a 1990, después de que la preocupación respecto a la calidad de vida de los mayores entrara en la agenda de la salud pública brasileña ${ }^{166}$. En el Plan Plurianual 2008-2011 del Presidente Luiz Inácio Lula da Silva, merece destacarse el Programa de Promoción y Defensa de los Derechos de la Persona Mayor. En consonancia con las recomendaciones de las Asambleas Mundiales sobre el Envejecimiento, el área de actuación de la Red Nacional de Protección y Defensa de los Derechos de la Persona Mayor (RENADI) discute a través de conferencias municipales, estatales y nacionales, distintos aspectos del desarrollo de la persona mayor, del fomento de la salud y el bienestar en la vejez y de la creación de un entorno propicio y favorable. Las conferencias son realizadas a nivel municipal, estatal y nacional. Mossoró celebró su I Conferencia Municipal en julio de 2008. A nivel nacional la I Conferencia se llevó a cabo en Brasilia en 2006 y en octubre de 2008 se realizó la segunda edición.

Centrándonos en las políticas y prácticas sociales de atención a los adultos mayores brasileños, hay que reconocer que las diversas iniciativas en favor de

\footnotetext{
166 Brasil. Presidência da República. Subsecretaria de Direitos Humanos. Plano de Ação para o Enfrentamento da Violência Contra a Pessoa Idosa / Presidência da República. Subsecretaria de Direitos Humanos. - Brasília: Subsecretaria de Direitos Humanos. 2005
} 
éstos que vienen realizando órganos públicos, entidades civiles, organizaciones no-gubernamentales e instituciones religiosas, han tenido y continúan teniendo un fuerte impacto positivo en todo el país. Merecen mención especial la PNI, el Estatuto del Mayor, la SBGG y el más reciente Pacto de Gestión por un Envejecimiento Digno y Saludable. Creado conjuntamente en 2008 por los poderes Ejecutivo, Legislativo y Judicial, el Ministerio Público y el Consejo Nacional de los Derechos del Mayor, el Pacto refuerza las política públicas en las cuestiones de género, raza, etnia, formación y capacitación de recursos humanos, co-financiamiento de beneficios, servicios y programas que guardan relación con el proceso de envejecimiento, ampliación, interacción, reestructuración, implementación y humanización de nuevas modalidades de servicios y programas que compone la RENADI.

Todas ellas aportan estrategias de atención imprescindibles para la ejecución de políticas públicas destinadas a las personas mayores y preconizan las directrices dirigidas a la consolidación de un sistema de defensa de los derechos y protección social de este colectivo. No obstante, es preciso que la sociedad, como un todo, participe de este propósito para que se produzcan los cambios necesarios en el trato dado a la cuestión del envejecimiento. Dicho con otras palabras, las personas de edad deben contar con políticas sociales que favorezcan un envejecimiento saludable y, para ello, es imprescindible una nueva actitud ante la vejez, un aumento de las políticas sociales, una reevaluación de las políticas públicas dirigidas a ese colectivo observando las variaciones socio-demográficas, y sobre todo reforzar el intercambio entre las naciones, en especial en América, para que se cumpla la "Estrategia Internacional para la acción sobre el envejecimiento".

En este capítulo, considerando los aspectos demográfico, epidemiológico y social en Brasil, discutimos sobre su envejecimiento en la perspectiva mundial. Si bien el envejecimiento se nos presenta hoy como una tendencia universal, su intensidad varía, sobre todo entre las distintas regiones. En ese sentido, a pesar de que aún estamos en la primera fase de este proceso, el ritmo de envejecimiento se acelera de forma especialmente rápida en nuestro 
país. Vimos que la situación social de la población senescente brasileña, dada la feminización de la vejez, la condición económica, el estado salud y la participación de este colectivo en la sociedad, aún está lejos de una sociedad para todas las edades. Sin embrago, las leyes oficiales implementadas para este grupo de edad establecen derechos sociales y garantizan la autonomía, integración y participación del mayor en seno de la sociedad brasileña. Como instrumentos del derecho propio de ciudadanía, han buscado mejorar la calidad de vida de las personas mayores de 60 años. Pero, en nuestro país se constata el no cumplimento y la omisión de los mecanismos de control y aplicabilidad, como ocurre por ejemplo con el Estatuto del Mayor. También se verifica la ausencia de estudios e investigaciones de la compleja diversidad del envejecimiento poblacional, que puedan subsidiar la efectividad de estas políticas públicas en las diferentes regiones de Brasil de tal manera que puedan ser cumplidas íntegramente. 


\section{El envejecimiento demográfico de Mossoró en el contexto del estado de Río Grande del Norte: Algunos indicadores básicos} Envejecer es como escalar una gran montaña;
mientras se sube las fuerzas disminuyen,
pero la mirada es más libre, la vista más amplia y serena.

Ingmar Bergman (1918-2007), Cineasta, guionista y escritor sueco.

\section{La prolongación de la vida, que aparece bajo el signo de} "abundancia de edad", como la ha denominado Harry R. Moody, afecta de modo diferente a las cinco Grandes Regiones de la Federación. La proporción relativa de personas de 60 años de edad o más residentes en estas regiones, según la Síntesis de Indicadores Sociales - un análisis de las condiciones de vida (IBGE/2007), era en el Sudeste de un $11,3 \%$, el Sur de un 10,9\%, el Nordeste de un 9,6\%, el Centro-Oeste del 8,2\% y el Norte apenas del 6,5\%. Entre estas, se observan también diferencias en la esperanza de vida al nacer. La mayor expectativa está en el Sur $(74,0)$, la segunda en la región Sudeste $(73,8)$, la tercera en el Centro-Oeste $(73,5)$, la cuarta corresponde al Norte $(71,3)$ y la última es la región Nordeste $(69,4)$. La expectativa media de vida en Brasil es de 72,4 años.

Concretamente, refiriéndonos a Río Grande del Norte (RN), según datos oficiales de IBGE, en 1991 el estado poseía 200 mil habitantes con edad superior a 60 años. Ese valor correspondía al 8,2\% de una población total de 2.415.567. En el año 2000 la población potiguar ${ }^{167}$ pasó a 2.776 .782 y el universo de los mayores con más de 60 años saltó hasta los 250 mil o, lo que es lo mismo, al 9,0\% del total. Actualmente, con una población superior a 3.051 .000 y una tasa de crecimiento del $2 \%$ al año, con perspectiva de desaceleración en los próximos años, el colectivo de 60 años es de 313 mil, lo

167 Potiguar - Es la denominación para las personas que nacen el Estado del Río Grande del Norte/RN. 
que representa en proporción relativa el 10,3\% del total de los potiguares. Así RN ostenta el segundo mayor índice de ancianos de la región Nordeste, inferior apenas al de Paraíba que encabeza la lista con el 10,8\%. Con una expectativa media de vida al nacer de 70,1 años, por debajo de la media nacional $(72,4)$, la sobrevida potiguar es considerada buena en relación a los nueve estados del Nordeste. Ocupa la tercera posición, siendo superada por Sergipe y Bahía con 70,6 y 71,7 años, respectivamente. Pero, es considerada baja si la comparación es a escala nacional ya que queda en el $20^{\circ}$ lugar, entre todos los estados de la Federación. En el ranking de los estados con mayor expectativa de vida, el Distrito Federal ocupa el $1^{\circ}$ puesto, con 74,9 años mientras Alagoas está en último lugar, con 66 años. En suma, 15 Estados aún tienen una esperanza de vida por debajo de la media nacional. Quedan por detrás de Río Grande del Norte, siete estados que son Ceará $(69,9)$, Roraima $(69,6)$, Paraíba $(68,6)$, Piauí $(68,6)$, Pernambuco $(67,9)$, Maranhão $(67,2)$ y Alagoas $(66,4)$.

Considerando esos datos presentaremos, en este último capítulo de la Parte I, una visión panorámica de algunos indicadores básicos del municipio brasileño de Mossoró en el contexto del estado de Río Grande del Norte. Ese municipio fue fundado en 1852 y es conocido como la "tierra del sol, de la sal y de la libertad".

FOTO 1

Vista aérea de Mossoró*
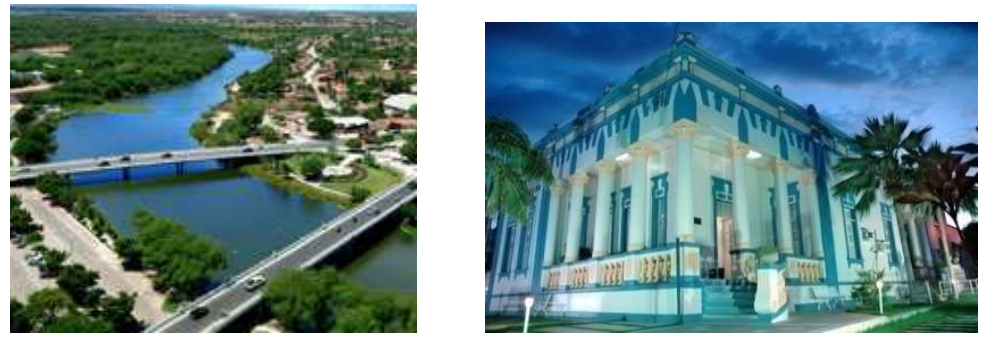

FOTO 3

FOTO 2

Palacio de la Resistencia *

Plaza Rodolfo Fernandes*

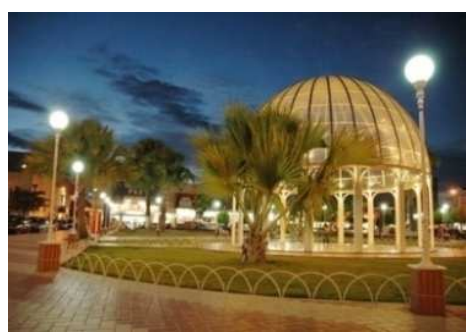

*Fotografía de Carlos Costa 


\section{Aspectos demográficos y sociales}

\subsection{Localización y Población}

De acuerdo con la división regional de Brasil, Río Grande del Norte/RN (véase figura 1), una de las 27 Unidades Federativas del país, tiene una población de 3.043.760 habitantes (PNAD, 2006), forma parte de la Macro región del Nordeste $^{168}$ y está dividida en cuatro meso regiones (Este Potiguar, Agreste Potiguar, Central Potiguar y Oeste Potiguar) y diecinueve microrregiones geográficas, que concentran un total de 167 municipios. Limita al norte y al este con el Océano Atlántico, al sur con el estado de Paraíba y al oeste con el Ceará. Como uno de los menores territorios de la región nordestina, ocupa una extensión de 52.796,8 $\mathrm{km}^{2}$ lo que representa el 3,41\% del Nordeste y cerca del 0,62\% del territorio nacional, siendo más grande que algunos países como Costa Rica $\left(51.100 \mathrm{Km}^{2}\right)$, Dinamarca $\left(43.093 \mathrm{Km}^{2}\right)$, Holanda $(41.526$ $\left.\mathrm{Km}^{2}\right)$, Suiza $\left(41.285 \mathrm{~km}^{2}\right)$, Bélgica $\left(30.518 \mathrm{~km}^{2}\right)$ e Israel $\left(20.700 \mathrm{~km}^{2}\right)$. El territorio de Río Grande del Norte, por excelencia, se localiza en la esquina del continente suramericano, el más cercano a los continentes africano y europeo. Su litoral posee cerca de $400 \mathrm{~km}$ de bellas playas y dunas. Su clima es tropical en el litoral y también al oeste y semiárido ${ }^{169}$ en el centro, con temperaturas medias anuales de alrededor de $26,8^{\circ} \mathrm{C}$. La pluviosidad media es inferior a $2000 \mathrm{~mm}$ anuales y presenta dos estaciones bien definidas, la lluviosa y la seca. En cerca del 75\% del territorio estatal predomina el clima semiárido con temperaturas superiores a $25^{\circ} \mathrm{C}$ y precipitaciones inferiores a

\footnotetext{
168 Debido a las diversas características físicas que presenta, la Región Nordeste está dividida en cuatro subregiones: medio-norte, zona de la selva, agreste y sertão (región alejada de los centros urbanos y caracterizada por el predominio del clima semiárido). El medio-norte comprende la franja de transición entre el sertão semiárido del Nordeste y la región amazónica. La zona de la selva comprende una franja litoral de alrededor de $200 \mathrm{Km}$. de anchura que se extiende de Río Grande del Norte al sur de Bahía. La agreste es el área de transición entre la zona de la selva, húmeda y llena de pantanos, y el sertão semiárido. Ya el sertão, predominante en el Nordeste, es una extensa área de clima semiárido, que en Río Grande del Norte y Ceará llega hasta la costa. Las lluvias son escasas y mal distribuidas. La vegetación típica es la caatinga (mata blanca exclusivamente brasileña). La desembocadura del Río San Francisco es la más grande de la región y la única fuente de agua perenne para las poblaciones que habitan sus orillas. Forman parte del Nordeste brasileño las provincias de Bahía, Sergipe, Alagoas, Pernambuco, Paraíba, Ceará, Piauí y Maranhão.
}

169 El semiárido tiene características distintas. Es una región donde llueve poco, la temperatura es elevada y la vegetación que predomina es la caatinga, con un suelo que retiene poca humedad. Disponible en www.tribunadonortel.com.br/anteriores/2005/03/11/brasil/bras1.html. Visitado el 20 de Junio de 2008. 
1000 mm. Entre los 1.132 municipios brasileños de clima semiárido están los de Río Grande del Norte, con precipitación pluvial menor a 800 milímetros, Brejinho, Lagoa da Pedra, Macaíba, Monte Alegre, Passagem, Várzea e Vera Cruz. El estado está localizado entre los trópicos de Cáncer y Capricornio, por eso, predominan las temperaturas elevadas durante todo el año.

\section{La vegetación está compuesta por áreas de mangue ${ }^{170}$ en el litoral y floresta tropical y caatinga ${ }^{171}$ en el interior (Sourient, 2005).}

\section{FIGURA 1}

\section{Río Grande del Norte entre las 27 Unidades Federativas de Brasil}

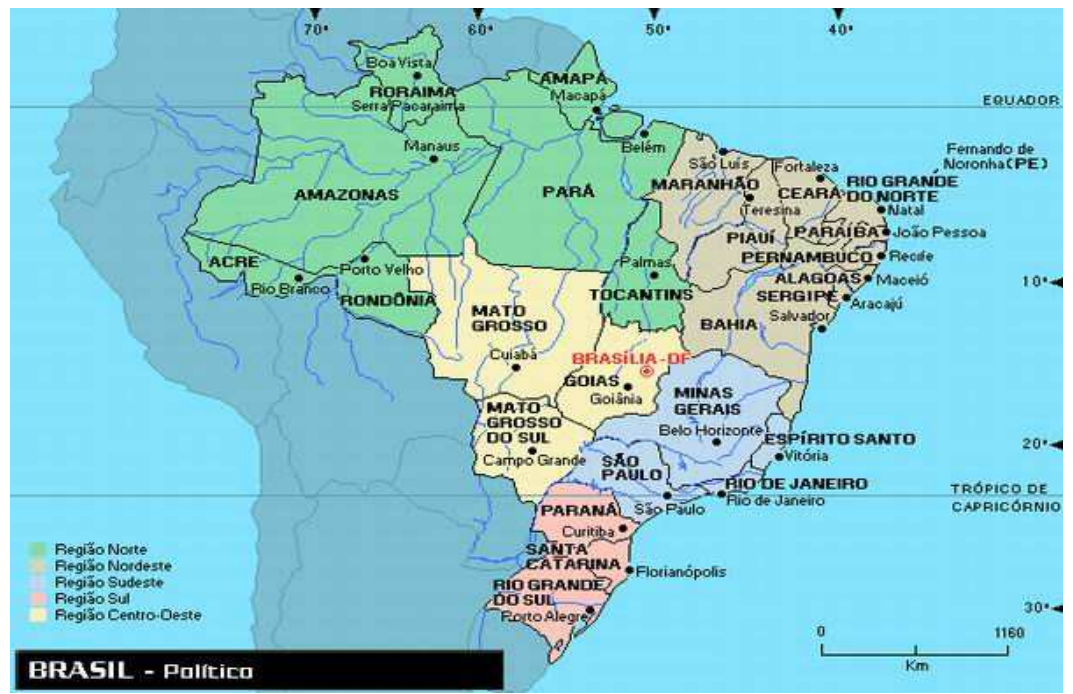

Fuente: http://www.portalbrasil.net

\footnotetext{
$170 \quad$ Mangue es un ecosistema particular de las regiones tropicales de todo el globo. Se origina a partir del encuentro de aguas dulces y saladas, que dan lugar a un agua salobre. Este ambiente presenta agua con salinidad variable, siendo exclusivo de regiones costeras. Los mangueares suministran una rica alimentación proteica a la población brasileña del litoral gracias a la pesca artesanal de peces, gambas, cangrejos y moluscos, que son para los habitantes de la costa la principal fuente de subsistencia. En Brasil, los mangues están protegidos por la legislación federal, debido a la importancia que tienen para el ambiente marino. Son fundamentales para la procreación y el crecimiento de las crías de varios animales, como ruta migratoria de aves y alimento de peces. Además, colaboran en el enriquecimiento de las aguas marinas con materia orgánica. Disponible en www.ambientebrasil.com.br/composer.php3?base=./agua/salgada/index.html\&conteudo=./ntural $/ \mathrm{bioms} / \mathrm{m}$

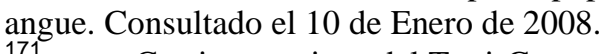

Caatinga - viene del Tupi-Guaraní caa (mata) + tinga (blanca) = mata blanca. Es el único bioma exclusivamente brasileño, lo que significa que gran parte de su patrimonio biológico no puede ser encontrado en ninguno otro lugar del planeta. La caatinga ocupa un área de cerca de $750.000 \mathrm{~km} 2$, lo que representa el $11 \%$ del territorio nacional englobando de forma continua parte de los estados de Maranhão, Piauí, Ceará, Río Grande del Norte, Paraíba, Pernambuco, Sergipe, Bahía y parte del Norte de Minas Gerais (Sudeste de Brasil). Disponible en http://pt.wikipedia.org./wiki/Caatinga. Consultado el 21 de Enero de 2008.
} 
Refiriéndonos a la ciudad de Mossoró ${ }^{172}$, (véase el mapa de abajo), está localizada en la meso región Oeste Potiguar, al sudoeste del Estado, aproximadamente a 285 kilómetros de la capital, Natal ${ }^{173}$. Su clima es semiárido, con lluvias concentradas entre los meses de enero y junio, lo que produce cambios significativos en la vegetación representada principalmente por la caatinga. Hay una gran amplitud térmica diaria en la ciudad, durante el día la media es de $33^{\circ} \mathrm{C}$, mientras que de noche, cae hasta una media de $24^{\circ} \mathrm{C}$. Dependiendo de la época del año se llega algunas veces, en el período nocturno, a temperaturas por debajo de $20^{\circ} \mathrm{C}$. A partir de septiembre el sol castiga Mossoró, y hasta el fin del año las temperaturas llegan a $40^{\circ} \mathrm{C}$ en las áreas más bajas de la ciudad.

Su extensión geográfica es de 2.110.207 km2, representa el 3.9968\% del Estado, el $0.1358 \%$ de la Región y el $0.0248 \%$ de todo el territorio brasileño. Mossoró está situada entre las capitales Fortaleza (Ceará) y Natal (RN), es la segunda ciudad más desarrollada del estado, posee una población de 234.392 habitantes (IBGE.2006) y recibe el apodo de "Capital del Oeste" por haberse destacado de las demás ciudades de la región.

\section{FIGURA 2}

\section{Mossoró en el Mapa de Río Grande del Norte}

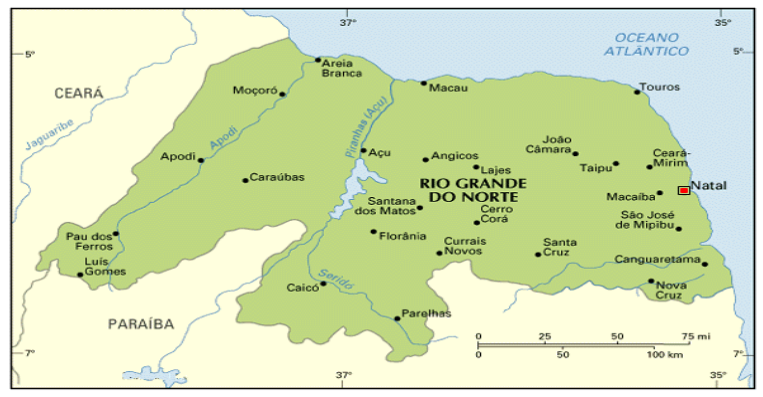

Fuente: http://www.guianet.com.br/rn/index.html

\footnotetext{
172 Según las normas ortográficas vigentes de la lengua portuguesa este topónimo debería ser escrito "Moçoró" pues se prescribe el uso de la letra "ç" para palabras de origen tupi. El nombre viene del tupi erosión, corte, ruptura (refiriéndose al Río Moçoró). A lo largo de la historia, la grafía fue cambiando a monxorós, mosoroka, moçoró y finalmente a Mossoró. Fuente http://pt.wikipedia.org. Consultado el 10 de Diciembre de 2006.

173 Ciudad costera localizada a nordeste del Brasil, Natal está situada en una especie de triángulo natural con un vértice orientado al Norte, un lado bañado por el Rio Potengi y el otro por el Océano Atlántico. Conocida como la Ciudad del Sol, está dotada de muchas bellezas naturales, razón del atractivo turístico del estado. La carne de sol con arroz con leche y los frutos del mar son elementos destacados de su culinaria.
} 
Según el censo demográfico del IBGE 2000, la población mossoroense estaba constituida por un $47,70 \%$ de hombres y un $52,30 \%$ de mujeres, distribuidos en 27 barrios, de los cuales cerca del 93\% vivía en el área urbana y el 7\% en la zona rural. Por lo que respecta a su composición racial encontramos pardos (63\%), blancos (31\%) y negros (6\%). En el período de 1991-2000, la población de Mossoró tuvo una tasa media de crecimiento anual del 1,23\%, pasando de 192.267 habitantes, en 1991, a 213.841 en 2000. En este último año, su población representaba el 7,70\% de la población del Estado y el 0,13\% de la población del país. Por edad, en la Tabla 1, podemos observar como cada década presenta cifras diferentes.

\section{$\underline{\text { TABLA } 1}$}

Constitución de la población mossoroense según grupos de edad, 1991 y 2000.

\begin{tabular}{|lccc|}
\hline GRUPOS DE EDADES & 1991 & 2000 & 2007 \\
\hline Menos de 15 años & 69.335 & 63.667 & 69.097 \\
\hline De 15 a 64 años & 114.307 & 138.648 & 145.146 \\
\hline De 60 o más años & 8.625 & 11.526 & 17.927 \\
\hline
\end{tabular}

(Elaboración de la autora).

Según Sourient, Rudek y Camargo (2005), cuando los primeros europeos llegaron a las tierras que hoy forman Río Grande del Norte encontraron diferentes grupos indígenas habitando ese territorio. Éstos se dividían en diferentes grupos denominados de acuerdo con la región en la que vivían Cariri, Tarairiu, Canindés, Caicó, Pataxó, Moxoró, entre otros. Así que la población de Río Grande del Norte se formó con la contribución de muchos pueblos como los indígenas que aquí vivían, los portugueses que vinieron a colonizar la tierra, los negros traídos de África para trabajar como esclavos, los holandeses que llegaron como invasores y los inmigrantes alemanes, españoles, italianos, ingleses y franceses.

Actualmente la población potiguar se distribuye de forma irregular por el territorio estatal. Debido a las necesidades de supervivencia existen áreas con gran número de habitantes y otras con menor densidad de población. 


\subsection{Economía}

El dinamismo económico de Río Grande del Norte se basa principalmente en actividades extractivas, agricultura, pecuaria, industria, comercio y turismo. La extractiva es una importante actividad económica que proporciona materia prima para la actividad industrial. Lo más destacado en Río Grande del Norte es la explotación de petróleo, gas natural, piedra caliza, arcillas y sal marina. Según informaciones del Sindicato de la Industria de Extracción de Sal de Río Grande del Norte (SIERSAL), de las salinas del estado es extraído más del 95\% de la sal nacional - el equivalente a 4,8 millones de toneladas al año resultado de las pocas lluvias, de la temperatura elevada y de los vientos secos de la región. La sal fue uno de los primeros productos explotados comercialmente en Río Grande del Norte. La explotación normal y extensiva de las salinas de Mossoró, del litoral de Areia Branca, Açu y Macau datan de 1802 aunque ya se sabía de la existencia de yacimientos espontáneos en la región desde el inicio de la colonización (Sourient, et. al, 2005). Actualmente, toda la producción de la sal potiguar se concentra en cinco municipios: Macau, Mossoró, Areia Branca, Galinhos y Grossos y emplea aproximadamente a 15 mil personas. Además del consumo interno, cerca del 25\% del producto es exportado a los Estados Unidos, África (Nigeria y Camerún) y Europa (Dinamarca y Bélgica). En este sentido, la sal continúa siendo una de las principales referencias de desarrollo de Mossoró.

\section{FOTO 4}

Pirámides de Sal Marina - Mossoró/RN

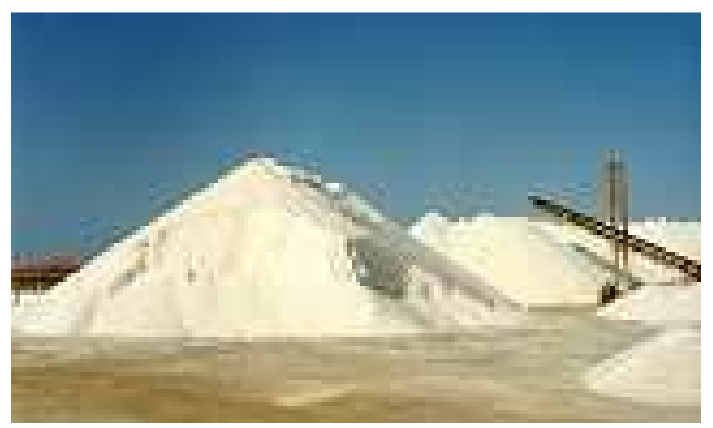

Otro punto destacado que ocupa el Estado en el escenario nacional está relacionado con la producción de petróleo y gas natural. El oro negro es 
actualmente el producto de mayor representación en la economía de Mossoró y de Río Grande del Norte. La región de Mossoró es el principal centro petrolífero de la Cuenca Potiguar, que se extiende entre Río Grande del Norte y Ceará. La producción de petróleo en el municipio comenzó en 1979, en el área próxima al Hotel Termas ${ }^{174}$, y hoy la cuenca es responsable del mayor volumen de producción en tierra del país. Los 3.500 pozos perforados que están operativos en el municipio garantizan una producción media de 57 mil barriles de petróleo diarios y 3,2 millones de metros cúbicos de gas natural por día. Genera cerca de 20 mil empleos directos e indirectos en la región y moviliza a decenas de empresas en la prestación de servicios relacionados con el sector. Su producción garantiza a Mossoró la llegada de royalties ${ }^{175}$ de la Petrobras (Petróleo Brasileiro S.A) ${ }^{176}$ en el Estado. La ciudad recibe, de media, R\$ 1,8 millones por mes, que son invertidos en su infraestructura urbana. RN produce, aproximadamente 80 mil barriles/día, perdiendo en producción sólo frente a Río de Janeiro, que produce casi 2 millones de barriles/día. La expectativa de la Petrobras es que RN produzca 115 mil

$174 \quad$ Hotel Thermas \& Resort - Su historia está literalmente asociada al descubrimiento de petróleo en la ciudad de Mossoró. Dicha relación está marcada por un hecho inusitado: cuando se llenaron las piscinas por primera vez - las bombas pasaron la noche trabajando - por la mañana, las piscinas estaban llenas de petróleo. El descubrimiento marcó el inicio de la explotación de petróleo en tierras de Río Grande del Norte. Ese pozo continúa funcionando hasta hoy en un área interna del Hotel. Actualmente, es movido a través de energía solar, una novedad tecnológica implantada por la Petrobras en la ciudad de Mossoró. Otro pozo fue perforado y cedido por la Petrobras (Petróleo Brasileño S.A.) para abastecimiento de agua, y de él chorrea agua caliente. Era el comienzo de la historia de las aguas calientes. Con 200 mil metros cuadrados de área, en medio de jardines y mucho verde, se destacan 11 piscinas de aguas termales, de propiedades terapéuticas comprobadas, captadas a más de 1.000 metros de profundidad, llegando a la superficie a 57 grados centígrados. Por gravedad, las aguas son distribuidas a las piscinas, cayendo gradualmente la temperatura hasta estabilizarse en torno a 28 grados. Disponible en http://www.brasilpordentro.com.br y http://www.hotelthermas.com.br. Consultado el 14 de Mayo de 2008.

175 Royalty es una compensación pagada a los Estados, Municipios y al Ministerio de la Marina, Ciencia y Tecnología, sobre la producción de petróleo y gas natural. Los royalties son enviados a 15 municipios productores de Río Grande del Norte. Esos municípios son: Alto do Rodrigues, Apodi, Areia Branca, Assú, Caraúbas, Carnaubais, Felipe Guerra, Governador Dix Sept Rosado, Guamaré, Macau, Mossoró, Pendências, Porto do Mangue, Serra do Mel e Upanema. De acuerdo con la Petrobras, entre los $\mathrm{R} \$ 283,4$ millones pagados en royalties en 2007, $\mathrm{R} \$ 159,57$ fueron destinados al Gobierno del Estado de RN y R\$ 123,91 a 93 municipios, de los cuales 15 son productores de petróleo y gas. Macau, Mossoró y Guamaré concentraron el 45,9\% de estos recursos. Juntos recibieron R \$ 56 millones de royalties. Estudios sobre el envío de Royalties realizado por la Universidad Cândido Mendes - Campos de Río de Janeiro, revelan que en 2006, apenas el 52,4\% del dinero de royalties enviado a los municipios potiguares revirtieron en inversiones en las ciudades. En Macau, el índice fue aún menor, del 21,2\%. Mossoró dio ejemplo, con un 99,1\%. Mientras Guamaré se quedó en el 44,8\%.

En 2006 la Petrobras (Petróleo Brasileño S.A.) completó 30 años de producción de petróleo en Río Grande del Norte. Empezó en 1976 con la entrada en activo del Campo de Ubarana, costa de Guamaré. 
barriles diarios en 2012. Los principales campos de exploración nacional en tierra están localizados en el Canto do Amaro y Mossoró. El Activo de Producción de Mossoró coordina las actividades petroleras en ocho municipios de Río Grande del Norte (Areia Branca, Apodi, Caraúbas, Felipe Guerra, Governador Dix-Sept Rosado, Mossoró, Serra do Mel y Upanema) y en dos de Ceará (Aracati y Icapuí). También Rio Grande del Norte, paralelamente al estado de Bahía, aparece como uno de los mayores productores de gas natural del Nordeste. Generando gas asociado, sus campos se localizan en la región de Macau y Mossoró. El gas natural después de procesado es inyectado en el Gasoducto Nordestão que une Fortaleza y Salvador para su distribución por la Petrobras. El Nordestão pasa en Mossoró a lo largo de la carretera BR 304 en el trecho recientemente construido para unir Fortaleza y Guamaré.

\section{FOTO 5}

Caballos Mecánicos

Extracción de petróleo polo - Mossoró/RN

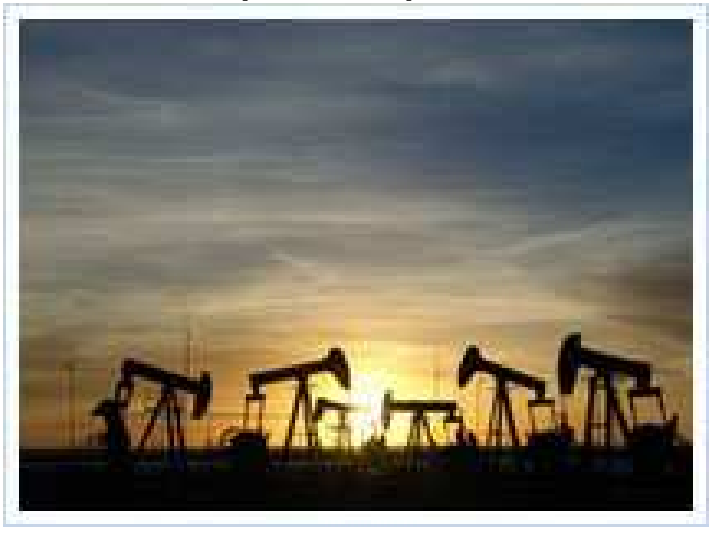

En cuanto a la agricultura de Río Grande del Norte verificamos en los últimos años, un crecimiento en el sector agroindustrial. El estado es el mayor exportador de frutas del país y el principal polo de producción de melón y castañas. Un estudio del Instituto Brasileño de Frutas (IBRAF) revela que, de 4,5 mil toneladas de melón exportadas por el país en el año 2007, 138,3 mil fueron producidas en territorio potiguar (el $67,6 \%$ del total). El estado también tiene una participación significativa en las ventas exteriores de banana $(41 \%)$, papaya $(24 \%)$, sandía $(50,6 \%)$ y mango $(6,15 \%)$. 
Siendo Río Grande del Norte uno de los principales polos agroindustriales del Nordeste brasileño, su crecimiento se apoya en la expansión de la fruticultura irrigada. Yuca, banana, anacardo, sandía y maíz son otros cultivos importantes en el área. Además de la fruticultura, la caña de azúcar también es uno de los principales productos agrícolas de RN. Esa labranza está asociada a la presencia de fábricas y destilerías, principalmente en los municipios de Ares, Canguaretama, Baía Formosa, Goiania y Ceará-Mirim. El estado también se destaca en la carcinicultura (cría de gambas en cautividad) y por ser responsable de cerca de $1 / 3$ del total de la producción de crustáceos. Los grandes compradores de gambas son Estados Unidos, Francia, Italia y Bélgica. Según la Secretaria de Agricultura, Pecuaria y Pesca de Río Grande del Norte, las gambas constituyen actualmente el principal producto de exportación potiguar, seguido del melón. Entre las áreas produtoras están Porto do Mangue, Pendências, Canguaretama, Carnaubais, Galinhos, São Gonçalo do Amarante, Mossoró, Guamaré, Macau y Nísia Floresta (Sourient et. al. 2005).

En Mossoró, la fruticultura tropical irrigada es una de las más importantes del país. El sol tropical, la calidad del agua, los diferentes suelos y la tecnología empleada en el cultivo garantizan la producción de frutas saludables y ricas todo el año. El riguroso control de calidad en todas las etapas de producción, selección y embalaje garantizan productos dentro de los más exigentes patrones internacionales. La región polarizada por Mossoró, que incluye los municipios de Baraúna, Apodi, Governador Dix-Sept Rosado, Tibau, Grossos, Areia Branca y Caraúbas, ha sido reconocida por el Ministerio de Agricultura, desde 1990, como área libre de Anastreph Grandis, más conocida como "Mosca de la Fruta", que afecta a la producción de melón, papaya y sandía y también como área libre de Sigatoka Negra, hongo que perjudica a bananicultura. Esto facilita la entrada de los productos en mercados consumidores internacionales exigentes, como la Unión Europea, Estados Unidos y Japón. En el centro de este escenario la EXPOFRUIT - Feria Internacional de la Fruticultura Irrigada, realizada en Mossoró desde 1992, reúne a productores, importadores, exportadores, distribuidores y 
Capitulo 5. El envejecimiento demográfico de Mossoró en El contexto del estado

delegaciones de países como Francia, Italia, Alemania, España, Holanda, República Checa, Bélgica, Noruega, Estados Unidos entre otros. La edición de 2007 generó negocios por valor de alrededor de US\$20 millones. Según el Comité Executivo de Fitosanidad de Río Grande del Norte (COEX) la fruticultura irrigada genera, actualmente, 24 mil empleos y otros 60 mil de forma indirecta. Las dos mayores empresas que explotan la fruticultura irrigada, desde la producción hasta la exportación, son la Nolem y la Del Monte.

Los números muestran la importancia que tiene el melón para la economía potiguar. En 2007, su exportación dio un salto del 57,6\% en relación a 2006. Datos de la Secretaria de Desarrollo Económico revelan que fue exportado el equivalente a 75,2 millones de dólares frente a 47,7 millones dólares en 2006. Tal resultado ayudó al estado a terminar el año 2007 con un record de ventas en el exterior, concretado en 390 millones de dólares. Además del melón, la región de Mossoró produce, por orden de importancia económica, sandía, maíz, anacardos, mango, frijoles (en granos), algodón herbáceo (en hueso), banana y coco-da-bahía. En el Polo del Vale del Açu, al cual pertenecen los municipios de Baraúna, Mossoró, Serra do Mel y Carnaubais, los cultivos de anacardo, sandía, banana y coco-da-bahía son utilizados como materia prima para la fabricación de zumos, dulces, helados y mermeladas (Sourient, et al. 2005). También la cría de gambas en cautividad está atrayendo a grupos nacionales y extranjeros que perciben un mercado lucrativo en la región salinera de Mossoró. De acuerdo con los datos del núcleo del Servicio Brasileño de Apoyo a las Micro y Pequeñas Empresas (SEBRAE), el municipio tiene relacionadas 400 industrias en los diversos ramos de esa actividad. 


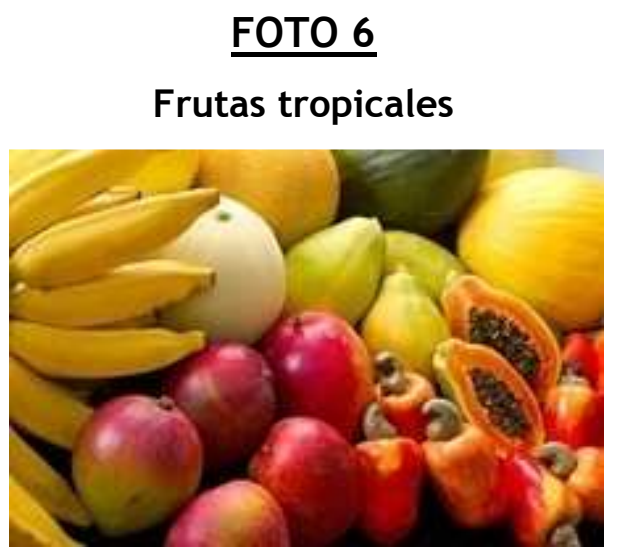

Otra actividad de importancia económica para el Río Grande del Norte es el turismo. Como generador de renta, empleos e impuestos en el estado, Natal se destaca por sus bellezas naturales. El Parque de las Dunas, considerado desde 1993 por la UNESCO como Patrimonio Ambiental de la Humanidad y las Playas de Genipabu, Ponta Negra y Pirangi, entre otras, son los principales atractivos turísticos. En Pirangi, encontramos el mayor anacardo del mundo, con una copa de 7 mil metros cuadrados.

Por lo que se refiere a Mossoró, observamos que, posee fácil acceso a las playas, siendo Tibau la más cercana y considerada "la playa de Mossoró", seguida por Areia Branca $(48 \mathrm{Km})$, Morro Pintado $(50 \mathrm{Km})$ y Ponta do Mel $(53 \mathrm{Km})$. Otros atractivos turísticos de Mossoró son las ferias y fiestas.

\section{FIGURA 3}

Playas cerca de Mossoró/RN

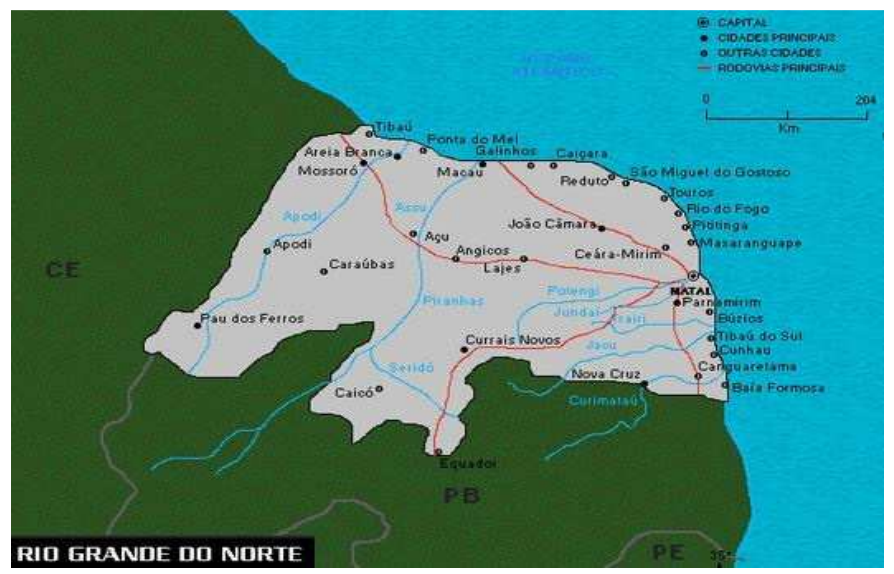

Mossoró Ciudad Junina, es una de las mayores celebraciones conmemorativas de San Juan del Nordeste. La ciudad Junina no se limita sólo 
a una fiesta, es en un gran evento cultural en el que se mezclan en completa simbiosis tradiciones populares, historia, música regional y arte. Está compuesta por varios eventos como un concurso de acordeones, el festival de guitarras, humor y cuadrillas y comidas regionales, destacando el espectáculo "Lluvia de bala en el país de Mossoró", que cuenta la historia de la resistencia de los mossoroenses a la banda de Virgulino Ferreira, o Lampião, en 1927. La importancia de la Ciudad Junina va más allá de las tradiciones populares, de la valoración de la cultura y el entretenimiento. La fiesta junina es un instrumento de generación de renta y mueve la economía del municipio.

La Fiesta del Cabrito es un evento de proporción nacional que consiste en la exposición de ganado caprino y ovino de varias razas. Realizada desde 1998 por el Gobierno del Estado de RN, el Ayuntamiento Municipal de Mossoró y el SEBRAE, es la mayor exposición de caprinocultura del RN. Premia a los mejores expositores, realiza ferias de animales y un torneo lechero con premio para los vencedores. Presenta una vasta programación en el área de capacitación de productores, con la presencia de técnicos, órganos de investigación y extensión universitaria. La fiesta se completa con la feria de productos y servicios ligados al área agrícola y pecuaria, un festival gastronómico caprino - en las categorías de culinaria libre y tradicional subasta, artesanía, festival de violas, repentistas e Shows artísticos culturales.

Auto de la Libertad es un espectáculo teatral al aire libre, creado a partir del libro del poeta Crispiniano Neto, “Auto da Liberdade”, que se celebra desde 1999 en septiembre, para recordar los cuatro momentos históricos más importantes de Mossoró:

* La abolición de la Esclavitud en 1883 (5 años antes de la Ley Áurea) ${ }^{177}$;

* El Motín de las Mujeres en $1875^{178}$;

\footnotetext{
177 Fuente: Documento de Sesión de la Abolición en la Cámara Municipal de Mossoró. Disponible en www.prefeiturademossoro.com.br.

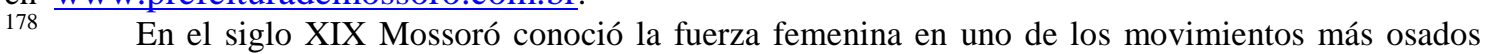
registrados en la historia de la ciudad. Armadas con mucho coraje y con hoyas en las manos, cerca de 300 mujeres, lideradas por Ana Floriano desafiaron a las autoridades y a la justicia local para impedir que sus
} 
* El primero voto femenino de RN y de América Latina, el de Celina Guimarães, en $1928^{179}$;

* La Resistencia a la banda del más famoso bandido del Nordeste, Lampião (Virgulino Ferreira) en $1927^{180}$.

Fiesta de Santa Lucía es la mayor fiesta popular religiosa de Río Grande del Norte. Hace más de 150 años que la Virgen de Siracusa recibe homenajes de los mossoroenses en el mes de diciembre. Durante nueve días fieles, romeros, visitantes y turistas participan de las novenas, misas, asisten en el atrio de la Catedral al espectáculo teatral Oratorio de Santa Lucía, que narra su historia $y$, en procesión acompañan a la imagen de la Patrona de la Vista por las principales calles de Mossoró el día 13 de diciembre.

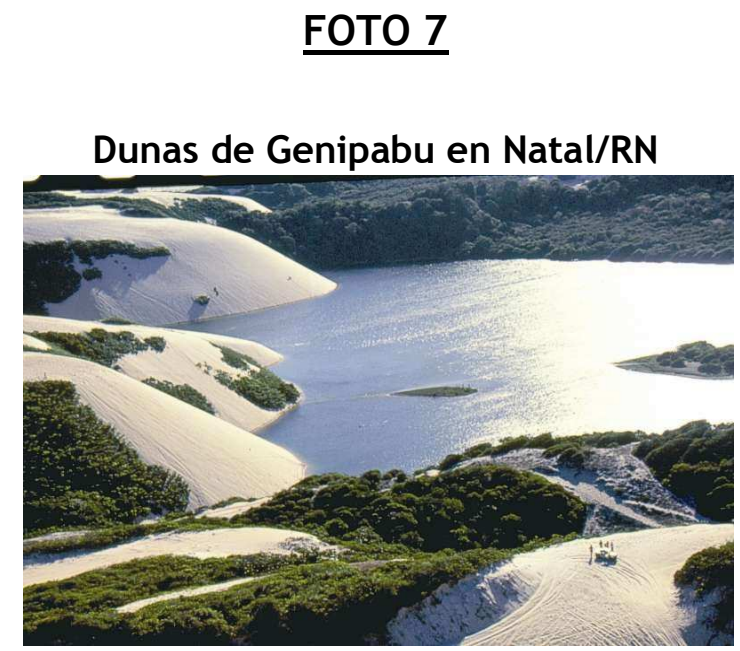

Actualmente pertenece al grupo de las ciudades que más crecen económicamente en Brasil. En los últimos años, principalmente, ha ganado fuerza el mercado de la construcción civil y la actividad industrial. Dada su expansión económica, Mossoró ha recibido dos homenajes nacionales. En junio de 2007 la ciudad fue clasificada por el periódico Gazeta Mercantil como una

hijos, esposos y novios fuesen reclutados para el Ejército y la Armada nacional (Decreto $\mathrm{n}^{\circ}$ 5851, de 27 de febrero de 1875).

179 Firmino, Jane Cortez. (2003), O voto de saias - a gênese do voto feminino do Rio Grande do Norte a través do jornal A República. Fundação Vingt-Un Rosado - Coleção Mossoroense, Serie C - Vol. 1375 , p. 26.

${ }_{180} \quad$ En 13 de junio de 1927 Lampião amenaza con invadir Mossoró y sembrar la destrucción. Los mossoroenses, sin embargo, liderados por el alcalde Rodolfo Fernandes, se enfrentaron a su pandilla y la vencieron. Había una razón para invadir Mossoró. La ciudad estaba experimentando un avance económico, con énfasis en la industria salinera, algodonera y de carnauba. Los productos eran exportados y el comercio se había fortalecido (Ver Geraldo Maia, 1980). 
de las más respetadas en la lista de los "Municipios Más Dinámicos de Brasil", publicándose en el Atlas del Mercado Brasileño 2007. El segundo reconocimiento vino de la mano de la Fundación Getulio Vargas, a través de la revista Você S/A (Editora Abril), que incluyó a Mossoró en la selecta lista de las cien mejores ciudades de Brasil para progresar profesionalmente. Entre los más de 5.500 municipios brasileños, Mossoró ocupa la 94a posición.

Por todo lo descrito, Mossoró la capital del Oeste Potiguar, está entre los cinco municipios que más contribuyeron al Producto Interior Bruto (PIB) de Río Grande del Norte en 2005. Según el Instituto Brasileño de Geografía y Estadística (IBGE/RN), mientras Natal proporcionó más de 7 R\$ billones del valor total del PIB (36,6\%), Mossoró contribuyó con R\$1,7 billones, valor que representa el 9,6\% de la contribución, São Gonçalo do Amarante lo hicieron con R\$ 1,1 billón (6,4\%) y Parnamirim y Areia Branca participaron con R\$ 914 millones $(5,1 \%)$ y $\mathrm{R} \$ 411$ millones $(2,3 \%)$, respectivamente. Juntos, los municipios registraron una concentración espacial de renta superior al $60 \%$.

\subsection{Indicadores de mortalidad y fecundidad}

Como ya se señaló en el capítulo IV, los niños brasileños están viviendo más. Esto es un indicador significativo para comprobar la calidad de vida de un pueblo. Según datos del informe Situación Mundial de la Infancia 2007 Supervivencia Infantil, divulgado por la UNICEF, agencia de las Naciones Unidas para la infancia, Brasil consiguió reducir casi a la mitad la tasa de mortalidad infantil entre 1990 y 2006, de 46,9 por mil nacidos vivos a 24 por mil, pero aún así continúa habiendo grandes disparidades entre las diversas regiones del país y entre diferentes grupos étnicos y raciales. La caída de la mortalidad infantil, es un importante indicador de progreso social. Factores como la expansión del saneamiento básico, la mejora de la alimentación de las familias, el acceso a una asistencia médica prenatal y neonatal y el avance del nivel educativo de las madres ha contribuido a reducir las muertes infantiles. Sin embargo, el informe de UNICEF muestra que los niños pobres tienen más del doble de posibilidades de morir, si se comparan con los niños de familias ricas. En términos geográficos, la Región Nordeste es la más 
vulnerable de Brasil en cuanto a mortalidad infantil. Su tasa equivale a más del doble de las tasas verificadas en las regiones Sur, Sudeste y Centro-Oeste.

Marie-Pierre Poirier, representante de UNICEF en Brasil, evalúa que la posibilidad de muerte de un niño en Alagoas es más de tres veces superior a la de uno nacido en São Paulo o en Santa Catarina; que la tasa de mortalidad entre niños negros brasileños es un 37\% mayor que entre los blancos y que entre los indígenas ese porcentaje sube hasta el 138\%. En este escenario, mientras el promedio nacional es de 24 muertes con menos de un año por cada mil niños nacidos vivos en el país, las regiones Nordeste y Norte ofrecen el peor resultado. A pesar de esto, la región Nordeste fue la que más avanzó entre 1990 y 2006, reduciendo un poco la desigualdad en relación a otras regiones del país.

Respecto a Río Grande del Norte, los datos del IBGE revelan que, en 1980 de cada 1.000 niños nacidos vivos morían 111,2. Ya en 2006, este índice cayó hasta 36,1 muertes por cada mil nacimientos, lo que representa un espectacular descenso de casi el $70 \%$ en un período de 26 años. Durante este periodo el mejor resultado fue obtenido por São Paulo $(-71,8 \%)$, Roraima ($72,3 \%$ ) y Ceará, el campeón con un $-72,4 \%$. La caída de la mortalidad infantil en RN fue la cuarta mayor del país, empatado con Minas Gerais. Con el nuevo índice, el Estado asume la quinta posición en mortalidad infantil en el ranking regional. Estos datos confirman que el semiárido continúa concentrando las peores tasas del país.

Las causas de la mortalidad infantil son de orden biológico, socioeconómico y socio ambiental. Cuestiones como la ausencia de servicios básicos de saneamiento y salud, especialmente la atención prenatal y la asistencia al parto y posparto, contribuyen decisivamente al aumento de la TMI en los municipios del semiárido brasileño y demuestran la falta de políticas públicas que promuevan el derecho a la supervivencia y al desarrollo integral de los niños. En Río Grande del Norte, por ejemplo, la red de alcantarillas no alcanza a la mitad de los domicilios, el 45,9\% en 2006 y el analfabetismo aún afecta al 21,8\% de la población. Las mayores tasas se registran en Alagoas (51,9\%), Maranhão (40,7\%), Pernambuco $(39,8 \%)$ y Paraíba $(39,4 \%)$. Esos 
porcentajes son superiores a los de Marruecos (32\%) y Paraguay (34\%). Los menores índices se registran en Piauí $(29,3)$, Ceará $(30,8)$ y Bahía $(34,5)$. En todo el país, la menor tasa de mortalidad infantil pertenece a Río Grande del Sur con un 13,9\%, semejante a los índices observados en Argentina (13\%) y Uruguay (12\%), por ejemplo. Las mayores tasas de mortalidad infantil se registran Alagoas $(51,9 \%)$,

De forma concreta, a pesar de la disminución, la TMI continúa por encima de la media nacional con un 36,1 frente al 24 de los índices permitidos por las Naciones Unidas y aún supera la de los estados de las Regiones Sur $(16,7)$, Sudeste $(18,3)$ y Centro-Oeste $(19,5)$ que son inferiores a 20 por mil (IBGE: 2006). Eso refleja las grandes desigualdades regionales y socio-económicas que continúan existiendo en Brasil.

En Mossoró, finalmente, la situación sigue el mismo parámetro nacional. Según el Atlas de Desarrollo Humano de Brasil, entre 1991-2000, la tasa de mortalidad infantil en el municipio se redujo un 45,12\%, pasando de 62,9 (por mil nacidos vivos) en 1991 a 34,5 (por mil nacidos vivos) en 2000. Gracias al acceso al agua potable que actualmente alcanza al 93,2\% de los domicilios, a la red de saneamiento básico que contempla al 52\% de las viviendas, a la vacunación infantil (entre 0 y 5 años) que ya inmuniza al 91\% de los niños y al incentivo al amamantamiento materno, revelados por el Ministerio de la Salud en 2007, indican que el índice de mortalidad se ha reducido al triple: del 63\% hasta el 21\%, en 15 años (1991-2006). Para contribuir a esa reducción, es muy probable que este índice continúe cayendo con la instalación de la Unidad de Terapia Intensiva neonatal de la maternidad Almeida Castro, la primera del interior del Estado.

Como firmante de la Declaración del Milenio y del documento Un Mundo para los Niños, Brasil se compromete a mejorar significativamente sus indicadores con relación a la infancia. Aunque la situación haya avanzado en la mayoría de las áreas, los números aún son preocupantes (Véase la tabla 2). 


\section{TABLA 2}

Tasas de Mortalidad Infantil, ambos los sexos 1980 - 2006 (Muertes para cada 1.000 nacidos vivos \%)

\begin{tabular}{|lccccc|}
\hline & 1980 & 1991 & 2000 & 2006 & $\begin{array}{c}\text { Declive (\%) } \\
\end{array}$ \\
\hline Brasil & 69,1 & 45,2 & 30,4 & 25,1 & $-64 \%$ \\
\hline RN & 111,2 & 72,1 & 44,7 & 36,1 & $-67 \%$ \\
\hline Mossoró & ${ }^{*}$ & 63 & 34,5 & 21 & ${ }^{*}$ \\
\hline \multicolumn{2}{r}{${ }^{*}$ Datos no disponibles. } & Fuente: IBGE (Elaboración de la autora).
\end{tabular}

La disminución de la fecundidad brasileña, como hemos visto a lo largo del capítulo IV, se debe a las transformaciones económicas y sociales que se acentúan en la segunda mitad del siglo XX, principalmente a la urbanización. La historia muestra que los avances en la educación, los cambios en el papel social de la mujer y la mejora de las condiciones de salud derrumban la tasa de fecundidad. En ese período la vida de la mujer cambia: deja de vivir exclusivamente en el núcleo familiar e ingresa de forma creciente en el mercado de trabajo. Como resultado de los avances de la medicina y de la educación, las mujeres pasan a tener cada vez más acceso y aclaraciones sobre los métodos contraceptivos. En ese sentido, se confirma que la tasa de fecundidad es inversamente proporcional a la escolaridad femenina. En otras palabras, cuanto más instruida, menos hijos tendrá la mujer. Esa reducción se inicia con las mujeres de clase media y alta de los centros urbanos del Sur y Sudeste del país en los años 60 y gradualmente alcanza a las demás clases sociales y regiones. De ese modo, la fecundidad es un trazo de desigualdad entre las clases sociales. Si las mujeres ricas tienen, de media, 1,4 niños, las más pobres tienen 3,7. Para el PNAD/IBGE esto significa una diferencia de 2,3 menos entre el número de hijos de las mujeres más ricas con respecto a las más pobres. Actualmente, esas diferencias se confirman entre las regiones brasileñas. El Norte presenta el mayor índice de fecundidad (2,3 hijos por mujer) y el Sur, el menor ( 1,7 hijos por mujer). Tener menos bebés y más personas con edad avanzada da lugar a una ecuación con graves consecuencias poblacionales a medio plazo.

Sin embargo, la población brasileña sólo comenzará a disminuir en su totalidad a partir de 2060, según estimaciones del Instituto Brasileño de 
Geografía y Estadística, con base en la cuantificación de la población realizada en 2007 por ese órgano. De acuerdo con el presidente del IBGE, Eduardo Nunes ${ }^{181}$, esa transformación se debe a la caída de la tasa de fecundidad de la población, principalmente en las zonas rurales de las ciudades del interior del país y en el Nordeste. La caída en las áreas rurales se consolidó y ganó fuerza en los siete años que separan el Censo 2000, y el que expresó numéricamente a la población en 2007, confirmando que la tendencia que comenzó en los años 60 en las áreas urbanas, llegó a todas las regiones y clases sociales. En las regiones Sur y Sudeste se mantiene el proceso de reducción de la fecundidad que sigue acelerado en la región Nordeste. Ana Amélia Camarano del IPEA, estima que el país comenzará a perder población entre 2035 y 2040 . La demógrafa prevé que desde 2025 hasta 2030 el crecimiento poblacional caerá un 0,5\% y la tasa de fecundidad bajará a 1,5 hijos. El resultado será la reducción de la población. Para los expertos la reducción acelerada de la natalidad refuerza la tendencia al envejecimiento poblacional. Esto tendrá implicaciones en el mercado de trabajo, en la medicina y en la Seguridad Social. El estado brasileño tendrá que hacer frente a nuevas cuestiones.

En cuanto a la fecundidad del Estado de Río Grande del Norte, observamos que hubo un periodo entre 1991/2000 de disminución de sus tasas de fecundidad total, siguiendo la tendencia del país y registrando en 2000 una proporción de 2,5 hijos por mujer. Sin embargo en 2006, la Pesquisa Nacional por Muestra de Domicilios (PNAD) aclara que Rio Grande del Norte tenía, en aquel año, 839 mil mujeres en edad reproductiva - de 15 a 49 años - siendo que apenas 530 mil tuvieron hijos vivos (el 29\% tuvieron un hijo, el $34,7 \%$ dos hijos y el $39,2 \%$ tres hijos o más). El número medio de hijos por mujer ha disminuido en los últimos años. En 1980 era de 5,7 hijos por mujer, mientras que en 2000 baja a 2,1. A pesar de eso, la investigación muestra que el tema de la fecundidad merece distinciones entre los grupos de edad. Aunque la reducción de fecundidad en Brasil haya declinado paulatinamente, provocando un estrechamiento en la base

181 Ver www.expressaorevista.com/expressnews página visitada en 05/10/2007. 
de la pirámide, en $\mathrm{RN}$ hubo un incremento en la proporción de nacidos vivos de madres adolescentes con edad entre de 15 y 19 años del 17,2\% en 1995 al 20,55\% en 2006.

En Mossoró, los indicadores de mortalidad y fecundidad indican un proceso muy importante: la reducción nítida de ambas tasas de población va definiendo un perfil nuevo de la población mossoroense, más maduro y envejecido. La proporción de niños se está reduciendo y la población de mayores aumentando, todo lo que indica que se producirán repercusiones en las políticas públicas de salud y pensiones.

\section{TABLA 3}

Tasas de Fecundidad Total (TFT), ambos los sexos 1980 - 2006.

\begin{tabular}{|lccccc|}
\hline & 1980 & 1991 & 2000 & 2006 & $\begin{array}{c}\text { Variación (\%) } \\
1980-2006\end{array}$ \\
\hline Brasil & 4,4 & 2,3 & 2,3 & 2,0 & $-32,1$ \\
\hline RN & 5,7 & 3,4 & 2,5 & 2,1 & ${ }^{*}$ \\
\hline Mossoró & ${ }^{*}$ & 3,0 & 2,2 & ${ }^{*}$ & ${ }^{*}$ \\
\hline & * Datos no disponibles. Fuente: IBGE (1980-2006) & (Elaboración de la autora).
\end{tabular}

\subsection{Educación, longevidad y renta}

Si por un lado los indicadores económicos son positivos en RN, por otro, los datos sobre la educación presentan índices preocupantes. Queda entre los últimos en el nuevo estudio del Ministerio de Educación y Cultura (MEC) de 2007. El Estado potiguar está entre los peores en enseñanza Primaria de $1^{\circ}$ ciclo, correspondiente a $1^{\mathrm{a}}$ a $4^{\mathrm{a}}$ serie. La última posición en el ranking de esta fase es compartida por los estados de Bahía (BA) y Piauí (PI). Mientras que la media nacional de evaluación quedó en 3,9 puntos, la media de RN, BA y PI fue de 2,6 .

En la enseñanza Secundaria de $2^{\circ}$ ciclo, ( $5^{\mathrm{a}}$ a $8^{\mathrm{a}}$ serie), Río Grande del Norte queda en $24^{\circ}$, con una media de 2,6. La media nacional fue de 3,3 puntos. Peor en esta fase que RN, fueron los estados de Pernambuco $(2,4)$, Alagoas $(2,5)$ y Paraíba $(2,5)$. En la enseñanza Medio (corresponde a la E.S.O. en España), RN presentó una media de 2,6. Es la antepenúltima posición. Piauí $(2,3)$ y Maranhão $(2,4)$ quedaron, respectivamente, en las últimas y 
penúltimas posiciones. En la enseñanza media, el estudio apuntó la media del país en 3,0.

En análisis de la enseñanza Fundamental de $1^{\circ}$ ciclo $\left(1^{\mathrm{a}}\right.$ a $4^{\mathrm{a}}$ serie), el Índice de Desarrollo de Educación Básica (IDEB) analizó 143 municipios potiguares, de los 167 existentes. El mejor nivel de esta enseñanza en la red municipal fue el de la ciudad de Acarí, que alcanzó una media de 4,7. Con eso, Acari es el único municipio de RN que consigue un puesto por encima de la media nacional de 3,8. La peor media en el Estado fue la del municipio de Olho D’Água dos Borges, con 1.4. Mossoró quedó en décimo lugar. En Natal la media fue de 3,3 y en Mossoró de 3,2. Una diferencia muy pequeña.

Otro dato que llama la atención es el analfabetismo. En RN, alcanza al 21,8\% del total de personas con edad superior a cinco años, o sea, 646 mil personas en esa franja no sabían leer ni escribir en agosto de 2007, según la Síntesis de Indicadores Sociales. En 2000 ese porcentaje era del 23,7\%. Una posición un poco mejor apenas que la de los estados de Alagoas $(26,4 \%)$, Piauí $(26,2 \%)$, Maranhão (22,8\%) y Paraíba (22,7\%). A pesar de que observamos una tendencia constante a la mejora en el nivel de instrucción de la población, este número continua siendo preocupante cuando se compara con la media nacional - alrededor del $11,4 \%$ de los brasileños con más de 5 años era analfabeto en 2007. En Mossoró, la cifra del analfabetismo sigue cayendo, aunque continúa siendo elevada y constituye un desafío para los gobiernos. Los datos del INEP revelan que entre 1991 y 2000, los índices mejoraron (Ver tabla 4). Entre el colectivo de las personas mayores en Brasil en 1991 (IBGE) el 55\% declararon saber leer y escribir al menos una nota simple, en 2000, ese porcentaje pasó al $64,8 \%$ y actualmente, según la investigación hecha por la Fundación Perseu Abramo, el 49\% de la población de mayores brasileños son analfabetos funcionales. 


\section{TABLA 4}

Analfabetismo en Mossoró, ambos los sexos 1991-2000

\begin{tabular}{|ccc|}
\hline GRUPOS DE EDAD & 1991 & 2000 \\
\hline 7 A 14 años & 31,2 & 12,3 \\
\hline 10 a 14 años & 19,8 & 6,1 \\
\hline 15 a 17 años & 14,5 & 4,6 \\
\hline 18 a 24 años & 16,1 & 7,5 \\
\hline Arriba de 24 años & 31,8 & 23,1 \\
\hline
\end{tabular}

(Elaboración de la autora)

Fuente: PNUD/Atlas del Desarrollo Humano (www.pnud.org.br). Informaciones metodológicas: Los porcentajes indican que las personas entre los grupos de edades subrayadas no saben leer ni escribir ni siquiera una nota simple.

Por otro lado, según el SIS (2007), de los 2.800 .000 personas con 5 años o más en RN, aproximadamente 926.000 eran estudiantes en 2007, lo correspondiente a un $76,92 \%$ del total de este colectivo. Pero, la mayor presencia de estudiantes en RN corresponde a la franja de 7 a 14 años, es decir 454 mil de este grupo (96,5\%) estaban en la escuela. En relación a los adolescentes entre 15 y 17 años, franja de edad correspondiente a la enseñanza Media, es posible observar que la tasa de escolaridad no alcanza ni siquiera a la mitad de este segmento poblacional de $\mathrm{RN}(34,1 \%)$. Para la Síntesis de Indicadores Sociales (2007) en RN, la media de años de estudio de las personas con 15 años de edad o más fue de 6,1 años de permanencia en la escuela. En esta franja de edad los jóvenes deberían poseer por lo menos 8 años de estudios. En general, a pesar de que los indicadores educativos han mejorado en la última década, aún subsisten desigualdades históricas en el país cuyos factores determinantes son: renta familiar, situación/región y raza. La población más instruida de Brasil vive en el Distrito Federal, Río de Janeiro, Santa Catarina, São Paulo y Río Grande del Sur.

En relación con la expectativa de vida los indicadores de IBGE/2007 revelan resultados significativos. La población de Rio Grande del Norte también está envejeciendo, el número de personas por encima de 60 años creció proporcionalmente más que la población joven (hasta cuatro años). El índice de niños cayó del 8,6\%, en 2005, al 8,2\%, en 2006, mientras que el porcentaje de mayores (a partir de 60 años) pasó del 9,9\%, en 2005, al 10,3\%, 
Capitulo 5. El envejecimiento demográfico de Mossoró en El contexto del estado del Rio Grande del Norte. Algunos Indicadores básicos

en 2006, lo que revela un ensanchamiento de la cúspide de la pirámide de la población potiguar. En ese universo Natal tiene 313 mil personas con 60 años o más y Mossoró alrededor de 18 mil.

Otro dato que llama la atención de la longevidad en RN es la concentración de mayores con más de un siglo de vida. El estado ocupa el séptimo lugar en el ranking nacional, con mayor índice de centenarios y el cuarto de la región Nordeste con 548 personas. En cuanto a los municipios con mayor proporción de centenarios entre los 20 contados por IBGE en 2007, São Luís es el campeón con 144 centenarios, seguido de Natal con 118, Maceió (93) y Manaus (89). De acuerdo con el recuento de la población hecho por el IBGE en 5.435 municipios del país, 11.042 personas tienen 100 años o más, siendo 7.950 mujeres y 3.472 hombres.

Sumado a todo eso, el IBGE (2007) revela que RN presentó el segundo mejor resultado en cuanto aumento de expectativa de vida de la población, que pasó de 58,1 años, en 1980, a 70,1 años en 2006. La situación de las mujeres es más favorable que la de los hombres, 74,1 frente a 66,3 años, respectivamente. Con este indicador, que representa un aumento del $20,5 \%$ en la expectativa de vida, RN ocupa la cuarta posición entre los estados del Nordeste en que la población vive más.

A nivel de Brasil, el levantamiento realizado por el IBGE apunta que, solamente Mato Grosso consiguió superar a Rio Grande del Norte y Paraíba, empatados en el índice de crecimiento de la expectativa de vida de la población, con un aumento del 20,8\%. El Estado mejoró su posición en el escenario nacional, saltando de la $23^{\mathrm{a}}$ posición a la $19^{\mathrm{a}}$ entre los años de 1980 y 2006. A nivel regional, el Estado consiguió superar a Piauí y Ceará, que en 1980 tenían expectativas de vida mayores que las de la población de RN. En todo el país, la media de crecimiento de la expectativa de vida de la población fue del $15,7 \%$ en un período de 26 años.

En nuestro ámbito de investigación, Mossoró, la esperanza de vida al nacer ha mejorado significativamente. Entre 1991 y 2000 el crecimiento fue de 8 años, pasando de 61,0 a 69,3 años. 
Desde nuestro punto de vista podemos decir que el perfil más envejecido pronostica cambios para la economía y las políticas públicas y sociales. Nuevas cuestiones se plantearan a las personas mayores. Acciones de carácter intersectorial que involucren a las políticas sectoriales de educación, vivienda, trabajo, asistencia y seguridad social, salud, justicia, entre otras, además de las acciones y servicios desarrollados por diferentes actores sociales en las tres esferas del gobierno.

\section{$\underline{\text { TABLA } 5}$}

Esperanza de vida al nacer, ambos los sexos 1980-2006

\begin{tabular}{|lccccc|}
\hline & 1980 & 1991 & 2000 & 2006 & $\begin{array}{c}\text { Aumento (\%) } \\
\text { Brasil }\end{array}$ \\
\hline RN & 62,5 & 66,9 & 70,4 & 72,4 & 15,7 \\
\hline Mossoró & 58,1 & 63,2 & 67,9 & 70,1 & 20,5 \\
\hline & ${ }^{*}$ Datos no disponibles. Fuente: IBGE & $(1980-2006)$ & (Elaboración de la autora).
\end{tabular}

Por último, sobre la renta de los mayores en Río Grande del Norte, según la SIS 2007, de las 313 mil personas con 60 años de edad o más en 2006, el $22,15 \%$ recibió hasta medio salario mínimo; el $43,9 \%$ ganó entre medio y un salario mínimo, el $21,1 \%$ entre uno y dos salarios mínimos y el $12,4 \%$ más de dos salarios mínimos. Como se ve, vivía en estado de pobreza un 22,15\% de los mayores potiguares, es decir con ingresos de hasta $1 / 2$ salario mínimo. Esto confirma que la mayor incidencia de la pobreza, en 2006, estaba entre los mayores del Nordeste, donde el 23,5\% recibía ingresos de este valor. En el país esto significa aproximadamente 2.4 millones de personas (el 12,4\%). A pesar de lo elevado del índice, estos valores mejoraron en la década de 19962006. En 1996, el $25,1 \%$ de los mayores con más de 60 años vivía con hasta $1 / 2$ salario mínimo. En 2006 ese índice cayó hasta el 12,4\%. Los datos refuerzan la discusión sobre el destino de los recursos de los programas sociales y sobre la sustentabilidad de la política social. De ese modo los beneficios son favorables en las capas de baja renta, pero las jubilaciones resultan insuficientes para sustentar a la propia familia.

La economía de Mossoró, como vimos anteriormente, está basada en el trípode: sal (mayor productor del país), petróleo (segundo mayor productor en volumen del país y primero en producción terrestre) y fruticultura tropical 
Capitulo 5. El envejecimiento demográfico de Mossoró en El contexto del estado

irrigada. En el ámbito laboral, las personas en edad económicamente activa, entre los 15 y 64 años en el año 2000 sumaban un total de 138.648 habitantes, sin embargo, en plena actividad estaban ocupadas sólo 88.530 personas, siendo 52.953 hombres y 35.637 mujeres, según el Atlas de Desarrollo Humano - PNUD. De estos, en condición de jefes de familia, en porcentaje, el 31,70 ganaba hasta 1 salario mínimo, el $22,22 \%$ hasta 2 salarios mínimos y el 33,04\% dijeron ganar más de 2 salarios mínimos. Sin ingresos estaba el 12,82\% de la población. En la condición de indigentes y de pobreza, aún según el Atlas, se encontraba, el $18,03 \%$ y el $40,78 \%$, respectivamente.

Sin embargo, Mossoró actualmente está entre las cincuenta ciudades del interior brasileño cuya la tasa de empleo crece satisfactoriamente. El municipio potiguar ocupa el $47^{\circ}$ lugar en el ranking nacional (julio/2008) de acuerdo con los datos del Catastro General de Empleados y Desempleados (CAGED) del Ministerio de Empleo (MTE). Según los datos, en la ciudad fueron generados 1.198 puestos de trabajo, con un crecimiento del 3,21\%. En julio la construcción civil fue el sector que más contrataciones realizó en Mossoró (752), alcanzando un saldo de 416 nuevos puestos de trabajo formal. En segundo lugar, la pecuaria con 727 contrataciones; le sigue el comercio, con 580 nuevos empleos y por último lugar, los servicios con 559 personas contratadas.

Con estos datos, Mossoró asume la quinta posición en generar empleo en el Nordeste de acuerdo con la clasificación del CAGED.

En cuanto a la situación financiera de los mayores mossoroenses, aunque no fuera posible encontrar datos fiables sobre los ingresos de las personas con más de 60 años en Mossoró, sobreentendemos que no deben encontrarse en situación mejor que la de los demás. Debe, por supuesto coincidir con lo descrito a nivel del estado de Rio Grande del Norte. 
Perfil sociológico de la vejez en Mossoró

Presentación y discusión de los resultados de la investigación

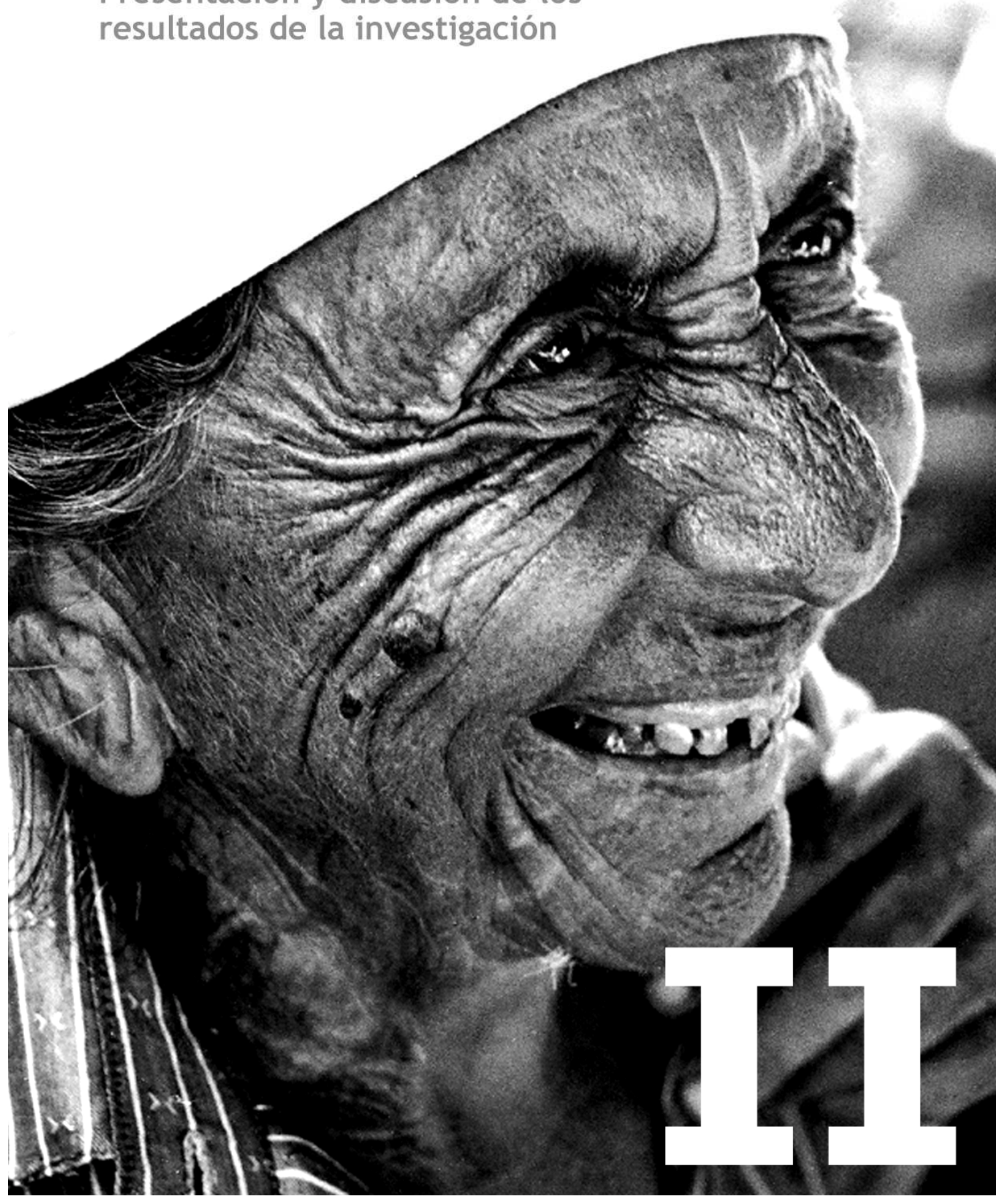




\section{La vejez en Mossoró}

Los que en realidad aman la vida son aquellos que están envejeciendo.

Sófocles (495 a.C.-406 a. C.), Poeta trágico griego.

\section{En este capítulo, serán presentados los resultados de una investigación ${ }^{182}$}

acerca de diversos aspectos de la realidad en la cual se encuentran varones y mujeres residentes en Mossoró, con 60 y más años de edad. Los datos de dicha investigación han permitido definir el perfil típico del anciano de esta ciudad, además de constatar la heterogeneidad de este grupo de población impuesto, sobre todo, por las variables de edad y género. Así pues, los aspectos socioeconómicos y las formas de vida de las mujeres ancianas tienen, explícitamente, características distintas de las de los hombres ancianos.

El reciente proceso de envejecimiento de la población brasileña ocurre de forma heterogénea, quizá también por la existencia de los dos “Brasiles”"183. De hecho, cabe sostener que, entre los mayores, son evidentes las

\footnotetext{
182 Considerando las proporciones continentales de Brasil y el nivel de subdesarrollo en muchas áreas de información y divulgación de datos, percibimos que los análisis demográficos sobre la población de Río Grande do Norte - RN y específicamente del municipio Mossoró, queda muy poco reflejada en las estadísticas, sobre todo, en las regionales y provinciales. En la página web Oficial http://www.ibge.org.br, sobre la población demográfica brasileña, a pesar de la riqueza de datos, se denota la insuficiencia de informaciones más detalladas sobre los municipios de menor tamaño. Otra página http://www.idema.rn ${ }^{\circ}$ com.br que divulga diversos estudios sobre RN, aún manifiesta poca preocupación con el envejecimiento de nuestra población potiguar (gentilicio nacidos en el Estado del Río Grande del Norte). Para recoger los datos en el municipio, buscamos en la Secretaria Municipal de Ciudadanía Gerencia Ejecutiva de Desarrollo Social del Ayuntamiento de Mossoró y en algunas monografías de los cursos de graduación de Servicio Social, Enfermería e Educación Física y en los Cursos de Postgrado en Políticas Públicas y Pluralidad Cultural en la Universidad Regional del Río Grande del Norte -UERN ${ }^{\circ}$ Además de esto, no he encontrado en el archivo de la Biblioteca de la Universidad del Estado de Río Grande del Norte - UERN, ningún trabajo de máster y tampoco tesis doctórales sobre la población que envejece en Mossoró.

183 Frecuentemente oímos decir que existen dos 'Brasiles'. El primero, un Brasil poderoso, comparado a países de primer mundo, como EEUU, Francia y Inglaterra debido al elevado nivel de renta, de consumo y de ahorro, que posee un alto nivel de bienestar social, lo que ocupa el $9^{\circ}$ puesto en la lista de las mayores economías mundiales. Este convive con el segundo Brasil injusto - cuarto país del mundo con peor distribución de renta, comparado a países clasificados bajo de la línea de la pobreza como Etiopía o Nigeria, colocado en un modesto $73^{\circ}$ lugar en el ranking que mide el IDH - Índice de Desarrollo Humano, en el conjunto de 173 naciones (PNUD:2000). En nuestro país, el 10\% de los más ricos concentran una renta equivalente a 44 veces mayor que la renta de los $10 \%$ más pobres, índice muy parecido al de países como Sierra Leona y Malí (IBGE:2000).
} 
disparidades de rendimiento, educación, composición familiar, género. Incluso entre las diferentes fases de edad de ese grupo se pueden notar diferencias.

De este modo, se cree que los datos adquiridos con nuestra investigación serán utilizados como el punto de partida para aquellos que inicien un estudio más profundo sobre los ancianos en Mossoró, o bien sirva de complemento esencial a los órganos de carácter oficial. Este trabajo de investigación ha sido realizado justamente en el marco de sanción del Estatuto del Anciano, a través de la Ley $n^{\circ} 10.741$, de $1^{\circ}$ de octubre de 2003 , destinado a regular los derechos asegurados a las personas con edad igual o superior a 60 años, después de su tramitación durante seis años en el Congreso de los Diputados. Por lo tanto, resulta conveniente crear líneas de investigación científica que pongan de relieve las necesidades y requerimientos que se van a demandar de los poderes públicos y de la propia sociedad en un futuro próximo.

En este estudio se desmenuzan categorías como la salud, la educación, la renta, la familia, la integración, la protección social, el envejecimiento activo y el suministro de cuidados y servicios a las personas que se encuentran en la etapa de la vejez. En la investigación se analizarán, entre otros múltiples aspectos, las informaciones divulgadas en el último Censo Demográfico del Instituto Brasileño de Geografía y Estadística (IBGE: 2000), del Instituto de Desarrollo Económico y Medio Ambiente del Río Grande do Norte (IDEMA/2004), del Departamento Intersindical de Estadística e Estudios Socio económicos (DIEESE/2000-2007), del Instituto de Investigación Económica Aplicada (IPEA/2000-2007) y de la Pesquisa Nacional por Muestra de Domicilios (PNAD/2000-2007). Dichas informaciones han sido elaboradas por estas instituciones en gráficos y tablas, junta a un análisis explicativo de las implicaciones sociales y económicas de los cambios demográficos ocurridos en las últimas décadas en Brasil.

En el primer apartado centraremos la atención en la situación de las estructuras socio-demográficas de Mossoró para dar cuenta del significado de este grupo, tanto en cifras absolutas como relativas, ya que cualquier acción encaminada a mejorar la calidad de vida de nuestros mayores debe asentarse 
sobre un conocimiento cabal de cuántos son, dónde viven y cuáles son sus características. En él según apartado, razonablemente extenso, diseñaremos el perfil de los mayores en Mossoró, desde datos generales (por ej. género, edad, nivel educativo, situación laboral actual), hasta los indicadores: formas de vida, vida cotidiana, entorno físico, salud y asistencia sanitaria, prestaciones y servicios a los ancianos, valoraciones respecto a la sociedad, al aborto, la pena de muerte, el divorcio, la paga de los impuestos, entre otros. Cuáles son sus sentimientos respecto a la vida, la muerte, la política y la religión Tales datos han facilitado el cuestionario compuesto por ochenta y tres preguntas.

A pesar, de que la perspectiva "socioculturalista" argumenta que las cuestiones demográficas $\mathrm{y} / \mathrm{o}$ económicas son aspectos plausibles justificativos para la reformulación de políticas públicas dirigidas a la población anciana, esto no es suficiente para revelar y explicar la totalidad de los hechos que emergen de la vejez como categoría analítica. De acuerdo con Guita Grin Debert (1999), explicar por razones de orden demográfica el aparente rompimiento de la "conspiración del silencio" en relación a la vejez es perder la oportunidad de describir los procesos por medio de los cuales el envejecimiento se transforma en un problema que gana expresión y legitimidad, en el campo de las preocupaciones sociales del momento. No obstante, nos parece pertinente empezar resaltando el campo demográfico, dado que, el interés sociológico y la política social se han centrado en las consecuencias que el envejecimiento de la población tiene para la sociedad, provocadas por el descenso de la fertilidad y el aumento de la longevidad (Laslett, 1987; Ermich, 1990). En ese sentido, lo tomaremos como una columna importante, ya que todo y cualquier desarrollo o retraso de una población pasa inevitablemente por una transformación demográfica. Así que empezaremos los análisis de modo cuantitativo para, concomitantemente, bucear en los análisis cualitativos.

El objetivo principal de esta investigación es analizar el Perfil Sociológico de la Vejez en Mossoró/RN en el contexto brasileño. Conocer las características para diseñar la situación actual de un grupo social del que se sabe poco en 
Brasil, dicho de paso, en Mossoró donde los recursos son escasos y la demanda creciente, la presente investigación sería una tentativa de reparar una deuda contraída con este colectivo hasta entonces aparentemente olvidado en los planes gubernamentales. Los análisis se realizarán hechos a partir de la primera encuesta a medio millar de ancianos residentes en todo el municipio, con base en los indicadores del Censo del Instituto Brasileño de Geografía y Estadística (IBGE: 2000), del Departamento Intersindical de Estadística y Estudios Socioeconómicos (DIEESE 2000-2007), del Instituto de Investigación Económica Aplicada (IPEA 2000-2007) y de la Investigación Nacional por Muestra de Domicilios (PNAD 2000-2007). El trabajo pone a disposición de todas las instancias administrativas el tema de la vejez ofreciendo, aún, un acervo de datos para ampliación y reflexión y para que el diseño de las políticas públicas pueda ser orientado con informaciones precisas. El texto presentado no pretende agotar los análisis sobre la vejez en Mossoró; el ejercicio aquí elaborado trata de ser un esfuerzo inicial de reflexión sobre los datos presentados. Nuestra propuesta pretende ayudar a la implantación de políticas de inclusión de los mayores en la sociedad mossoroense. Con esta Encuesta, esperamos estar contribuyendo a que este asunto forme parte de las pautas de los gobernantes, alcaldes, órganos legislativos de nuestra provincia.

1. Estructura socio-demográfica de las personas de 60 años en adelante

El conjunto de la población residente en Mossoró es de 213.841 habitantes ( $48,1 \%$ hombres y $51,9 \%$ mujeres). De estos habitantes se puede contabilizar una población mayor de 60 años compuesta por 16.510 habitantes, (el 7,7\% del total de población del Censo, IBGE: 2000). Si hacemos un repaso pormenorizado a la población de la localidad, según la edad, vemos que hay 19.282 habitantes de 0-4 años, de 5-9 años contabilizamos 20.865, en torno a 10-19 años 47.007 habitantes, de 20-29 años tenemos un total de 39.125 habitantes, entre 30-39 son 35.009 habitantes, los de 40-49 años suman 
22.071 y finalmente las personas entre 50-59 años presentan un total de $13.982^{184}$.

Observando el envejecimiento poblacional en proporción relativa en las cinco grandes regiones brasileñas, según datos de la última revisión patronal ${ }^{185}$, un 6,37\% personas mayores de 60 años reside en el Sudeste, 6,22\% en el Sur, $5,85 \%$ en Nordeste, 4,27\% en Centro Oeste y un 3,64\% en el Norte. Entre los entre los veintiséis Estados del Distrito Federal, Natal (capital de Río Grande del Norte - RN) ocupa la $9^{a}$ posición, con un 7,9\% del total de la población (712.317) de ese colectivo.

Según el género, en Mossoró, el grupo tiene un porcentaje sutilmente feminizado (véase Gráfico 1). Así por cada varón hay 1,3 mujeres, lo que confirma, también en Brasil, el predominio femenino en la vejez ${ }^{186}$.

Hace mucho tiempo que el número absoluto de mujeres confrontado al de los hombres de 60 años ha sido superior. La esperanza de vida superior en las mujeres tiene origen en factores biológicos (Coleman y cols., 1993; Schroots y Birren, 1990) y está acentuada por la incidencia de muertes por causas violentas, como homicidios y accidentes de tráfico, que alcanza a los varones en mayores proporciones. En Brasil, el demógrafo Simões (2002) señala que en el país tropical, desde 1940, este segmento poblacional disfruta de mayor esperanza de vida al nacer ${ }^{187}$. En un contexto general, en el año 1980 la estimación de vida brasileña al nacer, era de 57,2 años para el varón y 64,3 para la mujer. En 1990 estos datos eran 59,2 y 65,8 respectivamente. Seis años después, las cifras eran de 62,2 para el hombre y 69,8 para la mujer. Esa evolución continuó en los años siguientes, de modo que, en 2000, la expectativa de vida en el país era de 64,8 años para el hombre y 72,5 años

\footnotetext{
184 Para obtener más información sobre los datos socio demográficos de Mossoró, consultar la página web oficial del IBGE http://www.ibge.gob.br/cidades/xtras/SINTESE.php?nomemun=Mossoró.

185 Censo IBGE: 2000.

186 Según datos del Instituto Brasileño de Geografía y Estadística en la última revisión patronal (IBGE: 2000) había en Brasil 14.536 .029 personas de 60 y más años (8,6\% de la población), frente a 10.722.705 en 1991 (7,3\%), de los que 6.533.784 (44,9\%) eran varones y 8.002.245 mujeres $(55 \%)$. Conforme las previsiones de Organizaciones de Naciones Unidas (ONU), en los próximos 20 años, la población de mayores en Brasil podría traspasar los 30 millones de personas y debería representar casi el $13 \%$ de la población al final de ese período.

187 Simões, Celso Cardoso da Silva (2002): Perfis da saúde e de mortalidade no Brasil: uma análise de seus condicionantes em grupos populacionais específicos, ( $1^{\text {a }}$ ed.). Brasília: Athalaia Bureau, p. 29.
} 
para la mujer (Camarano, 2001: 36-48). Si establecemos una comparación de la expectativa de vida al nacer en Mossoró, con respecto a la media nacional, se observa que, a grandes rasgos, los parámetros regionales son distintos. Las regiones Sur y Sudeste presentan los mejores índices (71,03 y 69,58 años, respectivamente), seguidos de las regiones Centro-Oeste (69,42 años), Norte (68,47 años). La esperanza de vida al nacer más baja está en el Nordeste, con 65,78 años. Las previsiones para 2010 y 2020 mantienen una diferencia en torno a los 6 años $^{188}$.

En Mossoró, este nuevo grupo de edad muestra un panorama novedoso que se relaciona históricamente con un descenso de natalidad, combinado con la caída de mortalidad, lo que da mayor supervivencia a las generaciones, que ahora llegan más fácilmente a los 60 años. A nivel nacional, fueron determinantes para el sistemático envejecimiento poblacional hechos como la reducción de las enfermedades infecciosas (con la introducción de antibióticos) y la adopción de medidas preventivas de salud gracias a la expansión del saneamiento básico, principalmente de la red de agua, que benefició en particular la población infantil y a la femenina en edad fértil, en los períodos 1950/1960 y 1970/1980, (Camarano, 1997; Moreira, 1998; Carvalho, 1998; Berquó, 2001).

Resulta que, en Mossoró en 2000, la relación entre el número de mayores y la población total era de 12,95 mayores por cada 100 mossoroenses. En 1980, por cada mayor de 65 años de edad, había en Brasil casi diez jóvenes con menos de 15 años (eran 4,8 millones de mayores por 45,3 millones de niños y adolescentes). En 2005, por cada persona mayor de 65 años hay apenas 4,5 jóvenes con menos de 15 años (los mayores aumentaron en 11,2 millones y los jóvenes se quedaron en 51 millones).

\footnotetext{
188 Estimaciones de IBGE revelan que la esperanza de vida del brasileño al nacer es de 71 años. Con la tasa de mortalidad que tenía en 2002, Brasil ocupaba la $88^{\text {a }}$ posición en el ranking de la ONU, situándose por encima de la media mundial (65,4 años). El ranking compara la expectativa de vida en 192 países. En primer lugar está Japón, con una esperanza de vida de 81,6 años, seguido de Suecia $(80,1)$, Hong Kong (79,9), Islandia (79,8) y Canadá (79,3). El último del ranking es Zambia, con 32,4 años. Próximos a Brasil están países como Colombia $(72,2)$ Surinam $(71,1)$ China $(71,0)$, Paraguay $(70,9)$ y Ecuador (70,8). La media mundial para la esperanza de vida al nacer deberá rebasar los 74,3 años en 2045-2050.
} 


\section{GRÁFICO 5}

Población mayor de 60 y más años según el sexo en Mossoró/RN

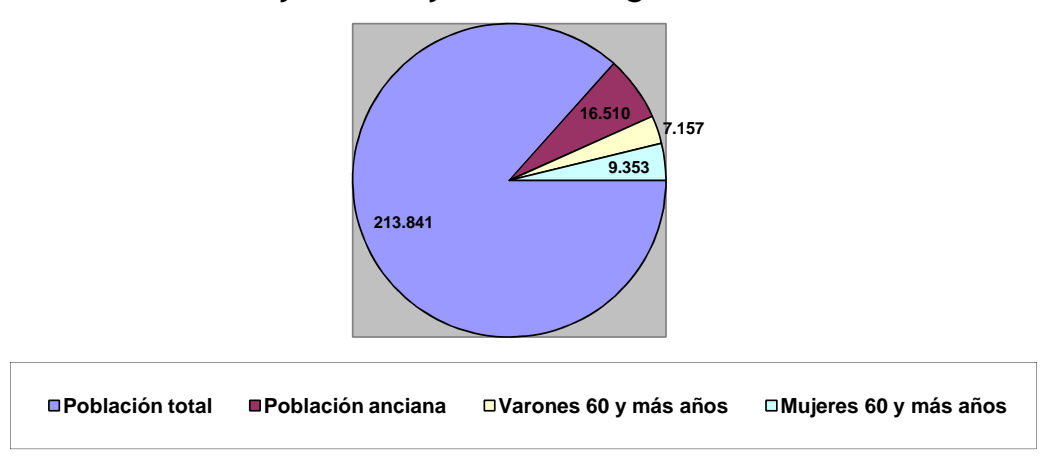

Fuente: IDEMA / CESE (Datos Básicos: IBGE, Censo Demográfico - 2000.) (Elaboración de la autora).

1.1. Estructura de la población anciana en Mossoró, según el sexo, edad, escolarización y renta

En Brasil, como hemos visto, la población de mayores es predominantemente femenina. En realidad, a menudo la vejez se contempla como una cuestión femenina, al menos desde el punto de vista demográfico ${ }^{189}$. En 2000, la mujer vivía una media de ocho años más que el hombre. Las diferencias de esperanza de vida entre los sexos muestran que en 1991, las mujeres suponían un $54 \%$ de la población de mayores. En el año 2000, los porcentajes indicaban que el $55,1 \%$ de los mayores eran mujeres y un $54,9 \%$ hombres. Por tanto, en el año 2000, por cada 100 mujeres mayores existían 81,6 hombres mayores ${ }^{190}$. En la estructura de la población vieja por sexo y edad, los indicadores del último Censo Decenal de Población ${ }^{191}$ evidencian, en Mossoró, el predominio de las mujeres en todos los grupos de edades. (Véase Tabla 1). Según las cifras patronales de 2000 había en la provincia 9.353 mujeres de edad avanzada y 7.157 varones, es decir, 2.196 mujeres más que hombres. Este sutil desequilibrio a lo largo de la pirámide de población, que se acentúa visiblemente, sin excepción, en todas las edades superiores a los 60 años, se

\footnotetext{
189 Sobre eso, ver McDaniel, 1986; Dentoy y cols., 1987; Gee y Kimbal, 1987.

190 IBGE: 2000.

$191 \quad$ IBGE: 2000.
} 
asemeja a los datos en el Estado de Río Grande del Norte ${ }^{192}$, donde entre los ancianos, el colectivo femenino supera en valores absolutos a los hombres. Es decir, en el año 2000, 72.729 personas pertenecían al conjunto de población entre 60-64 años. Los hombres eran 32.720 y las mujeres 40.009. En las edades comprendidas entre 65-69 años, los hombres sumaban un total de 23.574 mientras que las mujeres eran 29.061. Y entre las personas por encima de los 70 años de edad, los indicadores sumaban 57.825 y 67.405 para hombres y mujeres, respectivamente.

Si añadimos algunos datos socio demográficos, en cuanto al nivel de estudios de este subgrupo poblacional, podemos apreciar en la Pesquisa Nacional por Muestra de Domicilios (PNAD: 2007) un 14 millones de analfabetos (10,4\%). Por franja de edad, según la Fundación Perseu Abramo en el sondeo con mayores brasileños, había en mayo de 2007 una tasa de analfabetos funcionales del $36 \%$ correspondiente a las personas con 60 o más años. Para el Instituto Anísio Teixeira, el Nordeste brasileño era el primer en el ranking, con un 56,1\%; el Estado de Río Grande del Norte, también con una cifra muy alta, 54,9\% y Mossoró con casi la mitad $(48,4 \%)$ de ese colectivo analfabeto.

Otro factor importante para analizar el perfil de los mayores en Mossoró es la renta familiar. Una parte significativa de hombres y mujeres, de diferentes clases sociales en el medio urbano o rural, asumen cada vez más el papel de “proveedor" familiar en Brasil ${ }^{193}$. El 60\% de las personas con más de 65 años se constituye como la principal fuente de la renta familiar ${ }^{194}$. En Mossoró, los indicadores económicos han mostrado que esa condición de cabeza de familia no es diferente de la regla nacional.

\footnotetext{
192 A este respecto, visítese la página web del Instituto de Desarrollo Económico y Medio Ambiente del Estado de Río Grande del Norte - IDEMA http://www.idema.rn'gov.br/cese/censo2000/Grupo_Idade.xls.

Los cabezas de familia, son definidos por el Instituto Brasileño de Geografía y Estadística como aquellas personas que contribuyen con la mayor parte de la renta familiar. En Brasil, la mayoría son hombres. De acuerdo con el IBGE en el año 2007, más de la mitad de las viviendas con personas de 60 años o más era proveedora de casi el $90 \%$ del rendimiento mensual de la vivienda donde reside. En 2007, el $45 \%$ de los mayores en el país, eran cabezas de familia y cohabitaban con los hijos.

$194 \quad$ Datos de la Confederación Brasileña de Aposentados y Pensionistas (COBAP) 2007.
} 
El Plan Internacional sobre el Envejecimiento y la Declaración de Brasilia ${ }^{195}$, por ejemplo, llaman la atención de las naciones sobre la posición social de los mayores. En Brasil, según el IBGE en el año 2007, podrían ser considerados en situación de pobreza más de 2,5 millones de mayores $(12,2 \%)$ en el país, que vivían en domicilios cuyo rendimiento medio mensual per cápita era de hasta medio salario mínimo. El porcentaje de mayores que residían en domicilios en esta franja de rendimiento en las áreas rurales llegaba al 20,2\% del total de mayores, en cuanto en las áreas urbanas era del 11,1\%.

En definitiva, la región Nordeste fue la que alcanzó la mayor proporción de mayores en situación de pobreza $(24,2 \%)$ frente a la región Sur, que tuvo la menor proporción $(6,5 \%)$.

\section{$\underline{\text { TABLA } 6}$}

Población de 60 y más años según sexo y edad, Mossoró/RN - 2000 (Porcentajes)* $^{*}$

\begin{tabular}{|c|c|c|cccc|}
\hline & \multicolumn{2}{|c|}{ TOTAL } & \multicolumn{3}{c|}{ HOMBRES } & \multicolumn{2}{c|}{ MUJERES } \\
\hline EDAD & $>60$ & $\%$ & $>60$ & $\%$ & $>60$ & $\%$ \\
\hline $60-64$ & 4.984 & 2,33 & 2.097 & 0,98 & 2.887 & 1,3 \\
\hline $65-69$ & 3.537 & 1,65 & 1.549 & 0,72 & 1.988 & 0,9 \\
\hline $70-74$ & 3.345 & 1,56 & 1.501 & 0,70 & 1.844 & 0,8 \\
\hline $75-79$ & 2.266 & 1,05 & 984 & 0,46 & 1.282 & 0,5 \\
\hline 80 y más años & 2.378 & 1,11 & 1.026 & 0,47 & 1.352 & 0,6 \\
\hline T O T A L & 16.510 & 7,72 & 7.157 & 3,34 & 9.353 & 4,3 \\
\hline
\end{tabular}

* Los porcentajes se refieren a la población total del municipio (213.841 - 2000)

Fuente: IDEMA / CESE (Datos Básicos: IBGE, Censo Demográfico - 2000. (Elaboración de la autora).

\subsection{Personas de 60 años en adelante residentes en Mosssoró por barrio según sexo y grupos de edad}

En Mossoró, según los datos censales de 2000, el 93\% (199.081) de la población reside en áreas urbanas, contra apenas un $7 \%$ (14.760) de los que viven en las zonas rurales ${ }^{196}$. Por lo que respecta a la división territorial del municipio, según la Propuesta del Plan Director de Mossoró, ${ }^{197}$ la ciudad está formada

\footnotetext{
195 Declaración de Brasilia - fue la Segunda Conferencia regional intergubernamental sobre envejecimiento en América latina y el Caribe: hacia una sociedad para todas las edades y de protección social basada en derechos, realizada en Brasilia, de 4 al 6 de diciembre de 2007.

196 Sobre eso, conferir página web http://www.federativo.bndes.gov.br_Mossoró-RN.

197 A este respecto, ver la Propuesta del Plan Director de Mossoró-RN en la página web http://www.fiern.org.br. En Brasil el Artículo 182 y 183 de la Constitución Federal (1988) atribuye al poder público municipal la ejecución de la política de desarrollo urbano y hace obligatorio el Plan Director para ciudades con más de 20.000 habitantes. Pero, sólo en 2001, la Ley $\mathrm{N}^{\circ} .10 .257$ establece las directrices generales de la política urbana, a través del Estatuto de la Ciudad. En Mossoró, la Ley Orgánica Municipal, promulgada en Abril de 1990, prevé el Plan Director de Desarrollo Integrado
} 
por veintisiete barrios, como fue observado por el Censo Demográfico de 1991. Dicho censo establece la siguiente tipología socioeconómica para los barrios mossoroenses:

Barrio Tipo A - barrios con más del $20 \%$ de los cabezas de familia con un rendimiento mensual superior a 10 salarios mínimos, a saber: Nova Betânia y Centro, concentrando, por tanto, los extractos más altos de rendimiento de la ciudad.

Barrio Tipo B - barrios con entre el $10 \%$ al 20\% de los cabezas de familia con un rendimiento mensual superior a 10 salarios mínimos: Presidente Costa e Silva y Doze Anos.

Barrio Tipo C - todos los demás barrios de la Ciudad no agrupados en las categorías A, B, o D, es decir, Alto da Conceição, Aeroporto, Boa Vista, Santo Antônio, Bom Jardim, Paredões, Ilha de Santa Luzia, Alto de São Manuel, Planalto 13 de Maio y Abolição, que presentan los extractos de rendimiento medio de la ciudad.

Barrio Tipo D - barrios que presentan del $60 \%$ al $80 \%$ de los cabezas de familia con rendimiento medio inferior a 1 salario mínimo, o sea, Belo Horizonte, Alto do Sumaré, Dom Jaime Câmara, Pintos, Barrocas, Alagados y Itapetinga, conformando, por lo tanto, las áreas de pobreza de la ciudad.

Barrio Tipo E - barrios con más del $80 \%$ de los cabezas de familia con rendimiento medio inferior a 1 salario mínimo, constituyendo las bolsas de extrema pobreza de la ciudad, a saber: Dix-Sept Rosado y Bom Jesús.

En este campo, para mejor visualización de Mossoró, presentamos en la Tabla 7 la distribución de hombres y mujeres con 60 y más años de edad por barrios en la zona urbana del municipio, lo que nos permitirá identificar el nivel socioeconómico de este colectivo y consecuentemente suponer su grado de calidad de vida. Destacamos a continuación los diez primeros barrios que

(PDDI). No obstante, solo una década después, el convenio firmado entre la Federación de las Industrias del Estado del Río Grande del Norte, el Ayuntamiento de Mossoró y la Asociación Comercial e Industrial de Mossoró les ha sugerido la discusión de las condiciones del referido desarrollo urbano. Además de esto, la nueva gestión del Ayuntamiento Municipal de Mossoró para el cuadrienio 2005-2008, quiere impulsar el plan de la ciudad como instrumento básico de control y crecimiento urbano. 
tienen un mayor número de personas con edades superiores a 60 años: Alto de São Manuel (1.670), Abolição (1.248), Bom Jardim (1.243), Santo Antonio (1.211), Barrocas (1.210), Paredões (1003), Lagoa do Mato (946), Boa Vista (846), Alto da Conceição (727) y Belo Horizonte (669). Además de lo antedicho, existen según la Secretaría Municipal de la Ciudadanía de Mossoró ${ }^{198}$, una cantidad de 1.055 Mayores de 60 años, residentes en la zona rural, aquí denominado como barrio Sin Especificación (Barrio 28).

Como puede observarse en la Tabla 7, toda la nomenclatura especificada, queda claro que la mayoría de los ancianos en Mossoró viven en barrios del Tipo $C$, es decir de clase media, según la tipología del Instituto Brasileño de Geografía y Estadística (IBGE).

\section{TABLA 7}

Población de 60 y más años por barrio, Mossoró/RN - 2000

\begin{tabular}{|c|c|c|c|c|c|c|c|c|c|c|c|c|c|}
\hline & Hombres & Mujeres & Hombres & Mujeres & Hombres & Mujeres & Hombres & Mujeres & Hombres & Mujeres & Hombres & Mujeres & \multirow{3}{*}{\begin{tabular}{|c|}
$\begin{array}{c}\text { Total } \\
\text { general }\end{array}$ \\
1.248
\end{tabular}} \\
\hline BARRIOS & \multicolumn{2}{|c|}{$60-64$} & \multicolumn{2}{|c|}{$65-69$} & \multicolumn{2}{|c|}{$70-74$} & \multicolumn{2}{|c|}{$75-79$} & \multicolumn{2}{|c|}{$>80$} & \multicolumn{2}{|c|}{ SUBTOTAL>60 } & \\
\hline 01 & 159 & 244 & 106 & 142 & 115 & 144 & 64 & 105 & 79 & 90 & 523 & 725 & \\
\hline 02 & 79 & 118 & 79 & 74 & 54 & 74 & 44 & 28 & 44 & 61 & 300 & 355 & 655 \\
\hline 03 & 03 & - & 02 & 01 & - & 01 & 02 & - & 01 & 03 & 08 & 05 & 13 \\
\hline 04 & 71 & 126 & 67 & 96 & 60 & 109 & 38 & 58 & 33 & 69 & 269 & 458 & 727 \\
\hline 05 & 225 & 301 & 130 & 183 & 165 & 175 & 94 & 144 & 112 & 141 & 726 & 944 & 1.670 \\
\hline 06 & 29 & 29 & 22 & 28 & 24 & 20 & 15 & 17 & 13 & 15 & 103 & 109 & 112 \\
\hline 07 & 147 & 201 & 118 & 148 & 143 & 126 & 71 & 91 & 78 & 87 & 557 & 653 & 1.210 \\
\hline 08 & 93 & 120 & 67 & 83 & 64 & 75 & 48 & 43 & 36 & 40 & 308 & 361 & 669 \\
\hline 09 & 120 & 149 & 60 & 97 & 62 & 100 & 54 & 65 & 45 & 94 & 341 & 505 & 846 \\
\hline 10 & 124 & 215 & 101 & 163 & 96 & 171 & 70 & 112 & 84 & 107 & 475 & 768 & 1.243 \\
\hline 11 & 09 & 10 & 11 & 10 & 08 & 06 & 02 & 04 & 11 & 12 & 41 & 42 & 83 \\
\hline 12 & 32 & 87 & 30 & 59 & 29 & 69 & 29 & 54 & 19 & 53 & 139 & 322 & 461 \\
\hline 13 & 08 & 10 & 06 & 03 & 06 & 04 & 01 & 02 & - & 02 & 21 & 21 & 42 \\
\hline 14 & 81 & 69 & 50 & 57 & 50 & 49 & 33 & 35 & 27 & 31 & 241 & 241 & 482 \\
\hline 15 & 70 & 107 & 56 & 96 & 50 & 74 & 37 & 62 & 38 & 56 & 251 & 395 & 646 \\
\hline 16 & 19 & 44 & 31 & 40 & 22 & 44 & 13 & 23 & 23 & 30 & 108 & 181 & 289 \\
\hline 17 & 01 & - & - & 01 & - & 01 & 01 & - & - & 01 & 02 & 03 & 05 \\
\hline 18 & 123 & 170 & 98 & 123 & 81 & 91 & 56 & 75 & 65 & 64 & 423 & 523 & 946 \\
\hline 19 & 82 & 78 & 33 & 41 & 37 & 29 & 18 & 27 & 19 & 23 & 189 & 198 & 387 \\
\hline 20 & 85 & 167 & 77 & 112 & 82 & 127 & 70 & 100 & 70 & 113 & 384 & 616 & 1.003 \\
\hline 21 & 15 & 21 & 21 & 25 & 15 & 18 & 10 & 05 & 05 & 08 & 66 & 77 & 143 \\
\hline 22 & 33 & 58 & 32 & 36 & 22 & 37 & 14 & 15 & 12 & 25 & 113 & 171 & 284 \\
\hline 23 & 36 & 35 & 26 & 28 & 20 & 19 & 18 & 17 & 18 & 17 & 118 & 116 & 234 \\
\hline 24 & 22 & 23 & 19 & 15 & 15 & 09 & 04 & 10 & 07 & 09 & 67 & 66 & 133 \\
\hline 25 & 21 & 30 & 14 & 20 & 13 & 16 & 09 & 09 & 09 & 11 & 66 & 86 & 152 \\
\hline 26 & 64 & 99 & 53 & 49 & 35 & 46 & 25 & 29 & 27 & 34 & 204 & 257 & 461 \\
\hline 27 & 162 & 200 & 101 & 157 & 114 & 133 & 68 & 98 & 76 & 102 & 521 & 690 & 1.211 \\
\hline 28 & 184 & 176 & 139 & 101 & 119 & 77 & 76 & 54 & 75 & 54 & 593 & 462 & 1.055 \\
\hline TOT A L & 2.097 & 2.887 & 1.549 & 1.988 & 1.501 & 1.844 & 984 & 1.282 & 1.026 & 1.352 & - & - & 16.510 \\
\hline
\end{tabular}

Fuente: IDEMA / CESE (Datos Básicos: IBGE, Censo Demográfico - 2000 (Elaboración de la autora).

198 Documento Oficial No 046/2003-GG Ayuntamiento Municipal de Mossoró - Secretaría Municipal de Ciudadanía / Gerencia Ejecutiva de Desarrollo Social, 16 de Abril de 2004. 
1. Abolição

2. Aeroporto

3. Alagados

4. Alto da Conceição

5. Alto São Manuel

6. Alto do Sumaré

7. Barrocas

8. Belo Horizonte

9. Boa Vista

10. Bom Jardim

11. Bom Jesus

12. Centro

13. Governador Dix-Sept Rosado

14. D. Jaime Câmara

15. Doze Anos

16. Ilha de santa Luzia

17. Itapetinga

18. Lagoa do Mato

19. Nova Betânia

20. Paredões

21. Pintos

22. Planalto 13 de Maio

23. Presidente Costa e Silva

24. Redenção

25. Rincão

26. Santa Delmira

27. Santo Antônio

28. Sem especificação (Zona Rural). 


\section{Aspectos demográficos}

Nadie es tan viejo que no pueda vivir un año más, ni tan mozo que hoy no pudiese morir.

Fernando de Rojas (1470-1541), Dramaturgo español.

\section{Sexo y edad}

De las transformaciones demográficas observadas a finales del siglo XX, el envejecimiento poblacional, como es bien sabido, es una de las más importantes y, de hecho, debería proseguir en este nuevo siglo. En el caso brasileño, el aumento en la participación de población mayor de 60 años en el total de la población nacional aumentó del $4 \%$ en 1940, al 9\% en 2000 (Camarano; 2001). Así, pues, en el país, se incrementó la esperanza de vida. Esto se caracteriza, en primer lugar, por la disminución de la mortalidad, gracias a la introducción de antibióticos y a la adopción de medidas preventivas de salud pública, que ayudaron a combatir la mortalidad infantil y materna. En segundo lugar, el descenso de los índices de fecundidad, a causa de la expansión del saneamiento básico (principalmente de la red de agua en los grandes centros urbanos), hizo que el número de muertes de niños por dolencias infecciosas disminuyese. Por último, el saldo migratorio negativo contribuyó a que el número de ancianos aumentase su peso relativo en la población (Neri, 2004; Papaléo Netto, 2002; Camarano, 1997, Paiva, 1981; Carvalho, 1984). Por tanto, la media de 6,3 hijos por mujer en 1960 ha pasado a 2,3 hijos en 2000, lo que representa una caída de 62,1\% ${ }^{199}$. La reducción, según los investigadores, se debe a la disminución acentuada de la fecundidad en la región Sudeste, la más urbanizada del país y al aumento de esterilización femenina. El acceso a los métodos anticonceptivos representa una tendencia para la disminución de la tasa de fecundidad. En estos casos, es costumbre decir que el proceso de envejecimiento suele ocurrir por la base de

199 Almanaque Abril - A Enciclopédia da atualidade - Brasil, edição 2004, Ano 30, São Paulo, Editora Abril, p. 103. 
la pirámide. La tendencia de la caída debería acentuarse aún más en los próximos años, entre Brasil y los países desarrollados, en relación al envejecimiento, ya que en estos últimos ese índice es del 1,6\%.

Actualmente la población brasileña entre 0 y 5 años crece mucho menos que en la década de los 70 (Berquó, 1999). Según proyeccciones de la Organización de las Naciones Unidas (ONU), hasta 2020, el número de niños en esa franja de edad debería aumentar apenas 1 millón y la población con menos de 15 años no crecerá. En Río Grande del Norte (RN), la caída de la fecundidad pasó de 8,5 en la década de los setenta, a 2,5 en 1999, un declive de $72 \%$ en 30 años $^{200}$. Así, pues, en sintonía con el resto del país, sin olvidar las diferencias regionales e intraregionales que existen entre las cinco Grandes Regiones de la Federación de Brasil, en Mossoró la población de más edad ha crecido gradualmente a finales del siglo XX, llamando la atención de la sociedad local.

En lo que concierne a nuestro colectivo, por sexo y edad, los resultados obtenidos en la encuesta Perfil Sociológico de la Vejez en Mossoró, compuesto por un $50 \%$ de varones y un $50 \%$ de mujeres (total 500 personas), refleja un $34,20 \%$, de los entrevistados entre 60 y 65 años, proporción que decrece cuanto mayor es el grupo de edad que se considera, hasta llegar a un $0,60 \%$ de los entrevistados que superan los 80 años, lo que de momento no puede considerarse una proporción muy importante en términos relativos (Tabla 8). En cuanto al sexo, puede decirse que hay preponderancia numérica del sexo femenino en Mossoró, no sólo en conjunto, sino cada uno de los grupos de edad, como vimos antes. Al igual que sucede en el mundo ${ }^{201}$ y por supuesto también en todo Brasil ${ }^{202}$. En el Perfil Sociológico de la Vejez en

200 Cf. Primera página del Periódico Tribuna do Norte, bajo el título Migração cria 'desertos humanos' no $R N$ - Má distribuição demográfica é grave, en http://www.tribunadonorte.com.br de 2 de Septiembre de 2001.

201 Naciones Unidas, (1982): Consideraciones demográficas, Asamblea Mundial del envejecimiento, New york; OCDE (1988): Le vieillissement démographique, Paris.

202 En el país tropical, existen 4,2 millones de mujeres más que hombres. Los datos del Instituto Brasileño de Geografía y Estadística (IBGE), divulgados en el informe de la Investigación Nacional por Muestra de Domicilio (PNAD: 2002), muestran que el predominio de las mujeres ocurre en todas las regiones de Brasil. "Ellas son mayoría en los centros urbanos, pero minoría en las zonas rurales (48\%). En comparación por franjas de edades, se verifica que ellas nacen en menor cantidad que los varones y 
Mossoró, las mujeres destaca entre las edades de 60-65 años, con un 20\% contra un $14,20 \%$ de los varones; entre los $71-75$ años, con $9,80 \%$ y $9,40 \%$ respectivamente; entre los $81-85$ años con un porcentaje de 2,40\% para las mujeres contra el $2,20 \%$ de los hombres, además de superar la barrera de los noventa años $(0,60 \%)$.

\section{$\underline{\text { TABLA } 8}$}

Según el sexo y la edad

\begin{tabular}{|c|c|c|c|c|c|c|}
\hline \multirow[b]{2}{*}{ EDAD } & \multicolumn{2}{|c|}{ TOTAL } & \multicolumn{2}{|c|}{ HOMBRES } & \multicolumn{2}{|c|}{ MUJERES } \\
\hline & $>60$ & $\%$ & $>60$ & $\%$ & $>60$ & $\%$ \\
\hline $60-65$ & 175 & 34,20 & 71 & 14,20 & 100 & 20,00 \\
\hline $66-70$ & 123 & 24,60 & 72 & 14,40 & 51 & 10,20 \\
\hline $71-75$ & 96 & 19,20 & 47 & 9,40 & 49 & 9,80 \\
\hline $76-80$ & 60 & 12,00 & 34 & 6,80 & 26 & 5,20 \\
\hline $81-85$ & 23 & 4,60 & 11 & 2,20 & 12 & 2,40 \\
\hline $86-90$ & 23 & 4,60 & 14 & 2,80 & 9 & 1,80 \\
\hline Más de 90 & 03 & 0,60 & - & - & 3 & 0,60 \\
\hline NS / NR & 1 & 0,20 & 1 & 0,20 & - & - \\
\hline TO TA L & 500 & 100,00 & 250 & 50,00 & 250 & 50,00 \\
\hline
\end{tabular}

\section{Estado civil}

De acuerdo con la pauta que marca la edad entre los mayores, como se puede comprobar en la Tabla 9, el matrimonio es la forma de convivencia más extendida entre los mayores. Un $51,20 \%$ estaba casado; un $31,00 \%$ era viudo. Las demás categorías tienen una representación mínima: divorciados un $2,20 \%$, parejas de hecho un $2,20 \%$, separados un $6,20 \%$ y solteros un $7,20 \%$. Los datos se asemejan a los de otras investigaciones ${ }^{203}$.

En la encuesta titulada: Mayores en Brasil - Vivencias, desafíos y expectativas en la $3^{a}$ edad, realizada por la Fundación Perseu Abramo (2006), el estado conyugal de los mayores es similar a la nuestra. Cerca del $52 \%$ estaban casados, el $34 \%$ viudos y el $6 \%$ solteros. Las diferencias se acentúan por

están en menor proporción en la población hasta los 19 años de edad. A partir de entonces, empiezan a prevalecer. Según los demógrafos, el predominio femenino en las franjas superiores de edad se da por las altas tasas de mortalidad decurrentes de causas externas (accidentes y homicidios) y de la migración de la población masculina hacia otros países.” (Fuente Almanaque Abril, 2004:108).

203 Ver, Rivera, E. Pozo, Pérez, F. Rojo y Fernández, G. Fernández-Mayoralas.: Características demográficas y forma de vida de los ancianos madrileños, en Anales de Geografía de la Universidad Complutense, 2001, 285-308. pág. 288 y Gail Wilson (1996) Yo soy los ojos y ella los brazos: cambios en los roles de género en la vejez avanzada. En Arber, Sara y Ginn, Jay Relación entre género y envejecimiento - Enfoque sociológico, Narcea, Madrid, 1996, pp. 141-161. 
género: el $73 \%$ de los hombres estaban casados y el $14 \%$ viudos; mientras entre las mayores el $48 \%$ estaban viudas y el $37 \%$ casadas.

En general, los hombres tienen una expectativa de vida menor que las mujeres y por norma social occidental la tendencia es casarse con mujeres más jóvenes que ellos. Así que, es muy probable que sigan casados en la vejez $^{204}$ (un $33,20 \%$, frente al $18,00 \%$ de las casadas), o que vuelvan a casarse, cuando son viudos, en razón de que ellos tienen a su disposición un número mayor de compañeras potenciales. Mientras que también es mucho más probable que las mujeres mayores enviuden más que ellos ${ }^{205}$, como se observa en la referida tabla.

La encuesta deja al descubierto la causa de su mayor esperanza media de vida en relación con los hombres. Para éstos, la proporción de las mujeres casadas y viudas (un 18\% y un $21,60 \%$, respectivamente) no está tan lejana, además de producirse un elevado número de casos de viudez femenina (un 21,60\% frente a apenas un 9,40\% de viudos). En consecuencia, el desequilibrio entre sexos se torna irreparable. A este respecto, según la socióloga Bazo, "la viudez, como factor característico de la soledad, se experimenta más en las mujeres que en los varones merced a su mayor longevidad media. Además, suelen experimentar un declive en sus condiciones materiales de vida como consecuencia del importe de las pensiones de viudedad"206. En cuanto a la escasez de divorciados y separados, así como de las personas que cohabitan, se ha de tener en cuenta el bajo peso del divorcio dada su reciente legalización ${ }^{207}$ y el predominio en el pasado de normas sociales contrarias a la ruptura del matrimonio.

Estratificando la soltería, un 5,60\% de las mujeres están solteras, lo que casi cuadruplica el valor existente entre los hombres, 1,60\%. La reducida proporción de solteros responde también a razones socioculturales. En la sociedad tradicional, el matrimonio era considerado como la forma de vida única durante la etapa de la madurez, lo que difiere de la sociedad actual, en

Arber y Ginn (1996:107).

Gail Wilson, op. cit., p. 146.

Bazo, María Teresa (1990:223).

Artículo 226 de la Constitución de la República Federativa de Brasil, 1988. 
la que se entiende cada vez más la soltería como opción libremente elegida. En Brasil, la soltería entre las mujeres, respaldada en los datos del $\mathrm{IBGE}^{208}$, fue bautizada por la demógrafa Elza Berquó como Pirámide da Solidão Feminina: cuanta más vieja es la mujer, más difícil le es encontrar un compañero. ${ }^{209}$ Para la mujer, cuanto más avanza la edad, menor es la posibilidad de casarse. Aun en el entorno de la soltería de las mujeres en la vejez, Scott y Wenger (1996) suponen que ellas, "suelen tener redes de apoyo mayores que las de los hombres solteros. Sin embargo, en ambos sexos, la ausencia de un cónyuge, de hijas o hijos adultos (o de ambos), supone que no haya nadie en la red sobre quien recaigan unas expectativas de asistencia en la vejez. Las mayores redes de las mujeres solteras proporcionan un apoyo más expresivo, en cambio, los hombres solteros pueden quedar muy aislados" 210 . Pero, cuando el colectivo es de edad más avanzada, el cuadro se invierte. En las mujeres ancianas con menos parientes cercanos que los hombres ancianos, es más probable que, en la vejez, vivan solas ${ }^{211}$.

\section{TABLA 9}

Según el estado civil

\begin{tabular}{|l|c|c|cccc|}
\hline \multicolumn{1}{|c|}{ ESTADO } & \multicolumn{2}{|c|}{ TOTAL } & \multicolumn{2}{c|}{ HOMBRES } & \multicolumn{2}{c|}{ MUJERES } \\
CIVIL & $>60$ & $\%$ & $>60$ & $\%$ & $>60$ & $\%$ \\
\hline Soltero & 36 & 7,20 & 8 & 1,60 & 28 & 5,60 \\
\hline Casado & 256 & 51,20 & 166 & 33,20 & 90 & 18,00 \\
\hline $\begin{array}{l}\text { Pareja de } \\
\text { hecho }\end{array}$ & 11 & 2,20 & 8 & 0,60 & 3 & 0,60 \\
\hline Separado & 31 & 6,20 & 15 & 3,00 & 16 & 3,20 \\
\hline Divorciado & 11 & 2,20 & 6 & 1,20 & 5 & 1,00 \\
\hline Viudo & 155 & 31,00 & 47 & 9,40 & 108 & 21,60 \\
\hline T O T A L & 500 & 100,00 & 250 & 50,00 & 250 & 50,00 \\
\hline
\end{tabular}

Fuente: Encuesta Perfil Sociológico de la Vejez en Mossoró - Junio 2004/Junio 2005

(Elaboración de la autora)

\section{Nivel educativo}

En la última década del siglo XX, Brasil presentó avances sociales importantes: el número de niños en la escuela aumenta, la tasa de mortalidad infantil cae, la renta media crece, las mujeres ingresan más en el mercado de trabajo, los ancianos viven más y hay menos analfabetos. Particularizando el indicador

\footnotetext{
208 IBGE, (2003).

209 Almanaque Abril (2003:115).

210 Para una discusión pormenorizada ver: Scott, Anne y Wenger, G., Clare (1996:223); Mugford y Kending (1986).

$211 \quad$ Wenger y Scott, 1996 y Wilson Gail, 1996.
} 
educacional, en 1991, el 55,8\% de los ancianos declararon saber leer y escribir por lo menos una carta simple; en 2000 , ese porcentaje pasó al $64,8 \%$, lo que representa un crecimiento del $16,1 \%$ en dicho período. Estos datos son parte del Perfil de los Mayores Responsables por Domicilios en Brasil. Sin embargo, en un país que presenta uno de los peores índices de desigualdades sociales del mundo, donde ocupa el décimo lugar en el ranking mundial en una lista de 126 países y territorios (PNUD: 2006), la distribución de educación y del analfabetismo no podría ser diferente. De acuerdo con el IPEA de 2007, los diez por ciento de los más ricos del país concentran $75 \%$ de la riqueza nacional y pagan menos tributos que los pobres. El índice revela como en Brasil, a pesar de los programas asistenciales como la Bosla familia y de los beneficios de la Seguridad Social del Gobierno Luis Inácio Lula da Silva y de la creciente generación de empleo, está muy lejos de una nación justa.

A pesar de las mejorías, de 2006 a 2007, la tasa de analfabetismo pasó del $10,4 \%$ al $10 \%$, que representa cerca de 14,1 millones de analfabetos absolutos con 15 años o más y un $21,6 \%$ de analfabetos funcionales entre 15 y 64 años, lo que supone que las personas mayores de 15 años tienen menos de cuatro años de escolaridad ${ }^{212}$. Pero, la mayor concentración de analfabetos está en la población de 60 años o más, donde el 36\% de las personas no sabe ni leer ni escribir ${ }^{213}$. En la Región Nordeste, la situación es más dramática: el porcentaje era del 56,1\%. A nivel del Estado de Río Grande del Norte, los analfabetos con 60 y más años alcanzan una tasa del 54,9\% y en Mossoró del $48,4 \%{ }^{214}$. Según los datos de la proyección de la Organización de Naciones Unidas para la Educación, la Ciencia y la Cultura (Unesco), para tasas de analfabetismo en América Latina en 2007, la tasa brasileña es superior a la de los recopilados en países como Bolivia $(9,7 \%)$, Surinam $(9,6 \%)$, Paraguay $(6,3 \%)$, Chile (3,5\%), Argentina (2,4\%), entre otros.

\footnotetext{
$212 \quad$ PNAD, 2007.

213 Estas informaciones están en el Mapa do Analfabetismo no Brasil (2006), estudio producido por el Instituto Nacional de Estudios e Investigaciones Educacionales Anísio Teixeira (INEP), que traza un panorama de la situación educacional de todos los municipios brasileños. La publicación reúne indicadores producidos por el IBGE y por el Programa de Naciones Unidas para el Desarrollo (PNUD).

214 Las informaciones socioeconómicas públicas del Perfil de Mossoró se pueden encontrar en la página web http://www.federativo.bndes.gov.br/destaques "Municipios en Datos" del Banco de Desarrollo. Página visitada el 14 de Marzo de 2005.
} 
En general, hay distintos niveles educativos aunque dominan los estudios bajos y muy bajos, sobre todo en mujeres. Así pues, los hombres están, proporcionalmente, más alfabetizados que las mujeres (un 67,7\% contra un $62,6 \%$, respectivamente), ya que hasta los años 60 tenían más acceso a la escuela que las mujeres ${ }^{215}$. Después de los años sesenta el cuadro educacional comienza a favorecer a las mujeres. Para Elza Berquó ${ }^{216}$, las dificultades femeninas para ingresar en la escuela se agravaban por la tentativa de buscar condiciones de existencia y de supervivencia. No obstante, en nuestra muestra, como era posible presumir, el nivel de instrucción de las personas mayores de 60 años dibuja un cuadro ampliamente conocido: se trata de un colectivo muy poco instruido, puesto que esas personas nacieron entre la primera mitad del siglo XX cuando sólo unos bajos porcentajes de población tenían acceso a las escuelas, principalmente los hombres en detrimento de las mujeres. Además, históricamente, el país se fue constituyendo a partir de modelos excluyentes, concentradores de renta y productores de desigualdades de toda índole. Para ilustrar este hecho, basta observar que, como muestra la Tabla 10, carecen de estudios, es decir, un 19,80\% declaró ser analfabetos; 99 personas entre 60 y 80 y más años de edad. En el otro extremo sólo, 27 personas (un 5,40\%), han accedido al nivel superior universitario. En Mossoró, en 2000 casi la mitad de los ancianos eran analfabetos, el 22,5\% varones y el $13,30 \%$ mujeres. $^{217}$

Seguidamente, según la muestra, el grupo que declara tener estudios primarios es del $31,60 \%$ mientras que un 20,80\%, declara saber leer. Si consideramos los que apenas saben leer, como analfabetos funcionales (que leen y escriben de una manera rudimentaria y que son incapaces de entender textos de cierta longitud) y los sumamos a los analfabetos, tendríamos un $40,60 \%$ con un nivel educativo muy bajo. Como el Brasil es un país plural, con desigualdades sociales y regionales, no podría ser diferente con la política

\footnotetext{
215 Se pueden Consultar los detalles de estas informaciones visitando la página oficial http://www.ipea.gov.br del Instituto de Investigación Económica Aplicada (IPEA) en el Portal de Servicios e Informaciones del Gobierno.

216 Berquó, Elza (1999): Considerações sobre o envelhecimento da população no Brasil. En Anita Liberalesso Neri e Guita Grin Debert (orgs). Velhice e Sociedade. Campinas - São Paulo, Papirus, coleção vivaidade, p. 31 .

217 INEP/MEC (2000) Mapa del Analfabetismo en Brasil.
} 
educativa. Las regiones con menor desarrollo económico y de economía poco diversificada son las que presentan los peores indicadores de analfabetismo. De acuerdo con el PNAD del 2007, la mayor parte de los analfabetos del país está concentrada en la Región Nordeste $(19,9 \%)$, seguida por la Norte con el $10,8 \%$. Las menores tasas de analfabetismo de personas con 15 años o más fueron observadas en el Sudeste $(5,75 \%)$ y la Región Sur $(5,4 \%)$. Entre los adultos, en el Nordeste, casi mitad de la población mayor de 60 años (42,5\%) es analfabeta funcional, mientras que en el Sur la proporción es de un 20,5\% y en el Sudeste de un 20,7\%. Para Anísio Teixeira (1971), no basta la caída de la tasa de analfabetismo; es fundamental también su reducción en números absolutos. $Y$ en este aspecto aún hay mucho por hacer. Según el órgano de Gobierno, como hemos visto más arriba, el analfabetismo tiene mayor incidencia en la población de mayores, principalmente en la franja de edad de 60 y más años.

Evidentemente, esta deficiente situación de nuestros mayores nos remite a las dificultades existentes en la primera mitad del siglo XX, por la mala situación económica del país, el reducido número de dotaciones escolares y el importante absentismo escolar, sobre todo en las áreas rurales, donde la mano de obra infantil era notable. Todo ello, imposibilitaba o acortaba la permanencia en el sistema educativo. Si se tiene en cuenta que buena parte de la población de este colectivo, residente en Mossoró, procedía de zonas rurales y que a su llegada se asentaban en barrios periféricos donde los equipamientos escolares eran muy escasos o no existían, la consecuencia no es otra que las personas que son viejas en la actualidad tienen el nivel educativo más bajo.

Los datos aún señalan que un $14,60 \%$ concluyó el segundo ciclo fundamental (de la serie $5^{\mathrm{a}}$ a la $8^{\mathrm{a}}$ ) y que un porcentaje del $7,80 \%$ cuenta con estudios de enseñanza media ${ }^{218}$.

A juzgar por los resultados obtenidos, la variable sexo dibuja algunas diferencias en esta distribución general. Los hombres destacan en apenas dos categorías, es decir, mayoritariamente están en la condición de los que no

218 Que corresponde al bachillerato en la enseñanza española. 
tienen ningún estudio $(10,80 \%)$, al mismo tiempo que también alcanzan cifras superiores en las condiciones de los que saben leer (14\%). Sin embargo, las mujeres asumen el liderazgo en las cuatro situaciones siguientes: considerablemente aumenta el porcentaje en primaria, donde el $19,20 \%$ de las mujeres ha acudido a la escuela por sólo un $12,40 \%$ de los hombres que lo ha hecho. Para los que cursaron secundaria, la diferencia es muy pequeña, el $7,40 \%$ del colectivo femenino llega a ese nivel, en contrapunto al 7,20\% de los hombres. En la enseñanza media las mujeres afirman tener más instrucción que ellos (un 4,80\% frente un 3\%). Pero, no nos engañemos, el nivel de estudios de los mayores puede ser aún peor, dado que no les preguntamos si éstos fueron completos. $Y$ en cuanto al nivel universitario, existen únicamente pequeñas diferencias, pero las mujeres se mantienen en cabeza, con el 2,80\% frente al 2,60\%. Sin embargo, este escenario está cambiando en lo que se refiere a la cuestión de género. En Brasil, las mujeres ya ocupan la mayor parte de las matrículas en los diferentes niveles de la Enseñanza, con especial diferencia en la enseñanza superior (MEC/INEP: 2002). Es muy probable que tengamos en las próximas generaciones de senescentes una población más instruida.

\section{$\underline{\text { TABLA } 10}$}

Según el nivel educativo

\begin{tabular}{|l|c|c|cccc|}
\hline \multicolumn{1}{|c|}{ NIVEL } & \multicolumn{2}{c|}{ TOTAL } & \multicolumn{2}{c}{ HOMBRES } & \multicolumn{2}{c|}{ MUJERES } \\
\hline EDUCATIVO & $>60$ & $\%$ & $>60$ & $\%$ & $>60$ & $\%$ \\
\hline Ninguno & 99 & 19,80 & 54 & 10,80 & 45 & 9,00 \\
\hline Sabe leer & 104 & 20,80 & 70 & 14,00 & 34 & 6,80 \\
\hline Primaria & 158 & 31,60 & 62 & 12,40 & 96 & 19,20 \\
\hline Secundaria & 73 & 14,60 & 36 & 7,20 & 37 & 7,40 \\
\hline $\mathbf{2}^{\circ}$ Grado & 39 & 7,80 & 15 & 3,00 & 24 & 4,80 \\
\hline Superior & 27 & 5,40 & 13 & 2,60 & 14 & 2,80 \\
\hline T O T A L & 500 & 100,00 & $\mathbf{2 5 0}$ & $\mathbf{5 0 , 0 0}$ & $\mathbf{2 5 0}$ & $\mathbf{5 0 , 0 0}$ \\
\hline
\end{tabular}

Fuente: Encuesta Perfil Sociológico de la Vejez en Mossoró - Junio 2004/ Junio 2005 (Elaboración de la autora)

\section{Estructura familiar}

El tamaño de las familias brasileñas, tal como divulgó la Investigación Nacional por Muestra de Domicilios (PNAD: 2006), refleja que viven en Brasil 57,3 millones de familias, 15 millones más que en el principio de los años noventa. Dicha situación revela cambios importantes en el perfil de los 
domicilios brasileños. Uno de ellos fue la disminución del tamaño. Entre 1980 y 2005, la media de miembros en las viviendas pasó de 4,5 personas a 3,2. Actualmente, de cada diez familias, siete tienen entre dos y cuatro integrantes. La familia tradicional, o nuclear, compuesta por pareja con hijos, cayó de casi del $60 \%$, en 1992, al 55\% en 1999, al mismo tiempo que aumentó la proporción de otros tipos de composición familiar, a saber: mujeres sin cónyuge y con hijos (del 15,1\% al 17,1\%) y parejas sin hijos (del 12,9\% al 13,6\%). Ha crecido también el número de personas que viven solas, representando casi un $10,5 \%$ en todo el país ${ }^{219}$; en su mayoría son personas mayores de 60 años. La reducción del tamaño de la familia se puede explicar, sobre todo, por la acentuada caída en la tasa de fecundidad en las últimas seis décadas, de 6,2 hijos en 1940, pasa a 2,3 hijos en $2000^{220}$. No obstante también, influyeron en la reducción de familia hacia el núcleo conyugal con hijos $^{221}$, otros factores como el cambio de valores culturales del brasileño y el ingreso considerable de mujeres en el mercado de trabajo, acentuados en la segunda mitad del siglo XX.

En lo que se refiere a la distribución de los grupos familiares por número de integrantes, como se puede observar más detalladamente en la Tabla 11, alrededor de un cuarto de las personas de 60 y más años que residen en el hogar viven con hijo soltero. Las diferencias son claras: el 7,80\% de los hombres y el $14,60 \%$ de las mujeres viven en un hogar monoparental. En las palabras de Peixoto, "el desempleo, el divorcio, la viudedad, los hijos que nunca salen de casa, son razones que explican por qué, en Brasil, las generaciones más viejas cohabitan cada vez más con generaciones más jóvenes - fenómeno que es aún más frecuente en las familias de capas populares" (2004:75).

En ese sentido, vamos a profundizar en la situación del desempleo. Se estima que en 2002 existían 7,8 millones de desocupados en todo el país de acuerdo con los datos de la Investigación Nacional por Muestra de Domicilio

\footnotetext{
$219 \quad$ Almanaque Abril 2007, p. 134.

$220 \quad$ Berquó, E. 1999.

221 Ribeiro, R.M., Sabóia, A.L., Branco, H.C., y Bregman, S. (2004): Familia brasileira en dados, Em Kaloustian, S. M. Familia Brasileira a base de tudo, $6^{\mathrm{a}}$ ed., São Paulo, Cortez.
} 
PNAD/IBGE. El perfil del desempleado lo constituyen las mujeres, los jóvenes y las personas que están cursando la enseñanza general y media. En el Nordeste, la situación es más inquietante aún, pues muchos de los candidatos en busca de un puesto de trabajo, poseen bajo nivel de escolaridad y formación, con lo que quedan fuera del mercado laboral. Además, en todo el país la proporción de mujeres que ha asumido el mando de la familia brasileña alcanza un $\mathbf{2 7 \%}$ en 2002 de acuerdo con el referido órgano de gobierno. La creciente participación femenina en el mercado de trabajo tuvo lugar especialmente a partir de la década de 1970. En aquella época, apenas un $18,2 \%$ de las mujeres formaba parte de la población económicamente activa ${ }^{222}$, en 30 años ese porcentaje subió al $35 \%{ }^{223}$. El continuo crecimiento de actividad productiva femenina se debe a una combinación de factores, como los cambios en los patrones de comportamiento, en los arreglos familiares, junto con el aumento de la escolaridad y la caída de la tasa de fecundidad. Todos ellos son aspectos que han posibilitado una redefinición del papel de la mujer en todas las clases sociales ${ }^{224}$. En los años noventa, la reestructuración económica, con la reducción de puestos de trabajo en ocupaciones típicamente masculinas, el creciente desempleo, especialmente entre los jóvenes, la continúa terciarización de la economía y el deterioro de la renta familiar, favorecieron la participación femenina en el trabajo remunerado. ${ }^{225}$ Entre 1980 y 2003, la proporción de domicilios bajo la responsabilidad femenina creció del $15 \%$ al $28 \%$. Si tratamos este asunto desde la perspectiva del colectivo de mayores ${ }^{226}$, comprobamos que una quinta parte de los domicilios brasileños está bajo la responsabilidad de éstos. El censo de 2000 del IBGE muestra que el $62 \%$ de las personas con más de 65 años son responsables de la vivienda en la viven. En estas casas, la media de edad del cabeza de familia es de casi 70 años. Esta tendencia a la mayor copresidencia de los adultos mayores con más recursos implica que, en un

\footnotetext{
$222 \quad$ Bruschini \& Lombardi, 1996.

223 IBGE, 2000

$224 \quad$ Wajnman, op., cit., 1998.

225 Montali, 2000.

226 El Censo IBGE: 2000 verificó que 62,4\% de los mayores eran cabezas de familia de los domicilios brasileños, observándose un aumento en relación a 1991, cuando los mayores proveedores representaban un $60,4 \%$. Es importante destacar que en el conjunto de los domicilios brasileños (44.795.101), 8.964.850 tenían mayores como cabezas de familia y representaban el $20 \%$ del contingente total. En 1991, esa proporción quedaba en torno al 18,4\%.
} 
contexto familiar de escasos recursos, un mayor ingreso del adulto mayor puede aumentar la dependencia de hijos y otros familiares en relación con dicho adulto. Eso supone, para ambas situaciones, que si en Mossoró, hay cerca de 88.590 personas en edad económicamente activa ${ }^{227}$, de las que 52.953 son hombres $(59,77 \%)$ y 35.637 son mujeres $(40,23 \%)$, y que 18.930 están en el paro, es decir, un $21,36 \%$ de los mossoroenses, la convivencia con los progenitores o con uno de ellos se convierte en una cuestión de supervivencia. Como resume Souza (1998), la extensión de los beneficios de la Seguridad Social en Brasil ha beneficiado no sólo a los adultos mayores, sino también ha contribuido a mejorar la situación de sus familias de residencia.

Constatada la condición de empobrecimiento de estas familias, quisiera añadir dos ideas más: la primera sería que es pertinente recordar que la solidaridad familiar no va exclusivamente de los padres hacia los hijos, sino que va también de los hijos a los padres, es decir, tiene carácter recíproco. En la tradición brasileña, la familia tiene un papel importante en la sociedad. El Art. 229 de la Carta Magna de 1988 lo deja claro: los padres tienen el deber de asistir, criar y educar los hijos menores, y los hijos mayores tienen el deber de ayudar y amparar a los padres en la vejez, carencia o enfermedad (traducción libre). De forma similar, Carrajo (1999) afirma que "los hijos sienten en plena era industrial, la necesidad imperiosa de honrar y venerar a sus padres, de tal modo que se sentirían verdaderamente culpables si no hicieran caso al dictamen de su conciencia. [...] A pesar de las excepciones, por regla general los hijos sienten verdadero afecto hacia sus progenitores $y$, en la medida de lo posible, tratan de favorecerlos y ayudarles" (1999:91). Scherr (1960) y Blenkner (1965), llaman a eso "responsabilidad filial", o sea, la obligación de atender a las necesidades de los padres que envejecen Blenkner habla también de la "madurez filial", es decir de la capacidad de dar prueba de responsabilidad filial. Para Mishara y Riedel (1986),"la mayoría de las investigaciones indican que las personas de mediana edad alcanzan la madurez filial y, cuando es posible, cuidan de sus padres o les procuran la ayuda necesaria para que continúen siendo independientes. Tales estudios

\footnotetext{
227 Véase en la página web http://www.caged.com.br, Cadastro Geral de Empregados $e$
} Desempregados de Brasil - CAGED. 
contradicen la imagen estereotipada según la cual las familias "se descargan" de los viejos, confinándoles en un asilo en vez de cuidarlos" (1986:75). La segunda idea a destacar sería la existencia de generaciones que viven bajo un mismo techo debido probablemente a su edad $\mathrm{y}$, por consiguiente, a su estado físico o de salud que les impide valerse por sí mismos en su propio hogar. Particularizando nuestro caso, creemos que ambas situaciones están muy presentes en la realidad brasileña. Por un lado, la supervivencia cotidiana de las familias empobrecidas, que obliga a la solidaridad de parentesco ${ }^{228}$ y por otro el vínculo afectivo entre los individuos en las familias, que es un punto fuerte de confluencia de las realidades entre las generaciones.

Volviendo de nuevo a la Tabla 11, sus datos muestran que, una quinta parte vive en pareja con hijo $(20,20 \%)$, situación visiblemente más frecuente entre los varones $(14,40 \%)$ que entre las mujeres $(5,80 \%)$ y un $19 \%$ vive fundamentalmente con el cónyuge. También los varones (12\%) llevan ventaja sobre las mujeres $(7 \%)$ en esa situación familiar. Por otra parte, un $17,80 \%$ vive en hogares de cuatro o más miembros. Aquí la situación se equipara, los hombres ancianos (9\%) viven con casi la misma cantidad de gente bajo el mismo techo que las mujeres ancianas (8\%) lo que constituye una proporción significativa, en el sentido en que puede indicar la persistencia de estructuras familiares tradicionales, registrada en el último censo nacional. Además, la cohabitación familiar (dos o más familias viviendo bajo el mismo techo) constituye una realidad brasileña representada en un $56,1 \%$ por razones de

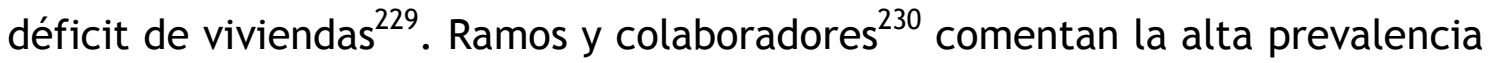
de domicilios multigeneracionales en Brasil y sobre la hipótesis de que ese arreglo sea mucho más una estrategia de supervivencia que una opción cultural. Mossoró, municipio polo de la región Oeste Potiguar, se enfrenta a

\footnotetext{
$228 \quad$ Carvalho; 2004:96.

229 De acuerdo con el estudio titulado "Déficit Habitacional no Brasil 2000" realizado por la Fundação João Pinheiro, se verificó un déficit de 6.656.526 nuevas viviendas, incidiendo notoriamente en las áreas urbanas, que evidenciaban un 81,3 por ciento del total del país. Considerando el perfil de rendimientos, 4.410 .385 familias, correspondiendo a 83,2\% del déficit urbano, tenían una renta inferior a tres salarios mínimos. En términos regionales, se verifica que el Nordeste lideraba la demanda habitacional, con necesidades estimadas en 2.631.790 unidades, siendo seguidas por la Región Sudeste, con una demanda de 2.412.460 unidades, la región Sur con 690,312 unidades, la región Centro-Oeste con 488.482 unidades y la región Norte con 411.625 unidades.

230 Ramos L.R, Rosa T.E.C, Oliveira Z.M, Medina M.C.G, Santos F.R.G. (1993): Perfil do idoso em área metropolitana na região sudeste do Brasil: resultados de inquérito domiciliar. Revista Saúde Pública, 27:87-94.
} 
los mismos problemas que otras ciudades medianas de Brasil en el tema de la vivienda. A pesar de la deficiencia de indicadores exactos, es de conocimiento público que una parte de la población comparte vivienda con más de una generación y muchas de ellas están en situaciones precarias. Por lo tanto, se estima que el déficit de viviendas está en torno a 10.392, el $21,32 \%{ }^{231}$. En efecto, la proliferación de chabolas es una consecuencia natural y la construcción de casas en lugares inapropiados es patente. Ahora bien, actualmente el modelo de vida familiar brasileño cuenta de media con 3,3 componentes. Como hemos dicho, las familias estaban compuestas por 4,5 individuos entre 1980-2003, mientras que en 1991, por 3,9. Como se ve, hay una tendencia a la disminución familiar. La muestra aún sitúa un $11 \%$ de personas mayores en situación de convivencia con otro familiar. Entre las mujeres es más frecuente esa realidad que entre los hombres, un $8 \%$ contra un $3 \%$, y un $6,40 \%$ viven solos. Finalmente, un $2 \%$ comparte la casa con otros individuos que no son familiares biológicos.

Desde luego, la edad y el sexo introducen diferencias sustanciales. Es conocido que la soledad es, sobre todo, un monopolio femenino (Bazo, 1900:223). Ya lo vimos más arriba en el variable estado civil. Aquí, la muestra ratifica lo de otras investigaciones, el $3 \%$ de los hombres vive solo, frente al $3,40 \%$ de las mujeres. Generalmente la frecuencia de este modelo de vida aumenta con la edad. Durán (1999:71) sostiene que si el número de hogares unipersonales formados por mujeres es más alto que el de los formados por varones, se debe no sólo a su mayor esperanza de vida, sino también a la definición social de la mujer como "generadora de hogar", es decir, a la capacidad de las mujeres de garantizar un núcleo de producción social que se mantiene incluso en condiciones poco favorables, como la residencia en solitario. Adjuntando los datos sobre el estado civil, podemos observar un destacado número de mujeres solteras y viudas viviendo en ambientes unipersonales. Añadamos que, dadas las peculiaridades reales en que viven los mayores, están los que prefieren vivir solos, a pesar de ser aún, pocos en la realidad mossororense. Las familias desean mantenerse en contacto, pero no 
vivir necesariamente en la misma casa, lo que Rosenmayr y Kosheis (1965) definen como "intimidad a distancia”.

\section{$\underline{\text { TABLA } 11}$}

Según la situación familiar actual

\begin{tabular}{|l|c|c|cccc|}
\hline & \multicolumn{2}{|c|}{ TOTAL } & \multicolumn{2}{c}{ HOMBRES } & \multicolumn{2}{c|}{ MUJERES } \\
\multicolumn{1}{|c|}{ CON QUIEN VIVE } & $>60$ & $\%$ & $>60$ & $\%$ & $>60$ & $\%$ \\
\hline En pareja & 95 & 19,00 & 60 & 12,00 & 35 & 7,00 \\
\hline Con hijo soltero & 112 & 22,40 & 39 & 7,80 & 73 & 14,60 \\
\hline Con pareja y hijo & 101 & 20,20 & 72 & 14,40 & 29 & 5,80 \\
\hline $\begin{array}{l}\text { Con pareja, hijo y } \\
\text { nieto }\end{array}$ & 89 & 17,80 & 45 & 9,00 & 44 & 8,80 \\
\hline Con otro familiar & 55 & 11,00 & 15 & 3,00 & 40 & 8,00 \\
\hline Con otro, no familiar & 10 & 2,00 & 3 & 0,60 & 7 & 1,40 \\
\hline Solo/a & 32 & 6,40 & 15 & 3,00 & 17 & 3,40 \\
\hline NS/NR & 6 & 1,20 & 1 & 0,20 & 5 & 1,00 \\
\hline T O T A L & 500 & 100,00 & 250 & 50,00 & 250 & 50,00 \\
\hline
\end{tabular}

Fuente: Encuesta Perfil Sociológico de la Vejez en Mossoró - Junio 2004/ Junio 2005 (Elaboración de la autora)

\section{Lugar de nacimiento}

Siendo el Río Grande del Norte un Estado que recibió flujo migratorio poco significativo, en comparación con las demás provincias brasileñas, su crecimiento poblacional se dio siempre de forma autónoma, con tasas, en la mayoría de las veces, inferiores al crecimiento observado en las otras regiones del país. Su población rural se presentó significativa hasta el año de 1972, cuando pasó a ser superada por la población urbana y, a partir de ese año, la población rural viene descendiendo sistemáticamente, debido al éxodo rural, cuya mayor intensidad se registró en el decenio de 1970 a 1980.

Esto mismo, sucedió exactamente en el conjunto de población de Mossoró, segunda ciudad más desarrollada del estado. En este esquema, se reflejaría el devenir de más de la mitad, $60 \%$, de los entrevistados, provenientes de otras localidades (Véase Tabla 12). El alto índice de personas que no han nacido en Mossoró, en este contexto, viene provocado sobre todo, por la migración de la zona rural y de las ciudades circunvecinas hacia la ciudad. Los motivos varían, desde la falta de empleo, hasta la inexistencia de políticas públicas, para la generación de empleo, la mejoría de la educación, salud, habitación y ocio, un ejemplo de lo que ocurre en todas las demás ciudades de Brasil. 
En cuanto a la variable sexo, identificamos una mayor cantidad de varones nativos ( $22 \%$ contra $17,80 \%$ ), mientras que el $32,20 \%$ de las mujeres proviene de otras localidades frente al $27,80 \%$ de los varones.

A la luz de los resultados, ningún encuestado ha declarado ser de otra nacionalidad. En todo el mundo dos razones marcan el fenómeno de la inmigración, con reflejos en Brasil: por un lado, hay un flujo de inmigrantes provenientes de naciones subdesarrolladas o en vías de desarrollo, que huyen de la creciente desigualdad social y económica, del desempleo o las guerras en su país de origen. Por otro lado, el desplazamiento de ejecutivos, que ocupan cargos de dirección en grandes multinacionales. En Mossoró no tienen lugar ninguno de las dos situaciones, dado que los extranjeros procuran llegar a los centros urbanos más desarrollados, es decir, a las regiones Sur y Sudeste de Brasil, en particular São Paulo, Río de Janeiro y Belo Horizonte. Todo ello nos lleva a deducir que los inmigrantes apenas se mueven entre provincias de la propia región de origen, caracterizando así los movimientos migratorios intra-regionales. Este tipo de migración resalta más en las regiones del Nordeste y del Sur, marcadas por un fuerte movimiento de evasión en las últimas décadas. Con el crecimiento económico de sus ciudades, tanto las metropolitanas como las del interior, esas regiones pasan a retener a sus pobladores, con riesgo de convertirse en polos de atracción de retorno.

$\underline{\text { TABLA } 12}$

Según el lugar de nacimiento

\begin{tabular}{|l|c|c|cccc|}
\hline \multicolumn{1}{|c|}{ LUGAR DE } & \multicolumn{2}{|c|}{ AMBOS SEXOS } & \multicolumn{2}{c}{ HOMBRES } & \multicolumn{2}{c|}{ MUJERES } \\
NACIMIENTO & $>60$ & $\%$ & $>60$ & $\%$ & $>60$ & $\%$ \\
\hline Mossoró & 200 & 40,00 & 110 & 22,00 & 90 & 18,00 \\
\hline Otra localidad & 300 & 60,00 & 140 & 28,00 & 160 & 32,00 \\
\hline T O T A L & 500 & 100,00 & 250 & 50,00 & 250 & 50,00 \\
\hline
\end{tabular}

Fuente: Encuesta Perfil Sociológico de la Vejez en Mossoró - Junio 2004/ Junio 2005 (Elaboración de la autora)

\section{Situación laboral actual}

En esta sección y las sucesivas estudiaremos las pautas relacionadas con el mundo laboral de los hombres y las mujeres mayores de 60 años residentes en Mossoró. Examinando primero la situación laboral actual, los resultados empíricos de la muestra, como pone de manifiesto la Tabla 13, apuntan que 
más de dos tercios se encuentran jubilados (76,80\%). Un $19,20 \%$ se declara laboralmente activo, un $16,20 \%$ afirma ser pensionista, un $31,60 \%$ son amas de casa y un $8 \%$ está en el paro. Advertimos que esta cuestión es de elección múltiple y el hecho de que los sujetos puedan encasillarse en más de una opción, hizo que los porcentajes sumasen más del cien por cien.

Por género, las mujeres suelen alcanzar porcentajes más altos en las situaciones de amas de casa $(26,80 \%)$ y pensionistas $(13,60 \%)$. Sin embargo, los varones están en un número proporcionalmente superior a ellas en la condición de jubilados $(41,80 \%)$, laboralmente ocupados $(12 \%)$ y entre los parados $(4,80 \%)$. Es preciso aclarar que las diferencias encontradas, sobre todo en las situaciones de jubilaciones y ocupaciones, pueden ampararse en las características del mercado de trabajo, mundialmente desigual entre sexos, sobre todo para ese colectivo nacido en la primera mitad del siglo XX.

Estratificando la variable sexo por edades, las mujeres tardan más en llegar a la jubilación. Es decir, de los 250 varones en edad de jubilarse que podrían hacerlo sea por edad ${ }^{232}$ o por tiempo de Contribución Subsidiaria ${ }^{233}$, 209 ya disfrutan de dicho beneficio. En cambio, del total de 250 mujeres entrevistadas, apenas 175 están jubiladas. La discrepancia puede ser reflejo de carreras profesionales femeninas incompletas y de mujeres que trabajan pero que están poco cualificadas (Donfut: 2004). Esto hace que la situación de las mujeres sea de mayor precariedad social y penuria económica. Por lo que se refiere al estado civil, la mayoría de los jubilados o pensionistas son hombres casados y viudos (un $25,20 \%$ y un $8,40 \%$, respectivamente) y mujeres casadas y viudas (un $11 \%$ y un $10,20 \%$ ). Entre los mayores que se encuentran en plena actividad laboral, destacan los hombres casados $(8,40 \%)$, en cambio, sobre la condición de pensionistas prevalecen las mujeres viudas (12\%).

\footnotetext{
232 Tienen derecho al beneficio los trabajadores urbanos del sexo masculino a los 65 años y del sexo femenino a los 60 años de edad. Los trabajadores rurales pueden solicitar jubilación por edad con cinco años menos: a los 60 años los hombres, y a los 55 años las mujeres (PEC 10/08).

${ }_{233}$ La jubilación por tiempo de contribución, puede ser íntegra o proporcional. Para tener derecho a la jubilación íntegra, el trabajador debe cumplir al menos 35 años de contribución y la trabajadora, 30 años. Para requerir la jubilación proporcional, el trabajador tiene que combinar dos requisitos: tiempo de contribución y la edad mínima. Los hombres pueden requerir la jubilación proporcional a los 53 años y 30 años de contribución (más un 40\% sobre el tiempo que falte para llegar al 16 de diciembre de 1998 para completar 30 años de contribución). Las mujeres tienen derecho a la jubilación proporcional a los 48 años de edad y 25 años de contribución (más un $40 \%$ sobre el tiempo que falte para llegar al 16 de diciembre de 1998 para completar 25 años de contribución).
} 
Puede que algunos de los entrevistados estén concomitantemente en la condición de jubilados y laboralmente ocupados. De acuerdo con el Instituto Brasileño de Geografía y Estadística (IBGE), permanecer en el mercado de trabajo por tener una jubilación insuficiente para mantener un patrón de vida razonable es una práctica común en Brasil. Para millares de jubilados, este tipo de ocupación es señal de la necesidad de lucha extrema por la supervivencia. En los países desarrollados, la realidad es diferente. Con una jubilación satisfactoria, que generalmente es reforzada por planes de jubilación complementaria, los mayores solo vuelven a trabajar si quieren ${ }^{\circ}$ Así pues, es probable que nuestros mayores no vean la jubilación como la interrupción de la vida laboral, ni tan poco como el merecido descanso, que se pregona habitualmente por ahí.

Otro aspecto relevante de la investigación, destacado por la PNAD/2002 sobre los mayores jubilados que trabajan, es que la mayoría de los trabajadores son hombres (un 30,2\% varones y un 14,1\% mujeres). En el Perfil Sociológico de la Vejez en Mossoró, la incidencia de varones ocupados es del 12\%, mientras que en las mujeres es del 7,20\%. Paralelamente, el aumento del número de domicilios dirigidos por mujeres mayores es una tendencia comprobada en las últimas décadas. Además de la autonomía económica y cultural de las mujeres, facilitada por su mayor participación en el mercado de trabajo, su expectativa de vida ocho años mayor a la de los varones, hace que sea natural que en edades avanzadas haya un gran número de ancianas al frente de los domicilios. En general, la población mayor de 60 años de edad que ejerce algún tipo de ocupación en el mercado de trabajo, está en torno al 10,62\% de los habitantes. José Miguel Guzmán, de la Comisión Económica para América Latina y Caribe (CEPAL/ONU), admite que este es uno de los movimientos que más se observa en el mercado de trabajo brasileño: una quinta parte de los domicilios brasileños está bajo la responsabilidad de los mayores. El censo de 2000 muestra que un 62\% de las personas con más de 65 años es responsable de la vivienda en la que vive. En estas casas, la media de edad del cabeza de familia es de casi 70 años. Para Guzmán, eso muestra que los mayores están sintiendo cada vez más la necesidad de encontrar formas de conseguir 
complementos a su renta. El problema es que los empleos son cada vez más escasos y los mayores tienen cada vez menos derechos ${ }^{234}$.

La misma situación tiene lugar en relación a los encuestados que están parados. Son el $4,80 \%$ de los hombres frente al 3,20\% de las mujeres los que se enfrentan al desempleo. Entre los años 2001-2002, se contabilizan 7,8 millones de personas desocupadas en el país (PNAD/IBGE). El perfil del desempleado es principalmente mujer, joven y que está frecuentando o ya concluyó la enseñanza general y media. Pero incluso las personas de niveles superiores tienen dificultad para encontrar un puesto de trabajo. En nuestra muestra, las mujeres superan a los hombres en las cifras de parados en Mossoró. Ellas se encuentran con mayores dificultades a la hora de buscar trabajo, en cualquier franja de edad. Sin embargo, para ambos sexos cuanto más edad más difícil es ingresar en el mercado laboral.

\section{TABLA 13}

Según la situación laboral actual*

\begin{tabular}{|c|c|c|c|c|c|c|}
\hline \multirow{2}{*}{$\begin{array}{c}\text { SITUACIÓN LABORAL } \\
\text { ACTUAL }\end{array}$} & \multicolumn{2}{|c|}{ TOTAL } & \multicolumn{2}{|c|}{ HOMBRES } & \multicolumn{2}{|c|}{ MUJERES } \\
\hline & $>60$ & $\%$ & $>60$ & $\%$ & $>60$ & $\%$ \\
\hline Jubilado & 384 & 76,80 & 209 & 41,80 & 175 & 35,00 \\
\hline Ama de casa & 158 & 31,60 & 24 & 4,80 & 134 & 26,80 \\
\hline Activo & 96 & 19,20 & 60 & 12,00 & 36 & 7,20 \\
\hline Pensionista & 81 & 16,20 & 13 & 2,60 & 68 & 13,60 \\
\hline Activo en paro & 40 & 8,00 & 24 & 4,80 & 16 & 3,20 \\
\hline
\end{tabular}

Fuente: Encuesta Perfil sociológico de la Vejez en Mossoró - Junio 2004 / Junio 2005 (Elaboración de la autora)

\section{Resumen}

La población de Mossoró está envejeciendo. La realización del Censo IBGE en el año 2000, ha permitido un conocimiento más detallado de nuestra ciudad. Mossoró tiene 213.841 residentes, de los cuales el $51,92 \%$ son mujeres y el $48,08 \%$ hombres. Del total de la población hay un 7,7\% que tiene 60 años 0 más, con una composición por sexos sutilmente diferente: hay más mujeres (9.353) que hombres (7.157), una cifra a la que se ha llegado tras un proceso de envejecimiento debido al descenso de mortalidad, combinado con la caída de natalidad, iniciada en la segunda mitad del siglo XX. 
La creciente importancia del envejecimiento poblacional como un logro social pero también como desafío al que la sociedad actual se enfrenta, sobre todo en un país en desarrollo, y la escasez de datos, nos ha motivado a investigar sobre este colectivo. La Encuesta Perfil Sociológico de la Vejez en Mossoró se ha basado en una muestra de 500 personas de 60 y más años residentes en el casco urbano, distribuidas en los veintisiete barrios de las cuatro regiones administrativas: Centro, Noroeste, Sudeste y Este de la Comunidad de Mossoró.

El primer aspecto a comentar versó sobre la caracterización del envejecimiento, de carácter demográfico, en el que los variables sexo y edad nos descubren a una población caracterizada por dos hechos importantes: la feminización de la vejez y el sobre-envejecimiento en todos los grupos de edad. Esto sucede en todas las regiones de Brasil. Según datos oficiales, el predominio de las mujeres que rebasan los 60 años (4,3\% frente a 3,3\%) se explica por cuestiones biológicas, por la mortalidad masculina, oriundas de causas externas (accidentes, violencia, homicidios, drogas) y la inmigración masculina hacia otras localidades.

El estado civil que comparten mayoritariamente los sujetos entrevistados es el de casado, estado en el que se encuentra más de la mitad del colectivo anciano (51,20\%). Si tomamos en cuenta el sexo, hay enormes diferencias. Los varones están más acompañados con esposas o compañeras y las mujeres están más solteras y viudas. Esta diferenciación entre varias causas es debida a la mayor esperanza de vida de la que gozan las mujeres, la normativa social de que las mujeres deben casarse con varones más viejos y la mortalidad masculina por causas externas. En la franja de edad por encima de los 70 años el $83 \%$ de los varones brasileños tienen esposas o compañeras, pero apenas el $27,9 \%$ de las mujeres está en esa situación (IBGE; 2000). A esta constatación llegó la demografía brasileña del Núcleo de estudios de población de la Universidad de Campinas (Unicamp), al bautizar esos datos estadísticos como Pirámide de la soledad femenina. 
En relación con el nivel de estudios logrado por los mayores de 60 años, la mayoría fueron muy poco instruidos. El indicador socio-cultural revela que hoy en día, de cada diez brasileños uno es analfabeto y dos leen muy precariamente. En ese escenario, la población de 60 y más años concentra el mayor índice (34\%) de los que no saben leer ni escribir. Si actualmente de la guardería a la Universidad llega poco menos de un tercio de la población del país (53 millones de personas), la población que frecuentó una institución de enseñanza hace medio siglo fue mucho menor. En Mossoró, en 2000, el 48,4\% de los analfabetos tenía edad igual o superior a 60 años, y son el 19,80\% de los entrevistados, frente a un reducido $5,40 \%$ los que han accedido al nivel superior universitario. Si consideramos el grupo de los analfabetos funcionales, que apenas sabe leer sin haber pasado por una escuela $(20,80 \%)$ y sumamos a los analfabetos absolutos, tendríamos un 40,60\% con un nivel educativo muy bajo. Eso corresponde a las cifras divulgadas por el Mapa del Analfabetismo en Brasil (2000). Por sexo, las investigadas están un poco más instruidas que los varones. Hemos obtenido resultados diferentes de otras investigaciones, donde las mujeres están menos instruidas que los hombres. Sin embargo, en ambos casos, la ausencia o deficiencia educacional tiene efecto negativo sobre varios aspectos personales y sociales, como la salud, la productividad, la protección ambiental, la participación política, la reducción de la mortalidad infantil y el aumento de la renta.

El cuarto aspecto digno de ser observado se refiere a la estructura familiar. Alrededor de tres cuartas partes de los participantes viven bajo el mismo techo con un mínimo de tres personas $(71,40 \%)$, razón por la que casi la mitad $(42,60 \%)$ de los sujetos están casados y comparten el hogar con hijos solteros $(22,40 \%)$, hijos casados $(20,20 \%)$, hijos y nietos $(17,80 \%)$ y otros $(11 \%)$. En cambio, un $6,40 \%$ de este colectivo vive solo, la mayoría de los cuales son mujeres viudas. Del 33,12\% de los entrevistados viudos, el $25,24 \%$ son mujeres. Debe resaltarse que los resultados concuerdan con el tamaño de las familias brasileñas, que se han reducido de 4,5 personas en la década de 1980 a 3,3 integrantes en 2002. Actualmente, de cada diez familias, siete tienen entre dos y cuatro integrantes de acuerdo con la Investigación Nacional por 
Muestra de Domicilios (PNAD: 2002). Además, la proporción de hogares habitados por una sola persona, la gran mayoría ancianos, es de casi un $10 \%$.

En el caso del lugar de nacimiento del grupo social entrevistado, más de la mitad de los que viven en la segunda ciudad más desarrollada del Estado de Río Grande del Norte/RN, Mossoró, provienen de otra localidad (60\%). No se ha observado ningún extranjero, y de acuerdo con las características de desarrollo urbano, el movimiento migratorio tuvo lugar del campo a la ciudad, práctica bastante común entre aquellos que buscan mejores condiciones de vida, marchándose de las pequeñas y subdesarrolladas ciudades circunvecinas. 


\title{
Profesión y recursos financieros
}

\author{
Los hombres son como los vinos: \\ la edad agria los malos y mejora los buenos. \\ Marco Tulio Cicerón (106 a.C.- 43 a.C.), \\ Político, filósofo y escritor romano.
}

\section{Fuente de la renta que cobra actualmente}

En lo que se refiere a la percepción de pensiones, jubilaciones y renta de que disponen los mayores residentes en Mossoró para sus gastos mensuales, la Tabla 14 nos indica que más de tres cuartas partes subsiste con los ingresos de la jubilación (un 77,80\%); alrededor de una quinta parte cuenta con renta propia (un 18,40\%); con cifras semejantes, los ingresos provienen de la colaboración financiera de los hijos (un 17,60\%); de la pensión de viudedad que reciben el $11,40 \% \mathrm{y}$, en proporciones menos acusadas, los ingresos provienen de la colaboración familiar en un 4,20\%, de la jubilación por invalidez en un $2,80 \%$ y de la benevolencia institucional en un $0,20 \%$.

En Brasil, la cobertura de la Seguridad Social (pensiones y jubilaciones) es responsable en apartados significativos de la renta de las provincias y municipios. Se observa que esto tiene un impacto significativo en la calidad de vida de los adultos mayores y de las familias en que ellos se insertan. Entre 1997 y 2005 (meses de mayo), la cantidad de beneficios pagados por la protección social, a través del Instituto Nacional de Seguro Social - INSS, aumentó un 38,7\%, pasando de 16,9 millones a 23,4 millones. Datos de enero de 2008 contabilizan 25.184.196 beneficiarios. De estos, poco más de 16,5 millones de asegurados reciben un beneficio igual a un salario mínimo. Según el IBGE, por cada beneficiario del subsidio social hay, de media, 2,5 personas beneficiadas indirectamente. Así, se estima que la Seguridad Social beneficia actualmente a cerca de 82 millones de personas en Brasil. Una mayor cobertura de la protección social tiende a disminuir la incidencia de la 
pobreza relativa y la desigualdad de ingresos. Tal beneficio es un derecho de todos, a partir del momento en que se contribuya. Sin embargo, hay diferencias en las categorías contributivas: así, quien tiene una nómina automáticamente está afiliado a la Seguridad Social. Los autónomos en general y los que prestan servicios temporales pueden inscribirse y pagar como contribuyentes individuales. $Y$ aquellos que no tienen renta propia, como estudiantes, amas de casa y desempleados pueden ser asegurados y pagar como contribuyentes facultativos. Además, la cobertura del seguro garantiza a las personas mayores de 60 años y a los discapacitados un salario mínimo mensual, siempre y cuando no posean medios de proveerse la manutención por cuenta propia o por parte de su familia.

En líneas generales, los ingresos son un parámetro importante para este colectivo y sus familias, cuya calidad de vida depende de una renta. Según investigaciones de la economista Ana Amélia Camarano del Instituto de Pesquisa Económica Aplicada (IPEA), los mayores contribuyen, de media, con un $53 \%$ de la renta familiar. Las jubilaciones y pensiones, pagadas por la Seguridad Social, terminan por llegar no sólo a los viejos, sino también a sus familiares, y la mayoría recibe ingresos por valor de un salario mínimo. Es con ese dinero, y poco más, con el que muchas familias resisten a la pobreza y sobreviven. En estos casos, los mayores son un factor de equilibrio social y no una carga.

En cuanto a la distribución por sexos según el estado civil surgen algunas diferencias. Los hombres solteros (6 de cada 8 ) y viudos (40 de cada 47 ) en condición de jubilados están proporcionalmente por encima con respecto a las mujeres solteras ( 21 de cada 28 ) y viudas ( 82 de cada 108). Tratándose de la jubilación por invalidez, las mujeres superan solo por dos la cifra de los varones. Entre ellas están 1 mujer soltera, 4 casadas y 3 viudas; en el caso de los hombres ancianos hay 4 hombres casados, 1 separado y 1 viudo. Si hablamos de la renta propia, los varones solteros ( 2 de cada 8 ) tienen renta propia frente a 8 de las 28 mujeres solteras. En el caso de los casados, 37 de 
Perfil sociológico de la vejez en Mossoró/RN.

Profesión y recursos financieros

los 166 también tienen renta propia, mientras las mujeres, apenas 14 de las 90 casadas se encuentran en esa situación.

Aún en la estructura de población senescente entrevistada por estado civil, se nota que a pesar de que los hijos ayuden financieramente con los gastos mensuales de sus padres, en porcentajes, los herederos ayudan más a los padres que a las madres casadas, y en proporciones iguales cooperan financieramente con los gastos de padres y madres viudos. En el ámbito de ayuda económica de familiares, se benefician más los varones viudos.

La inserción en el mercado de trabajo es uno de los factores que explican las condiciones de vida de las personas. Arber y Ginn (1996), argumentan que el estado civil influye en el bienestar económico de las mujeres en el último tramo de la vida, dado que sus historias laborales son frecuentemente más irregulares que las de los varones. Ellas tienden a depender de los varones tanto en el plano económico como en los recursos familiares y viven con pensiones menores.

Por otro lado, McDaniel (1986, 1989), supone que los hombres ancianos mantienen la misma clase social relativa que en edades anteriores, lo cual no ocurre en el caso de las mujeres. Así que, parece, en la presente investigación, que los varones al presentar mayor independencia económica que las mujeres, disfrutan de mejores condiciones de vida.

\section{$\underline{\text { TABLA } 14}$}

Según la fuente de renta que cobra actualmente*

\begin{tabular}{|l|c|c|cccc|}
\hline \multicolumn{1}{|c|}{$\begin{array}{l}\text { INGRESOS } \\
\text { PENSIONES }\end{array}$} & $>60$ & $\%$ & $>60$ & $\%$ & $>60$ & $\%$ \\
\hline Jubilación & 384 & 76,80 & 209 & 41,80 & 175 & 35,00 \\
\hline Viudedad & 57 & 11,40 & 5 & 1,00 & 52 & 10,40 \\
\hline Invalidez & 14 & 2,80 & 6 & 1,20 & 8 & 1,60 \\
\hline Renta propia & 96 & 19,20 & 57 & 11,40 & 35 & 7,00 \\
\hline $\begin{array}{l}\text { Ayuda } \\
\text { institucional }\end{array}$ & 1 & 0,20 & - & - & 1 & 0,20 \\
\hline Ayuda de hijos & 88 & 17,60 & 35 & 7,00 & 53 & 10,60 \\
\hline $\begin{array}{l}\text { Ayuda de otros } \\
\text { familiares }\end{array}$ & 21 & 4,20 & 9 & 1,80 & 12 & 2,40 \\
\hline
\end{tabular}

Fuente: Encuesta Perfil Sociológico de la Vejez en Mossoró - Junio 2004 / Junio 2005

(Elaboración de la autora) 


\section{Ingresos mensuales}

Una de las preguntas importantes del estudio, que nos permite una aproximación al conocimiento del nivel económico de los mayores que residen en Mossoró, se refiere a la cuantía mensual de los ingresos. Si se tiene en cuenta el estatus ocupacional actual de la mayoría, jubilados y pensionistas, como hemos visto más arriba, se observa el predominio de los ingresos bajos. Como la mayoría está poco instruida (sólo el 5,4\% llega a la facultad - ver cap. 2) numéricamente hablando, percibimos que distribución de la renta y educación son dos acciones que caminan juntas. Es decir, más de la mitad de los sujetos entrevistados (un 52,20\%) disponen de ingresos mensuales bajos, entre uno y dos Salarios Mínimos (SM) (Salario Mínimo R\$ 415,00 $\pm 166 €$ ), el $17,40 \%$ cuenta con ingresos por debajo de cuatro SM (cerca de 664€); el $13,60 \%$ recibe más de cinco SM $( \pm 830 €)$, un $5,60 \%$ está entre los que disponen de ingresos inferiores a un SM y por último estaría el 7,40\% de los casos que dijeron recibir de entre cuatro a seis SM, en otras palabras, entre $664 €$ y $996 €$ mensuales (véanse detalles en la Tabla 15).

Los referentes más destacados de nuestra investigación son jubilados y pensionistas, un contingente poderoso. Según el Censo de 2000 , el 62,4\% de los ancianos constituía el apoyo de la familia, frente al 60,4\% en 1991. Juntos suman una población de 8,9 millones, que garantiza el sustento de los hijos y hasta el de los nietos. Gracias a las jubilaciones y pensiones, esos mayores son cabezas de familia en un quinto de los domicilios. De los 15 millones de mayores confirmados en Brasil en 2000, 4,5 millones aún estarían en el mercado de trabajo y 3 millones serían pensionistas y jubilados ${ }^{235}$.

Aunque gran parte de la muestra esté constituida por jubilados y pensionistas, los datos no se alejan mucho de los porcentajes generales de la población mossoroense que se encuentra económicamente activa, dentro del contexto nacional. Del total de esta población residente en Mossoró, el 31,70\% gana hasta 1 SM mensual, el 22,44\% cuenta con hasta 2 SM, el 33,04\% dispone de

235 Indicadores Sociales Municipales (IBGE: 2000). 
Perfil sociológico de la vejez en Mossoró/RN.

Profesión y recursos financieros

más de 2 SM y un $12,82 \%$ de la población no tiene rendimiento económico ${ }^{236}$. A nivel nacional, según datos de la Pesquisa Nacional por Muestra de Domicilios (PNAD) publicada en 2006, el $8,5 \%$ de las familias brasileñas ganaba hasta una cuarta parte del SM en 2005. La gran franja de las familias brasileñas, correspondiente al $26,7 \%$ del total, recibe entre medio y un SM; las familias que ganan entre uno y dos $S M$ al mes representaban el $23,1 \%$. Mientras tanto, más del $60 \%$ de las viviendas brasileñas viven con menos de 2 SM y apenas el $6 \%$ ganaba por encima de $5 \mathrm{SM}$. Las discrepancias en los indicadores de renta se amplían más cuando son analizados por región. En el Nordeste, el 72,2\% del total de las familias sobrevive con menos de 2 SM. Sin embargo, en el Sur del país, el mismo grupo de renta no pasa del $40 \%$.

Si segmentamos la percepción de ingresos, de la muestra por sexo, como era esperado, la desigualdad social del trabajo va en perjuicio de las mujeres. Cuando el asunto es renta y trabajo, generalmente ellas acostumbran a enfrentarse a más problemas. Las investigaciones norteamericanas llevadas a cabo sobre la discriminación en el empleo por razones de edad y sexo son contundentes (McConnell, 1983 y Hess, 1986). En Brasil, a pesar de la creciente participación de las mujeres en el mercado de trabajo, ellas aún se enfrentan a las mayores tasas de desempleo y continúan recibiendo, de media, rentas inferiores a las de los hombres. Sin embargo, el grado de escolarización es mayor entre las mujeres. Según el Censo de 2000, las mujeres superan a los hombres en todos los niveles de escolaridad, pero aún están lejos de alcanzarlos en términos de salario. En la franja de hasta cuatro años de estudio, las mujeres ganaban el $79 \%$ del valor recibido por los hombres y en la franja superior - 12 años o más de estudio -, apenas el $60 \%$. En consecuencia las familias dirigidas por mujeres también tienen un nivel de renta más bajo: mientras que en las familias con ingresos mensuales de hasta un SM por cabeza, más del $40 \%$ tiene a una mujer como jefe, en las familias ricas, apenas el $15 \%$ están dirigidas por mujeres.

236 IDEMA (2003:12). 
En nuestra muestra, la discrepancia de los niveles económicos es clara: por encima de tres SM los porcentajes favorecen a los varones, en cambio las mujeres se quedan con ingresos más bajos. La norma del dominio financiero de los varones sobre las mujeres (Arber y Ginn, 1995), más allá de reforzar la ideología patriarcal que apoya el poder de los varones sobre las mujeres, tiene como consecuencia desigualdades en la calidad de vida entre los individuos.

En cuanto a la renta, los datos del IBGE (2000) revelaron una cierta mejora en los ingresos medios percibidos por los proveedores de los ingresos del hogar. Sin embargo, de una forma general, la distribución de los proveedores de mayor edad, por clases de rendimiento, aún se encuentra extremamente concentrada en los estratos de renta inferiores. De todos ellos, la mayoría tiene una renta mensual de entre uno y dos SM (el 52,20\% - conforme apunta la Tabla 15). Según el Perfil de los mayores proveedores de ingresos de la familia en Brasil, la media de ingresos es de R\$ 657,00 ( $\pm 220 €)$. De los 16,5 millones de mayores brasileños casi 10 millones reciben beneficios de la Seguridad Social ${ }^{237}$ y otros 600.000 reciben un salario mínimo por medio de la Ley Orgánica de Asistencia Social (LOAS). La Ley $n^{\circ}$ 8.742/93 asegura un subsidio para los que se compruebe que no poseen medios para proveer su subsistencia, ni la de su propia familia ${ }^{238}$. Este subsidio satisface las principales necesidades básicas, como alimentación, vestuario, habitación y transporte, de manera que cuando la jubilación es la única fuente del sustento familiar, se convierte en una misión casi imposible.

237 Establecida en Brasil en 1923, hoy la Seguridad Social actúa en cinco pilares principales: invalidez, vejez o tiempo de servicio; enfermedad y maternidad; accidente de trabajo; desempleo y cargas familiares. En prácticamente todos los países donde existe, la Seguridad Social está costeada por las contribuciones de los trabajadores, de las empresas y del Estado, en proporciones variables. En rigor, la Seguridad Social beneficia a las personas que ejercen una actividad remunerada, como trabajadores en empresas privadas y servidores públicos, lo que se distingue de la asistencia social, que se caracteriza por la atención a cualquier persona que de ella necesite. (Resumen extraído de Enciclopedias - Proyecto Renace Brasil - www.renascebrasil.com.br.

238 Beneficio destinado a personas que no tienen condiciones financieras para contribuir a la Seguridad Social. Tienen derecho al amparo asistencial los mayores de 65 años de edad que no desempeñen actividad remunerada y los portadores de deficiencia incapacitados para el trabajo y una vida independiente. Para tener derecho al beneficio, es preciso comprobar la renta mensual per cápita, que debe ser inferior a un cuarto del salario mínimo. Además, esas personas no pueden estar afiliadas a un régimen de Seguridad Social ni tan poco recibir beneficio público de especie alguna. 
Perfil sociológico de la vejez en Mossoró/RN.

Profesión y recursos financieros

TABLA 15

Según la renta mensual

\begin{tabular}{|l|c|c|cccc|}
\hline \multicolumn{1}{|c|}{ RENTA } & \multicolumn{2}{c|}{ TOTAL } & \multicolumn{2}{c|}{ HOMBRES } & \multicolumn{2}{c|}{ MUJERES } \\
\hline MENSUAL & $>60$ & $\%$ & $>60$ & $\%$ & $>60$ & $\%$ \\
\hline Masta 1 SM & 28 & 5,60 & 12 & 2,40 & 16 & 3,20 \\
\hline Más de 1 a 2 SM & 261 & 52,20 & 132 & 26,40 & 129 & 25,80 \\
\hline Más de 3 a 4 SM & 87 & 17,40 & 43 & 8,60 & 44 & 8,80 \\
\hline Más de cinco SM & 68 & 7,40 & 19 & 3,80 & 18 & 3,60 \\
\hline Ns / Nc & 19 & 13,60 & 38 & 7,60 & 30 & 6,00 \\
\hline T O T A L & 500 & 100,00 & 6 & 1,20 & 13 & 2,60 \\
\hline
\end{tabular}

Fuente: Encuesta Perfil Sociológico de la Vejez en Mossoró - Junio 2004/ Junio 2005

SM - Salario Mínimo $=\mathrm{R} \$ 415,00 \pm 166$ Euros

(Elaboración de la autora)

3. Grado de satisfacción de los mayores con su situación económica

Una vez estimada arriba la renta mensual de los mayores mossoroenses, factor imprescindible para la calidad de vida del colectivo, estamos en condiciones de valorar en esta sección el grado de satisfacción con los ingresos con que cuenta el anciano para cubrir sus necesidades.

En general los mayores en Brasil sobreviven con una renta pequeña. De éstos, según investigó el IBGE (2000) 8,9 millones eran proveedores de ingresos del hogar, siendo el $62,4 \%$ varones y el 37,6\% mujeres. La edad media del cabeza de familia estaba en torno a 69,4 años, con 70,2 años cuando el proveedor era del sexo femenino y 68,9 para el proveedor del sexo masculino. Esta situación, pone de relieve que en Brasil la jubilación no significa un reposo bien merecido, sino que antes bien, se convierte en una ocasión para acometer o proseguir una segunda carrera. Para Cutler (1972), la jubilación va siempre acompañada de una pérdida de prestigio. Así que, el estado inherente a la jubilación es a menudo considerado como una pérdida y no como una ganancia. Además, la persona mayor, tras la jubilación, se mantiene como cabeza de familia.

Como pone de manifiesto la Tabla 16 , el $42,60 \%$ de los entrevistados de más de 60 años han afirmado que los ingresos recibidos mensualmente cubren los gastos, un $42,80 \%$ dice que necesita complementar su renta, un $2,80 \%$ se abstuvieron de la respuesta y un $11,80 \%$ no recibieron sueldos. Por lo que respecta al sexo, lo trataremos en bloques por separado: el $23,20 \%$ de los 
hombres apunta que precisa complementar la renta mensual para cubrir los gastos, mientras que un $18,60 \%$ lo considera suficiente para cubrir sus necesidades. A este respecto, las mujeres también difieren en los porcentajes, un $24 \%$ se declaran "satisfechas", cubre los gastos y el 19,60\% dice necesitar más ingresos para completar la renta del mes.

El cuadro corrobora el perfil nacional de sueldos que reciben jubilados y pensionistas brasileños. Sobre el asunto es pertinente lo que escribió José Pastore $^{239}$ (2004): “el salario mínimo en Brasil en 2004 experimentó un aumento de $\mathrm{R} \$ 20,00( \pm 8 €)$. Cerca de 14 millones de beneficiarios, jubilados y pensionistas, recibirán $\mathrm{R} \$ 260,00( \pm 104 €)$ del Instituto Nacional del Seguro Social - INSS para pasar un mes, o sea, R\$ 8,66 al día $( \pm 3,46 €)$. En los casos de marido y mujer, donde sólo el primero es jubilado, esas personas tendrán que vivir con $\mathrm{R} \$ 4,33$ o menos de 1,73€ al día, lo que está próximo a la línea de pobreza mundial” (2004:21).

Las estrategias para buscar medios de subsistencia con sueldos tan bajos varían en cada pueblo o región. El caso extremo lo hemos encontrado en una mujer de 83 años, residente en Mossoró, que busca en la prostitución un recurso de supervivencia. Relata: "Con la pensión que recibimos resulta complicado sobrevivir, de ahí que haga los programas para completar mi renta, cobro unos diez reales a mis clientes" ${ }^{240}$.

El salario mínimo ${ }^{241}$, como derecho laboral, creado para atender las necesidades vitales básicas y las de la familia, a fin de proporcionar una vida

239

Bajo el título $A$ Informalidad asfixia o salario mínimo, publicado en O Estado de São Paulo el 4 de Mayo de 2004 (la traducción es de la autora), José Pastore hace un análisis preciso sobre las condiciones de vida, sobre todo de los brasileños jubilados y pensionistas, con parcos ingresos mensuales. El autor es sociólogo, especialista en relaciones de trabajo y desarrollo institucional, profesor (jubilado) de la Facultad de Economía y Administración e investigador de la Fundação Instituto de Pesquisas Econômicas, ambas de la Universidad de São Paulo. Es miembro efectivo de la Academia Paulista de Letras.

240 Bajo el título “D. Josefa cuenta cómo se mantiene como prostituta a los 83 años", la entrevista llegó al público, a través del periódico O Mossoroense en 7 de 0ctubre de 2005, tras la muerte de un anciano de 70 años durante el acto sexual con la pensionista y prostituta Doña Josefa.

$241 \quad$ Creado en 1945 por el presidente Getúlio Vargas, dice el artículo $7^{\circ}$ de la Constitución del país, que el valor del salario mínimo debe ser para el trabajador que lo reciba, capaz de atender sus necesidades vitales básicas y las de su familia, como vivienda, alimentación, educación, salud, ocio, vestuario, higiene, transporte y Seguridad Social. La Constitución establece que el valor del salario mínimo debe ser reajustado periódicamente, a fin de preservar su poder adquisitivo, o sea, el poder de comprar y pagar los costes de aquellas necesidades vitales arriba descritas. Pero, según declaraciones hechas por DIEESE, si el gobierno siguiera los preceptos constitucionales de que el salario mínimo debe ser suficiente para suplir 
Perfil sociológico de la vejez en Mossoró/RN.

Profesión y recursos financieros

decente al ciudadano, parece infringir, en este caso, un derecho social. Su repercusión más transparente es la insatisfacción de millones de brasileños, en cuyo número se incluyen nuestros investigados, sobre todo el $7,26 \%$, que recibe hasta 1 SM mensual y el 58,15\% que recibe hasta dos SM mensuales.

Si segmentamos la muestra por sexo y grupos de edad, en función de los estudios, y analizamos la respuesta en cada uno de los ítems, podemos apreciar las siguientes diferencias entre ellos. En el caso de todos los varones, excepto los de 66-70 años, que apenas saben leer, manifiestan más insatisfacción con los ingresos que poseen, es decir necesitan complementar la renta. Las mujeres, entre 60-80 años, con estudios primarios, señalan la misma situación. Las cifras más altas de insatisfacción se encuentran entre los hombres en condición de jubilados, amos de casa, activos y desempleados. En las mujeres el cuadro muestra a las jubiladas, amas de casa y desempleadas como las que viven esta experiencia con más intensidad.

\section{$\underline{\text { TABLA } 16}$}

Según el grado de satisfacción con su situación económica

\begin{tabular}{|l|c|c|cccc|}
\hline \multicolumn{1}{|c|}{ GRADO DE } & \multicolumn{2}{c|}{ AMBOS SEXOS } & \multicolumn{2}{c|}{ HOMBRES } & \multicolumn{2}{c|}{ MUJERES } \\
\hline SATISFACCIÓN & $>60$ & $\%$ & $>60$ & $\%$ & $>60$ & $\%$ \\
\hline $\begin{array}{l}\text { Necesita } \\
\text { complementar la renta }\end{array}$ & 213 & 42,60 & 93 & 18,60 & 120 & 24,00 \\
\hline Ns / Nc & 214 & 42,80 & 116 & 23,20 & 98 & 19,60 \\
\hline NSA & 14 & 2,80 & 10 & 2,00 & 4 & 0,80 \\
\hline T O T A L & 59 & 11,80 & 31 & 6,20 & 28 & 5,60 \\
\hline
\end{tabular}

\section{Trabajos anteriores a la jubilación}

Como dijimos antes, en una proporción relativamente grande, alrededor de tres cuartos, los participantes se encuentran jubilados, siendo un $41,80 \%$ varones y el 35\% mujeres. En esta sección preguntamos exclusivamente a las personas mayores jubiladas, después de dedicarse largos años de vida al mundo laboral, en qué área estuvieron actuando hasta el momento de

los gastos de una familia con alimentación, vivienda, educación, salud, transportes, higiene, ocio y Seguridad Social, su valor sería de R \$ 1.386,47. Valor muy distante del último aumento del salario R \$ 415,00 (Mayo de 2008). 
jubilarse.

La Tabla 17 muestra que la actividad predominante según el último empleo de la mayoría de los entrevistados fue el servicio público $(18,60 \%)$, luego un $14,40 \%$ se dedicó a la agricultura, seguido de cerca por los que dijeron haberse empleado en el comercio (13,60\%). Un pequeño porcentaje se jubiló del oficio de la construcción civil (4\%), una décima parte trabajó como autónomo (10\%) y el $9 \%$ está jubilado gracias a otros oficios. Con excepción de los que no supieron o no quisieron contestar a la cuestión, el 16\% de las cifras abarca a las amas de casa, que se jubilaron mediante el pago a la seguridad social ${ }^{242}$.

La agricultura, el comercio, el trabajo autónomo y la construcción civil fueron mayoritariamente los responsables de las jubilaciones masculinas. En cambio, el servicio público y otras actividades laborales fueron la salida de las jubilaciones femeninas. El estado civil altera la intensidad de los valores. Los varones casados están proporcionalmente más jubilados que las mujeres casadas de las actividades de agricultura, comercio, servicio público, trabajo autónomo y construcción civil. En cambio, las mujeres solteras están jubiladas de la agricultura, comercio y servicio público. $\mathrm{Y}$ las viudas, en mayor proporción que los viudos, disfrutan de jubilaciones del comercio, servicio público, trabajo autónomo y otras.

Por edad, las diferencias no son tan relevantes. La mayoría de los jubilados del oficio de la agricultura supera los 70 años, tanto varones como mujeres. En el comercio y el servicio público, las jubilaciones se alargan como máximo, hasta los 70 años. Por su parte en las actividades como trabajador autónomo las edades se acercan a los 80 años y en la construcción civil hasta los 75 años.

242 En la denominación de asegurado facultativo están todas las personas con más de 16 años que no tienen renta propia, pero deciden contribuir a la Seguridad Social. Por ejemplo: amas de casa, estudiantes, presidente de la comunidad de vecinos, desempleados, presidiarios no remunerados y estudiantes becarios. 
Perfil sociológico de la vejez en Mossoró/RN.

Profesión y recursos financieros

\section{$\underline{\text { TABLA } 17}$}

Según el trabajo anterior a la jubilación

\begin{tabular}{|l|c|c|cccc|}
\hline \multicolumn{1}{|c|}{$\begin{array}{c}\text { CATEGORIA } \\
\text { PROFESIONAL }\end{array}$} & \multicolumn{2}{c|}{ TOTAL } & \multicolumn{2}{c}{ HOMBRES } & \multicolumn{2}{c|}{ MUJERES } \\
\hline Agricultura & 72 & 14,40 & 49 & 9,80 & 23 & 4,60 \\
\hline Empresa/Comercio & 68 & 13,60 & 51 & 10,20 & 17 & 3,40 \\
\hline Servicio público & 93 & 18,60 & 49 & 9,80 & 44 & 8,80 \\
\hline $\begin{array}{l}\text { Trabajador } \\
\text { autónomo }\end{array}$ & 50 & 10,00 & 29 & 5,80 & 21 & 4,20 \\
\hline Construcción civil & 20 & 4,00 & 20 & 4,00 & - & - \\
\hline Ama de casa & 80 & 16,00 & 3 & 0,60 & 77 & 15,40 \\
\hline Otros & 45 & 9,00 & 17 & 3,40 & 28 & 5,60 \\
\hline Ns / Nc & 8 & 1,60 & 2 & 0,40 & 6 & 1,20 \\
\hline NSA & 64 & 12,80 & 30 & 6,00 & 34 & 6,80 \\
\hline T O T A L & 500 & 100,00 & $\mathbf{2 5 0}$ & $\mathbf{5 0 , 0 0}$ & $\mathbf{2 5 0}$ & $\mathbf{5 0 , 0 0}$ \\
\hline
\end{tabular}

(Elaboración de la autora)

\section{5. Área de trabajo actual}

En relación con la población mayor de 60 años que aún no se ha jubilado, bien por encontrarse en edad económicamente activa o bien porque continúa trabajando después de la jubilación (como observamos en la Tabla 18), el 19,20\% (96 personas) se encuentra desarrollando actividades laborales lucrativas. El 6,00\% lo hace en calidad de autónomo, el 4,20\% en el servicio público, el $3,20 \%$ se dedica a negocios relacionados con empresa y comercio y el 2,80\% a otras actividades, por ejemplo los “bicos"243. Una pequeña cantidad se dedica a la agricultura $(1,40 \%)$ y una parte muy reducida, a la construcción civil $(0,80 \%)$. Aquí también se establecen diferencias en cuanto a la variable "sexo": como vimos anteriormente, los hombres encuestados mayores de 60 años en Mossoró (12\%), están laboralmente más ocupados que las mujeres $(7,20 \%)$, así que, según indican los datos de la referida tabla, los varones continúan laboralmente más activos que las mujeres en todas las opciones de trabajo, es decir como agricultores, empleados del comercio, funcionarios públicos, trabajadores autónomos y trabajadores de obras.

Teniendo en cuenta lo anterior, los mayores siguen "preferentemente" trabajando como autónomos, seguido del comercio, del servicio público, de la agricultura y de la construcción civil. Se nota un fuerte descenso en las actividades relacionadas con el campo y las obras.

\footnotetext{
243 Bicos - pequeñas ganancias sueltas y/o tarea ocasional que las posibilita. Dicionário da Língua
} Portuguesa Aurélio 6 edição revisada e atualizada, Editora Positivo, 2007, p. 176. 
También es importante reseñar que en Mossoró, de acuerdo con datos del IDEMA (2003) la desigualdad por sexo en el mercado de trabajo es patente. De los 138.648 ciudadanos entre 15 y 64 años en edad activa ${ }^{244}$, había 88.590 incluidos en el mercado laboral. De éstos, existían 17.316 varones más que mujeres. A nivel nacional la situación tampoco es distinta, a pesar de que la participación femenina en la sociedad brasileña haya crecido en el mercado de trabajo en las últimas décadas. A finales del año 2003, 37.460,000 mujeres con más de diez años de edad estaban ocupadas o buscando empleo, lo que representa un $42,67 \%$ de la población económicamente activa. El resto, un $57,33 \%$, o lo que es lo mismo, $50.326,000$, estaba formado por personas del sexo masculino. Además, los puestos de trabajo que ocupan las mujeres están concentrados en los niveles de renta más bajos: el 32,5\% de las mujeres ocupadas recibe remuneración igual o inferior al salario mínimo, porcentaje que es del $24,4 \%$ en el caso de la fuerza de trabajo masculina ${ }^{245}$. A pesar del lado positivo, la inserción de la mujer en el mercado de trabajo aún no es suficiente para la disminución de la desigualdad de la distribución de la renta en el país.

\section{TABLA 18}

Según el área de trabajo actual

\begin{tabular}{|l|c|c|cccc|}
\hline \multicolumn{1}{|c|}{ CATEGORÍA } & \multicolumn{2}{c|}{ TOTAL } & \multicolumn{2}{c|}{ HOMBRES } & \multicolumn{2}{c|}{ MUJERES } \\
PROFESIONAL & $>60$ & $\%$ & $>60$ & $\%$ & $>60$ & $\%$ \\
\hline Agricultura & 7 & 1,40 & 7 & 1,40 & - & - \\
\hline Empresa/Comercio & 16 & 3,20 & 15 & 3,00 & 1 & 0,20 \\
& & & & & & \\
\hline Servicio público & 21 & 4,20 & 11 & 2,20 & 10 & 2,00 \\
\hline Trabajador autónomo & 30 & 6,00 & 19 & 3,80 & 11 & 2,20 \\
& & & & & & \\
\hline Construcción civil & 4 & 0,80 & 4 & 0,80 & - & - \\
\hline Ama de casa & 58 & 11,60 & 7 & 1,40 & 51 & 10,20 \\
\hline Otros & 14 & 2,80 & 7 & 1,40 & 7 & 1,40 \\
\hline NSA & 350 & 70,00 & 180 & 36,00 & 170 & 34,00 \\
\hline T O T A L & 500 & 100,0 & 250 & 50,00 & 250 & 50,00 \\
\hline
\end{tabular}

Fuente: Encuesta Perfil Sociológico de la Vejez en Mossoró - Junio 2004 / Junio 2005

(Elaboración de la autora)

244 En Brasil, el Departamento Intersindical de Estadística y Estudios Socio-Económicos (DIEESE) y la Fundación Sistema Estadual de Análisis de Datos (SEADE) utilizan para la población en edad activa el entorno de personas de 10 o más años de edad. Sin embargo el Instituto Brasileño de Geografía y Estadística (IBGE) considera edad activa aquellas personas entre 15 y 65 años de edad.

245 PNAD (2003). 
Perfil sociológico de la vejez en Mossoró/RN.

Profesión y recursos financieros

\section{Causas del desempleo}

Hemos demostrado anteriormente que el 19,20\% (Tabla 13) de los sujetos participantes en la Encuesta está trabajando, y entre los diferentes motivos con los que justifican la inserción en el mercado de trabajo encontramos los de orden personal y económico. En esta sección, el enfoque se centrará en los motivos por los cuáles las personas mayores de 60 años señalan no estar laboralmente activos. ¿Cuál es la causa preponderante?, ¿Qué impide a los mayores mossoroenses trabajar?

A pesar de que la gran mayoría esté jubilada y eventualmente algunos no pretendan asumir más compromisos laborales, un $14 \%$ estaría motivado para trabajar en actividades generadoras de renta. El 8,20\% alegó la enfermedad como el principal impedimento para ello, seguido del 5,80\% que señaló como obstáculo la falta de empleo. (Véase Tabla 19). En ambos casos las mujeres ancianas tienen cifras espectacularmente superiores a las de los varones. Veintinueve mujeres frente a apenas doce hombres se dicen enfermos, y diecisiete mujeres frente a doce varones tienen ganas de trabajar, pero "hacen falta los puestos". Si partimos del hecho de que la participación masculina en el mercado de trabajo es superior a la de las mujeres, de la constatación de que las mujeres son más proclives a las enfermedades en la vejez y de que hay fuerte discriminación en el mercado de trabajo para los que rebasan los 60 años, encontramos las razones para nuestros indicadores. Por lo tanto, podemos decir que los resultados revelan doblemente la desventaja femenina en relación a los varones respecto al ingreso en el mundo laboral y las condiciones de salud en la vejez. Efectivamente, estos problemas afectan en mucho a la calidad de vida, sobre todo de estas mujeres.

Comparando las respuestas de los mayores en relación a la edad y al estado civil, se aprecia que los varones entre 60-70 años casados y viudos protestan por la falta de un puesto de trabajo y por el padecimiento de una enfermedad. En las mujeres, hay una sutil diferencia; las que más acusan la falta de trabajo son menores, es decir, están en el umbral de los 60 a los 65 
años de edad, mientras que las que alegan enfermedad mayoritariamente son las mayores de 70 años. Para Bazo ${ }^{246}$, cada vez es más notorio el proceso de discriminación que tiene lugar en el mercado del trabajo con respecto a las personas por razón de su edad.

Si la inserción en el mercado de trabajo es uno de los factores que explican las condiciones de vida de las personas, a pesar de no ser el único y, constatado que la falta de salud es el mayor responsable de que los mayores mossoroenses estén en condición de inactivos, deducimos que los programas de atención a la salud, imprescindibles para una vida saludable del colectivo anciano, no están atendiendo las necesidades de los mayores. Llegar a una vejez saludable, más allá de las condiciones en que se vive, respecto a cosas tan básicas como la alimentación o la vivienda es una tarea pendiente. Es competencia del Estado la promoción y la manutención de políticas públicas y de servicios de calidad que posibiliten la garantía de un envejecimiento saludable. "Dar más vida a los años que se han agregado a la vida", recomendado por las Naciones Unidas (Resolución 46/91), como principio en favor de las personas de edad avanzada, aún es un anhelo que precisa convertirse en realidad.

\section{$\underline{\text { TABLA } 19}$}

Según las causas del desempleo

\begin{tabular}{|l|c|c|cccc|}
\hline \multicolumn{1}{|c|}{$\begin{array}{c}\text { CAUSAS DEL } \\
\text { DESEMPLEO }\end{array}$} & \multicolumn{2}{c|}{ TOTAL } & \multicolumn{2}{c|}{ HOMBRES } & \multicolumn{2}{c|}{ MUJERES } \\
\hline Jubilación & 331 & 66,20 & 174 & 34,80 & 157 & 31,40 \\
\hline Enfermedad & 41 & 8,20 & 12 & 2,40 & 29 & 5,80 \\
\hline Falta de trabajo & 29 & 5,80 & 12 & 2,40 & 17 & 3,40 \\
\hline Ns / Nc & 26 & 5,20 & 7 & 1,40 & 19 & 3,80 \\
\hline NSA & 73 & 14,60 & 45 & 9,00 & 28 & 5,60 \\
\hline T O T A L & 500 & 100,00 & 250 & 50,00 & 250 & 50,00 \\
\hline
\end{tabular}

Fuente: Encuesta Perfil Sociológico de la Vejez en Mossoró - Junio 2004 / Junio 2005 (Elaboración de la autora)

\section{Preferencias en el ámbito laboral}

La investigación gerontológica pone de manifiesto, en las secciones anteriores, que hombres y mujeres ancianos siguen cursos vitales diferentes,

246 Bazo. M. Teresa (1994): La jubilación desde la perspectiva macro y micro. Revista Española de Investigaciones Sociológica, 73, p. 271. 
Perfil sociológico de la vejez en Mossoró/RN.

Profesión y recursos financieros

que se traducen sobre todo en variaciones de bienestar económico en la vejez. La situación de las amas de casa, los parados, los enfermos y los que gozan de buena salud, los que dependen financieramente de recursos económicos de familiares y los que viven de la Seguridad Social, es fundamental para comprender esta cuestión. Sobre esto, como era previsible, es interesante mencionar que alrededor de una cuarta parte de los mayores apunta que les gustaría trabajar, bajo el deseo de poder pagar pequeños gastos y aumentar la renta. También dicen que les gustaría trabajar para no depender económicamente de nadie $(5,40 \%)$ y porque les gusta trabajar (12\%) o que podría constituirse un momento de puro placer, quizá para distraerse $(10,20 \%)$, es decir, mantener "la cabeza ocupada". Las cifras contenidas en la Tabla 20 ilustran estos aspectos implicados.

Si analizamos estos resultados, observamos que la necesidad de trabajar, para 119 sujetos entrevistados, justificada por la escasez de recursos financieros, está representada en un $23,80 \%$, frente a los que declararon que les gusta mantenerse "activos, comprometidos, plenos, ocupados" 247 laboralmente (un $22,20 \%$ ). Esto ratifica en parte, que son numerosos los jubilados que no desean parar de trabajar. La jubilación laboral está, la mayoría de las veces, en contra de la voluntad de muchos de estos individuos. Como señala Bazo ${ }^{248}$, "la edad oficial de jubilación cada vez tiene menos que ver con la edad real de jubilación". Peixoto, encuentra dos razones para eso: "la edad precoz de jubilación por tiempo de trabajo/contribución que retira de la vida productiva a individuos aún jóvenes que no desean quedarse inactivos, y la prolongación de la vida, estrechamente ligada al progreso de la medicina, que les proporciona mejores condiciones de salud, alejando el sentimiento de envejecimiento y favoreciendo la emergencia de una nueva categoría de jubilados trabajadores" (2004:72). Además, las pensiones, casi siempre reducidas, por jubilación y la devaluación del sueldo anualmente experimentada por los jubilados, constituyen una de las principales causas por las que las personas mayores intentan volver al mundo laboral. Tampoco podemos descartar que la pérdida de las relaciones sociales, sobre todo con 
los compañeros de trabajo, originen problemas sociales de gran envergadura. Para Giddens (1992), “ambas pérdidas, económicas y sociales, pueden tener sus efectos físicos en aquellos que se jubilan” (1992:634). Con el nivel de vida comprometido, no queda más remedio que los mayores deseen volver a una actividad lucrativa, no sólo para huir de la pobreza que prevalece entre ellos (Víctor, 1987; Juvenal, 1988 y Laczko, 1990), sino también para evitar el vacío social.

Así, pues, a la luz de estos resultados, se constata que los hombres y mujeres ancianos están igualmente preocupados por la necesidad de aumentar la renta familiar (un 12,20\% y un 9,20\%, respectivamente). Sin embargo, en las mujeres mayores la justificación del trabajo como algo placentero supera sutilmente a la de los varones $(11,40 \%$ y $10,80 \%$ respectivamente). Valorar la capacidad, los talentos que aún posee ese colectivo, estimulando sus capacidades, hará ciertamente que "envejezcan viviendo y no vivan envejeciendo"249.

Como se recordó en la Tabla 14, las mujeres ancianas dependen más que los hombres de los recursos económicos de sus descendientes. Por eso, ellas (un $4,20 \%$ ), más que los varones (un 1,20\%) afirmaron que uno de los condicionantes que les motivaría a trabajar es no depender económicamente de nadie. En nuestra sociedad actual, enfatiza Rodríguez ${ }^{250}$ "cuando los recursos son tan escasos que los ancianos han de depender de sus hijos, se producen situaciones tan traumatizantes como la rotación periódica de los padres en los hogares de los diferentes hijos, con la sensación subsiguiente de ser poco más que un objeto traspasado de uno a otro lugar de cuando en cuando. Es una triste realidad". Sin embargo, las mujeres más que los varones, tienen una especial tendencia en la vejez a vivir, forzosamente, dependientes de otras personas. Las razones señaladas por ellas se tornan obvias.

249 Conf. Fraternidade e pessoas idosas: texto-base CF-2003 / Conferencia Nacional de los Obispos de Brasil - CNBB. São Paulo: editora Salesiana, 2002, p. 19.

250 Rodríguez, G. Hernández (1988): La figura del anciano en la familia contemporánea: relaciones intergeneracionales y estatus social del anciano en Hacia una vejez nueva, 1988. p. 33. 
Perfil sociológico de la vejez en Mossoró/RN.

Profesión y recursos financieros

En los demás ítems no se aprecian grandes diferencias entre los sujetos. Pero, parece interesante destacar que los varones más que las mujeres casadas reclaman la necesidad de aumentar la renta, quizá por ser proveedores de ingresos de la familia, y las viudas más que los viudos manifiestan lo mismo. Y a los hombres casados les motivaría volver al mundo laboral por distracción. Las mujeres casadas lo harían más por el placer de trabajar.

Estos datos revelan que aunque el Estatuto del Mayor garantice la profesionalización y el trabajo y, vede la discriminación en virtud de la edad, inclusive en oposiciones, persiste la exclusión de personas de edad avanzada en el mercado de trabajo. En Brasil casi el 30\% de los jubilados continúa trabajando, por la necesidad de una remuneración y debido a las bajas jubilaciones. En ese sentido, según la $A$ Carta Aberta à Nação - Avaliação e Perspectivas do Estatuto do Idoso (SESCSP: 2005), corresponde al Estado crear servicios de informaciones, censo y recolocación profesional específicos para los mayores. También debe invertir en programas de actualización, formación y calificación profesional que consideren el potencial y los conocimientos acumulados de la persona mayor de 60 años, para la generación de renta, así como el desarrollo de alternativas de actividad profesional, como cooperativas y otras formas de trabajo solidario. Por último, es fundamental la movilización y la presión para se creen incentivos fiscales que beneficien a las empresas que emplean mayores, como estímulo a la ampliación del mercado de trabajo para los que rebasan los 60 años.

TABLA 20

Según preferencias para trabajar

\begin{tabular}{|c|c|c|c|c|c|c|}
\hline \multirow{2}{*}{$\begin{array}{c}\text { PREFERENCIAS } \\
\text { PARA TRABAJAR } \\
\end{array}$} & \multicolumn{2}{|c|}{ TOTAL } & \multicolumn{2}{|c|}{ HOMBRES } & \multicolumn{2}{|c|}{ MUJERES } \\
\hline & $>60$ & $\%$ & $>60$ & $\%$ & $>60$ & $\%$ \\
\hline $\begin{array}{l}\text { Pagar pequeños } \\
\text { gastos }\end{array}$ & 12 & 2,40 & 6 & 1,20 & 6 & 1,20 \\
\hline Aumentar la renta & 107 & 21,40 & 61 & 12,20 & 46 & 9,20 \\
\hline Distracción & 51 & 10,20 & 22 & 4,40 & 29 & 5,80 \\
\hline Le gusta trabajar & 60 & 12,00 & 32 & 6,40 & 28 & 5,60 \\
\hline $\begin{array}{l}\text { Para no depender } \\
\text { de nadie }\end{array}$ & 27 & 5,40 & 6 & 1,20 & 21 & 4,20 \\
\hline Ns / Nc & 18 & 3,60 & 11 & 2,20 & 7 & 1,40 \\
\hline NSA & 225 & 45,00 & 112 & 22,40 & 113 & 22,60 \\
\hline TOTA L & 500 & 100,00 & 250 & 50,00 & 250 & 50,00 \\
\hline
\end{tabular}

Fuente: Encuesta Perfil Sociológico de la Vejez en Mossoró - Junio 2004 / Junio 2005

(Elaboración de la autora) 


\section{Resumen}

La encuesta Perfil Sociológico de la Vejez en Mossoró permite conocer también los aspectos económicos y financieros del segmento social de población mayor de 60 años de edad. La situación actual para el 76,80\% de los entrevistados es de pensión de jubilación, un 19,20\% se declara laboralmente activo, un $16,20 \%$ afirma ser pensionista, un $31,60 \%$ es ama de casa, y un $8 \%$ está en el paro. Los porcentajes suman más del cien por cien, dado que la cuestión es de múltiple elección. De todos ellos, más de la mitad (52,20\%) tienen ingresos entre uno y dos Salarios Mínimos (SM) mensuales (R\$ 415,00 $\pm 116 €)$. Los motivos, en el $42,80 \%$, son la necesidad de completar la renta mensual en contraposición con los que afirman estar satisfechos con lo que reciben, o sea, cubren los gastos (42,60\%). Los ingresos medios de la población anciana brasileña se sitúan en torno a 2,3 SM sin embargo, varían regionalmente. Un aspecto importante, relacionado con los ingresos, es la diferencia socioeconómica entre los sexos. Los varones están laboralmente más ocupados (12\% frente a 7$)$ y tienen renta superior a las mujeres. En la muestra, ellas alcanzan cifras más altas en las categorías de amas de casa $(26,80 \%)$ y pensionistas $(13,60 \%)$. La distribución por sexo según el estado civil pone de manifiesto que los hombres solteros, casados y viudos en condición de jubilados son proporcionalmente superiores a las mujeres del mismo estado civil. Como la mayoría de los varones están casados $(33,20 \%)$ y el $21,60 \%$ de las mayores de 60 años están viudas, cabe juzgar que ellos viven socioeconómicamente mejor que las mujeres ancianas.

Continuando con la fuente de renta de que disponen los mayores residentes en Mossoró, podemos decir que alrededor de una cuarta parte cuenta con la ayuda económica de los hijos $(17,60 \%)$, el 4,20\% con la colaboración familiar y apenas un $0,20 \%$ con algún tipo de ayuda institucional. Se nota que la ayuda financiera de los descendientes hacia las madres es superior que hacia los padres $(10,60 \%$ frente al $7 \%)$, pero padres y madres viudos reciben las ayudas con equidad. La constatación de que el estado civil de las mujeres ancianas influye en el bienestar económico es patente. Su vida laboral remunerada es 
Perfil sociológico de la vejez en Mossoró/RN.

Profesión y recursos financieros

irregular, tienden a depender del varón y viven con bajas pensiones (Arber y Ginn, 1991).

En lo que se refiere a la última actividad económica que desarrollaron en el trayecto de su vida laboral, el servicio público fue el mayor responsable de las jubilaciones de los entrevistados mayores de 60 años $(18,60 \%)$, seguido de la agricultura $(14,40 \%)$, el comercio $(13,60 \%)$, el servicio autónomo $(10 \%)$ y la construcción civil (4\%). Además un $9 \%$ se jubiló en otras actividades no citadas. Si establecemos una comparación según el estado civil, los varones casados alcanzan un mayor porcentaje en las jubilaciones por agricultura, comercio, servicio público, trabajo autónomo y construcción civil. Por su parte, las mujeres solteras están mayoritariamente jubiladas por agricultura, comercio y servicio público. Por edad, los que tardaron más en jubilarse fueron los de la agricultura y construcción civil, superando los 70 años y los trabajadores que tenían su propio negocio, cercanos a los 80 años.

Teniendo en cuenta lo anterior, están incluidos en el mundo laboral casi una quinta parte de los mayores, sobre todo en actividades autónomas y públicas. Por sexo, la vida laboral se extiende más en los varones, suponiendo el doble (12\%) que las mujeres $(7,20 \%)$ en todas las actividades del mercado de trabajo sugeridas en la encuesta. Los datos confirman la estadística nacional. A nivel de Mossoró, 35.637 mujeres en edad económicamente activa de 10 a 65 años estaban incluidas en el mercado de trabajo, en contraposición con 52.953 varones (IDEMA, 2003:12). Una diferencia de 17.316 es un reflejo transparente para constatar la desigualdad de oportunidades de los diferentes sexos para ingresar en el mundo laboral, que repercute sencillamente en el reparto de las riquezas y la renta.

En el caso de las personas mayores de 60 años que están fuera del mercado de trabajo, pero que desearían estar ocupadas (14\%), apuntan la enfermedad $(8,20 \%)$ y la falta de empleo $(5,80 \%)$ como principales inconvenientes. Los porcentajes más elevados, en ambas situaciones, los encontramos en las mujeres. No podría ser diferente; ellas enfrentan más obstáculos para conquistar un espacio en las actividades generadoras de renta y experimentan más que los hombres los problemas de salud (BAZO, 1990). Los varones 
proveedores de ingresos del hogar y viudos entre 60-70 años de edad acusan primero la enfermedad y segundo, la falta de puestos de trabajo. En las mujeres, las que tienen dificultades para trabajar por motivo de enfermedad lo manifiestan por encima de los 70 años y por la falta de trabajo las que están entre 60-70 años de edad.

El hecho de que este grupo de mayores desee trabajar, alberga necesidades de carácter personal y económico. Es lo que revelaron casi un tercio de los sujetos entrevistados. La primera razón es de orden económico: un 21,40\% tenía ganas de trabajar para aumentar la renta, la segunda y tercera razón, casi idénticas, podrían ser el trabajo como un recurso para distraerse $(10,20 \%)$ o porque el hecho de trabajar les resulta algo agradable (12\%). Para no depender financieramente de nadie, contestó un 5,40\% y la quinta y última razón, para pagar pequeños gastos $(2,40 \%)$. Por sexo, ambos están igualmente preocupados por la cuestión financiera. Sin embargo, a las mujeres les agrada $(5,80 \%)$ más que a los hombres $(4,40 \%)$ la idea de trabajar para distraerse. Como también sería más conveniente para ellas (4,20\%) que para ellos $(1,20 \%)$ trabajar para no depender de nadie, ya que más arriba constamos que las ancianas dependen más económicamente de otros. Por estado civil, los varones casados están relativamente más preocupados que las mujeres casadas, en trabajar por razón financiera y para distraerse. Ellas volverían a trabajar más por satisfacción. En cambio, los viudos parecen menos preocupados que las viudas con el tema financiero. Si sumamos las cifras, la necesidad de trabajar por cuestiones económicas pasaría de un 21,40\% al $22,20 \%$ de los sujetos que dijeron que les complacería trabajar. Esto implica reflexionar hasta qué punto la cuestión del trabajo para los mayores es difícil en Mossoró. Cuanto más tiempo pasa, más difícil es encontrar un trabajo. Así pues, muchas veces, es la propia sociedad la que condena a los mayores a la inactividad, la improductividad y la dependencia. 


\section{4. \\ Entre la familia y la residencia}

Los árboles más viejos dan los frutos más dulces. Proverbio alemán

\section{Hijos vivos}

Uno de loS objetivos de esta investigación es el de realizar mapas de las formas de vida de los mayores en Mossoró, es decir, las estructuras familiares en las que viven, sus relaciones y convivencias personales, familiares y extra familiares y en general los diferentes modos de sociabilidad, o las dificultades para hacerlo, en la sociedad global. Además de los datos demográficos esenciales, las informaciones sobre actitudes sociopsicológicas y socio-políticas recogidas, completan el estudio.

Este apartado nos permite diseñar un cuadro actual de la familia y de las relaciones sociales del mayor a fin de ir completando el Perfil Sociológico de la Vejez en Mossoró.

Por lo que respecta al tamaño de las familias brasileñas, de acuerdo con Monteiro, "se reducen notablemente después de 1960, pasando de un nivel de fecundidad media por mujer, de seis hijos (algunas tenían nueve o diez, otras tenían dos o tres), a la mitad, en torno a 3 hijos en 2003. Todo ello, con grandes diferencias regionales en Brasil. Las áreas urbanas y rurales de las Regiones Sur y Sudeste, las más desarrolladas del país, presentaban tasas más bajas que las del Norte y Nordeste"251. Así que el tamaño de las familias está asociado a la situación socioeconómica. De modo general, se ha verificado 
que las familias de menos poder adquisitivo son tradicionalmente más numerosas que aquellas que poseen mejor patrón socio-económico ${ }^{252}$.

La falta de control de la natalidad contribuyó a la gran cantidad de hijos por mujer, sobre todo en la primera mitad del siglo XX, junto al papel de la mujer en el matrimonio, avocado solamente a la procreación, además de su ausencia en el mercado de trabajo.

Así pues, se observa en los datos del Perfil Sociológico de la Vejez en Mossoró (Véase Gráfico 6) la confirmación de algunos estudios. De hecho, el 93\% de las personas mayores entrevistadas tuvo hijos, sin importancia de sexo, edad, estado civil, nivel educativo o estatus económico. En contraposición, apenas un $7 \%$ de este colectivo no ha tenido herederos. También podemos observar que en casi todos los casos en los que hay herederos, los hombres entrevistados han tenido más hijos que las mujeres, con apenas tres excepciones: entre uno y dos hijos y más de ocho hijos. En estos casos las mujeres superan a los hombres.

Por edad, mayoritariamente, las personas encuestadas con edades comprendidas entre 60 y 80 años en ambos sexos, superan en número de hijos que aquellos con edades por encima de los 81 años.

En los matrimonios de 166 hombres $(33,20 \%)$ casados, 165 tuvieron un total de 883 hijos, mientras que en el conjunto de 90 mujeres (18\%) igualmente casadas, 89 afirmaron tener 450 descendientes. La proporción de mujeres que se encuentran comprendidas bajo el estado civil de solteras, separadas y viudas con hijos vivos es superior a la de los hombres. Es decir, de las 28 mujeres solteras de la muestra (5,60\%), 11 tuvieron 25 hijos, mientras que ningún hombre soltero declaró haberlos tenido. La condición en que se encuentran los separados subraya la superioridad en cifras de la mujer en torno a 16 mujeres $(3,20 \%)$ frente a 15 a los hombres $(3,00 \%)$ que tienen 72 y 80 herederos vivos, respectivamente. Para finalizar, entre las 108 mujeres

\footnotetext{
252 Ribeiro, R. M., Sabóia, A. L., Branco, H. C. y Bregman (2004): Estrutura familiar, trabalho e renda. Silvio Manoug Kaloustian (org.) Em Família Brasileira a base de tudo, $6^{a}$ ed. São Paulo: Cortez, p.146.
} 
viudas entrevistadas (21,60\%), 101 de ellas tuvieron 490 descendientes, mientras que entre todos los 47 viudos (9,40\%) registraron 202 hijos vivos. En general, el panorama dibujado confirma que las generaciones que nacieron en la primera mitad del siglo XX tuvieron una gran cantidad de hijos.

Particularizando la situación de las madres solteras, se supone que probablemente experimentaron más dificultades en la crianza de los hijos, principalmente por estar menos escolarizadas y por no pertenecer, en una proporción relativamente grande, al mundo laboral. Al igual que las solteras, las mujeres separadas, según Bazo (1992a), a menudo, se enfrentan más a la pobreza por quedarse solas y por la responsabilidad de cuidar de los hijos ${ }^{253}$. Sin embargo, pese a que las viudas no están tampoco exentas de pobreza y soledad, como plantea Bazo, puede ocurrir que en la muestra estén un poco más asistidas por los herederos que los varones, dada la gran cantidad de hijos que han tenido. Concretamente, por cada viudo y viuda $(4,25$ y 4,85) respectivamente, hay descendientes capaces de cuidarlos en la última etapa de la vida; es la "responsabilidad filial" planteada por Scherr (1960) y Blenkner (1965) la que aquí se concreta. Los autores suponen que los hijos son capaces de atender las necesidades de los padres que envejecen. Aunque hay evidencias de que los padres sostienen y apoyan económica y materialmente a los hijos, lo que los empuja a vivir bajo al mismo techo, no podemos negar que esta situación en el seno de su ambiente familiar puede evitar o paliar las situaciones de soledad y de desprotección de las personas mayores.

\section{GRÁFICO 6}

Cantidad de hijos vivos

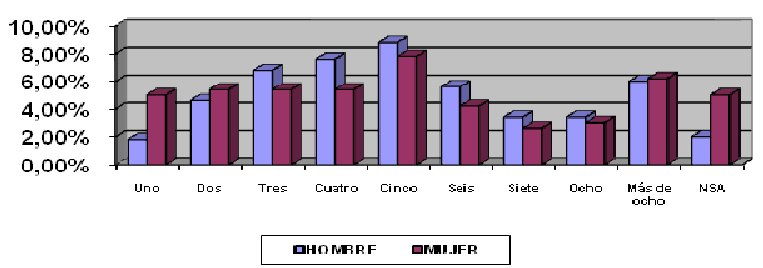

Fuente: Encuesta Perfil Sociológico de la Vejez en Mossoró - Junio 2004 / Junio 2005 (Elaboración de la autora) 


\section{Relación con las personas con quienes vive el mayor}

La vida familiar de los mayores, como anteriormente referí en la Tabla 11, está caracterizada por hogares múltiples en los que conviven tres o cuatro generaciones. Entre los ancianos, la mayoría se sitúa en familias extensas y en hogares que ellos mismos construyeron.

Al contrario de lo que se pregona en la sociedad moderna y urbana de que la utilidad de la familia se ha terminado, que ya no es relevante en el nuevo contexto ${ }^{254}$, hay quien la defiende. Según Ferrari y Kaloustian (2004), en la introducción de Familia brasileira - a base de tudo, "la familia brasileña, en medio de discusiones sobre su desagregación o debilitamiento, está presente y permanece en cuanto espacio privilegiado de socialización, de práctica de tolerancia y división de responsabilidades, de busca colectiva de estrategias de supervivencia y lugar inicial para el ejercicio de la ciudadanía bajo un parámetro de igualdad, de respeto y de los derechos humanos" (2004:11ss). Como una de las instituciones más antiguas del mundo, de carácter dinámico, la familia sigue siendo un elemento social básico importante; espacio indispensable para la garantía de la supervivencia de desarrollo y de la protección integral de los hijos y miembros, independientemente del arraigo familiar o de la forma en que se está estructurado. Sin embargo, la situación de las familias brasileñas también se caracteriza por problemas sociales de naturaleza diversa, como atentados frecuentes a los derechos humanos, explotación, abuso y malos tratos, barreras económicas, sociales y culturales para el desarrollo integral de los miembros, semejante a lo que ocurre en otros países, pero con peculiaridades propias.

Muchas de estas estructuras familiares, sobreviven en los tiempos modernos. Algunas son familias numerosas, con distintas generaciones compartiendo la vida, con "derecho" a las singularidades propias de cada edad, a menudo en nombre de carencias de todo tipo, sobre todo financieras. ¿Sería solamente un

\footnotetext{
$254 \quad$ No estamos negando que en la época actual la evolución social no haya afectado a la institución familiar. La familia extensa, tradicional, jerarquizada en su estructura y funciones ha cambiado a la familia de tipo nuclear reducida; la relación y el lugar que al anciano le corresponde en la familia también ha variado y previsiblemente continuará cambiando en el futuro. (Véase Hernández Rodríguez, G y Arbelo Curbelo, A: Demografía Sanitaria de la Ancianidad, Estudios ISAF N. 4 p. 58.)
} 
mal necesario? o ¿podemos creer que en medio de su utilidad puedan encontrar amor y libertad y que las personas estén juntas por puro gozo? En esta sección explicaremos el estado actual de las relaciones entre las diferentes generaciones de los entrevistados.

Así pues, de acuerdo con las opiniones de las propias personas mayores, como se puede observar en el Gráfico 7, el $41,88 \%$ de los mayores de 60 años o más que componen la muestra viven bien con las personas con quienes comparten la vida. Cruzando los datos con la cuestión anterior, en orden decreciente los que están más a gusto con sus familiares son: los matrimonios con hijos solteros $(11,02 \%)$, los matrimonios con hijos casados $(9,62 \%)$, las relaciones monoparentales $(7,82 \%)$, las familias múltiples $(6,42 \%)$, los que viven con otros familiares $(5,01 \%)$, y por último, los que comparten la vida con individuos sin relación parental (1\%). Esto datos, unidos al $36,07 \%$ que manifiesta tener una relación muy buena con los suyos, estaría indicando casi cuatro quintas partes $(77,95 \%)$ de individuos satisfechos con la convivencia familiar.

Siguiendo el mismo esquema de orden para estos últimos (36,07\%), destaca la convivencia sólo con el respectivo esposo $(8,62 \%)$, matrimonio con hijos casados $(7,81 \%)$, pareja con hijos solteros $(7,42 \%)$, matrimonio con hijos y nietos $(7,02 \%)$, con otros familiares $(3,61 \%)$ y con personas que no son de la misma familia $(0,60 \%)$. En resumen, todo indica que la convivencia familiar presenta vínculos fuertes en los lazos familiares y sociales. El aprecio a los ancianos, los vínculos afectivos entre los miembros ancianos y sus descendientes, se siguen manteniendo en la comunidad. Los beneficios se tornan recíprocos ya que los mayores tienen mucho que aportar a los demás miembros de la comunidad familiar: como un "ser biográfico y no sólo biológico" tiene una larga historia personal que ofrecer al ambiente, al mismo tiempo que aprende cosas nuevas de los más jóvenes. Estos almacenan los conocimientos que les han depositado sus abuelos para el usufructo necesario. En este juego, la interacción permite un crecimiento mutuo. 
Si se tiene en cuenta el estado civil, casi una cuarta parte de los hombres casados $(27,26 \%)$ están más satisfechos con la relación familiar que llevan que el total de las mujeres casadas (14,63\%). Cuando la condición es de viudedad la situación es inversa: una parte bien significativa de mujeres viudas $(15,63 \%)$ está más feliz con la convivencia familiar que los hombres viudos $(9,41 \%)$. En este campo nos adentramos en la muy corriente discusión de que el matrimonio es bueno para el hombre y para las viudas. Las ventajas de quienes se casaban en la primera mitad del siglo pasado eran evidentes para el sexo masculino, dado que todo estaba reservado para ellos: trabajo, educación, política, familia, ocio, entre otros. A este respecto Anna Freixas Farré relata que "las mujeres que han vivido vidas muy tradicionales, de sometimiento al marido y ausencia de poder, encuentran en la viudedad un camino de libertad y realización personal insospechado". 255 Por eso cabe conjeturar que, en la práctica, las mujeres mayores casadas, jubiladas o no, sigan ocupándose más que los hombres de las obligaciones domésticas y familiares, de manera que tienen menos "tiempo libre" que los hombres jubilados y están menos satisfechas. Por otro lado, en las viudas en muchos casos "tras los primeros momentos del proceso de adaptación a la nueva situación aparecen los sentimientos de independencia y el de libertad como los más positivos"256.

\section{GRÁFICO 7}

Relación con las personas con quienes vive el mayor

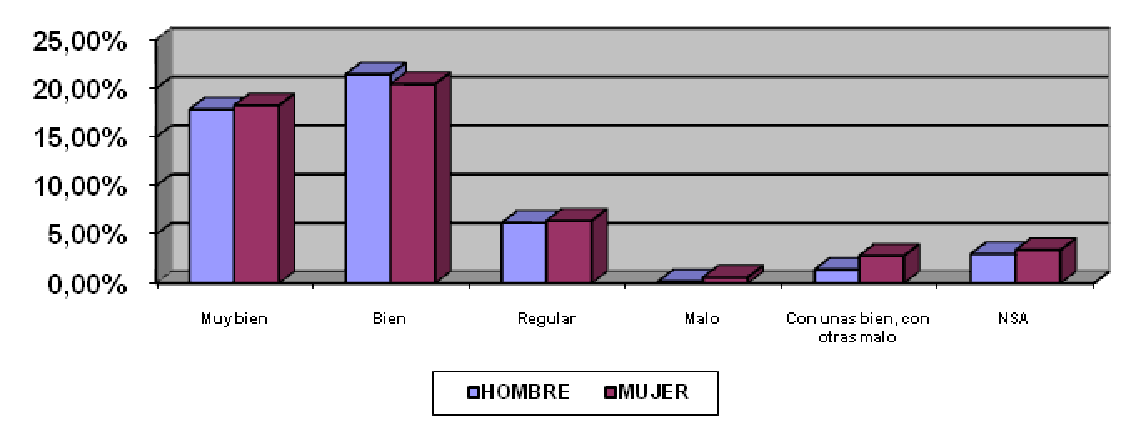

Fuente: Encuesta Perfil Sociológico de la Vejez en Mossoró - Junio 2004 / Junio 2005 (Elaboración de la autora)

255 Cf. Prólogo de la obra Relación entre sexo y envejecimiento, enfoque sociológico de Sara Arber y Jay Ginn. Narcea, edición española, 1996, p. 9.

${ }_{256}$ Bazo, María Teresa (1990): La sociedad anciana, Madrid, Centro de Investigaciones Sociológicas (CIS) y Siglo XXI, p. 223. 


\section{Formas de convivencia - Familia, vecindario y amigos}

En el proceso de envejecimiento, según Rodríguez (1988), “una de las amenazas más graves que pesan sobre el anciano es el aislamiento. En torno al anciano gravita el aislamiento físico, el aislamiento espiritual, el aislamiento familiar, el aislamiento social” (1988:233). Los mayores, más que cualquier otro colectivo, completa el autor, están más expuestos a la experiencia de la soledad como consecuencia de la pérdida del cónyuge, de los amigos del trabajo o vecindario y hasta de los miembros de la misma familia. Ante esta prerrogativa, aunque Mossoró se encuentre en la mitad del proceso de desarrollo y de los cambios típicos de sociedades urbanizadas, tales situaciones de "aislamiento físico, espiritual y familiar" no corresponden mayoritariamente al contexto mossoroense.

Los datos reafirman que ellos tienen una relación familiar y social constante, y aparentemente no parecen estar socialmente aislados en sus "nidos vacíos" (Ruth y Coleman, 1996). A través de lo que se preguntó a los mayores sobre la frecuencia con la que suelen hablar con las personas de su entorno familiar y vecindario, podemos apreciar altas tasas de relaciones familiares y vecinales. Como podemos observar en la Tabla 21, el 67,40\% de los mayores de ambos sexos, contestó que suele hablar todos o casi todos los días con los hijos e hijas que no viven en su compañía y más de cuatro quintas partes $(84,80 \%)$ se ven con vecinos todos o casi todos los días.

En nuestra muestra, los entrevistados que viven solamente acompañados por su cónyuge (19\%), evidenciaron que la tendencia de los mayores a vivir solos no tiene que ser necesariamente percibida como un reflejo de abandono por parte de los hijos o familiares. Para Rosenmayr y Koeckeis $(1963)^{257}$, ese tipo de convivencia, perfectamente descrita en sus estudios como "intimidad a distancia", no implicaría una transformación cualitativa en las relaciones

257 Rosenmayr, L. Y Koeckeis, E. (1963): Theory of aging and family. Internacional Social Science Journal, 15, 3. 
entre las generaciones familiares. En ese sentido, la "intimidad a distancia" percibida en nuestra investigación $(67,40 \%)$ es todavía actual y por lo tanto satisfactoria, como lo han dicho los citados autores.

De todos los encuestados, apenas un $13 \%$ de los mayores tiene contactos al menos una vez por semana con los descendientes que no viven bajo el mismo techo. Con respecto a los nietos, los porcentajes señalan significativamente que más de tres cuartas partes $(80,60 \%)$ tienen contactos con sus abuelos y abuelas, ya sea a diario (14,60\% para los hombres y $17,80 \%$ para las mujeres), ya sea al menos una vez por semana $(21,20 \%$ y $13,60 \%$, respectivamente) o al menos una vez al mes (7\% para los hombres y 6,40\% para las mujeres). Ante esta realidad, por consiguiente, los abuelos mantienen satisfactoriamente relaciones afectivas intergeneracionales. En cuanto a los otros miembros de la familia (hermanos, sobrinos, primos...) que no conviven con los entrevistados, en general un 75,60\%, afirma disfrutar de cercanía cotidiana, están en contacto una vez por semana o una vez al mes y alrededor de un tercio $(31,80 \%)$ se ve todos o casi todos los días con los amigos que no son vecinos. Éstos últimos sumados a los que se ven al menos una vez por semana $(33,80 \%)$, serían dos tercios $(65,60 \%)$ de mayores con contactos sociales regulares. Evidentemente, en los últimos casos a los que hemos aludido, la incidencia de cohesión del grupo descarta la noción de comportamiento familiar o social aislado.

Sin embargo, a pesar del expresivo contacto social, el sentimiento de soledad está presente en una minoría de este grupo de población. Los entrevistados que dicen no hablar nunca $(5,80 \%)$ con hijos, nietos, familiares, vecinos o amigos, o los que simplemente no contestaron $(9,40 \%)$, nos permite estimar en un quinto la proporción de "aislados socialmente" o en "soledad".

Entre las consecuencias más presentes que experimentan las personas de edad avanzada, de acuerdo con Bazo (1993), se hace referencia justamente a la soledad y al aislamiento social, que afecta principalmente a las mujeres. Así pues, la evidencia preponderante es que las mujeres experimentan más el aislamiento social o la soledad familiar que los varones, como comprobamos 
en la línea 3 "familiares que no viven con Usted" y en las columnas "Nunca y Ns/Nc" para el colectivo femenino (Tabla 21).

\section{TABLA 21}

Según la frecuencia que suele hablar con la familia, vecindario o amigos

\begin{tabular}{|c|c|c|c|c|c|c|c|c|c|c|c|c|c|c|}
\hline & \multicolumn{2}{|c|}{$\begin{array}{l}\text { TODOS O } \\
\text { CASI } \\
\text { TODOS } \\
\text { LOS DÍAS }\end{array}$} & \multicolumn{2}{|c|}{$\begin{array}{c}\text { AL MENOS } \\
\text { UNA VEZ } \\
\text { POR } \\
\text { SEMANA }\end{array}$} & \multicolumn{2}{|c|}{$\begin{array}{l}\text { AL MENOS } \\
\text { UNA VEZ } \\
\text { POR MES }\end{array}$} & \multicolumn{2}{|c|}{$\begin{array}{c}\text { MENOS DE } \\
1 \text { VEZ POR } \\
\text { MES }\end{array}$} & \multicolumn{2}{|c|}{ NUNCA } & \multicolumn{2}{|c|}{ NS / NR } & \multicolumn{2}{|c|}{ NSA } \\
\hline & H & $M$ & H & $M$ & $\mathrm{H}$ & $M$ & $\mathrm{H}$ & $M$ & $\mathrm{H}$ & $M$ & H & $M$ & $\mathrm{H}$ & $M$ \\
\hline 1 & 31,80 & 35,60 & 8,60 & 4,40 & 3,40 & 1,20 & 1,00 & 0,40 & 0,40 & 0,20 & 0,20 & 1,00 & 4,60 & 7,20 \\
\hline 2 & 14,60 & 17,80 & 21,20 & 13,60 & 7,00 & 6,40 & 2,40 & 2,40 & 0,40 & 1,00 & 0,60 & 2,20 & 3,80 & 6,60 \\
\hline 3 & 5,60 & 12,00 & 15,40 & 15,00 & 16,40 & 11,20 & 9,00 & 7,80 & 0,80 & 1,00 & 1,20 & 2,20 & 1,60 & 0,80 \\
\hline 4 & 42,20 & 42,60 & 5,80 & 4,40 & 1,00 & 1,20 & 0,80 & 0,60 & 0,20 & 0,20 & & 0,60 & & 0,40 \\
\hline 5 & 16,00 & 15,80 & 16,40 & 17,40 & 10,80 & 8,40 & 5,00 & 8,40 & 5,00 & 6,20 & 0,60 & 1,00 & 0,80 & 0,40 \\
\hline
\end{tabular}

1) $\mathrm{Hijo/as}$ que no viven con Usted

2) Nieto/as que no viven con Usted

3) Familiares que no viven con Usted

4) Vecinos

5) Amigos que no sean vecinos

\section{Forma de vida preferida por los mayores}

Para la conservación de la vida humana, necesitamos del otro para charlar, sonreír, llorar, entre otras necesidades imprescindibles. La convivencia familiar, como la concebimos, es la unidad primera de comunicación y socialización del ser humano, un elemento básico para el funcionamiento y desarrollo vital. Defendida como nuestro "puerto seguro", a pesar de las transformaciones en la contemporaneidad, es para muchas personas la forma de vida preferida hasta llegar a su etapa final, la de ancianidad. A fin de profundizar en las características de la población mayor de 60 años que componen la muestra de este estudio, se ha preguntado qué estilo de vida debe llevar una persona cuando alcanza la ancianidad. ¿Qué se considera mejor? ¿Con quiénes deben convivir las personas mayores? 
Como se refleja en el Gráfico 8, la preferencia de tres cuartas partes de que los ancianos vivan con su familia, para ambos sexos fue contundente $(77,20 \%)$. La segunda alternativa de mayor agrado: que vivan en su casa, pero recibiendo atención y servicios a domicilio, lo expresa alrededor de un quinto $(19,20 \%)$ de los entrevistados. En menor proporción, es decir los que no quisieron o no supieron responder a la cuestión, se manifestaron en un 2,80\%. Por último, la más rechazada, con un insignificante porcentaje del $0,80 \%$ : vivir en centros residenciales con gente de su edad y condición. En resumen, un $96,40 \%$ ha elegido permanecer en el seno de la familia, en el entorno social que conocen, con las personas con las que se relacionan habitualmente. Análisis de estudios brasileños sobre la vejez, realizados por Neri y Wagner (1985) con 360 habitantes de la ciudad de São Paulo (todos "no ancianos" entre 14-45 años), enfatizaron que el viejo debe vivir preferentemente con sus familiares, por quien debe ser ayudado, respetado y oído (Neri, Cachioni y Resende, 2002:975).

Añadiendo la dimensión de sexo y estado civil, y reafirmando la opinión predominante (un $77,20 \%$ ), se manifestaron un 39\% de los hombres y un $38,20 \%$ de las mujeres. Para la condición de casados y viudos tenemos respectivamente las siguientes cifras: $28 \%$ y $13,80 \%$, y entre las mujeres, se destaca un estado más que en los hombres: las solteras, el 3,80\% de las entrevistadas, expresan que los ancianos vivan con su familia, al igual que las casadas, el $6,40 \%$ y las viudas, el $16,20 \%$. Con relación a la segunda tendencia aceptada por los entrevistados: que vivan en su casa, pero recibiendo atención y servicios a domicilio (19,20\%), repartidos en un $8,60 \%$ de los hombres y un $10,60 \%$ de las mujeres, en la escena del estado civil cambia sutilmente: solamente se destacan los varones casados $(4,60 \%)$ y las mujeres casadas y viudas ( $3,80 \%$ y $4,80 \%$ respectivamente).

Todo indica, según las dos preferencias más evidentes arriba señaladas, y también según resultados semejantes de otras investigaciones (Cabral, 1997), que la familia continúa siendo la principal referencia de las relaciones humanas. Por un lado tenemos la exclusividad de tres cuartas partes que opina que los ancianos vivan con su familia. A nuestro juicio y sin muchas 
discusiones, los mayores entrevistados confieren gran relevancia a los valores de convivencia familiar e intergeneracional, que son de capital importancia en la vejez, a pesar de las implicaciones peculiares que conllevan los ancianos. Prioritario para exactamente 386 de los ancianos residentes en Mossoró ( $N=500$ ), se puede deducir que envejecer junto a los suyos supone el bienestar y la posibilidad de evitar la desvinculación personal y social en un futuro, que, por otra parte, aguarda a gran parte de ese colectivo. Todo indica que el mayor espera que la familia cumpla con el papel establecido por la sociedad. Cree que ella debe ser su sustentadora final y que le debe dar la atención necesaria para enfrentarse a las dificultades que la vida impone. Para Camarano y Pasinato (2002), “es común para las más variadas especialidades científicas que la permanencia de los mayores en sus núcleos familiares y comunitarios contribuye a su bienestar"258. Por otro lado, el grupo que manifestó el deseo de permanecer junto a la familia, pero con asistencia domiciliar - que vivan en su casa, pero recibiendo atención y servicios a domicilio - nos lleva a reflexionar sobre la necesidad de este tipo de prestación del sistema de servicios sociales, típico de Europa e inexistente en la localidad. "Apoyar a las personas mayores en su propia casa con una serie de atenciones y cuidados de carácter personal y doméstico, que por su estado de salud o edad avanzada no pueden realizar por sí mismos," es de indudable importancia para Carrión 259 , dado que posibilita a las personas mayores continuar en su entorno familiar. En este sentido, evitar la desvinculación con el entorno familiar y crear prestaciones cualificadas que impidan la dependencia y la institucionalización del mayor supone la alternativa más conveniente para este grupo de población.

Dicho todo esto, fortalecer la asistencia social, con énfasis en la asistencia domiciliar y en la ampliación de servicios del centro de convivencia, centros de día, además de invertir en servicios de teleasistencia y en la preparación de la familia para el cuidado de los mayores, en un contexto de baja

\footnotetext{
258 Camarano, A. A., y Pasinato, M. T. (2002): O envelhecimento populacional na agenda das políticas públicas. Rio de Janeiro: IPEA, p. 280 (Texto para Discusión).

259 Carrió, M. Navarro (1999): Políticas sociales para los mayores en la comunidad autónoma de Murcia, p. 169.
} 
cobertura de programas de atención institucionales en Brasil, supone una de las claves para el mantenimiento de los mayores en su propia familia.

\section{GRAFICO 8}

Forma de vida preferida por los mayores

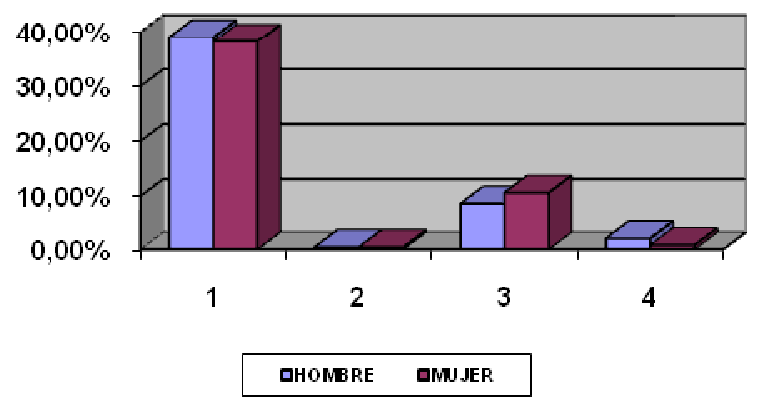

Fuente: Encuesta Perfil Sociológico de la Vejez en Mossoró - Junio 2004 / Junio 2005 (Elaboración de la autora)

1) Que los ancianos vivan con su familia

2) Que vivan en Centros Residenciales con gente de su edad y condición

3) Que vivan en su casa, más recibiendo atención y servicios en su domicilio

4) Ns / Nc

5. Bajo qué circunstancias estarían los mayores dispuestos a vivir en una Residencia para mayores

Coherentemente con lo anterior, cuando se pregunta a los mayores cuál sería su forma de vida preferida, el $96,40 \%$ prefieren vivir con familiares, en su entorno habitual. Cuando se preguntó bajo qué circunstancia estarían dispuestos a vivir en una residencia para mayores, percibimos un gran rechazo a la propuesta: un $42,60 \%$ menciona que no iría a vivir a una residencia bajo ninguna circunstancia (Véase Gráfico 9).

Para gran parte de los mayores, como si fuera una norma general, permanecer en su "zona de confort", en casa, "a toda costa", reafirma el profundo deseo al derecho ciudadano de envejecer en su propio ambiente ecológico, junto a los suyos (Baker y Prince, 1990; Callahan, 1993; Gonyea et al.; 1990). En las encuestas que se han hecho al respecto, mayoritariamente ellos contestan que el lugar más adecuado para envejecer es dentro de la familia (Bazo, 1990:75ss). La idea de ser "echado" de su propia casa, para muchos significa 
(más allá de constituir un momento de sufrimiento, cargado de tensiones emocionales) la pérdida de la independencia y de la autonomía, algo verdaderamente traumático. Este colectivo, independientemente de la clase social a la que pertenezca desearía concluir el ciclo vital atado a todo lo que fue posible construir, bienes y recuerdos preciosos arraigados a lo largo de los años, en su dominio.

Por otra parte, el 12,40\% afirma que decidirían vivir en una Residencia para evitar la soledad. Cada vez más presente en la sociedad actual, la soledad y sus desdoblamientos, principalmente el aislamiento social, cuando se presenta en las circunstancias de la vejez, es un momento determinante para que los mayores "busquen" los espacios dotados de servicios reservados para ellos. Si la soledad viene acompañada de la indigencia, el cuadro es aún más delicado. La "decisión" del mayor de macharse a una residencia para recibir los cuidados indispensables sería difícil en Mossoró pues sólo hay una unidad de esta naturaleza. En la cultura brasileña hay un enorme prejuicio en relación a las instituciones para ancianos, porque además de ser pocas, gran parte de las instituciones existentes prestan servicios de baja calidad (Machado y Queiroz, 2002). La escasez de servicios intermediarios, tan frecuentes en muchos países occidentales, principalmente en los Estados Unidos, Reino Unido y Europa, (Ej. centros de día, servicios de atención a domicilio, vivienda compartida, acogida familiar, teleasistencia, residencias no institucionales, estancias diurnas, residencias de día, casas rurales para mayores), así como otras alternativas para la asistencia de ancianos dependientes, que garantice los derechos de los ciudadanos mayores mossoroenses, ya no es sólo un anhelo, sino todavía una utopía en Brasil.

En cambio, un $11,60 \%$, dice que iría a una residencia si dependiera de otras personas. Conviene hacer notar que, generalmente, los problemas de salud incrementan las incapacidades y, como consecuencia, continuar en casa puede convertirse en una difícil tarea familiar. No obstante, no queda más remedio que la necesidad de cuidados especiales, por lo que irse a una institución geriátrica sería la posibilidad para aquellos que no quieran ser asistidos por la propia familia y sobre todo si no existen servicios alternativos. 
El 10,20\% lo haría para no molestar a los hijos o familiares. Nos parece que ese sentimiento expresado por nuestros entrevistados va unido al concepto negativo de que nuestra sociedad tiende a considerar a los ancianos como estorbo familiar y carga social y pasan a pertenecer a las llamadas "clases pasivas” ${ }^{260}$. Todas las demás razones, aunque minoritarias entre los mayores, fueron citadas en el orden de importancia que sigue: el 5,80\% afirma que sólo ingresaría en las residencias para mayores por razones económicas, un 5,40\% si tuviera problema de vivienda, un $3,20 \%$ si padeciera una enfermedad crónica, un $2,60 \%$ si enviudara y un $6 \%$ no contestó la pregunta.

Por sexo, analizamos los resultados más evidentes por considerarlos de mayor importancia. Por un lado, ambos sexos tienen opiniones muy semejantes en las categorías de respuestas 2, 6 y 8. Es decir, si padeciera alguna enfermedad crónica, si tuviera problemas económicos y por problemas de vivienda irían a una institución para mayores. Por otro lado, con diferencias marcadas, las mujeres aceptarían la idea de ir a una residencia, solamente bajo dos circunstancias muy bien definidas, en los ítems 7 y 9 . Es decir, para no molestar a los hijos o familiares y no iría a vivir a una residencia bajo ninguna circunstancia. $\mathrm{Y}$ entre éstos, hay una nítida resistencia femenina en el ítem 9, eso es un 19,40\% frente a un 23,20\%: en modo alguno iría a una Residencia. A este respecto, Gail Wilson señala "los estereotipos populares de roles de sexo: los hombres trabajan como asalariados y tienen una vida social relacionada con el trabajo, mientras que las mujeres crían a los hijos y cocinan, limpian y lavan. Las mujeres construyen y mantienen contactos sociales en familia e independientes del centro de trabajo" (1996:148). En otras palabras, los hombres, al alejarse del contacto social con los compañeros del mundo laboral mediante la jubilación y quedándose solos son más proclives a aceptar trasladarse a una residencia, mientras las mujeres que crean lazos mucho más fuertes y cercanos con su familia y otros, y sin "jubilarse" de ellos, evidentemente se resisten más a abandonar sus viviendas.

\footnotetext{
260 Rodríguez, Gerardo Hernández (1989): La figura del anciano en la familia contemporánea: relaciones intergeneracionales y status social del anciano, en Hacia una nueva Vejez I Simposio de Gerontología de Castilla y León, Editorial San Esteban, Valladolid, p. 227.
} 
La variable estado civil, señala que los varones casados tienen más recelo de la soledad que las mujeres. Aquellos $(5,20 \%)$ sólo irían a una institución asistencial para evitar la soledad mientras que entre las mujeres sólo un $1,80 \%$ haría lo mismo. Los hombres casados, el 13,80\%, las mujeres viudas, el $11,60 \%$ y un $7,40 \%$ de las mujeres casadas, enfatizan que no irían a vivir en una residencia para mayores bajo ninguna circunstancia. Un 3,60\% del colectivo femenino afirma que iría a una residencia para no molestar los hijos/as o familiares y un $3 \%$ de las entrevistadas viudas sólo irían si no se valieran por sí mismas. Así pues, dada la tendencia de la decreciente natalidad junto al incremento proporcional de mayores en Mossoró, y considerando el deseo minoritario de éstos de vivir en hogares colectivos, es decir, la preferencia de querer permanecer en sus viviendas el mayor tiempo posible, abogamos por la implantación de la asistencia a domicilio, por razones de tipo social, económico y político, bien defendida por Walker (1992:44). Sin embargo, para aquellas personas mayores, económica o familiarmente desamparadas, que no pueden ya valerse por sí mismas en su hogar será bien recibido la alternativa del internamiento en residencias públicas, que no institucionalicen a los mayores, para responder a las necesidades sociales presentes y futuras de las generaciones de mayores.

\section{GRÁFICO 9}

Bajo que circunstancia estarían los mayores dispuestos a vivir en una Residencia para mayores

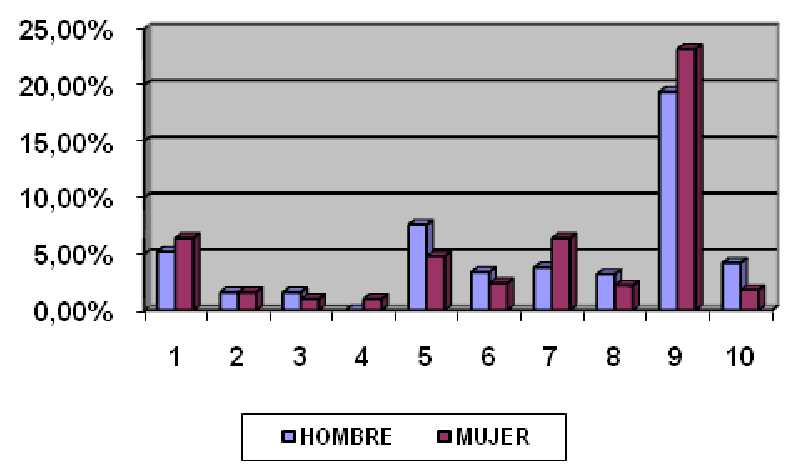

Fuente: Encuesta Perfil Sociológico de la Vejez en Mossoró - Junio 2004 / Junio 2005 (Elaboración de la autora)

1) Si dependiese de otras personas 
2) Si padeciese enfermedad crónica

3) Si enviudase

4) Para no realizar las tareas domésticas

5) Para evitar la soledad

6) Por razones económicas

7) Para no molestar a mis hijos o familiares

8) Por problemas de vivienda

9) No iría a vivir en una Residencia de ancianos bajo ninguna circunstancia

10) Ns / Nc

\section{Mayores que opinan que hace falta una Residencia en Mossoró}

Mossoró es una ciudad que no tiene tradición en asistir a los mayores en asilos. Esta modalidad, conocida como atención más antigua y universal para el anciano fuera de la familia, de cuño público o privado, con o sin ánimo de lucro, ofrece abrigo en régimen de internado, por tiempo indeterminado, a personas ancianas que no tienen condiciones de proveerse la subsistencia, ni familia para hacerlo, proporcionándoles vivienda, alimentación, vestimenta, cuidados sanitarios, recreación y convivencia social. Es una realidad poco notable en la ciudad. A expensas de la caridad cristiana, la única unidad, la residencia Amantino Câmara ${ }^{261}$, construida en 1945 por Don Jaime Barros Câmara, primer Obispo de la Diócesis de Mossoró en el municipio, es para muchos una realidad que pasa casi desapercibida. Sin embargo, la institución es imprescindible para aquellos que no tienen quién les cuide en los últimos años de su existencia.

A nivel de Brasil, en general, es reciente el proceso de desarrollo de iniciativas a favor de personas mayores realizadas por órganos públicos,

\footnotetext{
261 El Instituto es una sociedad civil filantrópica, de derecho privado, sin ánimo de lucro, de cuño social que tiene por objetivo el abrigo y asistencia a los mayores carentes. De carácter mixto, sobrevive gracias a inversiones del Ministerio de Seguridad y Asistencia Social, donaciones en metálico, en alimentos y bienes materiales de industrias y comercios de la comunidad mossoroense y de una simbólica gratificación de los albergados que disponen de algún tipo de ingreso. Tiene una ubicación muy céntrica, Barrio San José. Posee espacio para 80 personas y dispone de un cuadro funcional con director, presidente, administrador, tesorero, asistente social, médico, enfermero, terapeuta ocupacional, animador, secretario y personal de apoyo para cocina y limpieza general. Actualmente cuenta con 60 ancianos: 24 hombres y 36 mujeres, capacitados e incapacitados físicos y mentales, siendo la mayoría de ellos solteros y analfabetos, que por la condición de pobreza general, ingresaron por abandono, disgregación y/o inexistencia familiar. Los que tienen familiares reciben visitas y los que demuestran condiciones de lucidez y locomoción gozan de libertad para salir y pasear, conforme a las normas y reglas establecidas por el Regimiento Interno de la entidad.
} 
entidades civiles, organizaciones no gubernamentales o instituciones religiosas de las más diversas áreas. De acuerdo con el Informe Realidade dos Abrigos e Asilos de Idosos no Brasil ${ }^{262}$ en 2002, existían aproximadamente 19.000 mayores institucionalizados en todo el país, lo que representaba el $0,14 \%$ del total de los mayores brasileños. Sin embargo, es de esperar que ese número sea bastante mayor si consideramos las instituciones de asilos no catalogados y que posiblemente funcionen en la clandestinidad.

Hace menos de dos décadas que la atención a la población anciana es reconocida, al menos desde el punto de vista legal, a través de la Constitución Federal, bajo el Título VIII - De Orden Social, Capítulo VII - De la Familia, del Niño, del Adolescente y del Mayor. "Art. 230 - La familia, la sociedad y el Estado tienen el deber de amparar a las personas mayores, asegurando su participación en la comunidad, defendiendo su dignidad y bienestar, garantizándoles el derecho a la vida”. Después, con la publicación de la Ley n. 8.842, de 4/2/1994, la proclamación del Año Internacional del Anciano, en 1999 y de la implantación e implementación de la Política Nacional del Mayor (PNI) en 2000 se reforzaron las políticas de atención dirigidas a este segmento de la población.

Así pues, preguntamos a los entrevistados si el municipio carece de Residencia para mayores, visto que el aumento de la esperanza de vida de la población se revela en la sutil cantidad de ancianos en relación a otros segmentos de edad en Mossoró. Así, de acuerdo con los datos objetivos que ofrece la presente Encuesta en el Grafico 10, más de cuatro quintas partes $(88,60 \%)$ creen que en Mossoró hacen falta instituciones de internado para los ancianos, al contrario de los que opinan desfavorablemente (4,20\%). Poco más del $7,20 \%$ no contestaron a la cuestión.

Por categoría de sexo, el $42,40 \%$ de los hombres y el $46,20 \%$ de las mujeres se manifestaron a favor de la Residencia en Mossoró. En lo que concierne a nuestro colectivo, por sexo y estado civil, todos los hombres $(1,40 \%)$ y

262 La Comisión de Derechos Humanos de la Cámara de los Diputados publicó en 2002 el Informe Caravana Nacional de Derechos Humanos: una Muestra de la Realidad de los Albergues y Asilos de Mayores en Brasil. 
mujeres $(5,60 \%)$ solteros, con excepción de un hombre que no contestó la pregunta, son unánimes en la creencia de la necesidad de la creación de estos establecimientos. Con la misma opinión se manifestaron el $28,60 \%$ de los hombres y el $16 \%$ de las mujeres casadas, respectivamente. $Y$ en estado de viudedad el $7,80 \%$ de los viudos y el $20 \%$ de las viudas proporcionalmente, subrayan la importancia de esta política social.

En un primer análisis consideramos que los mayores entrevistados residentes en Mossoró son conocedores de que sólo existe una opción, la residencia Amantino Câmara, para las personas que envejecen fuera del ambiente familiar. Por eso creen que Mossoró carece de Residencia para mayores. También saben de la existencia de algunas políticas públicas - más adelante en la sección Prestaciones y Servicios a la Tercera Edad hablaremos de ese tema - que generan expectativas para las personas mayores que no suponen necesariamente un desarraigo familiar y ambiental. El segundo análisis, aunque quizá solamente en su opinión, refleja que los mayores nunca desean o creen que vayan a terminar en una Residencia, dado que "la voluntad más generalizada de las personas mayores es mantener su independencia el mayor tiempo posible" (Carrajo, 1999:217). Es probable que la defensa de estos establecimientos sea mayor en las próximas generaciones, quizá sus descendientes, por ser testigos de las nuevas formas y tendencias de composición familiar.

Para finalizar, entre los encuestados que juzgan positivo construir en Mossoró residencias para mayores, destacan los hombres y mujeres solteras, casadas y viudos. Impresiona que casi en su totalidad los hombres solteros (7 de los 8 encuestados) y el cien por cien de las mujeres solteras (28), sean favorables a la idea planteada. Vimos que 143 de los hombres y 80 de las mujeres casados también contestaron lo mismo, y los viudos (39 de los 47 y 100 de los 108 entrevistados) defienden la misma perspectiva de futuro. La sensación que nos invade es que nuestro colectivo encuestado, especialmente los subrayados en ese párrafo, parecen prever una necesidad en la que ellos pueden verse 
incluidos. En ese sentido, la alternativa de las residencias, según Katzelson ${ }^{263}$ es conveniente para aquellas personas que las necesiten a causa de su deterioro físico, psíquico, por circunstancias socio-familiar adverso o quienes no quieran ser asistidos por la propia familia.

Pero si la sugerencia se hace realidad, ésta debe ser diferente de la situación del "Amantino Câmara", que más allá de segregar a los residentes del mundo exterior, ha reflejado una serie de debilidades en cuanto a los servicios prestados en la Institución y la precariedad en cuestiones humanitarias. ${ }^{264} \mathrm{El}$ relato se basa en argumentos del tipo: "los ancianos son percibidos, por los funcionarios, como personas que están solamente esperando la hora de la muerte"; pensamiento reforzado por algunos empleados cuando tratan a los mayores de "viejos perezosos".

El proceso de envejecimiento de la población en Mossoró, el aumento de la expectativa de vida, que supone cada vez un mayor número de ancianos $\mathrm{y}$, en consecuencia, apunta al crecimiento de la población que sufre un declive funcional y cognitivo y, la tendencia a la nuclearización familiar, son factores que identifican las necesidades y recursos para la tercera edad. Se recomienda pues, atención por parte de los órganos gubernamentales y no gubernamentales hacia el problema que aún no está detallado en toda su extensión.

\footnotetext{
263 Citado por Pastor Ramos, Gerardo: Sociología de la Familia. Enfoque institucional y grupos. Sígueme. Salamanca 1988, p. 328.

264 Monteiro, A. P. B. de M., Magalhães, J. Da C., Floriano, V. dos Santos (1999): Um olhar sobre as condições de vida do idoso abrigado no Instituto Amântino Câmara. Facultad de Servicio Social (FASSO). Universidad del Estado de Río Grande del Norte (UERN), p. 49.
} 


\section{GRÁFICO 10}

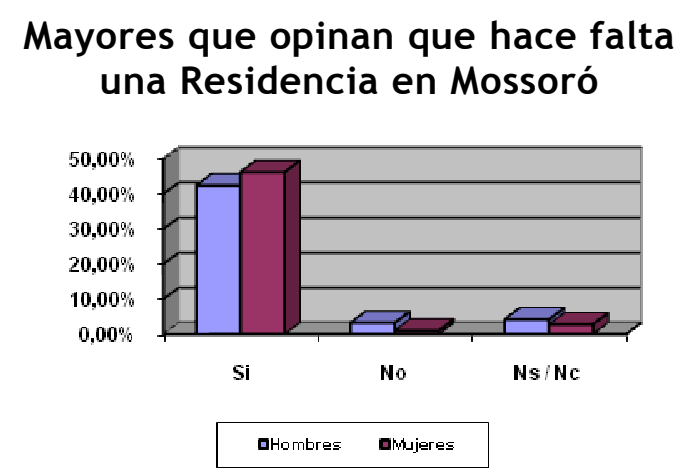

Fuente: Encuesta Perfil Sociológico de la Vejez en Mossoró - Junio 2004 / Junio 2005 (Elaboración de la autora)

\section{Sugerencia para la construcción de una Residencia}

El panorama mostrado anteriormente manifiesta el predominio de la idea de que Mossoró necesita la construcción de una residencia para las personas mayores. Como consecuencia de este hecho, convendría saber cuál sería para los mayores la ubicación geográfica más conveniente para tal "evento". ¿Dónde deberían construirse las residencias para mayores?, lo plantearemos a través de las siguientes variables: en el centro urbano, en los barrios o en las afueras de la ciudad.

Si se tiene en cuenta que los mayores entrevistados prefieren vivir en su entorno familiar y ambiental, dado que lo consideran la forma de vida más conveniente, o eso afirmaron ellos en el punto 1.4 de este apartado, y se tienen en cuenta las relaciones generacionales satisfactorias con familiares, amigos y vecindario también analizados anteriormente, es curioso que más de la mitad, el 59,80\%, de los sujetos, ha elegido la localización residencial para los mayores en el centro urbano, es decir, en el corazón de la ciudad, donde se concentran en gran proporción los mercados comercial y financiero. Creemos que esto pueda deberse a querer cambiar de aire, de entorno, pero sin alejarse de su comunidad social o quizá para apartarse de la periferia, donde viven muchos de los encuestados, donde es más frecuente la inseguridad ciudadana, la falta de prestaciones y servicios y la falta de infraestructura urbana ambiental. 
Por otra parte, el 23,10\% defiende que la nueva residencia debería construirse a las afueras de la ciudad, fuera de su entorno social, en una finca, pero, suponemos que con condiciones de acceso a los servicios necesarios para facilitar la relación con los suyos: transporte público colectivo, una zona con árboles, para mitigar las temperaturas de Mossoró que siempre rondan los $35^{\circ}$ grados.

Por último, el 17,20\% defiende la construcción de residencias en contacto con su entorno, donde siempre han vivido, es decir los barrios. Esta opinión, se apoya en la facilidad de los contactos del residente con su entorno de costumbre o de toda la vida, en la facilidad para salir y comunicarse con familiares, amigos y vecinos, además de hacer los viejos paseos desinteresados por el barrio o conocer a otras personas no residentes. Esto puede contribuir a cambiar la figura del anciano institucionalizado y justificar tal defensa.

Con relación al sexo, por un lado las mujeres $(31,60 \%)$ están más inclinadas que los hombres $(28,20 \%)$ a que las residencias se construyan en el centro urbano de Mossoró. En el otro extremo, los hombres $(13,60 \%)$ más que las mujeres $(9,40 \%)$ defienden que las edifiquen lejos de la ciudad. Para finalizar, con índices muy similares para ambos sexos, el $8,20 \%$ y el $9 \%$ opinan que se construyan en los barrios de la ciudad. Los resultados están a su disposición en el Gráfico 11. 


\section{GRÁFICO 11}

Sugerencia para la construcción de una Residencia

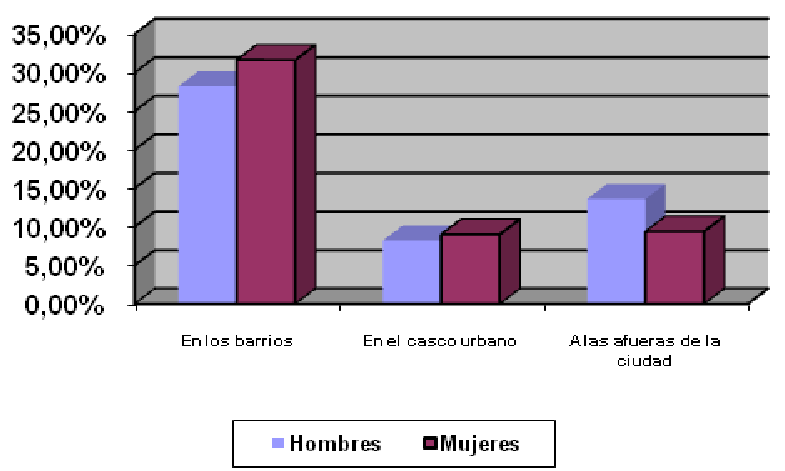

Fuente: Encuesta Perfil Sociológico de la Vejez en Mossoró - Junio 2004 / Junio 2005 (Elaboración de la autora)

\section{Resumen}

En esta segunda parte sobre el Perfil Sociológico de la Vejez en Mossoró, se analizaron algunos aspectos de la forma de vida de las personas mayores de 60 años residentes en la Capital del Oeste del Río Grande del Norte (RN). El entrelazado de las relaciones establecidas con la familia, el vecindario y la sociedad, además del pensamiento acerca de residencias para ancianos, nos dan la imagen peculiar del anciano mossoroense, con sus características propias y la heterogeneidad que alberga ese segmento social, influido, sobre todo, por las variables de sexo y edad.

El informe recaba informaciones respecto a un grupo de personas en una determinada realidad, crea condiciones para comprender mejor la actual etapa de sus vidas y mejorar algunas situaciones en favor del colectivo, además, de prepararlos para el devenir de la vejez.

No es novedad que el $93 \%$ de los entrevistados tuviera descendientes. En Brasil hasta 1940 las mujeres tenían, de media, 6,2 hijos por falta del control de la natalidad femenina, el papel de la mujer en el matrimonio se resumía en la procreación y su ausencia en el mundo laboral era evidente._Del entorno investigado, 465 personas tuvieron 2.301 descendientes, una media de 4,6 hijos por cada mayor. Ese panorama confirma que las generaciones nacidas en la primera mitad del siglo XX tuvieron familias numerosas. Las mujeres (45\%) tuvieron una prole más pequeña que los varones (48\%). Según el estado civil, 
los varones casados $(33,20 \%)$ tuvieron más hijos que las mujeres casadas (18\%), dada la superioridad de aquellos entrevistados. En cambio, la proporción de las mujeres solteras $(5,60 \%)$, separadas $(3,20 \%)$ y viudas $(21,60 \%)$ con herederos vivos, es superior a la de los varones en los mismos estados. Particularizando la situación de las mujeres, sobre todo, sin compañero, suponemos que experimentaron más las dificultades en la crianza de los hijos. En aquella época las mujeres tenían poca o casi ninguna oportunidad de ascenso socioeconómico.

Viviendo en estructuras familiares nucleares tradicionales, los entrevistados, dijeron gozar de una buena convivencia familiar con su cónyuge o compañero, con o sin hijos, y con o sin nietos $(77,95 \%)$. Cuando analizamos las respuestas en términos del estado civil, encontramos en los varones casados $(27,26 \%)$ y las mujeres viudas (15,63\%), a los más felices con el estilo de vida que llevan. La satisfacción de los sujetos con quienes comparten la vida a diario, se da en hogares monoparentales $(18,30 \%)$, matrimonio con hijos $(18,30 \%)$, matrimonio sin hijos $(14,19 \%)$ y hogares extensos $(6,62 \%)$. La idea de que el varón tiene más dificultad para independizarse, para vivir sin compañía, se ha confirmado en nuestra investigación. También constatamos la satisfacción vital en que se encuentran las mujeres viudas. Los entrevistados que viven en hogares de pareja sin hijos y en hogares extensos se revelan menos satisfechos. Esto nos da la impresión de que la vida marital resumida solo a la pareja, principalmente cuando éstos no disponen de muchos recursos, se torna en soledad. Por otro lado, una gran cantidad de gente compartiendo el mismo ambiente no deja de causar infortunio a los mayores, que supuestamente han adquirido otros hábitos de vida en la vejez.

Todos los datos afirman que ellos se relacionan bien con la familia, amigos y vecindario. Las relaciones sociales, a menudo se dan especialmente con hijos y familiares que no viven en el propio hogar, además de los nietos, vecinos y amigos. Por encima de dos tercios de los entrevistados $(67,40 \%)$ suele hablar todos o casi todos los días con los hijos que no viven en su compañía y por encima de cuatro quintas partes mantiene contactos a diario con los vecinos 
$(84,80 \%)$. A pesar de esto, muy pocos ancianos nunca $(3,80 \%)$ hablan con ningún miembro de la familia. Entre los que no contestaron la pregunta $(7,40 \%)$, se supone una cierta soledad o aislamiento social, dentro del colectivo investigado.

En lo que se refiere a la forma de vida preferida por los sujetos entrevistados, los datos nos permiten constatar que los mayores fueron taxativos al preferir vivir con su familia $(77,20 \%)$. En una proporción significativamente más baja, argumentaron que les gustaría vivir en su propia casa, pero recibiendo atención o servicio en el hogar $(19,20 \%)$ y la más rechazada, con apenas cuatro personas, se refería a que los ancianos vivan en una residencia de mayores. En las dos primeras opciones, los hombres presentan cifras relativamente superiores a las de las mujeres. Casados y viudos defienden con vehemencia la idea de permanencia en el ambiente doméstico. Una vez más, retomamos la cuestión del varón dependiente. La sensación de desprenderse de la familia parece que les hace sentir pavor, por lo que todo indica que la familia sigue siendo la principal referencia de las relaciones humanas y de capital valor en el último tramo de la vida. Sin embargo, según ellos, no estaría mal, la idea de continuar viviendo en casa, recibiendo atención domiciliar para realizar las gestiones cotidianas. Una actuación en ese campo facilitaría la vida de los mayores y los mantendría en el seno de la familia.

Comprobamos que la prioridad de los mayores es convivir con familiares hasta el final de la vida. Pero, también identificamos por qué motivos estarían dispuestos a vivir en una residencia para mayores. La mayoría, un 42,60\%, rechazó tal hipótesis. Por su parte, el 11,60\% aceptaría la idea si perdiese la independencia y autonomía. No valerse por sí mismo constituye el principal impulso para dejar la propia vivienda. Para huir de la soledad, estarían dispuestos a irse el $12,40 \%$ y si percibieran que causarían molestia a los hijos según el $10,12 \%$. Por razones financieras, lo haría el 5,80\% o por precariedad de la vivienda según el 5,40\%. Finalmente entre otras respuestas destacamos: si sufrieran una enfermedad crónica (el 3,20\%), y en menor proporción, si 
enviudaran (2,60\%). Las respuestas suenan distintas cuando tratamos a los dos sexos por separado. Las mujeres sólo saldrían de su zona de confort, por dos razones muy definidas: si dependiesen de otra persona y para no molestar a los hijos. En cambio, los varones la cambiarían mayormente para evitar la soledad y por razones económicas.

Después de estas afirmaciones, ampliamos el asunto de la Residencia y constatamos que casi el cien por cien se adhiere a la idea de que Mossoró precisa de una institución de esa naturaleza. La única casa de acogida existente en la provincia, Residencia Amantino Câmara, construida hace 68 años por la caridad de la Iglesia Católica, es una sociedad civil, de ámbito privado, sin ánimo de lucro, de carácter social, que dispone de 80 plazas para mayores, sobre todo pobres. La defensa hecha especialmente por los mayores solteros, casados y viudos parece prever la necesidad de que ellos puedan ser incluidos en un futuro próximo. Más de la mitad de los sujetos $(59,80 \%)$, sugiere que se construya la residencia en el centro urbano de Mossoró. En contraposición, alrededor de una cuarta parte defiende que se establezca a las afueras de la ciudad y la sugerencia que ha tenido menos adeptos ha sido la de que se construya en alguno de los barrios de Mossoró. 


\section{La ancianidad como categoría subjetiva}

Hay una enfermedad crónica, necesariamente mortal, que todos debiéramos evitar y que, sin embargo, todos deseamos: la ancianidad.

Ramón y Cajal (1852-1904),

\section{Lo que hace a una persona ser mayor}

¿Qué hace a una persona ser mayor? ¿Cuándo se llega a viejo? ¿Los años transcurridos? ¿Las leyes? ¿La jubilación? ¿Es la vejez un estado físico o de ánimo? Preguntas insistentemente planteadas por investigadores a las personas mayores para estimar el inicio de la vejez. Los investigadores han estudiado la vejez desde diferentes enfoques. Sin embargo, es posible considerar el envejecimiento al menos desde cuatro puntos de vista: cronológico (Burgess, Cavan y Havinghurst, 1948), físico y biológico (Birren, Butler, Greenhouse, Sokoloff y Yarron, 1971), psicológico (Neugarten, 1968) y social (Palmore, 1975). Todos estos campos de estudio ofrecen importantes hallazgos científicos, pero, la vejez, como hemos visto en el capítulo II, "no es un concepto fijo y objetivable, sino el resultado de un proceso continuo, cultural y social”265 (Havighurst, Munnichs, Neugarten, Thomae, 1969; Leer Dreher, 1968, Leer, 1969, Foucault, 1995). De hecho, no existe una frontera exacta que determine el paso de la edad adulta a la vejez. A pesar de ello, se acepta, en la mayoría de los países industrializados y en vías de desarrollo, que el umbral de la vejez viene señalado por la normativa social de los 60 ó 65 años cuando se abandona oficialmente la vida laboral ${ }^{266}$. "En nuestra época, desde una óptica sociológica son ancianas aquellas personas que han alcanzado la edad normal suficiente para retirarse del trabajo. En muchos países en desarrollo, el tiempo cronológico tiene poca o ninguna importancia

265 Hernández, Sánchez Alfredo (1988): Aspectos socio-económicos de la vejez, en Varios, Hacia una vejez nueva, I Simposio de Gerontología en Castilla y León, Salamanca, p. 129

266 Rodríguez Domínguez, S, La vejez: Historia y actualidad. Universidad de Salamanca, 1989, p. 87. 
para la definición de edad mayor. Por tanto, esta definición es considerada arbitraria, dado que la vejez biológica no siempre corresponde con la vejez cronológica”267.

A fin de profundizar en esta temática, lanzamos esta cuestión y, de acuerdo con lo que ya revelaron otras investigaciones sobre ese tema en Brasil, la mayoría cree que la vejez comienza a los 60 años o después de esa edad. Cerca del $30 \%$ la definió como un estado de espíritu ${ }^{268}$. Aunque, el ingreso en la vejez está establecido por decreto, se constata que la variable "jubilación" está desfasada. Como puede verse en el Gráfico 12, con poca representatividad, apenas el $3 \%$ de los sujetos que componen la muestra atribuye a la jubilación el paso a la vejez. Tal porcentaje puede deberse a que una parte de los entrevistados, en el momento de la jubilación se encontraba en buen estado de salud física y mental. Además, si tenemos en consideración que hoy podemos vivir más de tres décadas más allá de los 65 años, tenemos que admitir que ese concepto - aún aplicado - está desfasado en más de un siglo, cuando Von Bismarck creó en 1880 el primer plan de jubilación. En consonancia con esto, sólo el 3,20\% del grupo atribuye a las leyes tal hecho y un $1,60 \%$ optó por no contestar a la pregunta. Como cabía esperar, obviando el criterio cronológico, físico y biológico de la vejez, se observa que más de un tercio de los entrevistados (un 37,80\%) condiciona ese evento a la edad cronológica y un $31,20 \%$ la definía como la falta de salud. Por un lado, la opción mayoritaria supone una cierta correlación entre las mencionadas respuestas. Busse y colaboradores (1948) indican que la identificación con el grupo de los jóvenes, de los adultos, de las personas de edad madura o de los viejos no depende exclusivamente de la edad del sujeto sino también de su estado de salud y de su raza. De hecho, se puede decir que a medida que pasan los años, por lo general, acompañado de variaciones determinadas por una gran diversidad de causas, incluidas las de tipo

\footnotetext{
267 Casals, Ignasi (1989): Sociología de la ancianidad en España, Madrid, Mezquita, primera edición, p. 51.

268 Investigación realizada por Anita Liberalesso Neri - profesora e investigadora en Psicología de Vida Adulta y de la Vejez en UNICAMP, con 4.300 brasileños con edad entre 13 y 45 años, residentes en ciudades de las cinco regiones geográficas de Brasil entre 1985 y 1987, sobre actitudes en relación a la vejez y las expectativas en relación a la propia vejez.
} 
socioeconómico, nos acercamos a las debilidades típicas del envejecimiento y efectivamente aparece una persona mayor. Como sostiene Bazo ${ }^{269}$, "aunque la edad no es la variable decisiva en cuanto a la pérdida de salud e independencia, sin embargo existe una asociación entre ambas variables". Por otro lado, los cambios físicos y biológicos también son un indicador para definir el envejecimiento, aunque en determinados casos, se omiten las diferencias individuales, la naturaleza y la amplitud de los cambios físicos. Mishara y Riedel (1986) recuerdan que no todos los individuos envejecen al mismo ritmo ni de la misma manera, ya que muchas personas de edad tienen mejor salud que otras más jóvenes y en cualquier edad, la enfermedad puede proceder de un entorno y de condiciones sociales independientes de la voluntad del sujeto. Por fin, una proporción significativa para ambos sexos $(23,20 \%)$ subraya que el ser viejo es una decisión individual y subjetiva, respaldada en la edad psicológica. Podemos decir que cada uno va a decidir en un determinado momento de su vida cuando es viejo. Muchos creen que la vejez es un "estado de espíritu", es decir, no depende de la edad cronológica y de otros marcadores de la vejez. Según Neri, "personas de edad media o en el inicio de la vejez tienden a indicar una edad psicológica menor que su edad cronológica, en parte para salvaguardar la imagen social y autoestima, en parte, tal vez, por dificultades en la auto aceptación $y$, que a partir de mediados de la cuarta década de vida las personas pasan a pensar en sus vidas en términos de años que aún tienen por vivir en vez de en términos de años vividos" (2001:65).

Estratificando la discusión por sexo, examinaremos las pautas de las tres columnas más destacadas. De derecha a izquierda, las mujeres (14\%) con más intensidad que los hombres $(9,20 \%)$, clasifican la vejez como un estado de espíritu, postura profundamente condicionada a factores de personalidad, relacionada con el sentimiento de "ser viejo" (Mishara y Riedel, 1984; Neri y Wagner, 1985, Schroots y Birren, 1990). Como la auto percepción del envejecimiento es vivida por las personas de muy diversas formas, que no sólo dependen de la edad del sujeto, sino de su personalidad, de su contexto

269 Bazo, María Teresa y Domínguez-Alcón, Carmen (1996): Los cuidados familiares de salud en las personas ancianas y las políticas sociales, Reis, $n^{\circ} 73$, Madrid, p.43. 
sociocultural y, sobre todo, de su capacidad de adaptación a los cambios biológicos, psicológicos y sociales, quizá, una forma menos simplista de abordar esa cuestión sea por la visión negativa que soportan las personas ancianas, sobre todo si son mujeres.

En un mundo fuertemente marcado culturalmente por lo efímero de la belleza femenina, donde a menudo se dice que las mujeres "se pasan de años" o llegan a la fecha de caducidad a una edad más temprana que los hombres (Arber y Ginn, 1996:25), una de las formas de afirmarse como ancianas, se encuentra en la excusa de que la ancianidad es un "estado de espíritu" (la respuesta social más conveniente para ellas). En la columna siguiente, la cuestión tratará la categoría falta de salud, o dicho en otras palabras, la edad física y biológica, que evoca habitualmente cambios físicos desagradables, traducida en "la dependencia, la decrepitud y la muerte" (Laslett, 1989). En esta categoría sólo concuerda el $14,40 \%$ de los hombres, mientras una quinta parte de las mujeres $(16,80 \%)$ está de acuerdo.

Parece probable que, en el caso de las mujeres, por correr más riesgos de problemas de salud en la ancianidad (Arber y Ginn, 1996; Bazo, 1992), indiquen ese factor como el principal condicionante responsable de la causa de la vejez. La última columna indica una discrepancia en las opiniones de hombres $(22 \%)$ y mujeres $(15,80 \%)$ sobre la categoría edad cronológica (o de calendario) como factor determinante de la vejez. Quizá, este factor se relacione con el estilo de vida que llevan hombres y mujeres del Nordeste que envejecen antes en comparación con las regiones del Sur y Sudeste brasileño.

Concretamente, por existir varios criterios que pueden servir para definir el envejecimiento y, por regla general, afectar de forma diferente a hombres y mujeres (Marshall, 1987; Levy, 1988) en nuestra investigación, primero confirmamos que lo que define a una persona mayor está marcado por el carácter multidimensional del propio concepto de "vejez", definido en términos cronológicos (persona que ha cumplido los 60 ó 65 años), funcionales (discapacidad y pérdida de independencia) y de roles sociales (jubilación). Segundo, la existencia de una gran variabilidad en cuanto a la estimación del 
comienzo de la ancianidad, está nítidamente marcada por el sexo. Los entrevistados lo condicionan con cada una de las categorías sugeridas y, dado que todos los individuos no envejecen al mismo ritmo ni de la misma manera, no se puede generalizar siempre. $\mathrm{Y}$ tercero, podríamos decir que las situaciones que acompañan el concepto de envejecimiento de los entrevistados, sufren influencias de aspecto institucional y de tipo biológico, social, psicológico, económico y cultural.

\section{GRÁFICO 12}

\section{Lo que hace a una persona ser mayor}

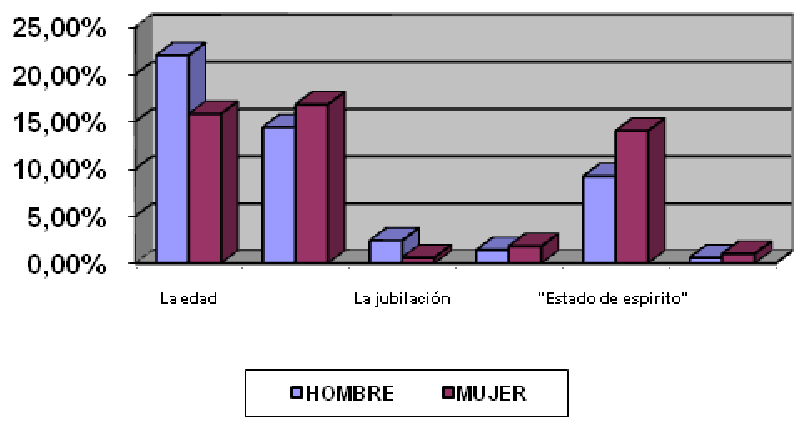

Fuente: Encuesta Perfil Sociológico de la Vejez en Mossoró - Junio 2004 / Junio 2005 (Elaboración de la autora)

\section{Mejor término para referirse a una persona mayor}

En nuestra época observamos una variedad de conceptos y términos que hacen referencia al grupo de personas que logran edades por encima de los 60 años, sin embargo no contamos con una designación satisfactoria para ellos, dado que el problema conceptual tiene que ver con la imagen social que se tenga (Da Motta, 1997). En la literatura especializada, para referirse a ese público, desde la óptica de las ciencias sociales, hallamos tanto vocablos creativamente valorativos, como lamentablemente eufemísticos. Según Fericgla (1992:67), prácticamente en todas las publicaciones aparecen, sin especificaciones semánticas, conceptos como viejo, mayor, anciano, tercera edad, cuarta edad, octogenarios, nonagenarios y otros significados, que no tienen correspondencia rigurosa con sus significados reales.

Partiendo de las expresiones culturales más difundidas y utilizadas en la sociedad actual (viejo) a las consideradas más modernas (tercera edad), 
preguntamos a las personas mayores directamente, de un abanico limitado de cinco sugerencias, cuál era el vocablo de su preferencia para referirse a ellas como colectivo, y los resultados se encuentran en el Gráfico 13.

En nuestro público de interés, los resultados obtenidos indican que existen diferencias significativas en la percepción de estos conceptos según la variable de género. Sin embargo, en general, un poco más de dos quintas partes $(41,60 \%)$ son favorables al término idoso (vocablo correspondiente a "Mayor" en español). El segundo término más votado, tercera edad, lo prefiere casi un tercio (32,60\%). En tercer lugar, con un porcentaje del 11,60\% señalan que ninguno de estos vocablos es adecuado para referirse a ellos. En menores medidas, los términos favoritos son viejos $(5,80 \%)$ y ancianos $(7,20 \%)$, proporcionalmente para ambos sexos.

A continuación, tratándose de género, se puso de manifiesto con toda claridad la preferencia de las mujeres por las terminologías mayor y tercera edad, en contra de los elegidos por los hombres, viejos y ancianos. Es decir, 108 mujeres y 100 hombres creen más conveniente para referirse a ellos el término mayor, y el vocablo tercera edad lo escogieron 89 mujeres y 74 hombres, respectivamente. Para los vocablos viejo y anciano, la preferencia de los hombres supera a la de las mujeres (20 contra 9 ) en el primer vocablo. En el segundo, tenemos 20 hombres frente a 16 mujeres.

Para explicar este perfil situacional, comenzamos por el término más aceptado por los entrevistados: idoso. En Brasil se nos ha dicho que la expresión es suave y se utiliza para referirse a las personas que viven durante más tiempo. Se acepta la denominación idoso frente a otras como "ancianos" o "viejos". Esta aceptación mayoritaria encuentra respaldo en un trabajo de Neri (2000) y con mucha frecuencia en los gestores de política económica y social, los medios de comunicación y los gerontólogos sociales. 
En la vasta bibliografía sobre esa terminología, Bandera ${ }^{270}$ es uno de los que argumenta que "el vocablo más conveniente para referirse a ese colectivo es el término personas mayores, (lo correspondiente a nuestro idoso) principalmente por no tener un sentido peyorativo. En lo referente a los términos "tercera edad" y "anciano", buscamos apoyo en los argumentos de Yubero y Larrañaga ${ }^{271}$, que consideran "adecuado tercera edad, oficialmente introducido en Francia ${ }^{272}$, por no tener carácter peyorativo y que ha tenido amplia difusión y buena aceptación, a pesar de la difícil explicación, ya que no existe una primera y una segunda edad". El término anciano parece conveniente utilizarlo, ya que podría justificarse, al tratarse del cuarto período o edad de la existencia humana, planteado por Aristóteles (después de la infancia, la adolescencia y la madurez). En cuanto al término viejo, Bandera descarta totalmente este vocablo, por tener un carácter peyorativo, de decadencia e inutilidad. Además, a la mayoría de los propios individuos de más de 60 ó 65 años no les gusta que les llamen viejos, como demuestran los números de nuestra encuesta.

Finalizando esta sección, nos parece conveniente destacar que los 58 encuestados $(11,60 \%)$ que rechazaron los vocablos sugeridos, lo hicieron por haberles ofrecido pocas opciones o quizá porque ya ha llegado la hora de acuñar nuevos términos para tipificarlos, de modo justo y sin prejuicios.

\section{GRÁFICO 13}

\section{Mejor término para referirse a una persona mayor}

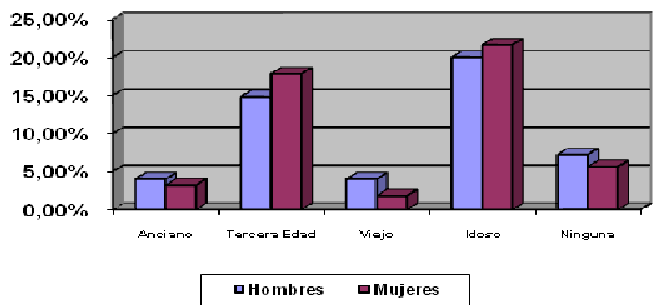

Fuente: Encuesta Perfil Sociológico de la Vejez en Mossoró - Junio 2004 / Junio 2005 (Elaboración de la autora)

\footnotetext{
$270 \quad$ Bandera, J. (1992): Interacción y elaboración de la identidad en la Tercera Edad, en P. SánchezVera (editor), Sociedad y población anciana, Universidad de Murcia, p. 103.

271 Yubero, Santiago y Larrañaga E. (1999): La imagen social del anciano, En Envejecimiento, sociedad y salud, ediciones de la Universidad de Castilla La Mancha, Cuenca, p. 60.

272 Lenoir, R. (1979): L'Invention du "Troisième Age": constitution du champ des agents de gestion de la vieillesse. Actes de la Reprocherche en Sciences Sociales, no 26/27, março/abril, pp. 57-82.
} 


\section{Percepción del trato}

A finales del siglo XIX se separan vejez y ancianidad en el anciano, teniendo lugar el nacimiento de la Gerontología y de la Geriatría, con Metchnicoff en 1903 y Nascher en 1909 como respectivos padres. Pero la sociedad no cambia sustancialmente y el anciano sigue marginado, aunque de una manera más sutil: nuestra civilización, basada en la cultura del trabajo, del rendimiento y del consumo, es una sociedad orientada básicamente hacia la juventud y sus valores. El mayor en la sociedad industrial, generalmente considerado improductivo, tiene relativamente pocas posibilidades para el consumo, por eso es marginado. Ser viejo significa estar envuelto en un halo de mitos y prejuicios, impuestos sobre todo por presiones económicas y sociales, dada la evidente combinación del deterioro físico y mental (MacTavish, 1971). En este contexto, se formuló una pregunta desde la perspectiva de uno de los temas más importantes para el futuro de nuestra sociedad que empieza a envejecer: el respeto a nuestros mayores. Queríamos saber si se sienten valorados, estimados en el seno de la comunidad mossoroense. ¿Cómo trata la sociedad a las personas mayores? A los entrevistados se les pidió que eligieran una de estas cuatro categorías de respuestas: bien, mal, con indiferencia y Ns/Nc. Los resultados aparecen en el Gráfico 14 y confirman otros estudios, como los de Bennett y Eckman (1973) o, más recientemente los de la Fundación Perseu Abramo en Brasil (2007) que investigaron sobre las actitudes negativas hacia los viejos.

En efecto, el hecho más destacable que surge en esta serie es que un $43,40 \%$ de los entrevistados afirmó que el tratamiento que la sociedad les ofrece es de pura indiferencia. Poco más de un tercio de los ciudadanos mayores $(34,40 \%)$ percibe que no reciben el tratamiento que merecen, o sea, es malo. Mientras que un quinto de este grupo de población (20,60\%), afirma que se les trata bien, con respeto. Apenas un pequeño porcentaje, del $1,60 \%$, no quiso responder a la pregunta en cuestión. Coherentemente con la encuesta Mayores en Brasil - Vivencias, desafíos y expectativas en la $3^{a}$ edad (2006), cuando se pregunta cómo son vistos los mayores por la sociedad, la 
investigación descubrió que el $85 \%$ de las personas con más de 16 años tiene prejuicios contra la vejez. En la opinión principalmente de los más jóvenes, el grupo de la tercera edad es incapaz, desfasado y triste.

Por sexos, de acuerdo con la muestra, igualmente hombres y mujeres dicen que la sociedad los trata con hostilidad. Por otra parte, cuando el tema es de buen o mal trato ellas son más optimistas que los varones. Resulta interesante observar que los mayores entre 60-75 años, acusan de modo más intenso el tratamiento manifestado por la sociedad hacia ellos. Los mayores entre 76-90 años, efectivamente fueron los que menos enunciaron comentario alguno sobre tales tratamientos. Quizá, los más afectados tengan contactos sociales en mayores proporciones que los otros. Se puede imaginar que a diario van al supermercado, toman autobuses, van al médico, salen a dar un paseo, entre otras actividades, por tanto lo que ocurre no es otra cosa que, al fin y al cabo, están más expuestos a situaciones típicas de marginación social y en ese sentido, suponemos que tienen más argumentos para quejarse.

De manera similar, cuando se tiene en cuenta el nivel educativo, los entrevistados con las edades anteriormente indicadas con una formación distribuida en las siguientes categorías: a) ninguna instrucción, b) sabe leer y c) nivel fundamental, dicen lo mismo del tratamiento que les es dispensado por la sociedad; esto es, la falta de respeto u hostilidad que perciben los mayores revela que el nivel educativo no influye en esa experiencia. En general, entendemos que los prejuicios y mitos son fundamentalmente fruto del miedo y del rechazo que las personas sienten en relación a la vejez y se producen tanto por razones infundadas como por la proximidad de la muerte. Coincidimos con Neri y colaboradores (2002), en que la superación de los prejuicios y de los mitos es posible a través de dos caminos: el aumento de conocimientos gracias a la educación y al aumento de contacto con los ancianos en contextos igualitarios e interdependientes. "Al contrario de lo que se pueda pensar a primera vista, esas soluciones no pertenecen a esfera de la educación formal y de los medios de información, sino que están en el ámbito de acción de otros segmentos de la sociedad, tales como los científicos, los empleadores, los empresarios, las organizaciones de salud, los 
religiosos, las agencias y los agentes públicos y los políticos" (2002:979). En este sentido, ese ideal social puede ser alcanzado mediante inversión en la divulgación de conocimientos científicos y mediante acciones educativas dirigidas a una nueva cultura sobre la vejez.

\section{GRÁFICO 14}

Percepción del trato

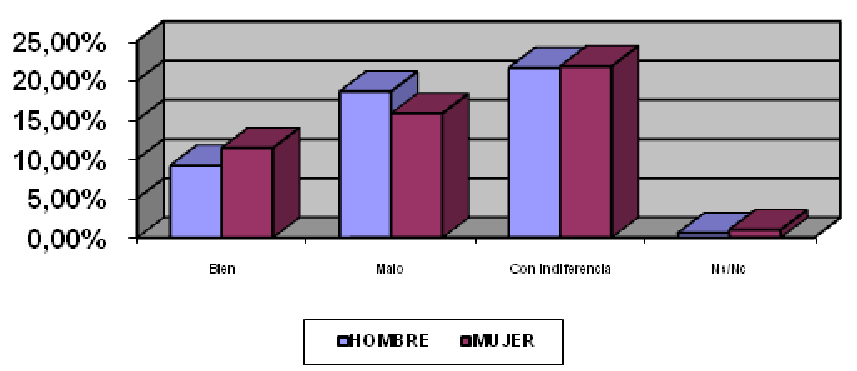

Fuente: Encuesta Perfil Sociológico de la Vejez en Mossoró - Junio 2004 / Junio 2005 (Elaboración de la autora)

\section{Opinión del mayor sobre cuándo debe producirse la jubilación}

Como apunta la Tabla 13 en la sección situación laboral actual, la mayoría de los individuos que componen la presente investigación se encuentra en la situación de jubilado o pensionista (93\%). En general, podemos imaginar que los cambios, experimentados por ellos, interpretados a menudo como un "reposo bien merecido" constituyen una ambigüedad. Los que creen que es el inicio de una vida satisfactoria, se amparan en la teoría de la desvinculación de Cummings y Henry (1961). Como ya se ha dicho, la teoría propone que el envejecimiento es un proceso de retraimiento y desvinculación, universal e inevitable, que además puede ser funcional, tanto para el mayor como para la sociedad. Se afirma que, al desconectarse de sus responsabilidades profesionales, y a veces sociales, encuentran satisfacción y agrado en este hecho. Mientras, los que creen que los mayores con mayor satisfacción son los que permanecen activos, dado que la actividad permite enfrentar la desvinculación social, se amparan en Havighurst y Albrecht (1953). La noción básica de la teoría de la actividad señala que cuanto mayor es la involucración de los mayores en nuevos papeles valorados por la sociedad, mayor es su satisfacción. Además, el hecho de jubilarse supone insatisfacción, la mayoría de las veces, por la restricción de salario, por la pérdida de compañeros de 
trabajo y por la disminución de funciones y roles sociales. Así pues, aunque el tema de la jubilación continúe generando una constante ambigüedad, impuesta sobre todo por la obligatoriedad de la ley, en la presente sección preguntaremos a los entrevistados en qué momento de la vida consideran adecuado retirarse del mundo laboral.

Coherentemente con lo analizado en la sección 1.1., donde los entrevistados subrayan que lo que hace a una persona mayor es la falta de salud, en primer lugar, casi la mitad de los mayores cree conveniente jubilarse sólo cuando la salud impida la realización de una actividad productiva (47,60\%). En segundo lugar, un poco más de una cuarta parte, menciona que se jubilaría cuando fuera conveniente $(28,40 \%)$ y en tercer lugar, con un $22,60 \%$, cuando 10 determine la ley. Apenas el $1,40 \%$ de los entrevistados no supieron o no quisieron contestar a la pregunta (Gráfico 15).

Para la mayoría de los entrevistados, la salud independientemente de la edad, debería ser el vértice para la desvinculación del sistema productivo. La jubilación debería ser definida a partir del momento en que las personas no puedan trabajar más. Exactamente, con la misma cifra (23,80\%), ambos sexos tienen en cuenta el criterio de salud para la adjudicación de la jubilación. La idea de retirase del proceso productivo vía jubilación, en plena disposición y salud, puede comprometer su forma de vida en esa etapa. Lo que debería representar un periodo de tranquilidad en su vida puede transformase en inseguridad, incertidumbres y privaciones, disminuyendo visiblemente su calidad de vida.

Para ambos sexos, de acuerdo con el nivel intelectual, la mayoría de los que tienen pocos estudios opina que los trabajadores sólo deben abandonar su trabajo cuando les falte la salud. Tal manifestación parece estar relacionada con la idea de que, mientras el individuo tenga la habilidad física y mental necesaria para una vida independiente y autónoma no se le debe "retirar" del trabajo forzosamente. Quizá la respuesta esté en los bajos salarios percibidos por los que tienen poca instrucción, lo que efectivamente repercute cuándo se jubilan. Por lo general, las pensiones son casi siempre menores que los sueldos que uno tenía en los últimos años de su vida activa. Además, ser 
anciano, con poca o ninguna formación o cualificación profesional en Brasil (más aún en la región Nordeste) significa sufrir con mayor incidencia la pobreza y sus consecuencias nefastas.

Por otra parte, como se trataba de la opción de jubilarse a partir de la conveniencia, la mayoría lo entendió, bien como abandonar el trabajo tan pronto como sea posible, voluntaria o anticipadamente, bien como que las personas trabajen toda la vida mientras puedan, es decir, más allá de la edad cronológica de sesenta y cinco años determinada legalmente. En base a lo anterior, cabe señalar que, mientras los varones dan el voto al hecho de jubilarse en el momento de la conveniencia, las mujeres refuerzan la práctica de la ley hacia la salida del sistema laboral.

El Programa de Dimisión Voluntaria (PDV) y el Plan de Jubilación Incentivada (PJI) garantizan la desvinculación voluntaria, la flexibilidad para desligarse del trabajo antes de cumplir todas las exigencias laborales. Estos programas vienen siendo aplicados desde los años noventa por empresas del sector público, privado, principalmente por bancos, como una forma menos traumática para el desligamiento necesario de funcionarios, inducido por la reestructuración productiva, la privatización o a veces por la crisis financiera que asola el país. No es necesario hacer muchos esfuerzos para comprobar que este tema es una paradoja, ya que hay individuos que, con tales programas encontrarán un buen cambio de vida, mientras que otros no.

El hecho de no tener una edad fija para jubilarse nos parece un anhelo necesario en el actual sistema de producción. Los mayores deben permitir a los más jóvenes ingresar en el mercado de trabajo. Sin embargo, parafraseando a Amando de Miguel, "algún día se planteará la abolición del retiro forzoso, como hace más de un siglo se planteó la abolición de la esclavitud"273.

273 De Miguel, Amando: La sociedad española 1992-93. Alianza Editorial. Madrid 1992, pp.104106. 


\section{GRÁFIC015}

Opinión del mayor sobre cuándo debe producirse la jubilación

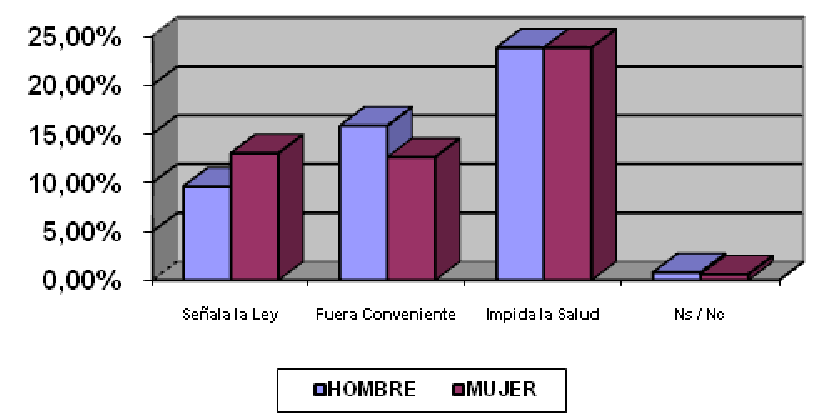

Fuente: Encuesta Perfil Sociológico de la Vejez en Mossoró - Junio 2004 / Junio 2005 (Elaboración de la autora)

\section{Responsabilidad del pago por jubilación según el mayor}

El surgimiento de la Seguridad Social está directamente relacionado con la constitución del obrero como clase social. Para enfrentarse a circunstancias como la enfermedad, la vejez o los accidentes de trabajo, agravados por la explotación capitalista, los trabajadores buscaron una protección colectiva, conquistando, por primera vez en Alemania en 1881, el primer sistema de Subsidio Social de la Historia.

En Brasil, de acuerdo con la Constitución la jubilación integra la Seguridad Social, donde también están la salud y la asistencia social. Es el programa de gobierno más importante en el área social. Tiene como finalidades: 1) ofrecer cobertura en casos de invalidez, muerte o edad avanzada; 2) proteger la maternidad; 3) proteger al trabajador en caso de desempleo involuntario; 4) garantizar el pago de un salario a la familia en situación de privación de libertad del proveedor familiar y 5 ) garantizar las jubilaciones y pensiones. Para asegurar la política social en Brasil, diversas son las fuentes de recursos para la Seguridad Social. De forma directa o indirecta, recibe recursos provenientes de la Unión, de los estados, del Distrito Federal, de los municipios y de diversas contribuciones sociales. El Subsidio procede de dos regímenes: el Régimen General de Subsidio Social (RGPS) y el Régimen Propio del Subsidio Social (RPPS). El primero es administrado por el Instituto Nacional 
de Seguro Social (INSS) y garantiza el pago de beneficios como jubilaciones, pensiones, auxilio de enfermedad, salario de maternidad y el auxilio de reclusión, mientras que el segundo es administrado por la Unión, por los Estados y por los Municipios, garantizando la jubilación y las pensiones de los servidores públicos. Ambos regímenes funcionan bajo la repartición solidaria o de capitalización. El sistema solidario es aquel en el cual el Estado se responsabiliza de la administración de sus presupuestos. Tiene carácter público ya que el Estado asegura el pago integro de beneficios a los trabajadores. $Y$ es solidario porque funciona bajo el principio según el cual las contribuciones de una generación sustentan el pago de las jubilaciones de la generación anterior. El sistema de capitalización es aquel que depende directamente del comportamiento del mercado para sustentarse.

Así pues, considerando que en 2000, en Brasil, el 66,8\% de las personas de 60 o más años de edad estaban jubiladas y el $11,2 \%$ eran pensionistas y, suponiendo que parte de los mayores entrevistados disponen de las informaciones y discusiones del mundo Subsidiario, les preguntamos directamente a quién corresponde la responsabilidad de pagar las jubilaciones o pensiones. Como se observa en el Gráfico 16, mayoritariamente los sujetos (83\%) opinan que ésta es una misión del Estado, un $5,80 \%$ cree que los trabajadores deben ser los responsables, un 3,40\% encargan esta atribución a los empresarios y $7,80 \%$ no supieron o no quisieron contestar la pregunta. No se han observado diferencias significativas en las opiniones de los mayores con relación a las variables independientes.

En general, hombres y mujeres parecen reforzar el concepto de Seguridad Social definido en la Constitución de 1988, que comprende un "conjunto integrado de acciones e iniciativas de los poderes públicos y de la sociedad, destinadas a asegurar los derechos relativos a Salud, Subsidio y Asistencia Social". 


\section{GRÁFICO 16}

Responsabilidad del pago por jubilación según el mayor

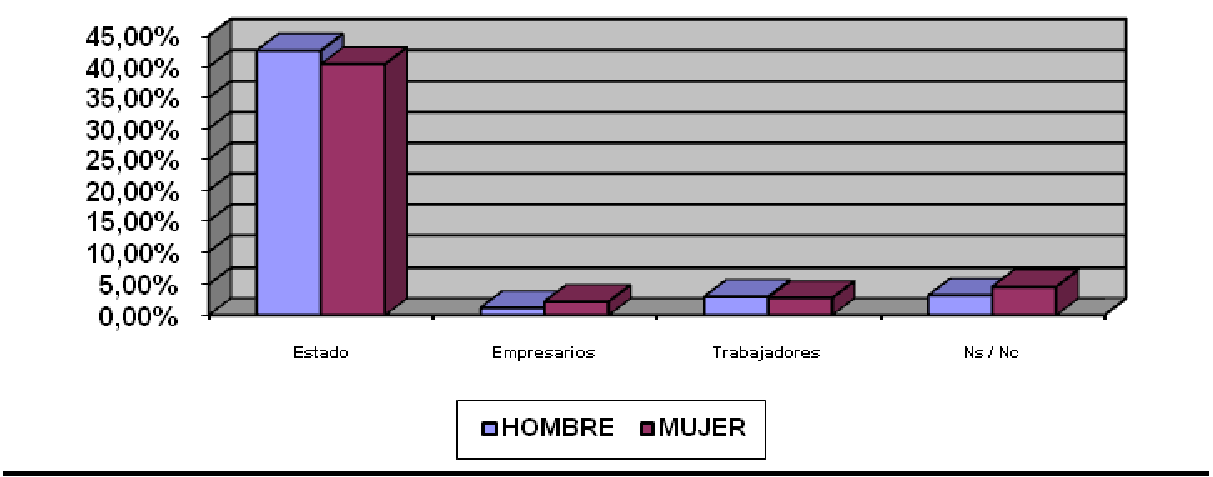

Fuente: Encuesta Perfil Sociológico de la Vejez en Mossoró - Junio 2004 / Junio 2005 (Elaboración de la autora)

\section{Resumen}

Una cuestión bastante compleja que se plantea sobre el mayor en relación a la sociedad es cuándo empieza la vejez. En general, el concepto actual más propagado se refiere a "aquellos, como grupo social, que se retiran del mundo productivo y que tienen que alimentarse sin trabajar" (Casals, 1982:26). Pero, también se valora la vejez en términos sanitarios, psicológicos y antropológicos, entre otros. Sobre ese tema, se observa que gran parte de los mayores opina que la edad cronológica es la responsable del comienzo de la vejez $(36,28 \%)$, frente a los que creen que su llegada viene acompañada de señales fisiológicas, de cambios orgánicos $(33,12 \%)$, sin olvidar los que opinan que ser viejo es algo subjetivo, un estado de ánimo (23,34\%). Con poca representatividad en la encuesta, en términos de roles sociales, uno es viejo cuando lo determinan las leyes o se jubila (2,82\% y 2,21\%, respectivamente). Las respuestas son distintas y justificables. Como el envejecimiento es distinto para hombres y mujeres, ellas se apoyan más en las ideas del estado de ánimo y los cambios funcionales. Quizá, por vivir en un mundo en el que la belleza femenina es valorada insistentemente, de ahí que la sensación psicológica de sentirse o no vieja (Casals, 1982:3), sea la idea más conveniente socialmente. A la inversa, los varones piensan que la edad cronológica marca el inicio de la vejez. Es muy probable que esa idea tenga relación con el estilo de vida adoptado por los hombres y mujeres del Nordeste que envejecen prematuramente, en comparación con las regiones 
del Sur y del Sudeste brasileño. Por último, el concepto de vejez se ampara en las bases legales, que no son casi de ninguna importancia para los mayores entrevistados, como lo han demostrado otras investigaciones.

En el caso de la vejez, la diversidad también se encuentra en la terminología para referirse al grupo de población mayor de 60 años: Viejo, mayor, anciano, persona de edad, tercera edad, entre otros, que a menudo son términos cargados de connotaciones positivas y negativas. Hemos propuesto a los mayores algunas de estas expresiones y el colectivo investigado prefirió el vocablo idoso (lo mismo que mayor en español) en un $42,90 \%$. El segundo en orden de preferencia es tercera edad, con un $31,23 \%$. Para el $11,04 \%$, todas estas expresiones son inadecuadas para referirse a los mayores. $Y$ en menor proporción, los vocablos viejo $(7,57 \%)$ y anciano $(7,26 \%)$ atienden a la nomenclatura de los sujetos. Los varones ancianos prefieren las terminologías viejos y ancianos, en cambio a las mujeres ancianas les gusta ser llamadas por los vocablos mayor y tercera edad. Las distintas posturas subrayadas sugieren que las mujeres toman una aptitud más optimista frente a la vejez y se apoyan en términos no peyorativos que parecen ayudar a enfrentar y superar los cambios desagradables en sus vidas. Por su parte, los varones al elegir la palabra en función del deterioro (viejo), podrían perder el placer de vivir los últimos años de la vida.

Otro tópico conocido y bastante investigado es el tratamiento que da la sociedad a los mayores. Conforme se envejece, el hogar político y social del mayor, presente en la historia de las civilizaciones, ha revelado formas distintas de valoración y actitud para ese colectivo. En la sociedad mossoroense, para el $42,59 \%$ de los mayores participantes en la Encuesta, son tratados con indiferencia por sus conterráneos. Más de un tercio recibe un tratamiento desagradable (35,65\%), y apenas alrededor de un quinto del colectivo cree que se les trata bien $(19,87 \%)$, con respeto y consideración. Excluidos del proceso productivo, su aparente inexistencia y falta de estima en la jerarquía de valores de la sociedad industrial, se convierte en una norma universal. Sumadas las dos primeras actitudes sociales, la cifra ronda los 
cuatro quintos $(78,24 \%)$ de la población anciana insatisfecha con el nivel de tratamiento que reciben en Mossoró. Es un dato negativo, y por lo tanto delicado, que denuncia la discriminación social y la falta de preparación con los 16.510 sexagenarios existentes, y los residentes actuales que llegarán a ser viejos en un futuro próximo. Esta es la única certeza hoy por hoy. Los más afectados por dichos tratamientos son las mujeres y los "viejos-jóvenes" (6075 años) y con poca instrucción educativa.

Un dato bastante interesante, apuntado por los mayores se refiere al momento adecuado para jubilarse. El 49,21\% de ellos lo cree apropiado sólo cuando la salud impida la realización de una actividad productiva. Un poco más de una cuarta parte $(27,13 \%)$, menciona que cuando sea conveniente y un $22,40 \%$ cuando lo determine la ley. En principio, la primera opinión parece relacionarse con la idea de que, mientras el individuo tenga la habilidad física y mental necesaria para llevar una vida independiente y autónoma no se le debe "retirar" del trabajo forzosamente. Por otro lado, quizá la respuesta esté relacionada con los bajos salarios percibidos por los que tienen bajo nivel educativo, lo que efectivamente repercute cuando uno se jubila. Segundo, la defensa del abandono del trabajo tan pronto como sea posible, por parte del empleado o del empleador, puede significar la jubilación antes o más allá de la edad cronológica de sesenta años determinada legalmente. Y por último, al rechazar lo que determina la ley, aquí entendida como la edad cronológica, los mayores refuerzan indirectamente las discusiones en torno al tema.

Para finalizar esta sección, la defensa del Estado como garante del pago de las jubilaciones fue mayoría entre los entrevistados. Garantizar las jubilaciones y pensiones, como derecho asegurado en la Constitución Federal de Brasil (1988), continua de plena actualidad para más de cuatro quintos de los entrevistados. 


\section{El peso del tiempo; trabajo, obligaciones del hogar, tiempo libre y ocio}

Cuando me dicen que soy demasiado viejo para hacer una cosa, procuro hacerla enseguida.

Pablo Ruiz Picasso (1881-1973), Pintor y escultor español.

\section{Ocupación del tiempo libre}

Es muy común encontrar a los mayores de paseo por las calles de Salamanca (España). Dos razones sustentan tal hecho: El turismo y el número de personas mayores en la provincia. Según el informe del Imserso (2004), cerca de un 23 por ciento de la población salmantina son personas mayores, cifra por encima de la media española, que es de un 17 por ciento ${ }^{274}$. Ver a tantos mayores ${ }^{275}$ disfrutando de su tiempo de ocio, echando un vistazo a los escaparates, tomando un café, jugando a las cartas o a la petanca, participando en los programas socioculturales, o simplemente sentados en los parques, jardines y en los espacios abiertos, forma parte del escenario cotidiano de la hermosa ciudad histórica y monumental de Castilla y León. Para los grupos de turistas mayores, que invaden cotidianamente la ciudad, las conductas de ocio generalmente posibilitan el crecimiento y desarrollo personal (Dumazedier: 1971). Así que, encontrarlos en la calle aprovechándose de estos momentos de encuentro e integración entre ellos y los transeúntes, transformando el tiempo libre en ocio constructivo, constituye un componente del bienestar y de la calidad de vida. (Vega, 1998).

Teniendo en cuenta la importancia del tiempo libre y el ocio para los mayores, nos interesa especialmente conocer qué actividades desarrollan en

\footnotetext{
274 Salamanca, una provincia cada vez más envejecida, DGratis, semana del 29 de julio al 4 de agosto de 2005. p. 21.

Martín, Alberto Boronat (1989): La evolución demográfica de Valladolid en el contexto de Castilla y León, en Hacia una vejez nueva - I Simposio de Gerontología de Castilla y León (cods.) Juan Manuel Almarza Meñica y Jesús Galdeano Aramendia, ed. San Esteban.
} 
su tiempo libre, para posteriormente poder proponer actividades socioculturales y educativas que contribuyan a llenar y a enriquecer el tiempo de los ancianos en la ciudad de Mossoró.

Dentro de las categorías del tiempo libre y ocio adoptamos las de Weber (1969) y Dumazedier (1971). El primero sostiene que se trata de un período de vida en que los individuos se sienten libres de determinaciones externas, sobre todo en forma de trabajo asalariado. En relación al ocio, el segundo autor lo clasifica como un conjunto de ocupaciones a las que las personas pueden dedicarse de manera voluntaria, sea para descansar, divertirse o desarrollarse, después de liberarse de sus obligaciones profesionales, sociales y familiares.

En base a los datos obtenidos (Tabla 22), las actividades que más realizan los sujetos cuando disponen de tiempo libre son: estar en casa, más de cuatro quintas partes afirman que este es su modo de vida a diario (84\%). En menor proporción, apenas un $1,80 \%$ suele ir al cine o al teatro. Dos tercios ven la televisión diariamente (64\%), un $36,40 \%$ de los mayores oye la radio. Alrededor de un tercio suele dar paseos y cuidar de los nietos (29,20\% y $27 \%$ respectivamente), y un $19,80 \%$ se dedica a manualidades. Cerca de una cuarta parte dice destinar momentos para leer el periódico o revistas $(22,20 \%)$, y en porcentajes más bajos juegan a las cartas o juegos de mesa (9,80\%). Muy pocos van a bares y cafeterías (6,60\%). Otros porcentajes inferiores a estas cifras acuden a conferencias y salen de fiesta $(4,40 \%$ y $4,20 \%$ respectivamente). Por último, un $18,40 \%$ se ocupa con otras actividades a diario. Posiblemente, por razón de su edad y condición socio-económicocultural, asisten a centros de convivencia o establecimientos similares, a la Iglesia para asistir a oficios religiosos, hacen ejercicio físico o no hacen nada.

Hay que recordar que alrededor de tres cuartas partes de los entrevistados tienen pocos estudios y poco más de la mitad gana entre uno y dos salarios mínimos. De ese modo, se observa cotidianamente que los mayores de 60 años suelen: estar en casa, ver la tele, oír la radio, pasear, cuidar y atender a las necesidades de los nietos, dedicarse a manualidades y hacer lecturas diversas. De modo similar, en Salamanca, según el Informe del Imserso, “las 
actividades que realizan con más frecuencia son ver la televisión, reunirse con los amigos, leer, ver a familiares que viven en otro domicilio o estar con sus nietos"276. Como cabría esperar, las actividades que suelen realizarse con menor frecuencia se refieren a las de los más jóvenes y las que exigen una inversión económica, como asistir a espectáculos, ir al cine, acudir a conciertos, conferencias, bares y cafeterías. Según Gil Villa (1998), por razón del capital, las prácticas del empleo del tiempo libre quedan pendientes. Curiosamente, una actividad muy propia de los mayores, como jugar a las cartas o juegos de mesa, no forma parte de las preferencias, sobre todo en los varones entrevistados. Es posible que haya pocos adeptos, dado que esta actividad no se integra culturalmente al tipo de diversión local.

Gil Villa (1998:42ss) percibe en la sociedad actual cierta desigualdad en el ámbito del ocio. En primer lugar, estarían los que practican actividades que no exigen ninguna inversión económica - como ver la televisión, oír la radio o dedicarse a manualidades - y los que realizan actividades que sí la exigen, como asistir al cine o acudir a conciertos. En segundo lugar, asociado a los recursos culturales, los que poseen pocos estudios, necesitan una competencia cultural que la mayoría de los entrevistados no posee. Razones como las que anteceden nos llevan a deducir que el ocio y el tiempo libre, para la mayoría de los ancianos mossoroenses, pueden llevar a vivir negativamente el tiempo libre, al contrario que el desarrollo personal planteado por Dumazedier (1971).

En función del género, se observa que las mujeres con más frecuencia, disfrutan del cine, pasean, cuidan de los nietos, se dedican a manualidades, acuden a conferencias y salen a fiestas. Efectivamente, la supuestas actividades a las que dedican las mujeres su tiempo libre, fuera del hogar, están vinculadas a las actividades de los centros de convivencia para mayores, dado que ellas participan en mayor proporción que los hombres. En menor medida que los hombres, las entrevistadas suelen acudir a los bares o cafeterías, juegan a las cartas o juegos de mesa y escuchan la radio. De

276 Semanario DGratis correspondiente a la semana del 5 al 11 de agosto de 2005, p. 21. 
costumbres semejantes, ambos suelen estar en casa, se dedican a lecturas y ven la tele.

Observaremos que según el sexo, las mujeres son quienes tienen mayor lugar en el espacio familiar, a pesar de la participación en los centros de la Tercera Edad. Es evidente la diferencia del empleo del tiempo libre por parte de los hombres y mujeres ancianos. Las actividades continúan siendo impartidas conforme a los papeles de sexo establecidos. Por ejemplo, sólo 1 varón por cada 1,64 mujeres se ocupa del cuidado de los nietos. Por cada 4,50 hombres sólo 1 mujer acude a las cafeterías o bares y por cada 3,45 hombres apenas 1 mujer disfruta de los juegos de mesa. Sin embargo, las actividades para ambos sexos parecen sedentarias y pasivas (ver la tele, escuchar la radio, quedarse en casa) y escasamente estimulantes para el desarrollo personalcultural (ir a conciertos, teatros). Según Acosta-Orjuela, “la fuerte adhesión de los mayores a la televisión puede ser explicada por su valor como recurso alternativo y socialmente aceptable para la satisfacción de necesidades psicosociales que no pueden colmarse por medios naturales. Ese tipo de sustitución, llamada por algunos de 'compensación', sería especialmente aplicable a los mayores que experimentan limitaciones de actividad o pérdidas económicas, sociales y físicas. Al revés, los sujetos más adinerados y cultos encuentran mayores posibilidades de entretenerse en conductas de ocio activas: ir al cine, teatro, conciertos" (2002:983).

En base a los datos obtenidos, los mayores entrevistados parecen carecer de una propuesta placentera y estimulante para el desarrollo personal, situación también confirmada en el Gráfico 45, cuando los servicios mencionados anteriormente destacan el desinterés o la falta de atracción.

Ofrecer buenas actividades de ocio, a fin de satisfacer las necesidades culturales, sociales y personales del mayor en Mossoró, permitiría garantizar un envejecimiento saludable. Entre los servicios existentes, ampliar el proyecto "Cuente un cuento, gane dos cuentos" (2005), permite a los ancianos mossoroenses aportar su contribución social a través de sus experiencias y memorias, como agentes transmisores de costumbres y conocimientos adquiridos para la revitalización y valoración de la cultura 
popular. Más allá de permitir a los participantes conocer las manifestaciones folclóricas, funciona como instrumento de socialización, cultura, arte, educación y recreación.

Según Kalish (1983:177), teniendo en consideración los ingresos, la salud, la capacidad de movimiento y las preferencias personales del individuo, se proponen plantear algunas sugerencias como fomentar el voluntariado social, crear clubes de jubilados, favorecer la vinculación de los ancianos con la sociedad, hacer que participen en sus actividades, entre otros. (Quintana Cabanas $^{277}$ ).

En consecuencia el anciano tiende a transformarse en un nuevo actor social, partícipe del conjunto de discursos que trata de los desafíos que la provincia afronta, sabiendo que el país será, en pocos años, uno de los mayores conglomerados de personas mayores de 60 años del mundo, ni dejará de hablar de política en momentos de elecciones, o de la plataforma de los partidos. Es un actor que, con certeza, también estará presente en la definición de nuevos mercados de consumo, trabajo y ocio.

\section{TABLA 22}

\section{Según en qué emplea su tiempo libre}

\begin{tabular}{|c|c|c|c|c|c|c|}
\hline \multirow{2}{*}{$\begin{array}{l}\text { ACTIVIDADES } \\
\text { FRECUENTES }\end{array}$} & \multicolumn{2}{|c|}{ AMBOS SEXOS } & \multicolumn{2}{|c|}{ HOMBRES } & \multicolumn{2}{|c|}{ MUJERES } \\
\hline & $>60$ & $\%$ & $>60$ & $\%$ & $>60$ & $\%$ \\
\hline Estar en casa & 420 & 84,00 & 207 & 41,40 & 213 & 42,60 \\
\hline $\begin{array}{l}\text { Acudir a bares, } \\
\text { cafeterías... }\end{array}$ & 33 & 6,60 & 27 & 5,40 & 6 & 1,20 \\
\hline $\begin{array}{l}\text { Leer el periódico, } \\
\text { revistas, libros }\end{array}$ & 111 & 22,20 & 54 & 10,80 & 57 & 11,40 \\
\hline Ir al cine, teatro & 9 & 1,80 & 3 & 0,60 & 6 & 1,20 \\
\hline Ver la televisión & 320 & 64,00 & 158 & 31,60 & 162 & 32,40 \\
\hline Pasear & 146 & 29,20 & 63 & 12,60 & 83 & 16,60 \\
\hline Cuidar de los nietos & 135 & 27,00 & 51 & 10,20 & 84 & 16,80 \\
\hline Oír la radio & 182 & 36,40 & 96 & 19,20 & 86 & 17,20 \\
\hline Manualidades & 99 & 19,80 & 22 & 4,40 & 77 & 15,40 \\
\hline $\begin{array}{l}\text { Jugar a las cartas, } \\
\text { dominó }\end{array}$ & 49 & 9,80 & 38 & 7,60 & 11 & 2,20 \\
\hline $\begin{array}{l}\text { Acudir a } \\
\text { conferencias }\end{array}$ & 22 & 4,40 & 6 & 1,20 & 16 & 3,20 \\
\hline $\begin{array}{l}\text { Ir a fiestas, } \\
\text { conciertos }\end{array}$ & 21 & 4,20 & 6 & 1,20 & 15 & 3,00 \\
\hline Otras cosas & 92 & 18,40 & 40 & 8,00 & 52 & 10,40 \\
\hline
\end{tabular}

* Pregunta de elección múltiple, por lo tanto suma más de $100 \%$.

Fuente: Encuesta Perfil Sociológico de la vejez en Mossoró - Junio 2004 / Junio 2005 (Elaboración de la autora) 


\section{Qué escuchan en la radio}

Como comprobamos en la Tabla 22, la segunda cosa que suelen hacer las personas mayores cuando disponen de tiempo libre es escuchar la radio. En el territorio nacional, entre los medios de comunicación de masas, éste recurso después de la televisión, es el más común en los domicilios brasileños, por lo que ocupa efectivamente el segundo lugar. Más del $80 \%$ de la población del país escucha la radio (AM o FM) por lo menos una vez por semana (Censo, IBGE: 2003).

En Brasil, incluso con el surgimiento de la televisión, la radio no ha dejado de tener su importancia, pese a experimentar un fuerte declive, especialmente por el abandono progresivo y constante del mercado publicitario. La radio, se vio obligada a transformarse, buscando nuevos caminos de viabilidad económica para sus programaciones, abriendo nuevos mercados que posibilitasen su supervivencia.

A pesar de las previsiones negativas, la radio cumple con su destino y su vocación real, y mantiene, hasta nuestros días, una cierta soberanía entre los medios de comunicación de masas, por la forma objetiva y audible de divulgar las noticias. Todos, sin distinción de clase o raza, escuchan la radio. Su mayor virtud está en su singular naturaleza sonora. Trabajar con el imaginario de las personas, a través de la música o de la información, además de proporcionar la sensación de tener una compañía constante, son características reseñables por las cuales tiene tantos adeptos, sobre todo, entre los mayores.

Cuando se pregunta a las personas con 60 años o más por sus preferencias respecto a la programación radiofónica, lo más frecuente es, por este orden: más de dos tercios afirmaron que les gusta, en primer lugar, oír los informativos, las noticias $(66,20 \%)$, como segunda opción de interés está escuchar música $(46,28 \%$ ) y en tercer lugar, los adeptos de la radio suelen escuchar los programas religiosos $(45,40 \%)$. Los de menos interés, pero de real significación, son los programas deportivos $(24,84 \%)$, políticos $(21 \%)$, los seriales o novelas $(8,60 \%)$ y los culturales $(6,20 \%)$ (Tabla 23 ). 
Los tres programas que suelen escuchar los hombres son: los informativos $(37,40 \%)$, los deportivos $(23,04 \%)$ y los musicales $(19,19 \%)$, mientras que las mujeres prefieren los religiosos (30\%), los informativos $(28,80 \%)$ y los musicales (24,84\%). También se puede destacar la preferencia de los varones por los programas políticos $(16,60 \%)$ superando a las mujeres $(4,40 \%)$ en el mismo campo. Así pues, se puede confirmar que algunos gustos 0 predilecciones para hombres y mujeres están muchas veces culturalmente establecidos. Los de menor interés para ambos sexos son los seriales y los programas culturales.

Como el interés de oír la radio es frecuente entre los mayores, a nuestro modo de ver, en los espacios radiofónicos bien podría haber más locutores mayores, anuncios publicitarios o incluir programas dedicados a las personas mayores. Proponer a la comunidad local conocimientos prácticos y teóricos, relativos al proceso de envejecimiento, para envejecer mejor y disminuir los prejuicios y mitos hacia los mayores, atendería a la exigencia del Art. 24 de la Ley $n$. 10.741 , de $1^{\circ}$ del octubre de $2003^{278}$.

\section{TABLA 23}

Según la preferencia en la programación radiofónica

\begin{tabular}{|l|c|c|cccc|}
\hline $\begin{array}{c}\text { PROGRAMA DE } \\
\text { RADIO }\end{array}$ & \multicolumn{2}{c}{ AMBOS SEXOS } & \multicolumn{2}{c|}{ HOMBRES } & \multicolumn{2}{c|}{ MUJERES } \\
\hline Musicales & 230 & $\%$ & $>60$ & $\%$ & $>60$ & $\%$ \\
\hline Informativos & 331 & 46,28 & 110 & 22,04 & 121 & 24,24 \\
\hline Seriados (novelas) & 40 & 86,20 & 187 & 37,40 & 144 & 28,80 \\
\hline Culturales & 31 & 6,20 & 10 & 2,00 & 30 & 6,60 \\
\hline Deportivos & 124 & 24,84 & 115 & 23,04 & 9 & 1,80 \\
\hline Religiosos & 227 & 45,40 & 77 & 15,40 & 150 & 30,00 \\
\hline Políticos & 105 & 21,00 & 83 & 16,60 & 22 & 4,40 \\
\hline Otros & 32 & 10,09 & 7 & 2,21 & 25 & 7,88 \\
\hline $\begin{array}{l}\text { No escucha la } \\
\text { radio }\end{array}$ & 84 & 16,80 & 28 & 5,60 & 56 & 11,20 \\
\hline
\end{tabular}

\section{Preferencia hacia los programas televisivos}

Como ya se indicó anteriormente en la Tabla 22, los mayores afirman ver la televisión como el primer pasatiempo. La pequeña pantalla está presente en el $96,21 \%$ de los domicilios de nuestros entrevistados (Ver Cuadro I), como lo 
está para el 97\% de los brasileños (Censo, IBGE: 2003). Su fuerte atractivo, la transmisión instantánea de la imagen, unida a la seducción de la diversión, hace que transmita una fuerte carga emocional, que fácilmente capta la atención de los telespectadores. Bajo el imperativo de informar, desde luego, pero en el marco del placer $^{279}$, se percibe frecuentemente una vivaz competencia entre canales que ofrecen nuevos atractivos y encantos para todos los gustos.

De acuerdo con las contestaciones de los propios entrevistados (véase la Tabla $24)$, la mayoría prefiere ver los informativos televisados $(72,20 \%)$, como segunda opción eligen las telenovelas $(53,60 \%)$ y en tercer lugar los programas religiosos $(45,20 \%)$. También presentan proporciones muy significativas los que afirman ver los programas deportivos $(30,80 \%)$, las películas $(16,40 \%$ ) y los programas musicales $(14,02 \%)$. Todas las demás preferencias fueron citadas en proporciones inferiores al $10 \%$.

Por edad, generalmente los que ven más la televisión a diario son los hombres entre 60-75 y las mujeres entre 60-80 años. Con respecto al género, en los hombres están por orden de preferencia, los informativos televisados $(40,40 \%)$, los deportivos $(28,40 \%)$ y las telenovelas $(17,40 \%)$. Mientras, en las mujeres se decantan por las telenovelas $(36,20 \%)$, los informativos $(31,80 \%)$ y los programas religiosos $(30,20 \%)$. Estos datos confirman los de la investigación de Acosta-Orjuela (2002), “las funciones más valoradas de la tele para un grupo de mayores brasileños fueron consonantes con las que aparecen en muestras extranjeras, esto es, acentúan la información, el entretenimiento y el mantenimiento de hábitos" (2002:985). Bajo la condición de estado civil, los ancianos casados y viudos son los que acuden más a los informativos televisivos. En cuanto a los programas deportivos y series son más aficionados los casados. Las mujeres ancianas solteras, casadas y viudas ven más las series, mientras que sólo las casadas y viudas suelen ver los informativos televisivos y los programas religiosos.

279 Lipovetsky, Gilles (1993): La cultura de la moda media, en El imperio de lo efímero, Barcelona, Anagrama, p. 262. 
Como se ve, la pantalla televisiva como medio y uno de los principales vehículos de la cultura contemporánea, atrae masivamente a hombres y mujeres sin distinciones de sexo o edad. Pero, tratándose del colectivo de mayores, sostiene Acosta-Orjuela (2002) que, "ningún grupo de edad supera a los mayores en el consumo de TV, conforme apuntan estudios realizados en diversas partes del mundo. Las investigaciones indican que las personas mayores mantienen los más altos niveles de exposición a la TV y que dedican más tiempo a ese medio que a cualquier otra actividad, excepto al sueño" (2002:982). La programación cultural o informativa, que supuestamente adopta una perspectiva de ocio para los mayores combina una serie de factores, entre ellos el socioeconómico, que aparentemente cumple el papel de distracción y diversión. Lástima que la televisión brasileña no ofrezca casi ninguna programación específica, a nivel nacional, para los mayores. Son pocos los presentadores, los anuncios publicitarios y actuaciones de mayores en series de TV. "Como telespectadores incondicionales, bien merecerían un trato adecuado, como lo reciben sobre todo los niños y jóvenes". ${ }^{280}$ Fomentar programas con finalidad informativa, educativa, artística y cultural, para el público en proceso de envejecimiento en Mossoró, no sería imposible, dado que recientemente se ha instalado una señal de televisión en abierto en la provincia.

\section{TABLA 24}

Según la preferencia en la programación televisiva

\begin{tabular}{|l|c|c|cccc|}
\hline $\begin{array}{l}\text { PROGRAMA DE } \\
\text { TELEVISIÓN }\end{array}$ & \multicolumn{2}{c}{ AMBOS SEXOS } & \multicolumn{2}{c}{ HOMBRES } & \multicolumn{2}{c|}{ MUJERES } \\
\hline Musicales & 70 & 14,02 & 36 & 7,21 & 34 & 6,81 \\
\hline Informativos & 361 & 72,20 & 202 & 40,40 & 159 & 31,80 \\
\hline $\begin{array}{l}\text { Seriados } \\
\text { (novelas) }\end{array}$ & 268 & 53,60 & 87 & 17,40 & 181 & 36,20 \\
\hline Culturales & 42 & 8,40 & 19 & 3,80 & 23 & 4,60 \\
\hline Deportivos & 154 & 30,80 & 142 & 28,40 & 12 & 2,40 \\
\hline Religiosos & 226 & 45,20 & 75 & 15,00 & 151 & 30,20 \\
\hline Debates & 35 & 7,00 & 22 & 4,40 & 13 & 2,60 \\
\hline Largometraje & 82 & 16,40 & 46 & 9,20 & 36 & 7,20 \\
\hline Concursos & 11 & 2,20 & 4 & 0,80 & 7 & 1,40 \\
\hline Otros & 38 & 7,60 & 13 & 2,60 & 25 & 5,00 \\
\hline No ve la TV & 32 & 6,40 & 18 & 3,60 & 14 & 2,80 \\
\hline
\end{tabular}

280 Confer. Art. 24 de la Ley n ${ }^{\circ} 10.741$, de $1^{\circ}$ de Octubre de 2003 en Franco, P. A.: Estatuto do Idoso Anotado, Editora de Direito, $1^{\text {a }}$ edición 2004, p. 54. 


\section{Actividad física que practica}

Sabemos que con el paso de los años, el desgaste físico se torna más acentuado, a pesar de que, probablemente, el ser humano comienza a envejecer desde el nacimiento. Sin embargo, como en las primeras etapas de la vida el organismo posee una capacidad más grande de restablecerse de los daños, minimizando el desgaste, casi no se percibe. En la vejez, la disminución de las capacidades físicas viene acompañada de cambios psicológicos y de comportamiento. Así, el “envejecimiento" no es simplemente un proceso físico, sino también un estado de ánimo. Por ser "la vejez un proceso vulnerable, los ancianos corren más riesgos que los de cualquier otra edad, con excepción de la infancia"281. De ese modo, es prudente prepararse de manera sensata y equilibrada para construir una vejez sana. Adoptar comportamientos y estilos de vida saludables desde la juventud es importante, señalan científicos como Kalish, (1982) y Neri (1999), dedicados al estudio y a los problemas de los mayores. La práctica de ejercicio es esencial en todas las fases de nuestra vida y aún más importante en la ancianidad, donde hay una pérdida de aptitud física con el debilitamiento de los músculos, que se atrofian lentamente y ganan grasa. Sin embargo, es posible minimizar los efectos del tiempo. El ejercicio físico en la tercera edad mantiene y mejora las actividades de la vida diaria como ducharse, hacer las compras y conducir. Los ejercicios físicos también son recomendados en la ancianidad para mejorar el ánimo y bienestar de los mayores.

Por lo descrito anteriormente, y como se señala más adelante (Tabla 25), en líneas generales, cuando se preguntó a los entrevistados si suelen practicar alguna actividad física, con la pretensión de evaluar la salud y el estado de ánimo de este colectivo, más de la mitad (56\%) menciona no practicar ninguna actividad física, un 33,60\% del total de entrevistados afirma ser aficionado a la caminata y una escasísima representación la forman los

281 Oliveira, Ricardo C. S. (1999): Terceira. Idade: do repensar dos limites aos sonhos possíveis, São Paulo: Paulinas, p. 55. 
sujetos que pedalean $(4,20 \%)$, practican hidrogimnasia $(1,80 \%)$, hacen gimnasia $(0,80 \%)$, natación $(0,20 \%)$, yoga $(0,20 \%)$ y otras actividades $(1,40 \%)$.

Disfrutar del ejercicio físico tras la jubilación parece adecuado, pues, una vez libres de las obligaciones laborales y de parte de las tareas domésticas, se dispone del tiempo suficiente para su práctica. En la distribución de los ejercicios físicos en la población anciana entrevistada, lo primero y más significativo que se observa son las diferencias en la distribución del ejercicio físico según el sexo. Entre los hombres los porcentajes son superiores. El índice para los varones mayores de sesenta años es de un $22,40 \%$ y el de las mujeres es de un 19,80\%. En contrapartida, las mujeres presentan superioridad en las cifras de sedentarismo. Afirman no practicar ninguna actividad el $26,60 \%$ de los varones, mientras que de las mujeres lo hacen un $29,40 \%$. La única modalidad significativamente practicada por los hombres y mujeres ancianos entrevistados es la caminata $(33,60 \%)$. Sus mayores adeptos son las mujeres casadas y viudas con edades entre 65-75 años y los hombres casados con edades entre 66-70 años. $Y$ entre los que no se adhirieron a ninguna práctica física deportiva, en gran proporción, están los sujetos masculinos casados entre 60-75 años y las mujeres casadas de entre 60-65 años y viudas de entre 71-80 años.

No obstante, a nivel del país, hombres y mujeres están abandonando el sedentarismo. Gran parte de los mayores, independientemente de la clase social, hace caminatas por las calles, plazas y espacios específicos de todo Brasil. Ésta práctica se ve confirmada en 2006 por el estudio de la Fundación Perseu Abramo que revela el perfil de los mayores en Brasil.

En Mossoró, a tenor del panorama presentado, todo parece indicar una vejez orientada casi al sedentarismo. Una de las posibles hipótesis que explican tal hecho en el que se encuentran los ancianos, es la limitación económica vigente. Los parcos ingresos son cada vez más restrictivos para un ocio básico. La prioridad para atender las necesidades vitales más básicas, y a menudo también de su familia, como vivienda, alimentación, educación, salud, 
vestuario, higiene y transporte, compromete una rama esencial del desarrollo del envejecimiento sano. Quizá de ese modo, la actividad física caminata, sea la única accesible para este estrato social ${ }^{282}$. Otra hipótesis sería que esta generación no está familiarizada con la práctica del cuidado del cuerpo. La cultura de esta generación, nacida en la primera mitad del siglo $\mathrm{XX}$, es muy diferente de las nuevas generaciones, donde la preocupación con el "culto al cuerpo", como rasgo característico de las sociedades contemporáneas, es algo que no comulga con los viejos valores culturales sobre el cuerpo y salud.

Quizá, el retorno de las actividades del "Mossoró camina con la gente" empiece a crear una nueva cultura de valorización del mayor para que se revitalice física, mental y psicológicamente. Ello se puede ver incrementado con la gimnasia al aire libre, como lo era antaño. También se pueden ofrecer actividades deportivas a los mayores, estimuladas por el poder público, mediante convenios con los clubes o asociaciones del comercio y la industria. También de la Universidad, que posee espacios para tales prácticas a través de cursos de educación física. Estudios nuevos del Massachusetts Institute of Technology (MIT), en Boston, indican que los cuidados de la salud posibilitan la recuperación de algunos años sin declive de las funciones mentales, sin pérdida muscular, cáncer o dolencias cardiovasculares.

\footnotetext{
$282 \quad$ En Mossoró el proyecto "Camina Mossoró" impulsa a llevar a cabo hábitos saludables en la práctica de actividades deportivas y de ocio para todos los ciudadanos mossoroenses, sobre todo para los ciudadanos de bajo poder adquisitivo. Creado hace menos de una década por la Secretaría Municipal de Ciudadanía y ejecutado por profesionales de las gerencias de Desarrollo Social, Educación y de Deporte, Salud y Fundación Municipal de Cultura, con el apoyo de la Secretaría del Desarrollo Territorial y Medio Ambiente, el "Camina Mossoró", estuvo instalado en diez espacios públicos de la ciudad, entre ellos los barrios: Alto da Conceição, São Manoel, Ilha de Santa Luzia, Costa e Silva, Belo Horizonte, Abolição II y III, de Santa Delmira. Actualmente, con la nueva gestión municipal (2005-2008), el proyecto, que pasó a denominarse "Mossoró camina con la gente", estaba siendo ejecutado solamente en un único espacio público de la provincia. La discontinuidad o la disminución del radio de actuación del proyecto puede hacer que disminuyan los ánimos de los mayores para la práctica de actividades físicas.
} 


\section{$\underline{\text { TABLA } 25}$}

Según la actividad física que practica

\begin{tabular}{|c|c|c|c|c|c|c|}
\hline \multirow{2}{*}{$\begin{array}{l}\text { TIPO DE } \\
\text { ACTIVIDAD } \\
\text { FÍSICA }\end{array}$} & \multicolumn{2}{|c|}{ AMBOS SEXOS } & \multicolumn{2}{|c|}{ HOMBRES } & \multicolumn{2}{|c|}{ MUJERES } \\
\hline & $>60$ & $\%$ & $>60$ & $\%$ & $>60$ & $\%$ \\
\hline Gimnasio & 4 & 0,80 & 2 & 0,40 & 2 & 0,40 \\
\hline Natación & 1 & 0,20 & 1 & 0,20 & - & - \\
\hline Yoga & 1 & 0,20 & 1 & 0,20 & - & - \\
\hline Caminata & 168 & 33,60 & 85 & 17,00 & 83 & 16,60 \\
\hline Bicicleta & 21 & 4,20 & 19 & 3,80 & 2 & 0,40 \\
\hline $\begin{array}{l}\text { Hidrogimnás } \\
\text { tica }\end{array}$ & 9 & 1,80 & 1 & 0,20 & 8 & 1,60 \\
\hline Otro & 7 & 1,40 & 3 & 0,60 & 4 & 0,80 \\
\hline No practico & 280 & 56,00 & 133 & 26,60 & 147 & 29,40 \\
\hline Ns / Nc & 9 & 1,80 & 5 & 1,00 & 4 & 0,80 \\
\hline TOTAL & 500 & 100,00 & 250 & 50,00 & 250 & 50,00 \\
\hline
\end{tabular}

\section{Frecuencia con la que sale de vacaciones}

El trabajo ocupa generalmente, un espacio muy importante en nuestra vida. Por él definimos nuestro modo de comportamiento, moldea nuestros pensamientos, nos permite comprar bienes y servicios, hacer amigos y a veces realizar nuestros deseos más íntimos o absurdos. Conquistar un puesto en el mundo laboral significa respeto y estatus. La realización profesional parece envanecer nuestro lado personal. Pero, descansar, relajarse, alejarse de los problemas temporalmente para después continuar o empezar algo nuevo, es sumamente importante. Según Andrews ${ }^{283}$, las vacaciones son fundamentales para el equilibrio del organismo. Y ese equilibrio, más allá de prevenir enfermedades, proporciona condiciones para que el profesional produzca más cuando regrese al trabajo.

En ésta sección y en la sucesiva, identificamos en nuestro colectivo de mayores primero, la frecuencia con la que disfrutan de vacaciones (Tabla 26) dado que nuestro entorno contempla también a los trabajadores activos y en la segunda los factores por los que los mayores entrevistados no suelen salir de vacaciones (Tabla 27). ¿Habrá ancianos que nunca salgan de vacaciones? 
¿Hombres y mujeres disfrutan por igual de este beneficio? ¿Por qué tan solo salen una vez de vacaciones? Lo veremos a continuación.

Esta cuestión, con posibilidad de algunas respuestas, ofrece una imagen según la cual, entre las personas entrevistadas con edades comprendidas entre 6090 años, apenas el 13,80\% afirman gozar de vacaciones todos los años. También están los que informan de que nunca han experimentado tal momento $(56,20 \%)$ y hay un $20,40 \%$ para el que gozar de este beneficio es algo infrecuente. Añadiendo la dimensión de género, hay algunas diferencias. Las mujeres suelen salir de vacaciones más que los hombres ( $8 \%$ frente a $5,80 \%$ ) pero tampoco hay diferencias significativas cuando el tema es salir una vez $u$ otra $(10 \%$ frente a $10,40 \%)$ y nunca $(28,40 \%$ frente a $27,80 \%$ respectivamente).

En una investigación exclusivamente sobre personas de 60 años o más, puede no ser extraño el hecho de que gran parte de hombres y mujeres $(27,80 \%$ y $28,40 \%$ respectivamente), nunca salgan de vacaciones, ya que la jubilación constituye unas "vacaciones permanentes". Pero, si el $28,40 \%$ de las mujeres afirma no haber disfrutado nunca de ese beneficio y el $31,60 \%$ se denomina ama de casa (Ver tabla 25), suponemos que en este grupo algunas amas de casa, por su condición de trabajo no asalariado, no saben qué es estar de vacaciones. Para los que todavía están en activo $(19,20 \%)$, imaginamos que apenas un $5,40 \%$ no goza del beneficio, ya que un $13,80 \%$ de estos declararon continuar disfrutando de las vacaciones. En este último caso, quizá no tengan vacaciones por poseer un negocio propio, un trabajo no asegurado legalmente o escasez de ingresos. Los restantes que no siguen la regla anual del descanso $(20,40 \%)$, evidencian porcentajes muy cercanos entre ambos sexos. De forma más general, ante la alternativa de gozar de vacaciones, solo un $34,20 \%$ de los mayores declara hacerlo.

Del análisis de todas estas características, que conforman las vacaciones disfrutadas por las personas mayores, se deduce poca existencia de la práctica del descanso ya que las vacaciones han sido creadas en la sociedad industrial, como descanso temporal de una actividad habitual, especialmente del trabajo remunerado o de los estudios, puede que estos elementos, en cierta medida, 
no incluyan a los mayores entrevistados, sobre todo por su condición de jubilados, pensionistas y amas de casa. Pero, ¿Qué puede proponerles la sociedad mossoroense? Quizá, el Programa Viaja Más Mejor Edad Hospedaje ${ }^{284}$, creado por el Ministerio de Turismo en 2007, incluido en el Plan Nacional de Turismo 2007-2010, pueda interesar y posibilitar a nuestros mayores materializar sus sueños y deseos de disfrutar de unas vacaciones con viajes de bajo coste y por ende, incidir directamente en el envejecimiento activo de las personas mayores, así como sucede con el programa de Vacaciones para Mayores en España con casi una década de existencia.

\section{TABLA 26}

Según la frecuencia con la que sale de vacaciones

\begin{tabular}{|l|c|c|cccc|}
\hline $\begin{array}{l}\text { FRECUENCIA QUE } \\
\text { DISFRUTA DE } \\
\text { VACACIONES }\end{array}$ & \multicolumn{7}{|c|}{ AMBOS SEXOS } & \multicolumn{2}{c|}{ HOMBRES } & \multicolumn{2}{c|}{ MUJERES } \\
\hline Todos los años & 60 & $\%$ & $>60$ & $\%$ & $>60$ & $\%$ \\
\hline Una vez o otra & 102 & 20,40 & 52 & 10,40 & 50 & 10,00 \\
\hline Nunca & 281 & 56,20 & 139 & 27,80 & 142 & 28,40 \\
\hline Ns / Nc & 48 & 9,60 & 30 & 6,00 & 18 & 3,60 \\
\hline T O T A L & 500 & 100,00 & 250 & 50,00 & 250 & 50,00 \\
\hline
\end{tabular}

\section{Motivo por el cual nunca sale de vacaciones}

Como se ha indicado en la sección anterior, poco más de un tercio del colectivo de ancianos goza de vacaciones, lo que nos da las claves para deducir el modo de vida que llevan. En general, las tareas y obligaciones familiares, "sin descanso", pueden tener un reflejo simbólico en nuestra vida y representar una reducción en su calidad. Cuando uno es mayor las consecuencias son aún más evidentes. La necesidad y valoración de este período es tan importante que se dice que durante las vacaciones las personas suelen conquistar una mejor calidad de vida, relajándose, paseando, realizando actividades físicas o no haciendo nada. Es importante tener un tiempo en el que una persona no esté obligada a hacer nada: tiempo libre es

\footnotetext{
284 El Programa Viaja Más Mejor Edad Hospedaje proporciona la posibilidad de disfrutar, a precio un 50\% más barato, de estancias en zonas turísticas de costa y de turismo en general en el período de septiembre a diciembre, cubriendo la denominada "temporada baja". El Programa tiene como objetivo "promover la inclusión social, fortalecer el turismo en el mercado interno y favorecer la creación de empleo en el sector turístico y su entorno". Según datos del Ministerio de Turismo, el programa incide directamente en el envejecimiento activo de las personas mayores.
} 
tiempo libre. Siguiendo este tema, la idea se amplía para cuestionar a los que nunca salen de vacaciones y a los que sólo salen irregularmente, ¿cuáles son los factores determinantes que les impiden disfrutar de las vacaciones, esté uno en situación de jubilado o no?

Para dar respuesta a ese interrogante, ofrecemos un cuadro muy variado de respuestas (Tabla 27), con el propósito de no dejar escapar el motivo más contundente referente al tema. En él, los porcentajes más altos son los motivos económicos, con un 17,20\%. A continuación, están los que dicen no tener la cultura de tener vacaciones $(10,40 \%)$, seguidos de los que dicen que no les gusta $(9,20 \%)$; luego estarían aquellos a los que les faltan oportunidades, según señala un 9,20\%. Después, los que tienen problemas de salud $(5,40 \%)$, seguidos en menores proporciones, de los que asumen otras responsabilidades, traducidos en las ocupaciones (5\%) y otros motivos (6\%). La última razón es la edad, con un 2,80\% de los encuestados.

Si nos fijamos en función del género, los hombres presentan porcentajes ligeramente más altos sólo en los motivos por ocupaciones (un 3,20\% frente a un $1,80 \%$ ) quizá, porque los varones están laboralmente más ocupados que las mujeres. Todas las otras cifras se aproximan para ambos sexos, principalmente en los motivos en que los sujetos están de acuerdo: problemas de salud, no me gusta, por edad, no tiene esta costumbre y otros.

Siendo la limitación económica el principal problema acusado por hombres y mujeres $(8,80 \%$ y $8,40 \%$, respectivamente) como responsable de que no disfruten de vacaciones, se encuentra mayor incidencia de insatisfacción entre las viudas y en hombres y mujeres casados, mujeres que viven con hijos solteros y aquellos que disponen de sueldos de hasta dos salarios mínimos (alrededor de 323€) mensuales. Si nos fijamos en el segundo motivo más aparente, la falta de oportunidad, encontramos principalmente a mujeres casadas y viudas, entre 60-65 años y hombres casados entre 66-70 años. En tercer lugar con la cifra más destacada, se nos dijo no tener esta cultura, 
afirmación que subrayan los hombres viudos entre 66-70 años y las mujeres casadas y viudas entre 60-65 años de edad.

Contrariando los mitos de que a los ancianos no les gusta disfrutar de la vida, porque asocian vejez a enfermedad o por tener “muchos” años, comprobamos que estos motivos tuvieron poquísima incidencia en el grupo entrevistado. La categoría edad $(2,80 \%)$ fue apuntada por ellos como el último indicador que podría impedirles salir de vacaciones y la falta de salud como antepenúltima $(5,40 \%)$. Lo más probable es que, puesto que las jubilaciones y pensiones son tan bajas que ni siquiera permiten la satisfacción de las necesidades primarias del individuo, (en la próxima sección me centraré en este aspecto) los mayores no se imaginan destinar una parte del sueldo para las vacaciones.

Mientras, el Programa Viaja Más Mejor Edad Hospedaje no alcance la totalidad de su expansión en todas la ciudades de país, los servicios sociales, en los centros de convivencia en Mossoró, tendrían que introducir actividades alternativas de bajo coste, como viajes o picnic para los mayores; aunque pueda no constituir la mejor sugerencia, al menos los mayores tendrían la oportunidad de un "respiro familiar" y disfrutarían mejor de su edad.

\section{TABLA 27}

Según los motivos por los que nunca salen de vacaciones

\begin{tabular}{|c|c|c|c|c|c|c|}
\hline \multirow{2}{*}{$\begin{array}{l}\text { MOTIVOS POR LOS } \\
\text { QUE NUNCA SALE } \\
\text { DE VACACIONES }\end{array}$} & \multicolumn{2}{|c|}{ AMBOS SEXOS } & \multicolumn{2}{|c|}{ HOMBRES } & \multicolumn{2}{|c|}{ MUJERES } \\
\hline & $>60$ & $\%$ & $>60$ & $\%$ & $>60$ & $\%$ \\
\hline Económicos & 86 & 17,20 & 44 & 8,80 & 42 & 8,40 \\
\hline Ocupaciones & 25 & 5,00 & 16 & 3,20 & 9 & 1,80 \\
\hline Problemas de salud & 27 & 5,40 & 12 & 2,40 & 15 & 3,00 \\
\hline $\begin{array}{l}\text { Falta de } \\
\text { oportunidad }\end{array}$ & 39 & 7,80 & 13 & 2,60 & 26 & 5,20 \\
\hline No le gusta & 46 & 9,20 & 24 & 4,80 & 22 & 4,40 \\
\hline Por la edad & 14 & 2,80 & 6 & 1,20 & 8 & 1,60 \\
\hline $\begin{array}{l}\text { No tiene esta } \\
\text { cultura(costumbre) }\end{array}$ & 52 & 10,40 & 26 & 5,20 & 26 & 5,20 \\
\hline Otro & 30 & 6,00 & 15 & 3,00 & 15 & 3,00 \\
\hline Ns/Nc & 23 & 4,60 & 12 & 2,40 & 11 & 2,20 \\
\hline NSA & 158 & 31,60 & 82 & 16,40 & 76 & 15,20 \\
\hline TOTAL & 500 & 100,00 & 250 & 50,00 & 250 & 50,00 \\
\hline
\end{tabular}

Fuente: Encuesta Perfil Sociológico de la vejez en Mossoró - Junio 2004 / Junio 2005 (Elaboración de la autora) 


\section{La valoración del sexo}

Abordar el tema de la sexualidad a lo largo de la historia humana no ha sido tarea fácil. La complejidad del cuerpo humano y los mecanismos biológicos de la sexualidad, abordada bajo muchos puntos de vista, contribuyó tanto a una relación más sana y completa con el cuerpo humano y sus posibilidades, como a desencadenar una serie de prejuicios. La sexualidad resumida en la "genitalidad"285 que condiciona la reproducción del individuo, es uno de ellos. El mito, asociado a esa prerrogativa, de que el mayor pierde la capacidad de manifestar su sexualidad es un desafío que todavía está por deshacer, porque las necesidades sexuales en sí mismas continúan en el transcurso de la vida (Sánchez Vera y Díaz, 2007). "La sexualidad abarca a toda la persona y mediatiza a toda persona sexuada. Somos personas sexuadas desde la primera célula a la última" (Pascual: 1988:201).

Se debe entender que la actividad sexual tiene lugar en todas las edades, como sostiene Calvo: "la capacidad para el placer sexual se inicia con el nacimiento, para no concluir hasta la muerte; sin duda la edad modela la expresión de esta sexualidad, al igual que modela nuestra forma de relacionarnos en otros órdenes de la vida. [...] cada uno expresa y vivencia su sexualidad en función de variables varias y, entre ellas, la de la edad”286. Así pues, preguntamos a las personas mayores de 60 años, si las actividades sexuales disminuían en los últimos años de la vida y si la sexualidad se había limitado en función de la edad, dada la carencia de estudios sobre la sexualidad en edades avanzadas y por la cultura sexual actual al situar la sexualidad del anciano en una posición de marginación sexual.

Más de la mitad de los entrevistados $(52,80 \%)$ afirma que el desempeño sexual se ve comprometido con la edad (Gráfico 17). El $26,80 \%$ no cree que haya un límite cronológico para la actividad sexual. Un 20,40\% prefirió no contestar a la cuestión. En cuanto al género, las mujeres confiesan, apenas en un 1,60\%

\footnotetext{
285 Goma, Francesc (1989): Afectividad y sexualidad, moral y vejez, en AVeni Casucci, M. A. y otros: Afectividad y sexualidad en la ancianidad. Barcelona: Fundación Caixa de Pensión, p. 35.

286 Calvo, Montserrat (1989): Algunas características de la sexualidad y de la sensualidad en la vejez, en Aveni CasucciI, M. A. y otros: Afectividad y sexualidad en la ancianidad. Barcelona: Fundación Caixa de Pensión, p. 123.
} 
más que los varones, que el desempeño sexual en la tercera edad no es el mismo que cuando eran más jóvenes. En este sentido, además de existir diferencias entre la sexualidad de los varones y las mujeres ${ }^{287}$, se observa que la actividad sexual se va espaciando con el paso del tiempo para la mayoría de los entrevistados, a pesar de las investigaciones que evidencian actividad sexual más allá de los 70 años. Por tanto, los datos están en consonancia con algunos estudios sobre la conducta humana sexual ${ }^{288}$, como por ejemplo, el estudio "Sexual Behaviour of Human Male" (Comportamiento sexual del hombre), de 1948 del americano Alfred Kinsey.

Estratificando el colectivo por estado civil, más de la mitad de los varones casados (56 de los 88 ) y viudos (13 de los 25 ), y de las mujeres casadas y viudas (52 de las 70 y 43 de las 80 , respectivamente) dicen que la actividad sexual depende de la edad. Varios indicadores son responsables de la reducción de la actividad sexual. Para Kalish (1983), "algunas personas mayores, desde luego, tienen problemas de salud que reducen sus deseos sexuales y/o las capacidades. Otras no han encarado nunca el sexo, utilizando la vejez como una excusa para rechazar la conducta sexual; por último, nuestra cultura ha creado una imagen, al menos en el pasado, de las personas mayores como faltas de deseo sexual y de respuestas sexuales, lo que debe influir a muchos de los viejos de hoy en día" (1983:158).

En términos generales, conviene subrayar que la mayoría, probablemente, haya manifestado sus opiniones bajo la presión social, que lleva a los mayores a no tener una vida sexual activa. "La sociedad desprecia o minusvalora la sexualidad del anciano, señal inequívoca de que desconoce que la sexualidad sólo acaba con la muerte”289. Una alternativa para que las personas aprueben el sexo entre las personas mayores y éstas consideren sus propios cuerpos deseables sexualmente y encuentren en otras personas patrones sexuales excitantes, sería empezar a impartir el tema de la sexualidad a todos los colectivos sociales desde la infancia, lo que efectivamente ayudaría a

\footnotetext{
287 Freixas Farré, Anna (1993): Mujer y envejecimiento: aspectos psicosociales. Barcelona: Fundación "la Caixa", pp. 26-27

$288 \quad$ Cf. Alfred Kinsey, 1948; Pfeiffer, Verwoerdt y Davis, 1972;

289 Carrajo Rodríguez, Manuel (1999): Sociología de los mayores, Publicaciones Universidad Pontificia de Salamanca, p. 109.
} 
desmitificar la percepción negativa de la sexualidad a medida que pasa el tiempo.

\section{$\underline{\text { GRÁFICO } 17}$}

La valoración del sexo

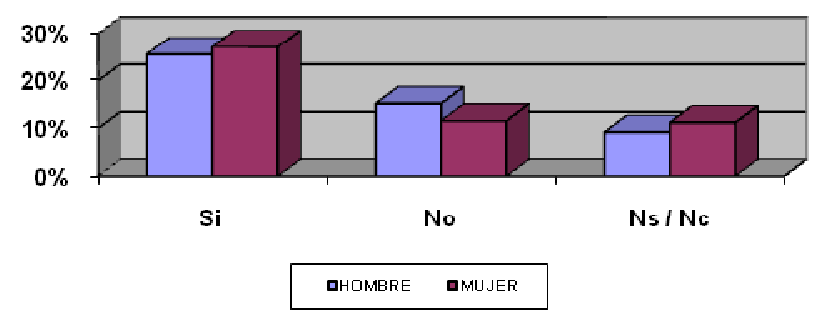

Fuente: Encuesta Perfil Sociológico de la vejez en Mossoró - Junio 2004 / Junio 2005 (Elaboración de la autora)

\section{Capacidad de administrar los ingresos}

Los cambios fisiológicos, psicológicos y sociales que ocurren con el proceso del envejecimiento van a influir de manera decisiva en el comportamiento de la persona mayor. Por esa razón, uno de los motivos que tornan a la vejez un fantasma es el miedo de las restricciones impuestas por esa fase de la vida. Con el declive gradual de las aptitudes físicas, el impacto del envejecimiento y de las enfermedades, el anciano tiende a ir alterando sus hábitos de vida y rutinas diarias por actividades y formas de ocupación poco activas. Como ha observado el británico Anthony Giddens (2002) “las personas, al envejecer, se enfrentan a una combinación de problemas físicos, emocionales y materiales que pueden resultar difíciles de superar. Una de las preocupaciones de los ancianos es mantener su independencia, su libertad de movimiento y la capacidad de tener una participación completa en su mundo social". (2002:224). Esta constatación nos permite confrontar el nivel de autonomía 290 que tiene el grupo investigado con respecto a la gestión de los ingresos que perciben.

\footnotetext{
290 Según Neri (2001:10), la autonomía es la noción y el ejercicio del autogobierno. El concepto incluye también los siguientes elementos: libertad individual, privacidad, libre elección, autogobierno, auto- regulación e independencia moral (Collopy, 1988), libertad para experimentar el "yo" y armonía con los propios sentimientos y necesidades (Gruen, 1986)".
} 
Como muestra la Tabla 28, más de tres cuartos de los mayores encuestados, una proporción importante dentro del conjunto informa que los ingresos son administrados por los respectivos titulares (79,60\%). Un 11,60\% atribuye esta responsabilidad a los/as hijos/as, un 6,60\% se encarga de uno de los consortes y un 2,20\% opina que es de la incumbencia de un pariente. Entre los sexos, las diferencias no son tan grandes: mientras que el $40,80 \%$ de los varones son independientes al administrar sus propios ingresos, las mujeres rondan el $38,80 \%$. Por otra parte el $3,80 \%$ de los varones reserva la autoridad para administrar los ingresos a la compañera, mientras que entre las mujeres solo dan este poder a apenas a un $2,80 \%$. Cuando el tema es la dependencia de los hijos, la situación se invierte: el 7,60\% de las mujeres ancianas "dependen" de que los hijos administren sus ingresos, mientras que apenas un $4 \%$ de los varones ancianos están en igual situación.

Con respecto al estado civil y la situación laboral actual, el $18,61 \%$ y el 5,36\% de los varones casados y viudos jubilados afirman administrar los ingresos que perciben, al igual que las mujeres solteras $(5 \%)$, casadas $(11,67 \%)$ y viudas $(10,41 \%)$. En la condición exclusiva de amas de casa, son responsables de los sueldos las mujeres casadas $(11,99 \%)$ y viudas $(6,94 \%)$. Los varones que se encuentran en actividad laboral (5,36\%) también afirman gestionar los ingresos mensualmente y las mujeres viudas pensionistas revelan que una parte de ellas son administradoras de los sueldos $(10,41 \%)$ mientras que en otros casos son los hijos quienes asumen esta función (3,79\%).

En general, el perfil que presenta el anciano de Mossoró en la capacidad de mantener su independencia y ser el principal gestor de los ingresos globales que percibe, parece positivo dado que de los 72 hombres casados jubilados, 59 de ellos administran sus propios ingresos y de los 22 viudos, 17 están en la misma situación. En el entorno femenino, de las 17 mujeres solteras jubiladas, 16 dominan esta condición, o sea, no hace falta que otros cuiden de sus finanzas. De las 47 mujeres casadas, 37 administran los ingresos y, entre las 52 mujeres viudas, 33 de ellas tienen este mismo dominio.

Todo parece indicar que el hecho de que el mayor es el sustentador principal, la persona que aporta más ingresos en el hogar donde vive, justifica tales 
condiciones. Asimismo, como se sabe poco de la población de ancianos de Mossoró, no descartamos que algunas personas de edad sean manipuladas y sufran extorsión por parte de sus familiares. Esa práctica identificada en familias brasileñas puede ser habitual entre los mayores mossoroenses. La vergüenza o el miedo de comentar tal situación, puede que haya contribuido a los resultados señalados. Queda en el aire la opinión de que se debe investigar sobre estas suposiciones.

\section{$\underline{\text { TABLA } 28}$}

Según las capacidad de administrar los ingresos

\begin{tabular}{|l|c|c|cccc|}
\hline \multicolumn{1}{|c|}{$\begin{array}{c}\text { MANEJO DE LOS } \\
\text { INGRESOS }\end{array}$} & \multicolumn{2}{|c|}{ AMBOS SEXOS } & \multicolumn{2}{c}{ HOMBRES } & \multicolumn{2}{c|}{ MUJERES } \\
\hline El propio & $>60$ & $\%$ & $>60$ & $\%$ & $>60$ & $\%$ \\
\hline Esposo/a & 398 & 79,60 & 204 & 40,80 & 194 & 38,80 \\
\hline Hijo/a & 33 & 6,60 & 19 & 3,80 & 14 & 2,80 \\
\hline Pariente & 58 & 11,60 & 20 & 4,0 & 38 & 7,60 \\
\hline Ns/Nc & 10 & 2,0 & 7 & 1,40 & 3 & 0,60 \\
\hline T O T A L & 1 & 0,20 & - & - & 1 & 0,20 \\
\hline Fuente: Encuesta Perfil Sociológico de la vejez en Mossoró - Junio 2004 / Junio 2005 \\
(Elaboración de la autora)
\end{tabular}

\section{Dónde suele comer habitualmente}

De los 5.564 municipios brasileños, Mossoró es uno de los que aún no ha perdido su aire de ciudad de interior, a pesar de exhibir, a nivel nacional, el título de mayor productor de petróleo en tierra, de producir el $97 \%$ de la sal brasileña, de irrigar gran parte de la fruticultura tropical, de criar langostinos en piscifactorías (cultura de la carcinicultura) y de engendrar la expectativa de transformarse, en un futuro próximo, en un polo ceramista de Río Grande do Norte ${ }^{291}$.

Estas características, a pesar de ser muy destacables, no hacen de Mossoró una ciudad cosmopolita y ni de lejos tiene la intensa movilidad y estrés típico de las metrópolis brasileñas como São Paulo, Río de Janeiro, Belo Horizonte, Salvador o Fortaleza. La ausencia de un gran polo industrial, que facilite su desarrollo y la equidad de oportunidades de empleo, contribuye a su interioridad. Por la arquitectura horizontal, es común que las mujeres barran las aceras por las mañanas o se sienten en ellas con familiares o vecinos en cualquier momento del día. Cerrar las tiendas a la hora de la comida es un 
rasgo cultural muy arraigado, a pesar de que las grandes superficies permanecen (con las puertas) abiertas en ese horario. La costumbre de los residentes de Mossoró de regresar a sus viviendas para el almuerzo familiar y de descansar un rato antes de continuar la jornada por la tarde, aún es disfrutada por muchos ciudadanos.

Todo esto es sólo una demostración de que alrededor del cien por cien de los hombres y mujeres mayores entrevistadas (92,20\%), habitualmente suelen disfrutar de las comidas en casa, en compañía de uno o algunos miembros de la familia (Tabla 29). Un 6,80\% afirma comer sin compañía y, por último en proporciones muy bajas, un 0,60\% suelen hacer las comidas en restaurantes o en casa de amigos $(0,40 \%)$. El género no introduce diferencias notables: el $46,40 \%$ de los hombres frente a $45,80 \%$ de las mujeres comen acompañados y en su domicilio. Apenas el $2,80 \%$ de los hombres, frente al $4 \%$ de las mujeres, suele comer a solas.

Todo parece indicar que una significativa parte de este colectivo $(92,40 \%)$ que convive con dos o más familiares consanguíneos (ver Tabla 11), por razones culturales o por razones económicas, justifica una cifra tan alta. Sin embargo, para los que viven solos, existe el programa del Restaurante Popular, el antiguo "Barriga Llena”, bajo la responsabilidad del Movimiento Estatal de Integración Social (MEIOS) que ofrece a la población comidas de calidad y precios más bajos que la media del mercado. Este programa, más allá de mantenerse, debería ampliarse a otros barrios, instalando otras unidades en Mossoró.

$\underline{\text { TABLA } 29}$

Según donde suele comer habitualmente

\begin{tabular}{|l|c|c|cccc|}
\hline \multicolumn{1}{|c|}{ HACE LAS } & \multicolumn{2}{|c|}{ AMBOS SEXOS } & \multicolumn{2}{c|}{ HOMBRES } & \multicolumn{2}{c|}{ MUJERES } \\
COMIDAS & $>60$ & $\%$ & $>60$ & $\%$ & $>60$ & $\%$ \\
\hline $\begin{array}{l}\text { En casa, con } \\
\text { hijo o familiar }\end{array}$ & 461 & 92,20 & 232 & 46,40 & 229 & 45,80 \\
\hline En casa, solo & 34 & 6,80 & 14 & 2,80 & 20 & 4,00 \\
\hline En restaurante & 3 & 0,60 & 3 & 0,60 & - & - \\
\hline $\begin{array}{l}\text { En casa de } \\
\text { amigos }\end{array}$ & 2 & 0,40 & 1 & 0,20 & 1 & 0,20 \\
\hline T O T A L & 500 & 100,00 & 250 & 50,00 & 250 & 50,00 \\
\hline
\end{tabular}

Fuente: Encuesta Perfil Sociológico de la vejez en Mossoró - Junio 2004 / Junio 2005

(Elaboración de la autora) 


\section{Comidas que suele hacer al día}

Según la Organización Mundial de la Salud (OMS: 2001), la calidad de vida en la ancianidad puede ser definida como la manutención de su salud en su mayor nivel posible en todos los aspectos de la vida humana: físico, social, psíquico y espiritual.

Desde el punto de vista fisiológico, el factor más importante en la manutención de la salud es el cuidado de la alimentación. Existe hasta un dicho popular que versa sobre el asunto: "somos lo que comemos". Así pues, dicen los expertos en salud que una alimentación saludable implica suministrar al organismo todos los nutrientes que necesita para su buen funcionamiento. Todo ello sirve para la conservación de un peso adecuado y funciona como elemento importante en la prevención de varias enfermedades (Woodruff, 1977). A pesar de que esta sección se centra en torno a la cantidad de las comidas, entendemos que la alimentación ideal es el equilibrio entre la calidad y la cantidad de los alimentos ingeridos diariamente, suficientes para atender las necesidades nutricionales del organismo.

Pero, tomando en consideración los varios cambios anatómicos y funcionales ocasionados en el proceso de envejecimiento, las enfermedades, que a veces inhiben o aumentan el apetito en la vejez, y la situación social, económica y familiar que vive el anciano, preguntamos al colectivo entrevistado ¿Cómo se alimentan diariamente? ¿Cuántas comidas hacen a diario? ¿La calidad es satisfactoria? Esas indagaciones están repartidas entre ésta y la siguiente sección.

En general, se puede comprobar en la Tabla 30, que casi la mitad de la muestra contesta que suele comer cuatro veces al día $(47,29 \%)$, un poco más de un tercio suele hacer tres comidas $(34,27 \%)$, un $12,02 \%$ dice que no sigue ninguna dieta y come cuando le da la gana y apenas un 0,60\% afirma sólo una vez al día. Estratificando por sexo y edad las cifras más significativas, se concentran en los hombres entre $60-70$ años, que suelen hacer cuatro $(8,86 \%)$ y tres $(10,13 \%)$ comidas diarias. Mientras, para las mujeres, las cifras crecen 
un poco con relación a las edades: entre 60-80 años afirman que comen cuatro veces al día $(27,85 \%)$ y tres veces lo afirman la mayoría entre $60-70$ años de edad (14,24\%).

En la distinción por sexo y situación laboral, los varones jubilados y pensionistas, en términos cuantitativos, hacen más comidas que las mujeres, es decir cuatro comidas. Mientras, las trabajadoras activas asumen el liderazgo.

Entre las diversas formas de orientación dietética, la más aceptada científicamente es la dieta equilibrada, con alimentos programados de entre cuatro a seis comidas por día, con carbohidratos, grasas y proteínas de acuerdo con la edad, peso, altura, composición corporal, patologías presentadas y estilo de vida entre otros factores. Si suponemos que los entrevistados tienen el hábito de alimentarse cuatro veces al día con un $12,02 \%$ que excede dichas comidas, tendríamos una cifra razonable de ancianos que sabe distribuir bien las comidas diariamente $(47,20 \%)$. Pero, si hacemos caso a los que no siguen ninguna dieta, hacen menos de cuatro comidas regularmente y sumados con los que comen tres, dos o una vez al día, resulta que la mitad de los ancianos come inadecuadamente.

Los hábitos alimenticios inadecuados desembocan generalmente en graves problemas de salud. Enfermedades del corazón, obesidad, diabetes y cáncer son sólo algunas de las que padecen millares de personas de edad y por supuesto, sobrecargan a los gobiernos con inmensos gastos en los sistemas sanitarios.

Es probable que el estado de salud de nuestros mayores sea resultado de una inapropiada alimentación. Entre ellos, el 26,80\% tiene enfermedades del corazón, el 15,20\% digestivas y el 33\% padece de otros problemas, quizá relacionados con el hábito alimenticio.

Nuestras últimas suposiciones se ven respaldadas por las estadísticas nacionales, que señalan que para un $32,80 \%$ de las familias brasileñas, a veces falta comida en la mesa y para un $13,83 \%$ de ellas, el alimento es normalmente insuficiente. Sumando las dos parcelas, se concluye que el 
46,63\% sufre algún tipo de restricción alimenticia, casi la mitad de la población brasileña ${ }^{292}$. Todo indica que el quid de la cuestión está arraigado en la situación económica, señalada por un 52,20\% de los entrevistados, que cuentan solamente con hasta dos salarios mínimos mensuales para su supervivencia. Así que, añadir años de vida a un grupo de población sin las condiciones necesarias para aprovechar los años ganados, no agrega ninguna ventaja.

\section{$\underline{\text { TABLA } 30}$}

Según las comidas que suele hacer al día

\begin{tabular}{|l|c|c|cccc|}
\hline \multicolumn{1}{|c|}{$\begin{array}{l}\text { COMIDA } \\
\text { EFECTUADA }\end{array}$} & \multicolumn{2}{c|}{ AMBOS SEXOS } & \multicolumn{2}{c|}{ HOMBRES } & \multicolumn{2}{c|}{ MUJERES } \\
DIARIAMENTE & $>60$ & $\%$ & $>60$ & $\%$ & $>60$ & $\%$ \\
\hline Cuatro & 236 & 47,20 & 106 & 21,20 & 130 & 26,00 \\
\hline Tres & 171 & 34,20 & 96 & 19,20 & 75 & 15,00 \\
\hline Dos & 27 & 5,40 & 15 & 3,00 & 12 & 2,40 \\
\hline Una & 3 & 0,60 & - & - & 3 & 0,60 \\
\hline $\begin{array}{l}\text { Come cuando le } \\
\text { da la gana }\end{array}$ & 63 & 12,60 & 33 & 6,60 & 30 & 6,00 \\
\hline \multicolumn{7}{|l|}{ T O T A L } \\
Fuente: Encuesta Perfil Sociológico de la Vejez en Mossoró - Junio 2004 / Junio 2005
\end{tabular}

(Elaboración de la autora)

\section{Grado de satisfacción con la comida}

Hemos señalado anteriormente la frecuencia del hábito alimenticio del colectivo de ancianos en Mossoró y hemos llegado a dos conclusiones: la primera consiste en que casi la mitad (los que suelen hacer cuatro comidas al día, el 47,20\%) se encuadra en el patrón considerado más saludable, al hacer varias comidas al día, en horarios determinados. La segunda estriba en que más de la mitad sufre cierta privación alimenticia, según la clase socioeconómica a la que pertenece, como está señalado en la Tabla 15.

Ante esta situación, como pone de manifiesto la Tabla 31, las respuestas sobre el grado de satisfacción del entrevistado acerca de la comida que suele consumir, se presentan bastante variadas en el conjunto de las cinco alternativas. Con la cifra más alta, el $44,80 \%$ de los ancianos que han sido

\footnotetext{
292 Los números forman parte de la Pesquisa de Orçamentos Familiares (POF) 2002-2003, realizada por el Instituto Brasileiro de Geografía e Estatística (IBGE). El sondeo escuchó a 48,5 millones de familias con 3,6 integrantes por casa. Es la investigación más grande de este género hecha a nivel nacional desde el bienio 1974-1975.
} 
entrevistados afirma que la comida es buena, seguidos del $28 \%$ que la califica de regular, después una cuarta parte expresa que es muy buena $(25,20 \%)$ y por último, los valores menos atribuidos fueron muy mala (1\%) y mala (1\%), respectivamente.

Por sexo, los hombres $(\mathrm{N}=250)$ se presentan más satisfechos que las mujeres $(\mathrm{N}=250)$ con lo que suelen alimentarse. El $36 \%$ de los ancianos califica la comida muy buena y buena, mientras que entre las mujeres ancianas este porcentaje era del 34\%. En razón del sexo y estado de salud, los varones con salud regular califican la comida de buena, mientras que a las mujeres con las mismas condiciones de salud, la comida les parece sólo regular.

En principio, la razón para dichas satisfacciones alimenticias estaría en el aumento de la venta de alimentos para el mercado interno del 2,81\%, en relación a 2003. Según datos presentados por la Asociación Brasileña de Industrias de Alimentación ( $\mathrm{ABI}$ ), el país consumió más y mejor. Productos como los derivados de la carne, con proteínas animales y los cereales tuvieron una producción mayor que los de conservas y congelados. Al hablar de la comida hecha en casa, ya que los ingresos que reciben es difícil comprarla hecha 0 irse a un restaurante, se supone una cierta calidad y variedad en la riqueza de productos producidos en Brasil de bajo coste, como la harina, los frijoles, el arroz, además de las frutas tropicales, típicas en todas las regiones. El acceso a todo ello sería positivo para este colectivo.

\section{TABLA 31}

Según el grado de satisfacción con la comida

\begin{tabular}{|lccccccc|}
\hline $\begin{array}{l}\text { SATISFACCIÓN } \\
\text { SOBRE LA } \\
\text { COMIDA }\end{array}$ & \multicolumn{1}{c}{ AMBOS SEXOS } & \multicolumn{2}{c}{ HOMBRES } & \multicolumn{2}{c|}{ MUJERES } \\
\hline Muy buena & 126 & 25,20 & 68 & 13,60 & 58 & 11,60 \\
\hline Buena & 224 & 44,80 & 112 & 22,40 & 112 & 22,40 \\
\hline Regular & 140 & 28,00 & 64 & 12,80 & 76 & 15,20 \\
\hline Mala & 5 & 1,00 & 5 & 1 & - & - \\
\hline Muy mala & 5 & 1,00 & - & - & 5 & 1 \\
\hline T O T A L & 500 & $\mathbf{1 0 0 , 0 0}$ & $\mathbf{2 4 9}$ & $\mathbf{5 0 , 0 0}$ & $\mathbf{2 5 0}$ & $\mathbf{5 0 , 0 0}$ \\
\hline
\end{tabular}




\section{Resumen}

La sexta parte de la Encuesta - El peso del tiempo: Trabajo, obligaciones domésticas, tiempo libre y ocio, perfila la vida diaria de los mayores de 60 años en Mossoró. El permiso para adentrarnos en un ámbito más íntimo de su vida nos ha revelado de modo amplio y variado algunas de las peculiaridades que en las personas de edad exigen un poco más de atención. Las informaciones estadísticas pueden mejorar enormemente los servicios y políticas sociales de desarrollo dentro de la comunidad local y quizá, dar pie a los programas de planificación.

Con el avance de la edad, muchas de las costumbres y actividades que antes solían hacerse, pueden mantenerse, cambiarse o unirse a otras tantas para encontrar la mejor manera de pasárselo bien durante la vejez. Si hablamos de los momentos libres, en los mayores entrevistados, lo más frecuente es quedarse en casa (84\%) y lo menos frecuente es asistir a conciertos $(4,20 \%)$, razón por la cual se justifica que el $64 \%$ vea la televisión diariamente, el $36,40 \%$ oiga la radio, el $27 \%$ cuide de los nietos, el $22,20 \%$, disfrute de lecturas diversas y el $19,80 \%$ se dedique a manualidades. Las mujeres destacan en casi todas las actividades más que los hombres, excepto en acudir a los bares y cafeterías, y jugar a las cartas. Por estado civil, los varones casados disfrutan más que las mujeres casadas de las actividades fuera del hogar, además de dedicarse a lecturas y ver la televisión. Sin embargo, con los viudos la situación se invierte. Son las viudas las que buscan el ocio en otros sitios, además de leer más que ellos. De hecho, como sería lógico esperar en ese grupo de edad, las costumbres siguen delimitadas conforme a los papeles de cada sexo y la presencia del sedentarismo es muy acusada. La falta de formación para una vida socio-cultural más amplia, sumada a la carencia de recursos financieros colabora para llegar a ese tipo de vida. Pero, es importante subrayar que las mujeres parecen conseguir incrementar la actividad después de la viudedad.

De acuerdo con los datos, para más de la mitad de los mayores entrevistados la preferencia en la programación radiofónica es predominantemente: los informativos, los musicales y los programas religiosos. Los de menos interés 
son los programas dedicados al deporte, los políticos y los seriales (telenovelas). En cuanto a los varones, están más pendientes de las informaciones, que de los musicales y de los momentos religiosos. Las mujeres prefieren los informativos, los momentos religiosos y el entretenimiento musical. Los hombres superan a las mujeres en el interés por los programas deportivos y políticos. En el escenario nacional, los medios de comunicación de masa son el segundo recurso más común en los domicilios brasileños (87\%). Se sobreentiende que las actividades más frecuentes realizadas por las personas mayores coinciden con las que se realizaban antes de la vejez.

Cuando el medio es la televisión, por encima de dos tercios eligen los informativos, aunque las telenovelas asumen la segunda opción $(58,04 \%)$ y en tercer puesto quedan los programas religiosos (47,95\%). También tienen importancia para ellos los programas deportivos $(24,60 \%)$, las películas $(17,03 \%)$ y los entretenimientos de auditorio $(15,46 \%)$. Los varones casados y viudos suelen ver más frecuentemente los telediarios, los programas deportivos y las telenovelas, mientras que las mujeres solteras, casadas y viudas prefieren las telenovelas, los telediarios y los programas religiosos.

Dentro de la perspectiva del entretenimiento y del ocio en la vida diaria del mayor, tras la jubilación, liberados en parte de las obligaciones domésticas, y más atentos al estado de ánimo del colectivo investigado, constatamos que el $56 \%$ no practica ninguna actividad física, como contrapunto a los que son aficionados a caminata $(33,60 \%)$. Los sujetos que están más alejados de las actividades deportivas son las mujeres. Sin embargo, entre quienes las practican, las casadas y viudas entre 60-75 años y los varones casados entre 66-70 años también prefieren caminar. El panorama indica un estilo de vida sedentario, lo que sugiere la limitación económica en la que se encuentran los ancianos y la cultura de no practicar ejercicio o cuidar del cuerpo entre aquellos que nacieron en la primera mitad del siglo XX. Además, se nota la carencia de alternativas para la práctica deportiva dirigida a los mayores 
junto con la falta de información y acceso al Proyecto "Mossoró camina con la gente", lo que contribuye a este cuadro sedentario de la comunidad.

En cuanto a las vacaciones, su práctica es una modalidad poco habitual en la vida de los mayores entrevistados. Algo más de la mitad $(56,20 \%)$ nunca ha gozado de dicho beneficio, un 20,40\% lo disfruta esporádicamente y apenas un $13,80 \%$ de estas personas siguen la regla anual del descanso. Por sexo, se supone que las amas de casa constituyen el grupo social que menos reposa, dado que, del $28,40 \%$ que nunca sale de vacaciones, un $26,80 \%$ son amas de casa. $\mathrm{Y}$ aunque entre las personas mayores, el $93 \%$ está en la condición de jubilados y/o pensionistas, de "vacaciones permanentes", libres de las tareas laborales, ello no significa que realmente aprovechen el tiempo como manda la norma vacacional. Entre los motivos por los que el mayor nunca sale de vacaciones, los porcentajes más altos señalan los de orden económico $(17,20 \%)$ y el no tener esta costumbre $(10,40 \%)$. Las razones, que impiden dicho reposo fueron apuntadas en proporciones por debajo del 10\%; no me gusta, por falta de oportunidad, por problemas de salud, por ocupaciones y por la edad. Las causas se aproximan para ambos sexos en las respuestas: por problemas de salud, porque no les gustan las vacaciones, no poseen esta cultura y por la edad. En general, llama la atención que la edad es el último motivo por el que no disfrutan de vacaciones. Al contrario de lo que pregona el mito, de que a los mayores no les gusta disfrutar de la vida porque asocian vejez a enfermedad o por tener muchos años, comprobamos que estos motivos tuvieron muy poca incidencia entre el colectivo.

Las personas mayores entrevistadas también se posicionaron sobre el tema de la sexualidad. La mayoría asocia la caída de la actividad sexual a la percepción negativa de que la sexualidad se ve afectada por el paso del tiempo $(58,68 \%)$. En cambio, poco más de una quinta parte no se siente afectada y un $17 \%$ no contestó a la cuestión. A pesar de que la sexualidad se manifiesta diferentemente para hombres y mujeres, en general, nuestros entrevistados se posicionaron de modo semejante. Ambos, sin grandes diferencias de edad o condición de estado civil, se incluyen en las diferentes 
opciones. A parte del estado de salud, que puede afectar tal desempeño, entre otros indicadores, las inhibiciones culturales pueden causar posturas reprimidas en los mayores.

Cuidar de las finanzas es un aspecto importante de la actividad instrumental de la vida diaria (AIVD) de una persona. En los ancianos, esa rutina diaria puede comprometerse con el impacto del envejecimiento (Giddens, 2002:224). En nuestra Encuesta, el 79,60\% de los mayores aún mantiene la libertad de movimiento cuando señalan que los ingresos son manejados por los propios titulares, en contraposición al 20,20\% de aquellos que incluyen a otras personas. Los datos no revelan por qué los ingresos son administrados por otros, aunque se supone que depende mayoritariamente de la situación laboral en que se encuentran. En general, la Encuesta presenta de modo positivo al mayor de Mossoró en el ejercicio del autogobierno traducido en el poder de supervivencia sin ayuda para las AIVDs.

Aún dentro de la parte de la encuesta dedicada al mundo cotidiano de los mayores entrevistados, uno de los momentos importantes es la hora de la comida, especialmente para los que se encuentran jubilados en casa. Por ello, el 92,20\% habitualmente suele disfrutar de las comidas en casa en compañía de uno o algunos integrantes de la familia. En cambio, apenas un 6,80\% está solo en ese instante $\mathrm{y}$, poquísimos suelen comer en un restaurante o en casa de amigos (0,60\% y 0,40\%, respectivamente). Considerando que el $62,32 \%$ de los mayores participantes suele comer entre tres y cuatro comidas a diario en casa, los datos sugieren contactos personales frecuentes entre ellos y sus familiares. Dicho promedio, un poco más de 9,2 personas que comparten las comidas a diario, es un dato positivo.

Para finalizar, entre los encuestados sobre el grado de satisfacción con la comida que suele consumir, las respuestas fueron bastante variadas. La cifra más alta, el 44,80\% de los mayores afirma que la comida es buena, seguidos del $28 \%$ que la califica de regular, después una cuarta parte expresa que es 
muy buena $(25,20 \%)$ y por último, los valores menos atribuidos fueron muy mala (1\%) y mala (1\%), respectivamente. 


\section{Vivienda}

Jamás un hombre es demasiado viejo para recomenzar su vida y no hemos de buscar que lo que fue le impida ser lo que es o lo que será.

Miguel de Unamuno (1864-1936), Filósofo y escritor español.

\section{La vivienda del mayor}

Como apuntábamos en la Tabla 22, el lugar donde los mayores encuestados de 60 años o más suelen pasar más tiempo es en su domicilio (84\%). Ver la televisión, escuchar la radio, leer, dedicarse a manualidades y cuidar de los nietos, eran las actividades más frecuentes. Así que resulta razonable, no sólo que los mayores juzguen con propiedad las condiciones y calidad de sus viviendas, sino también la infraestructura y servicios disponibles en su entorno. En este apartado se presentan indicadores sobre el contexto material y las condiciones en las que discurre la vida de los mayores mossoroenses. De modo particular, destacaremos las características de las viviendas en las que residen, y el acceso a los servicios disponibles en su entorno, existentes para atender sus necesidades reales.

La vivienda es, desde tiempos ancestrales, el refugio por excelencia, usado por el hombre para protegerse de las amenazas externas del medio ambiente o del humano enemigo. Definido como lugar en que se vive, los términos suelen ser diversos: casa, apartamento, residencia, domicilio, vivienda, quitinetes $^{293}$, chalet, entre otros. En Brasil, el tipo de vivienda es tan variado como el propio clima: las viviendas de las áreas tropicales son opuestas a las de las regiones forestales. Como ejemplo, es común, ver casas de madera flotante en la Amazonía y Manaus, rascacielos en São Paulo y Belo Horizonte,

293 Quitinetes es una clase de hogar modesto, muy pequeño, mono espacio, tipo estudio, donde generalmente vive una persona sola. En Brasil, dependiendo de la ubicación de las construcciones de quitinetes, generalmente en los barrios periféricos, suele existir servicios de baños colectivos en los pasillos. 
edificios divididos en varias viviendas, llamados $\operatorname{cortiços}^{294}$, en Recife y São Paulo e incluso casas de lujo edificadas muchas veces al lado de paupérrimas viviendas, las favelas ${ }^{295}$, en Fortaleza y Río de Janeiro, entre otras urbes de Brasil. Las formas y estilos arquitectónicos denuncian los patrones socioeconómicos de los brasileños en paisajes que cambian en cada una de las cinco grandes regiones del país.

Como en todos los 167 municipios del Estado del Río Grande del Norte, las viviendas en Mossoró son espacios horizontales y en su mayoría de tipo casa, que se esparcen por los veintisiete barrios existentes. Podemos ratificar que un espectacular $98,20 \%$ de mayores tiene como hogar una casa, a través del Gráfico 18, que tenemos más abajo. En todo el ámbito investigado sólo un $0,80 \%$ vive en quitinetes y apenas un $1 \%$ vive en apartamentos. Estos datos confirman los del Censo Decenal Demográfico de 2000, cuyo registro divulgado en el área urbana, en Mossoró, era de 47.892 casas $(98,25 \%), 538$ apartamentos $(1,10 \%)$ y 315 monos espacios $(0,65 \%)$. En el caso de los apartamentos, a pesar del potencial del sector inmobiliario en el que actualmente se construyen comunidades verticales, con modelos basados en la modernidad y con estilos diferenciados, ese tipo de vivienda es menos frecuente. La cultura de vivir en este tipo de vivienda está de moda y últimamente con más motivo en Mossoró, que además, en general, suele tener un coste muy alto.

El género, al igual que otras categorías, como es el caso de la edad, o el estado civil, no introduce diferencias significativas en el tipo de vivienda, dado que, mayoritariamente, los encuestados viven en casas. En cierta medida ese tipo de domicilio es positivo. Las casas, en Mossoró, no suelen

\footnotetext{
294 Generalmente situados en el centro de las ciudades, los cortiços son viviendas que albergan a varias familias. Los alquileres de bajo coste, la informalidad de los contratos, que no exigen comprobación de renta ni fiador, atraen a los moradores hacia ese tipo de vivienda. A cambio de esas facilidades, los moradores viven en condiciones precarias, en estancias sin iluminación ni ventilación. El número de cortiços registrados en el país sobrepasa los 33.000 en 2001, según la Pesquisa de Informaciones Básicas Municipales (Munich), IBGE/2003.

295 Una parte significativa de la población brasileña vive en domicilios precarios, reflejo entre otros, de un problema nacional conocido, como hemos visto más arriba, el déficit habitacional. Esa forma de vivienda dispone de infraestructura inadecuada y falta de servicios públicos esenciales de salud, educación y transporte, lo que contribuye a bajar los índices de calidad de vida de los brasileños. El número de favelas registradas pasó de 16.433 en 2001. Juntas, son más de 2,3 millones de viviendas en 1.269 municipios brasileños de acuerdo con la Pesquisa de Informaciones Básicas Municipales (Munic) IBGE/2003.
} 
tener escaleras, solo los mejor posicionados económicamente, construyen viviendas con un segundo piso. Eso evita las caídas y fracturas en las personas de edad avanzada. Otro dato importante es que las casas facilitan la sociabilidad con el vecindario y la acción de los bomberos en casos de accidentes o tragedias. Sin embargo, muchas casas ubicadas en barrios periféricos y construidas en zonas inadecuadas sufrieron los riesgos de inundaciones en el pasado invierno. Pero, como las lluvias son muy irregulares y poco a poco el Poder Público invierte en las mejoras urbanísticas, la mayoría de las viviendas son seguras.

\section{GRÁFICO 18}

La vivienda del mayor

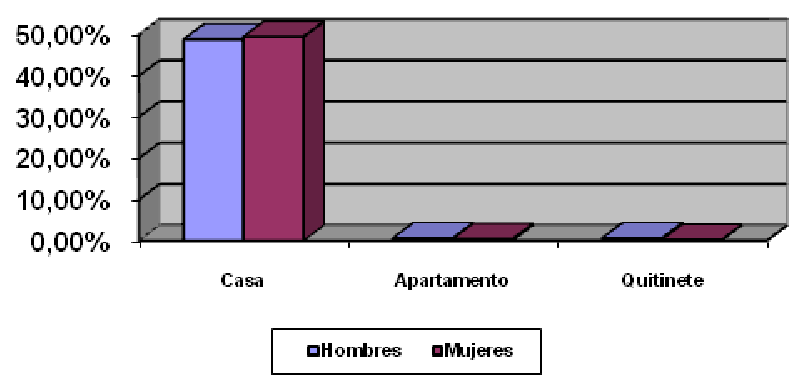

Fuente: Encuesta Perfil Sociológico de la Vejez en Mossoró - Junio 2004/ Junio 2005 (Elaboración de la autora)

\section{Régimen de tenencia de la vivienda}

A tenor de lo anterior, casi el $100 \%$ de los mayores de 60 años o más de edad, residentes en el municipio de Mossoró, viven en un domicilio del tipo casa. En un total de 52.121 domicilios particulares permanentes en la zona urbana (IBGE/2000/Cidades@), 33.893 unidades estaban pagadas, 6.488 en adquisición, 8.147 alquiladas, 499 cedidas por el empleador, 2.782 cedidas de otra forma y 312 en otros tipos de ocupaciones. En Brasil, en 2002, casi ocho de cada diez brasileños $(73,7 \%)$ residían en una vivienda en propiedad, el $15 \%$ alquilados, el $10 \%$, prestados y el porcentaje restante corresponde a domicilios ocupados en otras condiciones. Sin embargo, según los datos de la Síntesis de los Indicadores Sociales de 2002, del Instituto Brasileño de Geografía y Estadística (IBGE), "el porcentaje medio de viviendas propias en Río Grande del Norte (RN), era del $73,4 \%$, un poco inferior a la media brasileña $(73,7 \%)$ y a la del Nordeste $(77,5 \%)$. En cuanto a la región Nordeste, 
el $14,3 \%$ de los inmuebles eran alquilados, en el Estado de RN ese número era del $16,7 \%$. Eso representa casi 100.000 domicilios y aún se suman a esto los cedidos, que son más de 85.000". ${ }^{296}$ De acuerdo con los indicadores y particularizando la situación de Mossoró en porcentajes, las condiciones de ocupación de domicilio eran: en un 78,68\% de domicilios propios pagados o en adquisición, un 15,50\% de domicilios alquilados, un 5,47\% de domicilios cedidos y un $0,35 \%$ de domicilios adquiridos de otras formas.

De modo particular, el régimen de tenencia más extendida entre la población entrevistada es el de la propiedad. Según el Gráfico 19, un 80,40\% de los mayores tiene la vivienda en propiedad, estando totalmente pagada. Mucho menos extendido, sólo un 7,60\% de los mayores tiene su alojamiento de forma cedida, facilitada por un familiar u otros; alrededor de un 7,20\% está en régimen de alquiler, y en menor proporción un 4,80\% lo tiene en propiedad, pero con pagos pendientes. En general, la vivienda en propiedad, sin duda, significa un alivio para los presupuestos de este colectivo (Mutschler, 1993; Higgins, 1994), dado que la mayoría posee renta baja. Además, conlleva una gran libertad de elección a la hora de decidir dónde envejecer (Alguacil y Denche, 1991).

La distribución por sexo revela que los varones llevan sutilmente ventaja sobre las mujeres en dos de las situaciones de la vivienda. Es decir, poseen vivienda en propiedad en mayor medida (un 40,80\% frente a un 39,60\%) y dependen menos de la caridad de los familiares (un $3 \%$ frente a un $4,60 \%$ ). Sin embargo, sutilmente, las mujeres son las que poseen mayor cantidad de inmuebles propios con pagos pendientes (un 2,20\% frente a un 2,40\%) y viven menos de alquiler que los hombres (un $4 \%$ frente a un 3,20\%). Otras variaciones notables corresponden a las variables de estado civil y estatus social. En todo el ámbito entrevistado, las mujeres viudas son las que más viven en domicilios cedidos por familiares $(2,20 \%)$. Los varones casados

\footnotetext{
296 Para Informaciones más detalladas se puede a acudir a la página web http://www.tribunadonorte.com.br, artículo RN lidera en número de inquilinos, 21 de Junio de 2003.
} 
$(28,60 \%)$, separados $(2,60 \%)$ y viudos $(7 \%)$ y las mujeres solteras, $(3,60 \%)$, casadas $(15,60 \%)$, separadas $(2,80 \%)$ y viudas $(16,40 \%)$ están en régimen de tenencia en estas proporciones. En cuanto al análisis por nivel de estudios se observa que tienen casa propia los varones que saben leer $(11,40 \%)$ y las mujeres con estudios primarios $(14,80 \%)$.

En resumen, al constatar que cuatro quintos del grupo de población anciana entrevistado tienen vivienda en propiedad, comprobamos que el índice está dentro de la media mossoroense y por encima de la del Nordeste ya mencionada. Quizá porque la vivienda ocupa una de las primeras necesidades de supervivencia del hombre, nuestros ancianos han trabajado toda la vida para comprarse una. Pero, el hecho de que un domicilio sea propio no quiere decir que se trate del adecuado. El estado de conservación de la vivienda es una característica fundamental para medir las condiciones de vida y bienestar de los mayores.

La relación con la posición económica es evidente para parte de los que tienen la vivienda en régimen de tenencia. La suma de los mayores que viven bajo la condición de préstamo $(7,60 \%)$ y de alquiler $(7,20 \%)$ triplica, según datos de IBGE 2002, a los que están incluidos en los programas de casa propia subsidiados por el Poder Público (4,60\%). Para los que viven de alquiler, con sueldos bajos, puede que la reducción de presupuestos repercuta en la calidad de vida. Se supone, también, que las viviendas prestadas se encuentran en mal estado de conservación.

\section{GRÁFICO 19}

Régimen de tenencia de la vivienda

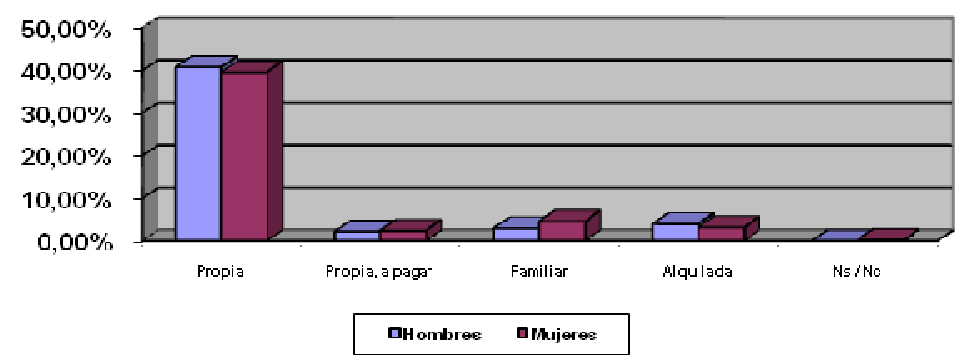

Fuente: Encuesta Perfil Sociológico de la Vejez en Mossoró - Junio 2004/ Junio 2005 (Elaboración de la autora) 


\section{Coste de la vivienda alquilada}

Los gastos en vivienda, alimentación y transporte continúan siendo los tres grandes grupos de gastos en el consumo del brasileño, que se han visto aumentados, en los últimos 30 años (1974-75 y 2002-03) del 74,59\% al 82,41\% del total de costes, según la Pesquisa de Previsiones Familiares (POF) ${ }^{297}$, órgano integrado en el Instituto Brasileño de Geografía y Estadística (IBGE). Siendo la vivienda el principal gasto familiar en Brasil (representado por un 29,19\% de la renta familiar, según la POF), el informe ha constatado que, de media, el alquiler consume el $17,27 \%$ de los ingresos de los brasileños con renta baja, mientras que sólo un $10,08 \%$ de los de clase más alta ${ }^{298}$

Del colectivo investigado (Gráfico 20), apenas 20 varones (4\%) y 16 mujeres $(3,20 \%)$ residen en domicilios alquilados, donde la mayoría paga rentas que oscilan entre $\mathrm{R} \$ 50,00$ y $\mathrm{R} \$ 200,00$ (alrededor de $20 €$ a $80 €$ ). Esto condiciona la situación financiera de los mayores (ver Tabla 15) y por supuesto su estilo de vida. Las demás rentas superiores a éstas ocupan un porcentaje muy bajo en el conjunto de la investigación.

Según las rentas, se supone que son viviendas de aspecto muy modesto, con infraestructura de pequeño porte, estado de conservación inadecuado y ubicación en los barrios periféricos de la provincia. Entre las clases de renta baja generalmente esta imagen posee un carácter universal.

La política pública de inversión habitacional para la población nacional y local es una política social en ascensión. En Mossoró, a pesar de los esfuerzos de la administración pública municipal y estatal para aminorar las desigualdades sociales, mediante la construcción de nuevos espacios habitacionales, "faltan

\footnotetext{
297 La POF analiza la composición de gastos y de consumo de las familias brasileñas según las clases de ingresos. Los análisis permiten verificar, en comparación con las pesquisas anteriores, los cambios significativos en los gastos y en los hábitos de los brasileños. El último análisis hecho por el órgano fue en julio de 2002 y julio de 2003.

Se puede encontrar más información en el artículo "Em 30 anos, importantes mudanças nos hábitos de consumo dos brasileiros - Comunicação Social do IBGE, 19 de Maio de 2004 en la página web http://www.ibge.gov.br/home/presidencia/noticias
} 
habitaciones en cantidad suficiente para sus habitantes, y aún hay un número considerable por debajo de los patrones mínimos de habitabilidad”299.

Constataciones como las que anteceden aconsejan que la revisión del Plan Director de Desarrollo Urbano de Mossoró, en proceso por la gestión 20092012, pueda atender y mejorar las condiciones de vivienda de los mossoroenses, para que en un futuro próximo los mayores puedan vivir en domicilios propios y adecuados.

\section{GRÁFICO 20}

\section{Coste de la vivienda alquilada}

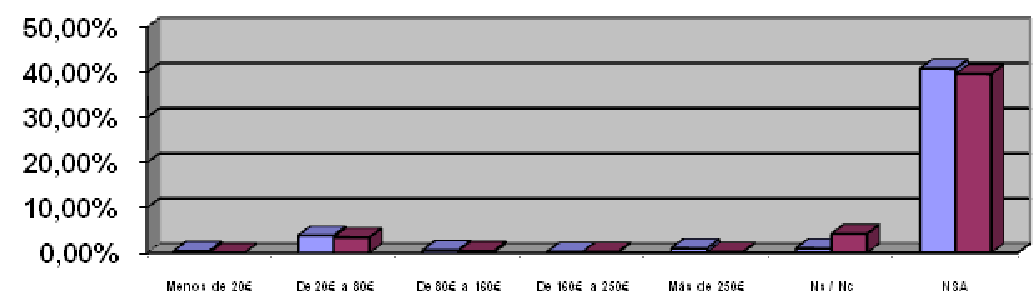

口Hombres aMujeres

Fuente: Encuesta Perfil Sociológico de la Vejez en Mossoró - Junio 2004/ Junio 2005 (Elaboración de la autora)

\section{Dispone o no de habitación propia}

Según la encuesta Perfil Sociológico de la Vejez en Mossoró (Gráfico 21), alrededor de cuatro quintas partes de los ancianos residentes en el municipio tiene dormitorio independiente $(79,80 \%)$, el $13,80 \%$ no lo tiene, quizá comparta con otra persona distinta al cónyuge u ocupe alguna otra estancia de la casa en los momentos de descanso o privacidad; para el $6,40 \%$ no se aplica la cuestión vivir en solitario.

Por sexo y estado civil, entre los que disponen de habitación propia, se destaca, el grupo de hombres casados $(27,20 \%)$ y viudos $(8 \%)$ y las mujeres solteras $(4,60 \%)$, casadas $(14,20 \%)$, separadas $(2,60 \%)$ y viudas $(16,80 \%)$. Los

\footnotetext{
299 Rocha, A. P. B.: Expansão Urbana de Mossoró - período de 1980 a 2004. Disertación de Máster - Universidad Federal del Río Grande del Norte. Centro de Ciencias Humanas, Letras y Artes. Departamento de Geografía. Programa de Posgrado y Pesquisa en Geografía. Natal, RN. 2005, p. 250.
} 
mayores que no cuentan con dormitorio independiente, están distribuidos de la siguiente forma: un $4,20 \%$ de los hombres casados, el 3,40\% de las mujeres casadas y el $4 \%$ de las viudas. Si buscamos quiénes entre los mayores no tienen dormitorios, encontramos aquellos que residen en hogares con familias más extensas. Los que viven en matrimonio con hijos $(20,20 \%)$ y en hogares múltiples, viviendo con el cónyuge, hijos casados y/o nietos (17,80\%).

Según la Encuesta, para 399 de los 500 casos investigados que disponen de habitación en privado, podrían considerarse estándares elevados de confort y calidad residencial. No se han evidenciado diferencias significativas de acceso a dormitorio independiente de acuerdo con el sexo y estado civil.

Por lo general, las viviendas de la clase baja en Mossoró, donde suelen vivir mayoritariamente las personas de clases sociales menos favorecidas, se componen de un salón, un pasillo, no más de dos habitaciones y un cuarto de baño. Por costumbre, cuando la familia es numerosa, los más pequeños y jóvenes suelen dormir en hamacas en el salón y pasillos y los mayores suelen quedarse en las estancias más confortables de la vivienda.

\section{GRÁFICO 21}

\section{Dispone o no de habitación propia}

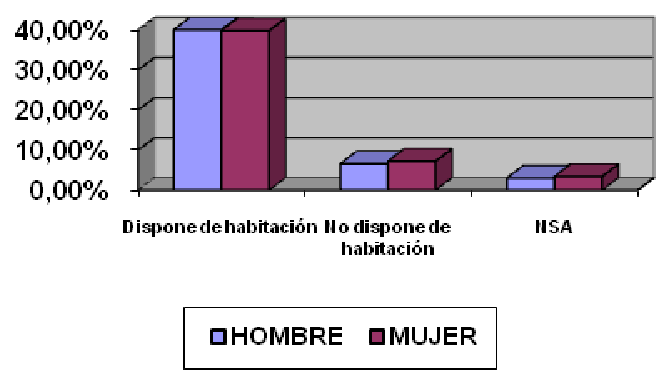

Fuente: Encuesta Perfil Sociológico de la Vejez en Mossoró - Junio 2004/ Junio 2005 (Elaboración de la autora)

\section{Grado de satisfacción con la vivienda}

En éste ítem sobre la vivienda del entrevistado, el interés se basa en saber el grado de satisfacción que demuestran los ancianos en relación a su domicilio. Después de conocer la información de que tres cuartas partes tiene casa 
propia $(80,40 \%$ - ver Gráfico 19) y más de dos tercios dispone de dormitorio independiente $(79,80 \%$ - ver sección anterior), ambos, factores son importantes para la tranquilidad y bienestar de los mayores. Así pues, nos parece lógico, como dibuja el Gráfico 22 , que más de la mitad se juzguen satisfechos con la propiedad del inmueble $(52,40 \%)$. Más de un tercio manifestó estar muy satisfecho $(37,20 \%)$ y en menor medida les siguen los que afirmaron estar insatisfechos (8\%), muy insatisfechos $(1,20 \%)$ y por último, los ancianos que no contestaron a la pregunta $(1,20 \%)$.

A primera vista, en los resultados obtenidos, observamos más de cuatro quintos del colectivo contentos con el hogar en el que viven. Al analizar la intensidad de la satisfacción según el sexo, a pesar de que la mayoría de las mujeres se declaran muy satisfechas (un $16,40 \%$ frente a un $20,80 \%$ ), en las demás, las cifras descienden. En la variable satisfecho para hombres y mujeres tenemos un $29,00 \%$ y un $23,00 \%$, respectivamente y en la categoría muy insatisfecho, ellas se revelan más descontentas (un $1 \%$ frente a un $0,20 \%$ ). Con relación a la edad y estado civil el panorama cambia sutilmente: los hombres se muestran tanto satisfechos como insatisfechos con las viviendas entre los 60-75 años de edad, mientras que para las mujeres, la satisfacción se extiende hasta los 80 años. Los datos ponen de relieve que los más contentos son los hombres casados y viudos, y en cuanto a las mujeres, la satisfacción también incluye a las mayores solteras. No obstante, destaca un porcentaje de viudas descontentas con la vivienda donde viven su senectud. En el tipo de hogar donde los mayores casados y viudos entrevistados suelen estar más satisfechos, predominan los matrimonios sin hijos, los monoparentales (que viven con hijos solteros) y los múltiples (que viven con el cónyuge e hijos casados).

Por lo revelado, en general, tenemos viviendas con condiciones apropiadas que permiten a los mayores mantenerse integrados en su hábitat sin mayores riesgos en el desarrollo de las actividades diarias. Tal vez, los menos satisfechos, encuentren alguna dificultad en el ambiente y esto pueda constituir una amenaza en la vida doméstica. 


\section{GRÁFICO 22}

\section{Grado de satisfacción con la vivienda}

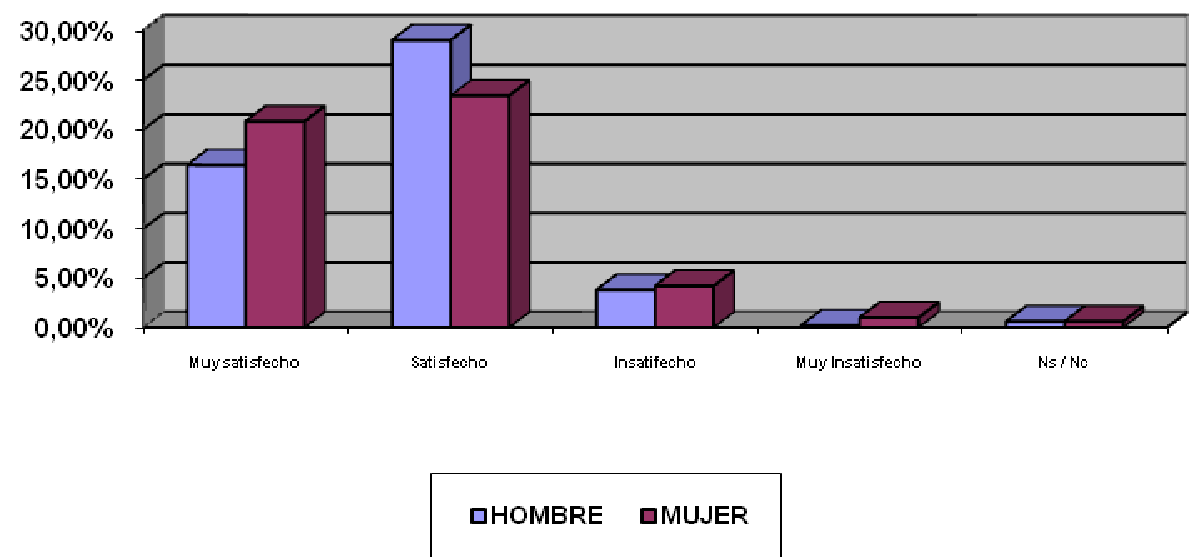

Fuente: Encuesta Perfil Sociológico de la Vejez en Mossoró - Junio 2004/ Junio 2005 (Elaboración de la autora)

\section{Problemas en el contexto de la vivienda}

Garantizar el acceso y mantener los servicios esenciales capaces de asegurar, tanto a ellos mismos como a su familia, seguridad y bienestar, con agua potable, sistema sanitario y eléctrico ligado a la red general, etc., exige tanto inversiones y medios de los poderes públicos constituidos, como la responsabilidad de los ciudadanos en la conservación.

En esta sección y la próxima proponemos averiguar el estado del acceso a bienes durables y servicios esenciales al desarrollo humano, así como revelar posibles dificultades o problemas causados por la ausencia de éstos en la vivienda de los mayores mossoroenses.

Así pues, los resultados obtenidos (Gráfico 23) apuntan, en líneas generales, que los hombres y mujeres ancianos tienen problemas en las viviendas con el abastecimiento sanitario $(20,60 \%)$, la humedad $(13,40 \%)$, la fontanería $(9,40 \%)$ y la estructura general $(8,20 \%)$. En menor frecuencia se indican problemas en el sistema eléctrico $(1,60 \%)$ y en el acceso a las escaleras $(1,40 \%)$.

En lo que concierne a nuestro colectivo, por sexo, los varones ponen más denuncias relacionadas con los problemas de humedad y del sistema sanitario. Las mujeres, por su lado, se centran más en la fontanería, las 
escaleras y la estructura general. Pero, por sexo y edad, en general, no apuntan dificultades significativas en relación a la red eléctrica y la escalera. Sin embargo, las mujeres de entre 60 y 70 años protestan con intensidad de los problemas de humedad (4,80\%), fontanería (3\%) y estructura general $(2,20 \%)$ en las viviendas. Mientras, los varones entre 60-80 años apuntan como su mayor problema el tema del sistema sanitario $(10,40 \%)$.

Aunque las dificultades señaladas por cada uno merezcan atención, en el conjunto, no suponen grandes porcentajes, aunque son suficientes en sí mismas para reflejar parte del descontento del colectivo y adivinar el nivel de bienestar objetivo de los mayores. Según Sancho (2001), la naturaleza de estos problemas ya es fatal para otros grupos de edad, imagínese para los ancianos que son considerados como "categoría de riesgo" "300 o vulnerables, en especial las mujeres y los de edad más avanzada.

Como en la investigación no preguntamos el porqué de dichos problemas, creemos que una parte de ellos existen por los parcos ingresos que reciben y por la responsabilidad del Poder Público. Un ejemplo claro estaría representado por el problema más acusado por los entrevistados, el sistema sanitario (20,60\%). En Brasil, los datos del IBGE ${ }^{301}$ revelan que las dotaciones básicas para el desarrollo normal de la vida de la población requieren aún grandes avances e inversiones por parte de los gobernantes. En todo el suelo tropical, aunque el porcentaje de domicilios con dotaciones básicas está prácticamente generalizado, con abastecimiento de agua tratada (83\%) y energía eléctrica $(97 \%)$, los servicios de infraestructura del sistema sanitario ligados a la red colectora alcanzan apenas un $69 \%$.

En Mossoró ${ }^{302}$, es patente la escasez de algunos servicios imprescindibles para el desarrollo humano. Apenas 11.025 de los domicilios particulares

\footnotetext{
300 Sancho, María Teresa, Ortiz, L. P, Aberllán, A. Y Rodríguez, Vicente (2001): Las personas mayores en España. Algunos indicadores básicos. Cuadernos de Trabajo Social, 14:221-253, Universidad Complutense de Madrid, p. 234.

$301 \quad$ Almanaque Abril, 2005 op. cit., p. 85.

302 El Instituto Brasileño de Geografía y Estadística (IBGE) facilita datos generales de cada municipio brasileño a través de IBGE Cidades@. Para mayores detalles de Mossoró visite la página web http://www.ibge.gov.br/cidadesat/xtras/SINTESE.php?nomemun=MOSSORO.
} 
permanentes $(21,15 \%)$ poseen cuarto de baño conectado al sistema general sanitario y sólo 45.059 viviendas poseen recogida de basura cada tres días $(86,45 \%)$. En cuanto al segundo problema citado por los mayores, el abastecimiento de agua potable de la red general, la situación mejora visiblemente, el recurso llega hasta 46.198 domicilios particulares permanentes, lo que significa un $88,36 \%$ de cobertura domiciliaria en la provincia. Pero no es suficiente para atender toda la demanda local. Aparte del Sistema Aductora Mossoró o Aductora Jerónimo Rosado, que suministra agua sobre todo para el consumo humano, Mossoró aún dispone de los acuíferos de Jandaíra, Açu, Barreiras y Aluvião (en su mayoría de agua potable para consumo humano, animal, industrial y otros) (IDEMA, 2004:10).

Efectivamente, las desigualdades sociales y económicas crean una realidad de contrastes para la salud. La falta de agua tratada y las condiciones sanitarias precarias facilitan el surgimiento de enfermedades infecciosas y parasitarias, como el cólera, el dengue, la tuberculosis y la hepatitis, por las que principalmente los niños, las mujeres y las personas de edad avanzada sufren graves consecuencias. La incidencia en Mossoró de casos registrados en 2002 (SESAP/SUS) de dengue (272), tuberculosis (136) y hepatitis (39), puede que se relacione con el saneamiento ambiental inadecuado.

\section{GRÁFICO 23}

Problemas en el contexto de la vivienda

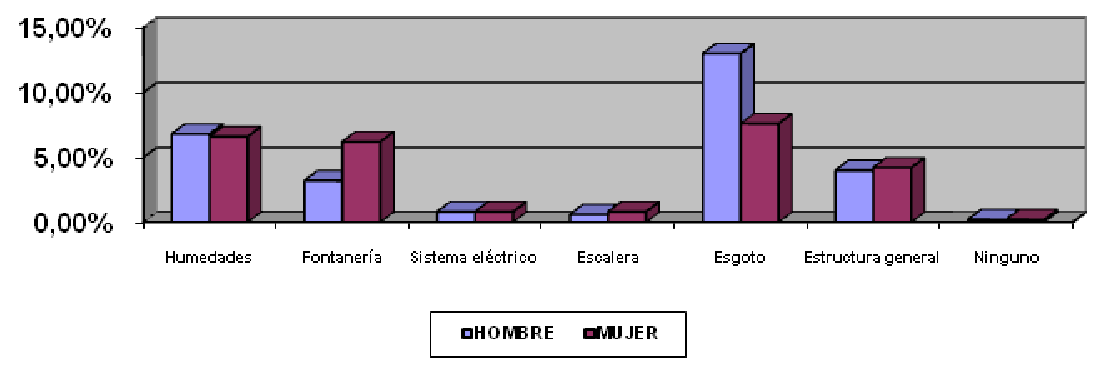

Fuente: Encuesta Perfil Sociológico de la Vejez en Mossoró - Junio 2004/ Junio 2005 (Elaboración de la autora) 


\section{Equipamientos y servicios de los que disponen en su domicilio}

Teniendo en cuenta los niveles de satisfacción residencial $(89,60 \%$, Gráfico 22$)$ expresados por el colectivo de mayores, volvemos a esta sección para relacionar dicha satisfacción con los servicios y equipamientos necesarios disponibles en su vivienda.

De acuerdo con la accesibilidad de equipamientos y servicios destacados para el conjunto de los entrevistados, como señala el Cuadro I, las dotaciones consideradas más básicas están presentes prácticamente en todos los domicilios de los mayores entrevistados. En conformidad con el Banco Nacional de Desarrollo Económico y Social (BNDES) ${ }^{303}$, el acercamiento de la universalización de algunos de estos servicios esenciales en Mossoró ya constituye una realidad. El abastecimiento de agua ${ }^{304}$ ligado al sistema general, que abarca casi al $90 \%$ de los domicilios, ha constituido una importante mejora y preservación de las condiciones de salud e higiene de los mossoroenses. Nuestra investigación ratifica que un $98,40 \%$ de los domicilios tiene agua corriente en su casa. No obstante, el agua saludable como necesidad humana fundamental, todavía le falta a alrededor de seis mil personas, a pesar de la existencia de reservas de agua en los acuíferos localizados en el suelo mossoroense.

La energía eléctrica también forma parte de este escenario, ya que de ella se beneficia un $88,5 \%$ de los domicilios mossoroenses ${ }^{305}$. A las casas de los mayores de nuestra muestra, la iluminación eléctrica llega en un 99,60\%, por encima de la media nacional que es del $93 \%$. Por otra parte, a pesar de que el 99,40\% afirma disponer de cuarto de baño en la vivienda, las condiciones

303 Consultar datos en la página web http://www.federativo.bndes.gov.br Según la Situación de los Domicilios Urbanos, investigados por la Pesquisa Nacional de Saneamiento Básico del Instituto Brasileño de Geografía y Estadística - IBGE/2000, divulgado por el Banco Nacional de Desarrollo Económico y Social (BNDES).

$304 \quad$ El Sistema de Abastecimiento de Agua: SAA de Mossoró, es administrado y operado por la CAERN - Compañía de Aguas y Cloacas de Río Grande del Norte, desde 1972. El sistema está subdividido espacialmente en 11 sectores, formados por 19 pozos tubulares en operación y 11 depósitos elevados. A nivel de Brasil, el agua abastece al 83\% de la población brasileña, en la Región Nordeste al $68 \%$ de los domicilios, mientras que en el Estado de Río Grande del Norte el agua potable llega al $78 \%$ de éstos. (Almanaque Abril 2004, pp. 156 e 402).

305 Consultar Informe de la Compañía Energética do Río Grande do Norte: COSERN, en la página web http://www.cosern.com.br. 
sanitarias ligadas al sistema general en el municipio no alcanzan al 30\% de los domicilios. ${ }^{306}$ Es probable que en parte de los domicilios particulares en los que viven estos mayores, el sanitario aún no esté conectado al sistema general, sino a un sistema de fosa séptica. El número de tales viviendas en Mossoró era de 37.096 en 2000 (IDEMA, 2000:10).

Entre los bienes durables con mayor presencia en los domicilios de los mayores están el fogón a gas butano $(97,80 \%)$, la nevera $(95,40 \%)$, la televisión $(95,20 \%)$, el ventilador $(89,20 \%)$, la radio $(87,80 \%)$ y el teléfono $(68,20 \%)$. Sin embargo, los bienes de equipamiento menos frecuentes en los domicilios, lo que es significativo, son el tocadiscos $(46,89 \%)$ y la lavadora automática $(43,60 \%)$. No obstante, aún son pocos los que disponen de dotaciones más sofisticadas como el vídeo $(30,60 \%)$, el ordenador $(13,20 \%)$ y el aire condicionado (10\%).

La variación en la proporción de las dotaciones existentes indica la desigualdad de confort, que puede ser consecuencia tanto de la definición de prioridades como del poder adquisitivo de las personas. Al comparar la adquisición de equipamientos en las residencias según la media nacional se comprueba como coincidencias más frecuentes el fogón de gas butano (97\%), la televisión (90\%) la nevera $(87 \%)$, la radio $(86 \%)$, el teléfono $(62 \%)$ y con menos incidencia en los domicilios brasileños el ordenador (14\%) y el aire condicionado $(9 \%)$.

Sin embargo, en los equipamientos durables con menor incidencia en los domicilios verificamos las diferencias entre las cinco grandes regiones del país. Si el $73 \%$ de los brasileños del Nordeste reciben hasta dos salarios mínimos mensuales, frente al $42,2 \%$ de los habitantes del Sudeste con esos ingresos, la desigualdad en el poder de compra es patente.

En general, tanto los bienes durables como los servicios ofertados en el barrio están distribuidos de modo equilibrado para ambos sexos, pero los únicos

\footnotetext{
Las condiciones de saneamiento en Brasil aún son muy precarias, a pesar de los avances presentados en el último Censo Nacional. El número de municipios con sistema sanitario aumentó un 10\% de 1989 a 2000, según la Pesquisa Nacional de Saneamiento Básico, realizada por IBGE. Pero, las desigualdades regionales persisten: el sumidero ligado al sistema general está distribuido de la siguiente forma: Norte 35,6\%, Nordeste 38\%, Sudeste 82,3\%, Sur 63,7\% y Centro-Oeste 40,7\%. En todo el territorio la fosa séptica alcanza sólo al $62 \%$ de los domicilios permanentes.
} 
equipamientos en los que las mujeres alcanzan una cifra sutilmente superior a los hombres son en el acceso al teléfono y al ventilador. Suponemos por ello que las mujeres, con el uso cotidiano del teléfono, se auxilian en el desarrollo de una vida independiente y de mantenimiento de lazos familiares y sociales (Fernández y cols., 2002:630) en proporciones superiores a las de los hombres entrevistados.

\section{CUADRO I}

Equipamientos y servicios de los que disponen en su domicilio

\begin{tabular}{|c|c|c|}
\hline $\begin{array}{c}\text { EQUIPAMIENTOS Y } \\
\text { SERVICIOS }\end{array}$ & $\begin{array}{l}\text { HAY } \\
\text { (\%) }\end{array}$ & $\begin{array}{c}\text { NO HAY } \\
(\%)\end{array}$ \\
\hline Agua potable & 98,40 & 1,60 \\
\hline Baño & 99,40 & 0,60 \\
\hline Luz eléctrica & 99,60 & 0,40 \\
\hline Televisión & 95,20 & 4,80 \\
\hline Vídeo & 30,60 & 69,40 \\
\hline Radio & 87,80 & 12,20 \\
\hline Tocadiscos & 46,89 & 53,11 \\
\hline Nevera & 95,40 & 4,60 \\
\hline Lavadora automática & 43,60 & 56,40 \\
\hline Fogón a gas & 97,80 & 2,20 \\
\hline Fogón de leña & 10,20 & 89,80 \\
\hline Teléfono & 68,20 & 31,80 \\
\hline Ordenador & 13,20 & 86,80 \\
\hline Ventilador & 89,20 & 10,80 \\
\hline Aire condicionado & 10,00 & 90,00 \\
\hline
\end{tabular}

(Elaboración de la autora)

\section{Prestaciones y servicios existentes cerca de su vivienda}

Al hablar de los equipamientos disponibles, en la sección anterior, hemos de hacer referencia a las dotaciones del barrio, entendiéndolas como un requisito necesario para la comodidad y el confort del conjunto de la población entrevistada.

Se ha querido saber la accesibilidad y dotaciones del barrio destacadas por los mayores. ¿Cuáles son los servicios y prestaciones ofertados que observan en su 
entorno? ¿Hay plazas y jardines como lugar posible de paseo y descanso? ¿Carece el barrio de algún servicio público o recurso para la tercera edad? ¿Los mayores forman parte del paisaje urbano?

De acuerdo con los datos obtenidos, casi el cien por cien de los entrevistados $(94,80 \%)$ afirma que existen pequeños comercios (supermercados, quioscos, etc.) cerca de su residencia, más de cuatro quintos cuentan con servicios de farmacias en el barrio $(82,80 \%)$, alrededor de tres cuartos tienen fácil acceso a un centro de salud $(71,60 \%)$, un $38 \%$ dispone de un centro para la tercera edad, un $89,40 \%$ cuenta con espacios religiosos, como iglesias o templos y por último, un 63,80\% afirma que cerca del domicilio hay plazas y jardines (Véase Gráfico 25).

Si analizamos las respuestas en función del sexo, edad o estado civil, no observamos diferencias significativas. De ese modo, optamos por analizar la cantidad de prestaciones y servicios de que disponen los ancianos cerca de su vivienda. Por tanto, se supone que están bien servidos, excepto en la disponibilidad de establecimientos destinados a las personas de edad avanzada. La existencia de treinta cinco centros de convivencia, distribuidos por los veintisiete barrios de Mossoró, ya evidencia la carencia de esas entidades prestadoras de servicios tan importantes para el desarrollo y valoración del anciano, en algunas localidades.

A continuación, se puede conjeturar que la cantidad de unidades básicas de salud y centros clínicos también se torna insuficiente en los barrios, por entender que Mossoró apenas dispone de 91 establecimientos de salud, divididos en 70 centros integrados al Sistema Único de Salud (SUS) y 21 unidades particulares de atención a la salud de los mossoroenses ${ }^{307}$. Atender a la demanda local, que ya sobrepasa los 229.787 habitantes (2007), a los moradores de las comunidades rurales y a los municipios circunvecinos menos desarrollados, pone en riesgo la salud de los mayores. Sin embargo, la Fundación Getúlio Vargas (FGV), clasificó la red de salud de Mossoró como la

$307 \quad$ IBGE, 2000. 
$13^{\mathrm{a}}$ mejor del país por ofrecer a la población $\mathrm{n}^{308}$ un servicio sanitario eficiente y de calidad.

Considerando que el ciudadano es el eje central y la razón de existencia de todo el sistema sanitario, es necesario facilitar la cohesión del sistema sanitario en los barrios, aumentar la actividad del sistema de salud, a fin de reducir las listas de espera, acercar a las áreas periféricas los servicios de atención geriátrica, la asistencia bucodental para mayores, las urgencias y el transporte asistido. Todas estas medidas son algunas sugerencias que se deberían adoptar, si entendemos la sanidad pública como un derecho de los ciudadanos que debe prestarse de forma universal, pública y accesible.

\section{GRÁFICO 24}

Prestaciones y servicios existentes cerca de su vivienda

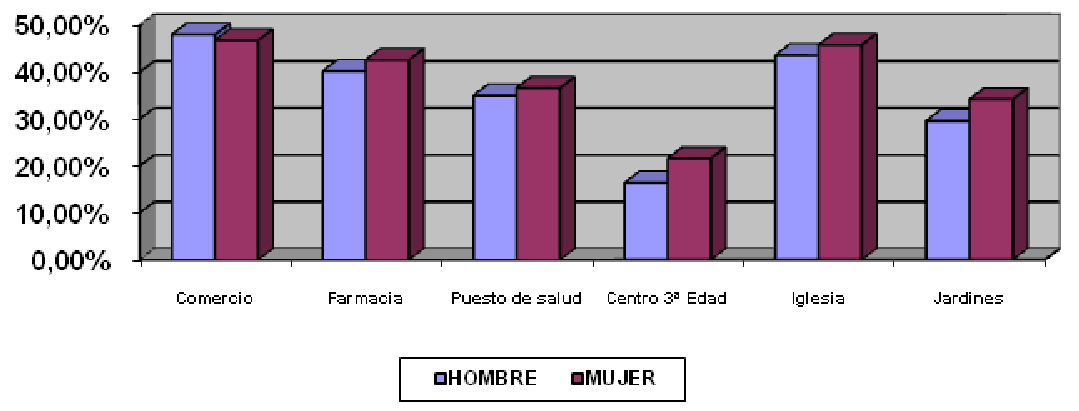

Fuente: Encuesta Perfil Sociológico de la Vejez en Mossoró - Junio 2004/ Junio 2005 (Elaboración de la autora)

\section{Situaciones que dificultan sus desplazamientos}

Si hablamos de las dotaciones y servicios disponibles en el barrio, también podemos hablar de los desplazamientos de los mayores hacia los servicios, no estrictamente en su barrio, más extendidos en las diversas partes de la provincia. Se preguntó a los mayores cuáles eran los inconvenientes, convirtiéndose en desafíos, que les dificultan los caminos que suelen recorrer cuando necesitan desplazarse. ¿Mossoró está pensada para los mayores? ¿Permite la accesibilidad física y social al anciano? ¿Los medios de transporte garantizan la accesibilidad? ¿Es acogedora y segura para quien envejece?

308 Consultar página web www.prefeiturademossoro.com.br en materia "Centro clínico realiza 37 mil análisis por mes”, publicado el 18 de Agosto de 2005. 
El 90\% de las opiniones de los mayores refleja que existen situaciones de dificultad en sus desplazamientos. De acuerdo con el Gráfico 25, las cifras más altas están representadas por: los desniveles en las aceras (86,20\%), el caos circulatorio $(85,40 \%)$, el cruce de calles sin semáforos $(84,80 \%)$, las avenidas y calles sin asfalto (80,40\%), los automóviles aparcados indebidamente $(78,40 \%)$, los semáforos que duran muy poco tiempo $(60,20 \%)$ y el difícil acceso a los transportes urbanos (60\%). Por último, en menor medida se refieren al difícil acceso a taxis $(36,20 \%)$ y moto-taxis $(21,20 \%)$.

Como era previsible, los mayores están más preocupados por aquellas situaciones que pueden comprometer su estado de salud física, poniendo en riesgo su vida. En primer lugar estarían las posibilidades que tiene una persona, principalmente de edad avanzada, de resbalarse, debido a los desniveles, traducidos en los altos y bajos de las aceras, todo ello sumado a una pésima conservación asfáltica de algunas calles y avenidas y a la total inexistencia de pavimentación en otras. El dañarse un hueso, entre los más descuidados, como los niños y ancianos, no es difícil ya que las aceras construidas en Mossoró parecen no seguir ninguna orientación del código de obras. Segundo, el caos circulatorio es algo a la orden del día, a pesar de la existencia de indicaciones, señalizaciones y normas de tráfico, así como de sanciones aplicadas a aquellos que infringen las leyes. La mezcla de coches, bicicletas, motos, carros, animales y gentes es algo frenético, donde, efectivamente la atención de los más viejos es fundamental. Para los más distraídos, ser atropellado es una cuestión de segundos. Y en tercer lugar, la ausencia de cruces de calles con semáforos. Los que hay tienen poco tiempo de duración y sólo aumentan el peligro para cualquier ciudadano, cuanto más para el anciano, generalmente más vulnerable a caídas y atropellamientos dada la presencia, a veces, de deficiencias auditivas, audiovisuales 0 motrices.

En Brasil, la preocupación sobre la mortalidad de ancianos por causas externas comenzó a partir de 1998. Según la investigación de Souza (1998), en Río de Janeiro, los accidentes de tráfico y transporte, especialmente para el sexo masculino, y las caídas en el sexo femenino, ocupan el sexto lugar en el 
cuadro general de mortalidad entre las personas de 60 años o más de edad. Machado y Queiroz (2002) subrayan que, en estudios hechos en algunos servicios de protección a los ancianos en Brasil, son reiteradamente mencionadas las reclamaciones sobre los transportes públicos, accidentes y caídas en vías públicas y muertes por atropellamientos y accidentes de tráfico.

Las demás situaciones colaboran con la inseguridad en los desplazamientos de los ancianos y de los demás ciudadanos mossoroenses, cuyas opiniones instan al Poder Público y a la sociedad civil a reconocer los problemas y a tomar las medidas necesarias.

Analizando el grupo por sexo, sobre todo los que utilizan como medios de trasporte coche propio, transporte colectivo público y moto-taxis, señalan los hombres que las situaciones más inconvenientes son los cruces de calles sin semáforos y el caos circulatorio. Además de éstas, las mujeres enfatizan la precariedad en la pavimentación de calles y avenidas que están sin asfaltar. Para los ancianos que suelen ir en bicicleta o a pie, las situaciones que les dificultan su desplazamiento son: coches aparcados indebidamente, avenidas y calles sin asfaltar, desniveles en las aceras y caos circulatorio. Las ancianas, aparte de las ya referidas, también se quejan de que los semáforos duran muy poco tiempo y de que los cruces de calles están sin semáforos. En la travesía de semáforos se da un tiempo insuficiente para que lleguen al otro lado de la acera. Es una reclamación generalizada en todos.

Centrarse en la planificación y la disciplina urbana serían formas de organizar y corregir problemas de esta naturaleza. Mossoró, a través de la Secretaría Municipal de Ciudadanía, está en proceso de actualización del antiguo Plan Director (1974). Según el secretario profesor Francisco Carlos Carvalho de Melo, el plan "es apenas una pieza de ordenamiento urbanístico y paisajístico de la ciudad. Incorpora también elementos como el código de postura, el código ambiental, el plan diario, el plan de metas, el código de obras..." ${ }^{309}$. El hecho de que población y provincia dispongan de estos instrumentos llega concedida al periódico O Mossoroense (www.omossoroense.com.br) en 1 de Julio de 2005. 
en un momento en el que Mossoró se encuentra en un intenso desarrollo social, económico y cultural.

Crear es importante, pero mantener y vigilar los servicios, con la colaboración de los ciudadanos, es imprescindible. El éxito depende también de la formación e información de la población.

\section{GRÁFICO 25}

\section{Situaciones que dificultan sus desplazamientos}

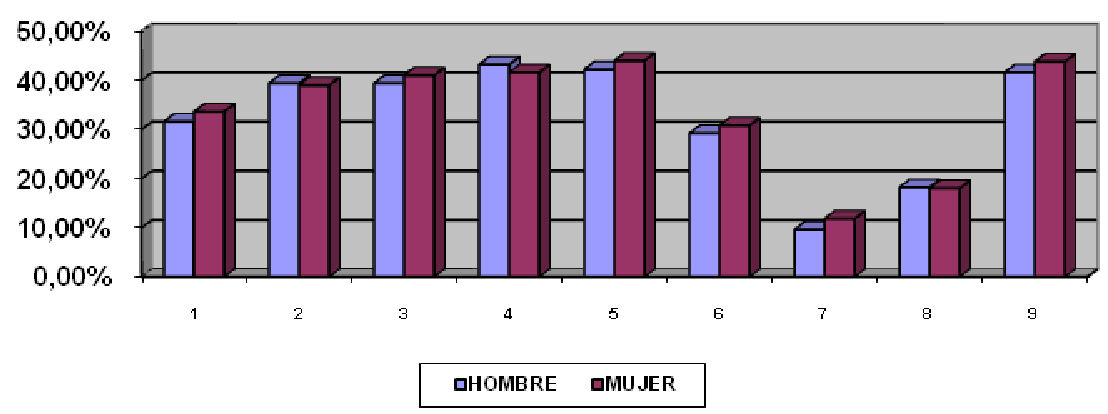

Fuente: Encuesta Perfil Sociológico de la Vejez en Mossoró - Junio 2004/ Junio 2005 (Elaboración de la autora)

1 - Semáforos muy breves

2 - Coches aparcados indebidamente

3 - Calles sin pavimentación

4 - Cruces de calles sin semáforos

5 - Desniveles en las aceras
6 - Difícil acceso al transporte urbano

7 - Difícil acceso a moto-taxis

8 - Difícil acceso a taxis

9 - Caos circulatorio

\section{Medio de transporte que suele usar}

De acuerdo con el último Censo Decenal $^{310}$, en las últimas décadas, los brasileños pasaron a tener amplio acceso a una serie de dotaciones necesarias para el bienestar poblacional. Coche y teléfono fueron los productos más consumidos. Señala el Informe que entre 1991 y 2000, aumentó un 41,6\% el número de familias que pasaron a contar con automóvil en su garaje. Sin embargo, muy poco de nuestro colectivo entrevistado ha aumentado esta lista, dado que sólo un 38\% afirma utilizar habitualmente el coche propio o de la familia como medio de transporte. Tal como vimos en la Tabla 11, más de la mitad de estos ancianos vive en familias monoparentales y múltiples. Un 
$27,80 \%$ asegura que suele utilizar el transporte colectivo público, un $15,20 \%$ indica que coge los servicios de moto-taxis, un $11,00 \%$ suele desplazarse a pie o no utiliza ningún tipo de transporte; en menores proporciones afirman que su medio de transporte es la bicicleta $(7,20 \%)$ y un $0,80 \%$ dice utilizar carros. El Gráfico 26 nos da el perfil completo de todas las informaciones recolectadas.

A pesar de que la gratuidad de los transportes colectivos urbanos para los mayores fue instaurada en la década de 1980, mucho antes del Estatuto, esta es una de las áreas más sensibles en la vida cotidiana de los mayores y todavía hay mucho que hacer para garantizar los derechos que la ley les otorga. Los mayores se enfrentan a un serio problema cuando la solución para trasladarse pasa por este medio de transporte. Además de que el sector de transporte público de Mossoró es deficitario, los usuarios denuncian el mal estado de la flota de autobuses y sus servicios ineficientes. La falta de respeto de una parte de los conductores del transporte colectivo público hacia los mayores, parece ser una práctica constante. Como no pagan el billete ${ }^{311}$, en Brasil hay datos que denuncian actitudes de violencia de ciertos conductores para con los ancianos. De acuerdo con datos del SUS, hay dos causas principales de muerte violenta de mayores: los accidentes de tráfico con cerca del $30 \%$ y las caídas, que cubren cerca del $23 \%$. Enseguida vienen los homicidios, con el $10 \%$ de muertes violentas y los suicidios con el 7,5\%. Para todas las causas, sobre todo las que son conocidas como accidentales, los riesgos aumentan con el paso de la edad, mereciendo atención especial de las familias, cuidadores y autoridades. La falta de respeto de algunos conductores de autobuses se transforma en un cuadro vejatorio y peligroso para la vida del anciano, cuando éste intenta tomar el autobús y el conductor acelera el vehículo en el momento de la subida del mayor ${ }^{312}$. En general, en el tráfico brasileño, los

$311 \quad$ En el año 2002, la Ley Orgánica del Municipio de Mossoró, asegura en el Inciso II, Art. 202 la gratuidad del transporte público colectivo a los mayores de 65 años de edad, reconocidos como pobres en la forma de la ley. Al siguiente año, se redujo la edad de 65 a 62 años respetando los mismos criterios para el beneficio social.

312 De acuerdo con Lan Hee Alves Castanha, coordinadora del Núcleo de Atención a las Víctimas de Violencia (Navv) del Hospital Municipal Dr. Arthur Ribeiro de Sabóia, situado en la capital paulista, el 32\% de las muertes de ancianos registradas son fruto de la violencia. La primera causa es el accidente en el transporte, seguida de malos tratos, agresión y atropellamiento. 
mayores pasan por una combinación de desventajas: dificultades de movimientos propias de la edad sumada a mucha falta de respeto e incluso a la violencia, practicadas por conductores, sin olvidar la negligencia del poder público. Una de las quejas de los mayores se refiere a las largas esperas en las paradas del autobús y las prisas de los conductores, que no esperan a que los mayores se acomoden en los asientos. En Mossoró, también se registran casos semejantes. Además, son reales las denuncias de que los conductores de autobuses no paran a los mayores en los puntos determinados de pasajeros. De hecho, las paradas apenas se efectúan, cuando en el momento de la espera hay pasajeros de poca edad. Muchas veces, las personas de edades avanzadas siguen su trayecto a pie, por no coincidir en las paradas con personas más jóvenes. Bennett y colaboradores (1997), consideran tres niveles de violencia hacia el anciano. Específicamente, este caso se encaja en el nivel medio, dado que se refiere a actitudes y conductas que afectan al anciano en la comunidad, incluyéndose conductas antisociales y el prejuicio contra la vejez, que llevan a la población anciana a vivir situaciones de marginalización y de discriminación.

Analizando por sexo, por un lado notamos que los varones más que las mujeres suelen utilizar los autobuses públicos, la bicicleta y el carro, como medio de transporte. Además de ir a pie con más frecuencia que ellas. Por otro, las mujeres disponen de coches propios o de familiares y cogen más los servicios de moto-taxis.

Por situación socioeconómica, entre los hombres que reciben entre uno y dos salarios mínimos es más frecuente utilizar el transporte público $(9,60 \%)$, coche propio o de un familiar (5,60\%), bicicleta (4,60\%) y moto-taxi $(2,20 \%)$. Mientras, las mujeres suelen acudir al transporte público $(9,60 \%)$, coche privado o de familia $(7,20 \%)$ y moto-taxis $(6 \%)$.

En general, es positivo que los mayores entrevistados parezcan disponer de autonomía e independencia en cuanto a sus desplazamientos. Los recursos de ir a pie y en bicicleta serían los más adecuados, aparte de ser más saludables y ecológicamente correctos, si no fuera por las dificultades encontradas en el tráfico de Mossoró. Por último, el servicio de transporte colectivo público 
parece el más grave. El mal estado de los vehículos (viejos y poco confortables) y el mal estado de conservación, ponen en riesgo, sobre todo, la vida de los pasajeros. El mal trato dispensado por parte de algunos conductores sin formación hacia los mayores mossoroenses, merece la atención pública. Es necesario impulsar programas de educación y profesionalización, enfocados a la humanización en el trato en los servicios del transporte colectivo público, desarrollar un programa de detención y asistencia para los mayores que sufren malos tratos a través de los servicios públicos. En resumen, garantizar los derechos de acceso al transporte colectivo urbano a las personas con edad igual o superior a los 60 años a través del Estatuto del Anciano (Ley n. 10.741, de $1^{\circ}$ de Octubre de 2003) es una obligación que deben compartir gobierno, empresarios y sociedad civil. Solo así podemos y debemos construir una sociedad para todas las edades.

\section{GRÁFICO 26}

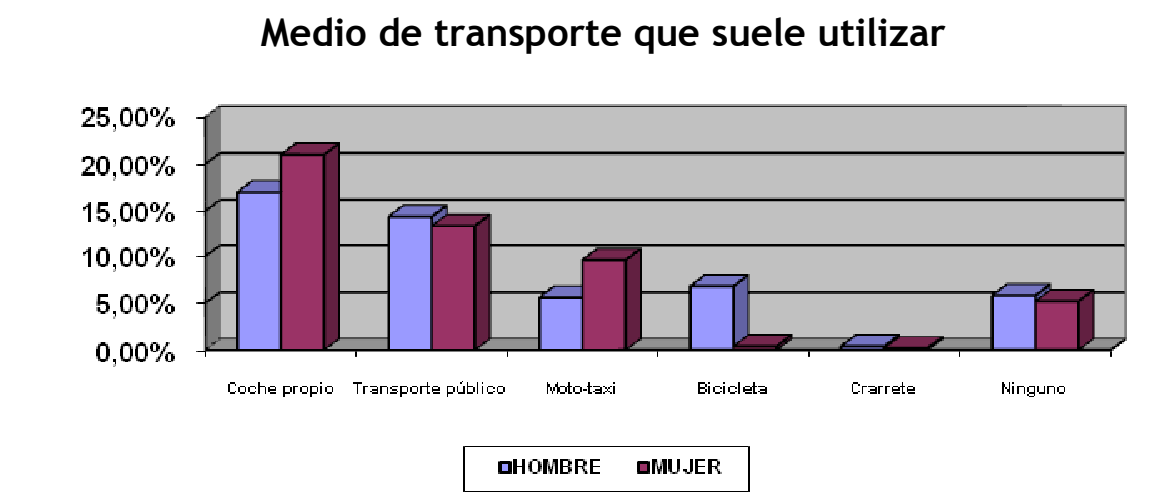

Fuente: Encuesta Perfil Sociológico de la Vejez en Mossoró - Junio 2004/ Junio 2005 (Elaboración de la autora)

\section{Resumen}

La investigación que se ha llevado a cabo en este apartado, el entorno físico del mayor, ha sido fundamentalmente cuantitativa, pero las dosis de análisis cualitativos puede que sirvan especialmente para el estudio e implementación de políticas públicas sociales dirigidas a este grupo demográfico de Mossoró. En este capítulo 7, nos hemos centrado en la vivienda del mayor y en el conjunto de rasgos que caracterizan el ambiente que rodea a los sujetos. Los detalles de los datos nos permiten penetrar en un tema crucial que enfrenta a muchos brasileños, el "déficit habitacional", además de las particularidades del entorno físico. También se analizan las prestaciones y servicios disponibles 
en la vivienda de la población de edad avanzada, además del mobiliario urbano e infraestructura de la ciudad.

Los resultados muestran un porcentaje muy elevado de mayores que tiene como tipo de vivienda una casa, (97,79\%). El resto vive en unidades denominadas apartamentos y “quitinetes". Cuatro quintos tienen la vivienda en propiedad $(80,40 \%)$, estando totalmente pagada, el $7,60 \%$ vive en alojamientos de forma gratuita facilitados por un familiar, el 7,20\% vive en régimen de alquiler y el menor porcentaje la tiene en propiedad pero con pagos pendientes (4,60\%). La gran mayoría de los sujetos residentes en el municipio tiene dormitorio independiente (79,80\%). A parte del 4,60\% que vive en solitario, lo que no se aplica en esta cuestión, el resto, el 15,40\% lo comparte con otra persona o utiliza otra estancia de la casa para los momentos de privacidad y descanso. Quizá por esa y otras situaciones reveladas se justifique que casi todas las personas mayores están satisfechas con el inmueble donde viven, el $89,60 \%$.

También resulta notorio que la propiedad del domicilio del grupo de población anciano entrevistado está dentro de la media del Nordeste $(77,5 \%)$ y por encima de la media del Estado de Río Grande del Norte (73\%). Es probable que la cifra se justifique, porque la vivienda para el brasileño constituye una prioridad de consumo, así que no es de extrañar que los mayores hayan trabajado toda la vida para comprarse una. No obstante, para los pocos que viven en domicilios alquilados, con rentas que oscilan entre el equivalente a 15 y 55 euros, son viviendas de aspecto muy modesto, con infraestructura de pequeño porte, en mal estado y ubicadas en barrios periféricos de la ciudad de Mossoró.

A pesar de los datos arriba indicados, que muestran la privacidad de gran parte de los mayores en su domicilio, alrededor de una quinta parte de los hombres casados, mujeres casadas y viudas vive en hogares con familias extensas y no disponen de dormitorios privados. La falta de confort y privacidad para ese grupo de edad puede influir en su estado de bienestar 
doméstico. Es posible que uno de los motivos del descontento con la vivienda donde viven su senectud esté en este campo.

Pero, hay algunos problemas en las viviendas, que desagradan a los ocupantes. En el conjunto de las dificultades señaladas que merecen más atención está el sistema sanitario $(20,60 \%)$, la humedad $(13,40 \%)$ la fontanería $(9,40 \%)$ y la estructura general $(8,20 \%)$. Creemos que estos problemas existen en parte, por incompetencia de los órganos públicos y a causa de la insuficiencia de ingresos. Para poner un ejemplo, el sistema de saneamientos en Mossoró sólo cubre 11.025 domicilios particulares permanentes, o sea, poseen cuarto de baño conectado al sistema general de saneamiento el correspondiente al $21,15 \%$ del total de domicilios, 52.212 (IDEMA, 2000:14). En todo el país este tipo de recurso aún requiere grandes avances e inversiones. La ausencia o mala calidad de tales recursos compromete la calidad de vida del ciudadano y, entre los que más sufren las consecuencias se debe incluir a los mayores.

Aún en el tema de la vivienda, relacionando la satisfacción y el bienestar del grupo de edad investigado con las dotaciones disponibles en su hogar, comprobamos que lo más básico está presente en casi todos los domicilios. El abastecimiento de agua conectado al sistema general abarca al 98,40\%; de energía eléctrica disponen el 99,60\%; de servicio de baño el 99,40\%. Entre los bienes durables más comunes con mayor incidencia en las viviendas de los mayores están la televisión $(95,20 \%)$, la nevera $(95,40 \%)$, el ventilador $(89,20 \%)$, la radio $(87,80 \%)$ y el teléfono $(68,20 \%)$. Por otra parte, los equipamientos necesarios en la actualidad, menos frecuentes en los domicilios son el tocadiscos $(46,89 \%)$, la lavadora automática $(43,60 \%)$, el ordenador $(13,20 \%)$ y el aire acondicionado (10\%). Comparados con la media nacional, se comprueba la compatibilidad en algunos de ellos: la radio $(87,4 \%)$, la televisión $(87 \%)$ y la nevera $(83,2 \%)$ y con menos incidencia en los domicilios brasileños, el ordenador $(10,6 \%)$ y el aire condicionado $(7,5 \%)$. 
Sin embargo, a través de los equipamientos durables con menor incidencia en los domicilios se verifican las diferencias entre las cinco grandes regiones del país. Es decir, el $73 \%$ de los habitantes del Nordeste que ganan hasta dos salarios mínimos, no consigue comprar estos equipamientos, y esta cifra desciende al 42,2\% para los habitantes del Sudeste en la misma condición. En la Encuesta Perfil Sociológico de la Vejez en Mossoró, el acceso a bienes y servicios iguala la media nacional. Las familias más estructuradas económicamente disfrutan en mayor proporción de las dotaciones necesarias para el desarrollo normal de la vida de la población.

La prerrogativa de bienestar, entre tantas definiciones, puede significar disponer de recursos necesarios dentro y fuera del hogar, para el pleno usufructo de la condición humana. Dentro de la población investigada, casi el cien por cien $(94,80 \%)$ debe vivir cómodamente porque cuenta con un pequeño comercio y tiendas cerca de su residencia. El $89,40 \%$ asegura que hay espacios para manifestaciones religiosas, el $(82,80 \%)$ dispone de servicios de farmacias en el barrio; cerca de tres cuartos tienen acceso a puestos de salud $(71,60 \%)$ y un $63,80 \%$ afirma que cerca del domicilio hay plazas y jardines. A primera vista, parece que los mayores están "bien servidos". Los datos no nos dicen nada acerca de la calidad de tales prestaciones y servicios. Quizá el buen funcionamiento atienda parte de las necesidades de los mayores. En Mossoró, los barrios están relativamente bien equipados, a pesar de que algunos conjuntos habitacionales en localidades alejadas del centro de la ciudad carecen de infraestructura urbanística. Sería conveniente dotar de infraestructuras a los barrios con la implantación de más unidades de salud pública y espacios abiertos, por ejemplo, como jardines. Si en 2000-2001, toda la ciudad disponía de apenas 91 establecimientos de salud con 1.048 camas de hospitales, para 213.841 habitantes, significa un promedio de 204 personas por cada cama. Hay que señalar la falta de previsión en esta área, ya que generalmente los ancianos la necesitan con más frecuencia.

Finalmente, en lo que se refiere al ordenamiento urbano, (la infraestructura y organización de algunos servicios disponibles para la población en Mossoró, para el grupo de edad investigado), entre las situaciones percibidas que más 
dificultan los desplazamientos están: los desniveles de las aceras (86,20\%), el caos circulatorio (85,40\%), el cruce de las calles sin semáforos $(84,80 \%)$, las avenidas y calles sin asfaltar (80,40\%), automóviles aparcados indebidamente $(78,40 \%)$, semáforos muy breves $(65,20 \%)$ y el difícil acceso a los transportes urbanos colectivos $(60 \%)$. En menores proporciones, se quejan del difícil acceso a taxis $(36,20 \%)$ y servicios de moto-taxis $(21,40 \%)$, respectivamente. Aunque a menudo los gestores públicos han tomado decisiones para mejorar estas condiciones, de forma ocasional, la situación para los mayores es algo desoladora. En general, casi todas las situaciones suelen apuntar hacia los riesgos para la vida. La falta de seguridad hace que caerse o ser atropellado en estas condiciones sea algo casi natural. Las ciudades deben estar pensadas para los mayores, y Mossoró, todavía no lo está. Ellos precisan moverse a través de su ambiente físico tanto como cualquier otro grupo de edad, así que nos parece que se deben tomar algunas decisiones para mejorar estas condiciones. Es conveniente que el Ayuntamiento Municipal de Mossoró retome y actualice el Plan Director de Mossoró; que el Departamento de Tránsito (DETRAN) revise y planifique medidas a favor del bienestar de los ciudadanos y que el Estatuto de la Ciudad (Ley 10.257, de 10.07.2001), responsable de la reglamentación de los instrumentos de política urbana aplicados por la Unión, Estados y Municipios se ponga efectivamente en práctica.

Un buen ordenamiento en el tráfico, además de calles pavimentadas, asfaltadas y aceras niveladas, facilitaría sin duda los desplazamientos, tanto de los mayores como de toda la población local.

En lo que se refiere al medio de transporte que suele utilizar, un $38 \%$ afirma utilizar habitualmente el coche propio o de la familia como medio de transporte. Un $27,80 \%$ asegura que suele utilizar el transporte colectivo público, un $15,20 \%$ indica que coge los servicios de moto-taxis, un $11,00 \%$ suele desplazarse a pie o no utiliza ningún tipo de transporte; en menores proporciones afirman que su medio de transporte es la bicicleta $(7,20 \%)$ y un $0,80 \%$ dice utilizar carros. 


\title{
Salud y asistencia sanitaria
}

\author{
No se trata de añadir años a la vida, \\ sino de dar vida a los años. \\ Antonio Gala (1932), \\ Dramaturgo, novelista y poeta español.
}

\section{Percepción del estado de salud durante el último año}

El tema del "envejecimiento poblacional” está, felizmente, cada vez más en discusión. Ya era hora de que se tomara en serio la realidad de un número de personas que se están haciendo cada vez más mayores. En Brasil, poco a poco, todos van enterándose de este triunfo, que al mismo tiempo es un desafío, entre tantos otros ya conocidos. Con el progresivo aumento de los mayores, las demandas sociales y económicas pasan efectivamente por un reordenamiento. Gobiernos, organizaciones y sociedad civil deberán implementar políticas y programas para el envejecimiento activo 313 , que mejoren la salud, la participación y la seguridad de los ciudadanos más viejos. De ese modo, el tema de la salud pasa a ocupar un lugar central, dado que los servicios y prestaciones sociales ofrecidos a los mayores por los órganos públicos y privados tienen relación directa con la prevención y cuidados de la salud de este segmento social ${ }^{314}$. A lo largo de este apartado, aportaremos datos que ayudarán a reflexionar sobre algunos aspectos inherentes al estado de la salud y las políticas sanitarias y sociales de prevención de las personas de 60 o más años de edad, que participaron de la investigación Perfil Sociológico de la Vejez en Mossoró, a fin de conocer el cuadro actual de estos adultos mayores y las necesidades de los que próximamente serán mayores, respecto a servicios y prestaciones sociales.

\footnotetext{
313 El término "envejecimiento activo", fue adoptado por la Organización Mundial de Salud (OMS) en 1990. Se procura transmitir un mensaje más amplio del "envejecimiento saludable", y reconocer, más allá de los cuidados de salud, otros factores que afectan al modo en que los individuos y las poblaciones envejecen (Kalache y Kickbush, 1997).

$314 \quad$ Neri y Cachioni, 1999.
} 
Como ya se señaló antes, es notorio que los mayores brasileños están viviendo más y en mejores condiciones de vida. Para Camarano ${ }^{315}$, las razones se encuentran en la acción conjunta de tres factores: la ampliación de cobertura de los servicios y prestaciones sociales, el mayor acceso a los servicios de salud y el avance de la tecnología médica. Por estas y otras razones, como hemos señalado anteriormente, la esperanza de vida masculina pasó de 58,6 años en 1980 a 64,77 en 2000 y la femenina, de 65 a 72,55 años, respectivamente. Sin embargo, un gran desafío que nos reserva la longevidad aumentada es el de conseguir que valga la pena vivir los años conquistados, y vivirlos sobre todo con salud. En este apartado analizaremos algunas cuestiones sobre el estado de salud de nuestros protagonistas. ¿Cuál es la percepción del propio estado de salud de los mayores en Mossoró? ¿Quiénes enferman más, hombres o mujeres? ¿Qué enfermedades padecen? ¿Cómo son asistidos? ¿De qué tipo de asistencia sanitaria disponen?

De acuerdo con la auto percepción del estado de salud del colectivo anciano, los datos podrían coincidir con los de la Pesquisa Nacional por Muestra de Domicilio (PNAD/1998), si sumamos las variables muy bueno, bueno y regular. En general, un $45,69 \%$ de los mayores ha declarado tener un estado de salud muy bueno y bueno en los últimos doce meses, un $47,29 \%$ lo ha calificado de regular y apenas un $6,61 \%$ lo ha calificado de malo o muy malo. A pesar de que las mujeres tienen una esperanza de vida superior a la de los hombres, ellas suelen quejarse más de su estado de salud, como declara Camarano, (2000). Así pues, los varones entrevistados aparentan estar más sanos que ellas en mayores proporciones. Para el $20,44 \%$ de los varones y el $15,03 \%$ de las mujeres el estado de salud ha sido bueno el último año, aunque ellas se sitúan en porcentajes más altos en los estados malo y muy malo. Casi diez años después, en 2006 la Fundación Perseu Abramo trazó el perfil de los mayores brasileños y reveló que en este colectivo el 19\% declaró no tener

315 Camarano, Ana Amélia. Brazilian population ageing: differences in well-being by rural and urban areas. Presentado, en el UNRISD Meeting on Ageing Development and Social Protection. MadridSpain, 2002, 7-9 April. 
ninguna enfermedad, mientras que el $81 \%$ afirmó tener una o más enfermedades.

Según Ana Collado (1989), "la salud y las enfermedades no se distribuyen en la población de manera homogénea. Variables como edad, sexo, clase social, educación y hábitat, ejercen una marcada influencia en las condiciones de salud y calidad de vida de los viejos. Existen, pues, diversas relaciones entre la estructura social de una sociedad, según el grado de salud, bienestar y enfermedad de dicha población" (1989:203). Todos estos factores relacionados entre sí, generalmente otorgan a las mujeres de edad avanzada una posición más desventajosa (Sancho y Pérez, 2001).

Los resultados obtenidos en el Gráfico 27 sobre las posibles discrepancias de salud entre los sexos indican diferencias significativas que están vinculadas a las características socio-demográficas del individuo. Tratándose de la variable edad, se nota que los estados de salud bueno y regular están más presentes entre los hombres de 60-75 años, mientras que para las mujeres sólo hasta los 70 años. En la calificación mala o muy mala, la queja de varones y mujeres se limita hasta 70 años y 80 años, respectivamente. Bajo la condición económica, los varones con hasta dos salarios mínimos señalan tener salud buena o regular, pero las mujeres con estos mismos estados de salud afirman necesitar ingresos superiores a estos valores. Para la relación de estatus ocupacional, los indicadores no presentan grandes diferencias, dado que la mayoría de los ancianos entrevistados se encuentran en la situación de jubilados $(76,80 \%)$ y pensionistas $(16,20 \%)$ con ingresos muy limitados.

Concretamente, considerando la propia apreciación del anciano en cuanto a su estado de salud, que puede ser un tanto subjetivo, en una primera observación nos parece que el estado de salud del colectivo es positivo, señalando algunas diferencias en cuanto al sexo. En una segunda observación, se demuestra que os brasileños que no viven en pie de igualdad en el campo de la salud. A pesar de todas las conquistas anteriormente señaladas, es en la región Nordeste donde hay menor expectativa de vida, con 65,78 años y 
Salud y asistencia sanitaria.

mayor mortalidad infantil, con 44,2 por cada mil nacidos vivos ${ }^{316}$. El indicador, puede aún ser utilizado como revelador de futuras situaciones de necesidades asistenciales y para la organización de programas, observando las diferencias entre hombres y mujeres ancianos.

\section{GRÁFICO 27}

Percepción del estado de salud durante el último año

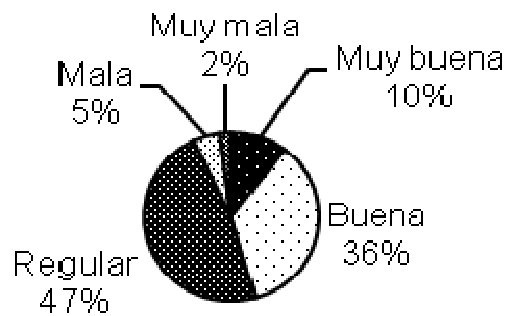

Fuente: Encuesta Perfil Sociológico de la Vejez en Mossoró - Junio 2004 / Junio 2005 (Elaboración de la autora)

\section{Enfermedades declaradas actualmente}

La mayor longevidad del ser humano fue alcanzada gracias al desarrollo socioeconómico y científico de la humanidad. Este plus de vida no garantiza por sí sólo una vida con buena calidad; hay implicaciones importantes en esta fase que debemos observar. La calidad de vida está comprometida por problemas de salud, que surgen a medida que la población se vuelve más anciana. Hay que tener en cuenta que en Brasil, donde las desigualdades sociales $^{317}$ son tan profundas, hay una evidencia de que la salud está mucho más relacionada con el modo de vivir de las personas que con la idea hegemónica de su determinación genética y biológica. A este respecto, Ramos

\footnotetext{
316 Fuente: Censo 2000 - IBGE y Ministerio de Salud (MS).

317 Brasil es el cuarto país del mundo con peor distribución de renta, la distancia entre ricos y pobres es tan grande que solo queda por detrás de Sierra Leona, República Centro Africana y Suazilandia. El 10\% de los más pobres tiene acceso a apenas el 1\% de la renta generada en el país y el 10\% de los más ricos recibe el 46,1\% de la renta total. Otro aspecto típico está relacionado con el mercado de trabajo brasileño. La alta disparidad entre los extremos de la pirámide salarial es patente: El 10\% de los más ricos en Brasil posee una renta media 85 veces mayor que la del $10 \%$ de los más pobres, diferencia que llega a ser cinco veces superior que en la mayoría de los países europeos. Almanaque Abril 2005, p. 51.
} 
(2002) señala que “las condiciones de higiene y trabajo, el bajo poder adquisitivo y una alimentación deficiente continúan afectando a la mayoría de la población". Con eso, continúa el autor, "se posterga la muerte, pero no se evitan las enfermedades."(2002:72).

Así pues, cada persona y cada generación, según Rodríguez y Rauth (2002), “experimentan la vejez de formas diferentes, dependiendo de una constelación de factores biológicos y ambientales; se permite constatar que no hay una exclusiva vejez, sino vejeces distintas" (2002:107).

Frente a lo ya descrito en los apartados anteriores, es perceptible, la evidencia de que un $78,60 \%$ padece una o más enfermedades. Según la clasificación de las distintas enfermedades en el Gráfico 28, más de una cuarta parte afirma padecer de afecciones cardiovasculares $(26,80 \%)$, un $18,40 \%$ de ellos menciona tener problemas de locomoción, un 15,20\% se refiere a dificultades digestivas, un 13,80\% afirma padecer de problemas respiratorios, un $10,80 \%$ de disturbios urinarios, un $11,40 \%$ de problemas neurológicos. Además de éstos, un 33\% padece otros tipos de enfermedades no nombrados y un $21,40 \%$ dice estar exento de enfermedades. Hay que tener en cuenta que los porcentajes superan el $100 \%$ dado que la cuestión es de múltiple elección. Dos años después de nuestra investigación, los datos de la Fundación Perseu Abramo (2006), que traza las condiciones de salud de los mayores en Brasil, revelaron que el $81 \%$ de las personas mayores de 60 años padece de alguna enfermedad. La hipertensión es la principal, seguida de los problemas de visión, columna, diabetes y dolencias cardíacas.

Analizando por sexo, las mujeres superan las cifras con enfermedades más numerosas que los hombres, excepto en la opción respiratoria, donde un $7,60 \%$ de los varones frente a un 6,20\% de las mujeres padece tal patología. Por edad, en los varones se hace patente la presencia de dolencias hasta los 70 años, mientras que en las mujeres podemos encontrar manifestaciones de síntomas más allá de los 80 años.

Tratándose de la media nacional en Brasil, ciertos estudios apuntan que el $85 \%$ de los ancianos presenta por lo menos una enfermedad crónica, y de 
éstos, el $10 \%$ posee, como mínimo, cinco de esas afecciones simultáneamente (Ramos, 1993). Entre las dolencias de mayor intervención geriátrica, según Marino y colaboradores ${ }^{318}$, están las cardiovasculares (arteriosclerosis: cardiopatía isquémica - accidente vascular cerebral), la cancerígenas, si mencionamos las dolencias respiratorias (dolencia pulmonar obstructiva crónica -DPOC), las enfermedades osteoarticulares (osteoporosis y osteoartritis) demencias, diabetes mellitus, depresión, parkinson, deficiencia visual y auditiva. En el grupo de las incapacidades, las más comunes son la incontinencia urinaria (pérdida de orina en cantidad o frecuencia grandes), trastornos de postura y enfermedades que llevan a la inmovilidad. De ese modo, la investigación se muestra coherente con la referida media.

Todas estas pautas y relaciones, según Ramos (2002) diseñan un gran desafío para Brasil en este nuevo siglo. Para el autor, cuidar de una población de más de 32 millones de ancianos, según las proyecciones para 2025, la mayoría con bajo nivel socioeconómico y educativo y un alto índice de enfermedades crónico-degenerativas e incapacitantes, se reflejará en las áreas, médica, social, económica y política, que se interrelacionan profundamente.

El conocimiento del estado de salud de los mayores en Mossoró, sin duda, amplía los estudios en las áreas biomédicas, pero también en las ciencias humanas y sociales. Se debe dar énfasis, tanto en el tratamiento como en la prevención de las enfermedades asociadas al envejecimiento. Ese abordaje, más allá de aumentar la duración de la vida y su calidad, también puede reducir el coste de tratamientos médicos diversos. Es necesario, disponer de políticas adecuadas que puedan garantizar un mínimo de calidad de vida para los que llegan a una edad avanzada (Kalache, 1996). Implementar, a corto plazo, las políticas sanitarias capaces de dar respuesta a las demandas de los propios ancianos mosoroenses, como prescribe la Política Nacional del Anciano (Ley Federal n. 8842/94), es un derecho inalienable.

\footnotetext{
318 Marino, M. C. de Abreu, Moraes, E. N. De y Santos, A. G. R. (2002): Avanços e perspectivas em geriatria. Em Freitas, Py, Neri, Cançado, Gorzoni e Rocha, Tratado de Geriatria y Gerontologia, Río de Janeiro: Editora Guanabara Koogan, Cap. 70 p. 589.
} 


\section{GRÁFICO 28}

Enfermedades declaradas actualmente

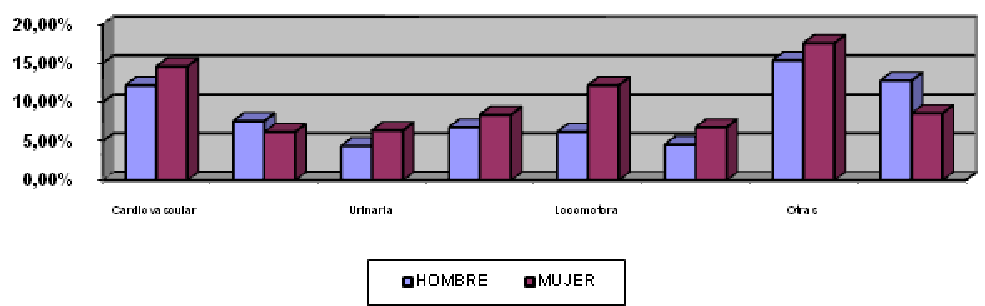

Fuente: Encuesta Perfil Sociológico de la Vejez en Mossoró - Junio 2004 / Junio 2005 (Elaboración de la autora)

\section{Capacidad auditiva}

La vejez es un proceso personal, natural, inevitable e irreversible para cualquier ser humano en la evolución de su vida. En esa fase siempre ocurren cambios biológicos, fisiológicos, y psicosociales que componen el mundo cotidiano de las personas. Las señales características de esas transformaciones son nítidas, debido a la acción social y del tiempo. Entre éstas, surgen los cambios físicos, que se dan de manera gradual y progresiva, a través de la aparición de las arrugas y de la pérdida de elasticidad y lozanía de la piel; disminución de la fuerza muscular, de la agilidad y de la movilidad de las articulaciones; aparición de las canas y pérdida de pelo entre los individuos del sexo masculino; reducción de intensidad sensorial, de capacidad auditiva y visual; trastornos del sistema respiratorio y circulatorio; alteraciones de memoria y otras (MacTavish, 1971; Palmore, 1971).

Especificando la cuestión auditiva, según los expertos en otología, la deficiencia auditiva puede ser más evidente después de los 65 años de edad y es conocida como presbiacusia ${ }^{319}$. En Brasil, trabajos recientes demuestran

\footnotetext{
$319 \quad$ La presbiacusia es la pérdida auditiva debido a cambios degenerativos en el sistema auditivo periférico y central que acompañan al envejecimiento. Sin embargo existen factores que pueden anteceder o estar asociados a la presbiacusia y que también pueden llevar a deficiencia auditiva, tales como los problemas metabólicos, la tensión arterial, las dolencias cardiovasculares, los problemas de huesos (osteosclerosis), la exposición prolongada al ruido y la herencia genética (Bilton, Viúde y Sánchez 2002:823).
} 
que la deficiencia auditiva es sufrida por 5,7 millones de brasileños, de los cuales 176.067 personas padecen una deficiencia auditiva total. Para el Dr. Sady Selaimen da Costa, presidente de la Sociedad Brasileña de Otología (SBO), de todas las privaciones sensoriales, la pérdida auditiva es la que produce un efecto más devastador en el proceso de comunicación del anciano, sin contar con que, muchas veces, la deficiencia auditiva puede ir acompañada de un zumbido que compromete aún más el bienestar del individuo. Los trastornos auditivos son responsables de una importante pérdida de calidad de vida, comprometiendo la independencia y movilidad del mayor.

Ante esta situación, nuestro objetivo en la presente sección se centrará en la cuestión de la capacidad auditiva de los ancianos. Vimos en las dos secciones anteriores que las personas mayores de 60 años residentes en Mossoró afirmaron gozar de buena salud (45,69\%) en el último año, a pesar de que un $78,60 \%$ sufriera algunos achaques, que habitualmente acompañan a la vejez.

En general, cuando les preguntamos sobre las alteraciones auditivas (Gráfico 29), casi dos tercios del conjunto de los entrevistados afirman oír perfectamente bien $(64,40 \%)$, algo menos de un tercio oye regularmente $(29,20 \%)$ y apenas un $6,20 \%$ dice oír mal. La variable edad parece influir de manera significativa en la calidad de la salud auditiva. Los problemas auditivos aumentan significativamente con la edad, siendo más frecuentes en los hombres que en las mujeres (Bilton y cols. 2002:824). Se observa en el grupo investigado, que los hombres presentan desventajas sobre las mujeres en las variables de audición buena y regular. Con relación a la edad, hombres y mujeres hasta los 70 años afirman oír bien, pero cuando la edad traspasa los 70 años oyen regular. Lo confirman los hombres entre 71-80 años y las mujeres entre 71-75 años. Las personas de edades más avanzadas, entre 80-90 años, para ambos sexos, aseguran oír mal.

Los aspectos reseñados permiten conocer la salud auditiva de la población de 60-90 años de Mossoró y suponer que, a pesar del desempeño funcional, los 
individuos entrevistados se van deteriorando poco a poco, debido al proceso natural y fisiológico del envejecimiento, que es lento, inexorable y universal. La mayoría del colectivo aparenta mantener su integridad auditiva. Sin embargo, esa cuestión debe merecer la consideración de las políticas de públicas de salud, dado que la expectativa de vida saludable es determinada por el número relativamente limitado de condiciones crónicas, que se tornan más frecuentes con el aumento de la edad. Invertir, sobre todo, en la intervención geriátrica primaria puede contribuir a la disminución de las secuelas incapacitadoras que afectan directamente a la calidad de vida del mayor.

\section{GRÁFICO 29}

\section{Capacidad auditiva}

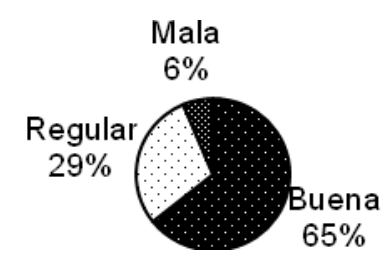

Fuente: Encuesta Perfil Sociológico de la Vejez en Mossoró - Junio 2004 / Junio 2005 (Elaboración de la autora)

\section{Uso de prótesis auditivas}

Los ancianos forman un grupo especial porque el envejecimiento avanza con alteraciones encaminadas, en su gran mayoría, a la disminución gradual de los diferentes sistemas orgánicos y funcionales (Boechat, 2001:685). Una de esas pérdidas es la audición, que puede ocasionar trastornos relativos a la independencia del individuo ${ }^{320}$, de ahí que constituya uno de los factores de desagregación social más importantes. En este caso, las enfermedades crónicas degenerativas requieren acompañamiento constante, siendo

$320 \quad$ Moriguchi, 2002:633. 
necesaria una adecuación de la evaluación geriátrica, con rutinas bien establecidas para ese colectivo, a fin de controlar la progresión de la dolencia, reduciendo el riesgo de incapacidad y aumentando la calidad de vida.

De los pacientes que sufren problemas de audición en Brasil, según el Dr. Luis Carlos Alves de Sousa, coordinador de la Campaña Nacional de Audición, "sólo el $40 \%$ de los afectados reconoce la enfermedad. La falta de información y prejuicios hacen que la mayoría tarde de media seis años en cambiar la actitud, escondiendo su problema". Así que, lo que podría solucionarse, sigue el otólogo, "a veces con tratamiento médico, quirúrgico o con el uso de aparatos de amplificación sonora (AAS), también llamados prótesis auditivas, y otros aparatos auxiliares para la audición, muchas veces imperceptibles gracias a la evolución tecnológica, llega a dimensiones preocupantes". ${ }^{321}$

A raíz de la última publicación del censo brasileño ${ }^{322}$, donde por primera vez aparecen personas con alguna deficiencia, psicológica, fisiológica o anatómica o con deficiencia auditiva, quizá las preocupaciones de Sousa contribuyan a que los gobernantes ejecuten sus plataformas administrativas con recursos suficientes en ésta área $y$, en un futuro próximo un número mayor de brasileños pueda detectar sus problemas auditivos más pronto.

En lo referente a nuestros investigados (Gráfico 30), quienes presentan un reducido $6 \%$ de disfunción en alguno de los componentes del sistema auditivo, menos de la mitad usa algún tipo de prótesis auditiva. El otro $4 \%$ oye mal, pero no usa prótesis y los demás que afirman tener audición regular, se constata que no acuden al médico, para no reconocer la patología o por falta de información sobre la necesidad de adoptar tal uso. Es igualmente relevante dotar a nuestra provincia de recursos y servicios que les permitan lidiar con las modificaciones que se evidencian con la transición epidemiológica. 321 Conferir entrevista en la página web www.saudeauditiva.org.br/imprensa/imprensa.
322 IBGE: 2000. 


\section{GRÁFICO 30}

Uso de prótesis auditivas

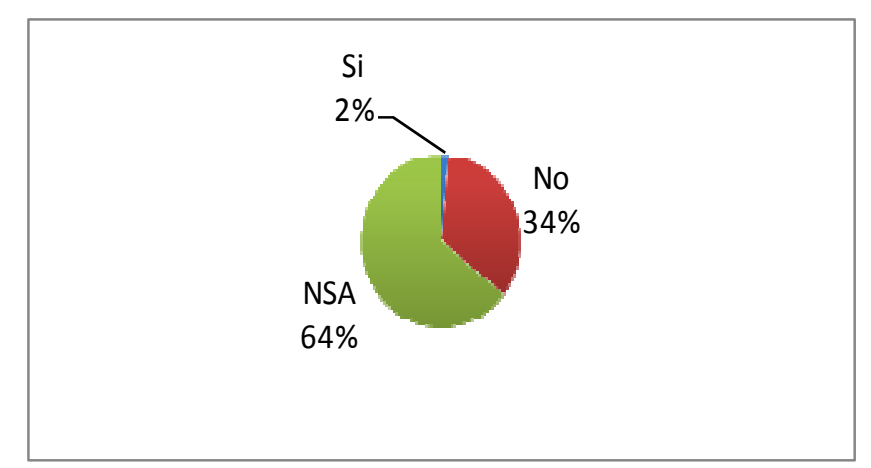

Fuente: Encuesta Perfil Sociológico de la Vejez en Mossoró - Junio 2004 / Junio 2005 (Elaboración de la autora)

\section{Vacunas administradas al año}

La prevención es importante para la conservación de la calidad de vida y uno de los puntos más importantes en los problemas de salud pública. Previniendo las enfermedades se evita el dolor, el sufrimiento y las molestias causadas por ellas, así como las posibles complicaciones manifestadas por las enfermedades. La prevención significa también reducir gastos en tratamientos y hospitalizaciones.

Entre las medidas preventivas se encuentran algunos cuidados a seguir como, una buena alimentación, cuidados básicos de la salud, higiene, uso adecuado de los medicamentos, sin abusos, con el debido acompañamiento especializado y el uso de vacunas, que estimulan el sistema de defensa para que el organismo produzca la protección contra los agentes causantes de las dolencias.

La vacuna es una de las conquistas de la historia de la Medicina y es uno de los medios más eficaces para prevenir dolencias infecciosas, que según la Organización Mundial de la Salud, son responsables de más de 1/3 de todas las 
muertes ocurridas en el mundo. El impacto positivo del control de varias dolencias por medio de campañas de inmunización está probado en ejemplos como la erradicación del sarampión o la eliminación de la poliomielitis del continente americano, entre otros.

Entretanto, a pesar del conocimiento con respecto a la eficacia de las vacunas, éstas muchas veces son poco utilizadas u olvidadas por parte de la población, debido al nivel de formación y la falta de explicaciones. Para las personas con más de 60 años, además de la necesidad de observar esfuerzos periódicos y seguir el calendario básico de vacunación, existen vacunas, según Neto y colaboradores ${ }^{323}$, específicamente recomendadas por la Organización Mundial de la Salud (OMS) para esta franja de edad, por ser más susceptible a las complicaciones de enfermedades como la neumonías virales y bacterianas. Es el caso de vacunas como la de la gripe, con dosis única y refuerzo anual, infecciones pneumocócicas (popularmente conocida como "vacuna contra la neumonía") y de la difteria y tétanos, aplicada en tres dosis, con intervalo de 60 días y refuerzo después de diez años.

Anualmente, el Ministerio de Salud Brasileño, estimulado por la Organización Mundial de la Salud, organiza una Campaña Nacional de Divulgación y Movilización de Vacunación del Anciano. Realizada desde 1999, tiene como objetivo la inmunización de individuos mayores de 60 años de edad, contra la gripe, difteria, tétanos, e infecciones neumocócicas. En 2002, fueron distribuidas 14,5 millones de dosis de vacunas contra la gripe, 4,6 millones de dosis de vacunas contra la difteria y tétanos y 480.000 dosis de vacunas contra el neumococo (causante de la neumonía bacteriana). En 1999, la Campaña tuvo un impacto del $87,3 \%$ de la población, en 2000 el total fue del $71,8 \%$ y en 2001, con un esfuerzo de movilización, abarcó a un $82,1 \%{ }^{324}$ En 2002, alcanza el número de 10,4 millones de mayores, es decir un $70 \%$ de las personas con 60 o más años de edad, dato inferior a los de los tres últimos

323 Neto, J. T., França, J. D. L. Y Halker, E. (2002): Vacunas en Freitas, Py, Neri, Cançado, Gorzoni e Rocha, Tratado de Geriatría y Gerontología, Río de Janeiro: Editora Guanabara Koogan, p. 560.

324 Silvestre, Jorge Alexandre (2002): O Impacto da Vacinação Antiinfluenza na População Idosa, em Freitas, Py, Neri, Cançado, Gorzoni e Rocha, Tratado de Geriatria e Gerontologia, Río de Janeiro: editora Guanabara Koogan, p. 569. 
años. A pesar de la caída verificada, el Ministerio de Salud establece la cifra como satisfactoria a partir del $70 \%$. Las campañas de este género buscan reducir la mortalidad de la población anciana en Brasil por infecciones causadas por la gripe, además de las complicaciones de orden pulmonar y de otros órganos.

Como la población anciana representa un grupo de riesgo muy particular para los virus, en Mossoró los cuidados son todavía mayores debido a las altas temperaturas del clima semiárido, y a la desertificación sufrida en la cuenca del río del Carmo, que provoca nubes de polvo, causantes de las dolencias respiratorias. En esta sección daremos a conocer la proporción del colectivo anciano entrevistado que utilizó las vacunas en la provincia, que forman parte del Programa Nacional de Inmunización del Ministerio de Salud.

En este grupo demográfico (véase Tabla 32), más de cuatro quintos dicen haberse vacunado contra la gripe $(85,40 \%)$, un $38,60 \%$ se ha puesto la de difteria y tétanos, apenas un $13,20 \%$ ha recibido la vacuna contra la neumonía y un $11,20 \%$ no supo o no quiso decir si lo hizo. Siendo la vacuna contra la gripe la pieza fundamental de la campaña, la aceptabilidad por parte de la clientela es mayoritaria. También lo demuestran nuestros datos, donde un $10 \%$ más de mujeres que de hombres se protegieron contra la gripe, al igual que en las otras dos enfermedades, aunque en porcentajes más pequeños.

Acompañando la estadística nacional, las cifras en el Estado de Río Grande del Norte, han sufrido también descensos en algunos años de aplicación. Cerca del $84,37 \%$ de los ancianos recibió la vacuna contra la gripe en el año de 1999, sin embargo, en los años siguientes, los índices alcanzados fueron del 78,74\% (2000), 73,20\% (2001), 75,95\% (2002) y del 79,98\% (2003) ${ }^{325}$. En Mossoró, según la Unidad Regional de Salud Pública ( $2^{\mathrm{a}}$ Ursaps), en los referidos años, también se han mantenido los porcentajes en torno al 70\%. En los años 2004 y 2005 , las cifras mejoraron y subieron hasta el $86,34 \%$ y el $84,26 \%$, respectivamente.

\footnotetext{
$325 \quad$ Para obtener más información, visite la página web oficial de salud pública de Río Grande del Norte - RN http://wwwassecom.rn.gov.br y lea el artículo sobre la campaña de vacunación para ancianos en RN de 17 a 30 de Abril de 2004, http://www.tribunadonorte.com.br, publicado el 14.04.2004.
} 
A partir de los datos verificados, podemos afirmar que existe una gran aceptación de las campañas de vacunación de ancianos, particularmente contra la gripe. Mossoró viene alcanzando una cobertura positiva más allá de la meta prevista, con resultados de impacto en la salud de la población anciana. Sin embargo, aunque el éxito del programa de inmunización de la gripe radica en la realización de las campañas, también se debe prestar particular atención a las vacunas contra las infecciones neumocócicas, el tétanos y la difteria.

Garzoni y $\operatorname{Costa}^{326}$ constataron que uno de los principales problemas de las enfermedades infecciosas en los mayores es el diagnóstico tardío y, consecuentemente, el retraso en el inicio del tratamiento, que sumado a otros factores, contribuye a mayores tasas de mortalidad en esa franja de edad. Así que invertir en campañas nacionales de divulgación y movilización, semejantes a las de la gripe, puede que reduzca la mortalidad, el sufrimiento del anciano infectado y el de sus familiares y la caída del número de ingresos hospitalarios.

\section{TABLA 32}

Según vacunas administradas al año

\begin{tabular}{|l|c|c|cccc|}
\hline $\begin{array}{c}\text { VACUNAS } \\
\text { ADMINISTRADAS } \\
\text { AL Año }\end{array}$ & \multicolumn{2}{|c|}{ AMBOS SEXOS } & \multicolumn{2}{c|}{ HOMBRES } & \multicolumn{2}{c|}{ MUJERES } \\
\hline Gripe & $>60$ & $\%$ & $>60$ & $\%$ & $>60$ & $\%$ \\
\hline Tétano y difteria & 427 & 85,40 & 218 & 43,60 & 209 & 41,80 \\
\hline Pneumococo & 193 & 38,60 & 92 & 18,40 & 101 & 20,20 \\
\hline Ns / Nc & 66 & 13,20 & 29 & 5,80 & 37 & 7,40 \\
\hline
\end{tabular}

Fuente: Encuesta Perfil Sociológico de la Vejez en Mossoró - Junio 2004 / Junio 2005 (Elaboración de la autora)

\section{Frecuencia con la que ha estado hospitalizado}

Como los mayores entrevistados han declarado gozar de buena salud (45\%, Gráfico 27 ), estar en estado regular (48\%, ídem 27) o que raramente o apenas

\footnotetext{
326 Garzoni, M. L. y Costa, E. F. de A. (2002): Manifestações atípicas das infecções, em Freitas, Py, Neri, Cançado, Gorzoni e Rocha, Tratado de Geriatria e Gerontologia, Río de Janeiro: Editora Guanabara Koogan, Capítulo 68, p. 754.
} 
una vez al año acuden a los médicos (66,40\%, Gráfico 35), no resulta, pues, admirable que muy raramente también ingresen en los hospitales o clínicas de asistencia médica. De todo el colectivo entrevistado, como se observa en el Gráfico 31, más de una quinta parte afirma haber ingresado una o más veces $(23,80 \%)$, frente a tres cuartas partes que no han sido internados nunca (72,80\%). De acuerdo con el gráfico, el sexo masculino (14,20\%) entra en los hospitales con más frecuencia que las mujeres $(9,60 \%)$. Aquí también la edad expresa sus diferencias: los varones entre 66-70 años se internan más que los de otras edades $(8,80 \%)$, mientras que entre las mujeres, los ingresos se dan en edades menores que ellos, entre $60-65$ años $(8 \%)$.

Aunque se observan proporciones muy bajas en cuanto a los ingresos, las pautas descritas anteriormente apuntan a un $78,60 \%$ con algún tipo de achaques, incluso con enfermedades que necesitan atención especial: problemas del sistema cardiovascular, que pueden afectar a las arterias del corazón (causando infarto), los vasos del cerebro (causando Accidente Vascular Cerebral, o AVC, popularmente conocido como derrame) y la circulación periférica (causando trombosis), que constituyen el mayor riesgo para la salud del grupo. 327

Ante lo expuesto, primeramente juzgamos que gran parte de los mayores entrevistados tienen una salud debilitada y carecen de acompañamiento médico. La precariedad del sistema público de salud contribuye a este cuadro, a pesar de la creación de la Contribución Provisional sobre la Movilidad Financiera (CPMF), que sería recaudada exclusivamente para suplir la financiación de la salud pública. De acuerdo con la Ley creada en 1996 sobre la CPMF: Art. 18. "O produto da arrecadação da contribuição de que trata esta Lei será destinado integralmente ao Fundo Nacional de Saúde, para financiamento das ações e serviços de saúde, sendo que sua entrega obedecerá aos prazos e condições estabelecidos para as transferências de que trata o art. 159 da Constituição Federal." (Ley n 9311, de 24 de octubre de 1996). La CPMF fue extinta en diciembre de 2007.

$327 \quad$ Investigado (II. 6.1.2.). 
Para Mansur (1990:116), “la finalidad de la provisión económica de la CPMF no ha sido aplicada totalmente, y en exclusiva, para el sector de la salud en todos los períodos. Hubo transferencia de recursos a otros sectores de la economía por ejemplo, para la financiación de la Provisión y para la composición de los fondos de desvinculación fiscal, FSE, FEF y DRU. Además de esos factores, se observó que la creación de la CPMF para financiar la salud provocó la disminución del aporte de otras fuentes de provisión económica para al sector"328. Es obvia pues, la falta de hospitales, ambulancias, equipamientos y medicamentos.

El no buscar atención hospitalaria, refuerza la idea de la resistencia de los mayores a acudir a los médicos. Una actitud muy típica entre los más viejos es creer que se puede mejorar o cuidarse uno mismo o entre los suyos, únicamente tomándose las pastillas. Para la mayoría $(64,60 \%)$, la falta de un plan de salud privado, que asegure una asistencia eficiente y de calidad, superior a la asistencia pública, puede que afecte aún más la calidad de vida de estos mayores.

\section{GRÁFICO 31}

Frecuencia con la que ha estado hospitalizado

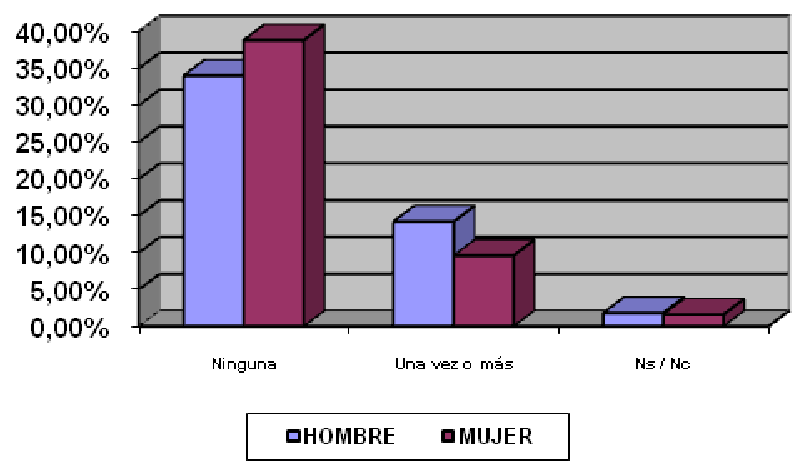

Fuente: Encuesta Perfil Sociológico de la Vejez en Mossoró - Junio 2004 / Junio 2005 (Elaboración de la autora)

328 Mansur, Marília Coser (2001): O financiamento federal da saúde no Brasil: tendências da década de 1990. [Mestrado] Fundação Oswaldo Cruz, Escola Nacional de Saúde Pública, p. 116. 


\section{Motivos del ingreso hospitalario}

Las personas mayores de 60 años residentes en Mossoró que estuvieron ingresados al menos una vez durante el último año, enumeraron los cuatro motivos que les llevaron al ingreso hospitalario. La mayoría, ingresó por motivos desconocidos (13,60\%), aquí definidos como otros, un 8,60\% motivado por una intervención quirúrgica; las demás razones de los internamientos apuntan a las enfermedades crónicas y accidentes, cuyos porcentajes sumados no rebasan el $5 \%$. El 3,20\% no supo o no quiso contestar a la cuestión. Todo esto se muestra en el Gráfico 32. Dentro de la distribución por sexo y edad, los motivos principales por los que estuvieron internados los varones, fueron otros, entre 66-70 años. Entre las pacientes femeninas, las motivaciones fueron la intervención quirúrgica y otros motivos, entre 60-65 años.

Como divulgó el sistema básico de banco de datos del Ministerio de Salud (MS), realizado por el Sistema Único de Salud (SUS), en 2003, las diez primeras causas de internamientos en Brasil, identificadas por el Código Internacional de Dolencias (CID-10) ${ }^{329}$ fueron: “embarazo, parto y posparto, enfermedades del aparato respiratorio, enfermedades del aparato vascular, enfermedades infecciosas y parasitarias, enfermedades del aparato digestivo, enfermedades del aparato genito-urinario, lesiones por causas externas, neoplasias, enfermedades endocrinas, nutricionales y metabólicas, trastornos mentales y comportamentales"330.

En nuestra investigación, los encuestados afirmaron sufrir más de problemas cardiovasculares, locomotores, digestivos, respiratorios y urinarios, ver Gráfico 28. Quizá, estos fueron los responsables de los ingresos en los hospitales. Parcialmente resueltas las tres primeras causas de los ingresos hospitalarios de los ancianos entrevistados, las enfermedades que causaron el cuarto motivo de las internaciones fueron las relacionadas con el aparato

\footnotetext{
329 Suponemos que entre éstas, exceptuando las tres primeras causas, se encaje tanto a los 43 ancianos entrevistados $(13,60 \%)$ que apuntaron otros motivos responsables de las internaciones hospitalarias, como a los 16 mayores que no supieron contestar a la pregunta $(3,20 \%)$.

$330 \quad$ Consultar páginas web www.ibge.com.br y www.datasus.com.br y Revista Sociedad Médica de Estado de Río de Janeiro http://www.somerj.com.br/revista/200410/2004_10_artigocientifico.htm.
} 
respiratorio. Las enfermedades crónicas, como asma y bronquitis, afectan sobre todo a los niños, mujeres y ancianos, y en Brasil afectan a cerca del 15\% de la población, según un informe de Ministerio de Salud (MS). Ese grupo de enfermedades es uno de los mayores causantes de internaciones en el Sistema Único de Salud (SUS) y figura entre las principales causas de mortalidad del país.

\section{GRÁFICO 32}

\section{Motivos del ingreso hospitalario}

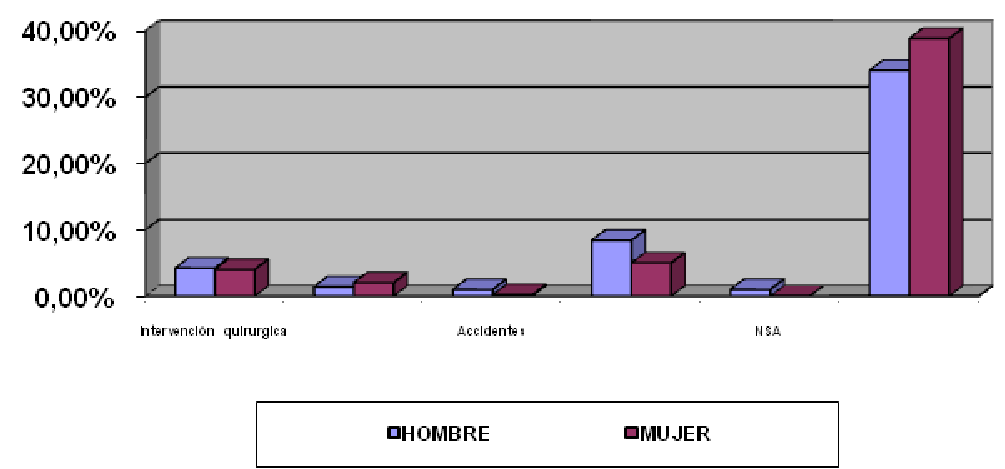

Fuente: Encuesta Perfil Sociológico de la Vejez en Mossoró - Junio 2004 / Junio 2005 (Elaboración de la autora)

\section{Realización de chequeos generales}

Hablar de chequeo general es hablar de vida saludable. Dicen los expertos en salud que es siempre aconsejable que hombres y mujeres de más de 35 años revisen su estado de salud anualmente. Constituido por una cantidad de pruebas clínicas administradas por médicos especializados, con aparatos sofisticados y precisos, el chequeo general da un diagnóstico detallado acerca del funcionamiento del cuerpo humano. De ese modo, mantener una periodicidad anual es importante, aunque en algunos casos, alertan los profesionales de la salud, para los individuos que sufren de hipertensión, colesterol o diabetes, se recomienda hacer los análisis con mayor frecuencia, a fin de evitar que algunas de estas enfermedades se vuelvan más graves y de difícil control o cura. 
El colectivo estudiado, está por encima de los 60 años de edad, es especialmente sensible y los médicos aconsejan por ello a hacer chequeos generales. En esta sección y la siguiente, sabremos quiénes se hicieron dichos análisis, y entre aquellos que no los hicieron, los motivos por los cuales no decidieron hacerlos. Antes de divulgar los porcentajes, quisiéramos aclarar que las cifras presentadas pueden corresponder tanto al año anterior como a los años recientemente terminados, dado que hacemos una pregunta muy generalizada. Sin embargo, al haber constatado en los apartados anteriores que menos de la mitad acuden al médico solamente cuando están enfermos $(49,60 \%)$, que poco más de la mitad de ellos se hicieron una revisión oftalmológica $(54,40 \%)$, y que apenas el $25,20 \%$ de las mujeres y, menos aún, el $15,20 \%$ de los hombres, se hicieron pruebas ginecológicas y urológicas, nos parece que contradicen en parte a lo que respondieron anteriormente, si tomamos las respuestas con referencia al último año.

De todo el grupo entrevistado, alrededor de dos tercios afirmaron positivamente haberse hecho un chequeo general $(61,60 \%)$, por el contrario, más de un tercio no lo hizo (36\%). Los porcentajes más elevados de quien se los hizo los encontramos en las mujeres, con un $34 \%$ frente a un $27,60 \%$ de los hombres. Efectivamente, entre los que no se los hicieron, las cifras son más acusadas entre los varones (21\%) que entre las mujeres (15\%). Ver Gráfico 33.

Si comparamos estas cifras en relación a edades entre $60-80$ años, el $24,20 \%$ de los varones se sometió a los análisis, mientras que entre las mujeres ese porcentaje llega a un 30,60\%. En las mujeres, el estado civil que predomina es el de soltera, casada y viuda, constituyendo el $38,80 \%$ del total de la población femenina mayor de 60 años entrevistada, mientras que en los hombres sólo representa un porcentaje del $23,60 \%$ entre los casados y viudos. Puede que esa diferenciación se deba a motivos como el de que las mujeres enferman en proporción superior a los hombres o que ellos culturalmente frecuentan menos los consultorios médicos. 
De hecho, es importante mantener una actitud preventiva respecto a la salud ya que, a partir de la vejez, las enfermedades se vuelven más frecuentes. Sin embargo, dotar a la población de recursos y medios para enfrentar situaciones amenazantes y desconocidas a través de información de fácil comprensión, como estrategia de asistencia a la salud pública, incluiría al sector de mayores, que tiende a crecer en la provincia.

\section{GRÁFICO 33}

\section{Realización de chequeos generales}

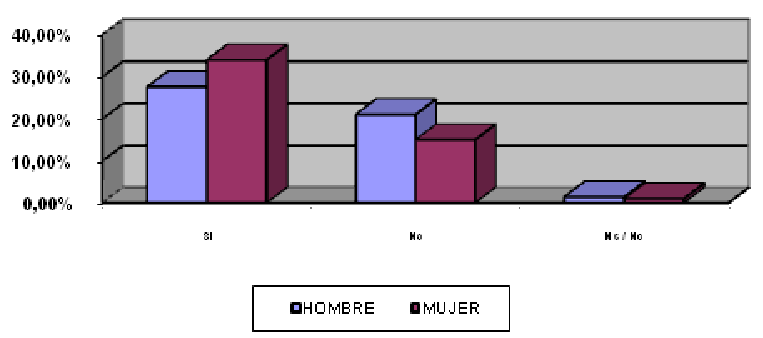

Fuente: Encuesta Perfil Sociológico de la Vejez en Mossoró - Junio 2004 / Junio 2005 (Elaboración de la autora)

\section{Motivo por el que nunca se ha hecho un chequeo general}

Como decíamos con anterioridad, el 61,60\% del grupo anciano entrevistado afirma haberse hecho un chequeo general. Debemos entender, por tanto, que está con la salud al día, porque ha calificado el estado de salud en el último año entre muy bueno y bueno $(45,69 \%)$. Para los mayores que no se hicieron chequeo, los motivos varían, desde los económicos hasta los asociados a la desconfianza de los servicios prestados por la salud pública brasileña.

Conforme a lo que indica el Gráfico 34 , la mayoría de los ancianos $(9,40 \%)$ señala que no le hace falta hacerse el chequeo general por encontrarse bien de salud. A continuación, los altos costes constituyen la segunda causa $(9,20 \%)$. Un $8,60 \%$ de los mayores apunta otros motivos. La cuarta causa que acusa al Sistema Único de Salud (SUS) de no disponer de este servicio para la población (4,40\%). Por último, el 3,20\% no cree que este tipo de análisis sirva para nada. 
Podemos observar que, según el sexo, los hombres se muestran menos crédulos que las mujeres en la eficacia del chequeo. En todas las otras alternativas los varones tienen porcentajes más elevados, aunque las diferencias no son excesivas.

En realidad, a pesar de existir un esfuerzo nacional para mejorar la salud pública en Brasil, traducido en el acceso de la población a los servicios, las deficiencias del sistema público ayudan a que gran parte de los ciudadanos no cuide adecuadamente de su salud. Así, juzgamos que los mayores encuestados se refieren a la eficiencia de los servicios de salud y no directamente a la eficacia del diagnóstico propiamente dicho. Ya se sabe que "es mejor prevenir que curar". Las medidas de prevención, sobre todo para esta franja de edad, son imprescindibles para ayudar en la calidad de vida. La falta de eficiencia, sumada a los parcos ingresos que reciben los ancianos en cuestión, contribuye al padecimiento de enfermedades y agraviamiento de las ya existentes.

Además de crear servicios de salud funcionales, propagar la cultura de prevención ante el tratamiento y poner a su disposición todas las herramientas para controlar y favorecer la lucha contra las enfermedades, contribuiría a la reducción del número de personas que no se hace un chequeo general.

\section{GRÁFICO 34}

Motivo por el que nunca se ha hecho un chequeo general

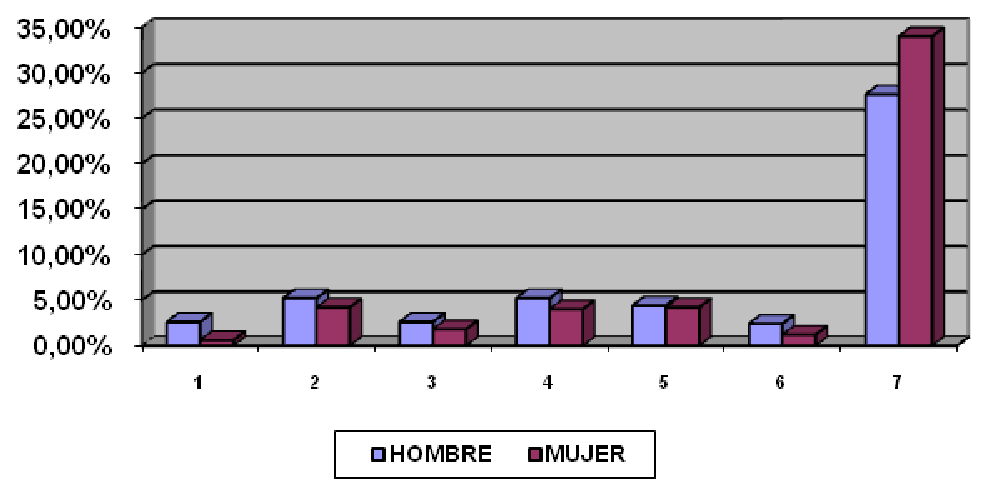

Fuente: Encuesta Perfil Sociológico de la Vejez en Mossoró - Junio 2004 / Junio 2005

(Elaboración de la autora)

1) No cree que sirvan para nada

2) Se encuentra bien de salud 
3) No se hace por el Sistema Único de Salud (SUS)

4) Es muy caro

5) Otros motivos

6) $\mathrm{Ns} / \mathrm{Nc}$

7) NSA

\section{Resumen}

La mayor preocupación de una persona que piensa en el propio envejecimiento es alcanzar la tercera edad sin tener una enfermedad que limite su vida cotidiana y le convierta en un sujeto dependiente de otras personas. Las investigaciones han demostrado que la mayoría considera la salud como el valor más importante, reforzando el dicho popular "salud es lo que interesa, el resto no tiene prisa”. En este séptimo capítulo, nos adentramos en varios temas que son centrales para nuestra investigación: entre ellos: el estado de salud actual del mayor, los cuidados para la preservación de la salud y las enfermedades que padecen actualmente. Por lo tanto, entre la población investigada, el $41,77 \%$ ha declarado tener un estado de salud muy bueno y bueno y casi el cincuenta por ciento ha afirmado que ha sido regular en los últimos doce meses $(49,68 \%)$. En cuanto a las mujeres, éstas suelen quejarse más de su estado de salud que los varones, a pesar de tener la esperanza de vida superior a éstos; los hombres afirman tener buena salud en mayor proporción que ellas.

Los problemas de salud más acuciantes que el colectivo entrevistado ha padecido son los cardiovasculares (20\%), las dificultades de locomoción (13\%), las molestias digestivas (11\%), los trastornos urinarios (8\%), respiratorios (8\%) y neurológicos (8\%). Según la media nacional en Brasil, los estudios señalan que el $85 \%$ de los ancianos presenta por lo menos una enfermedad crónica, y cerca del $15 \%$ por lo menos cinco. De nuevo, en las mujeres predominan las cifras más altas. En casi todas las enfermedades subrayadas, ellas sufren más que los varones.

Con respecto a las alteraciones auditivas, que generalmente son más evidentes después de los 65 años de edad, sólo el 6\% padece de deficiencia 
auditiva, frente al $29 \%$ que afirma oír regular y el $65 \%$ que oye bien. De los afectados, sólo la mitad usa prótesis auditiva. En Mossoró, no se tienen informaciones precisas sobre políticas públicas de aplicación otológica.

Entre las medidas preventivas, recomendadas por la Organización Mundial de la Salud (OMS), los mayores de 60 años son estimulados anualmente para que se inmunicen contra la gripe gracias a la exitosa Campaña Nacional de Vacunación del Anciano, realizada desde 1999. De los que participaron en las campañas, un $83,95 \%$ de nuestros entrevistados acudió en el último año a ponerse la vacuna contra la gripe. Pero, apenas el $37,22 \%$ se ha vacunado conta la difteria y el tétanos y el $13,25 \%$ contra la neumonía. Las mujeres se han vacunado contra la gripe un $10 \%$ más que los varones, en cambio, en las otras dos vacunas, los porcentajes son más bajos. La baja participación de los mayores en la prevención de la neumonía y la difteria y tétanos, está justificada por el criterio de su aplicación. Para mantener la protección adecuada, la primera vacuna, no necesita ser suministrada de nuevo antes de cinco años después de la primera dosis y la segunda vacuna, después de completada la serie de tres dosis, y una dosis de refuerzo cada diez años. La inmunización contra estas dolencias abarca el mismo nivel (mínimo el 70\%) que en los países desarrollados, según la Fundación Nacional de Salud (FUNASA). De ese modo, se concluye que las campañas de vacunación de la gripe han sido eficientes en Mossoró, además de contribuir a ampliar la anchura en la cúspide de la pirámide. Pero, aún así, hacen falta campañas para la prevención contra las infecciones neumocócicas y del tétanos y difteria.

En lo que respecta a la frecuencia con la que han entrado en los establecimientos sanitarios para tratamiento, sólo un quinto de los mayores afirma haber ingresado una o más veces en el último año, en contraposición a tres cuartas partes que no se han internado ninguna vez en un hospital o similar. Las mujeres ingresan con más frecuencia y son proporcionalmente más jóvenes que los varones. Los motivos fueron las intervenciones quirúrgicas, los accidentes y otros. 
Entre las prevenciones y revisiones médicas, de todo el ámbito entrevistado, más de dos tercios afirmaron haberse hecho un chequeo general, frente a los que no lo hicieron, un 30,28\%. El factor que complica esta cuestión es que no se hace referencia a la fecha del chequeo. No sabemos si se refieren a los últimos doce meses o a hace más tiempo. Entre las cifras más elevadas de los que se lo han hecho, encontramos a las mujeres en casi todas las edades y predominantemente entre las solteras, casadas y viudas. Quizá, la razón para que mujeres presten más atención a la salud que los hombres, está en que enferman en mayor proporción que ellos. La mayor excusa de los mayores que no lo hicieron recayó en los altos costes y en que no se hace por el Sistema Único de Salud (SUS). 


\title{
Cuidados de la salud
}

\author{
Ao contrário da velhice, a juventude não é durável. \\ Um jovem não fica mais jovem com o tempo. O velho \\ fica cada vez mais velho. \\ Millôr Fernandes (1923), \\ Dramaturgo, humorista y escritor brasileño.
}

\section{Frecuencia de consultas al médico}

El aumento de la expectativa de vida hace que hoy un gran número de personas viva más tiempo que en épocas pasadas, de ahí que se diga que es la etapa más larga de la existencia humana.

Esa victoria, que está rodeada de dificultades y desafíos, exige, también prestar atención a la salud. Tener una vejez más tranquila y saber distinguir lo que es patología de lo que es propio del envejecimiento supone tener una actitud preventiva ante la vida. Cuando el hombre y la mujer alcanzan la edad madura dicen que apenas están iniciando una nueva fase, bastante próspera en términos de proyectos, planes y anhelos. Es el momento de poner en práctica todos los beneficios de la experiencia acumulada a lo largo de los años. En ese proceso, velar por la propia salud, consultar periódicamente al médico (incluso cuando aparentemente esté todo bien), aclarar dudas, miedos e inseguridades son actitudes imprescindibles para una vida saludable.

Por tanto, la salud es una responsabilidad con una doble cara. Supone para el Estado $^{331}$ la promoción y la manutención de políticas públicas y servicios de calidad y, para el individuo, cuidar de él, procurándose alimentación y un modo de vida saludable, así como actividades físicas oportunas, las prevenciones sanitarias y alguna forma de espiritualidad.

\footnotetext{
331 Conforme la Constitución Federal de Brasil - 1988, Título VIII, De la orden social, Salud Art. 196 la salud es un derecho de todos y un deber del Estado, garantizado mediante políticas sociales cuyo objetivo es la reducción de riesgo de dolencias y de otros agravios y al acceso universal e igualitario a acciones y servicios para su promoción, protección y recuperación.
} 
Así, centrándonos en la situación sanitaria y médica de la población de 60 o más años de edad residentes en Mossoró, aquí representados por el $3 \%$ de la población, quisiéramos saber el interés de los mayores por su propia salud. Les preguntamos directamente cuál ha sido la frecuencia con la que han ido al médico. Este tipo de informaciones básicas pueden ser útiles para la planificación y el modelo de atención de la salud, a nivel individual o colectivo, de las personas de mayor edad en la capital del Oeste.

Los datos relativos a la búsqueda de atención sanitaria muestran que casi la mitad de los ancianos entrevistados sólo acuden al médico cuando sufren alguna enfermedad (49,60\%), una quinta parte afirma vigilar su salud cada tres meses (20\%), un $12 \%$ lo hace cada dos meses y un $16,80 \%$ acude al médico al menos una vez al año (Véase Gráfico 35). Las ancianas velan por la propia salud en niveles más altos que los hombres, con una periodicidad de dos o tres meses. En cuanto a la atención sanitaria, al menos una vez al año, ambos sexos tienen exactamente la misma actitud. Pero, cuando se trata de solamente ir al médico por sufrir alguna enfermedad, los hombres sobrepasan a las mujeres.

En relación al estatus socioeconómico del colectivo, aquellos que reciben entre uno y dos salarios mínimos, acuden al médico sólo cuando se encuentran enfermos. También en proporciones muy bajas acuden los hombres, una vez al año y las mujeres, cada tres meses o una vez al año, con los ingresos referidos anteriormente. Señalan igualmente menores frecuencias médicas aquellos con niveles menores de estudios y los de edades más avanzadas.

De acuerdo con las contestaciones de los propios entrevistados, tenemos una explicación para que exista tan baja atención dispensada a la salud: el deficiente sistema de asistencia de la salud pública a la población de baja renta en la comunidad mossoroense. A nivel nacional, la preocupación por los servicios de salud es unánime entre los mayores. Según Rodrigues y Rauth (2002), “los recursos en ese área se aplican mal, y se presta poca atención a los mayores como grupo de necesidades específicas... [...] las políticas son casi inexistentes" (2002:108). La utilización de servicios de salud puede estar 
influenciada directamente por el nivel de renta y el nivel educativo ${ }^{332}$. Para Rodrigues y Rauth (2002), "al lado de un Brasil industrializado, desarrollado y más o menos rico, hay un Brasil extremamente pobre, donde los viejos son numerosos, y las pensiones y jubilaciones bajas” (2002:108). De igual modo, es importante resaltar que la prevención de las dolencias se asocia mucho a la nutrición, a las condiciones de vida, al trabajo y al nivel educativo.

Promocionar la salud de los mayores y la demanda de los que empiezan a envejecer en Mossoró va más allá de la implementación de las políticas públicas y la garantía de los servicios sociales. La gestión de las políticas públicas, sostienen Rodrigues y Rauth (2002), requiere mecanismos de control social que propicien el acompañamiento y la fiscalización de ejecución, con la representación de los propios mayores, a través de los Consejos de Mayores. Además, el desafío a la pobreza es imperativo. Ofrecer condiciones cualificadas para el prolongamiento de la vida pasa por la distribución equitativa de las riquezas de la provincia y la sensibilización de la sociedad en las cuestiones del envejecimiento individual y poblacional en Mossoró.

\section{GRÁFICO 35}

Frecuencia de consultas al médico

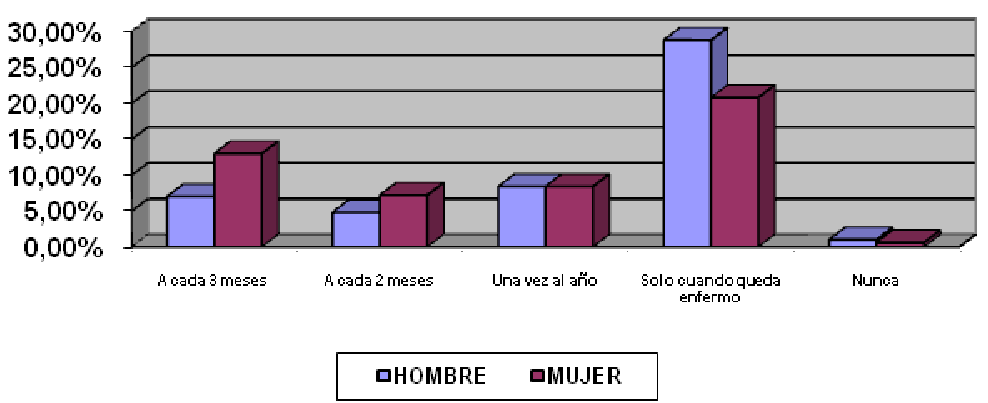

Fuente: Encuesta Perfil Sociológico de la Vejez en Mossoró - Junio 2004 / Junio 2005 (Elaboración de la autora)

\section{Medios por los que adquiere medicamentos}

\footnotetext{
332 Monteiro, M. F. G. (1991): Morbidade referida e acesso a serviços de saúde: padrões e diferencias. Rio de Janeiro: IBGE.
} 
Hemos visto en el Gráfico 28, que apenas un $21,40 \%$ de las personas mayores de 60 años entrevistadas padece alguna enfermedad, a pesar de que casi la mitad afirma que su estado de salud en el último año fue regular. Independientemente del grado de estado de salud en que se encuentre cada uno de ellos, de acuerdo con los expertos en Geriatría, la asistencia médica debe ser constante, principalmente para aquellos con más edad, que sufren enfermedades crónicas, como las cardiovasculares y las respiratorias. Pero, como podemos comprobar, la mitad del colectivo sólo acude al médico cuando enferma, incluso cuando el $71,60 \%$ de estos ancianos tiene servicios de salud cerca de su vivienda (véase el Gráfico 24).

Para ir completando el perfil de salud del colectivo estudiado, hemos preguntado cómo adquieren las medicinas tras la prescripción médica. Como se refleja en el Gráfico 36, en términos más generales, alrededor de dos tercios adquieren el medicamento comprando la caja completa en farmacias $(65,60 \%)$, alrededor de una quinta parte lo obtiene a través de un órgano público o similar $(18,80 \%)$, un $13,20 \%$ compra a granel y apenas un $1,20 \%$ afirma no comprar. La forma de obtener medicamentos también llama la atención de la encuesta de la Fundación Perseu Abramo, realizada con los mayores en 204 municipios brasileños. Aunque el 51\% consiga los medicamentos de forma gratuita en los puestos de salud del SUS, la falta eventual de los remedios lleva al $71 \%$ de los mayores a pagar por ellos en las farmacias.

Las diferencias entre hombres y mujeres, en cómo adquieren los medicamentos, no son tan destacables. Por una parte, las mujeres tienen la costumbre de comprar el medicamento completo, mientras que los varones lo compran fraccionado. Es posible que esto se relacione con el tipo y grado de dolencia que padecen. En nuestro estudio, de las siete patologías subrayadas, seis las mujeres afirman haberlas padecido en porcentaje superior a los varones. Por otra parte, ambos sexos consiguen los medicamentos en los órganos del gobierno, vía políticas públicas. Quizá, parte de ellos necesiten 
tratamientos especiales (prolongado o permanente) y por eso reciban los medicamentos gratuitamente.

Para intentar responder a estos datos, primero señalamos que según la Asociación Brasileña de Industria Farmacéutica (ABIFARMA), Brasil ocupa la cuarta posición en el ranking mundial de consumo de medicamentos. Para los que compran medicamentos y por supuesto para nuestros entrevistados, que no disponen de tanta renta, la posibilidad de acceder a los medicamentos genéricos contribuye a cuidar la salud ya que son un $40 \%$ más barato que los de referencia. Los genéricos fueron adoptados en Brasil a partir de 1999 y el $50 \%$ de las medicinas tiene correspondientes genéricos (ABIFARMA: 2000). Países como Estados Unidos y algunos de Europa tienen políticas semejantes en vigor desde hace más de veinte años. Además, el programa Farmacia de Todos, implantado en la comunidad mossoroense en 2005, prevé la comercialización de 130 medicamentos básicos, preconizados por el Ministerio de Salud (MS), con precios de medias unos 40\% más bajos de los que hay en las farmacias privadas. La meta del Gobierno Estatal es la de crear, en todas las regiones de Río Grande del Norte, 25 farmacias hasta 2007. Hace poco, fueron implantadas 10 unidades. La política ayuda a que la población de baja renta pueda incluir los medicamentos en las compras mensuales, ya que generalmente debido a los altos costos se hace inviable el cumplimiento del tratamiento de salud.

Los mayores que adquieren medicamentos de modo gratuito $(18,80 \%)$, encuentran amparo legal en la Ley $n^{\circ} 1.318$ del año 2002 del Ministerio de la Salud (MS). Compuesta por doce divisiones, el programa de distribución gratuita de medicamentos para la población en general cubre: los medicamentos de alto costo, para la salud mental, las DST/SIDA, la tuberculosis, la lepra, la asistencia farmacéutica básica, la distribución hospitalaria, las inmunizaciones, las hipertensiones y la diabetes, la salud de la mujer, las endemias y el cólera. Bajo la responsabilidad de la Unidad Central de Agentes Terapéuticos (UNICAT), la asistencia cubre a los individuos inscritos que necesitan tratamiento prolongado o permanente. 
Los que tienen la costumbre de comprar los medicamentos fraccionados, ahora encuentran respaldo en el Decreto $\left(n^{\circ}{ }^{5}\right.$.348) del Presidente Luiz Inácio Lula da Silva, publicado en el Diario Oficial de la Unión, día 20/01/2005. La medida es parte de un conjunto de acciones del Ministerio de Salud (MS) dirigidas a ampliar el acceso de la población a los medicamentos. El programa garantiza que el consumidor adquiera el producto en la dosis adecuada, de acuerdo con la prescripción médica, proporcionándose seguridad y economía, pues se evita el almacenamiento innecesario en casa.

Y finalmente, están los mayores que declaran no comprar el medicamento, probablemente porque estén entre los millones de brasileños excluidos del mercado laboral y que poseen una renta mínima para su supervivencia. Estos casos de pobreza limitan las necesidades básicas del individuo y la salud se vuelve una de las áreas más perjudicadas. Además, se puede conjeturar que los medicamentos distribuidos de modo gratuito tampoco atienden a la necesidad de todos en la provincia.

Parte de esta realidad se debe, primeramente, a los hábitos de gasto y consumo de las familias brasileñas. Entre éstos, la asistencia a la salud ocupa el quinto lugar $(4,08 \%)$, por detrás de los gastos de vivienda, alimentación, transporte y vestimenta, según informa la Pesquisa de Provisiones Familiares POF/IBGE (2002-2003) en su cuarta edición, hecha en once regiones metropolitanas del país. De ahí se puede también responder a la sección anterior: por qué los ancianos entrevistados sólo acuden a la orientación médica cuando se encuentran enfermos. Tratándose de los ancianos, según el Informe, entre los gastos básicos, las medicinas consumen una gran parte de sus ingresos. Los hombres ancianos, que ganan hasta dos salarios mínimos, gastan el $24,38 \%$ de su renta en la compra de medicinas. Mientras, el gasto de las mujeres en la misma franja de renta llega a ser del 33,2\%. Es decir, las mujeres en cierto modo gastan más, porque también enferman más que los hombres. (Bazo: 1990; INSERSO: 1990). 


\section{GRÁFICO 36}

\section{Medios por los que adquieren medicamentos}

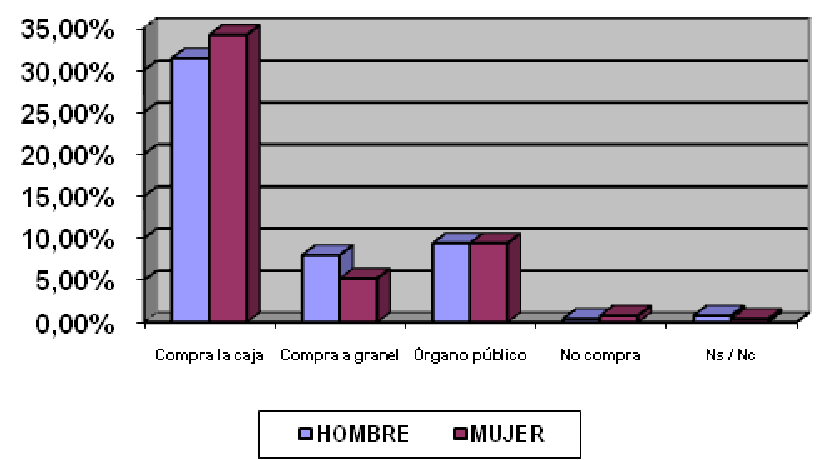

Fuente: Encuesta Perfil Sociológico de la Vejez en Mossoró - Junio 2004 / Junio 2005 (Elaboración de la autora)

\section{Revisiones oftalmológicas que le hicieron en el último año}

Las alteraciones degenerativas que aparecen por el fenómeno del envejecimiento son diversas. Entre éstas, la visión, como la audición ya referida anteriormente, sufre una significativa alteración, que puede ocasionar trastornos que afecten a la independencia del individuo. Para los autores Freitas, Miranda y Nery (2002), el deterioro de la visión normal en los ancianos es causado por las modificaciones fisiológicas del envejecimiento y las alteraciones mórbidas. Según los expertos, "los trastornos visuales son responsables de la pérdida de calidad de vida, comprometiendo la independencia y la movilidad. Entre las causas más comunes de trastornos visuales están: las cataratas, la degeneración macular, el glaucoma y la retinopatía diabética" (2002:611).

Es necesario diagnosticar las enfermedades oculares lo más temprano posible para prevenir traumas graves y rehabilitar las deficiencias visuales, sobre todo en las personas de edad avanzada, cuya tasa de problemas de visión es más frecuente que en otros grupos de edad. Nos interesa saber qué cuidados dedican a los ojos los ancianos residentes en Mossoró, cuando se sabe que cerca de 16,5 millones de brasileños (más del 10\% de la población) tienen algún tipo de deficiencia visual, según datos de IBGE en 2002. De éstos, el Consejo Brasileño de Oftalmología (CBO) estima que 2,9 millones son brasileños con 65 o más años de edad. 
A este respecto, los datos disponibles en el Gráfico 37 señalan que más de la mitad de los ancianos se ha hecho una revisión oftalmológica en el último año $(54,40 \%)$, mientras que un $42,40 \%$ del total de los entrevistados no se la hizo. La muestra revela que las mujeres se interesaron más que los varones por los problemas oculares. Por edad, acuden a los oftalmólogos los varones entre 6070 años, mientras, entre las mujeres ancianas, estos cuidados se extienden hasta los 80 años. Por estado civil, son los varones casados y viudos y las mujeres solteras, casadas y viudas quienes visitaron los consultorios of talmológicos con mayor frecuencia.

En concreto, los resultados muestran la paradoja que vive la oftalmología brasileña. Considerada de excelencia en todo el mundo, en Brasil es una de las especialidades con mayor número de médicos por habitantes, pero con ineficiencia pública. Es curioso que la Organización Mundial de la Salud, preconice un oftalmólogo por cada $\mathbf{2 0 . 0 0 0}$ habitantes, ya que en Brasil esa relación es de uno por cada 17.000. Significa que hay especialistas en número suficiente para la asistencia a los brasileños con problemas visuales. Sin embargo, para Elisabeto Ribeiro Gonçalves, presidente del Consejo Brasileño de Oftalmología (CBO), hay poca asistencia a través del servicio público, deficiencia en las condiciones de trabajo y carencia de políticas públicas de interiorización. Para Gonçalves, la mayoría de los oftalmólogos se encuentran en los grandes centros urbanos del país ${ }^{333}$. En Mossoró, hay un oftalmólogo por cada 18.744 ciudadanos, un porcentaje de asistencia dentro de la media establecida por la OMS y por debajo de la media brasileña.

Si más de la mitad de las personas mayores de 60 años que componen la muestra han realizado las revisiones oculares, esto significa una cierta satisfacción con los servicios oftalmológicos privados de la ciudad. Pero, si la otra mitad no lo ha hecho, puede que signifique la ineficiencia de los servicios oftalmológicos del Sistema Único de Salud (SUS), dado que la mayoría de los entrevistados dependen del SUS, o lo menos probable que gocen de una

\footnotetext{
333 Consultar más informaciones sobre el tema en la página web http://www.jornaldaeducacao.info.br Crianças de todo país recebem atendimento oftalmológico gratuito, edición 173, junio 2004.
} 
buena salud visual. En este sentido, estos mayores constituyen un grupo que puede sufrir pérdida de su autonomía e independencia en las actividades de la vida diaria, incluso pudiendo aumentar la lista de brasileños con deficiencia visual en un futuro próximo.

\section{GRÁFICO 37}

\section{Revisiones oftalmológicas que le hicieron en el último año}

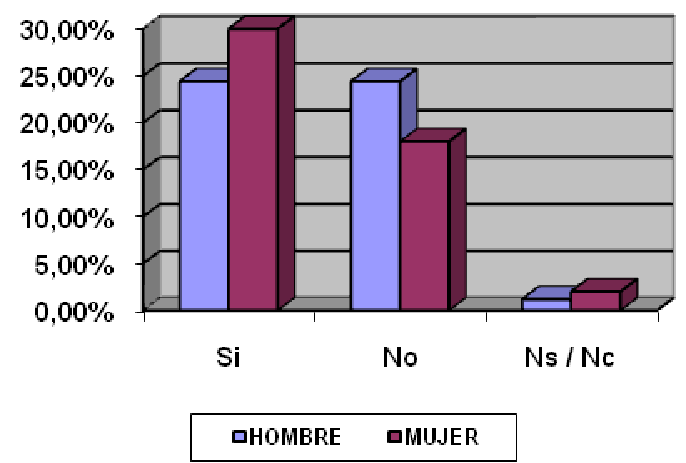

Fuente: Encuesta Perfil Sociológico de la Vejez en Mossoró - Junio 2004 / Junio 2005 (Elaboración de la autora)

\section{Mujeres que visitan al ginecólogo}

En todo el mundo hay una tendencia a la disminución de mortalidad femenina. Eso lleva al aumento de la expectativa de vida de la mujer. En Brasil, como mencioné anteriormente, en 2000, la esperanza de vida media de la mujer era de 72,55 años, y la del hombre era de 64,77 . Pero eso no significa que la atención a la salud de la mujer sea enteramente adecuada. La prueba es que, a pesar de morir más hombres que mujeres, en el país, según el Ministerio de Salud (MS), de las 389.907 muertes femeninas registradas en 1999 , el $10 \%$ se produjo por falta de asistencia médica. En la población masculina, el índice fue del $8,4 \%^{334}$. Para disminuir ese tipo de desigualdad entre sexos, en la década de los ochenta, el Gobierno Federal creó el Programa de Asistencia Integral de Salud de la Mujer (PAISM), con énfasis en la orientación de planificación familiar y la prevención del cáncer de mama, de colon uterino y de colon-recto. 
Centrándonos en los problemas cancerígenos en Brasil, hay que destacar que el Instituto Nacional de Cáncer (Inca), órgano del Ministerio de Salud (MS), ha desempeñado un papel importante en el desarrollo de acciones nacionales orientadas a la prevención y control del cáncer. Aunque la lucha contra el cáncer en Brasil se haya intensificado, las estimaciones del referido Instituto apuntan que hacia el año 2005 surgirán 467.440 casos nuevos de cáncer, siendo 229.610 nuevos casos para el sexo masculino y 237.830 para el sexo femenino. Los tipos más incidentes en la población brasileña, a excepción del de piel, no melanoma (113.000 nuevos casos), serán los de próstata y pulmón en el sexo masculino y mama y colon uterino para el sexo femenino (acompañando la misma magnitud observada en el mundo). El informe Inca, observa también que los cinco tipos de tumores con más incidencia en el sexo masculino se deberán al cáncer de piel no melanoma (56.000 casos nuevos), próstata (46.000), pulmón (17.000), estómago (15.000) y colon-recto (12.000). Para el sexo femenino se destacan los tumores de piel no melanoma (57 mil casos nuevos), mama (49 mil), colon uterino (21 mil), colon-recto $(14 \mathrm{mil}) \mathrm{y}$ pulmón (9 mil).

Entre los ancianos, las dolencias de cáncer son la segunda causa de mortalidad, precedida de las cardiovasculares y de las respiratorias ${ }^{335}$, excepto en la región Nordeste de Brasil, donde representa la tercera causa de muerte por enfermedades, precedida por enfermedades infecciosas y parasitarias. Sin embargo, lamentablemente, aún es una enfermedad cercada por muchos prejuicios y desinformación. Según los especialistas, el miedo al diagnóstico de la enfermedad distancia a las personas de los consultorios, haciendo que las oportunidades del paciente para curarse al diagnosticar precozmente la enfermedad disminuyan, además de poderse beneficiar con nuevas formas de tratamiento.

Ante esta situación, nuestra investigación, Perfil Sociológico de la Vejez en Mossoró, no podría dejar escapar un tema de tamaña envergadura. Nuestra preocupación se suma a la de los responsables de la salud pública, ya que hay 
un alto índice de cáncer entre las mujeres, de modo que los datos revelados en ésta y la siguiente sección pueden contribuir a informar sobre la necesidad de desarrollo y mejora de programas de prevención, de diagnóstico precoz y de tratamiento de la enfermedad en Mossoró, también en este grupo de edad.

El hábito de visitas al ginecólogo por parte de las mujeres mayores es escaso. Concretamente sólo el $24 \%$ de las ancianas entrevistadas ha acudido al ginecólogo para hacerse alguna revisión o prueba de citología o mamografía. El 25,20\% de ellas afirma no haber hecho consultas ginecológicas. Y apenas el $0,80 \%$ no contestó a la pregunta. Contabilizando todas, 120 mujeres $(N=250)$, menos de la mitad del entorno investigado acudió a las consultas ginecológicas (véase Gráfico 38). Semejante situación es confirmada por los datos de la encuesta Mayores en Brasil - Vivencias, desafíos y expectativas en la $3^{\mathrm{a}}$ edad de la FPA (2006). El 26\% de las mujeres con más de 60 años nunca se hizo una prueba ginecológica, como el Papanicolaou. Es casi igual al porcentaje de las mujeres que afirma hacerse ese tipo de prueba raramente: $27 \%$. Las que lo hacen una vez al año llegan apenas a un $22 \%$.

En las mujeres mossoroenses por edad, 55 mujeres de entre 60-65 años se hicieron un reconocimiento ginecológico, lo que corresponde al $22 \%$ del total. La segunda clase de mujeres en edades maduras que acudieron al ginecólogo fueron 25 mujeres de entre 66-70 años (10\%). Las que menos acudieron a los consultorios ginecológicos son el grupo de 21 mujeres de entre 71-75 años $(8,40 \%)$ y 11 mujeres de entre $76-80$ años $(4,40 \%)$. Por fin, sólo $8(3,20 \%)$ ancianas con 80 años o más utilizaron los servicios de ginecología. La situación por estado civil nos llama la atención: ir al ginecólogo sólo forma parte de la vida de 8 mujeres solteras de las 28 entrevistas, de 50 mujeres casadas de las 90,11 de las 16 separadas y 47 de las 108 viudas.

En definitiva, las cifras obtenidas, con todas las implicaciones que arriba señalamos, tal vez se sitúen dentro de las previsiones de nuevos casos de cáncer, conforme a lo que divulgó el Instituto Nacional de Cáncer (Inca), si el poder público y la sociedad civil no toman ninguna medida preventiva. Los datos señalan que visitar a un ginecólogo en la edad madura constituye una 
práctica poco habitual entre las mujeres mossoroenses. Aunque el trabajo de divulgación y prevención contra el cáncer exista en la provincia, a través de la Secretaría estatal de salud y del Instituto de mama de Mossoró (1994), único hospital especializado en cáncer y de la Asociación de mujeres, las dificultades que persisten en las mujeres son predominantemente culturales. No resulta nada alentador que más de la mitad de estas mujeres en edades avanzadas, en las que el cáncer se manifiesta con tanta propiedad, esté en una situación de riesgo. El interés por el cáncer debe contar con más especialistas en ginecología, dado que en la urbe apenas hay 26 profesionales, además de invertir en programas eficaces de prevención, diagnóstico precoz, intervención quirúrgica y ofrecer la reconstrucción plástica de la mama a través del Sistema único de Salud en Mossoró. Ampliar el acceso a la información para contener el desarrollo del cáncer en un centenar de mujeres mossoroenses y posibilitar la garantía del envejecimiento saludable implica una reflexión y acción del Estado y de la sociedad civil.

\section{GRÁFICO 38}

Mujeres que visitan al ginecólogo

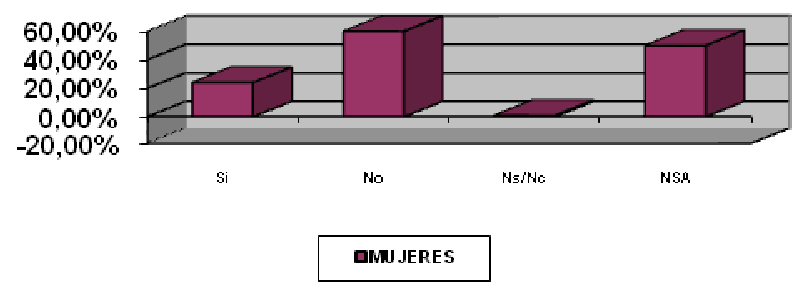

Fuente: Encuesta Perfil Sociológico de la Vejez en Mossoró - Junio 2004 / Junio 2005 (Elaboración de la autora)

\section{Hombres que visitan al urólogo}

Hemos señalado anteriormente que el cáncer está entre las cuatro primeras causas de muertes en Brasil. Es la segunda causa a nivel nacional y la tercera en el Nordeste. Los tipos más comunes que matan son los cánceres de piel, mama, próstata, pulmones (asociado directamente al tabaco), útero y estomago $^{336}$.

I36 IBGE: 2000. 
Actualmente, el cáncer de próstata es el que más acomete a los hombres con edades superiores a los 50 años, confirma Gomes, en Doenças da Próstata (2002:440). Aproximadamente, uno de cada 8 hombres, en esta franja de edad, podría desarrollar la enfermedad. Como el desarrollo del cáncer de próstata se produce lentamente, dicen los expertos, el hombre puede permanecer muchos años sin presentar ningún síntoma. Según el autor, los primeros síntomas tardan bastante en aparecer. Sin sintomatología alguna, dado que el cáncer es una dolencia de inicio insidioso, se recomienda el Tacto Rectal (TR, análisis rectal), además de la ecografía y del análisis de sangre, denominado PSA (Antígeno Prostático Específico), que mide una proteína producida por la próstata. En un nivel elevado, el PSA puede sugerir la presencia de un tumor o prostatita (infección de próstata), incluso aunque el hombre se encuentre bien y no presente problemas urinarios. Para Gomes (2002), los análisis permiten el diagnóstico del aumento prostático en su fase inicial, multiplicando las oportunidades de cura completa de la enfermedad. Así que los urólogos y proctólogos aconsejan que hombres con edad igual o superior a 50 años procuren atención médica regularmente para la realización del TR, en particular. Los urólogos y proctólogos alertan que en el caso de hombres con historial familiar de padre o hermano con cáncer de próstata, las pruebas deben ser solicitadas a partir de los 45 años.

Así pues, según los datos del Perfil Sociológico de la Vejez en Mossoró, 2004, apenas el 15,20\% afirma haber visitado un urólogo para hacerse alguna prueba o revisión de la próstata, frente al $32 \%$ de los ancianos que no se la hicieron. El 2,80\% no contestó a la pregunta (Gráfico 39). Se destacan como los más cuidadosos con la salud urológica 55 de los 166 varones casados (22\%) y 10 de los 47 hombres viudos (4\%). Con relación a la edad, percibimos que los mayores entre 66-75 años (43) fueron los que más buscaron orientación urológica, frente a los mayores de entre 60-65 años (13). Los que menos acudieron a los servicios urológicos en el último año fueron 20 varones de entre 76-90 años de edad (8\%). En relación a la prevención, los hombres que participaron en la encuesta de la Fundación Perseu Abramo en 2006, no quedan por detrás de las mujeres: el $42 \%$ nunca se hizo el análisis rectal para 
diagnosticar el cáncer de próstata. Todo indica que esa generación tiene un poco más de dificultades para ir al médico.

A medida que el hombre va envejeciendo, la incidencia de esa dolencia aumenta, sin embargo era previsible que un porcentaje tan bajo de hombres acudiera a los consultorios urológicos. En comparación con las mujeres entrevistadas, ellos cuidan mucho menos su salud que las mujeres ancianas. Los hombres generalmente tienen prejuicios, sobre todo por la falta de información, para hacerse los análisis de TR, que son indispensables para detectar el cáncer de próstata, debido a la forma en la que se realizan. Aunque la prueba sea desagradable, dicen los urólogos, es un eficiente método de diagnóstico, simple, rápido e indoloro. En nuestro caso, dado que la mayoría de los entrevistados tiene poco nivel de educativo y pertenece a extractos sociales bajos, señalamos que las informaciones sobre el cáncer y los programas preventivos dirigidos a los varones en Mossoró no se realizan convenientemente. La situación no podría ser más acuciante. Sólo hay tres urólogos en la ciudad para atender a los 7.157 mayores de 60 años. En otras palabras, si los 7.157 ancianos decidieran acudir a la atención especializada, serían 2.385 varones por cada urólogo. La situación en Mossoró puede que corrobore las premoniciones del Instituto Nacional de Cáncer en un futuro muy cercano, si no se amplían las medidas y servicios de atención Geriátrica, sobre todo para la población más desfavorecida.

\section{GRÁFICO 39}

Hombres que visitan al urólogo

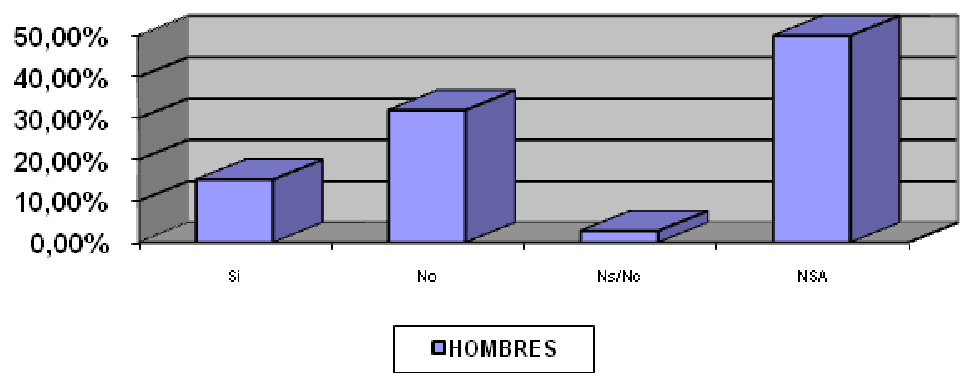

Fuente: Encuesta Perfil Sociológico de la Vejez en Mossoró - Junio 2004 / Junio 2005 (Elaboración de la autora) 


\section{Cobertura Sanitaria que tiene actualmente}

La población investigada de 60 o más años de Mossoró, como refleja el Gráfico 40, revela un alto porcentaje de usuarios del Sistema sanitario público de salud $(64,60 \%)$ como único medio para cubrir los cuidados relacionados con la salud, frente al $28,20 \%$ que afirma tener seguro de salud privado, y un reducido $5,60 \%$ que se vale de otro tipo de asistencia cuando lo necesita. La investigación realizada por la Fundación Perseu Abramo con los mayores en Brasil en 2006, también pone de relieve que los servicios públicos, como los puestos de salud, son los más demandados por los mayores. Si para el $24 \%$ de los entrevistados los planes de salud son las principales formas de contacto con el médico, el 68\% utiliza los servicios del Sistema Único de Salud (SUS) como forma de acceso.

Los varones son los mayores usuarios de los servicios sanitarios públicos $(35,40 \%)$, mientras que las mujeres prefieren la asistencia pagada (16\%). Por estado civil, apenas un selecto número de varones casados $(9 \%)$ y mujeres solteras $(2,20 \%)$, casadas $(4,60 \%)$ y viudas $(7,60 \%)$ dispone de cobertura sanitaria privada. Las razones socioeconómicas son determinantes para que el individuo disponga de algún tipo de servicio sanitario en Brasil. Así que, de acuerdo con el sexo y condiciones financieras, de los 61 varones que pagan un seguro privado $(12,20 \%)$, un $2,40 \%$ dispone de ingresos entre 1 y 2 salarios mínimos y un 5,60\% dispone de más de 4 salarios. Entre las 80 mujeres, que invierten en aseguradoras o cooperativas (16\%), el 5\% dispone de ingresos entre 1 y 2 SM, el $3,60 \%$ cuenta con un sueldo entre 2 y 3 SM y el $4,40 \%$ dispone de más de $4 \mathrm{SM}$.

Según Ministerio de Salud, la gran mayoría de los brasileños (90\%) en 2003, utilizó de alguna forma el Sistema Único de Salud (SUS). El SUS fue creado por la Constitución Federal de 1988 y reglamentado por la Ley 8080, de 19/09/1990, Título II, Artículo IV, con la finalidad de alterar la situación de desigualdad en la asistencia sanitaria de la población. Dicha medida hace obligatoria la asistencia pública a todo ciudadano, estando prohibido el cobro de dinero. A través del SUS, todos los ciudadanos tienen derecho a consultas, 
análisis, internaciones y tratamientos en las Unidades de Salud vinculadas al SUS, sean públicas (de la esfera municipal, estatal y federal) o privadas, controladas por el gestor público de salud. El sistema es financiado con recursos recaudados a través de impuestos, contribuciones sociales y pagos de la población y forma parte de los recursos del gobierno federal, estatal y municipal. Con ese modelo de salud pública, en palabras de Eduardo Jorge, Secretario de Salud de São Paulo, Brasil construyó uno de los más amplios y universales sistemas de salud del mundo, fruto de años de luchas de profesionales del área, líderes políticos y sociedad civil. Sin embargo, la situación de la salud brasileña es mucho más compleja de lo que las informaciones parecen indicar. Los problemas cotidianos que afectan al sector de la salud pública en Brasil crecen de norte a sur del país. Las quejas de quienes necesitan utilizar la asistencia pública son conocidas: filas interminables, gente amontonada en los pasillos de los hospitales, huelga de los empleados, demora en coger las citas, plazas insuficientes y defunciones por falta de asistencia médica. Estas son algunas de las situaciones que revelan diariamente la ineficiencia y la mala calidad de los servicios sanitarios públicos prestados a la población. Tal y como denunció el médico y profesor de la Universidad de São Paulo (USP) Wilson Carvalho, cuando se le brindó la oportunidad de debatir sobre el financiamiento del SUS, realizado en febrero de 2004, uno de los dos grandes obstáculos del SUS es "la insuficiencia de recursos y la ineficiencia de su uso".

En varias partes del país los servicios ineficientes, la inexistencia de asistencia médica y los altos costos de asistencia particular lleva a un número creciente de brasileños a optar por los planes de salud privada. Según la Asociación Brasileña de Medicina de Grupo (ABRANGE), aproximadamente 41,6 millones de personas tenían algún convenio con algún plan privado en 2002. Sin embargo, de acuerdo con la Agencia Nacional de Salud Suplementar (ANS), más de 2 millones de usuarios abandonaron la salud pagada del sistema privado, entre el final de 2003 y abril de 2005. En diciembre de 2003, el sistema contaba con 36,8 millones de usuarios. Ese número cayó a 34,4 
millones en abril de 2005. Todo esto es debido a los altos precios de los planes y la baja renta del brasileño.

En esta rueda de la evidente precariedad de los servicios de salud, particularmente para las de bajas rentas y los altos costos de la seguridad privada, se puede decir que la población de Mossoró no es inmune a esa realidad. $Y$ entre los perjudicados están los mayores, que sufren de modo particular, dado que con el aumento de la expectativa de vida se propicia una mayor exposición o riesgo para el desarrollo de enfermedades relacionadas con el envejecimiento.

En este escenario es fundamental que la sociedad civil reivindique programas de acciones básicas de salud, incluyendo en ellos la intervención Geriátrica. Como sostienen Marino y colaboradores ${ }^{337}$, los objetivos básicos de esa intervención "son los de aumentar la longevidad, y sobre todo, de recuperar, preservar o mantener la funcionalidad (autonomía e independencia), es decir calidad de vida". Para un abordaje adecuado, señala también la capacitación de agentes en esa área. Quizá, con la creación del Consejo del Anciano en Mossoró, previsto en el Estatuto del Anciano, mejore la atención a la salud de las personas mayores, con propuestas de cambios y sugerencias de nuevas políticas.

\section{GRÁFICO 40}

\section{Cobertura sanitaria que tiene actualmente}

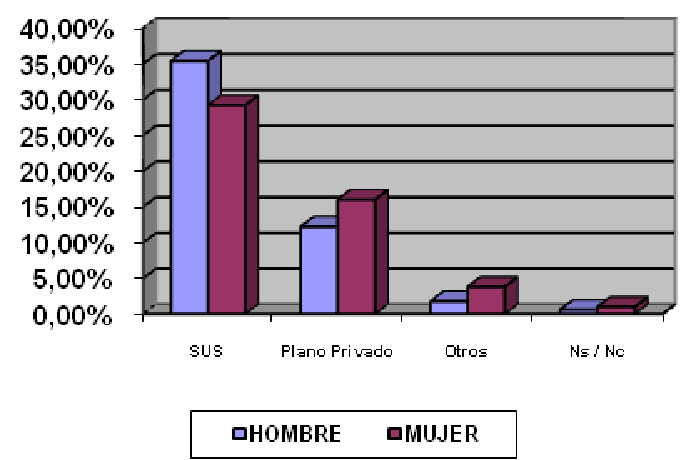

Fuente: Encuesta Perfil Sociológico de la Vejez en Mossoró - Junio 2004 / Junio 2005 (Elaboración de la autora)

\footnotetext{
337 Marino, M. C. A, Moraes, E. N. y Santos, A. G. R. (2002): Avanços e perspectivas em geriatria,
} em Tratado de Geriatria e Gerontologia, p. 588. 


\section{Cómo debe recibir asistencia médica el anciano}

Es un hecho que el organismo humano, con el paso del tiempo, se desgasta, sufriendo cambios muchas veces irreversibles. Por tanto, el goce por parte del individuo de una expectativa de vida saludable y los cuidados con el saneamiento básico constituyen un pilar importante. Todo ello va asociado al estilo de vida, como alimentarse correctamente, mantenerse activo físicamente y visitar al médico con regularidad.

Ya que la mitad de los sujetos sólo acuden al médico cuando enferman, les preguntamos, como alternativa para que reciban una asistencia médica adecuada, cómo deberían ellos y los de su edad recibir asistencia médica. Dado que a los mayores parece no "gustarles ir al médico", "se resisten a visitarlo regularmente", y, además, porque dependen de un sistema público sanitario ineficiente.

Entre este grupo de población, la asistencia a domicilio es lo más adecuado para tres cuartas partes $(75,80 \%)$ y casi una quinta parte prefiere la asistencia en el puesto de salud u hospital (23,20\%) (Véase Gráfico 41). De acuerdo con el sexo y el estado civil, son los varones casados y viudos y las mujeres solteras, casadas y viudas los que más reclaman ser asistidos a domicilio. Para los que prefieren la atención médica en casa, se observa un mayor porcentaje entre los varones $(23,20 \%)$ y mujeres $(14,80 \%)$ que sólo hacen las visitas médicas cuando sufren alguna enfermedad y entre los que no mantienen ninguna actividad física ( $21 \%$ y $20,40 \%$ hombres y mujeres, respectivamente).

Lamentablemente no les preguntamos si ya fueron atendidos a domicilio, dado que en Brasil la práctica de atender al paciente en su hábitat es una experiencia iniciada con el Programa de Agentes Comunitarios de Salud (PACS) en 1991 y posteriormente en 1994, reforzado por el Programa Salud de la Familia (PSF) ${ }^{338}$. Estos programas llegaron de países como Cuba, Inglaterra y Canadá, que alcanzaron altos niveles de calidad, con inversiones en la promoción de salud, y prevención de enfermedades. Los referidos programas

\footnotetext{
338 Ministério de Saúde, Programa Saúde da Família, Revista brasileira de saúde da família. Brasília, Ano II, 2002, pp. 7-17.
} 
fueron creados por el entonces ex-Presidente Itamar Franco, como estrategia del Ministerio de Salud (MS) para dar prioridad a las acciones de promoción, protección y recuperación de la salud de los individuos y de la familia, desde los recién nacidos a los ancianos, sanos o enfermos, de forma integral y continua. Experiencias pioneras muestran su eficacia y entre algunos hitos nacionales al respecto hay que destacar las ciudades de Icapuí (Ceará) y Catanduva (São Paulo).

En el Estado de Río Grande del Norte (RN), según la Secretaría de Salud Pública (Sesap) ${ }^{339}$, actualmente el PSF cuenta con 636 equipos, que cubren al $65 \%$ de la población del Estado. Con el programa instalado en 165 municipios, de los 167 existentes, el Estado tiene profesionales actuando en el 98\% de las ciudades potiguares, con índices superiores a los del Nordeste (90\%) y Brasil (87\%). En Mossoró, según el Informe Percepção dos Profissionais do Programa Saúde da Familia em Sistema de Informação da Saúde, 2004, de la Secretaría Municipal de Ciudadanía, el PSF implantado desde 1999 alcanza al 61\% de la provincia, cuenta con 41 equipos multiprofesionales, tiene 26 Unidades Básicas de Salud con PSF y 531 Agentes Comunitarios de Salud.

En teoría, los equipos, compuestos por médico, enfermero, auxiliar de enfermería y dentista, acompañan a los pacientes en las unidades de salud y domicilios. De este modo, actúan en la prevención y en el tratamiento de enfermedades como hipertensión o diabetes, más allá de promover acciones de ciudadanía y educación, especialmente con niños y ancianos.

Si tenemos en cuenta que los referidos programas están presentes en casi todos los 28 barrios de Mossoró, como asegura la Gerencia Ejecutiva de Salud (Secretaría de Ciudadanía), cuyos informes proclaman su excelencia, se puede conjeturar que los mayores, de algún modo, ya fueron atendidos por la asistencia a domicilio y por ese motivo refuerzan su manutención y mejorías.

Además del PSF existe el Programa de Internación Domiciliar (PID) destinado a pacientes ancianos asistidos por el Sistema Único de Salud. En la capital, 
Natal, los adultos mayores ya se benefician de la asistencia médica en casa. A partir de 2007 el Programa pasa a ser implantado en Mossoró con el objetivo de liberar las camas en los hospitales, reducir gastos y proporcionar más confort a los pacientes. Según los expertos de la salud, la experiencia con el PID agiliza la recuperación de los mayores que, en la vivienda, reciben más atención de la familia y no quedan expuestos a las infecciones hospitalarias. El perfil de los participantes del programa es el de víctimas de infartos, accidentes, pacientes en recuperación de cirugías y víctimas de accidente vascular cerebral (AVC).

\section{GRÁFICO 41}

\section{Como debe recibir asistencia médica el anciano}

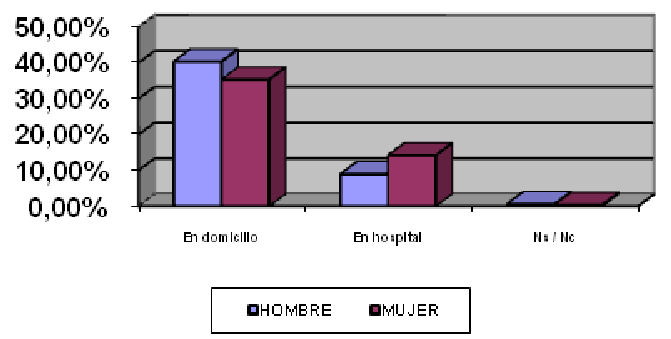

Fuente: Encuesta Perfil Sociológico de la Vejez en Mossoró - Junio 2004 / Junio 2005 (Elaboración de la autora)

\section{Consumo de tabaco}

El tabaquismo es considerado por la Organización Mundial de la Salud (OMS: 2000) como la cuarta causa principal de muerte evitable en todo el mundo ${ }^{340}$. La OMS estima que un tercio de la población mundial adulta, o sea, 1.300 millones de personas (entre los cuales hay 200 millones de mujeres), son fumadores. Nuestras investigaciones comprueban que aproximadamente el $47 \%$ de toda la población masculina y el $12 \%$ de la población femenina en el mundo, fuman. Mientras que en los países en desarrollo los fumadores constituyen el $48 \%$ de la población masculina y el $7 \%$ de la población femenina, en los países desarrollados la participación de las mujeres se

\footnotetext{
340 Informes Neurociencias: consumo y dependencia de sustancias psicoactivas de la OMS: 2000 en la página web http://www.jornaldaciencia.org.br.
} 
triplica: el $42 \%$ de los hombres y el $24 \%$ de las mujeres tienen la costumbre de fumar $^{341}$.

En Brasil, un tercio de la población adulta fuma, es decir 11,2 millones de mujeres y 16,7 de hombres, según el Ministerio de Salud (MS). A pesar de que los hombres fuman en mayor proporción que las mujeres en todas las franjas de edad, ellas van aumentando su participación en el número de fumadores, sobre todo en la franja más joven. Por año, según datos del Instituto Nacional de Cáncer (Inca), cerca de 200.000 brasileños mueren debido al tabaquismo y en el mundo la cifra llega a 5 millones. Sin embargo, una investigación realizada en 16 capitales brasileñas entre 2002 y 2003 por el MS, Inca y la Secretaria de Vigilancia Sanitaria (SVS), señala que el tabaquismo en el país tiene tendencia a la baja. En 1989, Río de Janeiro presentaba un 30\% de fumadores. En 2002, la tasa cayó al 17\%. En ese mismo periodo, Recife pasó del $28 \%$ al $18 \%$ y el Distrito Federal, del $26 \%$ al $17 \%$. De acuerdo con esta investigación, el tabaquismo se concentra en las capitales de las regiones más industrializadas y afecta, principalmente, a la población con menos escolaridad y renta.

Que el tabaco es malo para la salud y está asociado al desarrollo de innumerables enfermedades no es novedad. $Y$ siendo los ancianos un grupo de edad muy proclive a las dolencias por el consumo del tabaco, entre otras las respiratorias y la dolencia pulmonar obstructiva crónica (DPOC), nos interesó preguntar en esta sección cuál es la frecuencia del consumo de tabaco. Por cierto, el tabaco es la cuarta causa principal de muertes entre personas con edades entre 70 y 90 años ${ }^{342}$.

En base a los datos obtenidos en esta encuesta, puede observarse en el Gráfico 42 que hay un 14,23\% de los entrevistados de 60 o más años que son fumadores habituales, un 45,29\% que ha fumado alguna vez pero lo ha dejado, y un 40,28\% que no ha fumado nunca en la vida. El hábito de fumar

\footnotetext{
341 World Health Organization. World no - Tabaco Day, Tobacco and poverty: a vicious circle, 2004 y Ministerio da Saúdem Secretaria de Assistência à Saúde. Instituto Nacional de Câncer - INCA. Estimativas da Incidência e Mortalidade por Câncer. Rio de Janeiro: INCA, 2002.

342 Senger, João (2002): Doença Pulmonar Obstrutiva Crônica, en Freitas, Py, Neri, Cançado, Gorzoni y Rocha. Tratado de Geriatria y Gerontologia. Río de Janeiro: Guanabara Koogan, pp. 344-348.
} 
marca diferencias notables entre los sexos, entre los que fuman actualmente y los que antes fueron adictos al cigarro. Es decir, 41 varones $(8,22 \%)$ frente a 30 mujeres $(6,01 \%)$ fuman actualmente y 128 varones y 98 mujeres (el 25 y el 19,64\% respectivamente), abandonaron éste hábito. Esto pudo ser debido a restricciones por razones de enfermedad, o bien por razón de menores ingresos tras la jubilación o pensión. Sin embargo, la gran diferencia está en las mujeres que nunca fumaron durante su vida $(24,24 \%)$, en relación con los varones que afirmaron lo mismo (16,03\%). La proporción elevada de población anciana que nunca ha fumado, que se inscribe sobre todo el colectivo femenino, se basa en las costumbres sociales.

Existe un contraste también en cuanto a la variable de edad. Los hombres fuman en mucha mayor proporción que las mujeres en todas las edades, excepto entre los 60-65 años. También han abandonado el vicio en proporciones más altas en todas las franjas de edad. Por último, los datos señalan que el uso del tabaco se asocia con la clase social del individuo, lo que confirma los datos de la mencionada investigación del INCA. Así pues, entre los mayores fumadores encuestados están los que disponen de hasta dos salarios mínimos mensuales y los que nunca han fumado poseen ingresos superiores a tres salarios mínimos.

\section{GRÁFICO 42}

\section{Consumo de tabaco}

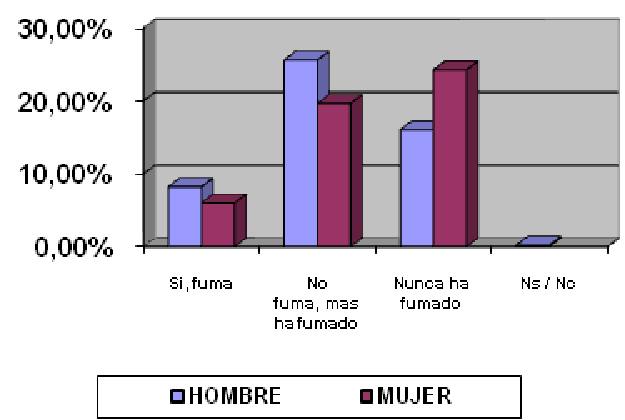

Fuente: Encuesta Perfil Sociológico de la Vejez en Mossoró - Junio 2004 / Junio 2005 (Elaboración de la autora) 


\section{Consumo de bebidas alcohólicas}

El tabaco y el alcohol, que son drogas lícitas, causan más daños a la salud pública que las ilícitas, como la cocaína. Datos de la Organización Mundial de la Salud (OMS) informan de que entre los diez factores de riesgo de adquirir dolencias evitables, el alcohol ocupa el quinto lugar. Su uso contribuyó al desarrollo de un 4\% de las enfermedades en 2000. Año tras año, las cifras de cáncer de esófago, hígado, cirrosis, violencias, casos de asesinatos, de accidentes de tráfico, y de lesiones voluntarias, además de los problemas sociales y familiares, dejan un saldo negativo en todo el mundo por culpa del consumo abusivo del alcohol.

Aunque el alcohol sea enemigo de la salud, atrae a jóvenes y adultos, sin discriminación de sexo, edad, raza, religión o clase social. Ya que abarca a cualquier individuo, quisiéramos saber, cuál es el hábito de los mayores de 60 años de ingerir bebidas alcohólicas. Lejos de constituir meras especulaciones, las informaciones recogidas en ésta y la siguiente sección, podrán contribuir a la inclusión del tema en las políticas sociales de prevención y recuperación del alcohol, dirigidas a los mayores mossoroenses.

La Encuesta, en general, señala que más de la mitad de los ancianos afirma no haber ingerido nunca una bebida alcohólica $(52,60 \%)$, una tercera parte dice que hizo uso de la sustancia, pero la han dejado $(34,20 \%)$ y un poco más de una décima parte hace uso actualmente (11,20\%) (Véase Gráfico 43). En relación al sexo, los hombres muestran propensiones más altas que las mujeres, tanto en relación al consumo alcohólico (un 9,20\% frente a un 2\%), como en relación a los que han dejado de beber (un $26,40 \%$ frente a un $7,80 \%)$. Sin embargo, las cifras suben significativamente en el entorno femenino cuando el tema es no haber bebido alcohol nunca: son un 39,20\% frente al $13,40 \%$ de los varones. Esto puede ser debido a los patrones culturales de épocas pasadas, que reservaban el consumo del alcohol a los varones.

Analizando el grupo por edad, se puede afirmar que el 6,40\% de los varones entre 60-70 años y el 1\% de las mujeres entre 71-75 años, consumen alcohol 
actualmente. Entre los mayores que han dejado el hábito de beber están los hombres de entre 66-70 años. Las mujeres lo han dejado más temprano, al menos una década (60-65). Entre el colectivo estudiado, según el estado civil, beben frecuentemente los varones casados $(5,80 \%)$ y las mujeres solteras y viudas (1,20\%). En el ámbito de los que han dejado los productos alcohólicos, destacan los varones casados y viudos (el 18,40 y el $4,80 \%$ respectivamente), y las mujeres casadas y viudas (el $3 \%$ y el $2,80 \%$ ). Los datos más altos, por estado civil, de los que nunca bebieron, aparecen dominados por las mujeres solteras $(3,60 \%)$, casadas $(14,40 \%)$ y viudas $(18,20 \%)$.

Como la sociedad occidental mantiene expectativas diferentes acerca de los papeles y comportamientos adecuados para uno y otro sexo, de la misma forma que también ofrece oportunidades distintas para hombres y mujeres, en el contexto del hábito de la bebida, en las mujeres hay un procedimiento diferente al de los hombres. Para el psiquiatra Dr. Joel Rennó, coordinador de Pró-Mujer, Proyecto de Atención a la Salud Mental de las Mujeres del Instituto de Psiquiatría del Hospital de las Clínicas, en São Paulo, ellas comienzan a beber más tarde, sufren más represión social y cultural y esconden el hábito, sintiéndose avergonzadas y culpables. Beben, al contrario que los hombres, aisladas en casa.

Aunque los resultados nos parezcan positivos, puesto que sólo 56 mayores mossoroenses $(\mathrm{N}=500)$ son consumidores de productos alcohólicos, en general las consecuencias de ese hábito no saludable para ambos sexos, son cruciales cuando los riesgos de las enfermedades como la cirrosis hepática y los cánceres de hipertensión siguen culminando en muerte en personas de la tercera edad.

Disponer de la información sobre los males que provoca el uso del alcohol de modo general, a fin de prevenir nuevos adictos y ofrecer asistencia específica para el tratamiento del alcoholismo a través de política públicas, ya que no hay clínicas especializadas para dependientes químicos en Mossoró, quizá reduzca el índice de los consumidores. 


\section{GRÁFICO 43}

\section{Consumo de bebidas alcohólicas}

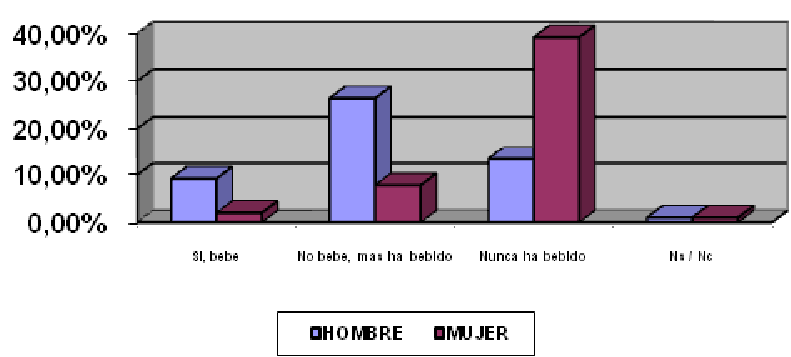

Fuente: Encuesta Perfil Sociológico de la Vejez en Mossoró - Junio 2004 / Junio 2005 (Elaboración de la autora)

\section{Hábitos y frecuencia de consumo de bebidas alcohólicas}

Un estudio realizado por la Organización Mundial de la Salud (OMS), divulgado en los medios científicos, revela que el alcoholismo es ya la tercera mayor enfermedad en el país, quedando por detrás de los males del corazón y los tumores. Los resultados del estudio, hecho en el año 2000, indican también que el 5,6\% de todas las muertes de hombres ocurridas en el planeta y el 0,6\% de las de las mujeres son atribuidas al consumo de alcohol. En 1990, la estimación de mortalidad de los dos sexos a consecuencia de la bebida era del $1,5 \%$, lo que indica una preocupante tendencia ascendente.

Ante esta escena no ficticia, la presente investigación también se interesó por saber la frecuencia con la que los mayores suelen ingerir bebidas alcohólicas. Así que, en general, como muestra el Gráfico 44, consumen alcohol a diario un $1,20 \%$, lo toman solamente los fines de semana un $2 \%$, hacen uso de productos alcohólicos esporádicamente un 12,80\%, prefirió no contestar a la cuestión un 7,20\% y por último, esta cuestión no se aplica a un $76,80 \%$ de los entrevistados por declarar que nunca han tomado una bebida alcohólica.

Los varones consumen alcohol diariamente el doble que las mujeres (el $0,80 \%$ frente al $0,40 \%$ de las mujeres). Entre los que suelen beber sólo los fines de semana, los porcentajes se disparan a favor de los hombres (el 1,80\% frente al $0,20 \%$ de las mujeres), y entre los que acostumbran a ingerir esporádicamente los hombres triplican las cifras de las mujeres (el 9,60\% frente al 3,20\%). 
Teniendo en consideración las edades, los varones de 60-70 años son los que más dijeron ingerir bebidas alcohólicas esporádicamente, mientras que las mujeres con el mismo hábito se quedan entre los 60-65 años. Los que tienen costumbre de beber semanalmente, son varones de entre 60-65 años y apenas una mujer entre 66-70 años y los que beben todos los días son cuatro hombres y dos mujeres de entre 60-76 años.

Según una investigación realizada por el Núcleo de Estudios sobre el Envejecimiento y la Salud de los Mayores ${ }^{343}$, la jubilación, la pérdida de parientes y amigos, los ingresos hospitalarios y el insomnio, incitan cada vez más, a una parte de la población anciana al consumo de alcohol. Beben para no sentirse abandonados, en un sitio cualquiera, viendo pasar los días sin ninguna motivación para actuar. Todos estos son algunos de los motivos que llevan a los mayores a ahogar el dolor en una copa de alcohol ${ }^{344}$. Para el citado colectivo, esto es, la población anciana, la situación se agrava, ya que una dosis de alcohol por día para alguien más viejo y con un organismo ya debilitado puede causar problemas cognitivos, dificultades de locomoción y habla, además de complicar las enfermedades vasculares.

Sabemos también que los casos de baja autoestima, depresión y desagregación familiar contribuyen al aumento de alcoholismo entre los mayores. Lamentablemente en Mossoró no se ha encontrado ninguno estudio específico sobre la práctica del alcoholismo entre los mayores. Es sintomática también, la falta de investigaciones y de interés sobre los estudios acerca de la violencia, el abandono y los malos tratos a mayores. Se trata de una verdadera "conspiración en silencio" contra la salud física y mental de la vejez en Mossoró, que precisa de atención por parte del Gobierno y de las políticas sociales. Sería una buena oportunidad para empezar a realizar estudios en ese campo.

\footnotetext{
343 Del Departamento de Administración y Planeamiento en Salud (Daps) de la Escuela Nacional de Salud Pública de la Fundación Oswaldo Cruz (Fiocruz).

344 Conferir Jornal o Estado de São Paulo - Abandono leva mais idosos ao alcoolismo http://www.alcoolismo.com.br/idosos.html.
} 


\section{GRÁFICO 44}

Hábitos y frecuencia de consume de bebidas alcohólicas

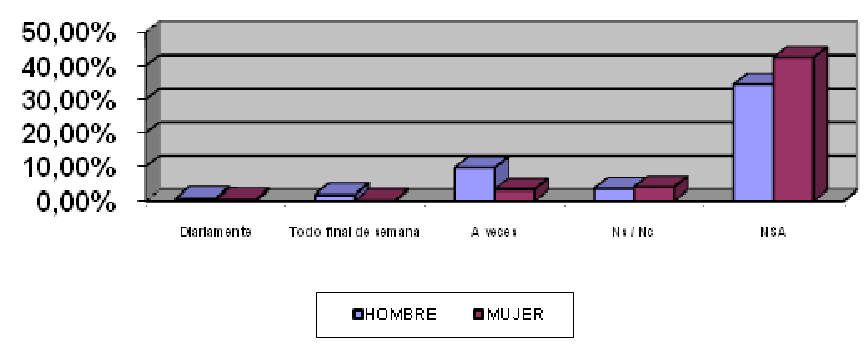

Fuente: Encuesta Perfil Sociológico de la Vejez en Mossoró - Junio 2004 / Junio 2005 (Elaboración de la autora)

\section{Resumen}

Esta parte del Perfil Sociológico de la Vejez en Mossoró, caracterizada por mostrar diversas informaciones sobre el cuidado de la salud del mayor en la comunidad, se proyecta como apoyo, que puede interesar de modo particular a los expertos, órganos e instituciones encargados de la salud pública, para las acciones relativas al envejecimiento, en una sociedad que empieza a envejecer. En líneas generales, menos de la mitad de los sujetos entrevistados sólo busca al médico cuando sufre alguna enfermedad (48,26\%), una quinta parte vigila la salud cada tres meses, el 12,93\% cada dos meses y un 17,35\% acude al médico una vez al año. De acuerdo con el sexo, las mujeres parecen más preocupadas por la salud que los varones y la periodicidad de las visitas médicas sugiere una relación fuerte con el estatus socioeconómico del colectivo. Los mayores que reciben entre uno y dos salarios mínimos acuden a la asistencia médica estrictamente sólo cuando están enfermos, al igual que los menos escolarizados y los de edades más avanzadas. De modo general, los mayores parecen esforzarse muy poco en la prevención de las enfermedades o de los tratamientos que requieren acompañamiento médico. La primera conclusión que se debe tener en cuenta es la situación económica de la mayoría, que entre las necesidades básicas, deja la asistencia de la salud en el $5^{\circ}$ lugar de la escala de interés ${ }^{345}$. La segunda, es que la precaria asistencia del sistema público de salud para la población con pocos recursos financieros en la Comunidad, contribuye al 
descrédito de los servicios, además de comprometer la calidad de vida de todos los que necesitan de ellos.

Los mayores de 60 años entrevistados, cuando están enfermos y después de medicados, adquieren las medicinas mediante compra de la caja completa $(65,30 \%)$, por encima de un quinto lo obtiene a través de un órgano público (22,71\%), una décima parte compra a granel y sólo un 1,26\% afirma no comprar. Las mujeres, como enferman en proporción mayor que los hombres, compran más que ellos las cajas completas. Dos vías facilitan tal adquisición: la compra de medicamentos genéricos, como alternativa, porque son un $40 \%$ más barato que los de las marcas comerciales, y la adquisición de medicamentos a través de programas de distribución gratuita, pero sólo para los tratamientos prolongados o permanentes. Otro camino de acceso a las medicinas, es la compra fraccionada, política reglamentada recientemente en Brasil, que permite a las clases sociales de bajo poder adquisitivo conseguir medicamentos. Antes era una costumbre practicada pero sin apoyo legal. El hecho de que los mayores dispongan de estos mecanismos - aunque se supone que ni todas las farmacias tienen genéricos suficientes para la demanda de la población en Mossoró, ni tampoco todos los establecimientos están ya reglamentados para la venta a granel - y teniendo en cuenta que la política de distribución gratuita de medicamentos apenas atiende a enfermedades específicas en los puestos de salud gubernamentales, supone que los mayores deben tener algunas dificultades a la hora de adquirir las medicinas.

Refiriéndose al cuidado de los ojos, algo más de la mitad de los mayores participantes se ha hecho una revisión oftalmológica $(52,37 \%)$, mientras que el 43,85\% del total no se la hizo. Los varones entre 60-70 años son más cuidadosos con los trastornos visuales comunes en la vejez. En las mujeres, esta atención se extiende hasta los 80 años. Si ampliamos aún más los asuntos preventivos, comprobamos que sólo el $28,39 \%$ de las mujeres y el $14,51 \%$ de los varones han acudido al ginecólogo y urólogo para hacerse pruebas citológicas y de próstata. Los índices son negativos y merecen especial atención. Aparte de revelar la falta de información, prejuicios y miedos al 
diagnóstico de las enfermedades, sobre todo las cancerígenas, mostrados por los participantes, sugiere la necesidad de una mejora eficaz de los programas preventivos creados para este grupo de población en Mossoró. La falta de atención en las referidas áreas, lamentablemente, podrá confirmar las estimaciones sobre nuevos casos de cáncer para ambos sexos.

En función del tipo de asistencia médica que utilizan, como ocurre con el 90\% de brasileños, casi dos tercios son usuarios del Sistema Único de Salud (SUS) (64,98\%), frente al $26,81 \%$ que prefiere el sistema privado. Las razones socioeconómicas son evidentes: la asistencia es cara y la gente gana poco. Los mayores que pagan la asistencia sanitaria privada disponen de ingresos mensuales entre 3 y 4 salarios mínimos. Conforme a la Ley 8080 , de 1990, el SUS es una asistencia pública y gratuita que da derecho a consultas, análisis, ingresos y tratamientos. Sin embargo, la realidad es otra. La mala valoración, en general, de las personas que han acudido a ella y la falta de respeto a sus derechos, se refleja diariamente en las quejas de escasez, ineficiencia y mala calidad de los servicios de salud.

El sistema sanitario brasileño reviste una enorme complejidad. Los mayores entrevistados opinan que ellos y los de su edad deberían ser asistidos en el propio domicilio $(72,56 \%)$, y una quinta parte manifiesta su predilección por la asistencia en el puesto de salud (26,81\%). La idea de ser asistidos en casa cuando están enfermos, agrada tanto a los usuarios de SUS como a los usuarios de los planes privados. La incidencia de los que desean ser tratados en casa se observa en mayores que sólo hacen visitas médicas cuando caen enfermos y en los ancianos sedentarios. Pero, puede ser que en este entorno, algunos hayan sido atendidos en su domicilio por el equipo del Programa de salud de la Familia (PSF) y por eso defiendan la política de asistencia domiciliar. Aquellos que prefieren la asistencia tradicional, en los establecimientos sanitarios, parecen subrayar cierta satisfacción con los servicios o bien creen que es el sitio más adecuado para la atención médica.

Para concluir el perfil de salud del mayor en Mossoró, tocaremos dos asuntos que siempre están en las pautas políticas, económicas y sociales: el consumo 
de tabaco y la ingesta de bebidas alcohólicas. En la población investigada, el $41,96 \%$ nunca ha fumado en la vida, el $42,27 \%$ ha fumado alguna vez, pero lo ha abandonado y sólo un $15,46 \%$ de los mayores fuma actualmente. El hábito de fumar anterior y actualmente no marca mucha discrepancia entre los sexos. Sin embargo, la gran diferencia estriba en las mujeres que nunca fumaron a lo largo de su existencia $(27,76 \%)$ en relación a los varones en las mismas condiciones $(14,20 \%)$. Los actuales fumadores tienen edades comprendidas entre 60-65 años, los que dejaron el hábito tienen edades más avanzadas y entre los que nunca fumaron encontramos ejemplos en todas las edades. Los adictos al tabaco disponen de hasta dos salarios mínimos, en cambio, los que nunca han fumado tienen ingresos superiores a tres salarios mínimos. En lo que respecta a la ingesta de bebidas alcohólicas, hemos visto que más de la mitad nunca ha bebido alcohol (52,21\%), frente a una tercera parte que lo ha ingerido y abandonado y menos de una décima parte que bebe actualmente. En relación al sexo, los varones son mucho más bebedores que las mujeres. Entre los que nunca adquirieron tal hábito, las mujeres asumen el liderazgo (el $46,06 \%$ frente al $9,15 \%$ de los varones). Los datos señalan resultados sorprendentes: los hombres que ingieren alcohol actualmente tienen entre 60-70 años, mientras que las mujeres tienen entre 71-75 años. La situación se invierte cuando han dejado dicha práctica. Las mujeres entre 6065 años la dejaron más temprano que los varones (66-70 años). En cuanto a la frecuencia con que los mayores suelen ingerir alcohol, un reducido porcentaje bebe diariamente $(1,26 \%)$, el $1,58 \%$ bebe solamente los fines de semana y un $11,67 \%$ lo hace esporádicamente. 


\section{Habilidades funcionales}

La vejez no es tan mala cuando se considera la alternativa.

Maurice Chevalier (1888-1972), Cantante y actor cinematográfico francés.

\section{Actividades que suelen realizar con ayuda}

Como ya se indicó anteriormente $e^{346}$, más de la mitad del colectivo investigado con 60 o más años de edad vive en hogares monoparentales, múltiples y de matrimonio con hijos (Tabla 11). Se supone que la mayoría de ellos, de un modo u otro, tiende a realizar las tareas del hogar según su situación socioeconómica (el $56,15 \%$ de los entrevistados declara que los ingresos que recibe están entre uno y dos salarios mínimos - ver Tabla 15). De ese modo, en ésta sección, se preguntó a los entrevistados con quién suelen hacer las actividades del hogar. ¿Son los mayores responsables de las tareas domésticas o cuentan con ayudas externas? El propósito es percibir su nivel de capacidad funcional, poner de manifiesto la posible sobrecarga en las labores domésticas y así contribuir a la reflexión en cuanto a la necesidad de prestaciones y servicios de ayuda a domicilio.

De acuerdo con los datos (ver Tabla 33), cuando se preguntó a los entrevistados quiénes contribuyen más a las tareas del hogar, se nos reveló que alrededor de casi tres cuartas partes de las personas suelen realizarlas en compañía de un familiar (74,80\%), un 8,40\% declara disponer de un servicio de empleado del hogar pagado, un 4,20\% cuenta con ayuda de un pariente, un $3,60 \%$ afirma tener ayuda de otros y en menor medida, al $1,20 \%$, le ayuda un vecino.

Si el $90,40 \%$ de los entrevistados afirma que vive en el mismo domicilio con algún familiar, parece razonable que cuenten con la colaboración de algunos de estos miembros. El $8,40 \%$ que dispone del servicio pagado, contempla

$346 \quad$ Parte I, Tabla 11. 
apenas a 42 personas, en su mayoría casados (16) y viudas (16). En todas estas situaciones, donde vive un mayor que cuenta con la ayuda de un empleado de hogar, y siendo responsable o no del pago de este servicio, dicho mayor sólo dispone de hasta dos salarios mínimos mensuales.

Aunque las actividades del hogar sean en gran parte realizadas por personas con parentesco de consanguinidad, se supone que a diario los miembros de estas familias (hijo/a, nuera, nieto/a) desarrollan sus actividades cotidianas (estudio o trabajo) y de ese modo las ancianas pueden verse cargadas con las tareas del hogar. En ese sentido, si las tareas domésticas suponen para la gran mayoría de las mujeres de edad una obligación, quizá se podría adoptar un servicio público de "ayuda a domicilio" en la provincia.

\section{TABLA 33}

Según las actividades que suelen realizar con ayuda

\begin{tabular}{|l|c|c|cccc|}
\hline $\begin{array}{l}\text { AYUDAS EN LAS } \\
\text { ACTIVIDADES } \\
\text { DIARIAS }\end{array}$ & \multicolumn{2}{|c|}{$\begin{array}{c}\text { AMBOS SEXOS } \\
>60\end{array}$} & \multicolumn{2}{c|}{ HOMBRES } & \multicolumn{2}{c|}{ MUJERES } \\
\hline $\begin{array}{l}\text { Familiar } \\
\text { próximo }\end{array}$ & 374 & 74,80 & 203 & 40,60 & 171 & 34,20 \\
\hline Pariente & 21 & 4,20 & 9 & 1,80 & 12 & 2,40 \\
\hline $\begin{array}{l}\text { Empleada de } \\
\text { hogar }\end{array}$ & 42 & 8,40 & 10 & 2,00 & 32 & 6,40 \\
\hline Vecino & 6 & 1,20 & 3 & 0,60 & 3 & 0,60 \\
\hline Otros & 18 & 3,60 & 8 & 1,60 & 10 & 2,00 \\
\hline Ns/Nc & 8 & 1,60 & 4 & 0,80 & 4 & 0,80 \\
\hline NSA & 31 & 6,20 & 13 & 2,60 & 18 & 3,60 \\
\hline T O T A L & 500 & 100,00 & 250 & $\mathbf{5 0 , 0 0}$ & $\mathbf{2 5 0}$ & $\mathbf{5 0 , 0 0}$ \\
\hline
\end{tabular}

\section{Grado de dificultad para realizar las AVDs y AIVDs}

El aumento sin precedentes de la expectativa de vida poblacional propicia una mayor exposición o riesgo para el desarrollo de enfermedades relacionadas con el envejecimiento. Entre éstas se encuentra la probabilidad de sufrir enfermedades crónicas degenerativas y también el desarrollo de incapacidad funcional, que generalmente interfiere en la independencia del mayor, lo cual genera preocupación en ese segmento de edad ${ }^{347}$.

347 Rosa T. E. C., Benício M. H. D., Latorre M. R. D. O., Ramos L. R. (2003): Fatores determinantes da capacidade funcional entre idosos. Revista Saúde Pública (37): 40-8. 
Pero, aunque la gran mayoría de estos ancianos sufre, al menos, una de esas enfermedades, dado que en esta edad la ausencia de achaques es privilegio de pocos, no todos quedan limitados por ellas, llevando una vida normal, independientemente de la presencia o no de las enfermedades.

Alargando un poco más la cuestión, entramos en el entorno de la autonomía en la vejez, traducida en la capacidad del anciano de determinar y ejecutar sus propios designios ${ }^{348}$. Esto significa gestionar su propia vida y realizar las Actividades de la Vida Diaria (AVDs) y las Actividades Instrumentales de la Vida Diaria (AIVDs) ${ }^{349}$, desde las más básicas como asearse y comer, hasta las más complejas, como hacer compras o preparar la comida. Christiansen y Baum (1997) definen estas actividades de la siguiente forma: por un lado, Actividades de la Vida Diaria (AVDs), relacionadas con los cuidados personales, tales como alimentarse, bañarse, vestirse y realizar su higiene (incluyendo la higiene oral). Por otro lado, las Actividades Instrumentales de la Vida Diaria (AIVDs) se relacionan con la administración del ámbito en el que se vive y establecen la relación entre el domicilio y el medio externo. Las actividades incluyen, por ejemplo: comprar y preparar alimentos, administrar el uso de la medicación, administrar finanzas, salir de casa para realizar actividades diversas, utilizar un transporte, etc.

En este apartado, bajo el título de habilidades funcionales, presentaremos el cuadro de los mayores, dentro del conjunto de población anciana en Mossoró, que presentan limitaciones en el desempeño de las AVDs y AIVDs. Según Diego y Duarte (2002), "la evaluación funcional es esencial para el establecimiento del diagnóstico, pronóstico y juicio clínico adecuados, que servirán de base para decisiones sobre los tratamientos y cuidados necesarios" (2002:762). Así, entendemos que la pérdida de la capacidad funcional del mayor sirve de excusa para solicitar ayuda, sea a través del ámbito institucional (residencias, centros de día) o de la asistencia domiciliaria. Los indicadores van completando el diseño del Perfil Sociológico de la Vejez en Mossoró.

\footnotetext{
$348 \quad$ Laslett, 1989.

349 Paula, J. A. M, Tavares, M. C. G. y Diogo M. J.D. (1998): Avaliação funcional em gerontologia. Gerontologia, 6(2): 81-8.
} 
A grandes rasgos, las personas mayores de 60 años entrevistadas afirman no tener ninguna dificultad funcional para realizar ciertas actividades cotidianas como comer $(96,19 \%)$, ducharse $(92,18 \%)$, vestirse $(91,78 \%)$, cuidar de su aspecto físico (90,38\%), andar (82,73\%) y tomar medicamentos $(78,96 \%)$. En las Actividades Instrumentales de la Vida Diaria, a pesar de registrar cifras superiores al 50\%, hay una sutil disminución en ir a comprar artículos de primera necesidad (74,55\%), ir de compras $(67,74 \%)$, acudir al consultorio médico (60,32\%), preparar la comida (58,72\%), realizar otras tareas del hogar $(52,30 \%)$, leer el periódico $(53,11 \%)$ y realizar gestiones $(51,50 \%)$. (Véase Tabla 34).

Por sexo, los hombres parecen tener la capacidad funcional ligeramente en mejor estado que las mujeres. De quince actividades de la vida diaria sugeridas, ellos muestran una capacidad superior en diez, las mujeres apenas se destacan en cuatro aunque en la capacidad de ejecución quedan empatadas. La capacidad funcional que más favorece al grupo masculino es la autonomía al andar. Y la menos favorable es la ejecución de las tareas domésticas. En general, todo indica que el desempeño funcional diario está directamente relacionado con el sexo, la edad, el estado de salud y con el estatus socioeconómico de los mayores.

A nivel nacional, las investigaciones pintan un cuadro más serio que nuestra muestra. En a cuanto los mayores de la Encuesta, sus capacidades funcionales (las habilidades físicas y mentales) no revisten gravedad ya que "cerca del 40\% de las personas de 65 o más años necesita de algún tipo de ayuda para realizar al menos una actividad instrumental, como hacer compras o preparar la comida. De esas, al menos el $10 \%$ requiere ayuda para realizar actividades diarias, como ducharse, vestirse y alimentarse. ${ }^{350}$ En la Política Nacional de Salud del Anciano (1999), el concepto de capacidad funcional se entiende como la "capacidad de mantener las habilidades físicas y mentales necesarias para una vida independiente y autónoma".

$350 \quad$ CNBB (2002), Fraternidade e pessoas idosas: texto-base CF-2003/ Conferencia Nacional dos Bispos do Brasil, São Paulo: Salesiana, 2002, pp. 90-91. 
Concretamente, el cuadro señala un saldo positivo, dado que una proporción significativa de los ancianos se vale por sí misma, tanto en las actividades básicas como en las definidas de difícil ejecución. En general, la población anciana investigada presenta una independencia elevada para realizar actividades prácticas de la vida diaria (o de auto cuidado), aunque posee una ligera dependencia funcional para realizar las actividades instrumentales cotidianas. Así pues, se puede concluir diciendo que las dimensiones de las enfermedades asumidas aún no comprometen la capacidad funcional del grupo de edad o que quizá se resisten a asumir las debilidades de la vejez. Entre tanto, es importante reflexionar sobre ese tema, dado que el número de ancianos comienza a aumentar en Mossoró y es necesario recoger datos sobre nuestra realidad para que podamos trabajar en la construcción de modelos de intervención adaptados a nuestras necesidades. Sobre todo cuando, en general, en Brasil, la práctica de apoyo emocional e instrumental a esas actividades se da de modo informal entre las generaciones, amigos y vecinos $^{351}$ y la ayuda formal sistemática constituye apenas una realidad en las ciudades más desarrolladas del país.

TABLA 34

Según el grado de dificultades para realizar las AVDs y AIVDs

\begin{tabular}{|ccccccccccccccccc|c|}
\hline $\mathbf{S}$ & & & $\mathbf{A}$ & $\mathbf{B}$ & $\mathbf{C}$ & $\mathbf{D}$ & $\mathbf{E}$ & $\mathbf{F}$ & $\mathbf{G}$ & $\mathbf{H}$ & $\mathbf{I}$ & $\mathbf{J}$ & $\mathbf{K}$ & $\mathbf{L}$ & $\mathbf{M}$ & $\mathbf{N}$ & $\mathbf{O}$ \\
$\mathbf{X}$ & & & & & & & & & & & & & & & \\
$\mathbf{0}$ & & & & & & & & & & & & & & & \\
\hline H & Nin & 45,80 & 48,08 & 47,09 & 44,38 & 47,09 & 38,68 & 19,44 & 20,64 & 27,86 & 38,08 & 40,68 & 33,87 & 29,06 & 27,45 & 25,85 \\
& Alg. & 3,20 & 1,00 & 2,40 & 4,62 & 2,20 & 9,02 & 19,84 & 18,84 & 15,23 & 10,02 & 8,22 & 12,83 & 16,83 & 16,23 & 15,03 \\
& Bast & 1,00 & 0,60 & 0,60 & 1,00 & 0,80 & 2,40 & 10,83 & 10,62 & 7,01 & 2,00 & 1,20 & 3,41 & 4,21 & 6,42 & 4,41 \\
& Ns/Nc & - & - & - & - & - & - & 3,48 & - & - & - & - & - & - & - & 4,90 \\
& Nin & 44,40 & 47,70 & 44,69 & 38,35 & 45,09 & 35,87 & 39,28 & 31,66 & 24,65 & 40,88 & 39,48 & 33,87 & 31,26 & 25,65 & 25,65 \\
\hline & Alg. & 3,80 & 1,40 & 4,01 & 8,84 & 3,01 & 9,62 & 6,61 & 12,22 & 15,23 & 6,21 & 7,62 & 9,82 & 12,63 & 14,43 & 15,63 \\
& Bast & 1,80 & 0,80 & 1,20 & 2,81 & 1,80 & 4,41 & 4,00 & 6,02 & 10,02 & 2,81 & 2,80 & 6,20 & 6,01 & 9,82 & 4,01 \\
& Ns/Nc & - & 0,42 & 0,01 & - & - & - & - & - & - & - & - & - & - & - & 4,52 \\
\hline
\end{tabular}

Fuente: Encuesta Perfil Sociológico de la Vejez en Mossoró - Junio 2004 / Junio 2005 (Elaboración de la autora)

351 Neri, A. L. (2002) : Cuidar de idoso no contexto da família: questões psicológicas e sociais. Campinas, São Paulo: Alínea. 

A) Cuidar su aspecto físico
J) Tomar medicamentos
B) Comer sólo
K) Manejo de dinero
C) Vestirse o desvestirse
L) Ir de compras
D) Andar
M) Ir a alguna consulta médica
E) Ducharse
N) Realizar gestiones
F) Ir a comprar artículos de primera
O) Leer el periódico, revistas necesidad $u$ otros
G) Preparar las comidas
H) Realizar otras tareas domésticas
I) Utilizar transporte urbano

\section{Quién desearía que le prestara ayuda para realizar las AVDs y} AIVDs

Vimos en la sección anterior que prevalece una tasa significativa de personas con más de 60 años de edad con un buen nivel de independencia, que en su expresión máxima significa poder sobrevivir sin ayuda, o sea, realizar las actividades básicas e instrumentales de la vida diaria (M. Baltes, 1996). Dichos mayores dicen no encontrar obstáculos para andar, comer, vestirse, realizar gestiones, etc., a pesar de que el proceso de senescencia provoca problemas de dependencia en algunas personas de edad avanzada. Dicha cifra supera a la de los que necesitan cierta ayuda, cuando contestaron sentir alguna $o$ bastante dificultad al realizar tales actividades.

Siguiendo sobre esta misma cuestión, conviene preguntar a los que necesitan ayuda, ¿de quién desearían recibirla? Para desarrollar este tema nos amparamos en la existencia del papel del cuidador familiar ${ }^{352}$, de la asistencia domiciliaria $^{353}$, de la política del sistema de salud y del servicio de ayuda en casa, que integran los Servicios Sociales ${ }^{354}$.

\footnotetext{
352 El cuidador familiar es la persona de la familia a la que le corresponde el papel y /o las tareas de cuidar a los ancianos que presentan dependencia asociada a incapacidades funcionales y / o a pobreza y / o a enfermedades, de modo que son incapaces de sobrevivir por sí mismos. (Neri, 2001).

353 Consiste en el suministro de servicios de atención sanitaria a personas enfermas, incapacitadas o crónicas de cualquier edad, en su domicilio o en cualquier ambiente no institucional, promoviendo un tratamiento y/o funcionamiento efectivo que engloba visitas programadas, para la realización de determinados procedimientos, por los integrantes del equipo. Hay que pensar en ese escenario con el cuidador como responsable de la continuidad de la asistencia a domicilio. (Duarte y Diogo: 2000).

354 Albuquerque, S. M. R. L. (2003): Qualidade de vida do idoso: a assistência domiciliar faz a diferença. São Paulo: cedecis, p. 27.
} 
El 91,20\% del grupo de edad avanzada estudiado afirma que les gustaría que les ayudara un familiar o vecino, el 6,20\% es favorable a que la ayuda venga gratuitamente de parte de algún organismo público y sólo un 2,60\% estaría dispuesto a pagar una cuota simbólica a cambio de ayuda. Las mujeres se inclinan por buscar ayuda en la familia o vecinos y organismos a sueldo para la asistencia o servicio, mientras que los varones prefieren los servicios de asistencia gratuita.

Los datos nos conducen hacia dos hipótesis. La primera es que una gran parte del colectivo (ver Tabla 35) optó por sus familiares o vecinos para el auxilio en las actividades ya que la principal fuente de soporte para dicho colectivo es la familia (principalmente aquella que cohabita en domicilios multigeneracionales, como vimos en la Tabla 11), además de llevarse muy bien con los vecinos, conforme a lo que podemos apreciar en el Gráfico 7 y la Tabla 21. Sobre esa perspectiva, Baum y Page (1991) dicen que la red de apoyo informal encontrada en la familia constituye el primer abrigo y fuente primaria de asistencia para los mayores. La segunda hipótesis nos lleva a pensar que, quizá por una limitación financiera (ver Tablas 15 y 16), lo conveniente sería que les asistiera un órgano público sin obligatoriedad de pago. Sin embargo, Neri (2002) denuncia que "en países como Brasil, que ofrecen pocas alternativas de apoyo formal (ejercido por profesionales y por instituciones de atención a la salud, tales como hospitales, ambulatorios, centros de día, casas de reposo y asilos), ese tipo de soporte es crucial" (2002:14).

En Brasil, en algunas ciudades de la región del Sudeste existen iniciativas públicas formales de asistencia a los ancianos y a sus familias como parte de un programa de atención familiar. (Perracini, 1994; Karsch, 1988). Según Neri (2002), "lamentablemente, las ofertas de servicios formales de buena calidad son raras, caras y restringidas. Buena parte de las ofertas gratuitas, de naturaleza filantrópica, son de calidad dudosa" (2002:47). 
De acuerdo con los datos de la investigación, por sexo y edad, se nota que hombres y mujeres ancianos, entre 60 y 70 años de edad mantienen las capacidades funcionales autónomas, principalmente para las actividades básicas cotidianas (vestirse, comer y asearse), mientras que para las actividades instrumentales más complejas, las habilidades funcionales y la dependencia, afecta sobre todo a los individuos de mayor edad dentro del colectivo de personas mayores. En general, se evidencia que, tanto en el ámbito nacional como internacional, hay una estrecha relación entre dependencia y edad, esto es, a medida que los individuos envejecen, la posibilidad de realizar autónomamente algunas actividades cotidianas se vuelve más difícil. Así pues, para Manton (1997), por un lado, la dependencia puede tener su origen en una o varias enfermedades crónicas; por otro lado, puede ser el reflejo de una pérdida general de las funciones fisiológicas, atribuible al proceso global de envejecimiento.

En resumen, frente al aumento de la longevidad y el número de ancianos en la población de Mossoró, no sería menos importante que algunos servicios de ayuda, al igual que en los países desarrollados, estuvieran sistemáticamente disponibles para los mayores. Las esferas pública y privada han de prestar atención a las nuevas demandas creadas por las necesidades de los mayores, frágiles y dependientes. Quizá, el municipio podría invertir en crear un voluntariado que esté disponible como servicio de apoyo familiar, ayude a satisfacer las necesidades de las personas mayores y al mismo tiempo sea un recurso de protección social.

\section{$\underline{\text { TABLA } 35}$}

Según preferencia de ayuda para realizar las AVDs y AIVDs

\begin{tabular}{|c|c|c|c|c|c|c|}
\hline \multirow{2}{*}{$\begin{array}{c}\text { PREFERENCIA Y } \\
\text { AYUDA DIARIA }\end{array}$} & \multicolumn{2}{|c|}{ AMBOS SEXOS } & \multicolumn{2}{|c|}{ HOMBRES } & \multicolumn{2}{|c|}{ MUJERES } \\
\hline & $>60$ & $\%$ & $>60$ & $\%$ & $>60$ & $\%$ \\
\hline $\begin{array}{l}\text { Familiar o } \\
\text { vecino }\end{array}$ & 456 & 91,20 & 221 & 44,20 & 235 & 47,00 \\
\hline $\begin{array}{l}\text { Órgano público } \\
\text { y gratuito }\end{array}$ & 31 & 6,20 & 23 & 4,60 & 8 & 1,60 \\
\hline $\begin{array}{l}\text { Órgano público } \\
\text { o privado con } \\
\text { cobro de cuota }\end{array}$ & 13 & 2,60 & 6 & 1,20 & 7 & 1,40 \\
\hline TO T A L & 500 & 100,00 & 250 & 50,00 & 250 & 50,00 \\
\hline
\end{tabular}


4. Motivos por los que no recibe ayuda para realizar las AVDs y AIVDs

La vejez es vista generalmente, como un período de decadencia física y mental. Es un concepto equivocado, pues muchos ciudadanos llegan a los 60 años completamente independientes y productivos. Prueba de esto, es que a la luz de los resultados de los estudios comentados en las secciones anteriores, la mayoría de los individuos investigados que componen la población anciana de Mossoró se muestra independiente en muchas de las actividades cotidianas, asemejándose a los individuos de menos edad, que hacen lo mismo. Apenas un reducido número ha manifestado alguna dificultad para la realización de actividades de la vida diaria y entre este grupo de individuos, la preferencia destacada para recibir ayuda, cuando lo necesite, sería por parte de algún familiar o vecino $(91,20 \%)$.

Cuando se pregunta a estas personas, que supuestamente precisarían de apoyo y cuidado personal y no lo están recibiendo actualmente, por qué no lo reciben, más de una cuarta parte no cree que sea necesario $(26,40 \%)$, dado que sus capacidades funcionales aún se encuentran en un buen estado (es decir, gran parte de este colectivo ha demostrado autonomía para realizar las actividades citadas); un $11,80 \%$ apunta que no recibe servicios de apoyo debido a los escasos ingresos, un 10,40\% señala otros motivos y los demás porcentajes no pasan del $6 \%$, excepto el $15,80 \%$ que no quiso contestar a la pregunta. (Véase Tabla 36). De acuerdo con el sexo, las mujeres ancianas destacaron, por encima de los hombres, los motivos económicos, la falta de personal para ayudar y otros motivos, como las principales razones para no recibir ayudas. De hecho, en general, entre los ancianos, las mujeres tienen una situación económica peor que los varones. Además, cuando se trata del cuidado de otros, según Bazo (2004), éste tiende a ser llevado a cabo por mujeres. Continúa diciendo la autora que los ancianos, "son una responsabilidad de las mujeres, debido a su supuesto instinto natural para este tipo de trabajo" (2004:47). 
En cuanto a las otras tres razones, las ideas de ambos se aproximan, es decir, no les gusta la presencia de extraños en su casa, no creen que sea necesario y no respondieron a la pregunta. De acuerdo con la edad y estado civil, los mayores casados entre 60-70 años son los que más se posicionan en cuanto a la cuestión, mientras que entre las mujeres se destacan las casadas y viudas entre 60-80 años.

Este enfoque permite explorar la inexistencia de servicios de apoyo a las personas mayores en Mossoró, al mismo tiempo que resulta evidente la necesidad de comenzar un debate sobre el papel de las familias y del sistema sanitario para que se impliquen en el cuidado de las personas ancianas que lo necesiten.

\section{$\underline{\text { TABLA } 36}$}

Según motivos por los que no recibe ayuda para realizar AVDs y AIVDs

\begin{tabular}{|l|c|c|cccc|}
\hline \multicolumn{1}{|c|}{$\begin{array}{c}\text { MOTIVOS DE NO } \\
\text { TENER APOYO }\end{array}$} & \multicolumn{2}{|c|}{ AMBOS SEXOS } & \multicolumn{3}{c}{ HOMBRES } & \multicolumn{2}{c|}{ MUJERES } \\
\hline $\begin{array}{l}\text { Por motivos } \\
\text { económicos }\end{array}$ & 59 & 11,80 & 27 & 5,40 & 32 & 6,40 \\
\hline $\begin{array}{l}\text { Porque no hay } \\
\text { nadie que me } \\
\text { ayude }\end{array}$ & 22 & 4,40 & 7 & 1,40 & 15 & 3,00 \\
\hline $\begin{array}{l}\text { Porque no me } \\
\text { gusta ver extraños } \\
\text { en mi casa }\end{array}$ & 21 & 4,20 & 13 & 2,60 & 8 & 1,60 \\
\hline $\begin{array}{l}\text { No cree que sea } \\
\text { necesario }\end{array}$ & 132 & 26,40 & 73 & 14,60 & 59 & 11,80 \\
\hline Otro motivo & 52 & 10,40 & 23 & 4,60 & 29 & 5,80 \\
\hline Ns/Nc & 79 & 15,80 & 44 & 8,80 & 35 & 7,00 \\
\hline NSA & 135 & 27,00 & 63 & 12,60 & 72 & 14,40 \\
\hline T O T A L & 500 & 100,00 & 250 & 50,00 & 250 & 50,00 \\
\hline Funte: Encuesta Perfil Sociológico & & & & & & \\
\hline
\end{tabular}

Fuente: Encuesta Perfil Sociológico de la Vejez en Mossoró - Junio 2004 / Junio 2005

(Elaboración de la autora)

\section{Capacidad para utilizar los cajeros automáticos}

Al diseccionar la vida cotidiana del anciano en la ciudad de Mossoró, no podríamos olvidar el tema de la informatización, dado que la tecnología ha invadido casi todos los ámbitos de nuestras vidas: casas, empresas e instituciones de todo tipo. Con la llegada de la tecnología, la sociedad poco a poco, está informatizándose y la sofisticación de los recursos de la tecnología conlleva el acceso fácil y rápido, casi instantáneo a las informaciones o servicios que necesitamos. Las generaciones nacidas en el mundo de los 
iconos, imágenes virtuales, botones y teclas, se mueven con desenvoltura en esta situación, sin embargo, la otra generación, nacida en tiempos de relativa estabilidad, convive de forma conflictiva con los rápidos y complejos cambios tecnológicos, cuya progresión es geométrica. Por tanto, la necesidad de dominar los omnipresentes recursos informáticos obliga a todos a adaptarse a un nuevo estilo de vida que tiende a difundirse más aún.

Cómo cuidar de las finanzas es un aspecto instrumental importante de las actividades instrumentales de la vida diaria (AVIDs) ${ }^{355}$ de una persona y la tecnología desempeña un papel importante en este entorno, con el empleo de máquinas electrónicas. Preguntamos a nuestro colectivo de ancianos si realizan con facilidad las operaciones de extracción de dinero, consulta de saldos, transferencias de valores y pagos en los cajeros automáticos que poseen los bancos en las agencias y en algunos puntos disponibles en la ciudad.

En general, como cabía esperar, solo un $31,60 \%$ afirma no encontrar dificultades en esa modalidad, pero alrededor de dos tercios encuentran cierta dificultad en efectuar dichas operaciones (63,60\%). Por sexo, los varones se muestran más hábiles que las mujeres en las operaciones bancarias. Es decir, el 18,20\% de los hombres frente al 13,40\% de las mujeres no encuentra ningún problema frente a las máquinas. Eso se explica porque apenas el $29,20 \%$ de ellos frente al 34,40\% de ellas reconoce las dificultades que surgen ante las máquinas (Tabla 37). Los mayores entrevistados que tienen más facilidad en operar en los cajeros automáticos son los hombres entre 60-80 años analfabetos y los que saben leer, sin haber asistido a la escuela. Entre las mujeres se encuentran las de 60-75 años, también las analfabetas absolutas y funcionales, además de las que cursaron la primaria.

Si las nuevas generaciones conviven con los medios electrónicos en una relación de identificación y fascinación (Pretto, 1996), de dominio y habilidad operacional, entre los mayores, las dificultades para entender este nuevo lenguaje y lidiar con el avance tecnológico se revelan diariamente en

$355 \quad$ Baltes, M. M.; Mayr, U.; Borchelt, M; M. A. S., I. \& Wilms, H.U. (1993): Everyday competence in old and very old age: An interdisciplinary y perspective. Aging Society, vol. 13, pp. 657-680. 
cualquier sitio en el que se encuentre alguno de estos aparatos. En la condición de analfabetos digitales o iletrados en informática, como son llamados los que no saben manejar estos recursos, se incluyen los mayores, que más allá de ser excluidos de los beneficios tecnológicos, se ven perjudicados por la tecnología en su vida social. Generar conocimiento tecnológico en todos los segmentos de la sociedad es necesario, pero promover sobre todo la inclusión del anciano en este nuevo lenguaje contribuye a facilitar la vida de estas personas, mejorando las condiciones de interacción social y estimulando la actividad mental.

El panorama que dibuja este conjunto de indicadores, más allá de hablar de una vejez excluida del mundo tecnológico, toca directamente a cerca de ocho mil mayores, analfabetos en Mossoró. La integración del anciano a la vida moderna, podría mejorar gracias a una educación básica (cursos especiales con contenidos relativos a las técnicas informáticas y demás avances tecnológicos) impartida por el poder público, a través de convenios municipales y estatales con los bancos. Quizá, las nuevas generaciones de mayores posean niveles de instrucción satisfactorios y sean digitalmente más instruidos. Por lo menos, en principio, los indicadores son optimistas al respecto, con la tasa de alfabetización en un $82,30 \%$ en la provincia (Censo: 2000).

\section{TABLA 37}

Según la capacidad para utilizar cajeros automáticos

\begin{tabular}{|l|c|c|cccc|}
\hline \multicolumn{1}{c|}{$\begin{array}{c}\text { MANEJO DE } \\
\text { CAJERO }\end{array}$} & \multicolumn{2}{c|}{ AMBOS SEXOS } & \multicolumn{2}{c}{ HOMBRES } & \multicolumn{2}{c|}{ MUJERES } \\
\multicolumn{1}{c|}{ AUTOMÁTICO } & $>60$ & $\%$ & $>60$ & $\%$ & $>60$ & $\%$ \\
\hline $\mathrm{Si}$ & 158 & 31,60 & 91 & 18,20 & 67 & 13,40 \\
\hline No & 318 & 63,60 & 146 & 29,20 & 172 & 34,40 \\
\hline Ns / Nc & 23 & 4,60 & 13 & 2,60 & 10 & 2,00 \\
\hline NSA & 1 & 0,20 & - & - & 1 & 0,20 \\
\hline T O T A L & 500 & 100,00 & $\mathbf{2 5 0}$ & $\mathbf{5 0 , 0 0}$ & $\mathbf{2 5 0}$ & $\mathbf{5 0 , 0 0}$ \\
\hline
\end{tabular}

Fuente: Encuesta Perfil Sociológico de la Vejez en Mossoró - Junio 2004 / Junio 2005 (Elaboración de la autora)

\section{Resumen}

La gran mayoría de los sujetos, principalmente las mujeres, pasa a menudo más tiempo en la vivienda, supuestamente con ocupaciones domésticas. La 
muestra señala que alrededor de tres cuartas partes de las personas suelen realizar estas labores con una ayuda familiar $(74,80 \%)$, un $8,40 \%$ cuenta con un servicio pagado y las que disponen de la cooperación de un pariente, otros y vecinos no alcanzan el $10 \%$. Considerando que el $92,40 \%$ vive en el mismo domicilio con algún familiar, se puede imaginar que realmente reciben ayuda, pero si éstos están ocupados con estudios o trabajo, efectivamente las tareas domésticas le tocarán a las mujeres ancianas.

Extendiéndonos en cuanto al tema de la salud, en este estudio también se investigó la autonomía e independencia de los entrevistados en la ancianidad. Las respuestas fueron muy esperanzadoras. La mayoría de los participantes no tiene ninguna dificultad funcional para realizar actividades cotidianas tales como: comer $(95,97 \%)$, ducharse $(91,11 \%)$, vestirse $(90,83 \%)$, cuidar del aspecto físico $(88,30 \%)$, andar $(81,01 \%)$, tomar medicamentos $(77,85 \%)$, gestionar las finanzas $(72,15 \%)$, ir de compras $(63,92 \%)$, preparar la comida (57,95\%) o acudir a consultorios médicos $(56,96 \%)$. El saldo positivo nos lleva a pensar que los mayores se valen por sí mismos, tanto en las actividades de la vida diaria como en las actividades instrumentales, vistas como de difícil ejecución. El único indicador que dificulta el desempeño funcional es la edad. Así pues, ambos sexos se muestran más independientes en la ejecución de las actividades básicas cuando tienen una edad menos avanzada y, cierta dependencia en las actividades que exigen más esfuerzos físicos más allá de los 75 años.

Aunque los sujetos hayan señalado pocos obstáculos para realizar dichas tareas, la idea de ser ayudado por un familiar o vecino agradó al $63,10 \%$ del grupo. Una quinta parte prefiere la ayuda de un órgano público de modo gratuito y sólo el $11,98 \%$ es favorable a pagar un servicio mediante una cuota. Centrándonos en los motivos por los mayores no reciben actualmente ayuda, el $14,51 \%$ señala el económico. Las demás causas tuvieron porcentajes muy bajos (hace falta una persona y no le gustan los extraños en la vivienda). Pero, como el $28,39 \%$ optó por otros motivos (no revelados) y no contestaron a la pregunta, ello sugiere situaciones oscuras, que posiblemente sea necesario investigar. Proponer y estimular servicios de atención domiciliaria 
destinados a garantizar la calidad de vida de los mayores para que ellos puedan permanecer con la familia, encaminados a evitar el ingreso institucional, contemplaría una de las políticas del Plan de Viena, elaborado con ocasión de la Primera Asamblea Mundial del Envejecimiento de las Naciones Unidas en 1982.

Salimos del tema de las vacaciones y entramos en el mundo de la tecnología que se amplía a una velocidad sin precedentes. Su presencia en casi todas las áreas de nuestras vidas repercute efectivamente en los actos de la vida cotidiana. Como cabía esperar, casi dos tercios de los mayores entrevistados encuentran dificultades al efectuar operaciones en los cajeros automáticos, frente a los que se manejan con facilidad $(31,60 \%)$. La habilidad operacional está más presente en los varones entre 60-80 años que saben leer y cursaron la primaria y en las mujeres entre 60-75 años con estudios a partir de la primaria. La mayoría de los sujetos participantes se encuentran en la condición de analfabetos digitales, son potencialmente excluidos de los medios electrónicos y se ven directamente afectados en su libertad individual. (Collpy, 1988, apud Kane, 1991). 


\section{Servicios y prestaciones sociales para personas mayores}

En los ojos del joven, arde la llama; en los del viejo, brilla la luz.

Víctor Hugo (1802-1885), Poeta, novelista y dramaturgo francés.

1. Servicios y prestaciones sociales conocidos o de los que se ha oído hablar destinados a las personas mayores

La tendencia a un futuro próximo más "encanecido" plantea nuevas necesidades y exige nuevos recursos para atender a los que alcanzan una vida larga. El Gobierno y la sociedad civil tienen la tarea de pensar y elevar la protección de la vejez, a través de servicios y prestaciones, para satisfacer las necesidades de los mayores y de aquellos que un día se encontrarán en ese período de la vida.

Un nuevo perfil demográfico presupone no sólo revisar programas y servicios existentes, sino priorizar la implementación de otros, crear y mantener políticas públicas sociales de calidad y crear mecanismos que auxilien y faciliten una saludable convivencia con la vejez, requisito básico para crear una sociedad para todas las edades. Asimismo, es necesaria una reformulación del modelo de vida y del papel del mayor en la sociedad.

En este escenario, es de suma importancia que la sociedad civil mossoroense y el poder público pasen a considerar la vejez como una de sus prioridades y ayuden a las personas a prepararse para un envejecimiento saludable. Ampliar leyes y fomentar programas y políticas que respondan a las necesidades de esta nueva población debe convertirse en algo extraordinario para la provincia, dado que las cuestiones referentes al envejecimiento poblacional y el entendimiento del proceso de envejecimiento deben ser observadas como un proceso histórico y socioeconómico. 
En este sentido, los problemas relacionados con una infraestructura inexistente o precaria dedicada a la población que envejece en la provincia, nos permiten conocer las necesidades de los mayores y los recursos disponibles para ellos en la comunidad mossoroense.

Así pues, una preocupación importante del presente estudio radica en conocer las necesidades de prestaciones y servicios sociales ofrecidos por entidades públicas, instituciones privadas, Organizaciones no Gubernamentales (ONG) y sociedad civil, no sólo para la población anciana residente en Mossoró, sino también para aquéllos que van a envejecer. En general, la preocupación por las políticas sociales de atención a los mayores se originó gracias a un gran esfuerzo por parte de segmentos específicos del Gobierno y a la gran movilización de la sociedad civil en busca del cumplimento de normativas internacionales, en lo tocante a la vida, a la libertad, a la salud, a la educación, a la profesionalización, a la seguridad social, a la vivienda y al transporte. Como el Plan de Viena (Austria), elaborado durante la I Asamblea Mundial sobre el Envejecimiento (1982) y los planes nacionales (la Ley de Organización de Asistencia Social - LOAS ( $n^{\circ}$ 8.742/1993), con la Política Nacional del Anciano - PNI ( $\left.n^{\circ} 8.842 / 1994\right)$ y el más reciente Estatuto del Anciano - $\left.n^{\circ} 10.741 / 2003\right)$. En ese universo, elegimos algunas de esas acciones en funcionamiento en la sociedad mossoroense a fin de saber el radio de conocimiento y alcance de estos servicios para quien realmente es objeto del derecho, los mayores.

Los datos pusieron de manifiesto que gran parte de los mayores participantes conoce la política de transporte colectivo urbano gratuito en Mossoró (un $88,80 \%$ ). A continuación, la segunda prestación de servicio más conocida por ellos se refiere a la salud: un $64,80 \%$ conoce la asistencia médica preventiva y curativa en los Centros de Salud. Luego, un 58,60\% afirmó tener conocimiento del Programa de Educación para Adultos. En cuarto lugar, un 48,40\% sabe que hay, o ha oído hablar, de las actividades socioculturales para mayores, promocionadas por el Ayuntamiento Municipal de Mossoró (PMM). Después, en proporciones más pequeñas pero significativas (un $39,80 \%$ ), un $39,80 \%$ conoce los Centros de Convivencia para Mayores, la terapia ocupacional un $29 \%$ y los 
descuentos especiales en algunos espectáculos culturales un $24 \%$. Cierran este listado, con la cifra más baja de todas, un $10,80 \%$, los que dijeron oír hablar de la Universidad Abierta para la Tercera Edad en la provincia (Véase Tabla 38). Para Costa y colaboradores (2002), es posible afirmar que las políticas dirigidas a los mayores están siendo implementadas en Brasil de manera gradual y de tal modo, que la sociedad, los mayores y los profesionales están poco a poco concienciándose de sus derechos y conquistando sus espacios.

En cuanto al sexo, las mujeres mayores afirman conocer más que los varones todas las prestaciones de servicios, excepto el transporte público gratuito. En relación a las edades, las diferencias son sutilmente relevantes: entre los varones, los que manifiestan conocer las prestaciones y servicios se concentran en la franja de entre 60-70 años, mientras que en las mujeres es hasta los 75 años. $Y$ tratándose del nivel educativo, se observa también una ligera diferencia: los varones que saben leer y las mujeres con estudios primarios son los más informados sobre la existencia de dichos servicios.

Estos datos nos permiten juzgar, por un lado, que el conocimiento de los mayores en relación a la oferta de estos servicios es relativamente negativo, dado que entre ocho servicios y prestaciones a elegir, apenas conocen la existencia de tres. Por lo menos, eso sugiere, en parte, que la política de divulgación e información publicitaria de los servicios a la población interesada no es tan eficiente o, quizá, las políticas disponibles para atender a la creciente demanda de mayores sean precarias. El mayor número de mujeres con más información que los varones suponen que ellas se mueven más en la vida diaria. Por medio de la comunicación y la información pueden aprovechar de manera favorable esa fase de la vida, tanto para ellas mismas como para los que viven alrededor. Es probable que la cadena de radio local constituya uno de los medios de información más utilizados entre esa población de edad avanzada, dado su alto número de oyentes.

Por otro lado, en los otros cinco servicios que conocen las cifras son inferiores al 50\%. De ahí que Costa (2002) tenga razón cuando subraya que la implementación de las políticas públicas en Brasil es gradual, aunque tampoco se descarta la idea de que muchas de estas acciones, por ser ineficientes, 
pasen desapercibidas. Sin inversión ni interés, muchos programas y proyectos están destinados al fracaso $y$, consecuentemente, a la desaparición. En diversos casos sirven solamente como campañas electorales.

Tomar conciencia de la existencia de una población cuyo número crece acentuadamente ayuda, por lo menos, a reflejar las necesidades de las transformaciones socioeconómicas que la provincia debe solucionar. Así que, promover y mantener políticas públicas y servicios de calidad que logren aminorar el pesado fardo de los que ingresan en la tercera edad, sobre todo a los de bajo poder económico, sería más que un deber político-social. Elevar a sus mayores a la categoría de sujetos dignos de respeto es imprescindible para una vida saludable. Además, conviene difundir las informaciones sobre las políticas, para que los mayores las aprovechen de la mejor manera posible. Teniendo en cuenta la situación socioeconómica de la mayoría de los participantes, se puede indicar que una parte del colectivo encuestado es usuaria potencial en casi todos los servicios.

\section{TABLA 38}

Según el grado de conocimiento de las prestaciones y servicios*

\begin{tabular}{|c|c|c|c|c|c|c|}
\hline \multirow{2}{*}{$\begin{array}{l}\text { GRADO DE CONOCIMIENTO DE } \\
\text { LAS PRESTACIONES Y } \\
\text { SERVICIOS }\end{array}$} & \multicolumn{2}{|c|}{ TOTAL } & \multicolumn{2}{|c|}{ HOMBRES } & \multicolumn{2}{|c|}{ MUJERES } \\
\hline & $>60$ & $\%$ & $>60$ & $\%$ & $>60$ & $\%$ \\
\hline Transporte público gratuito & 444 & 88,80 & 224 & 44,80 & 220 & 44,00 \\
\hline Educación de adultos & 293 & 58,60 & 138 & 27,60 & 155 & 31,00 \\
\hline $\begin{array}{l}\text { Acompañamiento médico } \\
\text { preventivo y curativo en los } \\
\text { Centros de Salud }\end{array}$ & 324 & 64,80 & 159 & 31,80 & 165 & 33,00 \\
\hline $\begin{array}{l}\text { Universidad de la Tercera } \\
\text { Edad }\end{array}$ & 54 & 10,80 & 20 & 4,00 & 34 & 6,80 \\
\hline $\begin{array}{l}\text { Actividad sociocultural } \\
\text { promocionada por el } \\
\text { Ayuntamiento de Mossoró }\end{array}$ & 242 & 48,40 & 107 & 21,40 & 135 & 27,00 \\
\hline Terapia Ocupacional - PMM & 145 & 29,00 & 55 & 11,00 & 90 & 18,00 \\
\hline $\begin{array}{l}\text { Descuento especial en } \\
\text { conciertos para Mayores }\end{array}$ & 120 & 24,00 & 55 & 11,00 & 65 & 13,00 \\
\hline Centro de Convivencia - PMM & 199 & 39,80 & 95 & 19,00 & 104 & 20,80 \\
\hline
\end{tabular}

* Pregunta de elección múltiple, por tanto, suma más de $100 \%$.

Fuente: Encuesta Perfil Sociológico de la Vejez en Mossoró - Junio 2004 / Junio 2005

(Elaboración de la autora)

2. Mayores que han utilizado o se han beneficiado de alguna de las prestaciones o servicios

Una vez destacadas las políticas públicas creadas por el poder público municipal y estatal para atender la demanda de los mayores residentes en 
Mossoró y las que ellos conocen, en este apartado y en el siguiente, nos proponemos divulgar su uso y cuáles son, específicamente, las más utilizadas. A pesar de ser algo positivo, nos parece que no basta sólo con conocer los servicios, sino que sería más importante tener acceso a ellos y utilizarlos, para incrementar la ayuda en la autonomía, la integración y participación efectiva de los mayores en la sociedad.

Como se refleja en el Gráfico 45, los que suelen utilizar alguna de las prestaciones o servicios alcanzan un mayor porcentaje (59\%), frente a de los que dijeron no haberse beneficiado nunca de ninguna (41\%). Por sexo, el grupo femenino sacó más provecho que los hombres de los servicios (el 39\% frente al 20\%). En cierto modo, como cabía esperar, en general las mujeres acuden en mayor cantidad que los hombres a la oferta de este tipo de servicios. Parece que están más abiertas a la participación, sobre todo en grupos sociales. La naturaleza femenina, de algún modo, siempre manifiesta más interés y participación en situaciones de cuño social en las que se desarrollan actividades socioculturales. Además, según Papaléo Netto (2002) "las mujeres ancianas han tenido, en nuestra experiencia, una participación cualitativa y cuantitativa mayor que los hombres en todas las actividades relacionadas con las políticas de salud del anciano, como foros de gerontología, consejos municipales y estatales de ancianos, y también en los cursos de universidad de la tercera edad" (2002:05). Se hace más relevante en este sector la cuestión de la salud, ya que ellas enferman más que los hombres $\mathrm{y}$, por ello, es natural que también busquen más los servicios de salud.

Considerando que siete de las ocho acciones sociales descritas, destinadas a los mayores, son de carácter público, con acceso gratuito, nos parece muy poca la participación de nuestro colectivo en ellas. Si menos de dos tercios se han beneficiado de algún tipo de servicio o prestación, quizá el problema de la escasa presencia resida en la precariedad del funcionamiento, dificultad en el acceso y/o divulgación deficiente por parte de cada órgano responsable del servicio. Lanzamos también otras dos hipótesis: 1) los servicios disponibles fueron creados sin la participación del anciano o de su organización 
representativa; de ese modo, a pesar de ser servicios útiles, la necesidad real del mayor está en otro tipo de servicio o actividad. 2) El escaso número de los servicios, por ejemplo, el de la Universidad de la Tercera Edad ${ }^{356}$ con solo una a las afueras de la ciudad, y los pocos Centros de Convivencia ${ }^{357}$ dificultan el ingreso de los mayores en ellos.

De ese modo, cabe deducir que si la sociedad mossoroense no proporciona los mecanismos eficaces para que los mayores disfruten con la vida personal, con los amigos, con el ocio, con la vida social, eso tiene un impacto negativo sobre la calidad de vida objetiva y subjetiva de los mayores y efectivamente puede comprometer el desarrollo de la deseada vejez exitosa.

\section{GRÁFICO 45}

\section{Mayores que han utilizado o se han beneficiado de alguna de las prestaciones o servicios}
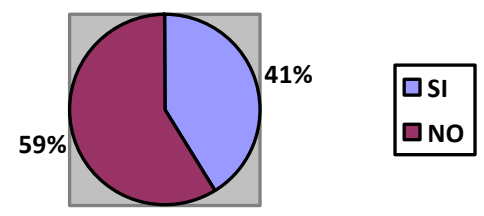

Fuente: Encuesta Perfil Sociológico de la Vejez en Mossoró - Junio 2004 / Junio 2005 (Elaboración de la autora)

\section{Cuáles son las prestaciones o servicios utilizados}

\footnotetext{
356 Creada en 1998 como programa del Núcleo de Estudio de Pesquisa da Tercera Edad (NEPTI) de la Facultad de Servicio Social (FASSO), no fue implantada como había sido proyectada, debido a las condiciones de infraestructura de la Universidad del Estado de Río Grande del Norte (UERN). Según la directora de la FASSO, la profesora Zélia Rodríguez Menezes de Vasconcelos, la UERN, por estar situada a las afueras de la ciudad, todavía no tiene líneas de autobuses sistemáticamente disponibles que vayan en aquella dirección y, una vez puesta de manifiesto la dificultad del acceso de los ancianos a la Universidad, el programa tuvo que adaptarse a esa realidad. Actualmente se desarrollan las actividades con los mayores en los Centros Comunitarios, Centros de Convivencia y Centros Sociales, en varios barrios de Mossoró, con prácticas de alumnos del Servicio Social y Educación Física. Las actividades, según la directora, tienen un carácter socio-recreativo. (Entrevista grabada en Enero de 2003).

El Ayuntamiento Municipal de Mossoró (PMM) utiliza treinta y cinco unidades entre Centros de Convivencia, Sedes de Consejos Comunitarios y Núcleos Integrados de Atención a Familias para el desarrollo de las actividades para los ancianos mossoroenses. En general, estas unidades desarrollan también acciones sociales para niños y mujeres embarazadas. Se atiende a cada uno de estos segmentos sociales en horarios distintos.
} 
Precisamente, en el abanico de las ocho acciones relacionadas con la asistencia a las necesidades del colectivo anciano, contemplamos las áreas de salud, educación, transporte, cultura y ocio (Véase Tabla 39). Todas reglamentadas por la Política Nacional del Anciano (PNI), Ley n. 8.842, de 4 de Enero de 1994 e implementadas por el Estatuto del Anciano (2003). Entre éstas, en la que se observa mayor participación de los ancianos entrevistados es en el acceso gratuito al transporte colectivo urbano (47\%). En Mossoró, esta política fue adoptada por la Ley Municipal en 2002, antes incluso de la reglamentación de la Política Nacional del Anciano, que pasó a asegurar, en 2003, a través del Art. 39, la gratuidad de los transportes colectivos públicos para los mayores de 62 años. Pero, conforme al párrafo tercero, queda a criterio de la legislación local ofrecer este beneficio a las personas comprendidas en la franja de edad de entre 60 y 65 años. En Mossoró, según la Gerencia Ejecutiva de Desarrollo Social, la cantidad de ancianos residentes en la localidad asegurados por la tarifa social de gratuidad de transportes, desde su creación, fue de 1.593 (2002), 1.550 (2003), 2.132 (2004), 5.182 (2005), 5.990 (2006), 6.471 (2007) y 6.910 (2008). Para tener acceso a la gratuidad en Mossoró basta que el mayor presente un documento personal oficial que pruebe su edad y renta igual o inferior a dos salarios mínimos. A pesar de que más del $80 \%$ de los mayores no está incluido en éste programa, tampoco se tienen motivos suficientemente satisfactorios para creer que el funcionamiento es eficiente. "La gran reclamación en cuanto al cumplimiento de la ley (Art. 39 - Estatuto del Anciano $n^{\circ}$ 10.741, de $1^{\circ}$ de Octubre de 2003) por parte de los conductores de autobuses, es que muchas veces no respetan el código, no parando en los puntos establecidos donde hay ancianos" ${ }^{358}$. La falta de respeto de la ley es evidente también en las declaraciones de los conductores de autobuses: "sólo paramos a los ancianos cuando vamos con tiempo y $\sin$ autobuses de la competencia cercanos" 359 , afirma uno de los

358 Por supuesto, el artículo Motoristas de ônibus estão se recusando a pegar (recoger) idosos publicado en 22-02-2003 en el periódico local http://www.omossoroense.com.br no es el único de ésta naturaleza. La falta de atención de los conductores con los ancianos en las paradas de autobuses portando la tarjeta de paso libre, es frecuente y gran parte de la población que coge los autobuses públicos es testigo de estos hechos.

359 Fuente www.omossoroense.com.br Columna Dia@Dia de 02 de febrero de 2001. 
conductores de la empresa de autobuses Santa Lucía, que no quiso identificarse.

El segundo servicio más utilizado por los mayores corresponde a la asistencia médica en los Centros de Salud Pública (34,40\%). Si a este ya de por sí bajo porcentaje añadimos que la población anciana, en su mayoría de bajo nivel socio-económico, y por lo tanto usuarios del transporte público, cuenta con sólo 25 unidades básicas de salud (en los 28 barrios de Mossoró) entonces nos damos cuenta de la dificultad de acceso a dichos servicios sanitarios. La gran competencia entre los usuarios de distintas edades y los de la zona rural y otros municipios circunvecinos compromete el nivel de atención a la salud del anciano y la calidad de la prestación del servicio para todos aquellos que precisan de los servicios de salud pública en Mossoró.

La tercera prestación de servicio que los mayores utilizan se relaciona con las actividades socioculturales (15,60\%) promocionadas por el Ayuntamiento de Mossoró, a través del proyecto Anciano Ciudadano (2001). En consonancia con el Art. 10 de la Política Nacional del Anciano (PNI/1994), el proyecto desarrolla actividades en las áreas de educación, salud y terapia ocupacional. Si hablamos de las actividades socioculturales, más allá de existir siete grupos populares folclóricos formados por ancianos en 2004, las acciones se enmarcan en el calendario anual del poder público municipal que contempla las fechas conmemorativas con ferias y fiestas de la cultura local. La ciudad también ofrece programas y proyectos de carácter Estatal destinados a los mayores y a grupos de la tercera edad, por iniciativa de la sociedad civil. Entre ellos destaca el Club de la Mejor Edad Revivir (1997) y el Grupo Madurez Saludable (2004).

Las actividades desarrolladas en los Centros de Convivencia (un 8,60\%) y el Programa de Educación para Adultos (un 6,60\%) se constituyen como la cuarta y quinta preferencia de las que se beneficiaron muy poco los participantes de la presente investigación. En ambos servicios, por segmento social, las mujeres ancianas tienen mayor participación que los varones ancianos, sin embargo, nos parece que, en ambos casos, la asistencia es muy baja. El 
Programa de Educación de Jóvenes y Adultos (EJA) funciona en 39 escuelas en Mossoró y el $41.64 \%$ de los mayores entrevistados declara no tener ningún nivel educativo y apenas saber leer (Véase Tabla 10). En los Centros de Convivencia para Mayores, conforme notifica la Gerencia Ejecutiva de Desarrollo Social, hay unos 3.950 ancianos participando en las actividades socioculturales, desarrolladas en las 35 Unidades, entre Centros, Consejos Comunitarios y Núcleos Integrados de Atención a la Familia dispersos en Mossoró. Entre nuestro universo entrevistado apenas 43 personas participan en alguno de ellos. Puede que la cantidad de Centros sea inferior a la demanda, pues si en 2004 había 17.553 ancianos en Mossoró, y de éstos alrededor de 3.000 acudían a uno de los centros, eso significa que alcanza apenas a un 17,09\% del total de este colectivo. Nuestra suposición se confirma cuando menos de la mitad de los sujetos informó de la existencia del Centro de Convivencia para Mayores cercano a su vivienda (38\%) (Véase Gráfico 24).

Para finalizar, las tres últimas prestaciones o servicios que menos han utilizado nuestros participantes son los programas de terapia ocupacional ${ }^{360}$ (5,80\%), los descuentos especiales en conciertos para mayores $(4,60 \%)$ y la participación en la Universidad Abierta a la Tercera Edad (1,60\%). En todas se observa la participación de mujeres en mayor grado que los varones. Nos llama la atención la mayor participación de la mujer en la Universidad para Mayores. Los datos hablan de un varón casado y dos separados de entre 60-65 años, y cinco mujeres (1 casada, 1 pareja de hecho y 3 viudas) con edad media de 70 años. Entendemos que los ocho mayores se refieren a la Universidad, cuando ésta funcionaba en la sede del Campus Central, o quizá se refieren a prácticas de los universitarios del curso de Trabajo Social realizadas en los Centros de Convivencia. En la terapia ocupacional destaca la participación de los varones casados y viudos y la de las mujeres casadas,

\footnotetext{
360 La terapia educacional para mayores es parte del Proyecto Anciano Ciudadano (1998) del Ayuntamiento Municipal de Mossoró (PMM). La dinámica consiste en desarrollar trabajos de artesanía y formación de grupos con el objetivo de potenciar la creación de pequeños negocios y generar renta familiar, sobre todo para las personas de baja renta. La producción de fregasuelos, lavavajillas, galletas y jarabes hecha por los mayores, inscritos en el programa, es vendida en parte, a las escuelas municipales como forma de ayudar financieramente al anciano involucrado en el programa. Entrevista grabada con Doña Claudia Regina Freire de Azevedo, Gerente Ejecutiva de Desarrollo Social del Ayuntamiento de Mossoró (Gestión 2001-2004) en el despacho de la Gerente en Enero de 2003. Actualmente, Doña Claudia es vicealcadesa de Mossoró, para la gestión 2005-2008.
} 
viudas y solteras. Quizá para aumentar la renta familiar o asumir el timón económico de la familia, las mujeres generalmente encuentran en estas actividades la única oportunidad de inserción en el mercado laboral.

En general, se puede decir que es lamentable que un porcentaje tan grande de nuestros entrevistados desperdicien la educación continuada a través del programa de educación para adultos. Además, acudir a la terapia ocupacional en busca de formación como incentivo para abrir pequeños negocios y acudir a conciertos, bien podrían también ocupar un espacio mayor en la vida de estos ancianos. Disfrutar de estos momentos posibilitaría una vida con más calidad. Posiblemente, las dificultades para utilizar dichos servicios pueden residir en el propio anciano: problemas de salud o por no formar parte de su cultura, o quizá también en los propios órganos que ofrecen los servicios, debido a la escasez de servicios frente a la demanda, la divulgación y la motivación y a la accesibilidad reducida.

\section{TABLA 39}

Según las prestaciones y servicios que ha utilizado el mayor*

\begin{tabular}{|c|c|c|c|c|c|c|}
\hline \multirow[t]{2}{*}{ SERVICIOS UTILIZADOS } & \multicolumn{2}{|c|}{ TOTAL } & \multicolumn{2}{|c|}{ HOMBRE } & \multicolumn{2}{|c|}{ MUJER } \\
\hline & $>60$ & $\%$ & $>60$ & $\%$ & $>60$ & $\%$ \\
\hline Transporte público gratuito & 235 & 47,00 & 124 & 24,80 & 111 & 22,20 \\
\hline Educación de adultos & 33 & 6,60 & 15 & 3,00 & 18 & 3,60 \\
\hline $\begin{array}{l}\text { Acompañamiento médico } \\
\text { preventivo y curativo en } \\
\text { los Centros de Salud }\end{array}$ & 172 & 34,40 & 85 & 17,00 & 87 & 17,40 \\
\hline $\begin{array}{l}\text { Universidad de la Tercera } \\
\text { Edad }\end{array}$ & 8 & 1,60 & 3 & 0,60 & 5 & 1,00 \\
\hline $\begin{array}{l}\text { Actividad sociocultural } \\
\text { promocionada por el } \\
\text { Ayuntamiento de Mossoró }\end{array}$ & 78 & 15,60 & 32 & 6,40 & 46 & 9,20 \\
\hline Terapia Ocupacional & 29 & 5,80 & 11 & 2,20 & 18 & 3,60 \\
\hline $\begin{array}{l}\text { Descuento especial en } \\
\text { conciertos para Mayores }\end{array}$ & 23 & 4,60 & 11 & 2,20 & 12 & 2,40 \\
\hline Centro de Convivencia & 43 & 8,60 & 19 & 3,80 & 24 & 4,80 \\
\hline
\end{tabular}

* Pregunta de elección múltiple, por lo tanto suma más de $100 \%$.

Fuente: Encuesta Perfil Sociológico de la Vejez en Mossoró - Junio 2004 / Junio 2005 (Elaboración de la autora)

4. Grado de conocimiento sobre las leyes que benefician a los mayores

Existen leyes generales aplicables al colectivo de mayores en Brasil. Entre las más importantes destacamos: La Constitución Federal de 1988, la Ley n 213 de 1991 - que dispone en lo relativo a los Planes de Beneficios de la Seguridad 
Social, la Ley $\mathrm{n}^{\circ} 8.078$ de 1990 - que dispone sobre la Protección del Consumidor, la Ley $\mathrm{n}^{\circ} 8.742$ de 1993 - que dispone a cerca de la organización de Asistencia Social, El Nuevo Código Civil $n^{\circ} 10.406$, de 2002, la Ley $n^{\circ} 8.842$ de 1994 - que dispone en lo relativo a la Política Nacional del Anciano y crea el Consejo Nacional del Anciano, la Ley $n^{\circ} 10.741$ de 2003 - que dispone sobre el Estatuto del Anciano.

Además de la esfera de acción gubernamental, son varias las organizaciones dedicadas a actividades en beneficio de la población anciana en Brasil. Para Debert, "es una cuestión que moviliza a la sociedad brasileña"361. Existen también Organizaciones no Gubernamentales (ONG) y entidades filantrópicas de alcance local, integradas por miembros de la propia comunidad. En el plan Nacional cabría destacar, entre otras entidades existentes, la Sociedad Brasileña de Gerontología y Geriatría (1961), la Asociación Nacional de Gerontología (1991) y la Pastoral de la Persona Anciana (2004) de la Conferencia Nacional de los Obispos de Brasil (CNBB). Otras iniciativas de gran impacto en las comunidades son los Clubes y Grupos para la Tercera Edad, las Universidades Abiertas para la Tercera Edad y los Centros de Convivencia en todo el país.

Pues bien, entre tantos recursos y leyes existentes para los mayores, convendría preguntar a las personas de 60 años de edad residentes en Mossoró, si tenían conocimiento, por lo menos, de alguna ley creada para ellos. A medida que va aumentando el número de personas ancianas, es necesario que estén preparadas para envejecer de modo digno y participativo. Y nada mejor y más completo que conocer las leyes y cuando es necesario poder hacer uso de ellas.

En líneas generales, el 47,09\% afirma conocer las leyes y casi el mismo porcentaje (el $46,29 \%$ ) afirma no tener ningún conocimiento. Por género, edad y nivel de estudios, los varones y mujeres de entre 60-75 años y aquéllos con estudios secundarios y superiores, son los que creen conocer más las leyes. Si estratificamos por sexo, las mujeres se destacan sobre los varones en

\footnotetext{
$361 \quad$ Lopes, Andrea (2000): Os Desafios da Gerontologia no Brasil, Anita Liberalesso Neri (ed.),
} Campinas, São Paulo (Prefacio de Guita Grin Debert). 
la respuesta positiva con un $24,45 \%$ frente a un $22,65 \%$, respectivamente. $Y$ en la respuesta negativa la situación se nivela (Véase Gráfico 46).

Por un lado, es de prever que los ancianos no se integren correctamente ya que, como se ha señalado en la sección anterior, la mayoría no participa en los programas y proyectos previstos en el plan de acción gubernamental para el desarrollo de la Política Nacional del Anciano. Dicho plan aspira a una calidad de vida cada vez mejor. Es por ello que la mitad de los entrevistados afirma no conocer las leyes $(47,09 \%)$. Si no las conocen, no participan y tampoco se reivindica lo que les corresponde por derecho. Por otro lado, se pone en duda si realmente ese grupo de personas conoce las leyes, dado que no les preguntamos qué tipo de ley conocen. Quizá el interés por participar se vea comprometido por la falta de información y motivación política en cuanto a la oferta de políticas públicas de carácter gubernamental, o no gubernamental, a la que el colectivo podría acceder.

\section{GRÁFICO 47}

\section{Grado de conocimiento sobre las leyes} que benefician a los mayores

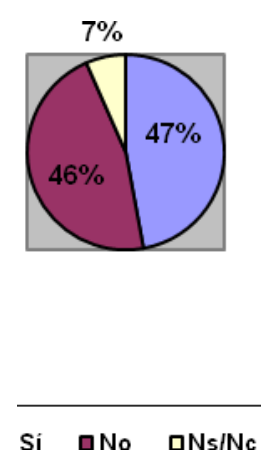

Fuente: Encuesta Perfil Sociológico de la Vejez en Mossoró - Junio 2004 / Junio 2005 (Elaboración de la autora)

\section{Resumen}

Tomando en consideración las prestaciones y servicios sociales que existen para los mayores en Mossoró, más de cuatro quintas partes conocen o han oído hablar de la gratuidad de los transportes públicos $(87,07 \%)$, cerca de dos 
tercios de la asistencia médica preventiva y curativa en los Centros de salud (63,09\%) y más de la mitad del programa de educación de adultos (57,47\%). Las menos conocidas son las actividades socioculturales para mayores $(43,22 \%)$, los centros de convivencia $(30,91 \%)$, los precios reducidos en eventos culturales $(22,77 \%)$, los programas de terapia ocupacional $(21,77 \%)$ y la Universidad de la Tercera Edad (10,09\%). En general, cabe destacar que los que conocen alguna prestación o servicio son los más escolarizados y en lo que se refiere a diferencias por sexo, las mujeres están más informadas que los hombres, dado que su presencia es más acentuada en casi todos los servicios.

Entre los que han hecho uso de las prestaciones o servicios se encuentra un $63 \%$ del colectivo. Es un dato razonablemente satisfactorio para el grado de conocimiento revelado. Por sexo, el grupo femenino sacó más provecho en todos los servicios que los varones. Tratándose del estado civil, quienes más se destacaron en las actividades de ocio fueron las viudas. Sin embargo, es discutible que más de un tercio no haya utilizado ninguna de las prestaciones o servicios (37\%), cuando siete de las ocho acciones son de carácter público y gratuito. Probablemente, el problema esté en la divulgación, acceso, calidad del servicio y, en que algunas de las expectativas de los mayores estén depositadas en otro tipo de servicios.

El servicio más utilizado por los sujetos es la gratuidad del transporte colectivo público $(51,01 \%)$. En proporciones bien inferiores ha utilizado la asistencia médica en los centros de salud un $38,85 \%$, las actividades socioculturales un $17,03 \%$, la educación de adultos un $7,57 \%$, las actividades ofertadas en los centros de convivencia un 7,57\%, los descuentos especiales en conciertos para mayores un 5,36\%, los programas de terapia ocupacional un $5,05 \%$ y la Universidad de la Tercera Edad un 1,58\%. A pesar de que la mitad se beneficia de la gratuidad del transporte público, el porcentaje es muy bajo entre la población de mayores en Mossoró ( $N=16.520)$, sólo el $18,17 \%$ está incluido en el servicio. Es probable que la escasez del servicio ${ }^{362}$, la falta

\footnotetext{
$362 \quad$ Franco (2004:66), entiende que pese a la importancia de ese servicio de transporte, las empresas son privadas pagan impuestos y tasas al gobierno y los costos del transporte, y por ello es difícil para ellas conceder transporte gratuito al mayor en la forma que determina la ley. Lo correcto sería que el gobierno
} 
de respeto a las leyes por parte de los conductores (con frecuencia los conductores no hacen caso de los mayores que están en las paradas de autobuses) y la divulgación ineficaz, contribuyan a crear este escenario.

La escasa utilización de los demás servicios, inferior al 50\% del colectivo, también merece atención. Los centros de convivencia aún no están extendidos por la ciudad y la Universidad de la Tercera Edad carece de implementación. Suponemos que entre todas las carencias las más graves residan en el área de salud. Como vimos anteriormente, gran parte de los mayores sólo acude al médico cuando está enfermo y mayoritariamente depende del Sistema Único de Salud (SUS). Estas constataciones pueden resumirse en la poca atención dada por los mayores a la salud.

La última parte de esta sección se centra en las leyes aplicables al colectivo de mayores en Brasil. Menos de la mitad de los entrevistados dice conocer, al menos, algunas leyes $(47 \%)$ y casi la otra mitad afirma no tener ningún conocimiento (46\%). Hombres y mujeres están en situaciones muy semejantes en ambos casos. No obstante, resulta difícil comprobar la veracidad de los declarantes, dado que la Encuesta no ha dispuesto una cuestión específica para las leyes. Sin embargo, partiendo del nivel socioeconómico (estatus económico familiar, nivel educativo y nivel de ingresos) de los entrevistados, suponemos que los índices puedan ser superiores, en relación al desconocimiento demostrado.

firmase un convenio con esas empresas, a través de órganos competentes: federales, estatales y municipales para resarcir a las mismas por dicho servicio. 


\section{La vejez ante el cambio social}

Estamos todos obligados a tener respeto a los ancianos, aunque no sean caballeros.

Miguel de Cervantes (1547-1616), Novelista, poeta y dramaturgo espanol.

1. Aborto, pena de muerte, divorcio, pago de impuestos, relación sexual antes del matrimonio, relación sexual entre personas del mismo sexo y liberalización de las drogas

Las informaciones que se presentan en este capítulo doce se refieren a los valores, las actitudes y opiniones de los mayores sobre algunos temas que a lo largo de la historia han causado siempre controversias en el medio social, político y religioso en distintas sociedades y que aún siguen siendo actuales.

Poniendo en práctica el ejercicio del derecho para decidir (Art. X), participar (Art. XXVII) y opinar (XIX), en rasgos esenciales de la democracia, asegurados en la Declaración Universal de los Derechos Humanos (1948) y a fin de ir completando el Perfil Sociológico de la Vejez en Mossoró, obtuvimos este conjunto de indicadores que exponemos.

De acuerdo con los resultados obtenidos en la Tabla 40, por orden de preferencia, casi la mitad de los mayores entrevistados está de acuerdo con el divorcio (49,20\%), más de un tercio asiente sobre el pago de los impuestos $(45,40 \%)$, menos de un tercio está a favor de la pena de muerte $(30,20 \%)$, menos de un quinto consiente el concubinato antes de la boda $(15,40 \%)$, una pequeña minoría acepta el aborto $(8,82 \%)$, menos aún concuerdan con la relación sexual entre el mismo sexo $(3,60 \%)$ y la liberalización de las drogas (3,20\%).

Siguiendo el mismo razonamiento en la exposición, casi el cien por cien de los mayores entrevistados residentes en Mossoró está en desacuerdo con la liberalización de las drogas $(91,80 \%)$, más de cuatro quintos son contrarios a la homosexualidad $(85,80 \%$ ) y al aborto $(80,76 \%)$, casi dos tercios manifiestan 
disconformidad con la relación sexual antes del matrimonio $(64,20 \%)$, más de la mitad son contrarios a la pena de muerte $(56,00 \%)$, a pagar los impuestos fiscales $(42,40 \%)$ y menos de un tercio está en desacuerdo con el divorcio $(31,80 \%)$.

Para analizar la opinión de los mayores, insistiremos más en las columnas de acuerdo y desacuerdo. Tal opción no disminuye la importancia de los mayores que se expresaron en la columna indiferente. Lo llevamos a cabo así solamente por preferir las opiniones que tienen mayor representatividad.

Las mujeres, una vez más, aparecen en mayor proporción que los hombres en casi todas las cifras. Sin embargo, en los temas señalados en la columna de acuerdo, los porcentajes suben sutilmente en las opiniones masculinas. Es decir, entre ocho temas sugeridos, los hombres se muestran más favorables que las mujeres en los asuntos aborto, relación sexual antes de la boda y liberalización de las drogas. Si nos fijamos en estas últimas tres opiniones mencionadas por los varones, se notará la mera predominancia de los patrones de conducta masculinos y femeninos previamente establecidos. En otras palabras, en la sociedad cobra menos importancia la responsabilidad y participación de los hombres en los temas relacionados con el aborto, al mismo tiempo que, por el contrario, éstos se implican más al dar total libertad e incentivo a prácticas sexuales prematrimoniales y al uso de las drogas lícitas. Del mismo modo, las mujeres se muestran aún reaccionarias en asuntos como el aborto y la pérdida de la virginidad, no obstante, ellas también se inclinan a favor de dos opiniones muy importantes: el divorcio y el pago de los impuestos. Apoyadas en una perspectiva de satisfacción individual y de conducta ciudadana, las mujeres ancianas revelan el deseo de actuar como mujeres independientes, quizá para evitar, o para poder salir de matrimonios desgraciados, como también para garantizar su participación en la ciudadanía. Para los contrarios a la obligatoriedad de pagar los impuestos, quizá la causa resida en el mal empleo de los mismos. De norte a sur del país se denuncia su falta de aplicación en los servicios más básicos para la población. La política de vivienda para cubrir el déficit habitacional de los que tienen pocos recursos es ineficiente; el saneamiento básico para evitar 
enfermedades ya extintas en países desarrollados, no llega a todos; las malas condiciones de las carreteras, que anualmente dejan un saldo nefasto de accidentes en el país, es un desafío nacional; la falta de recursos para la salud, incluso con la implantación de la Contribución Provisional sobre Movilidad Financiera-CPMF ${ }^{363}$, creada para financiar y mantener los deficitarios servicios del Sistema Único de Salud, es apenas una muestra, entre otros. Tratándose de la oposición a la liberalización de las drogas, un $91,80 \%$ cree que hay vínculo con la violencia urbana. La violencia que asola el país coloca a Brasil entre los países más violentos del mundo. Según un estudio de la Organización de Naciones Unidas (ONU), Brasil es responsable del $11 \%$ de los homicidios cometidos en todo el mundo, mientras que apenas tiene el 2,8\% de la población mundial. Para el Ministerio de Salud, el índice de homicidios en Brasil saltó de 11,7 por mil habitantes en 1980 a 28,36 en 2003. Las causas de violencia urbana son muchas, y es posible destacar factores que incentivan su crecimiento. Entre ellos está la desigualdad social, el desempleo, la exclusión o marginalización, la disgregación comunitaria y familiar, el mercado de armas, el uso de drogas y alcohol, las organizaciones criminales y la cultura de la violencia y del consumo ${ }^{364}$. Estratificando los géneros por edades, los datos señalan una incidencia de los participantes de entre 60-75 qué están de acuerdo con los temas subrayados y los que son opositores en los mismos temas sobrepasan los 80 años.

En general, parece que parte de los posicionamientos están muy unidos a las orientaciones religiosas. Era previsible que una elevada cifra se oponga a estos temas, ya que el $80,76 \%$ de los entrevistados asume la confesión Católica como normativa de vida religiosa (Tabla 43), bajo el refuerzo moralista del Papa Juan Pablo II (1920-2005) a través de las Encíclicas Veritatis Splendor (1993) y Evangelium Vitae (1995), que defiende, como

\footnotetext{
363 El tema de los impuestos es tan polémico en Brasil que en marzo de 2005 la Radio Nacional "Joven Pan" AM, transmitió en su programación diaria una campaña con la intención de alertar a la opinión pública, denominada "Brasil, el país de los impuestos", contra el "terrorismo tributario" y el "exceso de burocracia", cuyas consecuencias están sintiendo las empresas, los clientes y la sociedad brasileña en general, a través del aumento del costo de los productos y servicios. El programa "Jornal da Manhã" se trasmite en la red nacional a una media de 20 millones de oyentes. Los trabajos fueron dirigidos por los periodistas Anchieta Filho y Joseval Peixoto, presentadores del Periodismo de la Joven Pan AM. El Programa fue escuchado en los días 3 y 9 de Marzo de 2005.
}

$364 \quad$ Almanaque Abril 2005:1001. 
carro de batalla, el derecho a la vida, a la familia, la condena del concubinato antes del matrimonio y de las relaciones homosexuales. Es posible que tengamos en las próximas generaciones de ancianos un colectivo menos conservador en cuanto a los temas del aborto, el divorcio, la homosexualidad y el concubinato antes de la boda. La incidencia de los referidos asuntos es una ola en los medios de comunicación de masas, sobre todo en las telenovelas, donde Brasil tiene un público fiel. Sin embargo, en otros medios de información y en las escuelas hacen falta más debates.

\section{TABLA 40}

Según la opinión sobre temas actuales

\begin{tabular}{|c|c|c|c|c|c|c|c|c|c|c|c|c|}
\hline & \multicolumn{2}{|c|}{ De acuerdo } & \multicolumn{4}{|c|}{ Indiferente } & \multicolumn{2}{|c|}{ Desacuerdo } & \multicolumn{4}{|c|}{$\mathrm{Ns} / \mathrm{Nc}$} \\
\hline & $\mathrm{H}$ & $M$ & Total & H & M & Total & H & $\mathbf{M}$ & Total & H & M & Total \\
\hline 1 & 5,21 & 3,61 & 8,82 & 4,40 & 2,60 & 7,00 & 37,68 & 43,09 & 80,76 & 2,61 & 0,80 & 3,41 \\
\hline 2 & 17,20 & 13,00 & 30,20 & 5,00 & 4,60 & 9,60 & 25,40 & 30,60 & 56,00 & 2,40 & 1,80 & 4,20 \\
\hline 3 & 23,40 & 25,80 & 49,20 & 10,20 & 6,60 & 16,80 & 15,00 & 16,80 & 31,80 & 1,40 & 0,80 & 2,20 \\
\hline 4 & 23,40 & 22,00 & 45,40 & 5,60 & 5,20 & 10,80 & 19,80 & 22,60 & 42,40 & 1,20 & 0,20 & 1,40 \\
\hline 5 & 9,60 & 5,80 & 15,40 & 9,20 & 8,40 & 17,60 & 29,20 & 35,00 & 64,20 & 2,00 & 0,80 & 2,80 \\
\hline 6 & 1,60 & 2,00 & 3,60 & 4,00 & 4,40 & 8,40 & 43,60 & 42,20 & 85,80 & 0,80 & 1,40 & 2,20 \\
\hline 7 & 2,00 & 1,20 & 3,20 & 1,80 & 1,20 & 3,00 & 45,40 & 46,40 & 91,80 & 0,80 & 1,20 & 2,00 \\
\hline
\end{tabular}

Fuente: Encuesta Perfil Sociológico de la Vejez en Mossoró - Junio 2004 / Junio 2005 (Elaboración de la autora)
1) Aborto
2) Pena de muerte
3) Divorcio
4) Pago de impuestos fiscales
5) Relación sexual antes del matrimonio
6) Relación sexual entre el mismo sexo
7) Liberalización de las drogas

\section{Ejercicio del voto en las elecciones}

Países como Estados Unidos, Canadá, Alemania, Portugal, España y Suiza dan libertad al elector para decidir si quiere o no ir a las urnas. Argumentan historiadores y científicos sociales que el voto libre aumenta la conciencia del elector y representa el ideal de una democracia plena. Pero, eso exige 
madurez y responsabilidad. Al contrario, nuestra Constitución Federal ${ }^{365}$, a ejemplo de otros países de América Latina como Perú, Chile y Venezuela o de países europeos como Bélgica, Francia e Italia, establece como regla la obligatoriedad del voto electoral como un deber cívico público (Art. 14).

A pesar de la discutida ambigüedad derecho-deber, el voto obligatorio funciona más como un deber de participación, en la visión republicana y el facultativo con la noción de ciudadanía como derecho, en la visión liberal. Es difícil decidir, en teoría, cual es más adecuado, pues ambos tienen ventajas y desventajas. En Brasil, país con una democracia extremamente excluyente, el único día en que todos, absolutamente todos los ciudadanos son iguales es el día de las elecciones. Además, el voto impuesto puede ser un ejercicio, una forma de educar a los electores hasta que sean capaces de adoptar el voto libre. La excepción a esta regla, el sufragio universal previsto en la Carta Magna brasileña (1988), faculta el voto a los analfabetos, los mayores de setenta años y a los mayores de dieciséis y menores de dieciocho años (Art. 14 parágrafo $\left.1^{\circ}\right)$.

Este escenario nos permite, en esta sección y la siguiente, conocer el nivel de participación de los mayores, en edad de votar y de los votantes voluntarios, en las elecciones brasileñas, además de saber cuáles son los motivos por los que no acudieron a las urnas en las elecciones de 2002.

Según la encuesta el Perfil Sociológico de la Vejez en Mossoró/RN - Brasil, como se refleja en el Gráfico 47, casi cuatro quintas partes de los mayores afirmaron votar habitualmente en las elecciones $(78,60 \%)$, mientras que un quinto no hizo lo mismo (20,40\%). Del universo investigado, un $58,80 \%$ de los sujetos están obligados a votar, mientras que para un $41,20 \%$, el sufragio es facultativo. En ambas situaciones las cifras son semejantes. Sin embargo, entre los habilitados para votar, dieciséis varones $(3,20 \%)$ y diez mujeres $(2,00 \%)$ incumplieron las determinaciones legales del país en las elecciones de 2002. En lo que se refiere a la edad, sobre todo para los que están exentos de 
esa tarea, en los ciudadanos de la muestra sorprende la cantidad de varones (71) y mujeres (57) con edades entre 71 y 90 años que acudieron a las urnas, frente a 35 varones y 41 mujeres de igual edad que hicieron el uso del derecho a no votar.

En una lectura más generalizada, la proporción de mayores que acudió a las elecciones parece satisfactoria, dado que la cantidad de electores participantes superó los habilitados obligatoriamente por la ley. Eso puede significar, por un lado, que los mayores conceden importancia a la participación política y a su capacidad individual de ejercer su autonomía. Por otro lado, lo que es más probable, estando la mayoría compuesta por personas de baja escolaridad y renta, exactamente la franja de población menos preparada e informada para traducir sus deseos y aspiraciones en voto, queda así más expuesta a cualquier tipo de manipulación política. Este tipo de práctica está muy presente en el escenario político brasileño, sobre todo en los municipios más pobres de las regiones Norte y Nordeste del país.

\section{GRÁFICO 47}

\section{Ejercicio del voto en las elecciones}
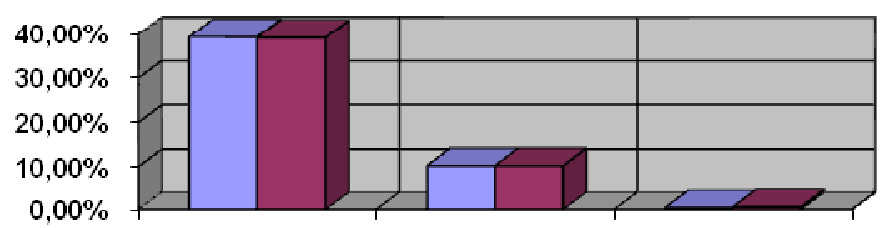

Sí

No

$\mathrm{Ns} / \mathrm{Nc}$

口HOMBRE QMUJER

Fuente: Encuesta Perfil Sociológico de la Vejez en Mossoró - Junio 2004 / Junio 2005 (Elaboración de la autora)

\section{Motivos aducidos por el mayor para no votar}

En Brasil, de los 169 millones de habitantes en 2000, más de 115 millones de personas estaban habilitadas para votar en las elecciones a la Presidencia en 2002. Acudieron a las urnas 94,8 millones de electores en la primera vuelta y 91,6 millones en la segunda ronda ${ }^{366}$. Para responder al descenso de la 
participación política brasileña, buscamos en el Estudio Electoral Brasileño $(E S E B)^{367}$, parte de estos motivos. Realizado en 2002, el estudio revela que casi dos tercios de los brasileños están insatisfechos con el funcionamiento de la democracia en el país (62\%), siendo prácticamente la mitad de los entrevistados los que aseguran que no harían uso de su derecho de voto si no fuera un derecho de ejercicio obligatorio. Entre otros datos de gran importancia del estudio, y para nuestro interés en esta sección, destacamos que entre los que revelan su escepticismo al voto, se incluyen: la poca o ninguna representatividad de senadores y diputados $(71 \%)$ y la corrupción de los políticos $(83 \%)$.

Para los pocos participantes de nuestra investigación que no participaron en el proceso electoral, la Tabla 41 indica que no votó un $21,40 \%$, entre éstos el $5,20 \%$ obligado a votar por ley. La mayoría se muestra desinteresada, sobre todo porque todos los partidos hacen lo mismo $(6,80 \%)$, no les interesa la política $(4,80 \%)$, otros motivos $(4,80 \%)$, están desilusionados con la democracia (3\%) y una reducida minoría porque se lo impide los problemas de salud (2\%). La mayoría de los que se muestran desinteresados son mujeres, con excepción de los hombres que indicaron otros motivos como la principal razón para no votar. Tales razones, quizá podrían encajarse en la falta de representatividad de los parlamentarios y en la sucesión de escándalos de corrupción de algunos políticos, como motivos fuertes para el desinterés en los sufragios electorales, según señaló el referido Estudio Electoral Brasileño.

Aparentemente, tal apatía de los sujetos participantes puede tener su origen en la pobreza y miseria en que continúan viviendo 57,9 millones de brasileños ${ }^{368}$. Las pruebas de esa desilusión quedan patentes también en un sistema educativo y de salud poco funcional, además de en la debilidad de nuestras instituciones políticas, que han sido históricamente motivo de vergüenza nacional. A éstas se les han sumado la inseguridad pública, la violencia, la exclusión social, que empuja a niños y ancianos a la calle, los sin techo y sin tierra, el descrédito judicial, la impunidad, la falta de expectativa

\footnotetext{
367 ESEB (2002): Estudo Eleitoral Brasileiro. Banco de Dados. Fundação Getúlio Vargas, Opinião Pública, vol. $10 \mathrm{n}^{\circ} 2$ Rio de Janeiro.

368 IPEA: 2003.
} 
económico-social, la falta de preparación educativa para afrontar los retos de la globalización, la deuda interna y externa con sus orígenes dudosos, la costumbre de vivir de la caridad internacional, entre otros.

\section{$\underline{\text { TABLA } 41}$}

Según los motivos aducidos por el mayor para no votar

\begin{tabular}{|l|c|c|cccc|}
\hline \multirow{2}{*}{$\begin{array}{c}\text { MOTIVOS POR LOS QUE NO } \\
\text { VOTARON }\end{array}$} & \multicolumn{2}{|c|}{ Total } & \multicolumn{3}{c|}{ Hombres } & \multicolumn{2}{c|}{ Mujeres } \\
\cline { 2 - 7 } & $>\mathbf{6 0}$ & $\mathbf{\%}$ & $>\mathbf{6 0}$ & $\mathbf{\%}$ & $\mathbf{7 6 0}$ & $\mathbf{\%}$ \\
\hline No se interesa en la política & 24 & 4,80 & 10 & 2,00 & 14 & 2,80 \\
\hline $\begin{array}{l}\text { Está desilusionado con la } \\
\text { democracia }\end{array}$ & 15 & 3,00 & 6 & 1,20 & 9 & 1,80 \\
\hline $\begin{array}{l}\text { Todos los partidos hacen lo } \\
\text { mismo }\end{array}$ & 34 & 6,80 & 17 & 3,40 & 17 & 3,40 \\
\hline $\begin{array}{l}\text { Se lo impiden los } \\
\text { problemas de salud }\end{array}$ & 10 & 2,00 & 4 & 0,80 & 6 & 1,20 \\
\hline Otra respuesta & 24 & 4,80 & 16 & 3,20 & 8 & 1,60 \\
\hline NSA & 393 & 78,60 & 197 & 39,40 & 196 & 39,20 \\
\hline T O T A L & $\mathbf{5 0 0}$ & $\mathbf{1 0 0 , 0 0}$ & $\mathbf{2 5 0}$ & $\mathbf{5 0 , 0 0}$ & $\mathbf{2 5 0}$ & $\mathbf{5 0 , 0 0}$ \\
\hline
\end{tabular}

Fuente: Encuesta Perfil Sociológico de la Vejez en Mossoró - Junio 2004 / Junio 2005

(Elaboración de la autora)

\section{Resumen}

Con el objeto de profundizar en las características de la población mayor de 60 años que compone la muestra de este estudio, se ha hecho un análisis de valoración de algunos temas y costumbres de la sociedad. En resumen, más de la mitad de los entrevistados está de acuerdo con el divorcio (52,68\%), más de un tercio está de acuerdo con el pago de impuestos (35,65\%), menos de un tercio es favorable a la pena de muerte $(30,92 \%)$, menos de un quinto consiente la relación sexual antes de la boda $(15,78 \%)$ y una minoría aprueba el aborto $(9,15 \%)$, la relación sexual entre personas del mismo sexo $(3,47 \%)$ y la liberalización de las drogas (3,15\%).

Por el contrario, resulta evidente que los mayores rechazan la liberalización de las drogas (92,75\%), la relación homosexual (87,38\%), el aborto $(83,28 \%)$, el concubinato antes de la boda $(66,68 \%)$, la pena de muerte $(58,04 \%)$, el pago de impuestos $(52,37 \%)$ y el divorcio $(30,29 \%)$.

Teniendo en cuenta la variable sexo, las opiniones parecen variar de acuerdo con el papel social que hombres y mujeres desempeñan en la sociedad. Los varones se inclinan favorablemente más en los temas del aborto, el sexo 
prematrimonial y la liberalización de las drogas. Mientras, las mujeres, lo hacen al divorcio y al pago de impuestos. El tema del aborto es una polémica a nivel mundial, y las razones por las cuales se lucha por su legalización ponen a la mujer en el centro de la cuestión. Defender el hecho de ser dueña de su propio cuerpo y de tomar sus propias decisiones, es un tema nuevo que supone un rumbo diferente del pensamiento masculino y que probablemente la mayoría de nuestros entrevistados "no tenga" una verdadera opinión sobre las nuevas discusiones. En cuanto al divorcio, quizá estas mujeres insatisfechas con el matrimonio encuentren en él una nueva forma de vivir, ya que antes las normas sociales no permitían la ruptura matrimonial ${ }^{369}$. En cuanto a pagar los impuestos, a pesar de que el país es bautizado como "Brasil, país dos impostos", las mujeres son más optimistas y siguen creyendo más que los hombres que con los beneficios del justo empleo de los impuestos la comunidad puede disfrutar de los servicios de salud, de vivienda y de enseñanza, entre otras prestaciones.

Como último análisis, en general, las opiniones de los entrevistados sugieren que están influidas en parte por las recomendaciones religiosas. Si el 80,76\% de los mayores asume la confesión Católica y acepta las orientaciones moralistas del Papa Juan Pablo II a través de los documentos oficiales de la Iglesia Veritatis Splendor (1993) y Evangelium Vitae (1995), que defienden el derecho a la vida y la institución familiar, la oposición al concubinato antes del matrimonio y a las relaciones homosexuales, es coherente que las opiniones de la gran mayoría de los sujetos hayan sido influenciadas por el credo apostólico romano.

El hecho de que este grupo de mayores esté formado desde el punto de vista jurídico, por votantes y no votantes $(58,80 \%$ y $41,20 \%$, respectivamente) en términos generales, todos parecen muy interesados en elegir a los representantes. Casi cuatro quintos afirman acudir a las urnas habitualmente para ejercer el derecho de la ciudadanía $(78,86 \%)$. Mientras, alrededor de un quinto revela lo contrario, ya que no participa $(19,87 \%)$. Eso significa un promedio de casi un quinto que hace uso del derecho del voto voluntario $369 \quad$ Art. 226 de la Constitución de Brasil, 1988. 
$(18,92 \%)$. En ambas situaciones, las mujeres acuden más que los varones a las convocatorias electorales. Sorprende la cantidad de varones (37) y mujeres (41) que por edad están exentos de la tarea de votar (los mayores de 70 años), que acudieron a las urnas en las últimas elecciones. Dos conclusiones se pueden apreciar: por una parte, puede significar la prueba de la importancia del evento para la democracia, conquistada hace menos de dos décadas (con la promulgación de la Carta Magna de 1988) que permite el derecho a elegir a los representantes. Por otra parte, dentro de este grupo, el menos escolarizado y de bajo poder adquisitivo se torna presa fácil de la manipulación política, evidente en los períodos de campañas electorales, en las regiones más pobres y desiguales del país, como por el ejemplo, el Nordeste.

Sólo una pequeña minoría de los mayores no votó $(19,87 \%)$; entre éstos, apenas el 5,05\% estaba habilitado para votar, según el Artículo 14 de la Constitución Federal de Brasil. Las causas se repartieron entre que todos los partidos hacen lo mismo $(7,89 \%)$, no les interesa la política $(4,42 \%)$, están desilusionados con la democracia $(3,47 \%)$ y, en menor proporción están los que tuvieron problemas de salud $(1,58 \%)$. No es una novedad que el colectivo exprese un cierto sentimiento apático con la política brasileña. El perfil del votante en el escenario nacional, según el Estudio Electoral Brasileño (2002), revela que el $62 \%$ de los entrevistados está insatisfecho con el funcionamiento de la democracia en el país. Sumado a los desafíos de pobreza y miseria en que viven miles de brasileños, la violencia, la corrupción y la alarmante impunidad, además de los débiles servicios de salud y educación, ayudan a semejante desengaño con la política. 


\section{La vejez ante la muerte}

La vejez tiene su belleza, es la belleza del crepúsculo.

Rubem Alves (1933), Educador, teólogo y escritor brasileño.

\section{Sentido de la vida}

El debate sobre el sentido de la vida, de la religión y de la muerte encarada por eruditos, filósofos y líderes religiosos desde hace muchos siglos, proporciona al ser humano indagaciones, respuestas científicas y transcendentales sobre su significado y valor. Son temas sobre los que, tarde o temprano, todos los individuos reflexionan. En este último capítulo, expondremos valores y opiniones de los mayores de 60 años entrevistados al respecto de estos "delicados" temas.

Antes que nada, entendemos la vida como un proceso continuo de redefiniciones y redescubrimientos. Por tanto, está marcada por instantes de cuestionamientos que van dando sentido a la propia existencia. Sin embargo, para la vejez, el sentido de esa existencia, tras la infancia, juventud y vida adulta, viene cargada de una sabiduría particular; en palabras del Papa Juan Pablo II (1999:10) "las vicisitudes os tornan más experimentados y maduros". Así que, considerando esas prerrogativas y, por supuesto, alcanzada la vejez, preguntamos a los participantes de la investigación, qué es la vida para ellos.

La Tabla 42 presenta en líneas generales, por un lado, a las personas mayores, bajo una perspectiva optimista, donde un $36,20 \%$ manifiesta que la vida es una cosa que vale la pena vivir, un $29,80 \%$ que afirma ser una ocasión de encuentro con Dios y casi una quinta parte que opina que es una oportunidad para construir un mundo mejor (19,20\%). Por otro lado, en una postura más negativa, apenas el 2,60\% ha dicho que es un desengaño, tan sólo un 1,40\% la denomina como una serie de fracasos y el $4,60 \%$ prefirió señalar otro motivo. 
Estratificando por sexo, las cifras revelan que los varones son menos optimistas en relación a la vida que las mujeres ancianas. Ellos la consideran como un desengaño y una serie de fracasos, pero también defienden más que ellas que la vida es un tiempo para construir un mundo mejor. En cambio, las mujeres, creen que la vida es algo que vale la pena vivir y una ocasión de encuentro con Dios. En relación con la edad y estado civil, los hombres casados, entre 60-70 años son los que más exteriorizan sus opiniones, mientras que entre las mujeres ancianas casadas y viudas los posicionamientos se intensifican hasta los 75 años.

Cada uno de estos resultados tiene sentido, pues cada uno de los sujetos ha vivido su propia historia de vida. De ello se deduce que no podemos juzgar la opinión del sentido de la vida para un sexo u otro, sino que creemos que los aspectos que les llevaron a pensar de este modo parecen estar relacionados con una familia estable que construyeron, la capacidad física y mental que disfrutaron, o las amistades y empleo que conquistaron; los frutos que han recogido durante su trayectoria, al fin y al cabo. Las mujeres siempre parecen más optimistas y más religiosas en esta fase de la vida.

\section{TABLA 42}

Según el sentido de la vida

\begin{tabular}{|l|c|c|cccc|}
\hline \multirow{2}{*}{ SENTIDO DE LA VIDA } & \multicolumn{2}{|c|}{ TOTAL } & \multicolumn{2}{c|}{ HOMBRES } & \multicolumn{2}{c|}{ MUJERES } \\
\cline { 2 - 7 } & $>60$ & $\%$ & $>60$ & $\%$ & $>60$ & $\%$ \\
\hline Un desengaño & 13 & 2,60 & 7 & 1,40 & 6 & 1,20 \\
\hline $\begin{array}{l}\text { Un tiempo para } \\
\text { construir un mundo } \\
\text { mejor }\end{array}$ & 96 & 19,20 & 59 & 11,80 & 37 & 7,40 \\
\hline Una serie de fracasos & 7 & 1,40 & 5 & 1,00 & 2 & 0,40 \\
\hline $\begin{array}{l}\text { Una cosa que vale la } \\
\text { pena }\end{array}$ & 181 & 36,20 & 86 & 17,20 & 95 & 19,00 \\
\hline $\begin{array}{l}\text { Ocasión de encuentro } \\
\text { con Dios }\end{array}$ & 149 & 29,80 & 57 & 11,40 & 92 & 18,40 \\
\hline Otro & 23 & 4,60 & 16 & 3,20 & 7 & 1,40 \\
\hline Ns /Nc & 31 & 6,20 & 20 & 4,00 & 11 & 2,20 \\
\hline T O T A L & 500 & 100,00 & 250 & 50,00 & 250 & 50,00 \\
\hline
\end{tabular}

Fuente: Encuesta Perfil Sociológico de la Vejez en Mossoró - Junio 2004 / Junio 2005 (Elaboración de la autora)

\section{Satisfacción con la vida}

La visión de los sujetos entrevistados sobre la vida, en la sección anterior, es un factor importante para prever el nivel de la satisfacción existencial. De 
modo que, los datos indican en el Gráfico 48 que más de dos tercios es decir 367 mayores, dijeron que estar satisfechos con el modelo de vida que llevan actualmente $(73,40 \%)$. Aunque sin grandes diferencias, en las cifras destaca un $2,20 \%$ de los varones más satisfechos que las mujeres, cuando el tema hace referencia a la vida agradable. Los varones han revelado anteriormente ser un poco menos optimistas con la vida, lo que aquí se traduce como desengaño o una serie de fracasos, pero presentan cifras relativamente más bajas que las mujeres cuando opinan que la vida actualmente es desagradable $(1,40 \%$ frente al $2 \%$ ) y ni agradable ni desagradable (10,40\% frente al 11,60\%).

Presumiblemente, estas personas mayores que encuentran placer en vivir, que se dicen satisfechas con la vida, quizá tienen lazos firmes con la familia, amistades y contactos sociales con los que disfrutan, lo que hace, junto a la conquista de algunos bienes materiales, que todo contribuya a ello. En el inicio del análisis de los datos (Gráfico 7), comprobamos que más de tres cuartas partes de los sujetos se llevan bien con los miembros de la familia con quienes suelen compartir el mismo techo y están satisfechos con la frecuencia con que hablan con sus familiares y con su vecindario (Tabla 21). Más de la mitad de las casas están llenas (Tabla 11): viven con pareja, hijos o nietos y, por lo descrito, viven bien afectivamente. La satisfacción con la comida $(66,47 \%$ - Tabla 31$)$ y la vivienda $(87,07 \%$ - Gráfico 22$)$ puede sumarse también a los indicadores para una vida feliz y agradable.

En cuanto a los desencantos con la vida, expresados por diecisiete de nuestros mayores entrevistados, a parte de las condiciones objetivas que llevan a ese estado (sueldo bajo, nivel de estudios deseado y jamás alcanzado, pérdida del empleo, vida de alquiler, enfermedades, relaciones negativas con la familia o con los vecinos), también pueden convertirse en pronósticos significativos, pero no quiere decir que sean criterios definitivos. Cada persona crea un mundo de ideas e intereses, a veces muy subjetivos, para encontrar la felicidad. Existen controversias importantes sobre la virtud de sentirse satisfecho con la vida en las que nuestra investigación, lamentablemente, no entró en la profundidad que el tema merece. 


\section{GRÁFICO 48}

Satisfacción con la vida

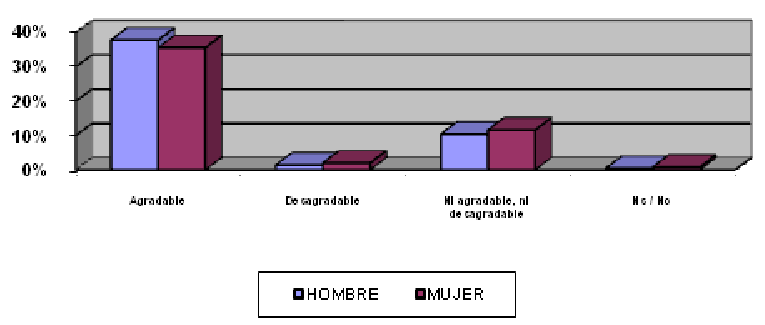

Fuente: Encuesta Perfil Sociológico de la Vejez en Mossoró - Junio 2004 / Junio 2005 (Elaboración de la autora)

\section{Auto definición religiosa}

La totalidad del individuo se basa en la existencia de las dimensiones biológica, psíquica, social y espiritual. Estas características posicionan el ser humano entre todas las especies del reino animal como la más completa de toda la Creación. Cuidar de que todas esas dimensiones sean adecuadamente desarrolladas, es decir, las necesidades físicas, sociales, y también las necesidades espirituales, es una tarea singular que toca a cada uno de nosotros a lo largo de nuestra existencia, con apoyo y participación de la familia, de la sociedad y del Estado.

Dotados de libertad de opción y respetando el derecho que tiene todo ser humano de vivir y manifestar sus propias creencias religiosas, aprovechamos para preguntar a los mayores entrevistados sobre sus credos, por suponer que están más abiertos y disponibles hacia lo trascendental en el último y más largo estadio de vida en qué ahora se encuentran.

La mayoría dijeron tener una religión (Tabla 43). Contabilizados los católicos apostólicos romanos, que frecuentan los actos litúrgicos y las celebraciones, comprobamos que son casi la mitad de los mayores $(49,80 \%)$ y menos de un tercio afirma no participar activamente de la vida cristiana $(28,80 \%)$, como prescriben los Mandamientos de la Iglesia, de acuerdo con el nuevo Código de Derecho Canónico (1983). Este dato muestra el sentir de esa generación, es decir, este segmento de edad siempre fue religioso y más religioso que los 
jóvenes y adultos actuales, porque crecieron bajo la norma social de la obligatoriedad de profesar una religión.

Estos datos coinciden con la muestra del Censo Demográfico 2000, del Instituto Brasileño de Geografía y Estadística (IBGE), al revelar que Brasil continúa siendo la nación más católica del planeta, con 124,9 millones de fieles, el $73,6 \%$ de la población. Aunque un $84,3 \%$ de los fieles confíen en la Institución y un $81,5 \%$ en el Papa, muchos católicos no son practicantes, dadas las divergencias entre las orientaciones de la Iglesia y el pensamiento de los fieles. Es decir, un $73,2 \%$ de los católicos son favorables a los métodos anticonceptivos, un $59,4 \%$ al divorcio, un $43,6 \%$ al sexo antes de la boda, todos oficialmente prohibidos por la Iglesia, según añade la investigación "Desafío del Catolicismo en la Ciudad", realizada por el Centro de Estadística Religiosa e Investigaciones Sociales ${ }^{370}$. En cambio, un $14,60 \%$ de los mayores afirma corresponder a otra denominación religiosa, aquí entendida como las descendientes de la Reforma Protestante europea del siglo XVI. Los evangélicos, como son denominados, representan un $13,1 \%$ de los brasileños, es decir 26,1 millones, conforme a los datos del último Censo ${ }^{371}$ sobre el número de fieles existentes en cada una de las congregaciones religiosas de Brasil. Sin embargo, apenas un 1,20\% afirma ser adepto de otra denominación no religiosa. Podemos aquí considerar los cultos afro-brasileños, las tradiciones esotéricas y los cultos orientales. Estas manifestaciones, en el escenario nacional, representan el 3,5\% de la población brasileña. Por último, un $3,60 \%$ se declara agnóstico. Los que no profesan ninguna religión, ascienden a 12,3 millones de brasileños, es decir, un 7,35\% del total de la población $^{372}$.

La clasificación por y por sexo hace aparecer algunas diferencias. Así, los varones y mujeres entre 60-80 años que se dicen católicos practicantes suman un $15,20 \%$ y un $29 \%$, respectivamente. Para los católicos no practicantes, los porcentajes son altos para los varones hasta los 80 años $(18,20 \%)$, mientras que las mujeres apenas suman un 4,60\% hasta los 65 años. Entre aquéllos de 
otra denominación religiosa, los varones más viejos se destacan como los que más frecuentan los eventos.

\title{
$\underline{\text { TABLA } 43}$
}

Según la auto definición religiosa

\begin{tabular}{|l|c|c|cccc|}
\hline \multicolumn{1}{r|}{\begin{tabular}{c} 
AUTO DEFINICIÓN \\
\multicolumn{1}{c|}{ RELIGIOSA }
\end{tabular}} & \multicolumn{2}{c|}{ TOTAL } & \multicolumn{2}{c|}{ HOMBRES } & \multicolumn{2}{c|}{ MUJERES } \\
\cline { 2 - 7 } & $>60$ & $\%$ & $>60$ & $\%$ & $>60$ & $\%$ \\
\hline $\begin{array}{l}\text { Católica Apostólica } \\
\text { Romana (practicante) }\end{array}$ & 249 & 49,80 & 88 & 17,60 & 161 & 32,40 \\
\hline Católico no practicante & 144 & 28,80 & 100 & 20,00 & 44 & 8,80 \\
\hline $\begin{array}{l}\text { Otra denominación } \\
\text { religiosa }\end{array}$ & 73 & 14,60 & 39 & 7,80 & 34 & 6,80 \\
\hline Otra religión no cristiana & 6 & 1,20 & 3 & 0,60 & 3 & 0,60 \\
\hline Indiferente - sin religión & 18 & 3,60 & 14 & 2,80 & 4 & 0,80 \\
\hline Ns / Nc & 10 & 2,00 & 6 & 1,20 & 4 & 0,80 \\
\hline T O T A L & 500 & 100,00 & $\mathbf{2 5 0}$ & $\mathbf{5 0 , 0 0}$ & $\mathbf{2 5 0}$ & $\mathbf{5 0 , 0 0}$ \\
\hline
\end{tabular}

Fuente: Encuesta Perfil Sociológico de la Vejez en Mossoró - Junio 2004 / Junio 2005

(Elaboración de la autora)

\section{Frecuencia del pensamiento sobre la muerte}

La muerte es siempre un tema delicado entre los hombres. Con frecuencia, asusta a las personas y en grandes proporciones parece algo maldito ${ }^{373}$. Pero también se puede encarar lo inevitable a través de la fe y del coraje, con serenidad, humor y paz ${ }^{374}$. Sin embargo, la evidencia de la primera idea, de hablar sobre la muerte sin escalofrío, parece estar cambiando, dejando de ser un tabú. Ya encontramos, sin muchas dificultades, en libros y películas, imágenes de la muerte sin horror, miedos y traumas, como algo natural: el camino de la vida es la muerte.

Todos somos vulnerables, en todas las edades, sin embargo, la disminución de la propia expectativa de vida acorta la senda de nuestra existencia humana. Es más probable con el paso de los años, que presenciemos con más frecuencia la muerte de nuestros parientes y amigos. Bajo esa perspectiva, preguntamos a las personas mayores entrevistadas con qué frecuencia suelen pensar en el fin del ciclo de la vida como una realidad única e inevitable.

Los resultados globales, por ítems, quedan claramente expresados en el Gráfico 49. Gran parte de los mayores dijo no hablar nunca sobre la muerte

\author{
Loureiro: 2000. \\ Jimmy Carter, 2002:71.
}


$(36,20 \%)$, el porcentaje de los que asume tocar el tema raramente suma un $29,80 \%$, sin embargo, las personas que ocasionalmente manifiestan interés totalizan un poco más de un quinto $(21,20 \%)$ Los demás ítems disminuyen considerablemente en relación a las otras cifras: apenas un 9,40\% de los sujetos habla sobre la muerte frecuentemente y un reducido porcentaje de un $3,40 \%$ no quiso contestar a la cuestión. No encontramos diferencias sustancialmente significativas en cuanto a la edad específica de los mayores que suelen empezar a hablar sobre la muerte.

No obstante, el sexo y el estado civil imponen importantes diferencias en esta distribución general. Las mujeres ancianas eligen, en mayor cantidad que los hombres las opciones de nunca y ocasionalmente, en cuanto a hablar sobre la muerte. En cambio, los varones suelen hablar más frecuentemente que ellas de la culminación del ciclo vital. Los varones casados, en las cuatro primeras variables, ofrecen cifras superiores a las mujeres ancianas. En cambio, las mujeres viudas presentan cifras elevadas en las mismas variables, sobre el fin del individuo. En resumen, parece que nuestros mayores no demuestran mucha apertura hacia esa realidad que es la muerte. No sabemos si atemorizados o resentidos con Dios, quizá la voluntad de vivir traspase el pensamiento de que la muerte pende sobre nuestras cabezas.

\section{GRÁFICO 49}

\section{Frecuencia del pensamiento sobre la muerte}

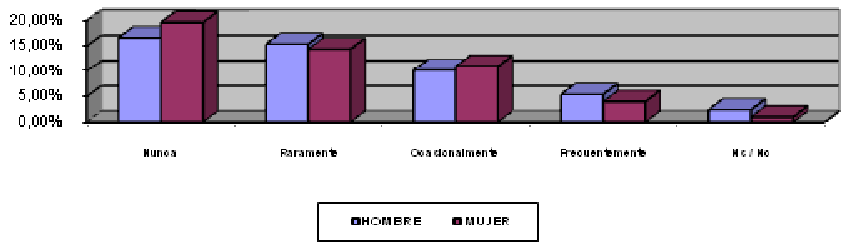

Fuente: Encuesta Perfil Sociológico de la Vejez en Mossoró - Junio 2004 / Junio 2005 (Elaboración de la autora)

\section{Con quién suele hablar de la muerte}

La reflexión sobre el fenómeno de la muerte, "acontecimiento universal por excelencia: única cosa de la cual nosotros estamos verdaderamente seguros, aunque ignoremos el día y la hora, el porqué y cómo es que se debe 
morir...”375, está presente, de modo frecuente, entre los pensamientos del $9,40 \%$ de los mayores participantes en el presente estudio empírico. En esta sección veremos detalladamente, a través de los análisis de la Tabla 44, con quiénes procuran entender la inexorabilidad y connotaciones de esta premisa.

Amparados en los datos del Perfil Sociológico de la Vejez en Mossoró/Rn Brasil, en líneas generales, hombres y mujeres mayores de 60 años intercambian ideas sobre la muerte con algún miembro de la familia (un $35,40 \%$ ). A continuación menos de una quinta parte prefiere el diálogo tanatológico entre amigos (18,80\%), un $8,40 \%$ no contestó a la pregunta y apenas un $1,20 \%$ de los participantes busca comprender la muerte con ayuda de un cura. Cada una de estas preferencias tiene una razón peculiar para los participantes. El grado de relación, amistad, conocimiento y propiedad en el tema tiene reflejo en nuestras elecciones. No obstante, nos parece importante plantear el tema naturalmente como otro cualquiera, lo antes posible, para facilitar la comprensión y aceptación de este evento, que todos tenemos que pasar. "Aceptarla como un paso más en la existencia, es prudente y consolador"376.

Podemos observar igualmente que, según el sexo, las mujeres prefieren plantear el tema con un miembro de la familia y con el cura. Sin embargo, los hombres privilegian la opción de hablar con amigos. Llama nuestra atención que ningún varón busque hablar de las inquietudes de la muerte con un cura, aunque un $17,60 \%$, es decir 88 ancianos, haya declarado que son católicos practicantes (Tabla 43). Los curas, que por formación y oficio del ministerio sacerdotal deben de tener más propiedad sobre el asunto, en nuestra interpretación, pueden ser piezas importantes en esta cuestión. El hecho de discutir sobre los últimos días de la vida con los amigos, presenta cifras relativamente similares para ambos sexos. La preferencia de hablar sobre el momento final con algún familiar se intensifica en los varones entre 60-70 años, sin embargo, las mujeres buscan este tipo de apoyo hasta los 80 años de edad. 


\section{TABLA 44}

Con quién suele hablar de la muerte

\begin{tabular}{|l|c|c|cccc|}
\hline \multirow{2}{*}{\begin{tabular}{l} 
CON QUIÉN SUELE HABLAR \\
\multicolumn{2}{c|}{ SOBRE LA MUERTE }
\end{tabular}} & \multicolumn{2}{|c|}{ TOTAL } & \multicolumn{2}{c|}{ HOMBRES } & \multicolumn{2}{c|}{ MUJERES } \\
\cline { 2 - 7 } & $>60$ & $\%$ & $>60$ & $\%$ & $>60$ & $\%$ \\
\hline Con algún familiar & 177 & 35,40 & 88 & 17,60 & 89 & 17,80 \\
\hline Con amigos & 94 & 18,80 & 53 & 10,60 & 41 & 8,20 \\
\hline Con el cura de la Iglesia & 6 & 1,20 & - & - & 6 & 1,20 \\
\hline No habla sobre la muerte & 181 & 36,20 & 83 & 16,60 & 98 & 19,60 \\
\hline Ns / Nc & 42 & 8,40 & 26 & 5,20 & 16 & 3,20 \\
\hline T O T A L & 500 & $\mathbf{1 0 0 , 0 0}$ & $\mathbf{2 5 0}$ & $\mathbf{5 0 , 0 0}$ & $\mathbf{2 5 0}$ & $\mathbf{5 0 , 0 0}$ \\
\hline
\end{tabular}

Fuente: Encuesta Perfil Sociológico de la Vejez en Mossoró - Junio 2004 / Junio 2005

(Elaboración de la autora)

\section{Resumen}

Concluimos el Perfil Sociológico de la Vejez en Mossoró con cuestiones relacionadas con la vida y la finitud humana. En primer lugar, la mayoría de los entrevistados tienen una visión optimista del sentido de la vida. El 37,22\% de los mayores afirma que la vida es una cosa que vale la pena vivir, el $31,86 \%$ opina que es una oportunidad de encuentro con Dios y el $18,30 \%$ cree que es una oportunidad para construir un mundo mejor. En segundo lugar, para una pequeña minoría, el sentimiento es más negativo. El 2,84\% la considera un desengaño, el 1,58\% la denomina como una serie de fracasos y el $4,10 \%$ la clasifica como otros sentimientos. En general, la propensión del pensamiento favorable a la existencia toca a más de cuatro quintas partes de los participantes $(87,38 \%)$. Las opiniones varían en cuanto al sexo. Los varones, tienen una postura más amarga sobre la vida: un desengaño y una serie de fracasos, pero también creen más que las mujeres que la vida es un proceso oportuno para la construcción de un mundo mejor. Sin embargo, ellas parecen más resignadas con las adversidades de la vida. Así pues, pase lo pase, la vida es una cosa que vale la pena vivir y bajo la influencia cristiana creen que la experiencia de vivir permite el encuentro con Dios.

Coherentemente con todo lo anterior, un poco más de dos tercios de los mayores dijeron que el modelo de vida que llevan es agradable $(67,19 \%)$. Las mujeres se revelan un diez por ciento más satisfechas que los varones. Pero, también se declaran sutilmente menos felices que ellos cuando opinan que la vida actual es desagradable. En la apatía existencial, ni agradable ni 
desagradable, ellas, de nuevo, asumen el liderazgo. Para la mayoría de esta gente, por vivir una vida humilde, sin muchos recursos, sin grandes ambiciones, sus satisfacciones personales se resumían en construir una familia, conseguir un hogar para vivir y tener asegurado el pan de cada día fruto del trabajo. En cuanto a los desánimos, se ven justificados por los objetivos no alcanzados, sumados a la vejez, que llega a veces sin salud ni asistencia eficaz.

Las personas mayores entrevistadas también se posicionaron sobre el tema de la sexualidad. La mayoría asocia la caída de la actividad sexual a la percepción negativa de que la sexualidad se termina con el paso del tiempo $(58,68 \%)$. En cambio, poco más de un quinto no se siente afectado y un $17 \%$ no contestó a la cuestión. A pesar de que la sexualidad se manifiesta diferentemente para hombres y mujeres, en general nuestros entrevistados se posicionaron de modo semejante. Ambos, sin grandes diferencias de edad o condición de estado civil, se incluyen en las diferentes opciones propuestas. A parte del estado de salud, que puede afectar tal actividad, entre otros indicadores, las inhibiciones culturales pueden causar posturas reprimidas en los mayores.

En cuanto a la calificación religiosa, cuatro quintas partes de los sujetos profesan el mismo credo, el catolicismo (80,76\%), siendo el $51,74 \%$ asiduos a los actos litúrgicos, como recomiendan la Santa Madre Iglesia y el 29,02\% los denominados católicos no practicantes. En cambio, un 12,62\% de los mayores participa de otra denominación religiosa, ramificaciones de la Reforma Protestante. Tan sólo un 1,89\% cultiva otro tipo de religión no cristiana y el $2,84 \%$ no siente ni inclinación ni repugnancia hacia la religión. Las mujeres entrevistadas católicas duplican a los varones, sin embargo, ellos aumentan la población que se dice creyente, pero sin participación en los actos litúrgicos, además de no estar interesados en los temas religiosos. También en mayor proporción, ellas aceptan con más frecuencia que los varones las invitaciones de otros credos religiosos. 
En general, estos resultados son muy semejantes a los obtenidos por el IBGE (2000) en una muestra nacional. A pesar de ser el país más católico del mundo en proporción de fieles, con 124,9 millones de fieles (el 73,6\% de la población), la adhesión es poca, principalmente en los grandes centros urbanos de Brasil. La divergencia entre las orientaciones de la Iglesia y el pensamiento de los fieles, en temas como los métodos anticonceptivos, el divorcio o el segundo casamiento, actitudes terminantemente prohibidas por la Iglesia Católica, la libertad de elección religiosa y el aumento de la diversidad de religiones contribuyen a la pérdida de espacio del catolicismo.

Sobre el tema de la finitud física humana; la muerte, en los posicionamientos de los mayores entrevistados, más de la mitad piensa o habla sobre la inexorabilidad de nuestra existencia (58,05\%), suponiendo el $38,49 \%$ los que nunca hablan sobre la muerte, el $28,71 \%$ los que raramente piensan sobre ese ciclo de la naturaleza, el 20,19\% los que ocasionalmente se interesan por tal transformación, menos del $10 \%$ de los sujetos encara el asunto frecuentemente y tan sólo un $3,15 \%$ no contestó a la pregunta. Los varones piensan y hablan frecuentemente del fin del ciclo vital, las mujeres son más reservadas para hablar sobre esa transitoriedad y no lo hacen nunca, raramente y ocasionalmente. Quienes más se interesan por el tema son los varones casados y las mujeres viudas. En general, por orden de preferencia, los mayores comparten las ideas respecto a la muerte con algún familiar $(34,70 \%)$, amigos $(15,77 \%)$ y el cura $(1,89 \%)$, conforme al grado de relación y amistad existente.

Todo indica que gran parte de los participantes no está muy interesada en el fenómeno de la muerte. El miedo a lo desconocido, la visión aún morbosa, triste y pavorosa que escapa a todo debate racional, predomina sobre la óptica de que es el coronamiento de la existencia humana terrenal, el destino definitivo que aguarda a todos. Las mujeres lo sienten más, quizá por vivir más plenamente la vida que nos fue dada gratuitamente (un $38,80 \%$ frente a un $28,39 \%$ está más feliz que los varones con la vida que llevan). Mientras, para los varones, aceptarla puede que represente la liberación de los 
Perfil Sociológico de la vejez en Mossoró/RN.

La vejez ante la muerte

desengaños y fracasos que dijeron haber atravesado a lo largo de la existencia. 


\section{Conclusiones}

El objetivo de este trabajo es contribuir al debate actual sobre la temática del envejecimiento y su consecuencia natural, la vejez. Así pues, en "La belleza de las arrugas. Un estudio sobre la vejez en el Nordeste de Brasil", queremos investigar el proceso demográfico y socioeconómico del envejecimiento de la población de Mossoró. En ese contexto es donde la notable Transición Demográfica en Brasil se está produciendo de modo más rápido e intenso, en razón del declive de la fecundidad y del aumento de la expectativa de vida. Como hemos dicho, se estima que en 2020 la población con más de 60 años en el país alcanzará los 30 millones de personas, el 13\% del total y una esperanza de vida de 70,3 años. Según la Síntesis de los Indicadores Sociales (SIS: 2006), el país tropical estará entre las diez naciones del mundo con mayor porcentaje de población con edad igual y/o superior a 60 años, ocupando en el año 2025 la $6^{\mathrm{a}}$ posición en el ranking mundial. Los datos sirven de alerta para que el Gobierno y la sociedad se preparen para esa nueva realidad tan cercana.

Se trata de un campo prácticamente inexplorado, principalmente porque el envejecimiento colectivo en Brasil es relativamente reciente - principios de los años sesenta - y existe en la sociedad moderna una sobrevaloración de la juventud, de la fuerza, de la agilidad y de la búsqueda desenfrenada de la belleza física ${ }^{377}$, donde las personas de edad tienden a ser socialmente excluidas del sistema. En Mossoró lamentablemente la realidad no es diferente. Es por ello, que nos pusimos a investigar sobre el asunto.

El tema de la belleza es muy subjetivo: puede estar en los rincones en los que no podemos tocarla, sí apreciarla y, por supuesto, desearla. La subjetividad

\footnotetext{
377 Según la Revista The Economist (Sept/2008), Brasil realiza cerca de 600 mil cirugías plásticas al año. Es el segundo mayor mercado mundial, quedando por detrás de Estados Unidos. El crecimiento de la clase media en el país trajo un aumento de la demanda de ropa, gimnasios, cosméticos y productos de belleza. En el año 2008, la Sociedad Brasileña de Cirugía Plástica (SBCP) cumple 60 años. Fundada en São Paulo para promover y privilegiar el estudio de la cirugía plástica en Brasil, cuenta actualmente con aproximadamente 4.000 mil cirujanos plásticos, entre titulares, asociados y aspirantes a miembros.
} 
de la belleza a la que me refiero se revela en la sabiduría, en la experiencia de vida, en la colaboración y en la prudencia humana que sólo el paso del tiempo es capaz de regalarnos y que encubre inevitablemente a la mera apariencia. Siempre que nos preocupemos sólo de la belleza exterior o artificial, nos alejaremos de lo humano. Es urgente crear nuevos modelos para mirar la vejez como un valor y no como una condena que sólo la muerte nos impide vivir, de modo que se rompa con el modelo de la vejez temida e inaceptable. Es necesario intervenir para conseguir el cambio de actitudes en los estereotipos e imágenes negativas del envejecimiento y de las personas de edad hacia una dirección positiva de la vejez.

Recordamos que poco se sabe sobre el perfil de este colectivo en Mossoró y sobre las particularidades del envejecimiento en nuestro contexto social. De un modo general, los estudios apuntan una gran falta de información de toda la sociedad hacia la vejez y las necesidades reales de esa población. De ese modo, nuestro propósito es el de generar datos sobre el grupo de personas con 60 años o más de edad, que corresponde al 7,8\% del total de la población del municipio y así contribuir a una mejor definición de la población mayor brasileña.

Teniendo en cuenta que esa transformación demográfica tiene dimensiones profundas y repercute en la sociedad, los datos analizados apuntan que las necesidades específicas de las personas de edad requieren una planificación de políticas públicas ajustadas y sólidas; políticas de protección, de solidaridad intergeneracional, de asistencia social y de apoyo a las familias. Además de los poderes públicos constituidos (Ejecutivo, Legislativo y Judicial), la sociedad civil, incluidas las ONGs, el sector privado, los voluntarios y las organizaciones de voluntarios, las propias personas de edad y sus asociaciones, así como las familias y las comunidades, deben involucrarse para responder a las oportunidades y los desafíos que plantea el envejecimiento de la población y así promover una sociedad para todas las edades. Desgraciadamente aún son pocas las entidades que actúan directamente en la protección social basada en derechos y en la exigencia de políticas públicas para los mayores en Mossoró, en el Nordeste o en Brasil. 
Destacamos que un estudio de esta magnitud, pionero en Río Grande del Norte, basado en indicadores fiables, es un instrumento indispensable para identificar nuevos problemas y facilitar la adopción de decisiones, la creación e implementación de legislaciones, políticas, programas, planes y servicios para mejorar las condiciones de vida de las personas de edad, como nos recomienda el Informe de la Segunda Asamblea Mundial sobre el Envejecimiento realizada en Madrid en 2002.

Crear condiciones económicas y sociales que permitan una buena calidad de vida a los mayores brasileños nordestinos es un desafío que ya está en curso. Los datos de que disponemos contribuyen a que la sociedad despierte y priorice las políticas pertinentes para este colectivo ${ }^{378}$, adopte nuevas políticas, en particular en materia de prevención. Estas políticas tienen que servirnos a nosotros, futuros mayores, que deseamos envejecer con salud, activos y participando de la sociedad. Por consiguiente, este estudio es casi una convocatoria para un trabajo más concreto y urgente en favor de los mayores. Reconocemos que en Brasil las políticas públicas enfatizan bastante las discusiones sobre los Derechos de la Infancia y de los Adolescentes, de las Mujeres, de los Portadores de Necesidades Especiales, de los Negros, de los Sin Tierra, de los Indios y de las Minorías. Ahora es el turno de reforzar los debates y políticas hacia los mayores en forma de red; es preciso hacer mucho más para que el ejercicio de sus plenos derechos sea garantizado.

Nos tomamos en serio la alerta que hizo Alexandre Kalache: ${ }^{379}$ cuando se pasa por una transformación tan rápida como la demográfica en nuestro país es necesario reinventar la sociedad. No se puede esperar que las reglas y estructuras permanezcan iguales, intocables, como si fuesen a reaccionar naturalmente. Es preciso tener visión, anticipar, liderar. Necesitamos cambios de actitudes y de prácticas en todos los niveles y sectores, para que puedan concretarse las enormes posibilidades que brinda el envejecimiento

\footnotetext{
$378 \quad$ Estatuto del Mayor ( $n^{\circ}$ 10.741/2003), Política Nacional do Idoso ( ${ }^{\circ}$ 8842/1994), Ley Orgánica de la Asistencia Social ( ${ }^{\circ}$ 8.742/1993), Sociedad Brasileña de Geriatría y Gerontología (SBGG), Asociación Nacional de Gerontología (ANG).

379 Bajo el título Inversión de la Pirámide Etaria, el médico epidemiólogo Alexandre Kalache concedió una entrevista a la Librería Cultura News en julio de 2007. Alexandre Kalache es brasileño, jefe del Programa de Envejecimiento y Salud de la Organización Mundial de Salud (OMS) en Ginebra, Suiza, desde 1994.
} 
en este siglo XXI. De ese modo, la longevidad debe convertirse en un valor y un compromiso de todos y Mossoró no está exenta de esa responsabilidad.

En ese sentido, en este trabajo, ponemos a disposición de la sociedad del Nordeste brasileño un conjunto de informaciones sobre la realidad de las personas en la franja de 60 años o más de edad, pertinente a los aspectos demográficos, económico y psicosocial. No pretendemos dar respuestas definitivas a todas las cuestiones que planteamos a lo largo del estudio, sin embargo, a partir de él, elaboramos cinco propuestas razonables, a modo de contribución, para responder a los retos que está planteando el envejecimiento de la población. Dichas propuestas pueden facilitar la adopción de decisiones públicas o privadas dirigidas a los mayores, teniendo en cuenta las recientes iniciativas mundiales, los principios orientadores establecidos en importantes conferencias y reuniones en la cumbre de las Naciones Unidas, de la Política Nacional del Mayor (1994), del Estatuto del Mayor (2003) y a las deliberaciones de la Red Nacional de Protección y Defensa de los Derechos del Mayor (RENADI: 2007) en Brasil. Es preciso reconocer que las personas, a medida que envejecen, deben disfrutar de una vida plena, con salud, seguridad y participación activa en la vida económica, social, cultural y política de su sociedad.

Las propuestas se refieren a la Seguridad Social, a la Salud y Asistencia Sanitaria, a la Educación, Cultura, Actividad Física y Ocio, a la Accesibilidad y a la Valoración y la Participación.

\section{1) Seguridad Social}

La Transición Demográfica, junto con la Transición Epidemiológica, resulta el principal fenómeno del pasado siglo. En Brasil, esa transformación viene sucediendo desde finales de la década de 1960 y está ligada a importantes desafíos. Uno de ellos se refiere al adecuado desempeño del sistema de Seguridad Social ${ }^{380}$, dado que cuanto más envejece la población, más gastará 
la seguridad con los beneficios, jubilaciones, pensiones y subsidios. Es un gran desafío, responder a las demandas de los actuales 19,1 millones de brasileños (11,1\%), que alcanzaron los 60 años de edad y que en su mayoría viven en la pobreza y, para los nuevos senescentes en un futuro próximo. Se estima que, anualmente ese aumento sea de 585.000 personas en la franja de los 60 años o más, entre el período de 2000-2020. Esto supone que dicho colectivo supondrá al 13\% de la población brasileña en el 2020.

Con este aumento de la esperanza de vida del brasileño, la Seguridad Social, que es, según algunos analistas, una herramienta importante para evitar y aliviar la pobreza, pasa a ser uno de los asuntos más polémicos de las últimas décadas. Variables como el aumento del salario mínimo, el número de beneficiados, que será proporcionalmente mayor que el de los afiliados, el aumento del valor medio de los beneficios sociales, las jubilaciones precoces, la evasión fiscal y los costos administrativos elevados, hacen estallar los inevitables debates sobre la "crisis financiera del sistema". Como consecuencia, la protección social está pasando por variados procesos de cambios y reestructuración, de manera casi ininterrumpida desde finales de la década de 1980, debido al cuadro de estancamiento económico y el agravamiento de la crisis social.

No obstante, según la PNAD 2007, Brasil ha superado los 40,1 millones de afiliados a la Seguridad Social en 2007, frente a los 37,4 millones del año anterior. La evolución fue del $11,7 \%$ si la comparamos con la de 2005 , que era de 35,9 millones. A pesar de que la participación de las mujeres ha aumentado en los últimos años, ellas aún son minoría entre los contribuyentes. Esto se debe a su menor inserción en el mercado de trabajo. En 2007, las mujeres representaban un $40 \%$ del total y los hombres, cerca del $60 \%$. En general, el número de afiliados asciende a 51,2 millones si se incluyen a las personas que pagan individualmente el seguro social, como los profesionales liberales ${ }^{381}$.

Social en los casos de la salud y la asistencia social son independientes de la contribución. Por otro lado, el acceso al seguro social, se da mediante cotización. Todos los brasileños deben tener el derecho a los beneficios que ella distribuye y el deber de contribuir para mantener la solidaridad entre las generaciones. $381 \quad$ Anuario Estadístico de la Seguridad Social de 2007. 
En este contexto, las personas socialmente protegidas, o sea, los que reciben jubilaciones y/o pensiones de la Seguridad Social, suman un total de 25.184.196, en enero de 2008. De estos, poco más de 16,5 millones de asegurados recibieron beneficio igual a un salario mínimo ( $R \$ 415,00 \pm 166 €$ ). Sin embargo, la distribución de estos beneficios, a su vez, se diferencia entre hombres y mujeres, reflejo de un mercado de trabajo que durante muchos años absorbía sólo a la población masculina. De acuerdo con el "Retrato de las Desigualdades de Género y Raza - $3^{\text {a }}$ edición (IPEA: 2006), el 78,6\% de los hombres mayores está cubierto por la Seguridad Social, mientras que la población de mujeres aseguradas es del 75,4\% en el mismo período.

De acuerdo con el PNAD (2006), por cada beneficiario del subsidio social hay, de media, 2,5 personas amparadas indirectamente. Así, se estima que la protección social atañe actualmente a cerca de 82 millones de personas en Brasil. Las jubilaciones y las pensiones, pagadas por el sistema, acaban atendiendo no sólo a los mayores, sino también a sus familiares. Según un análisis hecho por el IPEA, en el año de 2007, la Seguridad Social sacó a 20 millones de personas de la pobreza y a 17 millones, de la situación de indigencia. Con este recurso, muchas familias resisten a la pobreza y sobreviven. En estos casos, los mayores son un factor de equilibrio social y no un peso. Por esa razón, según el estudio de IBGE de 2007, las personas de 60 años en adelante pasan a tener un peso importante en la renta del brasileño. En más de la mitad de las viviendas con estas personas, los mayores son responsables de hasta un $90 \%$ de la renta mensual del domicilio. Existen no obstante, diferencias regionales. La participación de la renta del mayor en el Nordeste es más expresiva que en otras regiones, o sea el 63,5\% del total. En todo el país, la tendencia es mayor en las áreas rurales, donde este índice alcanza el $67,3 \%$.

Aún en este escenario, la cobertura de las pensiones y jubilaciones también es responsable de la renta de las provincias y municipios. Se observa que esto tiene un impacto significativo en la calidad de vida de los adultos mayores y de las familias con quienes cohabitan. Como una pilastra social, el sistema de la Seguridad Social funciona como un programa de transferencia de renta que 
impacta sobre la vida familiar, reduce en parte las desigualdades sociales y regionales, corrige injusticias al garantizar la ciudadanía, impulsa las economías locales, evita el éxodo rural, pero no es suficiente para solucionar la desigualdad en la distribución de renta en el país. Según datos del IPEA (2008), la renta media de los más ricos del país es 28 veces mayor que la renta media de los más pobres. Unos pocos acaparan mucho y muchos no poseen casi nada. Falta mucho para alcanzar la justicia social, la equidad e igualdad entre los brasileños.

No es novedad que la Seguridad Social constituye un avance extraordinario en la reducción de las desigualdades en Brasil, sobre todo en relación al descenso de la pobreza, pero su cobertura en el país es aún bastante baja. Datos de la PNAD de 2006 revelan que más de la mitad de la población ocupada del país no contribuye a la Seguridad Social $(51,2 \%)$, es decir, cerca de 29 millones de personas con edades entre 16 y 59 anos están "socialmente desprotegidas". De éstas, 15,4 millones reciben más de un salario mínimo ( $R \$ 415,00 \pm 166 €$ ) $y$, a pesar de tener ingresos, no contribuyen a la protección social. Sin esta protección, los futuros mayores y sus familias no tienen derecho a jubilaciones por edad, por invalidez, por tiempo de contribución, enfermedad, maternidad, reclusión y pensión por defunción.

En este contexto se sitúa Mossoró, donde la Seguridad Social efectivamente cumple su función, pero aún necesita mayor atención. Debido, en parte, a las dificultades de datos, creemos que lo descrito se aplica al municipio. Así pues, dirigimos nuestras sugerencias hacia dos puntos para que nuestros mayores y los que están camino de la vejez puedan disfrutar de esta etapa de la vida con más dignidad.

Primero, intensificar la política de expansión del sistema de protección social a todos los grupos de edad, y en particular a los mayores. Universalizar la Seguridad Social (contributiva o no contributiva) como derecho humano, observando sobre todo la persistencia de las desigualdades en relación al género. A pesar de no disponer de datos de la cantidad exacta de personas, de los 18.103 habitantes con 60 años o más (mayo/2008) residentes en el municipio de Mossoró protegidos por el sistema, la situación no difiere de la 
nacional. Sin embargo, en nuestra investigación un $41,80 \%$ de los hombres tenía la condición de jubilado, frente a un 35\% de las mujeres. En la condición de pensionista se encuentra un 16,20\% (hombres, un 2,60\% frente a un 13,60\% de mujeres) y en plena actividad laboral un $19,20 \%$. La mayoría tiene una renta mensual de entre uno y dos salarios mínimos $(52,20 \%)$, pero las mujeres reciben menos ingresos que los hombres. Sueldos más bajos, falta de desarrollo profesional debido a las interrupciones de la actividad laboral y las obligaciones relacionadas con la atención a la familia, son factores que contribuyeron a la situación de estas mujeres.

Por tanto, los ingresos son un parámetro importante para el colectivo y sus familias, cuya calidad de vida depende en su mayoría de estas rentas (alimentarse, vestirse, comprar medicinas, entre otros). Hacen falta medidas especiales de protección social para hacer frente a la feminización de la pobreza, en particular en el caso de las mujeres de más edad. En ese sentido, una mayor cobertura de la Seguridad Social tiende a disminuir la incidencia de la pobreza relativa a la desigualdad de ingresos.

Segundo, entendemos que uno de los problemas sociales más graves, que deben ser prioritarios en la agenda política socio-económica en Mossoró, estaría en el área de la irregularidad en el mercado de trabajo. Aunque haya aumentado el número de plazas de trabajo con contrato firmado - el municipio está entre las cincuenta ciudades del interior que más emplean en Brasil (el mayor nivel de contrataciones ocurre en el sector de la construcción civil, agropecuaria, comercio y servicios - MTE: CAGED, 2007), no existen datos oficiales sobre la economía sumergida en el trabajo. Se puede afirmar que son muchos los que trabajan en negro en Mossoró, es decir, sin condiciones de trabajo apropiado y sin la protección social que ofrece el sector estructurado de la economía. El desempleo, el subempleo y la rigidez del mercado laboral empujan a jóvenes, hombres, mujeres y hasta niños hacia el trabajo irregular. Sin fiscalización eficiente, las aceras son invadidas por una infinidad de productos y servicios; venta de ropas, calzados, comidas, CD y DVD, etc. En busca de mejorar de vida, pequeños comerciantes, moto taxistas, vendedores ambulantes, con trabajos precarios y mal remunerados, 
forman parte de la población en una situación de total desprotección, generada por la exclusión de los derechos de que disponen en la economía estructurada, como vacaciones, baja por maternidad, subsidio por desempleo, entre otros.

En este contexto, es indispensable adoptar medidas para ampliar y mejorar las políticas de desarrollo. Incrementar las tasas de empleo en la economía legal ayudará a recaudar impuestos y permitirá ampliar los sistemas de protección social, poco desarrollados en Mossoró, con los que los trabajadores mayores podrán jubilarse contando con una mayor seguridad financiera. Alentar el desarrollo de pequeñas empresas y microempresa; garantizar el acceso al crédito, también a las personas de edad sin discriminación por razones de sexo; cualificar a las personas para el mercado laboral y estimular la afiliación a la Seguridad Social a través de campañas informativas, serían cuatro pasos importantes para proteger socialmente a los futuros senescentes y a los que ya sobrepasan los 60 años de edad y disminuir la proliferación del trabajo irregular.

La irregularidad y la falta de respeto a las cuestiones del trabajo, fiscales y ambientales aún dependen del esfuerzo conjunto de gobiernos, empresas y agentes de desarrollo.

\section{2) Salud y Asistencia Sanitaria}

Vimos que la expectativa media de vida al nacer en Brasil alcanzó los 72,3 años de edad, en 2006. Un incremento de 5 años en la vida media al nacer, del brasileño entre 1992 y 2006, gracias al desarrollo científico, a la mejora de las condiciones de vida y de salud de la población. Sin embargo, existen aún grandes desigualdades regionales: mientras en la Región Nordeste la expectativa de vida al nacer era de 69,4 años en 2006, en el Sur era de 74,4 años. Vivir mucho no es suficiente, es preciso vivir mejor. En ese sentido, un gran desafío que la mejorada longevidad nos presenta es conseguir que dicho aumento sea digno y pleno en todo el país, visto que el estado de salud de las personas de edad, tanto del Nordeste como del Sur, carece de cuidados especiales, no sólo para vivir más, sino para vivir saludablemente. 
En Mossoró, la calidad de la supervivencia de los mayores, que también está relacionada con las condiciones sociales, económicas y ambientales, pone en evidencia que los cuidados dispensados a la salud, a través del uso de las políticas sanitarias existentes, no están bien aprovechados. Nuestros datos revelaron que el 49,60\% de los mayores sólo va al médico cuando se encuentra enfermo. Más de la mitad de los hombres nunca se hizo pruebas urológicas (64\%) y un porcentaje significativo de mujeres también reveló que nunca visitó a un ginecólogo para hacerse exámenes (50,40\%). En estas edades, muchos son los enemigos de la salud. Las dolencias más presentes en el colectivo son las cardiovasculares $(26,80 \%)$, las locomotoras $(18,40 \%)$, las digestivas $(15,20 \%)$, las respiratorias $(13,80 \%)$ y las neurológicas $(11,40 \%)$. Sin embargo, casi la mitad se autoevalúa el estado de salud como regular $(47,20 \%)$. En este contexto, la falta de algunos cuidados básicos preventivos, puede afectar decisivamente al campo físico ( $\mathrm{Ej}$. discapacidades y minusvalía), psíquico (Ej. depresiones) y/o social (Ej. aislamientos) del mayor ya que una mayor longevidad tiene implicaciones importantes para la calidad de vida del individuo.

En este escenario, no nos extraña que los mayores en Mossoró presenten un cuadro de "descuido" de su propia salud. La mayoría de las personas entrevistadas de 60 años o más de edad no posee un plan de salud privado (64,60\%), o sea, depende del Sistema Único de Salud (SUS), política universal, pública y gratuita, cuyo texto en la Constitución señala que "la salud es derecho de todos y deber del Estado, garantizado mediante políticas sociales y económicas que visen la reducción de riesgo de enfermedades y de otros agravios y al acceso universal e igualitario a las acciones y servicios para su promoción, protección y recuperación" (Art. 196). Aunque tengamos en cuenta los avances alcanzados por el SUS desde su implantación en 1986, como el aumento del acceso de la población a los medicamentos y a la atención médica y, más recientemente con la implantación del Pacto por la Vida, en Defensa del Sus de Gestión (2006), hay evidencias de la ineficiencia del funcionamiento del sistema que compromete la calidad de los servicios. En general, la falta de gestión en las políticas públicas de salud, el exceso de burocracia - que crea retrasos en la compra de medicamentos y 
equipamientos, y en la contratación de personal - y la falta de directivos cualificados, son algunos de los problemas que amenazan la salud pública en Brasil.

Por tanto, es imprescindible un mayor interés por parte de las autoridades y de los profesionales que lidian directamente con el área sanitaria para los mayores, específicamente en Mossoró. Adoptar una política de fortalecimiento en los Puestos de Atención Médica (PAM) y en las Unidades de Urgencias en los barrios periféricos, respondería a parte de las nuevas demandas y necesidades que conlleva el aumento del número y de la proporción de mayores unido al nuevo perfil epidemiológico de la salud en nuestra ciudad y, en consecuencia, desahogaría el colapso de los hospitales.

Los avances en las políticas en el ámbito de la salud son visibles, pero, aún no es suficiente. Sería conveniente aumentar la cobertura de los servicios del Programa Social de la Familia (PSF) a los mayores, implantar servicios de atención domiciliar - ya que nuestros protagonistas sugieren que la persona de edad avanzada debería recibir asistencia médica en casa $(75,80 \%)$. Invertir en la formación y acompañamiento de cuidadores de personas mayores dependientes y apoyar a las redes familiares reduciría los índices de ingresos en las hospitalizaciones indebidas, y por ende los riesgos de infecciones y los gastos sanitarios.

Además de lo antedicho, intensificar las campañas preventivas contra el cáncer y las enfermedades crónico-degenerativas, las caídas y la promoción de la salud, con énfasis en la actividad física regular y la alimentación saludable, sería socialmente correcto, si deseamos vivir en una sociedad integradora. Para mejorar este cuadro se debería aumentar la cantidad de especialistas en el área de Geriatría y Gerontología, proporcionar la formación y educación permanente de los profesionales de salud del SUS en el área de la persona de edad avanzada y facilitar el acceso de los profesionales al Manual de Atención Básica en el Envejecimiento - que los auxilian en el diagnóstico de dolencias y formas de tratamiento - y por último, invertir en programas de educación a lo largo de la vida. Es decir, con políticas sanitarias ajustadas, adecuadas a los mayores y a las próximas generaciones, Mossoró pasaría a 
prestar una atención integrada, de calidad y humana, y así garantizaría un envejecimiento activo, preservando la independencia y autonomía de los mayores actuales y futuros.

Suponemos que por depender del SUS, gran parte de los mayores mossoroenses evita los servicios ofrecidos en los puestos de salud gestionados por el sistema público. La insatisfacción en los Puestos de Atención Médica y las Unidades de Urgencias, se debe principalmente, a la falta de médicos y a la demora en el atención. En general los servicios no suelen estar a la altura de las expectativas. Persisten las desigualdades en el acceso a los servicios de salud, que impiden a las personas de edad disfrutar plenamente de una atención sanitaria de calidad. Queda aún mucho por hacer en este campo en Mossoró. Se plantea un gran desafío a la agenda política sanitaria. Con el aumento del predominio de las dolencias crónico-degenerativas, con sus secuelas y complicaciones, que lleva a muchos mayores a la incapacidad, dependencia y necesidad de cuidados de larga duración y de instituciones de larga permanencia, no podemos olvidar, invertir en los servicios de asistencia a domicilio, en los centros de día, en los centros de rehabilitación, así como comprender que las instituciones de larga permanencia conllevan características sanitarias y sociales concretas. La salud del ciudadano como derecho garantizado en la Constitución Federal (1988) debe ser respetada y disfrutada en su plenitud.

Por esa razón las políticas públicas, que propician la salud durante toda la vida, deben hacer hincapié en la promoción de una vida saludable y en los entornos propicios, en la prevención de las enfermedades, en los cuidados, en la rehabilitación, y en los servicios de salud mental, ya que el envejecimiento es un proceso que debemos controlar hasta que llegue nuestro último día. Fomentar la salud y el bienestar de los mayores actualmente y hasta la llegada de nuestra vejez es una de las prioridades del Plan de Acción Internacional sobre el Envejecimiento, de la Política Nacional de Salud de la Persona Mayor (2005) y del Pacto por la Salud con el Pacto por la Vida (2006). 


\section{3) Educación, cultura, actividad física y ocio}

Uno de los grandes desafíos que surge junto al fenómeno irreversible del envejecimiento en Mossoró, es garantizar vida activa y plena a las personas con 60 años o más de edad. Por tanto, uno de los caminos más obvios podría ser facilitar el acceso a la educación, a la cultura, al deporte y al ocio, a todos sin distinción. Generalmente, estos requisitos previos ejercen un papel fundamental en la superación de las desigualdades socio-económicas y en las formas de muchos prejuicios. Pero eso de momento es sólo una utopía, no una realidad concreta en el municipio.

Entre los mayores que participaron en nuestra investigación, un gran número llegó a la vejez con un conocimiento mínimo de las primeras letras y la aritmética elemental, requisitos básicos de cualquier educación. El 31,60\% hizo Primaria y el $20,80 \%$ se declaró analfabeto funcional. En otro extremo, el $19,80 \%$ era analfabeto y sólo el 5,40\% cursó la Universidad. Los que ya pasaron por el Centro de Educación de Jóvenes y Adultos (CEJA) totalizaron el 6,60\% y los que alcanzaron la Universidad Abierta de la Tercera Edad (Unati) sólo un $1,60 \%$. Todo indica que la educación como prioridad básica para los mayores no está en la agenda política. En todo el país, las personas con más de 60 años sin estudios o con menos de un año de estudio representaba el 32,2\% en 2008 (IBGE). El porcentaje es mayor en el Nordeste, donde el $52,2 \%$ posee aún bajo nivel educativo, pero el índice era peor hace diez años: 62,8\%. En el otro extremo está el Sudeste, con un $22,8 \%$ sin estudios, y el Sur, que posee el menor porcentaje brasileño, el 21,5\%.

Una educación básica de calidad, que permita el acceso a la información y al conocimiento culminaría en el tan deseado desarrollo económico y social, en la generación de trabajo y renta. Si queremos de hecho dar un salto hacia una sociedad para todas las edades, tenemos que invertir en una educación permanente de calidad para todos. En otras palabras, mejorar la calidad de la educación en Primaria y en Secundaria y aumentar la escolaridad de la población. Además se debe mejorar la formación de los profesores; apoyar a las escuelas en su funcionamiento y dotación de equipamientos y materiales. 
Para la educación del colectivo de mayores en Mossoró recordamos lo que nos recomienda el Plan de Acción Internacional sobre el Envejecimiento y el Estatuto del Mayor - Ley $n^{\circ} 10.71 / 03$. 1) Ofrecer un acceso equitativo a la educación básica y permanente para los adultos. Uno de los caminos más adecuados sería aprovechar mejor los programas que aseguran a todos los brasileños de 15 años o más que no tuvieron acceso a la escuela o que fueron excluidos de ella precozmente, con el ingreso, la permanencia y la conclusión del ciclo fundamental con calidad, a través del Centro de Educación de Jóvenes y Adultos (CEJA) y del Programa Brasil Alfabetizado. 2) Garantizar que todos los mayores puedan aprovechar los beneficios de las nuevas tecnologías (el $63,60 \%$ de los encuestados no sabe utilizar los cajeros automáticos), sobre todo, de la información y de las comunicaciones, teniendo en cuenta las necesidades de todos, para su integración a la vida moderna. Por último, un mayor acceso a la educación en la infancia y la juventud beneficiaría económica y socialmente a aquellos que un día alcanzarán la vejez.

En cuanto a la cultura y el ocio, éstos son vitales para el ser humano. Ir a la biblioteca a coger un buen libro para leer, ir al cine a ver una película que está en cartelera, ir al teatro para apreciar un espectáculo esperado, acudir a un concierto con los amigos, pasar un día en un museo rodeado por las más variadas historias... todos son momentos placenteros cultivados por el ser humano a lo largo de la historia. Pero en Brasil, casi sólo en las grandes metrópolis se da este lujo. Datos del IBGE (2005) revelan que la situación de carencia cultural en el país es patente. El $82 \%$ de los municipios brasileños no posee museos, el $84,5 \%$ no tiene teatro, el $92 \%$ no tiene siquiera una sala de cine. De éstas, casi la mitad están concentradas en los estados de São Paulo y Río de Janeiro (48\%) y cerca del $20 \%$ no tiene bibliotecas públicas. En los municipios que tienen bibliotecas, el $69 \%$ de ellos sólo posee una y, en los municipios con hasta 20.000 habitantes, 840 no tiene ninguna. Datos de la Cámara Brasileña del Libro del año de 2006 muestran que solo el 10\% de la población brasileña - 17 millones de un total de 170 millones - leen entre uno y dos libros por año. La media en Brasil está en 1,8 libros leídos al año por 
habitante, mientras que en Francia, por ejemplo, ese número se multiplica por siete.

Como se ve, no es de extrañar que entre nuestros mayores encuestados sólo el 4,60\% buscara los descuentos especiales para ver los espectáculos y sólo el $15,60 \%$ del total participó en las actividades socio-culturales promocionadas por el Ayuntamiento de Mossoró. La mayoría en su tiempo libre se queda en casa $(84 \%)$ viendo la tele $(64 \%)$, más de la mitad nunca salen de vacaciones $(56,20 \%)$, principalmente por motivos económicos $(17,20 \%)$ y de los que participan en algún grupo social, sólo el $8,60 \%$ acude a los encuentros de los Centros de Convivencia orientados a ellos.

Lamentablemente, el panorama no es de los mejores. No obstante, el problema no es tan grave como se presenta en un primer momento, por hablar de Mossoró que tiene el privilegio de ser considerada la capital cultural del Oeste Potiguar. La ciudad está bien servida de teatros, son seis en total. Sin embargo, no ocurre así en el campo cinematográfico, actualmente no tenemos ningún cine, después de un gran período áureo en el siglo pasado donde llegamos a tener más de doce casas de proyecciones. En el Mossoró West Shopping, inaugurado en 2007 con 140 tiendas, está prevista la apertura de cinco salas de cine. En cuanto a las asociaciones culturales, según la Fundación Municipal de Cultura (FMC), Mossoró tiene registrados 37 grupos de teatro y danza, cinco pastoris, cuatro de umbanda, 15 escuelas de música, 15 bandas de forró y 25 cuadrillas juninas. La fundación estima que esos números son mayores porque gran parte de los grupos no están registrados. Además del Museo Municipal, tenemos el de Petróleo y del Cangaço, una Biblioteca Municipal, instalaciones deportivas, estadio de Fútbol y Plaza de Convivencia. Así pues, no parece que falte vida cultural en Mossoró. Sin embargo, para que la ciudad sea más integradora es necesario desarrollar políticas para superar el cuadro cultural que dibujan los mayores, si entendemos que a través de la educación, la cultura, el deporte y el ocio se puede, sobre todo, potenciar el desarrollo personal y permitir una mayor participación de los mayores mossoroenses en la sociedad. 
En el ámbito de la práctica de actividad física o del deporte, vemos que son pocos los mayores que hacen uso de alguna modalidad. La práctica regular de ejercicio más frecuente es la caminata $(33,60 \%)$. Los sedentarios, o sea, los que no practican ninguna actividad física totalizan un $56 \%$. La idea de invertir en ese área se entiende, sobre todo, como una política preventiva. Existen cada vez más evidencias científicas de que la actividad física en las personas de edad ayuda a mantener y a mejorar las actividades de la vida diaria y contribuyen a la mejora del aspecto biológico, psicológico y social. Fomentar la prevención de la dependencia debería ser el buque insignia de una política de bienestar. Sumado a la alimentación equilibrada y a la participación en grupos sociales, tendríamos una buena manera de vivir un envejecimiento con éxito.

Para los mayores de Mossoró, que todavía no disponen de muchos recursos financieros, sugerimos que el Programa Mossoró Camina sea reactivado. El proyecto, desarrollado en las plazas públicas, ofrecía a los participantes la posibilidad de practicar deporte y actividades físicas, verificar la tensión arterial, vacunarse y asistir a conferencias sobre la salud. Las actividades estaban bajo la responsabilidad de los profesores de educación física, enfermeros, auxiliares de enfermería y médicos del cuadro funcionarial del Ayuntamiento municipal. Se desarrollaba en seis espacios públicos, a las seis de la mañana, para la práctica sobre todo de la caminata y estiramientos. Como reunía a jóvenes, adultos y mayores, el contacto intergeneracional se acentuaba. Es indispensable reconocer que la participación en actividades sociales, culturales y deportivas contribuye también a aumentar y mantener el bienestar personal.

Aún reforzamos la necesidad de tener en los temarios de los diversos niveles de la enseñanza formal, contenidos volcados al proceso de envejecimiento, al respeto y la valoración del mayor, de modo que se elimine el prejuicio y se llegue a producir conocimiento sobre la temática. Incluir la Gerontología y la Geriatría en los currículos de los cursos universitarios, como cuestión que interesa a toda la sociedad, es importante para un país que envejecerá en apenas 21 años (2011-2032). Como grandes consumidores de los medios de 
comunicación, principalmente de la televisión, convendría abrir espacios dirigidos a los mayores, con finalidad informativa, educativa, artística y cultural, y al público en general acerca de la problemática del envejecimiento. Por último, sugerimos la reapertura de la Universidad Abierta para la Tercera Edad en la Universidad del Estado del Río Grande del Norte (UERN) y/o la creación de nuevas UNATI's considerando el porcentaje de mayores en la localidad y la existencia de cuatro universidades nuevas en la ciudad.

\section{4) Accesibilidad}

La accesibilidad es un derecho inalienable de todo ser humano, conquistado y firmado como principio en la Declaración Universal de los Derechos Humanos (1948). Por esa razón, para que las personas de edad gocen de igualdad de derechos es necesario que el uso de las edificaciones, mobiliarios y equipamientos urbanos, espacios públicos, transportes y medios de comunicación se realice con seguridad y autonomía.

Primero, en relación al factor "Sistema de Transporte Colectivo Urbano", vimos en nuestra investigación que el $27,80 \%$ de los mayores entrevistados depende de este tipo de transporte y el $47 \%$ utilizó alguna vez este servicio. En este área hay un grave problema en Mossoró. La falta de respeto para con los mayores en la ciudad se concreta cuando los conductores no paran en los puntos establecidos o no esperan a que los mayores suban o bajen con seguridad. En Brasil, el artículo 39 del Estatuto del Mayor (Ley $\mathrm{n}^{\circ}$ $10.741 / 2003)$, que recoge la garantía constitucional del artículo $230, \$ 2^{\circ}$, de la Carta Magna, concede a los mayores con edad igual o superior a 65 años en Mossoró a partir de 60 años - el beneficio de la gratuidad en los transportes colectivos urbanos. Por esta razón cabe al Poder Público, gestor del Sistema de Transportes, asegurar tal política. Es muy probable que los conductores maleducados con los mayores no estén recibiendo la debida formación, capacitación y evaluación exigidas por ley. Educarlos para tratar con una sociedad en la que tiende a aumentar el número de personas que sobrepasan los 60 años y por ende, a no cometer tal infracción es responsabilidad de las concesionarias del servicio de transportes, del Poder Público y, por supuesto 
de los guardias de tráfico y de toda la sociedad. Añadimos que la garantía del referido derecho, debe estar condicionada únicamente a la presentación de cualquier documento que pruebe la edad de la persona mayor, independientemente de inscripción previa. Es imprescindible que los propios destinatarios del derecho a este servicio sepan exigirlo, a través del Consejo del Mayor.

En cuanto a la promoción de accesibilidad en los equipamientos y mobiliario urbanos y en las edificaciones públicas, que no es sólo un derecho de las personas con discapacidad, sino de las personas con movilidad reducida, entre los cuales están los obesos, las personas en sillas de ruedas y los mayores, destacamos que en nuestro estudio sobre los problemas de la infraestructura urbana de Mossoró, el que más dificulta los desplazamientos de los mayores en la ciudad es el de los semáforos muy breves $(65,20 \%)$, seguido de los coches aparcados indebidamente (78,40\%), las calles mal asfaltadas $(80,40 \%)$, los cruces de calles sin semáforos $(84,80 \%)$, los desniveles de las aceras $(86,20 \%)$ y el caos circulatorio $(85,40 \%)$. Además de esto, cabe resaltar la existencia de barreras en algunas vías públicas, obstáculos arquitectónicos en espacios de uso colectivo, falta de rampas en muchos edificios de uso público y privado y rampas de paseo y pasos de cebra en vías de mucho flujo de vehículos.

Para que Mossoró sea una ciudad para todas las edades y que los mayores alcancen otros derechos fundamentales como la educación, el ocio, la salud, entre otros, es imprescindible que se apliquen algunos cambios: la colocación de semáforos sonoros y con el contador del tiempo, más señalización en las vías públicas, la recuperación y mantenimiento del asfalto en las calles. El control efectivo del tráfico, fundamental para la organización y seguridad de todos, la obediencia a las normas técnicas de la Asociación Brasileña de Normas Técnicas (ABNT) para la adaptación de las edificaciones y espacios comunitarios ya construidos $y$, de forma preventiva, la vigilancia de los proyectos de edificaciones aún no construidas. Para una vida urbana saludable, con menos problemas y consecuentemente, con más calidad de vida para todos es importante el control municipal del tráfico. 
A fin de garantizar un acceso adecuado a todos los ciudadanos mossoroenses, es necesario que sean ejecutadas en su forma de ley el Estatuto de la Ciudad (Ley $\mathrm{n}^{\circ}$ 10.257/2001), que reglamenta los artículos 182 y 183 de la Constitución Federal de 1988, el Poder Público y en la legislación municipal como el Plan Director (Ley complementar n 012/2006), el Código de Obras, Postura y Edificaciones. La obediencia a los dictámenes legales da oportunidad a todos de disfrutar de una vida digna y sin exclusiones sociales. Velar para que los nuevos espacios urbanos no contengan obstáculos a la movilidad de acceso es un deber de todos.

\section{5) Valoración y participación}

Por último, planteamos la paradoja de lo que significa envejecer. Lo que es un logro, sigue siendo un problema en gran dimensión, tanto en las sociedades desarrolladas como en las no desarrolladas. El Nordeste no escapa a la “regla”. Los factores de la pobreza, la discriminación y la exclusión social en la que viven gran parte de las personas de edad son incongruentes con los derechos consagrados en la Declaración Universal de los Derechos Humanos.

De acuerdo con el Plan de Acción Internacional de Madrid (2002), la lucha contra la discriminación en razón de la edad y la promoción de la dignidad de las personas de edad son fundamentales para garantizarles el respeto que merecen y debe ser imprescindible en la construcción de una sociedad para todas las edades. Este concepto incluye el objetivo de que las personas de edad tengan la oportunidad de seguir contribuyendo a la sociedad a la que pertenecen. Para trabajar a favor de este propósito, es necesario eliminar todos los factores excluyentes o discriminatorios contra los ancianos en nuestras regiones.

A menudo se advierte que la probabilidad de convertirse en pobre, a medida que las personas envejecen, se fundamenta en la disminución de las posibilidades económicas y el deterioro de la salud. Pero, en general volverse pobre en la vejez varía con el nivel educativo, el género y la forma de vida.

En este ámbito de discusión sobre la pobreza, vimos en La Vejez en Mossoró (Cap. 1 - II Parte) que el mayor grupo de personas de 60 años en adelante vive 
en barrios Tipo C, lo que significa pertenecer a la clase media, según la tipología socio-económica establecida por el Instituto Brasileño de Geografía y Estadística. En esos barrios el mayor porcentaje de cabezas de familia sobrevive con un ingreso mensual de entre uno y dos salarios mínimos (R\$ $415,00 \pm 166 €)$. En nuestra Encuesta confirmamos este dato, ya que el 52,20\% reveló disponer de igual sueldo para sobrevivir. Además, cohabitan en una estructura familiar con más de una generación $(60 \%)$, son proveedores de familia con niveles bajos de estudios y debido a la ausencia o insuficiencia de las pensiones de vejez, una parte de esta personas de edad sigue trabajando $(19,20 \%)$ o desearía trabajar para aumentar la renta una vez alcanzada la edad legal de jubilación $(21,40 \%)$. Nuestros datos amplían la constatación del nivel de pobreza en que vive gran parte del colectivo de mayores en Mossoró.

En ese sentido, adoptar medidas encaminadas a incrementar la tasa de participación de los trabajadores mayores en Mossoró y permitir que las personas de edad puedan prorrogar la vida laboral y aumentar su contribución y participación en la economía, es una recomendación para un mundo que envejece. Ya que el progresivo envejecimiento de la población conlleva el creciente número de enfermedades crónicas, también conviene plantear la discusión sobre la creación de puestos de trabajo para las personas por encima de los 45 años, en los servicios de atención diaria para los potenciales ancianos dependientes. Por último, adoptar medidas para aumentar la participación en la tasa de población activa, contribuirá a la reducción de la pobreza y asegurará una mejor calidad de vida a los futuros senescentes.

En este estudio, también revelamos cierta discriminación que sufren las personas de edad en Mossoró. Según la Encuesta, los mayores tienen buenas relaciones con sus familiares (muy bien un $36,07 \%$ y bien un $41,88 \%$ ), lo que indica una convivencia sólida y saludable. Sin embargo, no ocurre lo mismo con el tipo de trato que reciben por parte de la sociedad civil. Un $43,40 \%$ del colectivo afirmó ser tratado con indiferencia y el 34,40\% declaró recibir un $\mathrm{mal}$ trato social. Esa postura refleja la imagen aristotélica que construimos sobre el envejecimiento y las personas de edad, en el curso de la historia, basada en los estereotipos negativos, asociándoles a una enfermedad natural, 
a la fragilidad y a la dependencia. En conjunto, esa postura lleva aparejada prejuicios y discriminación de todo tipo; el abandono, la negligencia, el maltrato y la violencia contra las personas de edad, es lo que refuerza las prácticas excluyentes.

Para ilustrar una de esas situaciones en Mossoró recordamos las actitudes de algunos conductores de autobuses para con las personas de edad, anteriormente subrayada en la sección Accesibilidad. El caso de violación de los derechos de esa franja de población confirma la necesidad de promover mecanismos necesarios y eficientes para la exigibilidad del respeto a los derechos humanos. Es ineludible para construir una sociedad para todos los grupos sociales, educar al público en general, valiéndose de los medios de difusión y campañas de concienciación, sobre la cuestión de los abusos y malos tratos contra las personas de edad y sus diversas características y causas. Es igualmente importante resaltar las calidades humanas, los puntos fuertes, las experiencias y las capacidades que han adquirido las personas de edad a lo largo de su vida, para contrarrestar mitos e ideas preconcebidas y, por consiguiente, tratarlas con respecto y gratitud, dignidad y consideración.

Para concluir, son diversas las situaciones en que se ignoran la existencia y la participación que puede aportar para el desarrollo de las sociedades el grupo de las personas de edad. En nuestra investigación, en las secciones estructura familiar, ingresos mensuales, vivienda y ejercicio del voto en las elecciones, constituye sólo una pequeña muestra de la importante contribución social y económica de los senescentes en Mossoró. Sin embargo, las cuestiones de potenciación y participación política y social de las personas de edad en las decisiones que afectan su bienestar y aseguran sus derechos fundamentales y de aquellos que envejecen, en los planes y programas de desarrollo gubernamentales, es casi inexistente en Mossoró. Aunque se reconozca el esfuerzo de desarrollo del programa municipal Mayor Ciudadano bajo la coordinación de la Gerencia Ejecutiva de Desarrollo Social, de la reciente implantación del Consejo del Mayor en Mossoró (octubre de 2007) y de las políticas del estado del Río Grande del Norte, las acciones, en su mayoría, son puntuales, desarticuladas y fallidas y la participación de los mayores reducida 
y descontinuada. En general, la atención prestada a las personas de edad sigue teniendo una base de asistencia social y de servicio en vez de introducir una perspectiva de desarrollo participativo o basado en los derechos.

Como desafíos, tenemos la necesidad de construir en el Nordeste brasileño un ambiente propicio, donde las personas de edad sean instruidas y estimuladas a actuar como los principales protagonistas del proceso de envejecimiento y por consiguiente, los más interesados en el reconocimiento y afirmación de sus derechos. Asimismo, suscitar la plena participación de las personas de edad en Mossoró, contribuiría a promover imágenes positivas de la vejez y potenciar el valor de las personas mayores.

La aplicación de las sugestiones exigirá la colaboración y la participación de muchas partes interesadas: organizaciones gubernamentales y no gubernamentales, profesionales, empresas, trabajadores y organizaciones de trabajadores, cooperativas, instituciones de investigación, universitarias y otras instituciones educativas y religiosas y los medios de comunicación. 


\section{REFERENCIAS BIBLIOGRÁFICAS}

ALBA, V. (1992): Historia Social de la vejez, (1 ${ }^{\mathrm{a}}$ ed. $)$. Barcelona: Laertes.

ACOSTA-ORJUELA, G.M. (2001): Como e por que idosos brasileiros usam a televisão: um estudo dos usos e gratificações associados ao meio. Tese de Doutorado. Faculdade de Educação, UNICAMP.

ALBUQUERQUE, S. M. R. L. (2003): Qualidade de vida do idoso: a assistência domiciliar faz a diferença. São Paulo: Cedecis.

ALGUACIL, J. y DENCHE, C. (1991): La vivienda: cambios en la simbología, uso de lenguaje. Documentación Social $n^{\circ} 85$ pp. 33-45.

ANDREWS, G. A. (1999): Los desafíos del proceso de envejecimiento en las sociedades de hoy y del futuro, en Encuentro Latinoamericano y Caribe sobre las personas de edad. Santiago: Anais, CELADE.

ANDREWS, S. (2001): Stress a seu favor: como gerenciar sua vida em tempos de crise. Porangaba: Instituto Visão Futuro.

ARBELO, A. y HERNÁNDEZ G. (1981): Demografía sanitaria de la ancianidad. Madrid: Karpos.

ARBER, S. y GINN, J. (1996): Relación entre género y envejecimiento. Un enfoque sociológico. Madrid: Narcea.

ARANÍBAR, P. (2001): Acercamiento conceptual a la situación del adulto mayor en América Latina, población y desarrollo, $n^{\circ} 21$, Santiago de Chile, Chile: CEPAL.

ATCHELEY, R. C. (1976): The sociology of Retirement, Schemnkman. Cambridge: Mass.

ALMANAQUE ABRIL (2000): A enciclopédia da atualidade Brasil. São Paulo: Editor Abril. (2001): A enciclopédia da atualidade Brasil. São Paulo: Editor Abril. (2002): A enciclopédia da atualidade Brasil. São Paulo: Editor Abril. (2003): A enciclopédia da atualidade Brasil, Ano 30. São Paulo: Editor Abril. (2004): A enciclopédia da atualidade Brasil. São Paulo: Editor Abril. (2005): A enciclopédia da atualidade Brasil. São Paulo: Editor Abril. 
(2006): A enciclopédia da atualidade Brasil. São Paulo: Editor Abril.

(2007): A enciclopédia da atualidade Brasil. São Paulo: Editor Abril.

BAZO, M. T. (1990): La sociedad anciana. Madrid: CIS/Siglo XXI.

(1992): La ancianidad del futuro. Barcelona: SG.

(1992): La nueva sociología de la vejez: de la teoría a los métodos, Revista Española de Investigaciones Sociológicas, (60): 75-90.

(1993): La vejez como problema social, en SÁNCHEZ VERA, P.: Sociedad y población anciana. Murcia: Servicio de publicaciones de Universidad de Murcia, pp.181-192.

(1994): La jubilación desde la perspectiva macro y micro, Revista Española de Investigaciones Sociológicas, (73): 269-294.

BAZO, M. T. y DOMíNGUEZ-ALCÓN, Carmen (1996): Los cuidados familiares de salud en las personas ancianas y las políticas sociales. Revista Española de investigaciones Sociológicas, (73): 43-56.

BALTES, M. M.; MAYR, U.; BORCHELT, M.; y WILMS, H. U. (1993): Everyday competence in old and very old age: An interdisciplinary y perspective, Aging Society, vol. 13, pp. 657-680.

BANDERA, J. (1993): Interacción y elaboración de la identidad en la tercera edad, en SÁNCHEZ VERA, P.: Sociedad y población anciana. Murcia: Servicio de publicaciones de Universidad de Murcia, pp. 77-109.

BARROS, R. P. de; MENDONÇA, R. y SANTOS, D. (1999): Incidência e natureza de pobreza entre idosos no Brasil, en CAMARANO, A. A.: Muito Além dos 60: os novos idosos brasileiros. Rio de Janeiro: IPEA.

BARENYS, M. P. (1993): El significado sociológico de la vejez y de las residencias de los ancianos en SÁNCHEZ VERA, P. (ed.): Sociedad y población anciana. Murcia: Publicaciones de Universidad de Murcia, pp. 55-76.

(1991): Residencia de ancianos: Análisis sociológico. Barcelona: Fundación Caixa de Pensiones.

BEAUVOIR, Simone de (1983): A velhice. Rio de Janeiro: Nova Fronteira. 
BERQUÓ, E. y BAENINGER, R. (2000): Os idosos no Brasil: considerações demográficas. UNICAMP, São Paulo: Núcleo de Estudos de População, Textos NEPO, (37).

BERQUÓ, E. (1999): Considerações sobre o envelhecimento da população no Brasil em NERI, A. L. e DEBERT, G. G. (eds.): Velhice e Sociedade. Campinas: Papirus, coleção vivaidade.

BERQUÓ, E. y CAVENAGHI, S. (2004): Fecundidade em declínio: breve nota sobre a redução de filhos por mulher no Brasil. PNAD.

BORGES, M. C. M. (2003): O Idoso e as Políticas Públicas e Sociais no Brasil, em SIMSON, V. NERI, A. L. y CACHIONI, M. (eds.): As múltiplas faces da velhice no Brasil. Capinas - São Paulo, Editora Elínea.

BÜHLER, Ch.; BRIND, A. y HORNER, A. (1968): Old age as a phase of human life, Human development.

BUSSE, E.W; BLAZER, D.G. (1996): Textbook of Geriatric Psychiatry, American Psychiatric Press, Washington.

BRASIL (2003): Constituição da República Federativa. São Paulo: Saraiva. (2001): Síntese de Indicadores Sociais: 1992/1999. Rio de Janeiro: IBGE. (1990): Lei n 8.080, de 19 de setembro de 1990, Brasília - Regulamenta o Sistema Único de Saúde.

(1994): Lei n. ${ }^{\circ} 8.844$, de 04 de janeiro de 1994, Brasília - Política Nacional do Idoso.

(2003): Lei n. ${ }^{\circ} 10.741$, de $1^{\circ}$ de Outubro de 2003, Brasília - Estatuto do Idoso.

BRIGEIRO, M. (2005): Envejecimiento exitoso y tercera edad: Problemas y retos para la promoción de la salud. Invest. educ. enferm, mar./sep, vol.23, $\mathrm{n}^{\circ} 1$, pp.102-109. ISSN 0120-5307.

CABRÉ, A. (1993): Algunas consideraciones sobre el envejecimiento demográfico en España y su evolución futura, SÁNCHEZ VERA, P. (ed.): Sociedad y población anciana. Murcia: Servicio de publicaciones de Universidad de Murcia.

CALVO, M. (1989): Algunas características de la sexualidad y de la sensualidad en la vejez en CASUCCIL, A. M. A. y otros (eds.): Afectividad y sexualidad en la ancianidad. Barcelona: Fundación Caixa de Pensión. 
CAMARANO, A. A. (1999): Como vive o idoso brasileiro em CAMARANO, A. A.: Muito Além dos 60 anos: os novos idosos brasileiros. Rio de Janeiro: IPEA.

(2002): Envelhecimento da população brasileira: uma contribuição demográfica, en Freitas, Py, Neri, Cançado, Gorzoni y Rocha (eds.).: Tratado de Geriatría e Gerontología. Río de Janeiro: Guanabara Koogan.

(2002): Brazilian population ageing: differences in well-being by rural and urban areas, UNRISD Meeting on Ageing Development and Social Protection, Madrid-Spain.

CAMARANO, A. A. e Beltrão K. I. (1990): Dinâmica Demográfica: passado e futuro. Relatórios Técnicos 07/90, Rio de Janeiro, ENCE/IBGE.

CAMARANO, A. A., BeltRÃO, K. I., ARAÚJO, H. E. y PINTO, M. S. (1997): Transformações no padrão etário da mortalidade brasileira em 1979-1994 e no impacto na força de trabalho. IPEA. (Texto para Discussão, 512).

CAMARANO, A. A. e Pasinato, M. T (2002): 0 envelhecimento populacional na agenda das políticas públicas, Rio de Janeiro, IPEA.

CARVALHO, J. A. M. de (1993): Crescimento populacional e estrutura demográfica no Brasil, Belo Horizonte, CEDEPLAR/UFMG. Apresentado no Seminário "Crescimento Populacional e Estrutura Demográfica", Rio de Janeiro.

CARVALHO, J. A. M. de e Garcia, R. A. O. (2003): Envelhecimento da população brasileira: um enfoque demográfico. Centro de Desenvolvimento e Planejamento Regional, Faculdade de Ciências Econômicas, Universidade Federal de Minas Gerais Belo Horizonte.

CARRAJO R. M. (1999): Sociología de los mayores. Salamanca: Servicios de publicaciones de Universidad Pontificia de Salamanca.

CARRIÓ, M. N. (1999): Políticas sociales para los mayores en la comunidad autónoma de Murcia en TORNERO, M. E. M. y LUNA, M. J. R. (eds.): Políticas sociales para las personas mayores en el próximo siglo. Murcia: Actas del congreso.

CASALS, I. (1982): Sociología de la ancianidad en España. Madrid: Editorial Mezquita.

CARBONI, R. M. y REPPETTO, M. A. (2007): Uma reflexão sobre a assistência à saúde do idoso no Brasil. Revista Eletrônica de Enfermagem (serie online) jan-abr; 9(1): 251-260.

CARTER, J. (2002): As virtudes de envelhecer. Rio de Janeiro: Rocco. 
CHAIMOWICZ, F. (1997): A saúde dos idosos brasileiros às vésperas do século XX: problemas, projeções e alternativas. Revista Saúde Pública 31(2): 184-200.

CELADE (2002): Estimaciones y proyecciones de población 1950-2050. Disponible en http//www.eclac.cl/celade/proyecciones/intentoBD-2002.htm.

CíCERO, M. T. (2000): De Senectute: a velhice saudável - O sonho de Cipião. Coleção Grandes Obras do Pensamento Universal, $n^{\circ} 63$ Texto Integral, Tradução: Luíz Feracine. São Paulo: Editora Escala.

CIS-IMSERSO (1998): La soledad de las personas mayores. Estudio 2.279.

COSTA SANTOS, S. S. (2003): O ensino da Enfermagem gerontogeriátrica no Brasil de 1991 a 2000, à luz da complexidade de Edgar Morin. Tese de Doutorado em Enfermagem. Santa Catarina: UFC

CEPAL (2005): Panorama Social de América Latina. Santiago de Chile: Serie LCG225.P.

COWGILL, D. O. y HOLMES, L. D. (1972): Aging and Modernization. Nueva York: Appleton Century Crofts.

CUMMING, E. y HENRY, W. E. (1961): Growing old. The process of disengagement. New York: Basic Book.

CHACKIEL, J. (2000): El envejecimiento de la población latinoamericana: ¿hacia una relación de dependencia favorable? Santiago de Chile: Centro Latinoamericano y Caribeño de Demografía (CELADE) - División de Población, Serie 4, población y desarrollo.

CNBB (2002): Fraternidade e pessoas idosas: texto-base CF-2003/. São Paulo: Editora Salesiana.

DEBERT, G. G. (1999): A Reinvenção da Velhice: socialização e processos de reprivatização do envelhecimento. São Paulo: FAPESP.

DE MIGUEL, A. (1992): La sociedad española 1992-93. Madrid: Alianza. (1997): La sociedad española, 1996-1997. Madrid: Alianza.

DICCIONARIO (2001): Lengua española - Real Academia Española, vigésima segunda edición. Madrid: Rodesa.

DOMÍNGUEZ, R. S. (1989): La vejez: historia y actualidad. Estudios pedagógicos $\mathrm{n}^{\circ} 29$, Salamanca: Universidad de Salamanca, Acta salmanticense. 
DURÁN, A. y E. CHÁVEZ (1998): Una sociedad que envejece: retos y perspectivas. Revista Temas n 14 Abril - Junio, Habana.

DUARTE, Y. y DIOGO, M. J. D. (2000): Atendimento domiciliário: um enfoque gerontológico (1ª ed.). São Paulo: Atheneu.

DUMMAZEDIER, J. (1971): Ocio y sociedad de clases. Barcelona: Fontanella.

EVANS J. G. (1984): Prevention of age-associated loss of autonomy: epidemiological approaches. J. Chron Dis, 37(5).

ESEB (2002): Estudo Eleitoral Brasileiro. Banco de Dados. Rio de Janeiro: Fundação Getúlio Vargas, Opinião Pública, vol. $10 \mathrm{n}^{\circ} 2$.

FERNÁNDEZ, G. F. M., PÉREZ, F. R. Y RIVERA, E. P. (2002): El entorno residencial de los mayores en Madrid, en Estudios geográficos, LXIII, C.S.I.C. Instituto de economía y geografía.

FERICGLA, J. M. (1992): Envejecer, una antropología de la ancianidad. Barcelona: Antropos.

FERREIRA, A. B. de H. (2004): Miniaurélio da língua portuguesa, revisão atualizada ( $6^{\mathrm{a}}$ ed.). Curitiba: Positivo.

FERRARI, M. y KALOUSTIAN, S. M. (2004): Família brasileira a base de tudo (6 $6^{a}$ ed.). São Paulo: Cortez.

FERNÁNDEZ-BALLESTEROS, R. (2004): Gerontologia social. Madrid: Pirámide.

(1998): La vejez con éxito o la vejez competente: un reto para todos, en Ponencias de las IV Jornadas de la AMG; Envejecimiento y Prevención, AMG, Barcelona.

FIRMINO, J. C. (2003): O voto de saias - a gênese do voto feminino do Rio Grande do Norte a través do jornal A República. Mossoró: Fundação Vingt-Un Rosado - Coleção Mossoroense, Serie C - Vol. 1375.

FONTE, I. B. da (2002): Diretrizes internacionais para o envelhecimento e suas conseqüências no conceito de velhice. Trabalho apresentado en el XII Encuentro de Asociación Brasileña de Estudios Poblacionales, realizado en Ouro Preto - Minas Gerais.

FOUCAULT, M. (1987): Historia de la sexualidad. La voluntad de saber, vol. 1. Madrid: Siglo XXI. 
FRANCO, P. A. (2004): Estatuto do idoso anotado (1 ${ }^{\text {a }}$ ed.). São Paulo: Editora de Direito.

FREIXAS F. A. (1993): Mujer y envejecimiento: aspectos psicosociales. Barcelona: Fundación "La Caixa”.

FRIAS, L. A. M. e CARVALHO, J. A. M. (1994): Fecundidade nas regiões brasileiras a partir de 1903: Uma tentativa de reconstrução do passado através das gerações. Em Encontro Nacional de Estudos Populacionais, Anais, v. 2, pp. 23-46. Belo Horizonte: Associação Brasileira de Estudos Populacionais.

GARZONI, M. L. y COSTA, E. F. de A. (2002): Manifestações atípicas das infecções, en Freitas, Py, Neri, Cançado, Gorzoni y Rocha (eds.).: Tratado de Geriatría e Gerontología. Río de Janeiro: Guanabara Koogan, pp. 574-577.

GAIL, W. (1996): Yo soy los ojos y ella los brazos: cambios en los roles de género en la vejez avanzada en ARBER, S. y GINN, J. (eds.): Relación entre género y envejecimiento. Enfoque sociológico. Madrid: Narcea.

GARCÍA, M. J. N. (1999): El tabú de la vejez, en YUBERO, LATORRE, LARRAñAGA y MONTAñ́́S (eds.): Envejecimiento, sociedad y salud. Cuenca: Humanidades.

GARCÍA, R. C. (2004): Bases biológicas del envejecimiento cerebral, en FERNÁNDEZBALLESTEROS, R. (eds.): Gerontología Social. Madrid: Pirámide.

GÉNOVA i MALERAS, R. (1994): Tendencias recientes de la mortalidad en la Comunidad de Madrid. Economía y Sociedad, nº 10.

GIDDENS, A. (2002): Sociología, (4ª ed.), versión castellana de Jesús Cuellar Menezo. Madrid: Alianza Editorial.

GIL CALVO, E. (2003): El Poder Gris: Una nueva forma de entender la vejez. Barcelona: Mondadori.

GIL VILLA, Fernando (2004): La delincuencia y su circunstancia: sociología del crimen y la desviación. Valencia: Tirant lo Blanch.

(2007): La juventud a la deriva. Barcelona: Ariel.

GRANJEL, L. S. (1991): Historia de la vejez - Gerontología Gerocultura Geriatría, Salamanca: Universidad de Salamanca. 
GOLDANI, A. M. (1999): Mulheres e envelhecimento: desafios para novos contratos intergeracionais e de gênero em CAMARANO, A. A. (ed.): Muito além dos 60: Os novos idosos brasileiros. Rio de Janeiro: IPEA.

GOLDMAN, S. N. (2003): Universidade para terceira idade: uma lição de cidadania. Olinda: Livro Rápido.

GODOY, T. (1999): Só é velho quem quer. Os segredos da longa juventude, ( $2^{\mathrm{a}}$ ed.). São Paulo: Loyola.

GOMA, F. (1989): Afectividad y sexualidad, moral y vejez, en CASUCCI, A.; M. A. y otros (eds.): Afectividad y sexualidad en la ancianidad. Barcelona: Fundación Caixa de Pensión.

GUILLERMAND, Anne-Marie (1972): La retraite: une mort sociale. Paris: Mouton.

(1993): Edad, empleo y jubilación: nuevos datos internacionales, publicado en Papers, Revista de Sociología (40): 35-56.

GUZMÁN, M. J. (2002): Envejecimiento y desarrollo en América Latina y el Caribe, CEPAL/ECLARC, Serie población y desarrollo (28), Santiago de Chile.

(2002): Redes de apoyo social, comunitario y familiar en personas adultas mayores, Programa de Envejecimiento y Desarrollo, División de población CEPAL, Naciones Unidas, Santiago, Chile.

GUSMÃO, N. M. M. de (2003): Infância e velhice. Pesquisas de idéias, Campinas: Alínea Editora.

HAVIGHURST, R. J.; NEUGARTEN, B. y TOBIN, S. S. (1968): Disengagement and patterns of aging, en NEUGARTEN, B (ed.): Middle age and aging. Chicago: The University of Chicago Press.

HERNÁNDEZ, Sánchez A. (1988): Aspectos socio-económicos de la vejez, en Varios, Hacia una vejez nueva, I Simposio de Gerontología en Castilla y León, Salamanca.

INEP/MEC (2000): Mapa del Analfabetismo en Brasil.

IBGE (2000): Perfil dos idosos responsáveis pelos domicílios no Brasil - 2000. http//www.ibge.gov.br/home/estatística.

INSERSO (2000): Las personas mayores en España. Informe 2000. Madrid: Ministerio de Trabajo y Asuntos sociales. 
YUBERO, S. y LARRANAGA, E. (1999): La imagen social del anciano, en Envejecimiento, sociedad y salud, Cuenca: Universidad de Castilla La Mancha.

KALACHE, A.; VERAS, R. P. y RAMOS, L. R. (1987): O envelhecimento da população mundial: um desafio novo. Revista Saúde Pública, (21):200-10.

KALISH, R. A. (1982): La vejez, perspectiva sobre el desarrollo humano, traducción de Juan Manuel Cosano. Madrid: Pirámide.

LAHUD, L. M. A. (200): A velhice, o tempo e a morte. Brasília: UnB

LEFRANÇOIS, R. (1997): Sociologie du Vieillissement, en Arcand M., Hébert R. Précis Pratique de Gériatrie. Québec: Edisem.

LEHR, U. (1980): Psicología de la Senectud, №60. Barcelona: Herder.

(1991): Aging in Europa: new directions in psychology. European Journal of Gerontology, 1.

LIPOVETSKY, Gilles (1993): La cultura de la moda media. En el imperio de lo efímero, Barcelona: Anagrama.

LORIAUX. M. (1995): El envejecimiento de la sociedad europea. El capital humano europeo en el umbral del siglo XXI. Colección seguridad social, Madrid: Ministerio de Trabajo y Seguridad Social.

LÓPEZ JIMÉNEZ, J.J. (1992): Causas del envejecimiento demográfico en el municipio de Madrid, Revista Española de Geriatría y Gerontología, Vol. 27, n¹.

LOPES, Andrea (2000): Os Desafios da Gerontologia no Brasil. Campinas: Alínea.

LOUREIRO, A. M. L. (1998): A velhice, o tempo e a morte. Brasília: UnB.

LENOIR, R. (1979): L'invention du Troisième Age: constitution du champ des agents de gestion de la vieillesse. Actes de la Reprocherche en Schinces Sociales, $n^{\circ}$ 26/27.

MARINO, M. C. de Abreu; MORAES, E. N. de y SANTOS, A. G. R. (2002): Avanços e perspectivas em geriatria em Freitas, Py, Neri, Cançado, Gorzoni e Rocha (Eds.): Tratado de Geriatria y Gerontologia. Rio de Janeiro: Editora Guanabara Koogan, PP. 388-602.

MANSUR, M. C. (2001): O financiamento federal da saúde no Brasil: tendências da década de 1990, Mestrado, Fundação Oswaldo Cruz, Escola Nacional de Saúde Pública. 
MADDOX, G. L. (1987): The encyclopedia of aging. New York: Spring.

MCTAVISH, D. G. (1971): Perceptions of old people: a review of research methodologies and findings. The Gerontologist.

McKEOWN, Thomas (1978): El crecimiento moderno de la población. Barcelona: Antoni Bosch.

MARTÍN, A. B. (1989): La evolución demográfica de Valladolid en el contexto de Castilla y León, en Hacia una vejez nueva - I Simposio de Gerontología de Castilla y León (cods.) Juan Manuel Almarza Meñica y Jesús Galdeano Aramendia, ed. San Esteban.

MARTÍN, García, A. V. (2000): Diez visiones sobre la vejez: del enfoque deficitario y de deterioro al enfoque positivo, Revista de Educación, $\mathrm{n}^{\circ} 323$.

MARTÍN, M. A. G. (2002): La actividad y el ocio como fuente de bienestar durante el envejecimiento, Revista Digital, Buenos Aires, Año 8, n 47.

METCHIKOFF, M. E. (2004): The nature of Man, Putman, Nueva York, 1903, pp. 297-298, en FERNÁNDEZ-BALLESTEROS, R.: Gerontología Social. Madrid: Pirámide.

MINOIS, G. (1987): Historia de la vejez de la Antigüedad al Renacimiento. Traducción: Celia María Sánchez. Madrid: Nerea.

MILL, J. S. (1909): On Liberty. Boston: Collier.

MISHARA, B. L. y RIEDEL, R. G. (1986): El proceso de envejecimiento. Madrid: Morata.

MPS (2004): Panorama da previdência social brasileira. Brasília: Assessoria de Comunicação Social - ACS.

MORLEY, S. (2000): La distribución del ingreso en América Latina y el Caribe, Santiago de Chile: CEPAL/FCE.

MORAGAS, M. R. (1981): Bienestar social del anciano, en Introducción a la gerontología social. Madrid: INSERSO, pp. 50-79. (1991): Gerontología Social. Envejecimiento y calidad de vida. Barcelona: Herder.

MONTEIRO, M. F. G. (2004): Saúde Reprodutiva em KALOUSTIAN, S. M. (ed.): Família Brasileira a base de tudo, (6 ${ }^{a}$ ed.). São Paulo: Cortez. 
(1991): Morbidade referida e acesso a serviços de saúde: padrões e diferencias. Rio de Janeiro: IBGE.

MONTES DE OCA, V. (2005): Redes comunitárias, gênero y envejecimiento. México: UNAM.

MOTTA, A. B. da (1999): As dimensões de gênero e classe social na análise do envelhecimento. Cadernos Pagu, vol. 13, pp. 191-221.

MOREIRA, M. M. (1998): O envelhecimento da população brasileira: intensidade, feminização e dependência. Revista Brasileira de Estudos Populacionais. Brasília, Vol.15, n 1, p. 79-93.

NERI, A. L.; WAGNER, E. C. de A. y M. (1985): Opiniões de pessoas de diferentes faixas etárias sobre velhice: um estudo exploratório. Estudos de Psicologia. Vol. 2, nº 2/3, p. 81-104.

NERI, A. L. (1991): Envelhecer num País de jovens. Significados de velho e velhice segundo brasileiros não idosos. Campinas: Editora da UNICAMP.

(1999): Envejecimiento competente en el trabajo, en Simposio Internacional Envejecimiento Competente, Retiro y Seguridad. Santafé de Bogotá: Caja Colombiana de Subsidio Familiar.

(2001): Palavras-chave em Gerontologia. Campinas: Alínea.

(2002): Cuidar de idoso no contexto da família: questões psicológicas e sociais. Campinas: Alínea.

NERI, A. L., CACHIONI, M. y RESENDE, M. C. (2002): Atitudes em relação à velhice, em em FREITAS, et. al. (eds.): Tratado de Geriatría e Gerontología. Río de Janeiro: Guanabara Koogan, pp. 972-980.

OCA, V. M. de (2003): El envejecimiento en el debate mundial: reflexión académica y política, Papeles de Población, enero-marzo, $n^{\circ} 35$. Toluca: Universidad Autónoma del Estado de México.

OLIVEIRA, L. A. P. e FELIX, C. (1995): A dinâmica demográfica recente: níveis, tendências e diferenciais. Indicadores sociais: uma análise da década de 1980. Rio de Janeiro: IBGE.

(1995): Novas tendências demográficas: breves notas a partir dos resultados do censo demográfico de 1991. Indicadores sociais: uma análise da década de 1980. Rio de Janeiro: IBGE. 
OLIVEIRA, J. de C.; ALBUQUERQUE, F. R. P. de C. y LINS, I. B. (2004): Projeção da população do Brasil por sexo e idade para o período 1980-2050 - Revisão 2004 Metodologia e Resultados Estimativos anuais e mensais da população do Brasil e das Unidades da Federação: 1980 - 2020. Rio de Janeiro: IBGE.

OLIVEIRA, R. C. S. (1999): Terceira. Idade: do repensar dos limites aos sonhos possíveis. São Paulo: Paulinas.

OLIEVENSTEIN, C. (2001): O nascimento da velhice. Tradução de Viviane Ribeiro. Bauru: EDUSC.

ONU (1982): Consideraciones demográficas, Asamblea Mundial del envejecimiento, Nueva York; OCDE (1988): Le vieillissement démographique, Paris.

(1982): Plan de Acción Internacional sobre el Envejecimiento. Viena, Austria, (Resolución $37 / 51)$.

(1998): Principios de las Naciones Unidas a favor de las personas de edad (DPI/1261/Rev. 1-98-18897 - Septiembre 1998/7).

(2002): Il Asamblea Mundial Sobre el Envejecimiento. Madrid: Publicación de las Naciones Unidas, número de venta: S.02.IV.4.

(2002): Plan de Acción Internacional sobre el Envejecimiento. Madrid, España, (Resolución 57/167).

NETO, J. T.; FRANÇA, J. D. L.; y HALKER, E. (2002): Vacinas, em Freitas, Py, Neri, Cançado, Gorzoni e Rocha (eds.): Tratado de Geriatría y Gerontología. Río de Janeiro: Editora Guanabara Koogan, pp. 550-567.

NETTO, M. P. (2002): O estudo da velhice no século XX: histórico, definição do campo e termos básicos, em FREITAS, et. al. (eds.): Tratado de Geriatría e Gerontología. Río de Janeiro: Guanabara Koogan, pp. 2-12.

PASCHOAL, S. M. (1996): Autonomia e independência, em M. PAPALÉO Neto (ed.): Gerontologia

PASCUAL, C. P. (1988): Hacia una nueva visión de la sexualidad geriátrica, en Hacia una vejez nueva - I simposio de gerontología de Castilla y León.

PAULO II, J. (1999): Carta aos anciãos. São Paulo: Paulinas. 
PÉREZ DÍAZ, J. (1998): La demografía y el envejecimiento de las poblaciones, a A.S. Staab y L.C. Hodges, Enfermería Gerontológica. México D.F., McGraw Hill, pp. 451-463.

(2002): Feminización de la vejez y Estado de Bienestar en España. REIS, 104: 91-121.

(2005): Consecuencias sociales del envejecimiento demográfico, publicado en Papeles de Economía Española, Transformación demográfica. Raíces y consecuencias, nº (104): 210226.

PINILLOS, J. L. y otros (1994): Una aproximación pluridisciplinar al entorno de la vejez. Madrid: Fundación Caja Madrid.

PERSEU ABRAMO, Fundação (2006): Pesquisa Nacional Sobre Idosos no Brasil - Vivências, desafios e expectativas na terceira idade. Rio de Janeiro.

PEIXOTO, C. E. (2004): Aposentadoria: retorno ao trabalho e solidariedade familiar em PEIXOTO, C. E. (ed.): Familia e envelhecimiento. Rio de Janeiro: FGV.

POZO, R. E. (1997): Cambios recientes en la mortalidad y morbilidad en Madrid. Anales de Geografía de la Universidad Complutense, $n^{\circ} 17$, pp. 223-238.

QUINTANA, C. J. M. (1993): Los ámbitos profesionales de la animación. Madrid: Narcea.

RAMOS, L. R.; ROSA, T. E. C.; OLIVEIRA, Z. M.; MEDINA, M. C. G. y SANTOS, F. R. G. (1993): Perfil do idoso em área metropolitana na região sudeste do Brasil: resultados de inquérito domiciliar. Revista Saúde Pública, (27):87-94.

KASTENBAUM (1980): Vejez, años de plenitud. México: Harper.

RAPPOPORT, L. (1986): La personalidad desde los 26 años hasta la ancianidad - El adulto y el viejo, $1^{\text {a }}$ reimpresión en España. Barcelona: Paidós, Psicología Evolutiva.

RIVERA, E. P.; PÉREZ, F. R. y FERNÁNDEZ, G. F. M. (2001): Características demográficas y forma de vida de los ancianos madrileños. Madrid: Anales de Geografía de la Universidad Complutense, pp. 285-308.

RIBEIRO, R. M.; SABÓIA, A. L.; BRANCO, H. C.; y BREGMAN, S. (2004): Família brasileira em dados em KALOUSTIAN, S. M. (ed.): Família Brasileira a base de tudo, (6 ${ }^{\mathrm{a}}$ ed.). São Paulo: Cortez.

(2004): Estrutura familiar, trabalho e renda em KALOUSTIAN, S. M. (ed.): Família Brasileira a base de tudo, (6 ${ }^{\mathrm{a}}$ ed.). São Paulo: Cortez. 
RILEY, M. (1976): Age strata in social systems, en R.H. Bistock y E. Shanas (eds.). Handbook of aging and the social sciences. New York: Van Nostrand.

ROWE, J.W. y KAHN, R.L. (1998): Successful Aging. New York: Pantheon Books.

ROCHA, A. P. B. (2005): Expansão Urbana de Mossoró - período de 1980 a 2004. Mestrado Universidade Federal do Rio Grande do Norte. Centro de Ciências Humanas, Letras e Artes. Departamento de Geografia. Programa de Pós Graduação e Pesquisa em Geografia. Natal.

RODRÍGUEZ, J. A. (1994): Envejecimiento y familia. Madrid: C.I.S. (137).

RODRIGUES, N. C. e RAUTH, J. (2002): Os desafios do envelhecimento no Brasil, em FREITAS, E. V. et. al. (eds.): Tratado de Geriatria e Gerontologia. Río de Janeiro: GuanabaraKoogan, p. 106-110.

RODRÍGUEZ, G. H. (1989): La figura del anciano en la familia contemporánea: relaciones intergeneracionales y status social del anciano, en Hacia una nueva Vejez. I Simposio de Gerontología de Castilla y León. Valladolid: Editorial San Esteban.

RODRÍGUEZ, D. S. (1989): La vejez: Historia y actualidad. Salamanca: Universidad de Salamanca.

ROSENMAYR, L. y KOECKEIS, E. (1963): Theory of aging and family. Internacional Social Science Journal.

SANCHO, M. T.; ORTIZ, L. P; ABERLLÁN, A. y RODRÍGUEZ, V. (2001): Las personas mayores en España. Algunos indicadores básicos. Madrid: Universidad Complutense de Madrid, Cuadernos de Trabajo Social, 14:221-253.

SÁNCHEZ C. S. (1982): La Vejez y sus Mitos. Barcelona: Salvat.

SÁNCHEZ VERA, P. (1993): Bases y fundamentos para una aproximación sociológica de la vejez. Papers, Revista de Sociología (40): 99-120.

(2003): La tercera edad ante el consumo. Murvia: Servicio de publicaciones de Universidad de Murcia.

SÁNCHEZ VERA, P. y DÍAZ, M. B. (2007): Los mayores y el amor. Una perspectiva sociológica. Valencia: Nau Libres. 
SALGADO, M. A. (1980): Velhice uma questão social. São Paulo: SESC.

SENGER, J. (2002): Doença pulmonar obstrutiva crônica, em FREITAS, et. al. (eds.): Tratado de Geriatría e Gerontología. Río de Janeiro: Guanabara Koogan, pp. 344-352.

SIQUEIRA, M. E. C. de (2002): Teorías sociológicas do envelhecimento, em FREITAS, et. al. (eds.): Tratado de Geriatría e Gerontología. Rio de Janeiro: Guanabara Koogan, pp. 4756.

SILVESTRE, J. A. (2002): O Impacto da vacinação antiinfluenza na população idosa, em FREITAS, et. al. (eds.): Tratado de Geriatría e Gerontología. Rio de Janeiro: Guanabara Koogan, pp. 569-573.

SIQUEIRA, R. L. de; BOTELHO, M. I. V. e COELHO, F. M. G. (2002): A velhice: algumas considerações teóricas e conceituais. Ciências saúde coletiva, vol.7, $n^{\circ} 4$, pp.899-906. ISSN 1413-8123.

SIMÕES, C. C. da Silva (2002): Perfis da saúde e de mortalidade no Brasil: uma análise de seus condicionantes em grupos populacionais específicos, ( $1^{\mathrm{a}}$ ed.). Brasília: Athalaia Bureau.

SCHROOTS, J. J. F. y BIRREN, J. E. (1990): Concepts of time and aging in science, in BIRREN, J. E.; WARNER, S. Handbook of psychology of aging. San Diego: Academic Press.

SHOCK, N. W. (1973): Teorías biológicas y fisiológicas del envejecimiento. Res. del Congreso Latinoamericano de Gerontología y Geriatría. Buenos Aires.

VÁZQUEZ, E. R. (1993): La Ancianidad, un producto social en SÁNCHEZ VERA, P. (ed.): Sociedad y Población Anciana. Murcia: Servicio de publicaciones de Universidad de Murcia.

VERAS, R. P. e CALDAS, C. P. (2004): Promovendo a saúde e a cidadania do idoso: o movimento das universidades da terceira idade. Temas Livres. Ciência e Saúde Coletiva, 9(2): 423432 p. 424.

ZIMERMAN, G. I. (2005): Velhice - Aspectos Biopsicossociales. Porto Alegre: Artmed.

VICENT, T. L. (1980): Antropologie de la muert. Paris: Payot.

WALLACE, P. (2000): El seísmo demográfico. Madrid: Siglo XXI.

WENGER, G. C. y SCOTT, A. (1996): Género y redes de apoyo social en la vejez, en ARBER, S. y GINN, J. (eds.): Relación entre género y envejecimiento. Enfoque sociológico. Madrid: Narcea, pp. 221-240. 
WILSON, G. (1996): "Yo soy los ojos y ella los brazos": cambios en los roles de género en la vejez avanzada, en ARBER, S. y GINN, J. (eds.): Relación entre género y envejecimiento. Enfoque sociológico. Madrid: Narcea, pp. 141-162.

WONG, L. R. y MOREIRA, M. M. (2000): Envelhecimento e desenvolvimento humano: as transformações demográficas anunciadas em América Latina (1950-2050). Belo Horizonte: Cedeplar/UFMG. 


\section{Índice de Gráficos}

GRÁFICO 1 Tasa de fecundidad en Brasil

GRÁFICO 2 Tasa de fecundidad de los países de América del Sur, 2000

GRÁFICO 3 Pirámide de la población brasileña

GRÁFICO 4 Esperanza de vida por sexo y continentes, 2001

GRÁFICO 5 Población mayor de 60 años según el sexo en Mossoró

GRÁFICO 6 Cantidad de hijos vivos

GRÁFICO 7 Relación con las personas con quienes vive el mayor

GRÁFICO 8 Forma de vida preferida por los mayores

GRÁFICO 9 Bajo qué circunstancias estarían los mayores dispuestos a

vivir en una Residencia para mayores

GRÁFICO 10 Mayores que opinan que hace falta una Residencia

en Mossoró

GRÁFICO 11 Sugerencia para la construcción de una Residencia

GRÁFICO 12 Lo que hace una persona ser mayor

GRÁFICO 13 Mejor término para referirse a una persona mayor

GRÁFICO 14 Percepción del trato

GRÁFICO 15 Opinión del mayor sobre cuándo debe producirse la jubilación

GRÁFICO 16 Responsabilidad del pago por la jubilación según el mayor

GRÁFICO 17 La valorización del sexo

GRÁFICO 18 La vivienda del mayor

GRÁFICO 19 Régimen de tenencia de la vivienda

GRÁFICO 20 Coste de la vivienda alquilada

GRÁFICO 21 Dispone o no de habitación propia

GRÁFICO 22 Grado de satisfacción con la vivienda

GRÁFICO 23 Problemas en el contexto de la vivienda

CUADRO I Equipamientos y servicios de los que disponen en su domicilio

GRÁFICO 24 Prestaciones y servicios existentes cerca de su vivienda

GRÁFICO 25 Situaciones que dificultan sus desplazamientos

GRÁFICO 26 Medio de transporte que suele utilizar 
GRÁFICO 27 Percepción del estado de salud durante el último año

GRÁFICO 28 Enfermedades declaradas actualmente

GRÁFICO 29 Capacidad auditiva

GRÁFICO 30 Uso de prótesis auditivas

GRÁFICO 31 Frecuencia con la que ha estado hospitalizado

GRÁFICO 32 Motivos del ingreso hospitalario

GRÁFICO 33 Realización de chequeos generales

GRÁFICO 34 Motivo por el que nunca se ha hecho un cheque general

GRÁFICO 35 Frecuencia de consultas al médico

GRÁFICO 36 Medios por los que adquiere medicamentos

GRÁFICO 37 Revisiones oftalmológicas que le hicieron en el último año

GRÁFICO 38 Mujeres que visitan al ginecólogo

GRÁFICO 39 Hombres que visitan al urólogo

GRÁFICO 40 Cobertura sanitaria que tiene actualmente

GRÁFICO 41 Como debe recibir asistencia médica el anciano

GRÁFICO 42 Consumo de tabaco

GRÁFICO 43 Consumo de bebidas alcohólicas

GRÁFICO 44 Hábitos y frecuencias de consumo de bebidas alcohólicas

GRÁFICO 45 Mayores que han utilizado o se han beneficiado de alguna de las prestaciones o servicios

GRÁFICO 46 Grado de conocimiento del mayor sobre las leyes que benefician a los mayores

GRÁFICO 47 Ejercicio del voto en las elecciones

GRÁFICO 48 Satisfacción con la vida

GRÁFICO 49 Frecuencia del pensamiento sobre la muerte 


\section{Índice de Tablas}

TABLA 1 Constitución de la población mossoroense según grupos de edad, 1991-2000

TABLA 2 Tasas de mortalidad infantil, ambos sexos 1980-2006, Mossoró/RN

TABLA 3 Tasas de fecundidad total, ambos sexos 1980-2006, Mossoró/RN

TABLA 4 Analfabetismo en Mossoró

TABLA 5 Esperanza de vida al nacer, ambos sexos 1980-2006, Mossoró/RN

TABLA 6 Población de 60 y más años según sexo y edad - 2000, Mossoró/RN

TABLA 7 Población de 60 y más años por Barrio, Mossoró - 2000

TABLA 8 Según el sexo y la edad

TABLA 9 Según el estado civil

TABLA 10 Según el nivel educativo

TABLA 11 Según la situación familiar actual

TABLA 12 Según el lugar de nacimiento

TABLA 13 Según la situación laboral actual

TABLA 14 Según la fuente de renta que cobra actualmente

TABLA 15 Según la renta mensual

TABLA 16 Según el grado de satisfacción con su situación económica

TABLA 17 Según el trabajo anterior a la Jubilación

TABLA 18 Según el área de trabajo actual

TABLA 19 Según las causas del desempleo

TABLA 20 Según las preferencias para trabajar

TABLA 21 Según la frecuencia que suele hablar con la familia, vecindario o amigos

TABLA 22 Según en que emplea su tiempo libre

TABLA 23 Según la preferencia en la programación radiofánica

TABLA 24 Según la preferencia en la programación televisiva

TABLA 25 Según la actividad física que practica

TABLA 26 Según la frecuencia con la que sale de vacaciones

TABLA 27 Según los motivos por los que nunca salen de vacaciones

TABLA 28 Según la capacidad de administrar los ingresos 
TABLA 29 Según donde suele comer habitualmente

TABLA 30 Según las comidas que suele hacer al día

TABLA 31 Según el grado de satisfacción sobre la comida

TABLA 32 Según las vacunas administradas al año

TABLA 33 Según las actividades que suelen realizar con ayuda domésticas

TABLA 34 Según el grado de dificultad para realizar las Avds y Aivds

TABLA 35 Según la preferencia de ayuda para realizar las Avds y Aivds

TABLA 36 Según los motivos por los que no recibe ayuda para realizar las AVDS y AIVDS

TABLA 37 Según la capacidad para utilizar los cajeros automáticos

TABLA 38 Según el grado de conocimiento de prestaciones y servicios

TABLA 39 Según las prestaciones y servicios que han utilizado el mayor

TABLA 40 Según la opinión sobre temas actuales

TABLA 41 Según los motivos aducidos por el mayor para no votar

TABLA 42 Según el sentido de la vida

TABLA 43 Según la auto definición religiosa

TABLA 44 Según con quien suele hablar de la muerte

\section{Índice de Figuras}

FIGURA 1 Río Grande del Norte entre las 27 Unidades Federativas de Brasil

FIGURA 2 Mossoró en el mapa del Río Grande del Norte

FIGURA 3 Playas cerca de Mossoró/RN

\section{Índice de Fotos}

$\begin{array}{ll}\text { FOTO } 1 & \text { Vista área de Mossoró/RN } \\ \text { FOTO } 2 & \text { Palácio de la Resistencia - Mossoró/RN } \\ \text { FOTO } 3 & \text { Plaza Rodolfo Fernandes - Mossoró/RN } \\ \text { FOTO } 4 & \text { Pirámides de sal marina - Mossoró/RN } \\ \text { FOTO } 5 & \text { Caballos mecânicos - Extracción de petróleo pólo Mossoró/RN } \\ \text { FOTO } 6 & \text { Frutas tropicales } \\ \text { FOTO } 7 & \text { Dunas de Genipabu em Natal/RN }\end{array}$

FOTO - Apertura de la Parte I y Parte II - Fred Veras (DRT 00079RF) 


\section{Universidad de Salamanca \\ Facultad de Ciencias Sociales \\ Departamento de Sociología y Comunicación \\ Salamanca / España \\ Universidade do Estado do Rio Grande do Norte - UERN \\ Mossoró/RN - Brasil \\ Pesquisa: Perfil Sociológico da Velhice em Mossoró/RN \\ QUESTIONÁRIO \\ BLOCO I - ASPECTOS GERAIS}
1. SEXO: (1) H ( )
(2) $M(\quad)$

2. IDADE: anos completos
(1) Entre 60-65
(2) Entre 66-70
(3) Entre 71-75
(4) Entre 76-80
(5) Entre 81-85
(6) Entre 86-90
(7) Mais de 90
(8) $N S / N R^{*}$

NS = Não sabe

NR = Não responde

NSA = Não se aplica

\section{Estado civil}
(1) solteiro/a
(2) Casado/a
(3) Amancebado/a
(4) Separado/a
(5) Divorciado/a
(6) Viúvo/a
(7) NS/NR

4. Lugar de nascimento
(1) Mossoró/RN
(2) Outra cidade ( )
(3) Estrangeiro/a ( ) 


\section{Qual a sua escolaridade?}
(1) Nenhuma
(2) Não sabe ler
(3) Sabe ler
(4) Primário
(5) Ginásio
(6) $2^{\circ} \mathrm{Grau}$
(7) Superior

(ATENÇÃO ENTREVISTADOR: esta questão é de MÚLTIPLA ESCOLHA: Pode responder mais de uma alternativa)

\section{Atualmente o/a senhor/a está?}
(1) Aposentado/a
(2) Dono/a de casa
(3) Ativo/a
(4) Pensionista
(5) Desempregado/a
(6) NS/NR

\section{Qual sua opinião sobre as seguintes questões?}

\begin{tabular}{llcccc} 
N & \multicolumn{1}{c}{ Temas } & Favor & Indiferente & Desfavorável & NS / NR \\
01 & Aborto & 1 & 2 & 3 & 4 \\
02 & Pena de morte & 1 & 2 & 3 & 4 \\
03 & Divórcio & 1 & 2 & 3 & 4 \\
04 & Pagar os impostos & 1 & 2 & 3 & 4 \\
05 & Relação sexual antes do & & & & \\
& casamento & 1 & 2 & 3 & 4 \\
06 & Relação sexual com o mesmo & & & & 4 \\
& sexo & 1 & 2 & 3 & 4
\end{tabular}

\section{BLOCO II - OPINIÃO SOBRE AVELHICE}

\section{0 que caracteriza uma pessoa ser idosa?}
(1) A idade
(2) A falta de saúde
(3) A aposentadoria
(4) As leis
(5) Um "estado de espírito" ( )
(6) NS/NR 
9. Como tratam à sociedade as pessoas idosas?
(1) Bem
(2) Mal
(3) Com indiferença ( )
(4) NS/NR

10. Qual a expressão que o senhor/a considera mais adequada para se referir a uma pessoa com 60 anos ou mais?
(1) Ancião
(2) Terceira idade ( )
(3) Velha
(4) Idoso
(5) Nenhuma
(6) NS/NR

\section{BLOCO III - SITUACCÃO FAMILIAR}

11. Com quem vive atualmente?

(1) Com meu/minha esposo/a

(2) Com o/as filho/as solteiro/as

(3) Com meu/minha esposo/a e filho/as

(4) Com meu/minha esp./a filho/as e neto/s

(5) Com outro familiar

(6) Com pessoas não é da família

(7) Sozinho/a

(8) NS/NR

(ATENÇÃO ENTREVISTADOR: esta questão é somente para o/a entrevistado/a que vive em companhia de alguém)

12. Em geral como o/a Senhor/a se relaciona com as pessoas com quem vive?
(1) Muito bem
(2) Bem
(3) Regular
(4) Mal
(5) Muito mal
(6) Com umas bem, com outras mal ( )
(7) Nenhuma
(8) NSA 
13. Com que frequiência o/a Senhor/a fala com as seguintes pessoas?

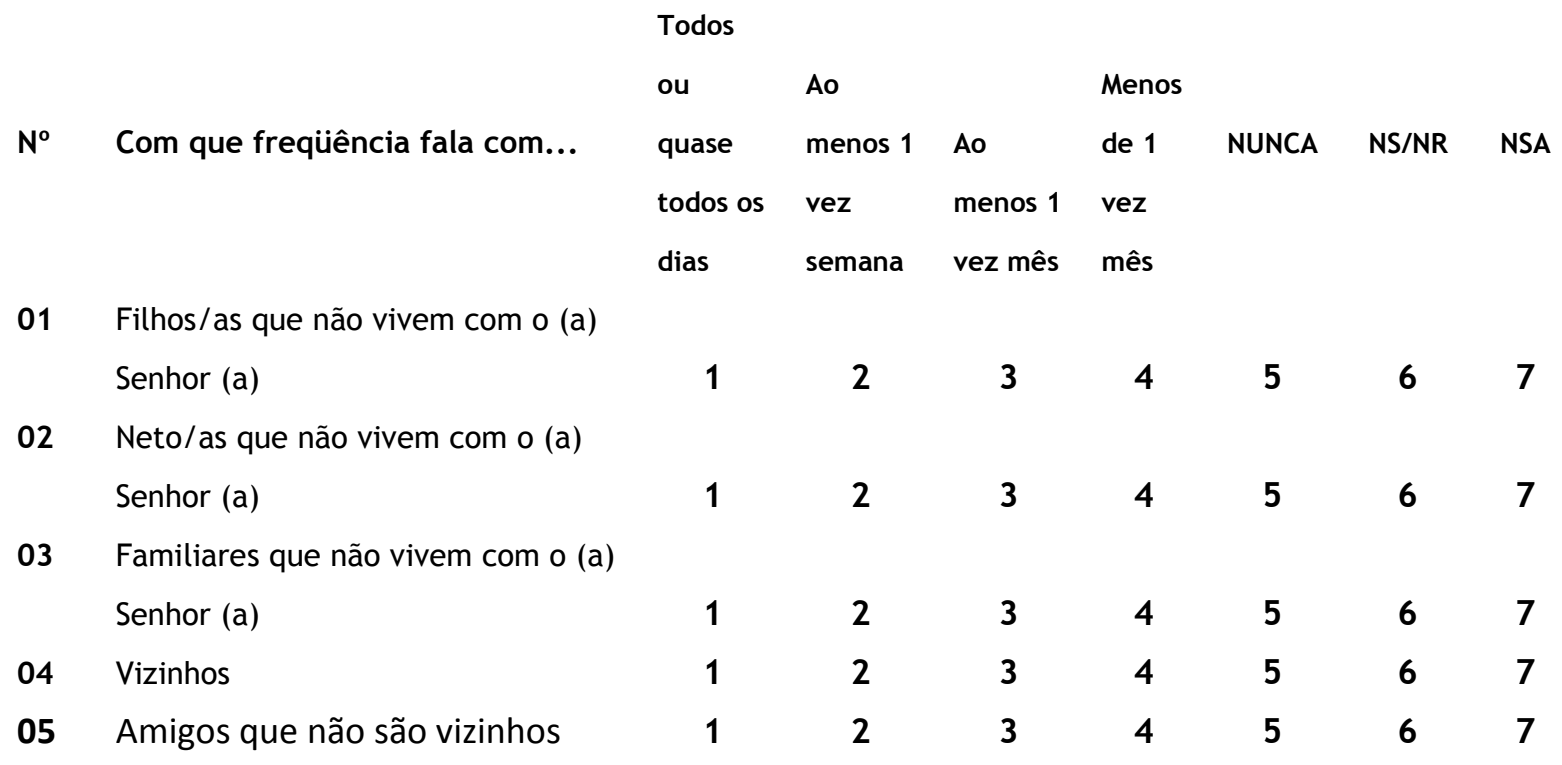

(ATENÇÃO ENTREVISTADOR: esta questão é somente para o/a entrevistado/a que tem filhos/as vivos)

14. Atualmente quantos filhos/as vivos têm?
(1) Um
(2) Dois
(3) Três
(4) Quatro
(5) Cinco
(6) Seis
(7) Sete
(8) Oito
(9) Mais de oito
(10) NSA

15. Em que circunstâncias o/a Senhor/a moraria numa Residência para Idosos se tivesse idade adequada para isso?
(1) Se dependesse de outras pessoas ( )
(2) Se sofresse alguma doença crônica ( )
(3) Se enviuvasse
(4) Para evitar fazer as tarefas domésticas ( )
(5) Para evitar a solidão
(6) Por razões econômicas
(7) Para não incomodar meus
filhos ou familiares 
(8) Por problemas de moradia

(9) Sob nenhuma circunstância iria a uma

Residência para idosos

(10) NS/NR

\section{BLOCO IV - MORADIA}

16. O lugar onde o/a Senhor/a vive atualmente é?
(1) Casa
(2) Apartamento
(3) Quitinete

17. A quem pertence à moradia em que o/a Senhor/a reside?

(1) Própria (quitada)

(2) Própria, restando algumas

prestações a pagar

(3) De um familiar

(4) Alugada

(5) NS/NR

(ATENÇÃO ENTREVISTADOR: esta questão é somente para o/a entrevistado/a que paga aluguel)

18. Quanto paga ao mês?
(1) Menos de 50,00 reais
(2) De 50,00 a 200,00 reais ( )
(3) De 201,00 a 400,00 reais ( )
(4) De 401,00 a 600,00 reais ( )
(5) Mais de 600,00 reais
(6) NS/NR
(7) NSA

19. O/a Senhor/a acredita que atualmente sua moradia (ou no edifício) tem problemas de:
(a) Umidade
(b) Encanação
(c) Rede elétrica ( )
(d) Escada (acesso) ( )
(e) Rede de esgoto ( )
(f) Estrutura geral ( ) 
(g) NR/NR

20. Qual sua opinião a respeito da moradia em que vive?

(1) Está muito satisfeito/a

(2) satisfeito/a

(3) Insatisfeito/a

(4) Muito insatisfeito/a

(5) NS/NR

(ATENÇÃO ENTREVISTADOR: esta questão é somente para o/a entrevistado/a que vive com outra pessoa)

21. Dispõe de um quarto de dormir só para o/a senhor/a?
(1) $\mathrm{Sim}$
(2) Não
(3) NSA

\section{Sua moradia dispõe de:}

$\begin{array}{llccc}\text { No }^{\circ} & \text { Produtos / serviços } & \text { SIM } & \text { NÃO } & \text { NS/NR } \\ 01 & \text { Água potável } & 1 & 2 & 3 \\ 02 & \text { Banheiro } & 1 & 2 & 3 \\ 03 & \text { Luz elétrica } & 1 & 2 & 3 \\ 04 & \text { Televisão } & 1 & 2 & 3 \\ 05 & \text { Vídeo } & 1 & 2 & 3 \\ 06 & \text { Rádio } & 1 & 2 & 3 \\ 07 & \text { Toca discos } & 1 & 2 & 3 \\ 08 & \text { Geladeira } & 1 & 2 & 3 \\ 09 & \text { Lavadora automática } & 1 & 2 & 3 \\ 10 & \text { Fogão a gás } & 1 & 2 & 3 \\ 11 & \text { Fogão a lenha } & 1 & 2 & 3 \\ 12 & \text { Telefone } & 1 & 2 & 3 \\ 13 & \text { Computador } & 1 & 2 & 3 \\ 14 & \text { Ventilador } & 1 & 2 & 3 \\ 15 & \text { Ar condicionado } & 1 & 2 & 3\end{array}$

23. Para sua comodidade qual dos seguintes serviços existe perto de sua moradia?

$\begin{array}{llccc}\text { No }^{\circ} & \text { Serviços } & \text { SIM } & \text { NÃO } & \text { NS/NR } \\ 01 & \text { Um pequeno comércio } & 1 & 2 & 3 \\ 02 & \text { Uma farmácia/drogaria } & 1 & 2 & 3 \\ 03 & \text { Um posto de saúde } & 1 & 2 & 3\end{array}$




$\begin{array}{lllll}04 & \text { Um centro para Terceira Idade } & 1 & 2 & 3 \\ 05 & \text { Uma Igreja/Templo } & 1 & 2 & 3 \\ 06 & \text { Um jardim/praça } & 1 & 2 & 3\end{array}$

24. Quem mais the ajuda em suas atividades diárias?

(1) Familiar próximo (esposo/a, filho/as, irmão/s)

(2) Outros familiares (primo/as, sobrinho/as, cunhado/as)

(3) Empregada doméstica

(4) Vizinhos

(5) Outros

(6) NS/NR

(7) NSA

25. Que considera melhor?

(1) Que as pessoas idosas vivam com sua família

(2) Que vivam em Abrigos com gente de sua idade e condição

(3) Que vivam em sua casa, mas recebendo atenção e serviços em domicílio

(4) NS/NR

26. Onde deveriam ser construídas as Residências para os idosos?

(1) Na cidade

(2) Ao redor da cidade

(3) Distante da cidade, (sítio, chácara)

27. O/a Senhor/a acha que Mossoró precisa de Residências para idosos?

(1) $\mathrm{Sim}$

(2) Não

(3) NS/NR

\section{BLOCO V - ESTRUTURA DA CIDADE E MEIO AMBIENTE}

28. Entre os problemas que se podem encontrar na infra-estrutura urbana de Mossoró quais das seguintes situações podem dificultar seu deslocamento?

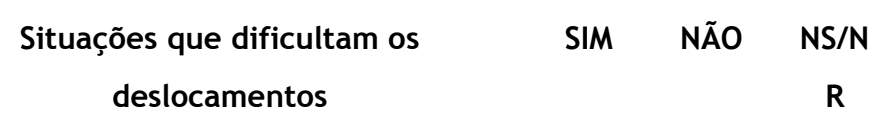
A Semáforos com pouco tempo de duração (muito breve)
B Carros estacionados indevidamente

$\begin{array}{lll}1 & 2 & 3 \\ 1 & 2 & 3\end{array}$




$\begin{array}{lllll}\text { C } & \text { Avenidas e/ou ruas mal pavimentadas } & 1 & 2 & 3 \\ \text { D } & \text { Cruzamentos de ruas sem semáforos } & 1 & 2 & 3 \\ \text { E } & \text { Desníveis de calçadas } & 1 & 2 & 3 \\ \text { F } & \text { Difícil aceso aos transportes } & & & \\ & \text { coletivos urbanos } & 1 & 2 & 3 \\ \text { G } & \text { Difícil aceso a motos táxis } & 1 & 2 & 3 \\ \text { H } & \text { Difícil aceso a táxis } & 1 & 2 & 3 \\ \text { I } & \text { Desordenamento no trânsito (carros, } & & & \\ & \text { pedestres, carroças, bicicletas, } \\ & \text { motos, etc.) } & 1 & 2 & 3\end{array}$

29. Qual meio de transporte utiliza?
(1) Carro próprio ou de família
(2) Coletivo público
(3) Moto-táxi/táxi
(4) Bicicleta
(5) Carroça
(6) Nenhum
(7) NS/NR

\section{BLOCO VI - ASPECTOS ALIMENTICIOS}

30. Onde come o/a Senhor/a habitualmente?
(1) Em casa, com filho/a ou familiar
(2) Em casa, sozinho/a
(3) Em um restaurante
(4) Em casa de amigos
(5) NS/NR

31. Quantas refeições o/a Senhor/a faz diariamente?

$\begin{array}{ll}\text { (1) Quatro (café da manhã, almoço, merenda e janta) } & (\text { ) } \\ \text { (2) Três (café da manhã, almoço e janta) } & (\text { ) } \\ \text { (3) Duas (almoço e janta) } & (\text { ) } \\ \text { (4) Somente uma } & (\text { ) } \\ \text { (5) Não sigo nenhuma norma, como quando } \\ \quad \text { tenho vontade } \\ \text { (6) NS/NR }\end{array}$

32. Como é a alimentação do Senhor/a?

(1) Muito boa ( )

(2) Boa 
(3) Regular ( )
(4) Mal ( )
(5) Muito mal ( )
(6) NS/NR ( )

BLOCO VII - SITUACCÃO SANITÁRIA E MÉDICA

33. Como foi seu estado de saúde no último ano?
(1) Muito bom ( )
(2) Bom
(3) Regular
(4) Mal
(5) Muito mal ( )
(6) NS/NR

34. Têm o/a Senhor/a dificuldades de realizar sozinho/a (sem ajuda) as seguintes situações?

Situações NEHUMA ALGUMA BASTANTE NS / NR

A Cuidar do seu aspecto físico (pentearse, etc.)

B Comer sozinho/a

C Vestir ou desvestir-se

D Andar

E Tomar banho

F Ir comprar artigos de primeira necessidade (pão, leite, carne, ovos...)

G Preparar a comida

H Realizar tarefas domésticas

I Utilizar transporte público

J Tomar medicamentos

K Manejar dinheiro

L Fazer compras

M Ir ao médico

N Realizar gestões (receber a pensão, organizar documentos, etc.)

O Ler jornal, revistas, etc

$\begin{array}{llll}1 & 2 & 3 & 4 \\ 1 & 2 & 3 & 4 \\ 1 & 2 & 3 & 4 \\ 1 & 2 & 3 & 4 \\ 1 & 2 & 3 & 4 \\ 1 & 2 & 3 & 4\end{array}$

35. Se o/a Senhor/a precisasse de algum tipo de ajuda, qual seria a mais conveniente?

(1) De um familiar ou vizinho 
(2) De um organismo ou serviço assistencial gratuito

(3) De um organismo público ou privado pagando uma pequena quota

(4) NS/NR

36. Por que razão o/a Senhor/a não recebe ajuda para realizar as atividades que tem dificuldades?

(1) Por motivos econômicos

(2) Porque não tem pessoas que the ajude

(3) Porque não gosta de estranhos em sua casa

(4) Porque não acha necessário ajuda de outra pessoa

(5) Outra

(6) NS/NR

(7) NSA

37. Com que frequiência o/a Senhor/a vai ao médico?
(1) A cada três meses
(2) A cada dois meses
(3) Uma vez por ano
(4) Só quando fica doente
(5) Nunca
(6) NS/NR

38. Quando medicado pelo médico, como adquire seu medicamento?

(1) Compra a caixa/completo

(2) Compra a granel

(3) Consegue o medicamento através de órgão público ou similares

(4) Não compra

(5) NS/NR

39. Como é a sua audição?
(1) Boa
(2) Regular
(3) Mal
(4) NS/NR

(ATENÇÃO ENTREVISTADOR: esta questão é somente para o/a entrevistado/a que tem problemas de audição)

40. Utiliza alguma prótese de audição? 


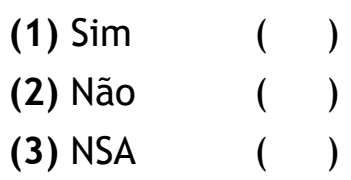

41. O (a) Senhor/a foi ao oculista no último ano?
(1) $\mathrm{Sim}$
(2) Não
(3) NS/NR

(ATENÇÃO ENTREVISTADOR: esta questão é somente para as MULHERES)

42. Tem ido ao ginecologista no último ano para fazer algum tipo de exame (citologia, mamografia, etc.)?
(1) Sim
(2) Não
(3) NSA
(4) NS/NR

(ATENÇÃO ENTREVISTADOR: esta questão é somente para os $\underline{\text { HOMENS) }}$

43. Tem ido ao urologista no último ano para fazer exame de próstata?
(1) $\operatorname{Sim}$
(2) Não
(3) NSA
(4) NS/NR

44. No último ano quantas vezes o (a) Senhor (a) foi internado (a) como paciente, ainda que somente por uma noite, em um hospital?
(1) Nenhuma
(2) Uma vez ou mais ( )
(3) NS/NR

45. Por que motivo esteve o (a) Senhor (a) internado (a)?
(1) Intervenção cirúrgica
(2) Enfermidade crônica
(3) Acidente
(4) Outro
(5) NS/NR
(6) NSA 
46. Qual Instituição recebe o (a) Senhor (a) assistência médica?
(1) Sistema Único de Saúde - SUS ( )
(2) Plano de Saúde privado (pago) ( )
(3) Outros
(4) NS/NR

47. Como, preferencialmente, uma pessoa de idade avançada, deveria receber assistência médica?
(1) Em sua própria casa
(2) Num posto de saúde ou hospital
(3) NS/NR

48. Já fez alguma vez um check-up geral?
(1) $\operatorname{Sim}$
(2) Não, nunca
(3) NS/NR

(ATENÇÃO ENTREVISTADOR: esta questão é somente para os QUE NUNCA FIZERAM CHECK-UP GERAL)

49. Mencionar o motivo mais importante por que nunca fez um check-up geral.
(1) Não crer que sirva para nada
(2) Se encontra bem de saúde
(3) Não se faz pelo SUS
(4) É muito caro
(5) Outros motivos
(6) NS/NR
(7) NSA

(ATENÇÃo ENTREVISTADOR: esta questão é de MÚLTIPLA ESCOLHA: Pode responder mais de uma alternativa)

50. Que tipo de enfermidade sofre o (a) Senhor (a) atualmente?
(1) Cardiovascular
(2) Respiratória ( )
(3) Urinária
(4) Digestiva
(5) Locomotiva ( )
(6) Neurológica ( )
(7) Outras 
(8) Nenhuma ( )

(9) NS/NR

51. O (a) Senhor (a) fuma ou já fumou?
(1) Sim, atualmente fuma
(2) Não fuma, mais já fumou
(3) Não fuma nem nunca fumou
(4) NS/NR

52. 0 (a) Senhor (a) ingere bebida alcoólica?

(1) Sim, atualmente bebe

(2) Não bebe, mais já bebeu

(3) Não bebe nem nunca bebeu

(4) NS/NR

53. Com que frequiência o/a Senhor (a), ingere bebida alcoólica?
(1) Diariamente
(2) Todo final de semana
(3) Às vezes
(4) NS/NR
(5) NSA

54. Que tipo de serviços destinados para idosos o (a) Senhor (a) conhece?

\begin{tabular}{llccc}
$\mathbf{N}^{\circ}$ & \multicolumn{1}{c}{ Serviços } & SIM & NÃO & NS/NR \\
01 & Transporte público gratuito & 1 & 2 & 3 \\
02 & Educação para adultos & 1 & 2 & 3 \\
03 & $\begin{array}{l}\text { Acompanhamento preventivo e curativo } \\
\text { nos centros de saúde }\end{array}$ & 1 & 2 & 3 \\
04 & Universidade da Terceira Idade & 1 & 2 & 3 \\
05 & Atividades sócio-culturais - PMM & 1 & 2 & 3 \\
06 & Terapia ocupacional - PMM & 1 & 2 & 3 \\
07 & Descontos especiais em espetáculos & & & \\
& culturais & 1 & 2 & 3 \\
08 & Centros de convivência para idosos & 1 & 2 & 3
\end{tabular}

55. Já utilizou ou se beneficiou de algum dos serviços que acabo de mencionar?
(1) Sim
(2) Não
(3) NS/NR 
(ATENÇÃO ENTREVISTADOR: esta questão é apenas para os que constataram SIM em ao menos um dos serviços)

56. Quais destes serviços destinados para idosos o (a) Senhor (a) já utilizou?

\begin{tabular}{llccc} 
No $^{\circ}$ & \multicolumn{1}{c}{ Serviços } & SIM & NÃO & NS/NR \\
01 & Transporte público gratuito & 1 & 2 & 3 \\
02 & Educação para adultos & 1 & 2 & 3 \\
03 & Acompanhamento preventivo e curativo & & & \\
& nos centros de saúde & 1 & 2 & 3 \\
04 & Universidade da Terceira Idade & 1 & 2 & 3 \\
05 & Atividades sócio-culturais - PMM & 1 & 2 & 3 \\
06 & Terapia ocupacional - PMM & 1 & 2 & 3 \\
07 & Descontos especiais em espetáculos & & & \\
& culturais & 1 & 2 & 3 \\
08 & Centros de convivência para idosos & 1 & 2 & 3
\end{tabular}

(ATENÇÃO ENTREVISTADOR: esta questão é de MÚLTIPLA ESCOLHA: Pode responder mais de uma alternativa)

57. O ministério da saúde realiza anualmente como ação preventiva a Campanha Nacional de Vacinação do idoso. Qual das vacinas deste programa o Senhor (a) já tomou?
(1) Contra gripe
(2) Tétano e difteria
(3) Contra o pneumococo
(causador da pneumonia bacteriana)
(4) NS/NR

\section{BLOCO VIII- TEMPO LIVRE E LAZER}

(ATENÇÃO ENTREVISTADOR: esta questão é de MÚlTIPLA ESCOLHA: Pode responder mais de uma alternativa)

58. Em que emprega seu tempo livre?

(1) Estar em casa

(2) Vai a bares, botecos, etc.

(3) Ler jornais, revistas, etc.

(4) Vai ao cinema/teatro

(5) Ver os programas televisivos

(6) Dar um passeio

(7) Cuida dos netos 


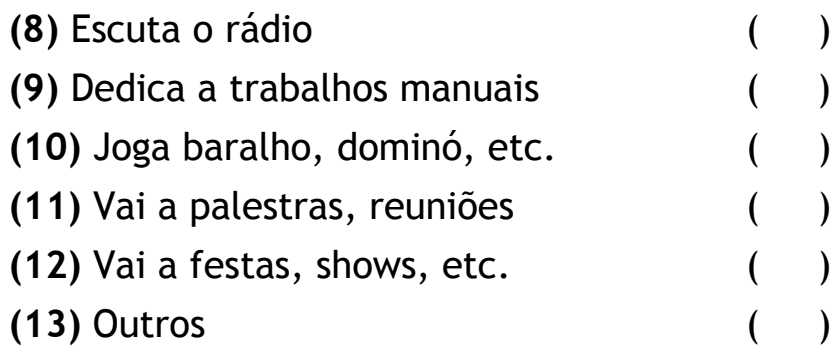

59. 0 que prefere escutar no rádio? Enumere três na sua ordem de preferência.
(1) Musicais
(2) Informativos
(3) Seriados (novelas)
(4) Culturais
(5) Esportivos
(6) Religiosos
(7) Políticos
(8) Outro
(9) Não escuta
(10) NS/NR

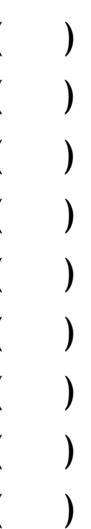

60. 0 que assiste na TV? Enumere três na sua ordem de preferência?
(1) Musicais
(2) Informativos
(3) Novelas (séries)
(4) Culturais
(5) Esportivos
(6) Religiosos
(7) Debates
(8) Filmes
(9) Concursos
(10) Outros
(11) Não assisto ( )
(12) NS/NR

61. Qual a principal atividade física, que o (a) Senhor (a) pratica?
(1) Academia
(2) Natação
(3) Yoga
(4) Caminhadas
(5) Bicicleta
(6) Hidroginástica
(7) Outro 

(8) Não pratico
(9) NS/NR

62. O Senhor (a) desfruta de férias?
(1) Sim, todos os anos
(2) De vez em quando
(3) Não, nunca
(4) NS/NR

63. Se não vai a férias, qual a causa?
(1) Por motivos econômicos
(2) Por motivos de trabalho ou ocupações ( )
(3) Por problemas de saúde
(4) Por falta de oportunidades
(5) Por que não gosto
(6) Pela idade
(7) Por não ter esta cultura
(8) Outro
(9) NS/NR
(10) NSA

\section{BLOCO IX- Vida, Sexo, Política, Religião e Morte}

64. 0 que é a vida para o Senhor (a)?
(1) Um desengano
(2) Um tempo para construir um mundo melhor
(3) Uma série de fracassos
(4) Uma coisa que vale a pena
(5) Ocasião de encontro com Deus
(6) Outro
(7) NS/NR

65. Como é hoje sua vida?
(1) Agradável
(2) Desagradável
(3) Nem agradável nem desagradável
(4) NS/NR

66. Crer que o sexo fica comprometido quando se chega aos 60 anos? (1) $\mathrm{Sim}$ 
(2) Não

(3) NS/NR

67. Vota habitualmente nas eleições?
(1) Sim, sempre que há eleições
(2) Não
(3) NS/NR

(ATENÇÃO ENTREVISTADOR: esta questão é somente para os QUE RESPOONDERAM NÃO).

68. Porque não vota?
(1) $\operatorname{Sim}$
(2) Não
(3) NS/NR
(4) NSA

69. Conhece as leis que beneficiam as pessoas maiores de 60 anos?
(1) $\mathrm{Sim}$
(2) Não
(3) NS/NR

70. Como se considera em matéria religiosa?
(1) Católico praticante
(2) Católico não praticante
(3) Outra denominação religiosa
(4) Outra religião que não cristã
(5) Indiferente
(6) Ateu
(7) NS/NR
(8) NSA

71. Com que frequiência pensa ou fala na morte?
(1) Nunca
(2) Raramente
(3) Ocasionalmente ( )
(4) Freqüentemente ( )
(5) NS/NR

72. Com quem fala sobre a morte?
(1) Com alguém da família ( )
(2) Com amigos
(3) Com o padre da Igreja ( ) 

(4) Não fala sobre a morte ( )
(5) NS/NR

\section{BLOCO X - ASPECTOS ECONÔNICOS}

(ATENÇÃO ENTREVISTADOR: esta questão é somente para os QUE ESTÃO SEM TRABALHAR).

73. Por que razões o/a Senhor/a está sem trabalhar?
(1) Por aposentadoria
(2) Por enfermidade
(3) Por falta de trabalho
(4) NS/NR
(5) NSA

74. Quais são suas fontes de renda para seus gastos?
(1) Pensão por aposentadoria
(2) Pensão por viuvez
(3) Pensão por invalidez
(4) Renda própria
(5) Ajuda de Instituições
(6) Ajuda dos finos
(7) Ajuda de outros familiares
(8) NS/NR

(ATENÇÃO ENTREVISTADOR: esta questão é somente para os que recebem pensão por aposentadoria).

75. Com a pensão que o/a Senhor (a) recebe:
(1) Cobre seus gastos
(2) Necessita complementar sua renda
(3) NS/NR
(4) NSA

76. Quem administra seu dinheiro?
(1) 0 próprio ( )
(2) Esposo/a ( )
(3) Filho/a ( )
(4) Parente ( )
(5) NS/NR 
77. Manuseia com facilidade as operações nos Caxias de auto-atendimento bancário?
(1) $\operatorname{Sim}$
(2) Não
(3) NS/NR

78. Quanto em dinheiro dispõe ao mês para seus gastos?
(1) Menos de um salário mínimo
(2) De 230,00 reais a 460,00 reais
(3) De 461,00 reais a 660,00 reais $($ )
(4) De 661,00 reais a 860,00 reais ( )
(5) Mais de 860,00 reais
(6) NS/NR

(ATENÇÃO ENTREVISTADOR: esta questão é somente para os que estão trabalhando)

79. Em que área atua profissionalmente?
(1) Agricultura
(2) Empresa, comércio
(3) Serviço público
(4) Trabalhador autônomo
(5) Construção civil
(6) Dona de casa

(ATENÇÃO ENTREVISTADOR: esta questão é somente para os QUE ESTÃO APOSENTADOS)

80. Qual a última profissão atuou profissionalmente?
(1) Agricultura
(2) Empresa, comércio
(3) Serviço público
(4) Trabalhador autônomo
(5) Construção civil
(6) Dona de casa
(7) Outros
(8) NSA
(9) NS/NR

(ATENÇÃO ENTREVISTADOR: esta questão é somente para os QUE GOSTARIAM DE TRABALHAR) 


\section{Por que motivo?}
(1) Para pagar pequenos gastos
(2) Para aumentara renda
(3) Por distração
(4) Por que gosta
(5) Para não depender
financeiramente de ninguém
(6) NS/NR
(7) NSA

82. Em sua opinião, quando deveria uma pessoa se aposentar?
(1) Quando determinar a lei
(2) Quando for conveniente

$(\quad)$
$(\quad)$
$(\quad)$
$(\quad)$

83. Em sua opinião de quem é a responsabilidade do pagamento de aposentadoria?
(1) 0 Estado
(2) Os empresários
(3) Os trabalhadores individualmente

$\begin{array}{ll}( & ) \\ ( & ) \\ ( & ) \\ ( & )\end{array}$
(4) NS/NR 


\section{DISTRIBUCIONES MARGINALES (En \%) \\ “PERFIL SOCIOLÓGICO DE LA VEJEZ EN MOSSORÓ/RN" - BRASIL JUNIO 2004 / JUNIO 2005 \\ BLOQUE I - ASPECTOS GENERALES}

\section{Pregunta 1}

¿Sexo?
1. Hombre
50,00
2. Mujer
50,00

(N)

(500)

\section{Pregunta 2}

¿Edad: años completos?
1. Entre 60-65
34,20
2. Entre 66-70
24,60
3. Entre 71-75
19,20
4. Entre 76-80
12,00
5. Entre 81-85
4,60
6. Entre 86-90
4,60
7. Más de 90
0,60
8. Ns/Nc
0,20

\section{Pregunta 3}

¿Cuál es su estado civil?
1. Soltero/a
7,20
2. Casado/a
51,20
3. Pareja estable $\quad 2,20$
4. Separado/a $\quad 6,20$
5. Divorciado/a $\quad 2,20$
6. Viudo/a $\quad 31,00$

\section{Pregunta 4}

¿Lugar de nacimiento?

1. Mossoró

39,80

2. Otra ciudad $\quad 60,00$

3. Ns/Nc

0,20

\section{Pregunta 5}

¿Cuál es su nivel de instrucción?
1. Ninguno
19,80
2. Sabe leer
20,80
3. Primaria
31,60
4. Secundaria
14,60
5. Bachillerado
7,80
6. Superior
5,40

\section{Pregunta 6}

¿Cuál es su situación laboral actual?
1. Jubilado
76,80 
2. Ama de casa $\quad 31,60$

3. Activo $\quad 19,20$

4. Pensionista $\quad 16,20$

5. Desempleado 8,00

Observación: pregunta de elección múltiple, por eso suma más de $100 \%$.

\section{Pregunta 7}

¿Cuál es su opinión sobre los siguientes temas?

Temas

$\begin{array}{ll}01 & \text { Aborto } \\ 02 & \text { Pena de muerte } \\ 03 & \text { Divorcio } \\ 04 & \text { Pagar los impuestos } \\ \mathbf{0 5} & \text { Relación sexual antes de La boda } \\ \mathbf{0 6} & \text { Relación sexual entre El mismo }\end{array}$

07 Liberación de lãs drogas
De acuerdo Indiferente En desacuerdo NS / NC

$8,80 \quad 7,00 \quad 80,80 \quad 3,40$

$30,20 \quad 9,60 \quad 56,00 \quad 4,20$

$49,20 \quad 16,80 \quad 31,80 \quad 2,20$

$45,40 \quad 10,80 \quad 42,40 \quad 1,40$

$15,40 \quad 17,60 \quad 64,20 \quad 2,80$

$\begin{array}{llll}3,60 & 8,40 & 85,80 & 2,20 \\ 3,20 & 3,00 & 91,80 & 2,00\end{array}$

\section{BLOQUE II - OPINIÓN SOBRE LA VEJEZ}

\section{Pregunta 8}

¿Lo que caracteriza una persona mayor?
1. La edad
37,80
2. La falta de salud
31,20
3. La jubilación
3,00
4. Las leyes
3,20
5. El "estado de espíritu" 23,20
6. Ns/Nc
1,60

\section{Pregunta 9}

¿Cómo tratan la sociedad a las personas de edad?
1. Bien
20,60
2. Mal
34,40
3. Con indiferencia
43,40
4. Ns/Nc
1,60

\section{Pregunta10}

¿En su opinión cuál el término más adecuado para referirse a una persona con 60 y más años de edad?
1. Anciano
7,20
2. Tercera Edad $\quad 32,60$
3. Viejo
5,80
4. Mayor
41,60
5. Ninguna
12,80 


\section{BLOQUE III - SITUACIÓN FAMILIAR}

\section{Pregunta 11}

¿Con quién vive Usted?

1. Con su cónyuge o pareja

19,00

2. Con sus hijo/s soltero/s

22,40

3. Con su pareja y con sus hijo/s

20,20

4. Con su pareja, con sus hijo/s y con sus nieto/s 17,80

5. Con otros familiares

11,00

6. Con otras personas que no son familia

7. Solo/a

8. Ns/Nc

\section{Pregunta 12}

¿En general, cómo se relaciona Usted con las personas con las que vive?
1. Muy bien
36,07
2. Bien
41,88
3. Regular
12,63
4. Mal
0,80
5. Con unas bien, con otras mal 2,81
6. Ninguna
0,0
7. NSA
5,81

\section{Pregunta 13}

¿Podría decirme con qué frecuencia habla con las siguientes personas?

$\begin{array}{llllllllll} & & \text { Todos o } & \text { Al } & \text { Al } & \text { Menos } & & & \\ \text { N}^{\circ} & \text { Frecuencia que habla con... } & \text { casi } & \text { menos } 1 & \text { menos } 1 & \text { de } 1 & \text { NUNC } & \text { NS/NR } & \text { NSA } \\ & & \text { todos } & \text { vez por } & \text { vez al } & \text { vez al } & \text { A } & & \\ & & \text { los días } & \text { semana } & \text { mes } & \text { mes } & & & \\ 01 & \text { Hijo/s que no viven con Usted } & 67,40 & 13,00 & 4,60 & 1,40 & 0,60 & 1,20 & 11,80 \\ 02 & \text { Nieto/s que no viven con Usted } & 32,40 & 34,80 & 13,40 & 4,80 & 1,40 & 2,80 & 10,40 \\ 03 & \text { Familiares que no viven con } & & & & & & & \\ & \text { Usted } & 17,60 & 30,40 & 27,60 & 16,80 & 1,80 & 3,40 & 2,40 \\ 04 & \text { Vecinos } & 84,80 & 10,20 & 2,20 & 1,40 & 0,40 & 0,60 & 0,40 \\ 05 & \text { Amigos que no son vecinos } & 31,80 & 33,80 & 19,20 & 11,20 & 1,60 & 1,40 & 1,00\end{array}$

\section{Pregunta 14}

¿Actualmente cuántos hijos vivos tiene Usted?
1. Uno
6,80
2. Dos
10,00
3. Tres
12,20
4. Cuatro
13,00
5. Cinco
16,60
6. Seis
9,80
7. Siete
6,00
8. Ocho
6,40
9. Más de ocho
12,20
10. NSA
7,00 


\section{Pregunta 15}

¿En qué circunstancia estaría Usted dispuesto a vivir en una Residencia para mayores si tuviera edad para ello?
1. Si no me pudiera valer por mi mismo
11,60
2. Si padeciera alguna enfermedad crónica
3,20
3. Si enviudara
2,60
4. Para evitar hacer las tareas domesticas
0,20
5. Para evitar la soledad
12,40
6. Por razones económicas
5,80
7. Para no molestar a los hijos/familiares
10,20
8. Por problemas de vivienda
5,40
9. Bajo ninguna circunstancia lo haría
42,60
10. Ns/Nc
6,00

\section{BLOQUE IV - VIVIENDA}

\section{Pregunta 16}

¿Dónde vive Usted actualmente?
1. Casa
98,20
2. Apartamento
1,00
3. Estudio
0,80

\section{Pregunta 17}

¿A quién pertenece la vivienda en que Usted vive?
1. Propia (pagada)
80,40
2. Propia, con pagos pendientes
4,60
3. De un familiar
7,60
4. Alquilada
7,20
5. Ns/Nc
0,20

\section{Pregunta 18}

¿Podría decirme cuánto paga al mes de alquiler?
1. Menos de 50,00 Reales $( \pm 20 €)$
2. De 50,00 a 200,00 Reales $( \pm 20 €$ a $80 €)$
0,40
7,20
3. De 201,00 a 400,00 Reales $( \pm 80,40 €$ a $160 €) \quad 1,00$
4. De 401,00 a 600,00 Reales $( \pm 160,40 €$ a $250 €) \quad 0,40$
5. Más de 600,00 Reales (Más de $250 €$ ) $\quad 0,40$
6. Ns/Nc
10,20
7. NSA
80,40

\section{Pregunta 19}

¿Cree Usted que su vivienda tiene alguno de los siguientes problemas?
1. Humedad
13,40
2. Fontanería
9,40
86,60
3. Sistema eléctrico 1,60
90,60
4. Escalera (acceso) $\quad 1,40$
98,40
5. Sanitario
20,60
98,60
6. Estructura general 8,20
79,40
7. Ns/Nc
0,40
91,80
99,60 
Pregunta 20

¿Cuál su opinión acerca de la vivienda donde vive?
1. Está muy satisfecho
37,20
2. Satisfecho
52,40
3. Insatisfecho
8,00
4. Muy insatisfecho
1,20
5. Ns/Nc
1,20

\section{Pregunta 21}

¿Dispone Usted de una habitación para dormir?
1. $\mathrm{Si}$
79,80
2. No
13,80
3. NSA
6,40

Pregunta 22

¿Podría decirme de cuáles de los siguientes servicios o bienes durables dispone en su vivienda?

$\begin{array}{llccc}N^{\circ} & \text { Productos / servicios } & \text { SI } & \text { NO } & \text { NS/NR } \\ 01 & \text { Agua potable } & 98,40 & 1,40 & 0,20 \\ 02 & \text { Cuarto de baño } & 99,40 & 0,60 & - \\ 03 & \text { Luz eléctrica } & 99,60 & 0,40 & - \\ 04 & \text { Televisión } & 95,20 & 4,80 & - \\ 05 & \text { Vídeo } & 30,60 & 68,60 & 0,80 \\ 06 & \text { Radio } & 87,80 & 12,20 & - \\ 07 & \text { Tocadiscos } & 46,80 & 52,10 & 1,10 \\ 08 & \text { Nevera } & 95,40 & 4,40 & 0,20 \\ 09 & \text { Lavadora } & 43,60 & 56,00 & 0,40 \\ 10 & \text { Fogón a gas } & 97,80 & 2,20 & - \\ 11 & \text { Fogón a Leña } & 10,20 & 89,20 & 0,60 \\ 12 & \text { Teléfone } & 68,20 & 31,60 & 1,20 \\ 13 & \text { Ordenador } & 13,20 & 86,40 & 0,40 \\ 14 & \text { Ventilador } & 89,20 & 10,80 & - \\ 15 & \text { Aire condicionado } & 10,00 & 89,40 & 0,60\end{array}$

\section{Pregunta 23}

¿Para su comodidad, cuáles de estas prestaciones o servicios hay cerca de su vivienda?
1. Pequeños comercios
$\mathrm{SI}$
NO
2. Una farmacia
94,80
5,20
3. Un Centro de Salud
82,80
17,20
4. Un Centro de Tercera Edad
71,60
28,40
5. Una iglesia o templo
38,00
62,00
89,40
10,60
6. Un jardín / plaza
63,80
36,20 


\section{Pregunta 24}

¿Quién le ayuda más en sus actividades diarias?
1. Familiar próximo (esposo/a, hijo/a, hermano/a)
74,80
2. Otros familiares (primo/a, sobrino/a, cuñado/a)
3. Empleado de hogar
8,40
4. Vecino
1,20
5. Otros
3,60
6. Ns/Nc
1,60
7. NSA
6,20

\section{Pregunta 25}

¿Qué situación considera Usted mejor?
1. Que las personas mayores vivan con su familia
77,20
2. Que vivan en Residencia con gente de su edad y condición
3. Que vivan en vivienda, pero recibiendo servicio en su domicilio $\quad 19,20$
4. Ns/Nc
2,80

\section{Pregunta 26}

¿En su opinión, dónde debería ser construida la Residencia para mayores en Mossoró?
1. En el centro de la ciudad
59,80
2. En los barrios
17,20
3. Lejos de la ciudad, (finca, hacienda)
23,00

\section{Pregunta 27}

¿Cree Usted que Mossoró precisa de una residencia para Mayores?
1. $\mathrm{Si}$
88,60
2. No
4,20
3. $\mathrm{Ns} / \mathrm{Nc}$
7,20

\section{BLOQUE V - ESTRUCTURA DE LA CIUDAD Y MEDIO ANBIENTE}

\section{Pregunta 28}

¿Entre los problemas que se puede encontrar en la infraestructura urbana de Mossoró, cuáles de los siguientes puede dificultar sus desplazamientos?

$\begin{array}{lcc}\text { 1. Semáforos muy breves } & \text { SI } & \text { NO } \\ \text { 2. Coches aparcados indebidamente } & 65,20 & 34,80 \\ \text { 3. Calles mal asfaltadas } & 78,40 & 21,60 \\ \text { 4. Cruces de calles sin semáforos } & 80,40 & 19,60 \\ \text { 5. Desniveles de aceras } & 84,80 & 15,20 \\ \text { 6. Acceso difícil de autobuses públicos } & 86,20 & 13,80 \\ \text { 7. Acceso difícil a las moto taxis } & 60,00 & 40,00 \\ \text { 8. Acceso difícil a los taxis } & 21,40 & 78,60 \\ \text { 9. Caos circulatorio } & 36,20 & 63,80 \\ \text { (peatones, carros, bicis, motos...) } & 85,40 & 14,60\end{array}$

\section{Pregunta 29}

¿Qué medio de transporte suele usar Usted?
1. Coche propio (familia) 
2. Autobús público 27,80

3. Moto/Moto-taxi y taxi $\quad 15,20$

4. Bicicleta $\quad 7,20$

5. Carro $\quad 0,60$

6. Ninguno $\quad 11,00$

7. Ns/Nc $\quad 0,20$

\section{BLOQUE VI - ASPECTOS ALIMENTICIOS}

\section{Pregunta 30}

¿Dónde come Usted habitualmente?
1. En casa, con hijos o familiar
92,20
2. En casa, solo/a
6,80
3. En restaurante
0,60
4. En casa de amigos
0,40

5. Ns/Nc

\section{Pregunta 31}

¿Cuántas comidas suele hacer Usted a diario?
1. Cuatro (desayuno, almuerzo, merienda y cena)
47,20
2. Tres (desayuno, almuerzo y cena)
34,40
3. Dos (almuerzo y cena)
5,40
4. Solamente una
0,60
5. No sigue ninguna norma, come cuando da la gana
12,60
6. Ns/Nc
0,40

\section{Pregunta 32}

\section{¿Cómo es su alimentación?}
1. Muy buena
25,20
2. Buena
44,80
3. Regular
28,20
4. Mal
1,00
5. Muy mal
0,40
6. Ns/Nc
0,40

\section{BLOQUE VII - SITUACIÓN SANITARIA Y MÉDICA}

\section{Pregunta 33}

¿Cómo fue su estado de salud en el último año?
1. Muy bueno
10,20
2. Bueno
35,60
3. Regular
47,20
4. Malo
5,00
5. Muy malo
1,60
6. Ns/Nc
0,40

\section{Pregunta 34}

¿Tiene Usted dificultad para realizar solo (sin ayuda), las siguientes actividades? 
A Cuidar de su aspecto físico (peinarse, etc.)

$\begin{array}{cccc}90,40 & 6,80 & 2,60 & - \\ 96,20 & 2,40 & 1,00 & 0,40 \\ 91,80 & 6,40 & 1,60 & 0,20 \\ 82,80 & 13,40 & 3,60 & 0,20 \\ 92,20 & 5,20 & 2,40 & 0,20 \\ & & & \\ 74,60 & 18,60 & 5,80 & 1,00 \\ 58,80 & 26,40 & 11,40 & 3,40 \\ 52,40 & 31,00 & 13,60 & 3,00 \\ 52,60 & 30,40 & 13,00 & 4,00 \\ 79,00 & 16,20 & 4,00 & 0,80 \\ 80,20 & 15,80 & 3,20 & 0,80 \\ 67,80 & 22,60 & 8,20 & 1,40 \\ 60,40 & 29,40 & 8,00 & 2,20 \\ & & & \\ 53,20 & 30,60 & 12,80 & 3,40 \\ 51,60 & 22,20 & 17,80 & 8,40\end{array}$

B Comer solo/a

C Vestirse o desvestirse

D Andar

E Ducharse

F Ir a comprar artículos de primera necesidad (pan, leche, etc.)

G Preparar la comida

H Realizar tareas domésticas

I Utilizar el transporte público

J Tomar medicamentos

K Manejar el dinero

L Ir de compras

M Ir al médico

N Realizar gestiones (recibir la pensión, organizar documentos, etc.)

o Leer el periódico, revistas, etc

sión,

\section{Pregunta 35}

¿Si Usted precisase de algún tipo de ayuda, cual convendría mejor?
1. De un familiar o vecino
91,20
2. De un organismo o servicio de asistencia gratuita
6,20
3. De un organismo público o privado con pago de una cuota
2,60

Observación: pregunta de elección múltiple, por eso suma más de 100\%.

\section{Pregunta 36}

¿Por qué razón Usted no recibe ayuda para realizar las actividades que tiene dificultad?
1. Por motivos económicos
11,80
2. Porque no tiene personas que le ayuden
4,40
3. Porque no quiere extraños en la vivienda
4,20
4. Porque no es necesario
26,40
5. Otra
10,40
6. Ns/Nc
15,80
7. NSA
27,00

\section{Pregunta 37}

¿Con qué frecuencia va Usted al médico?
1. Cada tres meses
20,00
2. Cada dos meses
12,00
3. Una vez al año
16,80
4. Solo cuando está enfermo
49,60
5. Nunca
6. $\mathrm{Ns} / \mathrm{Nc}$ 


\section{Pregunta 38}

¿Cuándo le receta el médico, cómo adquiere el medicamento?

1. Compra la caja completa $\quad 65,60$

2. Compra a granel 13,20

3. Consigue el medicamento a través de un órgano
público/similares
18,80

4. No compra $\quad 1,20$

5. Ns/Nc 1,20

\section{Pregunta 39}

¿Cómo es su audición?
1. Buena 64,40
2. Regular 29,20
3. Mal 6,20
4. Ns/Nc $\quad 0,20$

\section{Pregunta 40}

¿Usa Usted alguna prótesis auditiva?
1. $\mathrm{Si}$
2,00
2. No
34,00
3. NSA
64,00

\section{Pregunta 41}

¿Ha ido Usted al oftalmólogo en el último año?
1. $\mathrm{Si}$
54,40
2. No
42,40
3. $\mathrm{Ns} / \mathrm{Nc}$
3,20

\section{Pregunta 42 (Solo a mujeres)}

¿Ha ido al ginecólogo en el último año para hacer alguna prueba?
1. $\mathrm{Si}$
24,00
2. No
25,20
3. Ns/Nc $\quad 0,80$
4. NSA $\quad 50,00$

\section{Pregunta 43 - (Solo a varones)}

¿Ha ido al urólogo en el último año para hacer alguna prueba de próstata?
1. $\mathrm{Si}$
15,20
2. No
32,00
3. Ns/Nc 2,80
4. NSA
50,00

\section{Pregunta 44}

¿En el último año, cuantas veces fue ingresado en un hospital, aunque solo fuera por una noche?
1. Ninguna
72,80
2. Una vez o más 23,80
3. Ns/Nc
3,40

\section{Pregunta 45}

¿Por qué motivo estuvo Usted ingresado?
1. Intervención quirúrgica
8,60
2. Enfermedad crónica
3,60 

3. Accidente
1,20
4. Otro
13,60
5. Ns/Nc
3,20
6. NSA
69,80

\section{Pregunta 46}

¿De qué institución recibe Usted asistencia sanitaria?
1. Sistema Único de Salud (SUS)
64,60
2. Plan privado (pagado)
28,20
3. Otros
5,60
4. Ns/Nc
1,60

\section{Pregunta 47}

¿Cómo debería una persona de edad avanzada recibir asistencia médica?
1. En su propia casa
75,80
2. En un centro de salud u hospital 23,20
3. Ns/Nc
1,00

\section{Pregunta 48}

¿Se ha hecho Usted alguno chequeo general?
1. Si
61,60
2. No
36,00
3. Ns/Nc
2,40

\section{Pregunta 49}

Mencionar el motivo más importante porque nunca ha hecho un chequeo general
1. No cree que sirva para nada
3,20
2. Si encuentra bien de salud
9,40
3. No se hace por el SUS
4,40
4. Es muy caro
9,20
5. Otros motivos
8,60
6. $\mathrm{Ns} / \mathrm{Nc}$
3,60
7. NSA
61,60

\section{Pregunta 50}

¿Qué enfermedades padece Usted actualmente?
1. Cardiovascular
26,80
2. Respiratoria
13,80
3. Urinaria
10,80
4. Digestiva
15,20
5. Locomotiva
18,40
6. Neurológica
11,40
7. Otras
33,00
8. Ninguna
21,40
9. Ns/Nc
2,00

Observación: pregunta de elección múltiple, por eso suma más de100\%.

\section{Pregunta 51}

¿Fuma actualmente o ha fumado Usted?
1. Si, actualmente fuma
14,23
2. No fuma, pero ha fumado
45,29 
3. No fuma ni ha fumado nunca $\quad 40,28$

4. Ns/Nc $\quad 0,20$

\section{Pregunta 52}

¿Ingiere bebida alcohólica o ha bebido Usted?

1. Si, actualmente bebe $\quad 11,20$

2. No bebe, pero ha bebido $\quad 34,20$

3. No bebe ni ha bebido nunca $\quad 52,60$

4. Ns/Nc 2,00

\section{Pregunta 53}

¿Con qué frecuencia ingiere Usted bebida alcohólica?
1. Diariamente
1,20
2. Cada fin de semana
2,00
3. A veces
12,80
4. Ns/Nc
7,20
5. NSA
76,80

\section{Pregunta 54}

¿Qué tipo de prestaciones y servicios destinado para los mayores conoce Usted?

1. Transporte colectivo público gratuito

SI NO NS/NC

2. Educación para adultos

$88,80 \quad 9,80 \quad 1,40$

3. Acompañamiento médico preventivo y $58,60 \quad 37,80 \quad 3,60$ curativo en los centros de salud

$64,80 \quad 30,20 \quad 5,00$

4. Universidad de la Tercera Edad $10,8083,00 \quad 6,20$

5. Actividades socio-culturales promocionadas por el Ayuntamiento

6. Terapia ocupacional

$48,40 \quad 46,00 \quad 5,60$

$29,0063,60 \quad 7,40$

7. Descuento especial en espectáculos culturales

$24,0069,00 \quad 7,00$

8. Centros de convivencia para mayores

$32,80 \quad 53,00 \quad 7,20$

\section{Pregunta 55}

¿Ha utilizado Usted o se ha beneficiado de alguna de estas prestaciones o servicios que acabo de mencionar?
1. Si
59,00
2. No
40,60
3. $\mathrm{Ns} / \mathrm{Nc}$
0,40

\section{Pregunta 56}

¿Cuáles de estas prestaciones o servicios para mayores ha utilizado Usted?

1. Transporte colectivo público gratuito

SI NO NS/NC NSA

2. Educación para adultos

$47,00 \quad 30,80 \quad 0,40 \quad 21,80$

$6,60 \quad 63,80 \quad 0,60 \quad 29,00$

3. Acompañamiento médico preventivo y curativo en los centros de salud

$34,40 \quad 34,60 \quad 1,00 \quad 30,00$

4. Universidad de la Tercera Edad

$\begin{array}{llll}1,60 & 57,60 & 0,80 & 40,00\end{array}$

5. Actividades socio-culturales promocionadas por el Ayuntamiento

6. Terapia ocupacional 
7. Descuento especial en espectáculos culturales $\quad 4,60 \quad 58,40 \quad 1,20 \quad 35,80$

8. Centros de convivencia para mayores $\quad 8,60 \quad 56,20 \quad 1,00 \quad 34,20$

\section{Pregunta 57}

El Ministerio de Salud realiza todos los años la Campaña Nacional de Vacunación. ¿Qué vacuna ha recibido Usted?
1. Contra la gripe
85,40
2. Tétano y difteria
38,60
3. Contra el pneumococo
13,20
4. Ns/Nc
11,20

Observación: pregunta de elección múltiple, por eso suma más de 100\%.

\section{BLOQUE VIII - TIEMPO LIBRE Y OCIO}

\section{Pregunta 58}

¿En qué emplea Usted su tiempo libre?
1. Estar en casa
84,00
2. Acudir a bares, bodegas
6,60
3. Leer el periódico, revistas
22,20
4. Ir al cine / teatro
1,80
5. Ver la televisión
64,00
6. Pasear
29,20
7. Cuidar de los nietos
27,00
8. Oír la radio
36,40
9. Manualidades
19,80
10. Jugar a cartas, dominó...
9,80
11. Acudir a conferencias
4,40
12. Ir a fiestas / conciertos
4,20
13. Otros
18,40

Observación: pregunta de elección múltiple, por eso suma más de 100\%.

\section{Pregunta 59}

¿Qué programas prefiere Usted escuchar en la radio?
1. Musicales
46,28
2. Informativos
66,20
3. Novelas
8,60
4. Culturales
6,20
5. Deportivos
24,84
6. Religiosos
45,40
7. Políticos
21,00
8. Otros
10,09
9. No escucha
10. Ns/Nc
16,80

Observación: pregunta de elección múltiple, por eso suma más de 100\%.

\section{Pregunta 60}

¿Qué ve Usted en la televisión?
1. Musicales
14,02
2. Informativos
72,20 
3. Novelas $\quad 53,60$

4. Culturales $\quad 8,40$

5. Deportivos $\quad 30,80$

6. Religiosos $\quad 45,20$

7. Debates $\quad 7,00$

8. Películas $\quad 16,40$

9. Concursos 2,20

10. Otros 7,60

11. No ve la televisión 6,40

Observación: pregunta de elección múltiple, por eso suma más de100\%.

\section{Pregunta 61}

¿Qué tipo de actividad física práctica Usted?
1. Gimnasia
0,80
2. Natación
0,20
4. Caminata
33,60
5. Bicicleta
4,20
6. Hidrogimnasia
1,80
7. Otra
1,40
8. No práctica
56,00
9. Ns/Nc
1,80

\section{Pregunta 62}

¿Disfruta Usted de vacaciones?
1. Sí, todos los años
13,80
2. De vez en cuando
20,40
3. No, nunca
56,20
4. Ns/Nc
9,60

\section{Pregunta 63}

Si no sale de vacaciones, ¿cuál es la razón?
1. Por motivos económicos
17,20
2. Por motivos de trabajo
5,00
3. Por problemas de salud
5,40
4. Por falta de oportunidad
7,80
5. Porque no le gusta
9,20
6. Por la edad
2,80
7. Por no tener esta costumbre
10,40
8. Otra
6,00
9. Ns/Nc
4,60
10. NSA
31,60

\section{BLOCO IX - OPINIÓN SOBRE LA VIDA, EL SEXO, LA POLÍTICA, LA RELIGIÓN Y LA MUERTE}

\section{Pregunta 64}

¿Qué es la vida para Usted?
1. Un desengaño
2. Un tiempo para construir un mundo mejor
3. Una serie de fracasos
4. Una cosa que vale la pena
36,20
5. Una ocasión de encuentro con Dios
29,80
6. Otro 


\section{Pregunta 65}

¿Cómo es su vida hoy?
1. Agradable
73,40
2. Desagradable
3,40
3. Ni agradable, ni desagradable
22,00
4. Ns/Nc
1,20

\section{Pregunta 66}

¿Cree Usted que el sexo queda comprometido con la edad?
1. $\mathrm{Si}$
52,80
2. No
26,80
3. Ns/Nc 20,40

\section{Pregunta 67}

¿Vota habitualmente en las elecciones?

1. Sí, siempre que hay elecciones 78,60

2. No

3. Ns/Nc

20,40

1,00

\section{Pregunta 68}

¿Por qué no vota?
1. No le interesa la política
4,80
2. Está desilusionado con la democracia
3. Todos los partidos hacen lo mismo
4. Se lo impide los problemas de salud
5. Otra respuesta
4,80
6. NSA
78,60

\section{Pregunta 69}

¿Conoce las leyes que benefician a las personas mayores de 60 años?
1. Si
47,00
2. No
46,00
3. Ns / Nc
7,00

\section{Pregunta 70}

¿Cómo se considera en materia religiosa?
1. Católico practicante
49,80
2. Católico no practicante
28,80
3. Otra denominación religiosa
14,60
4. Otra religión no cristiana
1,20
5. Indiferente
3,60
6. Ateo
0,20
7. Ns/Nc
1,80

\section{Pregunta 71}

¿Con qué frecuencia piensa Usted o habla sobre la muerte?
1. Nunca
36,20
2. Raramente
29,80
3. Ocasionalmente
21,20
4. Frecuentemente
9,40
5. Ns/Nc
3,40 


\section{Pregunta 72}

¿Con quién habla Usted sobre la muerte?
1. Con un miembro de la familia 35,40
2. Con amigos
18,80
3. Con el cura de la iglesia
1,20
4. No habla sobre la muerte
36,20
5. Ns/Nc
8,40

\section{BLOQUE X - ASPECTOS ECONÓMICOS}

\section{Pregunta 73}

¿Por qué está Usted sin trabajar?
1. Por jubilación
66,20
2. Por enfermedad
8,20
3. Por falta de trabajo
5,80
4. Ns/Nc
0,60
5. NSA
19,20

\section{Pregunta 74}

¿Cuáles son las fuentes de renta para sus gastos?
1. Pensión por jubilación $\quad 77,80$
2. Pensión de viudedad $\quad 11,40$
3. Pensión por invalidez $\quad 2,80$
4. Renta propia $\quad 18,40$
5. Ayuda de institución $\quad 0,20$
6. Ayuda de hijos $\quad 17,60$
7. Ayuda de otros familiares 4,20
8. Ns/Nc

Observación: pregunta de elección múltiple, por eso suma más de100\%.

\section{Pregunta 75}

¿Con la pensión que Usted recibe...
1. Cubre sus gastos
42,60
2. Necesita complementar la renta 42,80
3. $\mathrm{Ns} / \mathrm{Nc}$
2,80
4. NSA
11,80

\section{Pregunta 76}

¿Quién administra sus ingresos?
1. Yo mismo
79,60
2. Esposo/a
6,60
3. Hijo/a
11,60
4. Pariente
2,00
5. Ns/Nc
0,20

\section{Pregunta 77}

¿Maneja Usted con facilidad las operaciones en los cajeros automáticos?
1. $\mathrm{Si}$
31,60
2. No
63,60
3. Ns/Nc
4,80 


\section{Pregunta 78}

¿De cuánto dispone Usted al mes para sus gastos?

1. Menos de un salario mínimo $( \pm 92 €)$

2. De 230,00 reales a 460,00 reales $( \pm 92 €$ a $184 €) \quad 52,20$

3. De 460,00 reales a 690,00 reales $( \pm 184 €$ a $276 €) \quad 17,40$

4. De 690,00 reales a 920,00 reales $( \pm 276$ a $368 €) \quad 7,40$

5. Más de 920 reales $(+368 €) \quad 13,60$

6. Ns/Nc

3,80

Pregunta 79 - (Solo para los que están trabajando) ¿En qué área actúa Usted profesionalmente?
1. Agricultura
1,40
2. Empresa / Comercio 3,20
3. Servicio Público $\quad 4,20$
4. Trabajador autónomo $\quad 6,00$
5. Construcción civil $\quad 0,80$
6. Ama de casa $\quad 11,60$
7. Ns/Nc 2,80
9. NSA 70,00

Pregunta 80 - (Solo para los que están jubilados)

¿Cuál fue la última profesión que desempeño Usted profesionalmente?
1. Agricultura
14,40
2. Empresa / Comercio $\quad 13,60$
3. Servicio Público $\quad 18,60$
4. Trabajo autónomo $\quad 10,00$
5. Construcción civil $\quad 4,00$
6. Ama de casa $\quad 16,00$
7. Otros 9,00
9. Ns/Nc $\quad 1,60$
10. NSA 12,00

\section{Pregunta 81 - (Solo para los que les gustaría trabajar)}

¿Por qué razón le gustaría trabajar?
1. Para pagar pequeños gastos
2,40
2. Para aumentar la renta
21,40
3. Por distracción
10,20
4. Porque le gusta
12,00
5. Para no depender financieramente de nadie $\quad 5,40$
6. Ns/Nc
7. NSA
45,00

\section{Pregunta 82}

¿En su opinión, cuándo debería uno jubilarse?
1. Cuando determine la Ley
22,60
2. Cuando fuera conveniente
28,40
3. Cuando se lo impida la salud
47,60
4. Ns/Nc
1,40

\section{Pregunta 83}

¿En su opinión, quiénes es el responsable del pago de la jubilación?
1. El Estado
83,00
2. Los empresarios
3,40 
3. Los trabajadores individualmente 4. Ns/Nc

5,80

7,80 